\title{
Estudos Teórico e Experimental de Propriedades Estruturais e Eletrônicas da Molécula Emodina em Solvente e em Bicamadas Lipídicas.
}

Antonio Rodrigues DA CUNHA
\[ \begin{array}{l}\text { Tese de doutorado apresen- } \\ \text { tada ao Instituto de Física } \\ \text { para a obtenção do tí- } \\ \text { tulo de Doutor em Ciências. }\end{array} \]

Orientadora: Profa. Dra. Kaline Rabelo Coutinho Co-Orientadora: Profa. Dra. Maria Teresa Lamy

Banca Examinadora:

Profa. Dra. Kaline Rabelo Coutinho (IFUSP)

Profa. Dra. Karin do Amaral Riske (UNIFESP)

Prof. Dr. Hubert Karl Stassen (UFRGS)

Prof. Dr. Eudes Eterno Fileti (UNIFESP)

Prof. Dr. Luiz Carlos Gomide Freitas (UFSCar) 


\section{FICHA CATALOGRÁFICA \\ Preparada pelo Serviço de Biblioteca e Informação do Instituto de Física da Universidade de São Paulo}

Antonio Rodrigues da Cunha

Estudos Teórico e Experimental de Propriedades Estruturais e Eletrônicas da Molécula Emodina em Solvente e em Bicamadas Lipídicas.

Tese de Doutorado - Universidade de São Paulo. Instituto de Física. Depto. de Física Geral.

Grupo de Biofísica

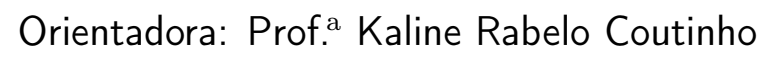

Área de Concentração: Física

Unitermos: 1. Física Atômica e Molecular/Biofísica;

2. Cálculos Quânticos - Simulações Computacionais;

3. Processo de protonação/desprotonação;

4. Constante de acidez $\left(\mathrm{pK}_{\mathrm{a}}\right)$;

5. Espectroscopia Eletrônica - Solvatocromismo;

6. Titulação espectroscópica;

7. Medidas de calorimetria diferencial de varredura.

USP/IF/SBI-065/2014 
"A mente que se abre a uma nova ideia jamais voltará ao seu tamanho original "

Albert Einstein

"A todo instante Cálculos Quânticos e Simulações Computacionais se confrontam em escalas diferentes." Antonio R. da Cunha. 



\section{Agradecimentos}

À Profa. Kaline Coutinho, pela orientação, amizade, apoio e por sua enorme dedicação no desenvolvimento desta tese de doutorado, e por estar sempre presente com seus ensinamentos, pelas oportunidades oferecidas, meu sincero agradecimento.

À Profa. Teresa Lamy, pela orientação da parte experimental desta tese de doutorado, por acreditar e ter paciência suficiente de me iniciar e guiar no laboratório na área de Biofísica molecular, por está também sempre presente com sua amizade, apoio e pelas oportunidades oferecidas, meu sincero agradecimento.

Ao Prof. Sylvio Canuto, pela amizade, colaboração, discussão e pelas opotunidades oferecidas.

Ao Prof. Alan Mark e todo o seu grupo, pela oportunidade de estágio na University of Queensland, em Brisbane, Autrália, pelo apoio e orientação durante os seis meses de estadia na terra do canguru.

Ao Dr. Evandro Duarte, pela amizade, colaboração e acompanhamento constante no Laboratório de Biofísica durante todo o doutorado. Obrigado pela oportunidade de trabalharmos juntos, pelas nossas conversas no laboratório, científicas ou não, que contribuíram para minha formação profissional.

Aos colegas dos grupos de Física Molecular e Modelagem, e Biofśica Molecular, tanto os teóricos como os experimentais, em especial, T. Oliveira, D. Koga, T. A. Enoki, D. A. Nomura, J. R. Alves, F. da Silva, M. V. A. Damasceno, V. W. D. Cruzeiro, G. Barbosa, E. G. Lacerda Júnior, J. H. Rozenfeld, C. C. V. Suplicy, C. E. Bistafa, L. Modesto, M. Hidalgo, R. Barreto, R. Gester, Y. Orozco e P. Jaramillo, sem esse pessoal, realizar este trabalho e cursar o doutorado em Física, no mínimo não teria sido tão divertido.

À minha família em especial, minha mãe, Irene Cunha e meu pai, Francisco Borges e aos meus irmãos, pelo incentivo e apoio incondicional. Ao casal Prof. Paulo Ramos e Profa. Sofia Almeida, por me incentivar nos primeiros passos em direcão ao conhecimento. À Cristiane pelo apoio incondicional, dedicação e companheirismo.

Ao CNPq, pelo apoio financeiro concedido para realização deste trabalho com a bolsa de doutorado (156287/2010) e doutorado sanduíche na Austrália (236669/2012). 



\section{Resumo}

A Emodina (EMH) é uma das antraquinonas mais abundantes na natureza. Essa molécula vem sendo largamente usada como material de estudo científico por apresentar diversas atividades farmacológicas, tais como antiviral, antitumoral, antifungal, digestiva e outras. É conhecido que a Emodina em solução aquosa alcalina pode sofrer mais de um processo de desprotonação, apresentando-se na forma desprotonada, $\mathrm{EM}^{-}$, após a primeira desprotonação. Nesta tese de doutorado estudamos as propriedades estruturais e eletrônicas da molécula Emodina em meio solvente e em bicamadas lipídicas a fim de caracterizar as propriedades relacionadas à espectroscopia UV-Vis, à reatividade e à termodinâmica dessa molécula nesses ambientes. Realizamos cálculos quânticos com a Emodina em vácuo e em meio solvente, onde consideramos todos os possíveis sítios de desprotonação. Como resultados desses cálculos, identificamos os sítios da primeira, segunda e terceira desprotonação. Calculamos o pK $\mathrm{a}_{\mathrm{a} 1}$ da Emodina em água e o $\mathrm{pK}_{\mathrm{a} 1}^{*}$ em metanol através de simulações computacionais com o método Monte Carlo e cálculos quânticos, com o solvente descrito com o modelo contínuo polarizável. Nossos melhores valores para o $\mathrm{pK}_{\mathrm{a} 1}$ da Emodina determinados nesses solventes foram $8.4 \pm 0.5$ e $10.3 \pm 1.5$, que estão em boa concordância com os valores experimentais, $\left(\mathrm{pK}_{\mathrm{a} 1}=8.0 \pm 0.2 \mathrm{e} \mathrm{pK}_{\mathrm{a} 1}^{*}=11.1 \pm 0.1\right)$ obtidos nesta tese para Emodina em água e metanol, respectivamente. Adicionalmente realizamos simulações com Dinâmica Molecular com as espécies EMH e EM- em bicamada lipídica de DMPC, para investigar a nível atômico as interações dessas espécies com a bicamada e determinar as posições preferenciais dessas espécies nesse ambiente anfifílico. Os resultados dessas simulações mostraram que as espécies EMH e EM- ficam inseridas na bicamada, na região polar dos lipídios, próximos aos gliceróis. Esses resultados corroboram as nossas medidas do espectro de absorção dessas espécies em bicamada lipídica, onde mostramos de forma qualitativa, que ambas as espécies ficam inseridas na bicamada, na região das cabeças polares dos lipídios. A análise das propriedades estruturais da bicamada na vizinhança das espécies da Emodina como área por lipídio e densidade eletrônica dos lipídios, mostrou que o efeito da $\mathrm{EM}^{-}$na estrutura da bicamada lipídica é maior do que o da EMH. Esses resultados corroboram as nossas medidas de DSC(Differential Scanning Calorimetry) das espécies da Emodina na bicamada. 



\section{Abstract}

Emodin (EMH) is one of the most abundant anthraquinone derivatives found in nature. This molecule has been used widely as research material, due to its biological and pharmacological activities such as antiviral, anticancer, antifungal, digestive and antibacterial activities. It is known that Emodin in alkaline aqueous solution can undergo more than one deprotonation, leading to the specie $\mathrm{EM}^{-}$in the first deprotonation process. In this PhD thesis, we studied the structural and electronic properties of this molecule in several solvents and lipid bilayers, in order to characterize the properties related to UV-Vis absorption spectroscopy, reactivity and thermodynamics of this molecule in these environments. Performing quantum mechanics (QM) calculations for all possible deprotonation sites and tautomeric isomers of Emodin in vacuum and in water, we identified the sites of the first, second and third deprotonations. We calculated the $\mathrm{pK}_{\mathrm{a} 1}$ of Emodin in water and $\mathrm{pK}_{\mathrm{a} 1}^{*}$ in methanol with free energy perturbation method, implemented in the Monte Carlo simulation, and with QM calculations, where the solvent was treated as a polarizable continuum medium.

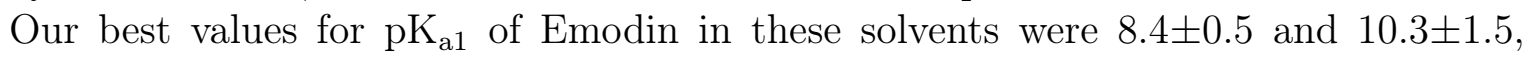
which are in very good agreement with the experimental values obtained in this thesis $\mathrm{pK}_{\mathrm{a} 1}=8.0 \pm 0.2$ and $\mathrm{pK}_{\mathrm{a} 1}^{*}=11.1 \pm 0.1$, for water and methanol, respectively. Additionally, we performed molecular dynamics simulations of both species in fully hydrated lipid bilayers of DMPC to investigate at atomic detail the molecular mechanism of the interaction of these species with lipid membrane and its preferred positions in this amphiphilic environment. As results of these simulations, we obtained that both species of Emodin have a strong tendency to insert into the lipid bilayer, remaining near the glycerol group of DMPC. These results corroborate our measured absorption spectra of these species in the bilayer, which qualitatively showed that both species are within the bilayer, inserted in the lipid headgroup region. Our results also show that the effect of $\mathrm{EM}^{-}$specie in the lipid bilayer structure is stronger than the EMH, which corroborate our DSC(Differential scanning calorimetry) measurements. 



\section{Sumário}

Lista de Abreviaturas xiii

1 Introdução 13

1.1 A molécula de Emodina . . . . . . . . . . . . . . . 16

1.2 Descrição do solvente e bicamada lipídica . . . . . . . . . . . . . . . 22

1.3 Bicamadas lipídicas . . . . . . . . . . . . . . . . 26

1.4 Organização do texto . . . . . . . . . . . . . . . . . 30

2 Metodologias Teóricas e Experimentais 33

2.1 Introdução . . . . . . . . . . . . . . . . . . . . 33

2.2 Metodologias Teóricas . . . . . . . . . . . . . . . . . 33

2.2.1 Cálculos Quânticos ... . . . . . . . . . . . . 33

2.2.1.1 Teoria do funcional da densidade . . . . . . . . . 37

2.2.1.2 Aproximação LCAO e funções bases . . . . . . . . . 41

2.2.1.3 Cálculo das cargas atômicas com CHELPG . . . . . . 42

2.2.1.4 Modelo contínuo polarizável (PCM) . . . . . . . . . 44

2.2.2 Simulação computacional . . . . . . . . . . . . . . 47

2.2.2.1 Dinâmica Molecular . . . . . . . . . . . . . . . 48 
2.2.2.2 Termostato e Barostato . . . . . . . . . . 51

2.2.2.3 Método Monte Carlo . . . . . . . . . . . . . . . 53

2.2.2.4 Potencial de Interação e Campo de Força . . . . . . 58

2.2.2.5 Cálculo da energia livre com FEP . . . . . . . . . . 63

2.3 Metodologias Experimentais . . . . . . . . . . . . . . . 65

2.3 .1 Absorção Óptica . . . . . . . . . . . . . . . . . . 65

2.3.2 Calorimetria diferencial de varredura (DSC) . . . . . . . . 72

3 Materiais e Métodos $\quad 75$

3.1 Introdução . . . . . . . . . . . . . . . . . . . . 75

3.2 Materiais ........................ . . . . . . . . . . .

3.3 Preparação das amostras . . . . . . . . . . . . . . . . 76

3.3.1 Preparação de Emodina em solventes . . . . . . . . . . . . . 76

3.3.2 Preparação de Emodina em dispersões lipídicas . . . . . . . . . 78

3.4 Equipamentos utilizados . . . . . . . . . . . . . . . . . . 79

3.4.1 Espectroscopia UV-Vis . . . . . . . . . . . . . . . . . 79

3.4.2 Calorimetria diferencial de varredura (DSC) . . . . . . . . . . 79

3.5 Métodos teóricos . . . . . . . . . . . . . . 80

3.5.1 Cálculos quânticos . . . . . . . . . . . . . . . . . . 80

3.5.2 Simulações computacionais . . . . . . . . . . . . . . . 82

3.5.2.1 Simulação da hidratação da EMH e EM- $\ldots$. . . . . . 82

3.5.2.2 Cálculos do $\mathrm{pK}_{\mathrm{a}}$ da Emodina . . . . . . . . . 85

3.5.2.3 Cálculo da diferença de energia livre de solvatação. 88 
3.5.2.4 Simulação em bicamada lipídica da EMH e EM- com

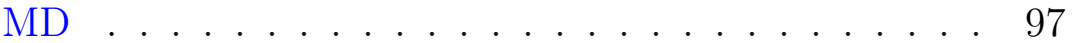

4 Resultados e Discussões

4.1 Introdução . . . . . . . . . . . . . . . . . . . . . . . 103

4.2 Desprotonação da Emodina . . . . . . . . . . . . . . . . . . . . . 104

4.2.1 Posições e ordem das desprotonações . . . . . . . . . . . . . . . . 104

4.2 .2 Cálculo do $p K_{\mathrm{a}}$ da Emodina . . . . . . . . . . . . . . . 110

4.2.2.1 Processo de desprotonação em fase gasosa: cálculo do $\Delta G_{g} \ldots \ldots \ldots \ldots \ldots \ldots$

4.2.2.2 Processo de desprotonação em solução: cálculo do $\Delta G_{\text {Sol. }}$. e $p K_{\mathrm{a}} \ldots \ldots \ldots \ldots \ldots \ldots$

4.2.3 Titulação espectroscópica da Emodina em água e em metanol 119

4.2.3.1 Medida do $p K_{\mathrm{a}}$ da Emodina em água . . . . . . . . 123

4.2.3.2 Medida do $\mathrm{pK}_{\mathrm{a}}^{*}$ da Emodina em metanol . . . . . . . . 129

4.2.3.3 Considerações parciais da desprotonação da Emodina . 133

4.3 Efeito do ambiente no espectro de absorção . . . . . . . . . . . . . 136

4.3.1 Efeito do solvente no espectro de absorção . . . . . . . . . . . 136

4.3.2 Efeito da bicamada lipídica no espectro de absorção . . . . . . . . 141

4.3.3 Cálculo do Espectro eletrônico de absorção das espécies . . . . . 145

4.4 Interação da Emodina com o ambiente . . . . . . . . . . . . . . . . 155

4.4.1 Modelagem da EMH e EM- em solução aquosa . . . . . . . . . . 156

4.4.2 Modelagem da EMH e EM- em bicamada lipídica . . . . . . . . 168

4.4.2.1 Propriedades das bicamadas lipídicas ..... 169 
4.4.2.2 Localização e orientação das espécies da Emodina na bicamada .................. . . 181

4.4.2.3 Análise estrutural das espécies da Emodina na bicamada lipídica . . . . . . . . . . . . . . . . . 191

4.4.2.4 Interação das espécies da Emodina com a bicamada hidratada . . . . . . . . . . . . . 195

4.4.2.5 Efeito das espécies da Emodina na bicamada . . . . . 200

4.4.3 Medidas de calorimetria de varredura . . . . . . . . . . . 208

5 Conclusões

Referências Bibliográficas

A Informações Complementares

A.1 Introdução . . . . . . . . . . . . . . . . . . . . . . . . 243

A.2 Henderson-Hasselbalch (Eq. 4.2) . . . . . . . . . . . . . . . . . . 244

A.3 Equação do $\mathrm{pK}_{\mathrm{a}}($ Eq. 3.6) . . . . . . . . . . . . . . . . . . . . 248

A.4 Análise dos Espectros de Absorção . . . . . . . . . . . . . . . . . . . . 251

A.5 Tabelas Complementares . . . . . . . . . . . . . . . 254

A.6 Figuras Complementares . . . . . . . . . . . . . . . . 260

B Arquivos de Coordenadas e de Topologia das espécies da Emodina e da molécula de DMPC 285

B.1 Arquivo EMH.gro . . . . . . . . . . . . . . . . 285

B.2 Arquivo EM-.gro . . . . . . . . . . . . . . . 286

B.3 Arquivo DMPC.gro . . . . . . . . . . . . . . . . . 286 
B.4 Arquivo EMH.top . . . . . . . . . . . . . . . . . . . 288

B.5 Arquivo EM-.top . . . . . . . . . . . . . . . . . . . . . 292

B.6 Arquivo DMPC.top . . . . . . . . . . . . . . . 296

C Realizações no Doutorado 303 


\section{Lista de Abreviaturas}

$\begin{array}{ll}\text { DMPC } & \text { 1,2-dimiristoil-sn-glicero-3-fosfocolina } \\ \text { DMPG } & \text { 1,2-dimiristoil-sn-glicero-3-fosfoglicerol } \\ \text { DEPE } & \text { 1,2-dielaidoyl-sn-fosfatidiletanolamina } \\ \text { DSC } & \text { Calorimetria diferencial de varredura } \\ \text { RPE } & \text { Ressonância paramagnética eletrônica } \\ \text { HSV } & \text { Vírus da Herpes } \\ \text { EMH } & \text { Emodina neutra ou protonada, carga total igual a zero } \\ \text { EM- } & \text { Emodina desprotonada na posição 3, carga total igual a -1 } \\ \text { 3,8-EM } & \text { Emodina desprotonada na posição 1, carga total igual a -1 } \\ \text { 1,8-EM- } & \text { A mesma, EM- } \\ \text { 1,3-EM- } & \text { Emodina desprotonada na posição 8, carga total igual a -1 } \\ \text { SAXS } & \text { Espalhamento de raios X a baixos ângulos } \\ \text { INDO } & \text { Intermediate neglect of differential overlap } \\ \text { CIS } & \text { Configuration interaction singles } \\ \text { SCRF } & \text { Self-consistent reaction field } \\ \text { HF } & \text { Hartree-Fock } \\ \text { MCM } & \text { Modelo contínuo polarizável } \\ & \text { Medo Monte Carlo }\end{array}$




\begin{tabular}{|c|c|}
\hline $\mathrm{MD}$ & Dinâmica Molecular \\
\hline DPPC & 1,2-dipalmitoil-sn-glicero-3-fosfocolina \\
\hline DLPC & 1,2-dilauroil-sn-glicero-3-fosfocolina \\
\hline $\mathrm{DOPC}$ & 1,2-dioleoil-sn-glicero-3-fosfocolina \\
\hline SANS & Espalhamento de neutrons a baixos ângulos \\
\hline $\mathrm{DFT}$ & Teoria do Funcional da Densidade \\
\hline MPn & Teoria de perturbações Moller-Plessett Møller-Plesset \\
\hline $\mathrm{BO}$ & Bohr-Oppenheimer \\
\hline ZDO & Zero differential overlap \\
\hline CNDO & Complete neglect of differential overlap \\
\hline NDDO & Neglect of diatomic differential overlap \\
\hline MINDO & Modified intermediate neglect of differential overlap \\
\hline MNDO & Modified neglect of diatomic overlap \\
\hline AM1 & Austin model 1 \\
\hline PM3 & Parameterized model number 3 \\
\hline $\mathrm{KS}$ & Kohn-Sham \\
\hline LSD & Local spin density approximation \\
\hline GGA & Generalized gradient approximation \\
\hline B3LYP & Funcional híbrido de exchange de (Becke, three-parameter, \\
\hline \multicolumn{2}{|c|}{ Lee-Yang-Parr) } \\
\hline B88 & Gradiente de correção do funcional de exchange de Becke de 1988 \\
\hline LYP & Funcional de correlação de Lee-Yang-Parr \\
\hline VWN & Funcional de correlação de Vosko-Wilk-Nusair \\
\hline $\mathrm{TD}$ & Time-dependent \\
\hline
\end{tabular}


LCAO Linear combination of atomic orbitals

GTO Gaussian-type-orbitals

NBO Natural bond orbital analysis

RESP Restrained electrostatic potential

CHELPG Charges from electrostatic potential grid based

OPLS Optimized potentials for liquid simulations

GROMOS Groningen molecular simulation

LJ Lennard-Jones

FEP Free energy perturbation theory

NPT Ensemble onde o número de partículas, a pressão e

a temperatura são constantes

NVT Ensemble onde o número de partículas, o volume e

a temperatura são constantes

QM Química quântica

MM Mecânica molecular

HOMO Highest occupied molecular orbital

LUMO Lowest unoccupied molecular orbital

$\mathrm{HCl} \quad$ Ácido hidroclorídrico

$\mathrm{NaOH} \quad$ Hidróxido de sódio

$\mathrm{NaH}_{2} \mathrm{PO}_{4} \cdot \mathrm{H}_{2} \mathrm{O} \quad$ Bifosfato de sódio monohidratado

$\mathrm{Na}_{2} \mathrm{HPO}_{4} .7 \mathrm{H}_{2} \mathrm{O} \quad$ Fosfato de sódio bib. heptahidratado

$\mathrm{NaHCO}_{3} \quad$ Bicarbonato de sódio

$\mathrm{Na}_{2} \mathrm{CO}_{3} \quad$ Carbonato de sódio anidro

8-EM EM $^{2-} \quad$ Emodina com duas desprotonações nas posições 3 e 1

1-EM ${ }^{2-} \quad$ Emodina com duas desprotonações nas posições 3 e 8 


$\begin{array}{ll}\text { 9-EM- } & \text { Forma tautomérica da Emodina com duas desprotonações } \\ \text { EM }^{3-} & \text { Emodina com três desprotonações nas posições 1, 3 e } 8 \\ \text { SPC } & \text { Simple point charge model } \\ \text { PME } & \text { Particle Mesh Ewald } \\ \text { PCM-UAHF } & \text { Polarized continum model-united atoms Hartree-Fock } \\ \text { LINCS } & \text { A linear constraint solver for molecular simulations } \\ \text { DMSO } & \text { Dimetilsulfóxido ou sulfóxido de dimetilo } \\ \text { ZINDO } & \text { Zerner's intermediate neglect of differential overlap } \\ \text { RDF } & \text { Função de distribuição radial de pares } \\ \text { MDDF } & \text { Função de distribuição de mínima distântica } \\ \text { HB } & \text { Hydrogen bond } \\ \text { NMR } & \text { Nuclear magnetic resonance } \\ \text { CM } & \text { Centro de massa da molécula Emodina } \\ \text { MT } & \text { Carbono do metil da Emodina }\end{array}$




\section{Capítulo 1}

\section{Introdução}

Os fármacos derivados de antraquinonas extraídos de plantas naturais vêm sendo usados pela humanidade desde a antiguidade devido às suas propriedades medicinais como anti-inflamatórios e laxativos [1-3]. Atualmente, esses fármacos vêm ganhando destaque na ciência graças a suas atividades biológicas e farmacológicas, tais como antiviral [4,5], estimulante do fígado [3], diurético [6], antiúlcera [7], antitumoral [8,9], antifungal [10], antiparasita [11], estimulante cardíaco [12], digestivo [13, 14], e outras. Devido a essa ampla atividade biológica e farmacológica, diversos estudos científicos vêm buscando examinar as propriedades estruturais e eletrônicas desses fármacos, e entender como eles interagem com o meio biológico $[15,16]$. Uma propriedade estrutural importante das antranquinonas é que elas apresentam ligações de hidrogênio intramoleculares, que desempenham um papel fundamental na interação e manutenção de suas estruturas funcionais com o meio biológico $[17,18]$. Recentemente foram analisadas as interações dessas moléculas com membranas modelo formadas por lipídios de 1,2-dimiristoil-sn-glicero-3-fosfocolina (DMPC), 1,2-dimiristoil-sn-glicero-3fosfoglicerol (DMPG) e 1,2-dielaidoyl-sn-fosfatidiletanolamina (DEPE), usando técnicas experimentais de Calorimetria Diferencial de Varredura (DSC), Espalhamento de Luz, Fluorescência e Ressonância Paramagnética Eletrônica (RPE) de marcadores de spin anfifílicos incorporados à bicamada lipídica, e foi mostrado que as antraquinonas 
alteram as propriedades estruturais da bicamada lipídica, mostrando que essas moléculas se incorporam na bicamada $[15,16]$. Entretanto, não existe na literatura um estudo detalhado mostrando a localização preferencial das antraquinonas dentro da bicamada.

A antraquinona mais abundante na natureza é a Emodina (1,3,8-trihidroxi-6metil-9,10-antraquinona), ver figura 1.1 Essa molécula também vem sendo largamente usada como material de estudo científico nos últimos anos por apresentar as atividades biológicas e farmacológicas da família das antraquinonas [7, 19,20]. Estudos científicos têm mostrado que a atividade antiviral da Emodina é mais eficiente em comparação a outras antraquinonas, tais como a Aloe Emodin, Rhein e Promazina [21-23]. Além disso, tem sido comprovado que a atividade antiviral dessa molécula é eficiente até mesmo em vírus encapsulados por bicamadas lipídicas, como o vírus da herpes (HSV), onde o mecanismo molecular vem sendo bastante estudado nos últimos anos $[21,23,24]$. É conhecido que quando células sadias são infectadas por esse vírus é ativada uma serie de atividades enzimáticas relacionadas ao metabolismo do DNA, tais como as atividades das enzimas DNA polimerase e nuclease [25].
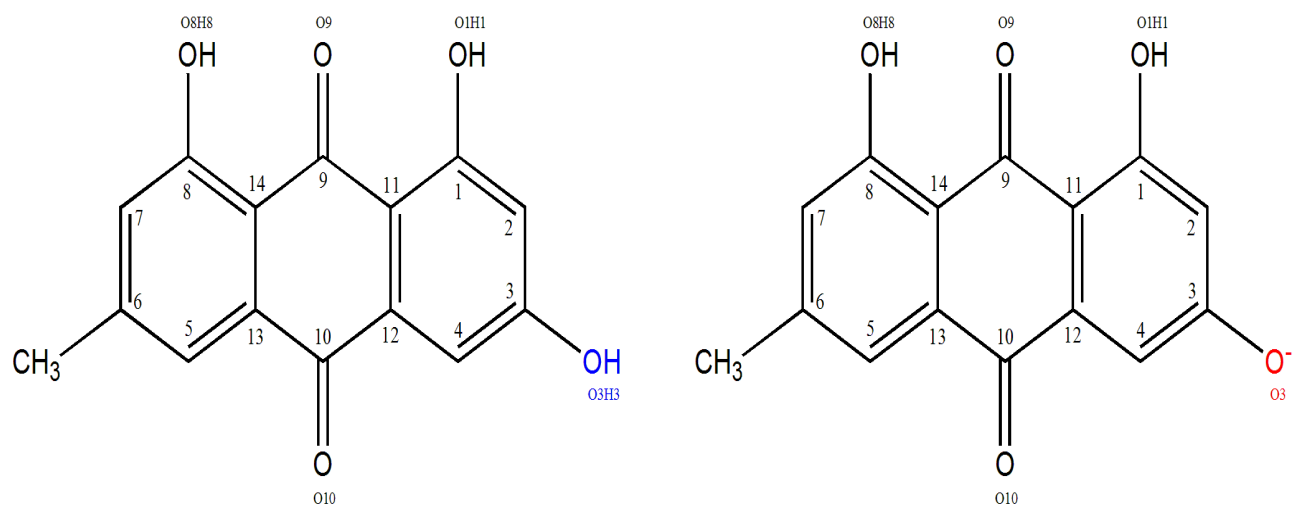

Figura 1.1: Estrutura química da molécula Emodina neutra à esquerda e Emodina desprotonada à direita.

Recentemente Hsiang e Ho comprovaram que a Emodina inibe a atividade enzimática da nuclease alcalina causada pelo vírus HSV [23]. Trabalhos científicos têm 
mostrado que a nuclease alcalina de células infectadas por HSV apresentam atividades exonucleases e endoclease intensa em condições de $\mathrm{pH}$ alcalino, com o $\mathrm{pH}$ entre 8 e 9 [25-27]. Sabemos que nessas condições de pH, a Emodina sofre processos reativos de desprotonação em alguns solventes, apresentando-se na forma desprotonada, $\mathrm{EM}^{-}$, ver figura 1.1. Alguns cientistas têm estudado esses processos da Emodina em solventes orgânicos e misturas, como em metanol, etanol, acetonitrila, entre outros [28-30]. Porém, até onde conhecemos, não existe na literatura um estudo que relaciona esses processos de desprotonação da Emodina com sua capacidade de inibição de atividades enzimáticas da nuclease alcalina. Além disso, não existe também um estudo aprofundado do processo da internalização da Emodina no HSV (que é um vírus encapsulado por membrana lipídica), associado a uma investigação da forma como essa molécula interage com a membrana desse vírus, pois esses estudos serão determinantes para caracterizar o mecanismo farmacológico dessa molécula. Portanto, existe a necessidade de um estudo detalhado da molécula Emodina neutra (EMH) e da Emodina desprotonada $\left(\mathrm{EM}^{-}\right)$, ambas isoladamente, em meio solvente e em bicamada lipídicas, a fim de examinar as propriedades estruturais da EMH e EM- e suas interações com o meio biológico, para um melhor entendimento do mecanismo reativo da Emodina.

O objetivo desse trabalho de doutorado é estudar as propriedades estruturais e eletrônicas da molécula Emodina em meio solvente e em bicamadas lipídicas, a fim de caracterizar as propriedades relacionadas à espectroscopia UV-Vis, à reatividade, à termodinâmica e às interações intramoleculares e intermoleculares dessa molécula em diferentes meios. Esse estudo está sendo realizado através do uso de técnicas experimentais e teóricas. Na parte experimental, utilizamos técnicas de Calorimetria Diferencial de Varredura e espectroscopia eletrônica de absorção de luz na região UVVis da Emodina em meio solvente e em bicamada lipídica. Na parte teórica, utilizamos modelos atomísticos com cálculos quânticos e simulações computacionais com campos de forças clássicos para caracterização das propriedades estruturais e eletrônicas da 
Emodina e suas interações com o meio solvente e bicamada lipídica.

Com esse estudo pretendemos fornecer respostas para as seguintes perguntas: (i) Qual a ordem das posições de desprotonação na molécula da Emodina?; (ii) Quais são as constantes de acidez dessas desprotonações da Emodina em água e metanol?; (iii) Quais são as afinidades das espécies da Emodina EMH e EM- pelos ambientes aquoso e anfifílicos?; (iv) Quais são as localizações preferenciais dessas espécies na bicamada lipídica?; (v) Qual é o efeito dessas espécies na estrutura da bicamada lipídica? Adquirindo as respostas dessas perguntas, colocaremos na literatura, com clareza, as propriedades relacionadas à reatividade e a afinidade dessas espécies em solvente e em bicamada lipídica, assim como as localizações preferenciais dessas espécies nesses meios anfifílicos.

\subsection{A molécula de Emodina}

A Emodina é um produto natural de cor amarelo-laranja extraída de plantas tais como as dos gêneros Rheum, Polygonum, Rhamnus e Senna [15,31]. Essa molécula é formada por grupos hidrofóbicos (1 antraceno, e 1 metil) e hidrofílicos (3 hidroxilas (O8H8, O1H1 e O3H3) e 2 carbonilas C9O9 e C10O10), o que em princípio podem lhe atribuir um caráter hidrofílico ou lipofílico. A Emodina apresenta uma alta solubilidade em solventes orgânicos como metanol, etanol, benzeno, clorofórmio, diclorometano, dioxano, álcool isopropílico, acetona, acetonitrila e tetracloreto de carbono, e baixa solubilidade em água $<1 \mathrm{mg} / \mathrm{mL}$ nas condições normais de pressão, temperatura e pH [28]. Nas condições de $p H>8$, ou seja, em meio alcalino, a Emodina é solúvel em água, onde é observada uma mudança de cor amarelo-laranja para o vermelho com a mudança do $\mathrm{pH}$ da solução de $p H \sim 7$ para $p H>8$. É observada também uma mudança de cor de amarelo-laranja para amarelo com a mudança do pH da solução de $p H \sim 7$ para $p H<6$. Nessas condições a Emodina apresenta uma menor 
solubilidade em solução aquosa. Em 2004, Alves e colaboradores [15], mediram o coeficiente de partição $\left(K_{p}\right)$ da Emodina em água/octanol no valor de $(13.93 \pm 2.24) x 10^{3}$, que está associado com uma energia livre de partição da Emodina água/octanol de $\left.\left(\Delta G_{a g \rightarrow o c t}=-R T \ln K_{p}\right)=-5.7 \pm 0.1 \mathrm{kcal} / \mathrm{mol}\right)$, indicando que essa molécula apresenta uma alta afinidade por ambientes lipídicos. Adicionalmente, no nosso trabalho de mestrado [32], foi realizado um cálculo da energia livre de partição da Emodina água/metanol e água/clorofórmio, e obtivemos os valores de $-4.9 \pm 1.3$ e $-2.6 \pm 1.5$ $\mathrm{kcal} / \mathrm{mol}$, respectivamente. Esse resultado mostrou que entre uma solução aquosa e de clorofórmio, a Emodina prefere o clorofórmio, portanto prefere um ambiente hidrofóbico. Porém entre metanol e clorofórmio, a Emodina prefere o metanol, portanto mostra uma afinidade por ambientes próticos, ou seja, ambientes com habilidades em formar ligações de hidrogênio.

Trabalhos prévios têm sido publicados na literatura focados nos processos de desprotonação da Emodina [28, 29], que ocorrem nas hidroxilas dessa molécula em alguns solventes sob condições alcalinas, ou próxima dessas condições. Por exemplo, em solução aquosa, essa molécula pode sofrer até 3 desprotonações, numa faixa de pH entre 6 e 20, uma vez que ela contém 3 hidroxilas. Existem na literatura uma proposta para a ordem das posições de desprotonação nessa molécula: primeira desprotonação na posição 3 (3-óxido-6-metil-1,8-dihidroxi-9,10-antraquinona), segunda na posição 8 (3,8-óxido-6-metil-1-dihidroxi-9,10-antraquinona) e terceira na posição 1 (1,3,8-óxido6-metil-9,10-antraquinona) [28], porém não existe um estudo teórico comprovando essa sequência. Experimentalmente têm sido investigados os processos de desprotonação da Emodina em solventes orgânicos, onde foram determinadas as constantes de acidez da Emodina em misturas de água-metanol $\left(p K_{a 1}=7.2\right)$ [28], água-etanol $\left(p K_{a 1}=6.24\right)$ [29] e acetonitrila $\left(p K_{a 1}=5.7\right.$ and $\left.p K_{a 2}=7.9\right)$ [30]. O $p K_{a}$ dessa molécula em água não é ainda conhecido, portanto é de interesse determinar com precisão essa propriedade em solução aquosa. Essa é uma tarefa difícil, pois a Emodina apresenta 
baixa solubilidade em solução aquosa ácida [28,33,34].

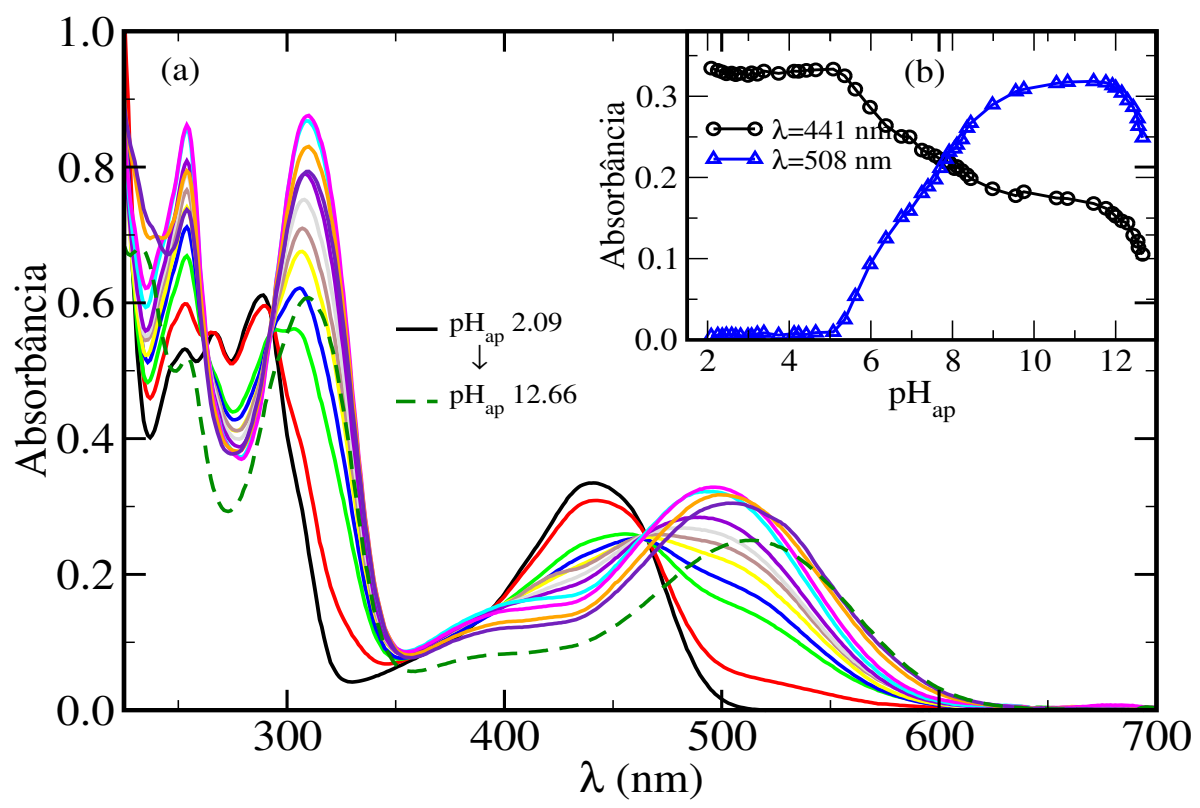

Figura 1.2: Na figura (a) está ilustrado o efeito do $\mathrm{pH}_{\text {ap }}$ no espectro de absorção da Emodina $\left(2.5 \times 10^{-5} \mathrm{~mol} / \mathrm{L}\right)$ na mistura de água $(25 \%)$ e metanol $(75 \%)$, com o $\mathrm{pH}_{\mathrm{ap}}$ variando de $2.09 \mathrm{a}$ 12.66. Já na figura (b), está ilustrado o efeito do $\mathrm{pH}_{\mathrm{ap}}$ na absorbância da Emodina no máximo de absorção em $441\left(\mathrm{pH}_{\mathrm{ap}}=2.09\right)$ e $508\left(\mathrm{pH}_{\mathrm{ap}}=12.66\right) \mathrm{nm}$. Os dados dessa figura foram obtidos neste nosso trabalho e estão de acordo com as figuras 2 e 3 da referência [28].

O trabalho de Pal e colaboradores [28], evidenciou a desprotonação da Emodina em solução, pois foi realizada uma análise detalhada da dependência do espectro eletrônico de absorção da Emodina com o pH aparente, $\mathrm{pH}_{\mathrm{ap}}(\mathrm{pH}$ medido com pHmetro calibrado para água) da solução água-metanol, onde essa molécula em $\mathrm{pH}_{\mathrm{ap}}<6.0$ é caracterizada por uma banda intensa na região de $440 \mathrm{~nm}$. Já em solução com $\mathrm{pH}_{\mathrm{ap}}$ entre 6.0 a 7.5, essa banda sofre um deslocamento para $496 \mathrm{~nm}$, não mudando mais a posição para mudanças no $\mathrm{pH}_{\mathrm{ap}}$ da solução de 7.5 a 10.0. Quando aumenta o $\mathrm{pH}_{\mathrm{ap}}$ da solução para 12, essa banda volta a sofrer lentamente um deslocamento para 526 $n m$. Esse comportamento está ilustrado na figura 1.2. Nessa figura está mostrado o efeito do $\mathrm{pH}_{\mathrm{ap}}$ na absorbância da Emodina, onde o aumento da intensidade da banda em $508 \mathrm{~nm}$ com $\mathrm{pH}_{\mathrm{ap}}$, está associado com o processo de desprotonação dessa molécula 
em soução.

Outro trabalho que corrobora a desprotonação da Emodina é o de Nguyen e colaboradores [29]. Nesse trabalho é realizada uma análise qualitativa do espectro de absorção da Emodina em solução água-etanol, para três condições de $\mathrm{pH}_{\mathrm{ap}}$ da solução, ácido, neutro e alcalino, indicando que a Emodina nessa solução, nas condições normais de pressão e temperatura, sofre processos de desprotonação, sendo que em solução ácida encontra-se a Emodina neutra, EMH, em solução alcalina encontra-se a Emodina na sua forma desprotonada $\mathrm{EM}^{-}$, ou seja, na forma aniônica. Já em solução neutra encontra-se uma mistura de ambas as formas da Emodina, EMH+EM-. Esse trabalho está em boa concordância com o trabalho de Pal e colaboradores [28], mencionado anteriormente, que indica que a Emodina $\mathrm{pH}_{\mathrm{ap}}<6.0$ apresenta a forma neutra.

Adicionalmente foi realizado no nosso trabalho de mestrado [32] um estudo detalhado do espectro de absorção da Emodina em solventes de diferentes polaridades, onde usamos água, clorofórmio e metanol. Nesse trabalho foram caracterizadas as posições, intensidades e formas das bandas do espectro de absorção da Emodina nesses solventes, onde foi verificado que o espectro de absorção da Emodina neutra não é sensível à mudança do meio. Além disso, foram realizadas medidas do espectro de absorção da Emodina em água e metanol nas condições ácida e alcalina de pH. Em meio alcalino foi realizado um estudo detalhado do espectro da Emodina desprotonada nesses solventes e foram caracterizados os máximos das posições das bandas do espectro de absorção da EM- Nas tabelas 1.1 e 1.2, apresentamos um sumário desses resultados e também de resultados encontrados na literatura, incluindo valores obtidos através de técnicas experimentais e de métodos teóricos. Nessas tabelas estão listados somente valores correspondentes às três primeiras bandas mais intensas do espectro de absorção da Emodina, que segundo nosso trabalho de mestrado e alguns trabalhos da literatura são caracterizadas por transições do tipo $\pi-\pi^{*}[18,29,35,36]$. 
Tabela 1.1: Sumário dos valores experimentais para os máximos de absorção (nm) das bandas do espectro da Emodina apresentados na nossa dissertação de mestrado e encontrados na literatura.

\begin{tabular}{|c|c|c|c|c|c|c|c|}
\hline \multirow[b]{2}{*}{ Solução } & \multirow[b]{2}{*}{ Bandas } & \multicolumn{3}{|c|}{ Dissertação [32] } & \multicolumn{3}{|c|}{ Literatura [29] } \\
\hline & & Água & Metanol & Clorofórmio & $\begin{array}{l}\text { Água- } \\
\text { etanol }\end{array}$ & $\begin{array}{l}\text { Polím.- } \\
\text { PVA }\end{array}$ & Etanol \\
\hline \multirow{3}{*}{ Ácida } & $1^{\mathrm{a}}$ & 434 & 436 & -- & 437 & 444 & 440 \\
\hline & $2^{\mathrm{a}}$ & -- & 290 & -- & 290 & 290 & -- \\
\hline & $3^{\mathrm{a}}$ & 266 & 267 & -- & 266 & 269 & -- \\
\hline \multirow{3}{*}{ Neutra } & $1^{\mathrm{a}}$ & 434 & 440 & 442 & -- & -- & -- \\
\hline & $2^{\mathrm{a}}$ & -- & 294 & 290 & -- & -- & -- \\
\hline & $3^{\mathrm{a}}$ & -- & 256 & 268 & -- & -- & -- \\
\hline \multirow{3}{*}{ Alcalina } & $1^{\mathrm{a}}$ & 520 & 513 & -- & 505 & 505 & 526 \\
\hline & $2^{\mathrm{a}}$ & 309 & 309 & -- & 314 & 307 & -- \\
\hline & $3^{\mathrm{a}}$ & 257 & 256 & -- & 255 & 257 & --- \\
\hline
\end{tabular}

Do ponto de vista experimental existem poucos trabalhos na literatura que investigaram a interação de antraquinonas com bicamadas lipídicas. Dois trabalhos que merecem destaque são o trabalho de Alves e colaboradores [15], que investiga a interação de duas antranquinonas, a Emodina e Barbaloína com bicamada lipídica formadas por lipídios de DMPC, DMPG e DEPE, usando técnicas de DSC, espalhamento de luz e fluorescência, e o trabalho de Duarte e colaboradores [16], que usa as técnicas de RPE, DSC, viscosidade e espalhamento de raios X a baixos ângulos (SAXS) para caracterizar as propriedades estruturais e investigar as mudanças causadas pela presença da Barbaloína em bicamadas de DMPG. 
Tabela 1.2: Sumário dos valores teóricos para os máximos de absorção (nm) das cinco primeiras bandas do espectro da Emodina apresentados na nossa dissertação de mestrado (calculados com método $B 3 L Y P / 6-31 G * / / I N D O / C I S(S C R F))^{\text {a }}$ e encontrados na literatura calculados com diversos métodos.

\begin{tabular}{cccccccc}
\hline \multicolumn{4}{c}{ Dissertação [32] } & \multicolumn{2}{c}{ Literatura [29,37] } \\
\hline Bandas Gas & Água & Metanol Clorofór. $\begin{array}{l}\text { Mét. } \\
\alpha(\beta)\end{array}$ & Mét. ${ }^{\chi(\delta)}$ & Mét. ${ }^{\varepsilon}$ \\
\hline $1^{\text {a }}$ & 440 & 444 & 444 & 443 & $364(263)$ & $445(433)$ & 450 \\
$2^{\text {a }}$ & 351 & 350 & 350 & 351 & $-\ldots$ & $-\ldots$ & $402 ; 395$ \\
$3^{\text {a }}$ & 322 & 321 & 321 & 321 & $-\ldots$ & $-\ldots$ & $385 ; 333$ \\
$4^{\text {a }}$ & 291 & 291 & 291 & 291 & $-\ldots$ & $-\ldots$ & $318 ; 284$ \\
$3^{\text {a }}$ & 258 & 259 & 259 & 258 & $-\ldots$ & $-\ldots$ & $269 ; 257$ \\
\hline \hline
\end{tabular}

(a) A notação indica que a otimização de geometria foi realizada com método $B 3 L Y P / 6$ - $31 G *$ e o cálculo do espectro com o método INDO/CIS(SCRF). ${ }^{\alpha} \mathrm{AM} 1 / / \mathrm{ZINDO},{ }^{\beta} \mathrm{HF} / 6-31 \mathrm{G}(\mathrm{d}) / / \mathrm{CIS} / 6-31 \mathrm{G}(\mathrm{d})$,

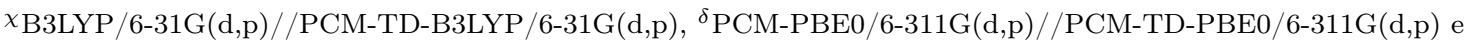
${ }^{\varepsilon}$ B3LYP/6-31G(d,p)//PCM-TD-B3LYP/6-31+G(d,p)

O uso dessas técnicas para estudar a interação das antraquinonas com bicamadas lipídicas mostrou que a presença dessas moléculas nas bicamadas lipídicas alteram as propriedades estruturais dessas bicamadas, pois tanto a Emodina como a Barbaloína mostraram interagir com as bicamadas de DMPC, DMPG e DEPE. Isso fica claro analisando as medidas de DSC desses trabalhos, pois é mostrado que o aumento da concentração dessas antraquinonas na bicamada lipídica provoca um deslocamento da temperatura da pré-transição, e da transição de fase gel para fluido ou líquidocristalina $\left(L_{\beta} \rightarrow L_{\alpha}\right)$, para baixos valores de temperatura. Esse comportamento é 
acompanhado por uma redução considerável da entalpia com o aumento da concentração da antraquinona em bicamada lipídica. Na figura 1.3 estão mostrados os gráficos dessas medidas de DSC da Emodina em bicamada DMPC, DMPG e DEPE.
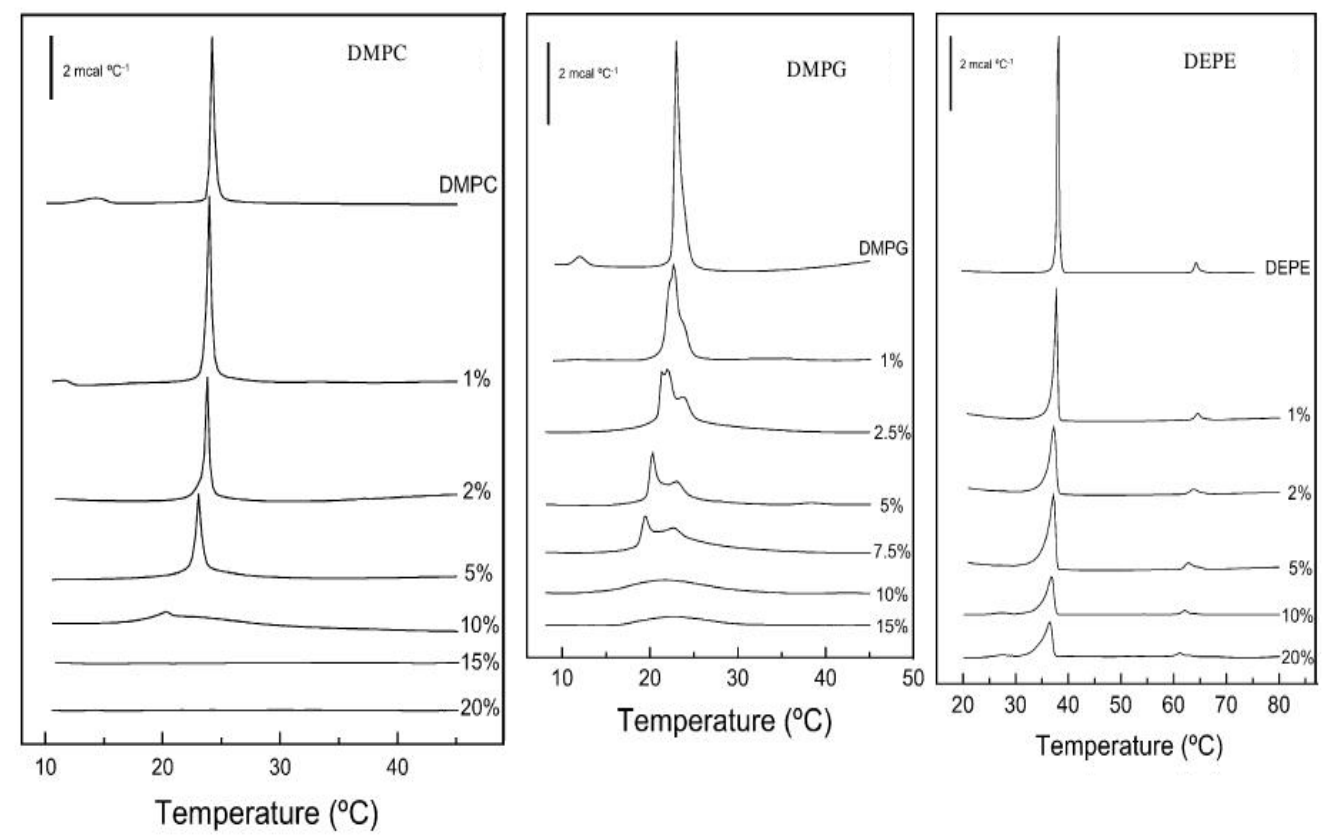

Figura 1.3: Curvas de DSC de dispersões lipídicas de DMPC, DMPG e DEPE contendo a Emodina em diferentes concentrações. Essa figura foi extraída do trabalho de Alves e colaboradores [15].

\subsection{Descrição do solvente e bicamada lipídica}

Existe um grande interesse em estudar as interações de moléculas com meios biológicos a fim de caracterizar o efeito do meio nas propriedades físico-químicos das moléculas ou usar as moléculas como sondas do ambiente. É conhecido que diferentes meios geram inúmeras possibilidades como mudanças nas propriedades eletrônicas, conformacionais e químicas de moléculas. Neste trabalho estamos interessados em estudar particularmente moléculas em meios homogêneos (solventes) e heterogêneos (bicamadas lipídicas). 
Uma das primeiras metodologias para incluir o solvente no cálculo de propriedades físico-químicas de moléculas surgiu no início do século XX com os modelos contínuos de solventes com os trabalhos de Born [38], Onsager [39] e de Kirkwood [40]. Nesses trabalhos, a descrição do solvente é dada através de um meio dielétrico caracterizado por parâmetros macroscópicos, tais como a constante dielétrica ou índice de refração. Assim, a idéia principal da solvatação por modelos contínuos de solventes é inserir a molécula do soluto isolada numa cavidade circundada por um meio dielétrico contínuo polarizável de constante dielétrica $\epsilon$. A distribuição de cargas desse soluto dentro da cavidade polariza o meio dielétrico, que por sua vez polariza a distribuição de carga do soluto através de um campo de reação. Assim, ao resolver esse problema usando a mecânica quântica, é gerado um processo interativo de autoconsistência, daí o nome do modelo, Campo de Reação Autoconsistente (SCRF). Esse modelo foi introduzido na mecânica quântica por Rivail e Rinaldi [41,42], e Tapia e Goscinski [43] na década de 70 do século XX.

Uma característica em comum entre os modelos contínuos de solventes é o conceito de cavidade. Esses modelos são compostos de uma molécula ou poucas moléculas dentro de uma cavidade circundada por um meio dielétrico contínuo. Assim, as propriedades relacionadas à solvatação do soluto nesse meio são dependentes da forma e tamanho da cavidade em que o soluto é circundado por esse meio dielétrico. Como praticamente cada modelo define a cavidade de forma diferente, eles fornecem valores diferentes para as propriedades relacionadas à solvatação. Assim, vários trabalhos têm sido publicados a fim de minimizar esse problema [44-48]. No trabalho de Onsager [39] é condicionado que a cavidade deve ter um significado físico, e que ela não deve ser criada usando apenas artifícios matemáticos. Nesse trabalho é proposto cavidades com simetria esférica ou elipsoidal. Baseado nesse trabalho, alguns modelos têm sido propostos onde a cavidade é delimitada pela superfície acessível ao solvente [49-52]. Outros modelos definem a cavidade como uma superposição de esferas centradas nos 
átomos do soluto, com os raios dessas esferas próximo dos valores de raios de van der Waals, gerando, portanto, uma cavidade no formato do soluto [53,54]. Dentre os modelos que utilizam esse tipo de cavidade, está o modelo contínuo polarizável (PCM) desenvolvido há 30 anos em Miertus e colaboradores [55].

Apesar da proposta do modelo PCM ter sido inicialmente para meios homogêneos, nos últimos anos, alguns trabalhos foram publicados, onde eles propõem extensões desse modelo para meios heterogêneos através de propostas mais gerais para densidade de cargas geradas na superfície da cavidade e mudanças do meio homogêneo dielétrico representado por $\epsilon$ e por um meio heterogêneo representado por uma constante dielétrica $\epsilon(r)$, dependente da posição radial [56-58]. Dentre esses modelos o CPCM [59] e IEFPPCM [49], têm se destacado na literatura, em particular o IEFPPCM que têm sido aplicados na descrição de soluções iônicas, líquidos cristalinos e também no estudo do efeito de bicamadas lipídicas na estrutura eletrônica de moléculas de interesse biológico [60,61]. Uma descrição ampla desses novos modelos contínuos pode ser encontradas nos seguintes artigos de revisão [49,62-64].

Além da descrição de meios moleculares por modelos contínuos, existem outras formas de descrever esses meios através de modelos discretos de moléculas. Nesses modelos, as moléculas que compõem o meio são incluídas explicitamente nos cálculos. Esses modelos discretos podem ser usados para descrição de meios moleculares, homogêneos (solventes puros, sólidos puros) e heterogêneos (misturas de solventes, soluções iônicas, líquidos cristalinos e bicamadas lipídicas). Atualmente, a inclusão de moléculas explícitas no cálculo pode ser feita através de cálculos quânticos, simulações com dinâmica quântica ou de primeiros princípios e simulações computacionais clássicas. Tanto no cálculo quântico como na dinâmica quântica a descrição do sistema molecular é baseada em um hamiltoniano quântico, onde as interações moleculares são descritas pela Mecânica Quântica através de métodos ab initio. A solvatação com cálculo quântico é baseada na a proximação de aglomerados otimizados, conhecida também como 
aproximação de "clusters" [65-67]. Nessa aproximação a solvatação é limitada, pois o cálculo quântico é realizado em um aglomerado formado pela molécula do soluto e poucas moléculas do solvente, numa conformação de mínima energia. Além disso, essa aproximação despreza dois aspectos importantes de soluções: a temperatura e a natureza estatística do solvente. A inclusão desses dois aspectos na dinâmica quântica é sem sombra de dúvidas a principal diferença entre a dinâmica e aproximação de aglomerados, visto que a dinâmica quântica gera novas configurações moleculares acessíveis a uma dada condição termodinâmica. Embora na dinâmica quântica os efeitos térmicos e a natureza estatística do solvente são levados em consideração, a definição da solvatação é também limitada a poucas moléculas explícitas do solvente devido à capacidade computacional. Essa limitação praticamente impossibilita a abordagem de sistemas muito grandes, como bicamadas lipídicas, através desses modelos.

A simulação computacional surgiu na metade do século XX como uma nova ferramenta para estudar meios moleculares de modo mais geral. Usando essa ferramenta é possível descrever tanto meios homogêneos como heterogêneos levando em consideração os principais aspectos de dispersões, como a temperatura e a natureza estatística desses sistemas. Atualmente existem duas metodologias bem estabelecidas que permitem realizar esse tipo de simulação computacional, o método Monte Carlo (MC) que surgiu com a publicação dos trabalhos de Metropolis e colaboradores [68] e a Dinâmica Molecular (MD) ${ }^{1}$ introduzida por Alder e Wainwright [69,70], ambas introduzidas na década de 50 do século XX. Com o desenvolvimento dessas técnicas de simulações computacionais tornou-se possível estudar as propriedades fundamentais de sistemas moleculares desde sistemas pequenos como um soluto solvatado por algumas centenas de moléculas de solvente, como sistemas enormes, como bicamadas lipídicas. Uma descrição ampla dessas duas metodologias pode ser encontrada nas seguintes referências [71,72].

\footnotetext{
${ }^{1}$ Molecular dynamics (MD)
} 


\subsection{Bicamadas lipídicas}

Membranas biológicas são estruturas essenciais para os organismos vivos, pois são responsáveis por funções importantíssimas para vida, tais como a separação e proteção das células do meio externo, como também a compartimentalização de células e organelas, e envoltório de vírus encapsulados. Essas membranas participam de processos biológicos fundamentais para a manutenção da vida como divisão celular, controle e regulagem intracelular de nutrientes, íons, água e outras substâncias para dentro e fora das células. Embora essas membranas sejam compostas por uma grande variedade de componentes, incluindo lipídios, proteínas, esteróis e carboidratos, elas são formadas predominantemente por lipídios e proteínas, em particular os fosfolipídios [73-77].

Os fosfolipídios são moléculas anfifílicas formados por uma cabeça polar e duas cadeias hidrocarbônicas. Essas moléculas são responsáveis pela formação espontânea de estrutura em bicamadas lipídicas, que podem se fechar e formar liposomos, quando dispersas em solução aquosa. Isso ocorre devido ao caráter anfifílico dessas moléculas, onde a cabeça polar fica exposta à água, enquanto as cadeias hidrocarbônicas ficam em contato entre si. Em concentrações adequadas de fosfolipídios, é observado que as bicamadas lipídicas podem formar estruturas volumétricas unilamelares ou multilamelares [78-81].

Bicamadas fosfolipídicas vêm sendo amplamente estudadas como modelos para membranas biológicas. É conhecido que essas bicamadas apresentam transições de fase em uma dada temperatura, onde os fosfolipídios deixam um estado ordenado, chamado de fase gel, para um estado desordenado, chamado de fase fluida ou líquido-cristalina [82-84]. Do ponto de vista biológico, é a fase fluida, ou líquido-cristalina a fase mais relevante nas condições fisiológicas, onde as cadeias hidrocarbônicas dos fosfolipídios estão flexíveis e desordenadas favorecendo diversos mecanismos biológicos, tais como o transporte de íons, água e outros nutrientes para dentro e fora das células [85, 86]. 
Nos últimos anos diversos cientistas têm tentado compreender esses sistemas através do uso de técnicas experimentais e teóricas [87-90].

As simulações computacionais com Dinâmica Molecular vêm sendo amplamente utilizadas em modelagem molecular de bicamadas fosfolipídicas, contribuindo de forma significativa no entendimento e caracterização de propriedades relacionadas à estrutura e à dinâmica desses sistemas, e na interpretação de resultados experimentais de membranas biológicas. Vários processos moleculares relacionados a esses sistemas, tais como a formação espontânea de bicamada lipídicas por fosfolipídios [91], formação e fusão de vesículas [92], transporte de íons e formação de poros na membrana [93, 94] e formação da fase gel [95] e "ripple" [96] têm sido modelado através de Dinâmica Molecular nos últimos anos. Com essas simulações tem sido possível analisar, a nível atômico, as interações moleculares, identificar, por exemplo, interações específicas como ligações de hidrogênio entre o grupo da colina ou grupos de interesse com as moléculas de água, e localizar posições características de moléculas de interesse biológico nas bicamadas lipídicas [90, 97, 98].

A credibilidade e a qualidade dos resultados de uma dinâmica molecular clássica dependem crucialmente do campo de força usado na descrição das interações intermolecular e intramoleculares do sistema molecular estudado. A escolha ou construção desse campo de força é sem dúvida um dos maiores desafios na realização de uma simulação computacional. Existe uma variedade de campos de forças disponíveis que podem ser usados para estudar uma série de sistemas moleculares. Atualmente, os campos de força mais usados para descrição de sistemas fosfolipídicos são: CHARMM $[99,100]$, OPLS [101, 102] e GROMOS96 [103]. Neste trabalho, escolhemos a última versão do GROMOS96, (GROMOS 54a7) [104, 105], para realização das nossas simulações computacionais das bicamadas lipídicas. Esse campo de força é uma versão corrigida do GROMOS 53a6, que foi desenvolvido e validado pelo grupo do W. F. van Gunsteren [106], tendo como filosofia principal a reprodutibilidade de propriedades 
termodinâmicas, tais como entalpia e energia livre de solvatação de moléculas biológicas.

O campo de força GROMOS 53a6 vem sendo amplamente usado e validado com sucesso em modelagens de sistemas biológicos como peptídeos, proteínas, DNA e fármacos solvatados em água $[107,108]$. Embora esse campo de força consiga descrever bem esses sistemas, para sistemas fosfolipídios ele tem sido falho, pois ele não consegue descrever adequadamente as interações interatômicas dos fosfolipídios do grupo fosfatidilcolina, como por exemplo, 1,2-dimiristoil-sn-glicero-3-fosfocolina (DMPC), 1,2dipalmitoil-sn-glicero-3-fosfocolina (DPPC), 1,2-dilauroil-sn-glicero-3-fosfocolina (DLPC) e 1,2-dioleoil-sn-glicero-3-fosfocolina (DOPC), etc. Esse problema foi resolvido pelo grupo do W. F. van Gunsteren, onde foram aumentados os raios de van der Waals dos grupos metilas da colina e dos oxigênios do fosfato não pertencente ao grupo do éster, aumentando com isso a repulsão entre esses grupos. Além disso, eles mudaram o conjunto de cargas atômicas dos fosfolipídios para o um conjunto de cargas, obtido por Chiu e colaboradores, através de um cálculo quântico, usando um método $a b$ initio [109]. Essa correção foi implementada no campo de força GROMOS G53a6, chamada de G53a6L [110], que posteriormente foi usada no desenvolvimento do campo de força GROMOS $54 a 7$ [104,105]. Esse campo tem descrito bem as propriedades das bicamadas lipídicas de DMPC, DPPC, DOPC, DLPC, etc., tais como, área e volume por fosfolipídio, densidade eletrônica, parâmetro de ordem e conformação das cadeias hidrocarbônicas com boa concordância com os resultados experimentais [111]. Portanto neste trabalho, usamos esse campo de força para realizar as simulações computacionais das espécies da Emodina neutra e desprotonada em bicamadas lipídicas, particularmente, bicamadas formadas pelo fosfolipídio DMPC, ver figura 1.4. Através dessas simulações estudamos a nível atômico as interações moleculares das espécies da Emodina com esse meio anfifílico, e caracterizamos as propriedades, como também monitoramos as posições dessas espécies dentro da bicamada. 
Tabela 1.3: Sumário das propriedades estruturais de bicamadas lipídicas hidratadas puras de DMPC, obtidas através de medidas experimentais e simulações computacionais com dinâmica molecular. As propriedades listadas nessa tabela são a área por lipídio $\left(A_{L}\right)$, volume por lipídio $\left(V_{L}\right)$, módulo de compressibilidade isotérmica da área $\left(K_{A}\right)$, espessura da bicamada $\left(D_{H H}\right)$ e espessura de Luzzati $\left(D_{B}\right)$.

\begin{tabular}{llllll}
\hline \hline DMPC & $\mathrm{A}_{\mathrm{L}}\left(\mathrm{nm}^{2}\right)$ & $\mathrm{V}_{\mathrm{L}}\left(\mathrm{nm}^{3}\right)$ & $\mathrm{K}_{\mathrm{A}}\left(\mathrm{mN} . \mathrm{m}^{-1}\right)$ & $\mathrm{D}_{\mathrm{HH}}(\mathrm{nm})$ & $\mathrm{D}_{\mathrm{B}}(\mathrm{nm})$ \\
\hline Experimental & $0.58-0.67^{\alpha}$ & $1.09,1.10^{\chi}$ & $234,257^{\phi}$ & $3.44-3.60^{\eta}$ & $3.07-3.69^{\eta}$ \\
Simulação & $0.57-0.66^{\beta}$ & $0.98-1.23^{\varepsilon}$ & $226-475^{\gamma}$ & $2.92-3.35^{\varepsilon}$ & $2.99-3.49^{\varepsilon}$ \\
\hline \hline
\end{tabular}

Ver as seguintes referências: $\alpha$ - [112-119] ; $\beta$ - [110,111,120-126]; $\chi$ - [81,118,119,127]; $\varepsilon$ - [110,111,128, 129]; $\phi-[81,130] \gamma-[110,111,129] ; \eta-[81,118,119]$.

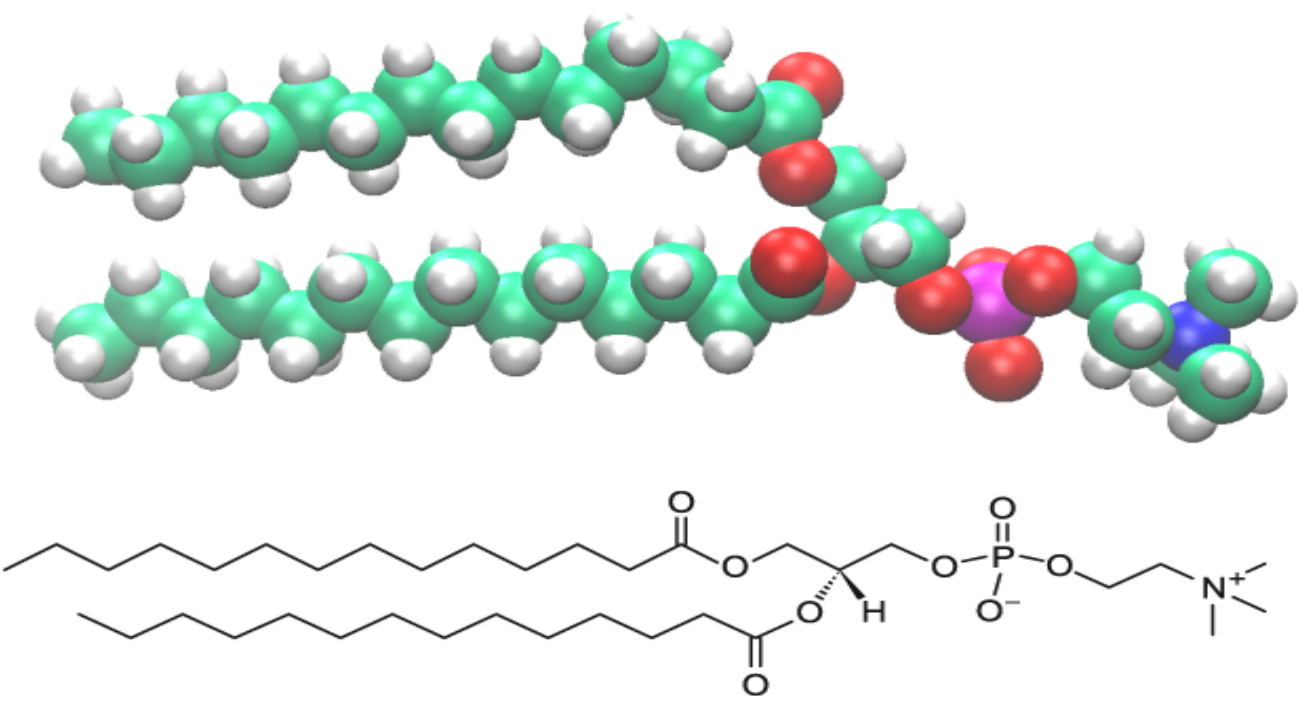

Figura 1.4: Estrutura molecular e química da molécula do fosfolipídio 1,2-dimiristoil-snglicero-3-fosfocolina (DMPC).

O fosfolipídio DMPC é um lipídio saturado, zwitteriônico formado por 2 cadeias hidrocarbônicas contendo 14 carbonos em cada e um fosfato e um grupo colina na 
cabeça polar, ver figura 1.4. Esse fosfolipídio é um dos lipídios pertencente ao grupo fosfatidilcolina $(\mathrm{PC})$ mais estudado, devido à sua grande abundância nas membranas biológicas dos seres vivos com células eucarióticas [77, 81, 131-133] e em envoltório de vírus encapsulados por membranas lipídica como o HIV [134] e HSV [135]. Devido a isso, as bicamadas lipídicas formadas de DMPC vêm sendo largamente usadas e estudadas como modelos para as membranas do envoltório desses vírus encapsulados [136-143]. Do ponto de vista experimental e teórico, essas bicamadas lipídicas puras, ou seja, formadas apenas com um tipo de fosfolipídio, vêm sendo amplamente investigadas. Experimentalmente, vários trabalhos têm determinado as propriedades estruturais, tais como área por lipídio $\left(A_{L}\right)$, volume por lipídio $\left(V_{L}\right)$, parâmetro de ordem, módulo de compressibilidade isotérmica da área $\left(K_{A}\right)$ e espessura da bicamada $\left(D_{H H}\right)$ e espessura de Luzzati $\left(D_{B}\right)^{2}[77,81,111,112,144-147]$. Na tabela 1.3 apresentamos um sumário dos valores experimentais e teóricos dessas propriedades encontrados na literatura para bicamadas lipídicas hidratadas puras de DMPC.

\subsection{Organização do texto}

Este texto é composto por cinco capítulos. No capítulo 2 apresentamos as metodologias teóricas e experimentais, ambas aplicadas para estudarmos as espécies da Emodina em diferentes ambientes. Neste capítulo, como metodologia teórica, foram descritas, de modo resumido, as técnicas de cálculos quânticos e simulação computacionais. Como metodologia experimental, foram descritas, também de modo resumido, as duas técnicas experimentais utilizadas, a absorção óptica e calorimetria diferencial de varredura. No capítulo 3, apresentamos os materiais e métodos utilizados nas medidas experimentais, nos cálculos quânticos e simulações computacionais. A descrição dos materiais e métodos utilizados foi separada em quatro partes: (i) descrevemos os

\footnotetext{
${ }^{2} D_{B}$ é a espessura dada pela diferença entre a distância de repetição da estrutura lamelar $(D)$ e a espessura da água $\left(D_{w}\right)$ na bicamada lipídica, ou seja, $D_{B}=D-D_{w}$.
} 
materiais utilizados, assim como suas fontes de onde eles foram adquiridos; (ii) descrevemos o preparo das amostras tanto para as medidas de absorção óptica como para medidas de DSC; (iii) apresentamos os equipamentos utilizados; (iv) descrevemos os detalhes dos métodos utilizados para os cálculos quânticos e as técnicas de simulações computacionais, bem como os parâmetros de controle dessas simulações. No capítulo 4, apresentamos nossos resultados obtidos nesta tese de doutorado. Neste capítulo, devido à complementabilidade teórica e experimental ou vice-versa das seções desse capítulo, optamos por uma apresentação dos resultados teóricos e experimentais em conjunto. A apresentação desses resultados foi dividida em três partes (seções): estudo da desprotonação da Emodina (Capítulo 4, Seção 4.2), o efeito do ambiente no espectro de absorção das espécies da Emodina (Capítulo 4, Seção 4.4) e o estudo da interação das espécies da Emodina com o ambiente (Capítulo 4, Seção 4.4). 


\section{Capítulo 2}

\section{Metodologias Teóricas e Experimentais}

\subsection{Introdução}

O estudo de sistemas moleculares requer o uso de técnicas tanto experimentais como teóricas. As propriedades eletrônicas e estruturais desses sistemas vêm sendo investigadas através do uso de técnicas experimentais principalmente no ramo da espectroscopia e cristalografia e teóricas como cálculos quânticos e simulações computacionais. Esta tese de doutorado foi desenvolvida através do uso de metodologias experimentais (medidas de absorção óptica e calorimetria diferencial de varredura) e teóricas (cálculos quânticos e simulações computacionais). Neste capítulo descreveremos de forma sucinta essas metodologias, citando as referências originais para um estudo mais completo de cada tópico.

\subsection{Metodologias Teóricas}

\subsubsection{Cálculos Quânticos}

Cálculos quânticos de moléculas requerem o uso de métodos aproximativos, que em geral tentam resolver a equação de Schrödinger independente do tempo, em sua 
maioria para os elétrons. Todos os métodos que se baseiam na obtenção de alguma solução dessa equação, fundamentados apenas nos postulados da mecânica quântica são considerados ab initio ou de primeiros princípios. O primeiro método ab initio, considerado o mais simples, desenvolvido para cálculos de estrutura eletrônica é o método de Hartree-Fock(HF) [148, 149]. Todos os demais métodos ab initio correlacionados pós-HF, como a teoria de perturbação de Møller-Plesset(MPn) [150], o método de interação de configuração (CI) [151-153], o método Coupled-Cluster(CC)) [154], e mais outros métodos foram formulados baseados no método HF. Para uma listagem completa dos métodos ab initio, veja as seguintes referências [155-159]. Uma característica comum entre esses métodos, é que todos eles utilizam a função de onda de $\mathrm{N}$ elétrons como variável básica para calcular os observáveis físicos de interesse. Devido a essa característica e às suas formulações, esses métodos seguem praticamente um mesmo roteiro descrito pela sequência abaixo,

$$
v(\mathbf{r}) \Longrightarrow \Psi\left(\mathbf{r}_{1}, \mathbf{r}_{2}, \ldots, \mathbf{r}_{N}\right) \Longrightarrow \text { observáveis, }
$$

ou seja, uma vez conhecido o potencial de interação do sistema molecular, $v(\mathbf{r})$, é definido o hamiltoniano $\hat{\mathbf{H}}$ e resolvido a equação de Schrödinger para obtenção da função de onda, $\Psi$, e calculado os observáveis. Um dos observáveis que pode ser calculado através desses métodos é a densidade eletrônica do sistema,

$$
\rho(\mathbf{r})=\int \ldots \int \Psi\left(\mathbf{r}_{1}, \mathbf{r}_{2}, \ldots, \mathbf{r}_{N}\right)^{*} \Psi\left(\mathbf{r}_{1}, \mathbf{r}_{2}, \ldots, \mathbf{r}_{N}\right) d \mathbf{r}_{2} d \mathbf{r}_{3} \ldots d \mathbf{r}_{N}
$$

O fato desses métodos ab initio dependerem da função de onda, que depende das $3 \mathrm{~N}$ variáveis espaciais mais as variáveis do spin, em que $\mathrm{N}$ é o número de elétrons do sistema, de certo modo, limita os tamanhos do sistema que podem ser tratados através desses métodos. Sistemas moleculares contendo centenas de átamos são muitos custosos de serem tratados com esses métodos [158,159].

Além desses métodos, existem os métodos baseados na Teoria do Funcional da 
Densidade $(\mathrm{DFT})^{1}$ [161,162], que também se baseiam na obtenção de alguma solução para a equação de Schrödinger, fundamentados nos princípios da Mecânica Quântica, porém utilizam a densidade eletrônica, $\rho$, como variável básica, em vez de se utilizar a função de onda, $\Psi$. Devido a isso, esses métodos seguem um roteiro diferente dos métodos ab initio mencionados acima. Os métodos DFT seguem praticamente a seguinte sequência,

$$
\rho(\mathbf{r}) \Longrightarrow \Psi\left(\mathbf{r}_{1}, \mathbf{r}_{2}, \ldots, \mathbf{r}_{N}\right) \Longrightarrow \text { observáveis, }
$$

ou seja, uma vez conhecida a densidade eletrônica do sistema, é possível determinar a função de onda e o potencial de interação do sistema, e consequentemente todos os observáveis físicos de interesse. Embora a sequência acima descreva a estrutura conceitual dos métodos DFT, na prática esses métodos não seguem necessariamente essa sequência, pois, em geral, os observáveis, tais como energia cinética $(T)$ e potencial $(U)$ são calculados sem o uso explícito da função de onda, visto que esses observáveis são definidos como funcionais de $\rho(\mathbf{r})$, ou seja, $T[\rho]$ e $U[\rho]$. A vantagem de se utilizar metodos DFT, em vez de métodos baseados na função de onda, para cálculo de estrutura eletrônica, é que eles são considerados mais viáveis e versáteis computacionalmente, pois o uso de $\rho(\mathbf{r})$, como variável principal, reduz a dimensionalidade do problema de $3 \mathrm{~N}$ variáveis para somente 3 , visto que, independentemente da quantidade de elétrons do sistema, a densidade eletrônica é sempre dependente de três dimensões $x, y$ e $z$.

Devido ao alto custo computacional, os métodos ab initio e DFT ainda não são a melhor opção para o estudo de sistemas moleculares grandes (milhares de átomos). Para isso, existem os métodos semi-empíricos, que são construídos baseados, princi-

\footnotetext{
${ }^{1} \mathrm{O}$ rótulo de "ab initio" dos métodos de DFT é condicionado ao funcional. Se o funcional dispensa qualquer tipo de parametrização, ou seja, são contruídos baseados somente nos princípios da Mecânica Quântica, devem ser considerados métodos ab initio. Porém, se o funcional requer algum tipo de parametrização, como os funcionais híbridos de DFT, que utilizam resultados obtidos a partir de cálculos Hartree-Fock em suas parametrizações, devem ser considerados métodos semi-empíricos. Embora essas definições pareçam simples, existem na literatura controvésias quanto a aplicação do rótulo de "ab initio" aos métodos DFT. Mas, em geral, os métodos DFT são classificados em dois tipos, DFT puro e DFT híbrido, em vez de DFT ab initio e DFT semi-empíricos, para uma discussão mais ampla desse assunto, recomendamos a seguinte referência [160].
} 
palmente no método Hartree-Fock. Os métodos semi-empíricos buscam resolver as equações de HF, porém utilizando parametrizações [156, 158, 163]. Esses métodos, em geral, negligenciam ou aproximam determinadas integrais por valores empíricos confiáveis obtidos a partir de cálculos ab initio ou de dados experimentais, de modo que os resultados produzidos por esses cálculos apresentam boa concordância com os dados experimentais ou com os resultados obtidos de cálculos ab initio. Os principais métodos semi-empíricos disponíveis são ZDO [164], CNDO [165-167], INDO [168,169], NDDO [165,166], MINDO [170], MNDO [170,171], AM1 [172], PM3 [173], RM1 [174] e outros. Esses métodos são muito importantes no cenário atual da química quântica, pois suas aproximações permite o tratamento de sistemas moleculares grandes, onde o uso de métodos ab initio se torna muito caro.

Vale a pena salientar que tanto os métodos ab initio como os métodos DFT não obtém uma solução exata para equação de Schrödinger, uma vez que algumas aproximações são realizadas em alguma fase do desenvolvimento desses métodos ou em suas aplicações de modo a tornar os cálculos flexíveis e viáveis do ponto de vista computacional. Uma aproximação fundamental e comum em todos esses métodos mencionados acima é a de Bohr-Oppenheimer (BO), que simplifica a solução da equação de Schrödinger para moléculas através do desacoplamento dos movimentos dos núcleos e elétrons, visto que as energias cinéticas dessas partículas, em geral, têm ordens de grandeza diferentes [175]. Essa aproximação é válida para sistemas moleculares desde que não haja um acoplamento significativo entre diferentes estados eletrônicos [155]. Assim, em termos gerais a aproximação BO permite separar o hamiltoniano complexo em dois termos, um correspondente a parte eletrônica, $\hat{H}_{\text {elet }}$, e outro a parte nuclear, $\hat{H}_{n u c l}$, ou seja,

$$
\begin{gathered}
\hat{H}_{\text {elet }}(\mathbf{r} ; \mathbf{R}) \Psi(\mathbf{r} ; \mathbf{R})=\varepsilon_{\text {elet }} \Psi(\mathbf{r} ; \mathbf{R}) \\
\hat{H}_{\text {núcl }}(\mathbf{R}) \chi(\mathbf{R})=E_{\text {núcl }} \chi(\mathbf{R})
\end{gathered}
$$

em que $\mathbf{r}$ e $\mathbf{R}$ são, respectivamente, o vetor posição dos elétrons e o vetor posição 
dos núcleos, enquanto $\Psi$ e $\chi$ denotam as autofunções dos elétrons e núcleos; $\varepsilon_{\text {elet }}$ e $E_{\text {núcl }}$ são as autoenergias dessas partículas, respectivamente. Assim, baseado nessa aproximação, a descrição do movimento nuclear é obtida a partir da solução da parte eletrônica, que é a parte mais complicada de se resolver. Portanto, o maior esforço dos cálculos quânticos, tanto os ab initio, como os DFT é dedidado a resolver a estrutura eletrônica. Na descrição seguinte dos métodos quânticos, devido ao uso, em geral, de um método DFT nos cálculos quânticos desta tese de doutorado, optamos por uma descrição da Teoria do Funcional da Densidade, mas recomendamos a leitura das seguintes referências $[155,156,158-160,176,177]$ para uma discussão mais ampla dos métodos de química quântica.

\subsubsection{Teoria do funcional da densidade}

Em 1998 Walter Konh da Universidade da Califórnia da Santa Barbara, USA, e John A. Pople, da Universidade Northwestern, USA, foram agraciados pelo prêmio Nobel em Química por suas contribuições pioneiras no desenvolvimento de métodos teóricos para examinar as propriedades moleculares e processos químicos envolvidos em sistemas moleculares [178]. Especificamente, W. Kohn recebeu esse prêmio por ter desenvolvido a Teoria do Funcional da Densidade (DFT) e J. Pople, por suas contribuições no desenvolvimento de métodos computacionais em Química Quântica. Apesar de W. Kohn ter recebido o Nobel recentemente, a Teoria do Funcional da Densidade foi desenvolvida em 1964 no trabalho de P. Hohenberg e W. Kohn [161]. Desde então, o DFT tem se tornado um método útil, poderoso e popular dentro da Química Teórica.

O DFT fornece uma estratégia inteligente de determinar a energia do estado fundamental $E_{0}$ e a densidade eletrônica $\rho(\mathbf{r})$ para um sistema de $\mathrm{N}$ elétrons interagentes na presença de um potencial externo $v(\mathbf{r})$, que no caso molecular é devido aos núcleos. Essas propriedades são determinadas mediante um procedimento autoconsis- 
tente da resolução da equação de Schrödinger para um sistema fictício de "elétrons não interagentes",

$$
\hat{\mathbf{H}}^{K S}\left|\psi_{i \sigma}^{K S}\right\rangle=\epsilon_{i \sigma}\left|\psi_{i \sigma}^{K S}\right\rangle,
$$

em que $\hat{\mathbf{H}}^{K S},\left|\psi_{i \sigma}^{K S}\right\rangle$ e $\epsilon_{i \sigma}$ são, respectivamente, o hamiltoniano, a autofunção e a autoenergia propostos por Kohn e Sham para um dado elétron $i$ com $\sigma=\uparrow$ ou $\sigma=\downarrow$ que representa a componente $\mathrm{z}$ do spin $(1 / 2$ ou $-1 / 2)$. Esse hamiltoniano é escrito em termos de um potencial local efetivo como,

$$
\hat{\mathbf{H}}^{K S}=-\frac{1}{2} \nabla_{i}^{2}+v_{e f}([\rho] ; \mathbf{r})
$$

onde o primeiro termo do lado direito da equação 2.7 é o operador energia cinética e o segundo termo é potencial local efetivo, que é dado por,

$$
v_{e f}=v(\mathbf{r})+\int \frac{\rho\left(\mathbf{r}^{\prime}\right)}{\mathbf{r}-\mathbf{r}^{\prime}} d^{3} \mathbf{r}^{\prime}+v_{x c}^{\sigma}\left(\left[\rho_{\uparrow}, \rho_{\downarrow}\right] ; \mathbf{r}\right) .
$$

Na equação 2.8, o primeiro termo representa o potencial externo devido aos núcleos, o segundo termo é o potencial de Hartree e o último termo é o potencial de troca e correlação que contempla os termos de natureza quântica da interação elétronelétron. A densidade eletrônica para um conjunto de elétrons com um dado valor de $\sigma$ é definida como segue:

$$
\rho_{\sigma}(\mathbf{r})=\sum_{i} n_{i \sigma}\left|\psi_{i \sigma}(\mathbf{r})\right|^{2}
$$

em que $n_{i \sigma}$ é definido como os possíveis números de ocupação, que está relacionado com o potencial químico $\mu$, através de uma "função step", $n_{i \sigma}=\theta\left(\mu-\epsilon_{i \sigma}\right)$, o que garante que todos os orbitais de Kohn-Sham com $\epsilon_{i \sigma}<\mu$ estão individualmente ocupados e $\epsilon_{i \sigma}>\mu$ estão vazios. Portanto a densidade eletrônica total do sistema é escrita como,

$$
\rho(\mathbf{r})=\rho_{\uparrow}(\mathbf{r})+\rho_{\downarrow}(\mathbf{r}) .
$$

Na equação 2.9, o potencial químico é escolhido de modo a satisfazer as seguintes condições,

$$
\rho(\mathbf{r}) \geq 0,
$$




$$
\int \rho(\mathbf{r}) d^{3} \mathbf{r}=N
$$

onde $\mathrm{N}$ representa o número total de elétrons do sistema. Assim, a energia total do sistema é dada por,

$$
E_{0}=T_{S}\left[\rho_{\uparrow}, \rho_{\downarrow}\right]+\int v(\mathbf{r}) \rho(\mathbf{r}) d^{3} \mathbf{r}+U[\rho]+E_{x c}\left[\rho_{\uparrow}, \rho_{\downarrow}\right]
$$

onde o funcional $T_{S}\left[\rho_{\uparrow}, \rho_{\downarrow}\right]$ representa a energia cinética do sistema de elétrons que não interagem, que é calculada exatamente pela equação,

$$
T_{S}\left[\rho_{\uparrow}, \rho_{\downarrow}\right]=\sum_{\sigma} \sum_{i} \theta\left(\mu-\epsilon_{i \sigma}\right)\left\langle\psi_{i \sigma}^{K S}\left|-\frac{1}{2} \nabla_{i}^{2}\right| \psi_{i \sigma}^{K S}\right\rangle .
$$

O segundo termo da equação 2.13, representa a energia devido à interação dos elétrons com o potencial externo e o terceiro termo, representa o potencial de Hartree que contempla a autointeração coulômbiana da densidade eletrônica, que é dada por,

$$
U[\rho]=\frac{1}{2} \int d^{3} \mathbf{r} \int \frac{\rho(\mathbf{r}) \rho\left(\mathbf{r}^{\prime}\right)}{\left|\mathbf{r}-\mathbf{r}^{\prime}\right|} d^{3} \mathbf{r}^{\prime} .
$$

A energia de troca e correlação $E_{x c}\left[\rho_{\uparrow}, \rho_{\downarrow}\right]$, que é o último de termo na equação 2.13, representa não só a energia de interação elétron-elétron, mas também a diferença residual da energia cinética $T\left[\rho_{\uparrow}, \rho_{\downarrow}\right]-T_{S}\left[\rho_{\uparrow}, \rho_{\downarrow}\right]$, em que $T\left[\rho_{\uparrow}, \rho_{\downarrow}\right]$ é a energia cinética exata total do sistema de elétrons interagentes. A derivada do funcional $E_{x c}\left[\rho_{\uparrow}, \rho_{\downarrow}\right]$ com relação a densidade eletrônica produz o potencial de troca e correlação da equação 2.8,

$$
v_{x c}^{\sigma}\left(\left[\rho_{\uparrow}, \rho_{\downarrow}\right] ; \mathbf{r}\right)=\frac{\delta E_{x c}}{\delta \rho_{\sigma}(\mathbf{r})}
$$

A energia total do estado fundamental seria exatamente determinada através da equação 2.13, se fosse conhecida completamente à dependência da energia de troca e correlação com a densidade eletrônica do sistema, porém não existe uma expressão exata para o termo $E_{x c}\left[\rho_{\uparrow}, \rho_{\downarrow}\right]$, de modo que na prática esse termo é calculado através de aproximações. As duas principais aproximações para calcular esse termo são: (i) 
LSD (Local Spin Density Approximation) - Nessa aproximação o termo $E_{x c}$ é assumido como sendo o mesmo de um gás eletrônico homogêneo. A energia de troca e correlação é calculada usando o seguinte funcional,

$$
E_{x c}^{L S D}\left[\rho_{\uparrow}, \rho_{\downarrow}\right]=\int \rho(\mathbf{r}) e_{x c}^{L S D}\left[\rho_{\uparrow}(\mathbf{r}), \rho_{\downarrow}(\mathbf{r})\right] d^{3} \mathbf{r},
$$

em que $e_{x c}^{L S D}\left[\rho_{\uparrow}(\mathbf{r}), \rho_{\downarrow}(\mathbf{r})\right]$ é a energia de troca e correlação por elétron para um gás eletrônico homogêneo, veja as seguintes referências [179,180]. (ii) GGA (Generalized Gradient Approximation) - Nesta aproximação a energia de troca e correlação é calculada usando um funcional que depende da densidade eletrônica e também do gradiente dessa densidade. Esse funcional é calculado através da seguinte equação,

$$
E_{x c}^{G G A}\left[\rho_{\uparrow}, \rho_{\downarrow}\right]=\int \rho(\mathbf{r}) e_{x c}^{G G A}\left(\rho_{\uparrow}, \rho_{\downarrow}, \nabla \rho_{\uparrow}, \nabla \rho_{\downarrow}\right) d^{3} \mathbf{r}
$$

onde, similarmente a LSD, o termo $e_{x c}^{G G A}\left(\rho_{\uparrow}, \rho_{\downarrow}, \nabla \rho_{\uparrow}, \nabla \rho_{\downarrow}\right)$ é a energia de troca e correlação por elétron para um gás eletrônico não homogêneo. Para mais detalhes dessa aproximação consultar as seguintes referências [181-185].

Além das aproximações LSD e GGA, existem na literatura várias outras propostas para o funcional $E_{x c}\left[\rho_{\uparrow}, \rho_{\downarrow}\right]$ como o GGA híbrido [177, 186-188]. Esse funcional mistura uma fração da energia de troca de Hartree-Fock na energia de troca do DFT. Um exemplo desse tipo de funcional é o B3LYP (Becke, three-parameter, Lee-YangParr) $[185,187,189,190]$, que foi usado nesta tese de doutorado nos cálculos quânticos. No B3LYP a energia de troca e correlação é calculada através do seguinte funcional,

$$
E_{x c}^{B 3 L Y P}=\left(1-a_{0}\right) E_{x}^{L S D}+a_{0} E_{x}^{H F}+a_{x} \Delta E_{x}^{B 88}+a_{c} E_{c}^{L Y P}+\left(1-a_{c}\right) E_{c}^{V W N},
$$

em que o termo $\Delta E_{x}{ }^{B 88}$ representa o gradiente de correção do funcional de troca de Becke de 1988 [185], e $E_{c}^{L Y P}$ e $E_{c}^{V W N}$ representam o funcional de correção de LeeYang-Parr [187] e Vosko-Wilk-Nusair [191], respectivamente. Atualmente o B3LYP é considerado, dentro do DFT, como um funcional padrão para determinar a geometria de estado fundamental e propriedades eletrônicas como a absorção eletrônica e 
dicroísmo circular [192-195]. Esse funcional apresenta ótimos resultados para essas propriedades e baixo custo computacional quando comparado com cálculos com teoria de perturbação de Møller-Plesset de segunda ordem (MP2) e com os métodos Coupled-Cluster(CC).

\subsubsection{Aproximação LCAO e funções bases}

Nessa seção descreveremos a técnica usada nos métodos quânticos, tanto nos métodos ab initio, como nos métodos DFT, para descrever os orbitais moleculares. Nesses métodos é usado uma aproximação chamada Combinação Linear de Orbitais Atômicos (LCAO) [196]. Essa aproximação consiste em descrever cada orbital molecular desconhecido $\psi_{i}$ como uma combinação linear de orbitais atômicos conhecidos $\phi_{\nu}$

$$
\psi_{i}=\sum_{\nu}^{\kappa} C_{\nu i} \phi_{\nu} .
$$

onde $\kappa$ representa o número total de orbitais atômicos usado em cada orbital molecular. Note que uma descrição exata dos orbitais moleculares requer um conjunto de funções bases infinito, porém, isso é impraticável computacionalmente, de modo que os resultados gerados através de cálculos quânticos advém de conjuntos finitos, e apresentam, em geral, uma dependência com o tamanho do conjunto de funções bases. Embora existe essa dependência, o que se observa na prática, é uma convergência lenta para os resultados exatos do modelo, a medida que se aumenta o número de elementos que compõem esse conjunto [197].

As funções mais utilizadas em cálculos quânticos são funções do tipo Gaussianas GTO (Gaussian-Type-Orbitals). Essas funções do tipo GTO, em coordenadas cartesianas, podem ser escritas na seguinte forma,

$$
g(x, y, z)=N x^{l_{x}} y^{l_{y}} z^{l_{z}} e^{-\alpha r^{2}}
$$

onde $N$ é uma constante de normalização, $l_{k}$ é a componente do momento angular 
na direção $k$, e $r=\sqrt{x^{2}+y^{2}+z^{2}}$. A função gaussiana apresentada na equação 2.21 é geralmente conhecida como função gaussiana primitiva. Um conjunto de funções GTO primitivas pode ser representado por uma única gaussiana, chamada gaussiana contraída, dada por,

$$
g_{c}=\sum_{i}^{\kappa} a_{i} g_{p},
$$

onde os subíndices $c$ e $p$ designam contraída e primitiva, respectivamente. Esse processo de contração de várias gaussianas primitivas em uma única gaussiana, reduz a quantidade de coeficientes que precisam ser otimizados para compor a base, consequentemente, reduz o esforço computacional. Nesta tese de doutorado utilizamos a função base $6-311++\mathrm{G}^{* *}$ com o funcional B3LYP, ou seja, B3LYP $/ 6-311++\mathrm{G}^{* *}$. Essa função base, 6-311 $++\mathrm{G}^{* *}$, foi desenvolvida por Pople e colaboradores [198, 199], e é conhecida como uma função gaussiana Split-valence-triple-zeta. Essa função significa que 6 funções gaussianas primitivas foram utilizadas para descrever os orbitais do caroço, e que os orbitais de valência são subdivididos em três partes (311), sendo a primeira composta pelos orbitais de valência mais internos, em que são utilizadas 3 gaussianas primitivas, e a segunda com os obtitais de valência intermediários, em que é utilizada 1 gaussiana primitiva, e por último, com os orbitais de valência mais externos, em que é utilizada também 1 gaussiana primitiva. Na sequência, ++ significa que funções difusas nos átomos mais pesados e também nos átomos de hidrogênio e hélio são utilizadas, e o G, obviamente, é de gaussianas, e os asteriscos, **, indicam que funções polarizadas são incluídas nos orbitais atômicos de valência.

\subsubsection{Cálculo das cargas atômicas com CHELPG}

A distribuição de elétrons numa molécula é assimétrica e depende de vários fatores como composição atômica, tipos de ligações, conformação e meio em que essa molécula se encontra. Essa distribuição define as propriedades eletrostáticas da molécula através das cargas atômicas que são representadas por valores não inteiros, 
geralmente definidos em unidades de carga elementar. O conjunto de cargas atômicas pode ser determinado tanto para molécula em fase gasosa como em meio solvente através de cálculos quânticos. Os principais métodos usados para calcular as cargas atômicas em uma molécula são a análise populacional de Mulliken [200], Merz-SinghKollman [201], NBO (Natural Bond Orbital analysis) [202], RESP(Restrained Electrostatic Potential) [203] e CHELPG (Charges from a ELetrostatic Potencial using a Grid) [204].

Como veremos na seção 2.2.2, as cargas atômicas fazem parte dos parâmetros necessários para realizar uma simulação clássica, visto que elas são utilizadas no potencial coulombiano. Nesta tese de doutorado optamos por utilizar o método CHELPG, visto que ele foi desenvolvido com o objetivo de descrever o potencial eletrostático, e é bastante recomendado no cálculo de cargas atômicas para simulações computacionais [205-209]. Esse método foi desenvolvido por Breneman e Wiberg, em que as cargas atômicas são ajustadas de modo a reproduzir o potencial eletrostático molecular em um número de pontos definidos em torno da molécula. O procedimento completo para obtenção das cargas atômicas nesse método se resume da seguinte forma: no primeiro passo desse procedimento, o potencial eletrostático é calculado em um número de pontos de uma grade retangular, espaçados de $0.3 \AA$, regularmente distribuídos em torno da molécula numa caixa retangular. As dimensões da caixa são escolhidas de modo que a molécula fique localizada no centro da caixa adicionando um espaço de $2.8 \AA$ entre a molécula e o fim da caixa em todas as três dimensões. Todos os pontos que caem dentro dos raios atômicos de van der Waals da molécula são descartados no procedimento de ajuste. Uma vez determinado o potencial em todos os pontos da caixa, as cargas atômicas nas posições dos núcleos atômicos são determinadas de modo a reproduzir o potencial eletroestático, com uma única condição de que a carga total obtida seja igual a carga efetiva da molécula que gerou o potencial. 


\subsubsection{Modelo contínuo polarizável (PCM)}

O modelo PCM foi proposto inicialmente em 1981 por Tomasi e colaboradores [55], e hoje ele representa um dos mais bem sucedidos modelos em que o solvente é descrito como um meio dielétrico polarizável e o soluto descrito com a mecânica quântica. A formulação desse modelo está fundamentada na solução da equação de Poison,

$$
-\nabla \mathbf{x}[\epsilon(\mathbf{r}) \nabla V(\mathbf{r})]=4 \pi \rho_{M}(\mathbf{r}),
$$

em que $\rho_{M}(\mathbf{r})$ representa a distribuição de carga no soluto, $\epsilon(\mathbf{r})$ é a permissividade elétrica dependente da posição radial $\mathbf{r}$ e $V(\mathbf{r})$ é o potencial elétrico. O modelo PCM assume que a distribuição de carga do soluto está contida dentro de uma cavidade $C$ com forma e dimensões apropriadas, imersa num solvente homogêneo e isotrópico de modo que a permissividade desse solvente assume a seguinte relação,

$$
\epsilon(\mathbf{r})=\left\{\begin{array}{cc}
1 & \mathbf{r} \in C \\
\epsilon & \mathbf{r} \notin C
\end{array},\right.
$$

onde $\epsilon$ é a constante dielétrica do solvente.

Usando a equação 2.24 com as condições de contorno apropriadas, a equação 2.23 pode ser resolvida em termos do potencial $V$, que representa a soma do potencial molecular do soluto $\left(V_{M}\right)$ mais a contribuição do potencial eletrostático do solvente na superfície da cavidade devido à distribuição de cargas $\left(V_{\sigma}\right)$ fictícias na superfície da cavidade $C$. Esse potencial é dado, então, por,

$$
V(\mathbf{r})=V_{M}(\mathbf{r})+V_{\sigma}(\mathbf{r})
$$

em que $V_{\sigma}$ é dado por,

$$
V_{\sigma}(\mathbf{r})=\int_{\Gamma} \frac{\sigma(\mathbf{s})}{|\mathbf{r}-\mathbf{s}|} d^{2} \mathbf{s}
$$

Se a distribuição de cargas $\sigma(\mathbf{s})$ for conhecida, a solução para a equação poisson é determinada e a contribuição eletrostática para a energia livre de solvatação do soluto 
pode ser escrita da seguinte forma,

$$
\Delta G_{\text {elet. }}=\frac{1}{2} \int_{\Gamma} \sigma(\mathbf{s})\left[\int_{V} \frac{\rho_{M}(\mathbf{r})}{|\mathbf{r}-\mathbf{s}|} d^{3} \mathbf{r}\right] d^{2} \mathbf{s} .
$$

As interações eletrostáticas entre o soluto e o solvente são dominantes no efeito do solvente em particular nos solventes polares. Porém, só essas interações não são suficientes para descrição completamente do efeito do solvente, de modo que as interações não eletrostáticas devem ser incluídas para uma melhor descrição. As contribuições não eletrostáticas para a energia livre de solvatação são incluídas no modelo PCM baseada na partição da energia livre de solvatação em quatro contribuições,

$$
\begin{aligned}
\Delta G_{\text {solv }} & =\Delta G_{\text {elet. }}+\Delta G_{\text {não-elet. }} \\
& =\Delta G_{\text {elet. }}+\Delta G_{\text {rep. }}+\Delta G_{\text {dis. }}+\Delta G_{\text {cav } .}
\end{aligned}
$$

em que $\Delta G_{\text {elet. }}$ está definido pela equação $2.27, \Delta G_{r e p .}$ e $\Delta G_{\text {dis. }}$ representam as contribuições devido à repulsão e dispersão e $\Delta G_{c a v}$. é o termo de cavitação que representa o trabalho necessário para criar uma cavidade dentro do meio dielétrico. Embora a definição original da energia livre de solvatação seja a diferença entre a energia livre do soluto em solução $\left(G_{\text {sol }}\right)$ e a energia livre em fase gasosa $\left(G_{\text {gas }}\right)$,

$$
\Delta G_{\text {solv }}=G_{\text {sol }}-G_{\text {gas }}
$$

no modelo PCM e em outros modelos contínuos de solventes, a energia livre de solvatação é calculada através da seguinte forma,

$$
\Delta G_{\text {solv }}=\left(E_{\text {sol }}+\Delta G_{n a \tilde{o}-e l}\right)-E_{\text {gas }},
$$

onde os termos $E_{\text {sol }}$ e $E_{\text {gas }}$ representam a energia eletrônica do soluto na presença e

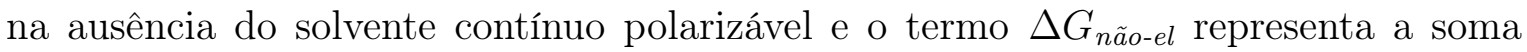
das contribuições não eletrostática, as mesmas apresentadas na equação 2.28. Observe que a equação 2.30, assume implicitamente que as contribuições térmicas devido 
aos movimentos dos núcleos (translação, rotação e vibração) do soluto em solução e em fase gasosa são similares de modo que há um cancelamento dessas contribuições. Essa estratégia de cancelamento só deve funcionar para soluções ideais, de modo que para soluções reais essas contribuições não se cancelam e um termo referente às contribuições térmicas deve ser incorporado na equação 2.30. Na prática o que se faz é incorporar implicitamente as contribuições térmicas no termo $\left(E_{\text {sol }}+\Delta G_{n \tilde{a} o-e l}\right)$ através da parametrização da equação 2.30 para reproduzir resultados experimentais para energia livre de solvatação.

Os programas mais populares que realizam cálculos quânticos tais como o Gaussian03 e o GAMESS [210] determinam a energia livre nas condições de temperatura de $298.15 K$ e pressão de 1 atm, usando uma definição padrão do processo de solvatação definida por: gás (1 atm) $\rightarrow$ solução $(1 \mathrm{~mol} / \mathrm{L})$ [211], que é geralmente denotado por $G^{0}$. Entretanto experimentalmente a energia livre de solvatação é apresentada no estado padrão referente ao processo de solvatação definido por Ben-Naim como: gás (1 $\mathrm{mol} / \mathrm{L} \rightarrow$ solução $1 \mathrm{~mol} / \mathrm{L}$ ) [212], denotado por $G^{*}$. A relação entre as energias livre dos dois processos descritos acima é dada por,

$$
\Delta G_{\text {solv }}^{*}=\Delta G_{\text {solv }}^{0}-\Delta G\left(P_{0} \rightarrow P\right),
$$

onde $\Delta G\left(P_{0} \rightarrow P\right)$ é a contribuição de energia livre para levar o sistema do estado de $P_{0}=1$ atm para $1 \mathrm{~mol} / \mathrm{L}(\mathrm{P}=24.46 \mathrm{~atm})$, ou seja, $\Delta G\left(P_{0} \rightarrow P\right)=R T \ln (24.46)$, em que $R$ é a constante universal dos gases e $T$ é tamperatura. Embora os programas listados acima determinem as energias livre usando o primeiro processo, $G^{0}$, é desnecessário a correção dos valores obtidos pela equação 2.31, pois como mencionado acima, a equação 2.30 é parametrizada para reproduzir resultados experimentais da energia livre de solvatação no estado padrão de $1 \mathrm{~mol} / \mathrm{L}, G^{*}$. 


\subsubsection{Simulação computacional}

A simulação computacional é uma técnica poderosa usada para gerar configurações moleculares acessíveis num dado ensemble termodinâmico. Essa técnica permite estudar a nível atômico sistemas moleculares fornecendo informações microscópicas desses sistemas para várias configurações como posições, velocidades e interações entre átomos e moléculas. Essas informações são usadas com a mecânica estatística para determinar as propriedades macroscópicas de interesse experimental como equação de estado, coeficientes de difusão, parâmetros de ordem entre outros [71]. Essas propriedades são determinadas nas simulações computacionais a partir de modelos idealizados para o potencial de interação molecular [213].

A simulação computacional tem um papel importante no estudo de sistemas moleculares por produzir resultados exatos de modelos para problemas de interação de muitas moléculas ou átomos, a menos de um erro estatístico, que só seriam solúveis por métodos aproximativos da mecânica estatística que na maioria dos casos são intratáveis analiticamente [214]. Nesse sentido, a simulação computacional fornece resultados relevantes para a ciência molecular que serve para diversos fins: (i) testar teorias estabelecidas; (ii) comparar com resultados experimentais e oferecer para os experimentalistas informações preciosas que ajudem na interpretação de novos resultados; (iii) fornecer propriedades que são difíceis ou impossível de serem acessadas por experimentos sob condições extremas de temperatura e pressão; (iv) investigar eventos moleculares que ocorrem numa escala de tempo muito curto que do ponto de vista experimental é difícil de serem estudados.

Nos modelos de simulações, o sistema é representado por N átomos ou moléculas, descrito por um hamiltoniano clássico, $\mathcal{H}(\mathbf{r}, \mathbf{p})=\mathcal{T}(\mathbf{p})+\mathcal{U}(\mathbf{r})$, onde $\mathcal{T}$ é o termo da energia cinética e $\mathcal{U}$ é o termo da energia potencial. O estado microscópico desse sistema pode ser caracterizado em termos das posições atômicas $\mathbf{r}=\left(\mathbf{r}_{1}, \mathbf{r}_{2}, \ldots, \mathbf{r}_{N}\right)$ e 
momentos $\mathbf{p}=\left(\mathbf{p}_{1}, \mathbf{p}_{2}, \ldots, \mathbf{p}_{N}\right)$, que definem uma configuração do sistema através de $6 N$ variáveis, pois cada posição e momento são representados pelas três componentes $x, y$ e $z$ no espaço tridimensional. A evolução do sistema se dá através de regras que definem os movimentos dos átomos, gerando assim novas configurações. Existem dois métodos que geram configurações, ou melhor, que realizam simulações computacionais: o determinístico e o estocástico. No método determinístico as configurações são geradas através da dinâmica molecular. Neste método é calculada a força em cada átomo a partir do potencial de interação molecular $\mathcal{U}(\mathbf{r})$ e as novas posições e velocidades são determinadas através da resolução das equações clássicas (newtonianas) de movimentos dado um incremento $\Delta t$ do tempo. Calculadas as novas posições e velocidades é gerada uma nova configuração do sistema, que automaticamente é usada para desenhar a trajetória dos átomos. As propriedades observáveis dessa configuração são determinadas através de médias temporais sobre as trajetórias dos átomos. No método estocástico as configurações do sistema são geradas através do método Monte Carlo com amostragem de Metropolis [68]. Neste método as configurações são geradas através de um processo estocástico que seleciona aleatoriamente as novas posições, de modo a satisfazer a distribuição de probabilidades de Boltzmann. Geralmente, no cálculo dos propriedades, tanto na dinâmica molecular como no método Monte Carlo, o termo correspondente a energia cinética, $\mathcal{T}(\mathbf{p})$ é resolvido analiticamente, de modo que o esforço maior nas simulações computacionais é dedicado ao termo do potencial de interação, $\mathcal{U}(\mathbf{r})$. Apresentaremos a seguir uma descrição sucinta desses dois métodos citando referências importantes para um estudo mais amplo dos dois métodos de simulação computacional.

\subsubsection{Dinâmica Molecular}

A dinâmica molecular (MD) é uma técnica de simulação computacional usada para resolver as equações clássicas de movimento para um sistema de $N$ moléculas 
interagindo através de um potencial conhecido $\mathcal{U}$. Através dessa técnica é possível obter a evolução temporal do sistema, dado o conjunto inicial de posições e velocidades. A primeira simulação realizada usando essa técnica foi na década de 50 por Alder e Wainwright $[69,70]$, para investigar a dinâmica de um sistema de partículas. Só com o desenvolvimento dos computadores modernos é que essa técnica foi aplicada para estudar sistemas líquidos. Os primeiros líquidos reais estudados usando essa técnica foram o argônio líquido simulado em 1964 por Rahman [215] e a água líquida em 1971 por Rahman e Stillinger [216].

A simulação com MD requer um método de integração para resolver as equações de movimento. Os principais métodos de integração estão fundamentados nos métodos de diferenças finitas $[217,218]$, onde a ideia geral desses métodos é dada da seguinte forma: fornecidas as posições e velocidades em um dado instante de tempo $t$, o método tenta obter as posições e velocidades em um instante de tempo $t+\delta t$, dentro de uma precisão aceitável. Atualmente existem vários algoritmos disponíveis que utilizam esse método, embora com diferentes aproximações para resolver as equações de movimentos [71,213,214]. Um bom algoritmo de integração deve obedecer os seguintes critérios: (i) o algoritmo deve ser rápido, fácil de implementá-lo e que requer pouca memória de computador para produzir as trajetórias clássica das moléculas; (ii) o algoritmo deve permitir o uso do passo de integração o maior possível, de modo a economizar tempo de simulação e gerar o maior número possível de configurações descorrelacionadas; (iii) é desejável que o algoritmo satisfaça as leis de conservação de energia e momento e que as trajetórias produzidas por ele sejam reversíveis no tempo.

Um dos algoritmos mais conhecidos para integração das equações de movimento é o de Verlet [219]. Este algoritmo parte da expansão de Taylor da posição dos átomos em torno do instante de tempo $t$, adiantado e atrasado por $\delta t, \mathbf{r}(t+\delta t)$ e $\mathbf{r}(t-\delta t)$,

$$
\mathbf{r}(t+\delta t)=\mathbf{r}(t)+\delta t \mathbf{v}(t)+\frac{1}{2} \delta t^{2} \mathbf{a}(t)+\ldots
$$




$$
\mathbf{r}(t-\delta t)=\mathbf{r}(t)-\delta t \mathbf{v}(t)+\frac{1}{2} \delta t^{2} \mathbf{a}(t)-\ldots
$$

Somando as equações 2.32 e 2.33, e desprezando os termos de quarta ordem e superior se obtém a seguinte equação para a posição $\mathbf{r}(t+\delta t)$,

$$
\mathbf{r}(t+\delta t)=2 \mathbf{r}(t)-\mathbf{r}(t-\delta t)+\delta t^{2} \mathbf{a}(t)
$$

Subtraindo as equações 2.32 e 2.33, se obtém a expressão para a velocidade $\mathbf{v}(t)$

$$
\mathbf{v}(t)=\frac{\mathbf{r}(t+\delta t)-\mathbf{r}(t-\delta t)}{2 \delta t}
$$

Note que a integração usando o algoritmo de Verlet produz um erro da ordem de $\delta t^{4}$ nas posições e $\delta t^{2}$ nas velocidades. Esses erros, em particular das posições são cumulativos durante a simulação o que acaba causando pequenos desvios nas trajetórias das moléculas em simulações extremamente longas quando comparadas com as trajetórias "exatas". Outra observação que merece ser ressaltada é que esse algoritmo é devidamente centrado, isto é, $\mathbf{r}(t+\delta t)$ e $\mathbf{r}(t-\delta t)$ desempenham funções simétricas na equação 2.34, o que torna o algoritmo reversível no tempo. Desta forma, ao utilizar forças conservativas para determinar as acelerações usadas na equação 2.34, garante a conservação da energia e momento no sistema. Estudos têm mostrado que a energia determinada através desse algoritmo se conserva até mesmo para valores grandes de $\delta t$, da ordem de $\delta t \sim 0.1 f s[220]$.

Outro algoritmo bastante usado em simulações com dinâmica molecular é leapfrog [221]. Esse algoritmo além de utilizar as posições $\mathbf{r}(t)$ e acelerações $\mathbf{a}(t)$ no instante $t$, ele também utiliza passos intermediários da velocidade, $\mathbf{v}\left(t+\frac{\delta t}{2}\right)$ e $\mathbf{v}\left(t-\frac{\delta t}{2}\right)$. Esse algoritmo é implementado através das seguintes equações,

$$
\begin{gathered}
\mathbf{r}(t+\delta t)=\mathbf{r}(t)+\delta t \mathbf{v}\left(t+\frac{\delta t}{2}\right) \\
\mathbf{v}\left(t+\frac{\delta t}{2}\right)=\mathbf{v}\left(t-\frac{\delta t}{2}\right)+\delta t \mathbf{a}(t)
\end{gathered}
$$


A vantagem desse algoritmo, além da reversibilidade temporal, simplicidade e conservação da energia e momento, está na maneira como ele determina a velocidade, apresentando uma melhora significativa na precisão dessa propriedade em relação ao algoritmo de Verlet.

\subsubsection{Termostato e Barostato}

Os algoritmos de Verlet e leap-frog apresentados acima evoluem no tempo as posições das moléculas dentro de uma caixa de simulação de volume $V$, mantendo a conservação do momento e energia, o que leva o sistema naturalmente ao ensemble NVE (número de moléculas, volume e energia constantes). Embora as simulações nesse ensemble pareçam mais simples de serem realizadas, na prática o que se faz são simulações nos ensembles NPT (número de moléculas, pressão e temperatura constantes) e $N V T$ (número de moléculas, volume e temperatura constantes), visto que a maioria das propriedades termodinâmicas é definidas nesses ensembles [222]. Além disso, o controle da temperatura nas simulações é necessário para manter o sistema numa temperatura desejada. As principais propostas de algoritmos para manter a temperatura ou pressão fixa na simulação estão fundamentadas na ideia de acoplamento do sistema com um reservatório térmico. Os principais algoritmos disponíveis para manter a temperatura fixa (termostato) são o de Berendsen [223], Nosé-Hoover [224, 225] e o Parrinello-Donadio-Bussi [226], que utilizam esquemas de reescalonamento da velocidade. Já para manter a pressão fixa (barostato), os algoritmos disponíveis são o de Berendsen [223] e Parrinello-Rahman [227,228].

Nesta tese de doutorado usamos o algoritmo de Berendsen tanto para o termostato como para o barostato, mas antes de apresentá-los vamos mostrar como se determina a temperatura e a pressão numa simulação computacional. Para um sistema contendo $N$ moléculas, a temperatura é determinada a partir da energia cinética das 
moléculas através da equação,

$$
\frac{3}{2} N k_{B} T=\frac{1}{2} \sum_{i=1}^{N} m_{i} v_{i}
$$

em que $N$ é o número de átomos, $k_{B}$ é a constante de Boltzmann e $m_{i}$ e $v_{i}$ são a massa e a velocidade do átomo $i$, respectivamente. A pressão é determinada a partir do traço do tensor de pressão $P=\operatorname{traço~}(\mathbf{P}) / 3$, onde $\mathbf{P}$ que é dado pela diferença entre a energia cinética e o termo de virial,

$$
\mathbf{P}=\frac{2}{V}\left(E_{c i n}-\Xi\right)
$$

onde $V$ é o volume da caixa de simulação e $\Xi$ é o tensor de virial que é determinado através da seguinte equação,

$$
\Xi=-\frac{1}{2} \sum_{i<j} \mathbf{r}_{i j} \otimes \mathbf{F}_{i j}
$$

O termostato de Berendsen é considerado um dos mais simples algoritmos que mantêm o acoplamento entre o sistema e o reservatório térmico. Esse algoritmo considera que a diferença de temperatura entre o sistema $(T)$ e o reservatório $\left(T_{0}\right)$, obedece a seguinte relação,

$$
\frac{d T}{d t}=\frac{T_{0}-T}{\tau}
$$

em que o desvio da temperatura do sistema decai exponencialmente com o tempo, com uma constante de acoplamento $\tau$. A grande vantagem desse algoritmo é que a "força de acoplamento" pode ser alterada mudando apenas o valor de $\tau$, de modo a ter um controle mais preciso da temperatura do sistema. É recomendado que a constante de acoplamento seja maior que o passo de integração $(\tau>\delta t)$, sendo para simulações no processo de equilíbrio é recomendado $\tau=0.01$ ps e para simulações de produção ( após atingir o equilíbrio) $\tau=0.5$ ps [229]. O controle do fluxo de calor entre sistema e reservatório é efetuado escalonando-se as velocidades de cada átomo em cada passo 
por um fator $\lambda$ dado pela seguinte equação,

$$
\lambda=\left[1+\frac{\Delta t}{\tau_{T}}\left(\frac{T_{0}}{T\left(t-\frac{\Delta t}{2}\right)}-1\right)\right]^{1 / 2},
$$

em que $\tau_{T}$ é uma constante que está relacionada com a constante de acoplamento e o calor específico a volume constante $\left(C_{v}\right)$, através da equação 2.43 ,

$$
\tau_{T}=\frac{3 k_{B}}{2 C_{v}} \tau
$$

O algoritmo de Berendsen para o barostato usa a mesma filosofia aplicada ao termostato, onde neste caso, o sistema é acoplado a um reservatório de pressão constante, de modo que a diferença de pressão ente o sistema $(P)$ e o reservatório $\left(P_{0}\right)$ obedece uma relação similar a equação 2.41 ,

$$
\frac{d P}{d t}=\frac{P_{0}-T}{\tau_{p}}
$$

onde similarmente $\tau_{p}$ é uma constante de acoplamento. Esse algoritmo altera o volume da caixa de simulação escalonando-se as coordenadas dessa caixa a cada passo de simulação por uma matriz $\xi_{i j}$, onde cada elemento dessa matriz é dado por,

$$
\xi_{i j}=\delta_{i j}-\frac{\Delta t}{3 \tau_{p} \beta_{i j}\left\{P_{0 i j}-P_{i j}(t)\right\}},
$$

em que $\delta_{i j}$ é o delta de Kronecker, e $\beta$ é a compressibilidade isotérmica do sistema.

\subsubsection{Método Monte Carlo}

O método Monte Carlo é uma técnica de simulação computacional usada dentro da física, química e matemática para obter soluções numéricas de diversos problemas que envolvem muitas partículas. Na modelagem molecular esse método é usado para gerar novas configurações de um sistema molecular através de um processo estocástico, em que números aleatórios são utilizados para promover os deslocamentos aleatórios das moléculas. Uma nova configuração do sistema é gerada após o movimento aleatório de cada molécula do sistema, e o conjunto de todas as configurações geradas nesse 
processo representa uma amostra aleatória do sistema. Entretanto, essa amostragem aleatória não é conveniente para muitos problemas que envolvem muitas partículas, pois o número de configurações necessárias para calcular uma propriedade de interesse deve ser muito grande em um espaço multidimensional. Embora computacionalmente seja possível obter todas essas configurações, poucas delas são configurações representativas para a estatística do cálculo das propriedades do sistema, pois a amostragem aleatória permite gerar configurações de baixo peso estatístico, em que as moléculas estão muito próximas ou até mesmo superpostas, gerando com isso potenciais fortemente repulsivos entre as moléculas.

Uma maneira de contornar esse problema é através da amostragem preferencial de Metropolis, proposto em 1953 por Metropolis e colaboradores [68]. Essa amostragem evita as configurações de baixo peso estatístico através da seleção de configurações mais prováveis, ou seja, de alto peso estatístico no espaço de fase termodinâmico. Essa seleção é executada através de um processo de Markov [222,230], em que uma nova configuração do sistema é gerada a partir da configuração atual, sendo essa nova configuração dependente exclusivamente da configuração atual sem nenhuma dependência das configurações passadas do sistema. A probabilidade de uma dada configuração $\nu$ ser observada é dada pela distribuição de Boltzmann,

$$
P\left(r_{\nu}^{N}\right)=\frac{e^{-\frac{\mathcal{U}\left(r_{\nu}^{N}\right)}{k_{B} T}}}{Z},
$$

em que Z é a função de partição configuracional do sistema, $\mathcal{U}\left(r_{\nu}^{N}\right)$ é o potencial de interação para átomos não ligados da configuração $\nu, k_{B}$ é a constante de Boltzmann e T é a temperatura. Nesse algoritmo a probabilidade de transição de uma dada configuração $\nu$ para outra $\nu^{\prime}$ é dada pela razão entre os fatores de Boltzmann das configurações $\nu$ e $\nu^{\prime}$,

$$
T_{\nu \rightarrow \nu^{\prime}}=\frac{e^{-\frac{\mathcal{U}\left(r_{\nu^{\prime}}^{N}\right)}{k_{B} T}}}{e^{-\frac{\mathcal{U}\left(r_{\nu}^{N}\right)}{k_{B} T}}}=e^{-\frac{\Delta \mathcal{U}}{k_{B} T}},
$$


onde $\Delta \mathcal{U}$ é a diferença de energia potencial entre as duas configurações $\nu$ e $\nu^{\prime}$. A equação 2.47 se aplica ao ensemble NVT, e no caso do ensemble NPT, a probabilidade de transição $T_{\nu \rightarrow \nu^{\prime}}$ é dada pela seguinte equação,

$$
\begin{aligned}
& T_{\nu \rightarrow \nu^{\prime}}=e^{-\frac{(\Delta \mathcal{U}+p \Delta V)}{k_{B} T}+N \ln \frac{V_{\nu^{\prime}}}{V_{\nu}}} \\
& T_{\nu \rightarrow \nu^{\prime}}=e^{-\frac{\Delta H}{k_{B} T}+N \ln \frac{V_{\nu^{\prime}}}{V_{\nu}}}
\end{aligned}
$$

em que $\Delta V$ representa a variação de volume envolvida na transição da configuração $\nu$ para $\nu^{\prime}$, e o produto $p \Delta V$ é a contribuição para a diferença de entalpia $(\Delta H=$ $\Delta \mathcal{U}+p \Delta V)$, a pressão constante. Na prática o algoritmo de Metropolis gera novas configurações da seguinte maneira: inicialme é definida uma caixa de simulação com N moléculas. Em geral, as dimensões iniciais da caixa de simulação são escolhidas de modo a reproduzir a densidade experimental. Uma nova configuração do sistema é gerada efetuando-se movimentos aleatórios de translação e rotação combinados na molécula escolhida aleatoriamente. Assim, a nova configuração é obtida transladandose o centro de massa da i-ésima molécula através das seguintes relações,

$$
\begin{aligned}
& x_{\nu^{\prime}}^{i}=x_{\nu}^{i}+\left(2 \xi_{x}-1\right) \Delta r_{\max } \\
& y_{\nu^{\prime}}^{i}=y_{\nu}^{i}+\left(2 \xi_{y}-1\right) \Delta r_{\max } \\
& z_{\nu^{\prime}}^{i}=z_{\nu}^{i}+\left(2 \xi_{z}-1\right) \Delta r_{\max }
\end{aligned}
$$

onde os $\xi_{k}$ são os números aleatórios no intervalo de 0 a 1, e $\Delta r_{\text {max }}$ é o deslocamento máximo permitido, e, portanto, o produto, $\left(2 \xi_{k}-1\right) \Delta r_{\max }$ é o deslocamento na direção $k$, que poderá variar no intervalo $\left[-\Delta r_{\max }, \Delta r_{\max }\right]$. A rotação da i-ésima molécula, em torno do centro de massa, é realizada sorteando-se aleatoriamente um eixo dentre os eixos x, y e z, e rotacionando a molécula em torno desse eixo, através da relação,

$$
\alpha_{\nu^{\prime}}^{i}=\alpha_{\nu}^{i}+\left(2 \xi_{k}-1\right) \Delta \Theta_{\max }
$$

onde o produto $\left(2 \xi_{k}-1\right) \Delta \Theta_{\max }$ é o ângulo de rotação da molécula em torno do eixo $k$, que poderá variar no intervalo $\left[-\Delta \Theta_{\max }, \Delta \Theta_{\max }\right]$. Feito isso, a diferença de energia 
entre as duas configurações é calculada. Para o ensemble NVT, se aplica a seguinte condição: Se $\Delta \mathcal{U}<0$, o movimento da molécula é aceito pelo algoritmo de Metropolis, caso contrário, é sorteado um número aleatório $\varrho$ no intervalo $[0,1]$, e esse movimento é aceito se $\varrho \leq T_{\nu \rightarrow \nu^{\prime}}$. Caso contrário, esse movimento é proibido pelo algoritmo e a configuração $\nu$ é mantida como uma nova configuração. Uma vez obtida a nova configuração, ela é registrada e o procedimento é repetido de modo a obter outras configurações.

Se o ensemble for NPT, além de aplicar as equações 2.49 e 2.50, é necessário realizar mudanças no volume da caixa de simulação, através da seguinte relação,

$$
V_{\nu^{\prime}}^{i}=V_{\nu}^{i}+\left(2 \xi_{V}-1\right) \Delta V_{\max }
$$

onde o produto $\left(2 \xi_{V}-1\right) \Delta V_{\max }$ é a variação do volume da caixa, que poderá variar no intervalo $\left[-\Delta V_{\max }, \Delta V_{\max }\right]$. Feito isso, calcula-se a variação de entalpia, $\Delta H$, e aplica-se então o algoritmo de Metropolis para aceitar ou rejeitar a configuração. As configurações registradas pelo algoritmo de Metropolis estão todas distribuídas de acordo com a distribuição de Boltzmann, de modo que uma dada propriedade termodinâmica do sistema pode ser calculada através de uma média aritmética simples, ou seja,

$$
\langle\mathcal{A}\rangle=\frac{1}{M} \sum_{\nu=1}^{M} \mathcal{A}\left(r_{\nu}^{N}\right),
$$

em que $\mathcal{A}\left(r_{\nu}^{N}\right)$ é o valor da propriedade $\mathcal{A}$ calculada no sistema em uma dada configuração $\nu$.

Nesta tese de doutorado utilizamos o programa DICE [231] para a realização das simulações das espécies da Emodina em água e metanol. Nesse programa a implementação do método de Monte Carlo segue o seguinte algoritmo:

1. Inicialização: Uma configuração inicial do sistema é gerada, geralmente sorteando aleatoriamente as posições das moléculas dentro de uma caixa retangular, ou cúbica, com o volume dado através da densidade inicial fornecida do sistema. 
2. Nova configuração: Uma nova configuração é gerada a partir da configuração atual, sorteando uma molécula aleatoriamente no sistema e realizando um deslocamento aleatório nessa molécula, seguido por uma rotação também aleatória ao redor de um eixo. Feito isso, calcula-se a energia $\mathcal{U}\left(r_{\nu^{\prime}}^{N}\right)$ dessa nova configuração.

3. Aceitação ou rejeição da nova configuração: A partir da nova configuração, é calculada a diferença de energia, dada por:

$$
\Delta \mathcal{U}=\mathcal{U}\left(r_{\nu^{\prime}}^{N}\right)-\mathcal{U}\left(r_{\nu}^{N}\right)
$$

Para simulações em NVT, aplica-se as seguintes condições: se $\Delta \mathcal{U} \leqslant 0$, então, essa nova configuração é aceita. Caso contrário, ou seja, se $\Delta \mathcal{U}>0$, é gerado um número aleatório $\varrho$ no intervalo $[0,1]$. Se $\varrho<T_{\nu \rightarrow \nu^{\prime}}$, essa nova configuração é aceita, caso contrário, essa nova configuração é rejeitada e o processo volta para o item 2. Para simulações em NPT, calcula-se a variação de entalpia, $\Delta H$, e aplica-se então esse mesmo teste de aceitação e rejeição.

4. Cálculo das propriedades termodinâmicas: Em cima de cada nova configuração do sistema é realizado um cálculo de algumas propriedades termodinâmicas, tal como energia interna, pressão, primeiro e segundo coeficiente de virial, entre outras [71,214]. Feito isso, armazena-se esses valores para o cálculo da média e volta-se para a item 2 do processo, completando com isso, um passo de Monte Carlo. Geralmente, o conjunto de N passos de Monte Carlo, onde $\mathrm{N}$ é o número de moléculas do sistema, é definido como um ciclo de Monte Carlo. Ao final da simulação, as médias acumuladas são utilizadas para calcular algumas propriedades termodinâmicas como calor específico a volume ou pressão constante, compressibilidade isotérmica, coeficiente de expansão térmica, entre outras.

Ressaltamos que as simulações computacionais, tanto com o método de Monte Carlo, como com dinâmica molecular requerem o uso do método das imagens, associado 
com as técnicas de condições periódicas de contorno e raio de corte [71,214]. Essas técnicas se fazem necessárias para minimizar os efeitos de sistemas finitos, conhecido também como efeitos de superfície, causados pela interação das moléculas com as paredes da caixa de simulação. O método das imagens consiste em rodear a caixa de simulação por réplicas idêndicas dessa caixa, de modo que todas as moléculas localizadas num dado instante na face inferior da caixa intaregem com as moléculas da face superior e assim ocorre para as demais faces da caixa. A aplicação desse método, além de evitar que as moléculas da caixa original interajam com as paredes da caixa, leva às condições periódicas de contorno. Assim, na interface entre a caixa e suas réplicas aplica-se a seguinte condição: se uma molécula movimenta para fora da caixa de simulação, uma réplica indêntica correspondente entra nessa caixa pelo lado oposto que ela saiu, mantendo constante o número de moléculas na caixa de simulação.

O uso do método das imagens associado as condições periódicas de contorno leva a introdução de periodicidade que é eliminada através da utilização de um raio de corte, $r_{c}$. Assim, as interações são consideradas levando em conta esse raio de corte, de modo que cada molécula interage explicitamente com as outras moléculas dentro desse raio. Geralmente, para moléculas localizadas além do raio de corte se utiliza correções de longo alcance. Essa correção é necessária devido principalmente às interações coulômbianas, por decairem lentamente com a distância. Os principais algoritmos de correção de longo alcance disponíveis são a soma de Ewald [214], Particlemesh Ewald (PME) [232, 233] e campo de reação [234].

\subsubsection{Potencial de Interação e Campo de Força}

Um dos maiores desafios para a realização de uma simulação computacional é a escolha do campo de força, pois ele define o potencial de interação usado para calcular as forças e as energias do sistema. Um campo de força é composto por um conjunto de equações que descreve o potencial de interação e um conjunto de parâmetros usado nes- 
sas equações. Atualmente, os campos de força mais usados para descrição de sistemas moleculares são: GROMOS [103], OPLS [102], CHARMM [99,235], AMBER [236,237], entre outros. O campo de força OPLS foi desenvolvido por Jorgensen e colaboradores, tendo como filosofia principal a reprodutibilidade de propriedades estruturais e energéticas tais como densidade, distribuição radial de pares (RDFs), energias de ligação de agregados obtidas com QM, energias livres de solvatação, entre outras. Já o campo de força GROMOS foi desenvolvido por van Gunsteren e colaboradores tendo como foco principal a reprodutibilidade de propriedades termodinâmicas, tais como entalpia e energia livre de solvatação de moléculas biológicas.

As equações dos campos de força OPLS e GROMOS são praticamente as mesmas, com exceção de algumas especificidades no que se refere à formulação. Porém os conjuntos de parâmetros desses campos de forças são inteiramente diferentes. Nesta tese de doutorado testamos ambos OPLS e GROMOS 54a7, sendo o OPLS aplicado nas simulações com dinâmica molecular e método Monte Carlo e o campo de força GROMOS 54a7 nas simulações com dinâmica molecular. Esse teste foi necessário para validar, através de comparação das propriedades estruturais e energéticas, o conjunto de parâmetro do campo de força GROMOS 54a7 para a Emodina.

Nesses campos de força o potencial de interação é escrito através de uma soma de potenciais para átomos ligados $\left(\mathcal{U}_{\text {átomos-lig }}\right)$ e não ligados $\left(\mathcal{U}_{\text {átomos-não-lig }}\right)$. O potencial

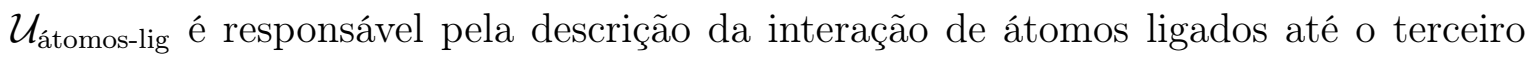
vizinho. Esse potencial é dado por uma soma dos três seguintes termos: (i) $\mathcal{U}_{\text {ligação }}$ O potencial que descreve a variação na distância entre um dado átomo e seus primeiros vizinhos ligados; (ii) $\mathcal{U}_{\text {angular }}$ O potencial que descreve a distorção no ângulo formado por um dado átomo e seus primeiros e segundos vizinhos; (ii) $\mathcal{U}_{\text {torção }}$ - O potencial que descreve a distorção no ângulo de torção formado por um dado átomo e seus primeiros, segundos e terceiros vizinhos. Assim, o potencial $\mathcal{U}_{\text {átomos-lig é dado pela }}$ 
seguinte equação,

$$
\mathcal{U}_{\text {átomos-lig }}=\mathcal{U}_{\text {ligação }}+\mathcal{U}_{\text {angular }}+\mathcal{U}_{\text {torção }}
$$

em que cada termo dessa equação no campo de força padrão do GROMOS é dado por,

$$
\begin{gathered}
\mathcal{U}_{\text {ligação }}=\sum_{\text {ligações }} \frac{1}{2} k_{i j}^{r_{e q}}\left(r_{i j}-r_{e q}\right)^{2}, \\
\mathcal{U}_{\text {angular }}=\sum_{\text {ângulos }} \frac{1}{2} k_{i j k}^{\theta_{e q}}\left(\theta_{i j k}-\theta_{e q}\right)^{2}, \\
\mathcal{U}_{\text {torção }}=\sum_{\text {torções }} \sum_{\mathrm{n}}^{5} C_{n}\left(\cos \left(\phi-180^{\circ}\right)\right)^{n},
\end{gathered}
$$

em que $k_{i j}^{r_{e q}}, k_{i j k}^{\theta_{e q}}$ e $C_{n}$ são as constantes de forças desses potenciais e $r_{e q}$ e $\theta_{e q}$ são

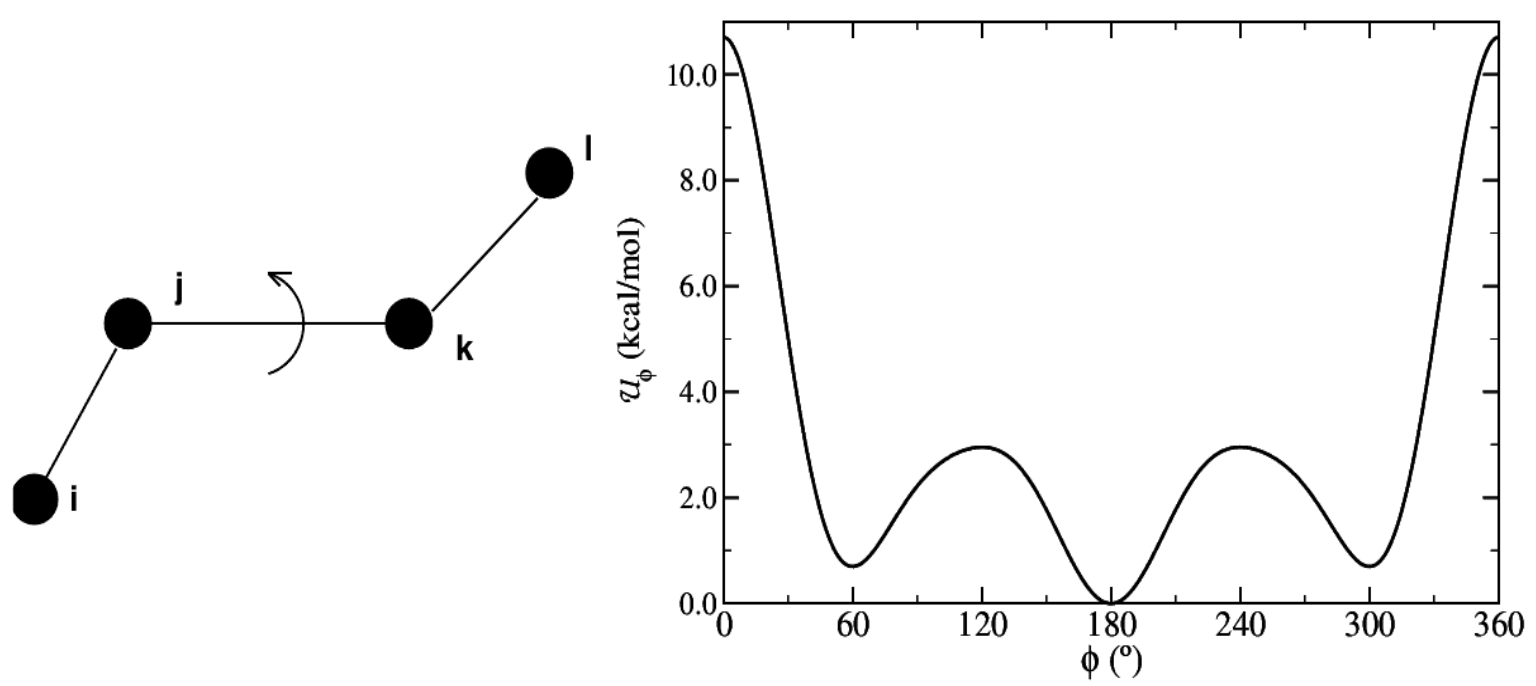

Figura 2.1: Ilustração do ângulo de torção (lado esquerdo) e o potencial desse ângulo (lado direito).

as constantes de equilíbrio da posição e do ângulo, respectivamente e $\phi$ é o ângulo entre os planos $i j k$ e $j k l$, definido de forma que $\phi=0$ corresponde a conformação cis, com os átomos $i$ e $l$ no mesmo plano e lado, veja a figura 2.1. No campo de força OPLS se utiliza as mesmas equações 2.55 e 2.56 do campo de força GROMOS, porém para o potencial de interação dos ângulos de torção, a equação 2.57 é substituida por 
uma soma de até seis termos de uma série de Fourier. ${ }^{2}$ Para moléculas que apresentam grupos planares e tetraédricos é necessário acrescentar na equação 2.54 mais um termo, que corresponde o potencial que descreve a distorção no ângulo de torção impróprio. Esse potencial é dado por uma função quadrática, similar a equação 2.56, em que, nesse caso, $\theta$ representa um ângulo de torção impróprio $\left(\theta_{i j k l}\right)$.

Quando se utiliza algum tipo de vínculo intramolecular como restrições nas posições de átomos, ângulos e ângulos de torção, é necessário acrescentar na equação 2.54 mais termos, chamados de potenciais de vínculos. Esses potenciais são, na maioria dos casos, dados por funções quadráticas, similar as equações 2.55 e 2.56.

O potencial $\mathcal{U}_{\text {atomos-não-lig }}$ é responsável pela descrição da interação de átomos não ligados. Entenda-se como interação de átomos não ligados todas as interações possíveis entre pares de átomos de diferentes moléculas, e interações intramoleculares entre um dado átomo e seus vizinhos mais distantes, geralmente além do terceiro vizinho. ${ }^{3}$ Essas interações são geralmente dadas pelo potencial de Lennard-Jones mais o potencial de Coulomb, como mostrado a seguir, para o campo de força GROMOS,

$$
\mathcal{U}_{\text {átomos-não-lig }}=\sum_{\mathrm{ij}}\left[\frac{C_{i j}^{(12)}}{r_{i j}^{12}}-\frac{C_{i j}^{(6)}}{r_{i j}^{6}}\right]+\frac{q_{i} q_{j}}{4 \pi \epsilon_{0} r_{i j}}
$$

onde os parâmetros $C_{i j}^{(12)}$ e $C_{i j}^{(6)}$ são constantes do potencial de LJ e dependem exclusivamente do tipo de átomos envolvidos na interação, $r_{i j}$ é a distância entre os átomos $i$ e $j, q_{i}$ é a carga no átomo $i$ e $\epsilon_{0}$ é a constante de permissividade do vácuo.

\footnotetext{
${ }^{2} \mathrm{O}$ potencial de interação dos ângulos de torção no campo de força OPLS é dado pela seguinte equação, $\mathcal{U}_{\text {torção }}=\mathcal{U}_{0}+\frac{1}{2}\left[\mathcal{U}_{1}(1+\cos (\phi))+\mathcal{U}_{2}(1+\cos (2 \phi))+\mathcal{U}_{3}(1+\cos (3 \phi))\right]$, em que $\mathcal{U}_{\text {i }}$ são as constantes de forças que estão relacionadas com as constantes $C_{n}$ da equação 2.57 , através das seguintes relações: (i) $C_{0}=\mathcal{U}_{0}+\mathcal{U}_{2}+\frac{1}{2}\left(\mathcal{U}_{1}+\mathcal{U}_{3}\right)$; (ii) $C_{1}=\frac{1}{2}\left(3 \mathcal{U}_{3}-\mathcal{U}_{1}\right)$; (iii) $C_{2}=-\mathcal{U}_{2}$; (iV) $C_{3}=-2 \mathcal{U}_{3}$; (v) $C_{4}=0$; (vi) $C_{5}=0$. Comumente, os parâmetros $\mathcal{U}_{\mathrm{i}}$ e $C_{n}$ são apresentados em kcal $/ \mathrm{mol} \mathrm{e} \mathrm{kj} / \mathrm{mol}$, respectivamente. Assim, ressaltamos a necessidade de uma conversão de unidade na transmutação desses parâmetros, embora isso não seja recomendado.

${ }^{3}$ Ressaltamos a necessidade de excluir obrigatóriamente as interações de Lennard-Jones mais a interação de Coulomb entre um dado átomo e seus primeiros, segundos e terceiros vizinhos. No campo de força GROMOS, a exclusão da interação do terceiro vizinho está condicionada a seguinte condição: se a molécula apresenta grupos planares, é necessário manter a exclusão, porém para grupos não planares, excepcionalmente aos grupos envolvidos nas torções próprias é necessário a inclusão no cálculo do potencial de LJ e Coulomb.
} 


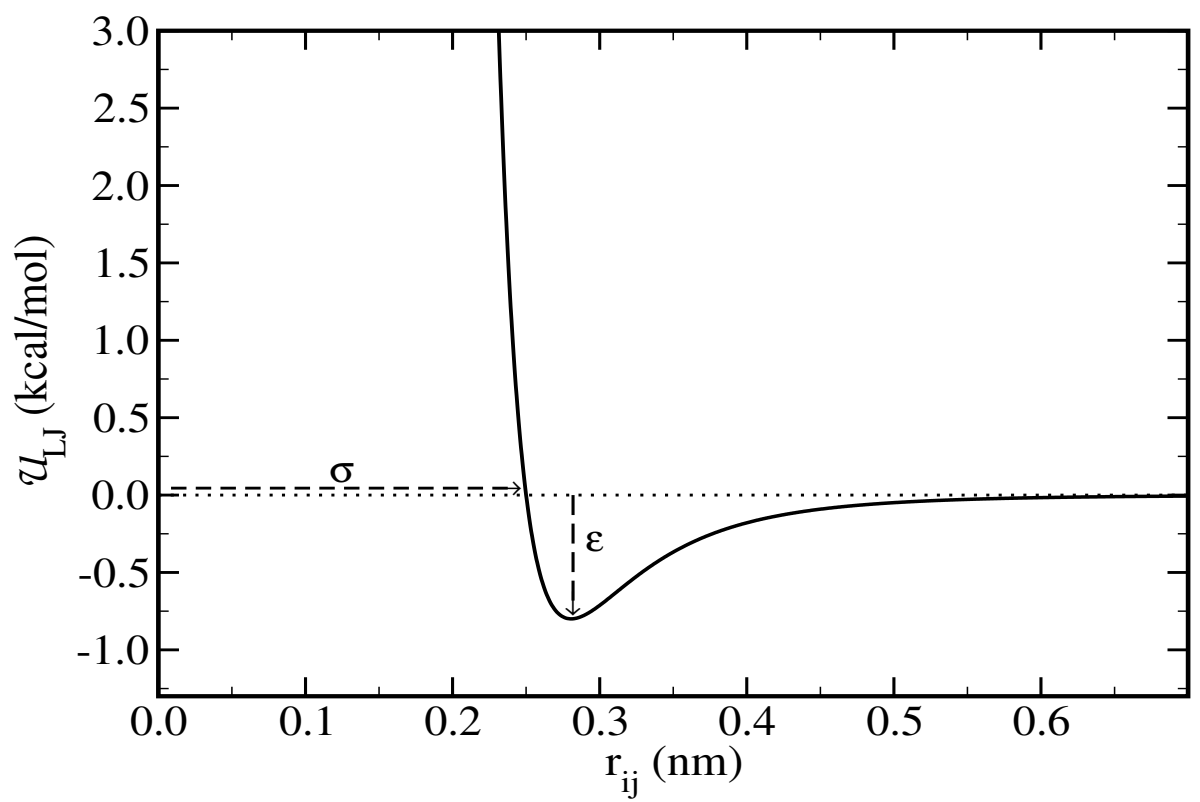

Figura 2.2: Ilustração do potencial de Lennard-Jones para os parâmetros do campo de força OPLS $\left(\epsilon_{i}=\epsilon_{j}=0.8 \mathrm{kcal} / \mathrm{mol} \mathrm{e} \sigma_{i}=\sigma_{j}=0.25 \mathrm{~nm}\right)$.

O campo de força OPLS utiliza a equação 2.58 para o potencial intermolecular ${ }^{4}$, a mesma usada no campo de força GROMOS, porém o potencial de LJ é comumente escrito em função das constantes $\epsilon_{i j}=\left(\epsilon_{i} \epsilon_{j}\right)^{1 / 2}$ e $\sigma_{i j}=\left(\sigma_{i} \sigma_{j}\right)^{1 / 2}$, em que $\epsilon_{i}$ e $\sigma_{i}$ correspondem a energia de ligação e o raio de van der Waals, respectivamente, veja figura 2.2. Essas constantes estão relacionadas com os parâmetros $C_{i j}^{(12)}$ e $C_{i j}^{(6)}$ através das seguintes relações, $\sigma_{i j}=\left(\frac{C_{i j}^{(12)}}{C_{i j}^{(6)}}\right)^{1 / 6}$ e $\epsilon_{i j}=\frac{\left(C_{i j}^{(6)}\right)^{2}}{4 C_{i j}^{(12)}}$.

Nas simulações com dinâmica molecular, utilizamos moléculas flexíveis, em que foram utilizados todos os termos dos potenciais de interação $\mathcal{U}_{\text {átomos-lig }}$ e $\mathcal{U}_{\text {átomos-não-lig }}$, ou seja, as equações 2.54 e 2.58. Essas simulações foram realizadas no programa GROMACS [238]. Nas simulações com método Monte Carlo, utilizamos moléculas rígidas, em que foi utilizado apenas o potencial intermolecular (equação 2.58). Essas simulações com as moléculas rígidas foram realizadas no programa DICE [231].

\footnotetext{
${ }^{4}$ No campo de força OPLS o potencial de LJ geralmente é escrito da seguinte maneira: $\mathcal{U}_{\mathrm{LJ}}=$ $\sum_{\mathrm{ij}} 4 \epsilon_{i j}\left[\frac{\sigma_{i j}^{12}}{r_{i j}^{12}}-\frac{\sigma_{i j}^{6}}{r_{i j}^{6}}\right]$.
} 


\subsubsection{Cálculo da energia livre com FEP}

A energia livre é sem dúvida uma das propriedades termodinâmica mais importante. Muitas das propriedades de sistemas físico-químicos dependem direta ou indiretamente da energia livre do sistema. Por exemplo, as constantes de equilíbrio, ligação, acidez e processos como tautomerização, dimerização, etc, estão diretamente relacionados com a diferença de energia livre envolvida no processo.

A energia livre de um sistema num dado estado termodinâmico $J$ é definida como,

$$
\mathcal{A}=-k_{B} T \ln \left(Z_{J}\right),
$$

em que $k_{B}$ é a constante de Boltzmann, T é a temperatura e $Z_{J}$ é a função de partição. Se o estado termodinâmico do sistema for definido no ensemble $N V T$, $\left(Z_{J}=\int_{\mathbf{r}^{N}} e^{-\frac{\mathcal{U}_{J}\left(\mathbf{r}^{N}\right)}{k_{B} T}} d \mathbf{r}^{N}\right)$, a energia livre é escrita como a função de $\operatorname{Helmholtz}(\mathcal{A} \rightarrow F)$, se o ensemble for $N P T,\left(Z_{J}=\int_{V} \int_{\mathbf{r}^{N}} e^{-\frac{\left.\mathcal{u}_{J^{(}} \mathbf{r}^{N}\right)+p V}{k_{B^{T}}}} d V d \mathbf{r}^{N}\right)$, a energia livre é escrita como a função de $\operatorname{Gibbs}(\mathcal{A} \rightarrow G)$.

A forma como é escrita a energia livre do sistema em relação a função de partição, seja a de Helmholtz ou de Gibbs, deixa claro que essa é uma propriedade global que depende de todas as configurações acessíveis pertencentes ao espaço de configurações do sistema. Assim para obter uma boa estimativa da energia livre absoluta do sistema é necessário acessar todo o espaço de configurações, que é praticamente impossível do ponto de vista de simulação computacional. Na prática, o que se faz é o cálculo da diferença de energia livre entre dois estados do sistema,

$$
\Delta \mathcal{A}(J \rightarrow N)=\mathcal{A}_{N}-\mathcal{A}_{J}=k_{B} T \ln \left(\frac{Z_{N}}{Z_{J}}\right),
$$

em que $J$ e $N$ são dois estados do sistema. Alguns métodos baseados em fatores de acoplamentos têm sido propostos na literatura [239-244] com o objetivo de calcular a equação 2.60, através de simulações computacionais e determinar a diferença de energia livre. Nesta tese de doutorado utilizamos o método da teoria de perturbação 
termodinâmica (FEP, Free energy perturbation), proposta inicialmente por Zwanzing [245], para calcular $\Delta \mathcal{A}$. Esse método está implementado no programa DICE que utilizamos para realizar nossas simulações com método de Monte Carlo e calcular as diferenças de energia livre.

No método FEP, a equação 2.60 é reescrita inserindo a expressão de $Z$ e introduzindo no numerador dessa equação o termo $e^{\frac{\mathcal{U}_{J}}{k_{B} T}} e^{-\frac{\mathcal{U}_{J}}{k_{B} T}}$, que leva, no caso do ensemble NVT, a seguinte equação para a diferença de energia livre de Helmholtz,

$$
\Delta F(J \rightarrow N)=k_{B} T \ln \left\langle e^{-\frac{\Delta \mathcal{u}}{k_{B} T}}\right\rangle_{J}
$$

onde \langle\rangle$_{J}$ significa que é a média sobre o estado termodinâmico $J$. Similarmente, no ensemble $N P T$, a diferença de energia livre de Gibbs é dada por,

$$
\Delta G(J \rightarrow N)=k_{B} T \ln \left\langle e^{\left.-\frac{(\Delta \mathcal{U}+p \Delta V)}{k_{B} T}+N \frac{V_{N}}{V_{J}}\right\rangle_{J}}\right.
$$

onde $\Delta \mathcal{U}$ e $\Delta V$ representam a diferença de energia e volume, entre os estados $J$ e $N$, respectivamente. A diferença de energia livre entre os dois estados $J$ e $N$, pode ser obtida através de simulações, calculando, no caso do ensemble $N V T$, o valor esperado da grandeza de $e^{-\frac{\Delta \mathcal{U}}{k_{B} T}}$, e no ensemble NPT, o valor de $e^{-\frac{(\Delta \mathcal{U}+p \Delta V)}{k_{B} T}}$. Embora as equações para determinar esses valores sejam simples, a convergência do cálculo é lenta se os estados $J$ e $N$ forem muito diferentes. Na prática, o que se faz em simulações com métodos perturbativos, é definir uma série de pontos intermediários entre esses dois estados, de modo que o estado $J$ é gradualmente transformado no estado $N$. Isso é feito usando um fator de acoplamento $\lambda$, que recebe valores discretos no intervalo de 0 a 1, tal que o potencial de interação, torna-se uma função desse parâmetro,

$$
\mathcal{U}(\lambda)=(1-\lambda) \mathcal{U}_{J}+\lambda \mathcal{U}_{N}
$$

em que o potencial $\mathcal{U}(\lambda)$ atende as seguintes condições, em $\lambda=0, \mathcal{U}=\mathcal{U}_{J}$, e em $\lambda=1$, $\mathcal{U}=\mathcal{U}_{N}$ 
Na equação 2.63, o potencial $\mathcal{U}(\lambda)$ também pode ser interpretado como o $i$-ésimo estado intermediário entre os estados $J$ e $N$, em que $\lambda$ é substituído por $\lambda_{i}$. Assim, o estado anterior e posterior a $\mathcal{U}\left(\lambda_{i}\right)$ é dado pelas seguintes expressões,

$$
\begin{aligned}
& \mathcal{U}\left(\lambda_{i+1}\right)=\mathcal{U}\left(\lambda_{i}+\delta \lambda_{i}\right), \\
& \mathcal{U}\left(\lambda_{i-1}\right)=\mathcal{U}\left(\lambda_{i}-\delta \lambda_{i}\right) .
\end{aligned}
$$

A diferença de energia livre total do processo é dada por uma soma de todas as contribuições,

$$
\Delta \mathcal{A}_{\text {total }}=\sum_{i=1}^{M} \Delta \mathcal{A}_{\left(\lambda_{i-1} \rightarrow \lambda_{i}\right)},
$$

em que cada contribuição para a diferença de energia livre é obtida, no caso do ensemble $N V T$, através da equação 2.61, e no ensemble NPT, pela equação 2.62. Em cada novo valor de $\lambda_{i}$, o potencial de interação sofre uma pequena perturbação, sendo, portanto, necessário esperar o sistema se reequilibrar ao novo potencial de interação para poder calcular o valor médio da energia livre. Assim, o processo perturbativo que leva o sistema do estado $J$ para o estado $N$ é longo e demorado, e requer uma série de simulações. Na prática, o que se faz é uma única simulação para obter duas contribuições para a diferença de energia livre, através de um procedimento de simulação para os dois lados ("double-wide") [246], em que o potencial $\mathcal{U}\left(\lambda_{i}\right)$ é perturbado para ambos os estados, $\mathcal{U}\left(\lambda_{i+1}\right)$ e $\mathcal{U}\left(\lambda_{i-1}\right)$.

\subsection{Metodologias Experimentais}

\subsubsection{Absorção Óptica}

A absorção óptica por moléculas é um fenômeno puramente quântico. Ela pode ocorrer quando moléculas são expostas a radição eletromagnética, e os elétrons dessas moléculas absorvem energia dessa radiação (fótons), promovendo a excitação de um elétron de um orbital ocupado para um orbital desocupado de energia mais alta, 
processo conhecido como transição eletrônica. Geralmente, a transição mais provável é do orbital ocupado de maior energia (HOMO) para o orbital desocupado de menor energia (LUMO). A diferença de energia entre níveis eletrônicos moleculares é da ordem de 30 a $150 \mathrm{kcal} / \mathrm{mol}[247,248]$, veja a figura 2.3, com as curvas de energia dos níveis eletrônicos de uma molécula diatômica.

Assim, os elétrons de uma molécula estão localizados nos orbitais moleculares. Os orbitais moleculares são definidos a partir de uma combinação linear dos orbitais atômicos, como apresentado na subseção 2.2.1.2 . Comumente, eles são divididos em orbitais ligantes, anti-ligantes e não-ligantes. Na maioria das moléculas, os orbitais ocupados de menor energia são os orbitais $\sigma$, que são orbitais ligantes. Esses orbitais podem ser formados pela combinação de dois orbitais atômicos do tipo s ou dois orbitais do tipo p tendo um eixo de simetria colinear, ou ainda um do tipo s e um do tipo p. Os orbitais do tipo $\pi$, que também são ligantes, são orbitais ocupados em níveis de energia um pouco mais altos. Esses orbitais são formados por dois orbitais p sobrepostos lateralmente. Já os orbitais do tipo $n$ são orbitais não ligantes, e ficam em energias ainda mais altas. Os orbitais desocupados, ou antiligantes ( $\pi^{*}$ ou $\left.\sigma^{*}\right)$ são aqueles de maior energia.

O espectro de absorção óptica de interesse nesta tese de doutorado compreende radiações com comprimento de onda na faixa de 800 a $200 \mathrm{~nm}$, que cobre a região do visível e ultravioleta próximo. Essa faixa corresponde a energias entre 1.55 e $6.19 \mathrm{eV}$, o que permite investigar estados eletrônicos moleculares e transições entre esses estados.

Do ponto de vista da mecânica quântica, a taxa de transição entre dois estados eletrônicos $a$ e $b$ é dada através da regra de ouro de Fermi,

$$
\frac{d P_{b \leftarrow a}}{d t}=\left(\frac{2 \pi^{2}}{3 \hbar^{3}}\right)\left|\left\langle\Psi_{b}|\boldsymbol{\mu}| \Psi_{a}\right\rangle\right|^{2} E_{0}^{2}
$$

em que $\hbar$ é a constante de Planck dividida por $2 \pi, \Psi_{a}$ e $\Psi_{b}$ são as funções de onda dos estados eletrônicos $a$ e $b, E_{0}$ é módulo do campo elétrico da radiação incidente e $\boldsymbol{\mu}$ é 


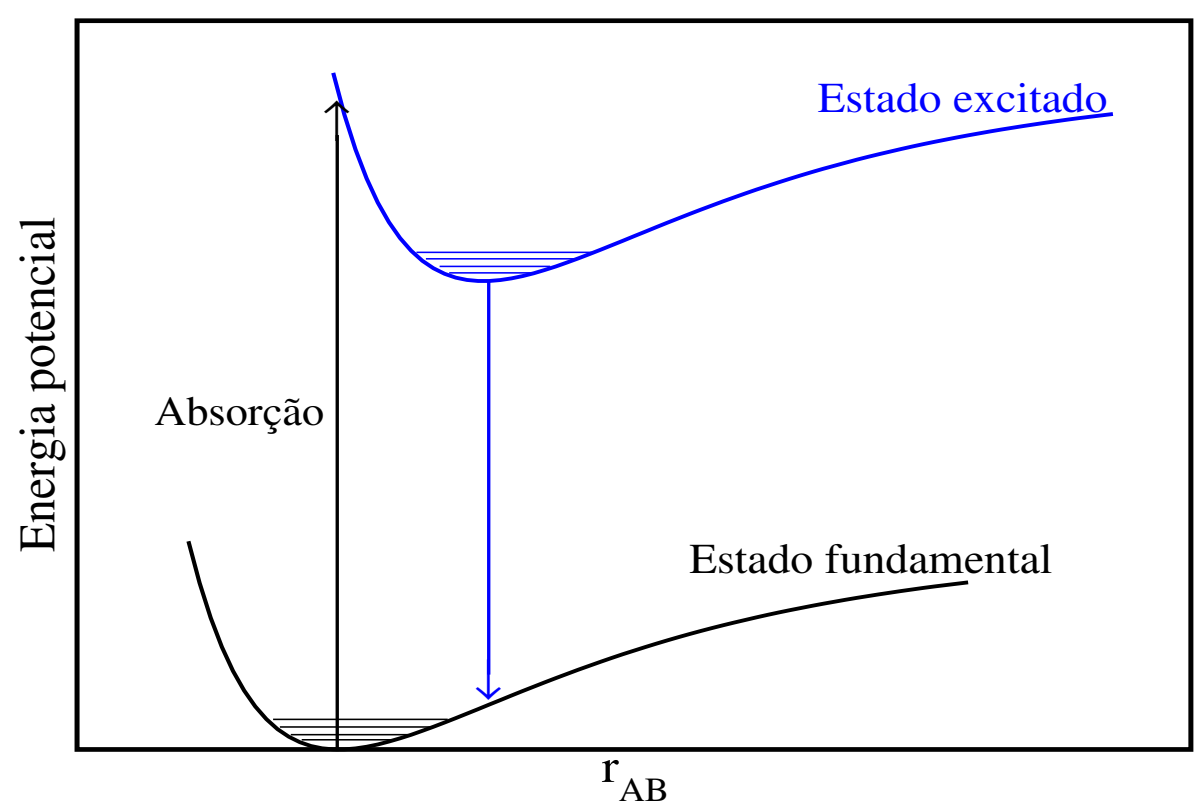

Figura 2.3: Ilustração das curvas de energia potencial para uma molécula diatômica de átomos A e B. Nessa figura estão mostrados apenas os níveis de energia do estado fundamental e excitado.

vetor momento de dipolo elétrico que caracteriza a molécula na presença da radiação. O termo $\left\langle\Psi_{b}|\boldsymbol{\mu}| \Psi_{a}\right\rangle$, é conhecido como momento de dipolo de transição, que é dado pela seguinte integral, $\left\langle\Psi_{b}|\boldsymbol{\mu}| \Psi_{a}\right\rangle=\int \Psi_{b}(r) \boldsymbol{\mu} \Psi_{a}(r) d^{3} r$ [249]. Como podemos observar nessa integral, nem todas as transições são observadas. Para valores dessa integral igual a zero, as transições são proibidas.

Do ponto de vista experimental, uma medida de absorção óptica é obtida fazendo incidir um feixe de luz monocromática de intensidade $I_{0}$ sobre uma amostra de interesse. A razão entre a radiação incidente $I_{0}$ e a intensidade do feixe transmitido $I$ fornece a absorbância, que é uma grandeza adimensional definida como,

$$
A=\log \left(\frac{I_{0}}{I}\right) .
$$

A equação 2.68 fornece uma definição para absorbância, e é usada como base na formulação da expressão principal do tratamento clássico da absorção de luz, chamada de Lei de Lambert-Beer. Essa lei revela que a absorbância está relacionada com a 
concentração da amostra e o caminho ótico (caminho percorrido pela luz dentro da amostra), como mostraremos a seguir. Considerando que a fração de luz absorvida $(-d I / I)$ por unidade de caminho ótico (ou seja, por uma parte da amostra suficientemente fina $(d l)$ e perpendicular à direção de propagação da luz) deve ser proporcional às características e ao número de moléculas absorvedoras, pode-se escrever a seguinte equação,

$$
-\frac{d I}{I}=\epsilon^{\prime} C d l
$$

onde $C$ é a concentração dessas moléculas na amostra e $\epsilon^{\prime}$ representa a constante de proporcionalidade chamada de coeficiente de extinção molar, que depende apenas da molécula absorvedora. O coeficiente de extinção molar, conhecido também como absortividade molar é uma propriedade intríseca da molécula, ela depende, além da molécula e do comprimento de onda da radiação, da temperatura e do solvente no qual a molécula está dissolvida. Integrando a equação 2.69, e convertendo os logarítimos, obtêm-se a expressão para a absorbância,

$$
A(\lambda)=\log \left(\frac{I_{(\lambda)}^{0}}{I_{(\lambda)}}\right)=\epsilon(\lambda) C l,
$$

em que $\epsilon=\epsilon^{\prime} / \ln 10$ é definido também como coeficiente de extinção molar (comumente dado em $\left.L . m o l^{-1} . \mathrm{cm}^{-1}\right), C$ é a concentração $\left(\mathrm{em} m o l . L^{-1}\right)$ das moléculas absorvedoras e $l($ em $\mathrm{cm})$ é o caminho ótico. Essa equação é conhecida como a lei de Lambert-Beer, ela expressa a proporcionalidade entre concentração e absorbância. A lei de LambertBeer é rigorosamente obdecida quando se têm dispersões moleculares, contendo uma única espécie, na forma monomérica gerando a absorção. Quando uma dispersão não obedece essa lei, pode ser um indicativo que existem diferentes espécies absorventes em equilíbrio, ou a formação de agregados através de algum mecanismo de associação entre soluto-soluto e soluto-solvente. Para mais detalhes da lei de Lambert-Beer, como deduções e limitações, recomendamos consultar as seguintes referências [247,250,251]. A escolha do solvente a ser usado nas medidas de absorção óptica está condicio- 
nada a determinados critérios: (i) o solvente deve ser capaz de dissolver a substância de interesse; (ii) o solvente não deve absorver radiação na região do visível e ultravioleta próximo, ou seja, ele não deve absorver radiação na mesma região que a molécula cujo o espectro está sendo medido; (iii) O solvente deve apresentar um baixo efeito na estrutura fina das bandas de absorção, por exemplo, solventes apolares não formam ligações de hidrogênio com a molécula, e o espectro de absorção dessa molécula dissolvida nesses solventes ficam bem próximo do espectro de vácuo. Já os solventes polares, que formam ligações de hidrogênio podem causar o desaparecimento da estrutura fina nas curvas dos espectros. (iv) outro critério para escolha do solvente está na sua capacidade de influenciar o comprimento no qual ocorre o máximo de absorção $\left(\lambda_{\text {máx }}\right)$. É conhecido que as posições das bandas dos espectros de algumas moléculas são drasticamente deslocadas para baixas ou altas energias com a mudança do solvente [252]. Esses deslocamentos são causados principalmente devido às interações intermoleculares entre soluto e solvente, tais como as interações dipolo-dipolo, íon-dipolo, ligações de hidrogênio, dipolo-dipolo induzido e as interações de van der Waals. Essas interações, listadas acima, tendem a alterar a diferença de energia entre os estados excitado e fundamental das moléculas absorvedoras.

A capacidade de uma dada molécula deslocar as posições das bandas de absorção com a mudança da polaridade do solvente é chamada de solvatocromismo. As moléculas que apresentam essa capacidade são geralmente chamadas de sondas solvatocrômicas. Uma sonda solvatocrômica pode ter qualquer um dos dois tipos de efeitos no espectro de absorção: (i) solvatocromismo batocrômico, que é um deslocamento das posições das bandas para região de comprimento de onda maiores (menores energias), ou seja, um deslocamento para o vermelho; (ii) solvatocromismo hipsocrômico, é um deslocamento das bandas para a região de comprimento de onda menores (maiores energias), ou seja, um deslocamento para o azul. O tipo de solvatocromismo de uma dada sonda, se é batocrômico ou hipsocrômico depende além do cromóforo, da 
natuteza das transições eletrônicas (se é $\sigma \rightarrow \sigma^{*}, n \rightarrow \sigma^{*}, \pi \rightarrow \pi^{*}$ e $n \rightarrow \pi^{*}$ ).

As transições do tipo $\sigma \rightarrow \sigma^{*}$ e $n \rightarrow \sigma^{*}$ são transições de energias tão altas (baixos comprimento de ondas, na faixa de 200 a $110 \mathrm{~nm}$ ) que são dificilmente acessíveis por espectrofotômetros convencionais [247,253]. Já as transições do tipo $\pi \rightarrow \pi^{*}$ e $n \rightarrow \pi^{*}$ são caracterizadas por energias dentro da região do visível e ultravioleta próximo, devido a isso, elas são as transições mais estudadas dentro da espectroscopia de absorção óptica. É conhecido que solventes polares provocam deslocamentos das bandas de transição $\pi \rightarrow \pi^{*}$ para o azul (região de comprimento de onda menores ou maiores energias). Quando as transições são do tipo $n \rightarrow \pi^{*}$, temos o efeito contrário, é observado um deslocamento para o vermelho (região de comprimento de onda maiores ou menores energias) com solventes polares [252].

Outra maneira qualitativa de determinar o tipo de solvatocromismo de uma sonda é através da análise das seguintes características da molécula: (i) momentos de dipolo dos estados excitado $\left(\mu_{E}\right)$ e fundamental $\left(\mu_{G}\right)$; (ii) diferença entre o dipolo permanente desses dois estados; (iii) mudança do dipolo do estado fundamental induzida pelo solvente e; (iv) princípio de Franck-Condon ${ }^{5}$

(i) Soluto apolar em solvente apolar: a principal contribuição para a energia de solvatação da molécula nos estados fundamental e excitado é devida principalmente à interação de dispersão, que é assumido ser praticamente a mesma nos dois estados. Nesse caso, a solvatação provoca um pequeno deslocamento para o vermelho e a amplitude desse deslocamento depende além da característica do solvente, do índice de refração do mesmo;

${ }^{5}$ O princípio de Franck-Condon pode ser interpretado por dois pontos de vista: (i) clássico, que diz que uma transição eletrônica é mais provável de ocorrer sem a alteração nas posições dos núcleos da molécula e em seu ambiente. O estado resultante, ainda não relaxado, é chamado de estado de Franck-Condon e a transição é vertical.; (ii) quântico, que diz que a intensidade de uma transição vibracional é proporcional ao quadrado da integral de sobreposição entre as funções de onda dos dois estados que estão envolvidos na transição. Para mais detalhe desse princípio, recomendo consultar as seguintes referências [254-256] 
(ii) Soluto apolar em solvente polar: esse caso é similar ao caso (i), embora o solvente seja polar, a ausência do momento de dipolo do soluto significa que não ocorre nenhuma orientação significativa do solvente em torno do soluto. Similarmente ao caso (i), a solvatação nesse caso provoca um deslocamento para o vermelho, com a amplitude desse deslocamento dependente do índice de refração;

(iii) Soluto polar em solvente apolar: como o solvente é apolar, espera-se que não ocorra nenhuma orientação do solvente ao redor do soluto. As principais contribuições para energia livre de solvatação são devidas principalmente às interações de dispersões e dipolo-dipolo induzido. Nesse caso o deslocamento pode ocorrer tanto para o vermelho como para o azul, dependendo da mudança no momento de dipolo durante a transição: se o momento de dipolo do soluto aumenta, o deslocamento é para o azul, mas se o momento de dipolo diminui, é registrado um deslocamento para o vermelho. Similarmente aos casos anteriores, o deslocamento vai depender além do momento de dipolo do soluto, do índice de refração do solvente;

(iv) Soluto polar em solvente polar: nesse caso, a energia de solvatação do soluto depende muito da interação dipolo-dipolo. Como ambos soluto e solvente são polares, espera-se que as moléculas do solvente em torno do soluto fiquem orientadas de acordo com o seu momento de dipolo, levando a uma maior estabilização do estado fundamental. Se o momento de dipolo do soluto aumenta durante a transição eletrônica, $\left(\mu_{G}<\mu_{E}\right)$, isso gera uma maior estabilização do estado excitado. Nesse caso, se tem uma diminuição na energia, portanto é registrado um deslocamento para o vermelho. Quando o momento de dipolo diminui com a transição eletrônica $\left(\mu_{G}>\mu_{E}\right)$, temos o efeito contrário e o deslocamento para o azul acontece. Uma descrição completa dessas regras e suas limitações pode ser encontrada nas seguintes referências [247,252,257]. 


\subsubsection{Calorimetria diferencial de varredura (DSC)}

O DSC é uma técnica que mede a diferença de capacidade térmica entre uma amostra e um material referência, em função da temperatura, enquanto a amostra e o material são submetidos a uma programação controlada de variação de temperatura [258]. Essa técnica vem sendo largamente aplicada no estudo de sistemas biológicos, particularmente no estudo de transição de fase de bicamadas lipídicas [259-262]. A grande vantagem da aplicação dessa técnica nesses sistemas é que ela fornece propriedades termodinâmicas importantíssimas acerca das bicamadas na região da transição de fase, como calor específico a pressão constante, entalpia, entropia e temperatura de transição de fase.

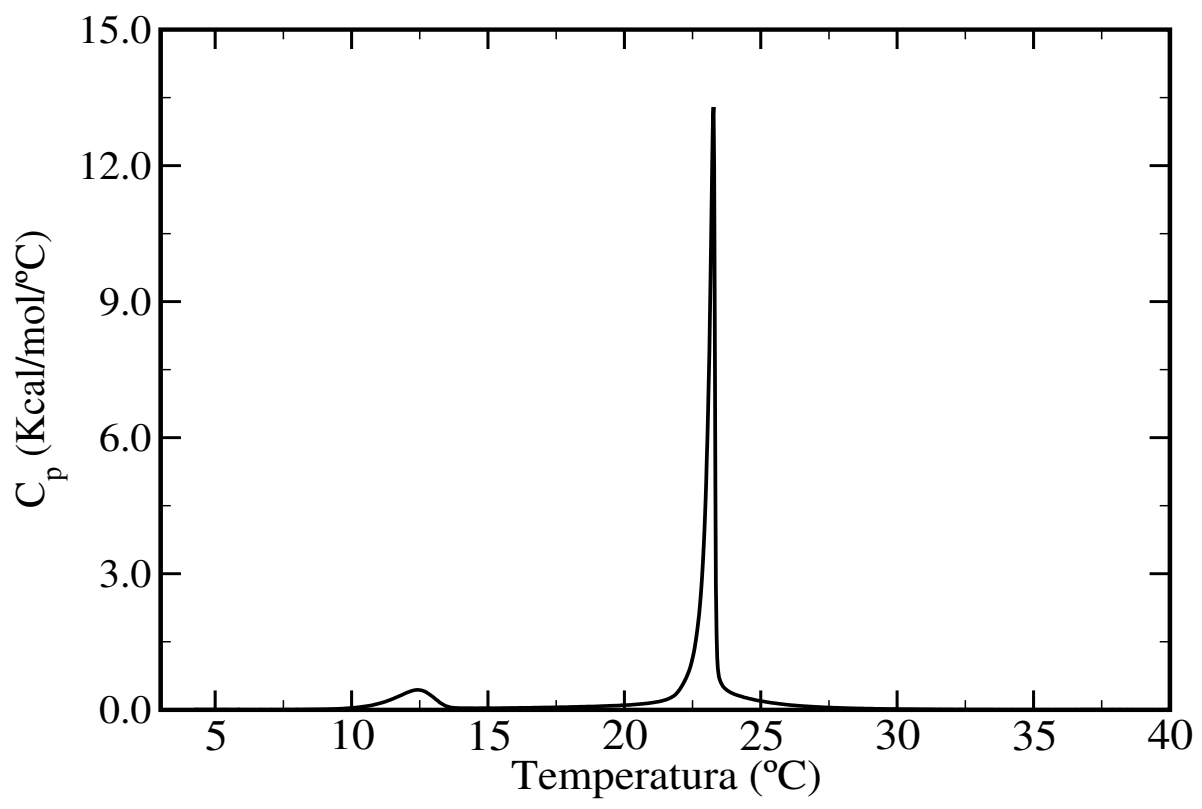

Figura 2.4: Curva de DSC de dispersões lipídicas de DMPC na concentração $5 \mathrm{mM}$ em tampão hepes pH 7.4. A taxa de aquecimento foi $20{ }^{\circ} \mathrm{C} / \mathrm{h}$.

A principal informação fornecedida por um experimento de DSC é sem dúvida a curva do calor específico à pressão constante em função da temperatura. Na figura 2.4 mostramos um exemplo dessa curva de DSC de uma dispersão lipídica de DMPC. Essa figura mostra um pico estreito de calor específico na temperatura de transição 
de fase gel-fluida $\left(\mathrm{T} \sim 23^{\circ} \mathrm{C}\right)$. Além disso, existe um outro pico menor, porém mais alargado, com a temperatura em torno de $12{ }^{\circ} \mathrm{C}$, que está relacionado à pré-transição de fase [263]. Usando essa curva do calor específico à pressão constante em função da temperatura é possível determinar as variações de entropia $(\Delta S)$ e entalpia $(\Delta H)$ através das seguintes relações termodinâmicas,

$$
\begin{aligned}
& \Delta S=\int \frac{c_{p}}{T} d T, \\
& \Delta H=\int c_{p} d T,
\end{aligned}
$$

visto que o calor específico à pressão constante está relacionado com a entropia e entalpia através das derivadas termodinâmicas, $c_{p}=\frac{T}{N}\left(\frac{\partial S}{\partial T}\right)_{p, N}$ e $c_{p}=\left(\frac{\partial H}{\partial T}\right)_{p, N}$. Assim, a variação de entalpia é determinada através da integração da curva de DSC num dado intervalo de temperatura, que corresponde justamente a área sob essa curva. 


\section{Capítulo 3}

\section{Materiais e Métodos}

\subsection{Introdução}

Neste capítulo apresentaremos os materiais e equipamentos usados nos experimentos como também descreveremos o preparo das amostras usadas nesses experimentos. Descreveremos também os métodos teóricos utilizados nos cálculos quânticos e simulações computacionais.

\subsection{Materiais}

Os compostos: 1,3,8-trihidroxi-6-metil-9,10-antraquinona (Emodina), ácido hidroclorídrico $(\mathrm{HCl})$ e hidróxido de sódio $(\mathrm{NaOH})$ e os tampões (Hepes (ácido de $\mathrm{N}-(2$ Hidroxietil)-Piperazina-N'-2-etano sulfônico), bifosfato de sódio monohidratado $\left(\mathrm{NaH}_{2} \mathrm{PO}_{4} \cdot \mathrm{H}_{2} \mathrm{O}\right)$, fosfato de sódio bib. heptahidratado $\left(\mathrm{Na}_{2} \mathrm{HPO}_{4} \cdot 7 \mathrm{H}_{2} \mathrm{O}\right)$, bicarbonato de sódio $\left(\mathrm{NaHCO}_{3}\right)$ e carbonato de sódio anidro $\left.\left(\mathrm{Na}_{2} \mathrm{CO}_{3}\right)\right)$ foram comprados da Sigma-Aldrich Co. (St. Louis, MO, USA), o fosfolipídio 1,2-dimiristoil-sn-glicero3-fosfocolina (DMPC) foi comprado da Avanti Polar Lipids, Inc. (Birmingham, AL, USA). Os solventes usados foram: metanol, etanol, 2-propanol, acetonitrila, dimetilsulfóxido (DMSO), acetona, diclorometano, clorofórmio, dioxano e benzeno, todos esses solventes orgânicos foram comprados da Sigma-Aldrich Co. (St. Louis, MO, 
USA), e a água utilizada foi padrão Milli-Q obtida do instrumento Milli-Q Plus da Millipore ( $\mathrm{pH} \sim 6.5)$.

\subsection{Preparação das amostras}

\subsubsection{Preparação de Emodina em solventes}

Uma solução estoque de Emodina $(10 \mathrm{mM})$ foi preparada em uma mistura de etanol e metanol (4:1) em (v/v). Alíquotas dessa solução foram distribuídas em tubos de ensaio de acordo com a concentração final desejada para as medidas. Um fluxo de nitrogênio $\left(\mathrm{N}_{2}\right)$ com 99,999\% de pureza foi utilizado para secar o solvente, e em seguida as amostras foram colocadas sob baixa pressão por, no mínimo, 2 horas para remover qualquer traço de solvente orgânico. Após a secagem, filmes de Emodina foram formados nos tubos de ensaio, e depois, foram ressuspendidos no solvente e concentração final desejada para realização das medidas.

Para o procedimento de titulação espectroscópica, os filmes de Emodina foram ressuspendidos em dois solventes diferentes, em água, nas concentrações 0.1 e 0.025 mM, e em metanol, na concentração de 0.025 mM. Para cada concentração de Emodina, foram preparadas duas soluções em valores diferentes de $\mathrm{pH}$, sendo uma alcalina com pH 13 (concentração de NaOH, 17.5 mM), e uma solução ácida com pH 2 (mistura de hidroclorídrico/solvente $(1: 500 \mathrm{v}: \mathrm{v}))$. O pH dessas soluções foi variado de aproximadamente 2 a 13, ou vice-versa, titulando essas soluções adotando critérios de acordo com o solvente. Por exemplo, para as medidas em água, foi escolhida a solução aquosa alcalina e titulado o pH dessa solução por adição de pequenas alíquotas da solução ácida, com a medida do pH após cada adição. Já para as medidas em metanol, foi realizado o contrário, a solução ácida de metanol foi escolhida, o pH dessa solução foi titulado adicionando-se pequenas alíquotas da solução alcalina, provocando pequeno aumento do pH dessa solução, medidos com pHmetro a cada adição. Esse 
procedimento foi adotado a fim de evitar, no caso da água, efeitos de agregação, visto que a Emodina precipita, formando agregados em solução aquosa ácida, como será discutido no capítulo 4, seção 4.2.3.1.

Para estudar o efeito do ambiente nos espectros eletrônicos de absorção da Emodina foram preparadas soluções dessa molécula em água, metanol, etanol, 2-propanol, acetonitrila e DMSO nas condições de pH ácido (mistura de hidroclorídrico/solvente $(1: 500 \mathrm{v}: \mathrm{v})$ ), neutro e alcalino (concentração de $\mathrm{NaOH}, 10.0 \mathrm{mM})$. A acidez ou basicidade das soluções foi confirmada para todas as soluções através da coloração da Emodina, pois essa é uma boa indicadora de pH do ambiente local, uma vez que em solução ácida ela apresenta uma cor amarela e em solução alcalina uma cor vermelha. Nesses solventes nós evitaremos apresentar valores quantitativos de $\mathrm{pH}$, exceto em água que existe uma escala de $\mathrm{pH}$ definida e em metanol, que existem propostas na literatura que relacionam a escala de $\mathrm{pH}^{*}$ nesse solvente com a escala de $\mathrm{pH}$ aparente, $\mathrm{pH}_{\mathrm{ap}}$ ( $\mathrm{pH}$ medido com pHmetro calibrado para água). Essas escalas estão relacionadas, baseasada num procedimento descrito por Ligny e colaboradores [264-266], onde eles determinaram os valores do $\mathrm{pH}^{*}$ e $\mathrm{pH}_{\text {ap }}$ de duas soluções tampão de metanol, uma com oxalato $\left(\mathrm{pH}^{*}=5.79, \mathrm{pH}_{\mathrm{ap}}=3.46\right)$ e a outra com succinato $\left(\mathrm{pH}^{*}=8.75, \mathrm{pH}_{\mathrm{ap}}=6.51\right)$. Baseado nessas medidas eles propuseram uma correção linear nos valores de $\mathrm{pH}_{\mathrm{ap}} \mathrm{em}$ metanol dado por $\mathrm{pH}^{*}=\mathrm{pH}_{\mathrm{ap}}+\delta$, onde é $\delta=2.34$. Recentemente Beckers e colaboradores [267] realizaram as medidas do $\mathrm{pH}^{*}$ e $\mathrm{pH}_{\mathrm{ap}}$ nos mesmos tampões usados por Ligny e colaboradores e propuseram um novo valor para correção $(\delta=2.25)$. Neste trabalho nós usamos o valor de $\delta=2.30$, determinado a partir da média dos valores de Ligny e Beckers, e também coerente com o valor de ambos trabalhos com apenas 1 ou 2 algarísmo significativos. Preparamos também soluções de Emodina nos solventes acetona, diclorometano, clorofórmio, dioxano e benzeno nas condições neutra de pH. Entenda-se como condição neutra de pH, soluções sem a adição de quaisquer reagentes que venham modificar a quantidade de íons dessas soluções, apenas as moléculas do 
solvente e as da Emodina estão presentes nessas soluções.

\subsubsection{Preparação de Emodina em dispersões lipídicas}

Para as medidas de DSC, uma dispersão lipídica de DMPC em clorofórmio a 5 mM foi preparada. Alíquotas dessa dispersão foram distribuídas em tubos de ensaio, em seguida, alíquotas da solução estoque de Emodina foram adicionadas à dispersão lipídica, com o intuito de obter as seguintes frações molares, 5, 10, 15 e $20 \mathrm{~mol} \%$ em relação à concentração de lipídio. Seguindo o mesmo protocolo mencionado anteriormente, o solvente foi evaporado sob um fluxo de nitrogênio $\left(\mathrm{N}_{2}\right)$ ultra-puro e em seguida, as amostras foram mantidas sob baixa pressão por, no mínimo, 2 horas para remover traços do solvente. Essas amostras foram ressuspendidas nas soluções tampão desejada, e em seguida foram agitadas, através de um agitador mecânico vórtex por aproximadamente 2 minutos, a uma temperatura acima da temperatura de transição de fase do DMPC $\left(23.5^{\circ} \mathrm{C}\right)$. A concentração final de DMPC foi $5 \mathrm{mM}$. As soluções tampão usadas neste trabalho foram: (i) solução aquosa com $10 \mathrm{mM}$ de Hepes, ajustada com $\mathrm{NaOH}$ para pH 7.4; (ii) mistura de soluções aquosas com $10 \mathrm{mM}$ de bifostato de sódio monohidratado e $10 \mathrm{mM}$ de fostato de sódio heptahidratado (1:1), ajustada com $\mathrm{NaH}_{2} \mathrm{PO}_{4} \cdot \mathrm{H}_{2} \mathrm{O}$ para $\mathrm{pH}$ 6.0; (iii) mistura de soluções aquosas com 10 $\mathrm{mM}$ de bicarbonato de sódio e $10 \mathrm{mM}$ de carbonato de sódio anidro (1:1), ajustada com $\mathrm{NaHCO}_{3}$ para $\mathrm{pH} 10.0$.

Para as medidas do espectro eletrônico de absorção, seguiu-se o mesmo protocolo descrito acima, porém, neste caso, as mostras foram preparadas somente com $1 \mathrm{mM}$ de DMPC mais Emodina na fração molar de 2 mol\%. Essas amostras foram extrusadas em um mini-extrusor da Avanti Polar Lipids, Inc., onde as dispersões foram passadas 31 vezes por um filtro de $100 \mathrm{~nm}$, mantendo a temperatura da amostra acima da temperatura de transição de fase do DMPC. Esse procedimento foi adotado a fim de tornar as amostras mais homogêneas, com relação ao diâmetro das vesículas lipídicas, 
reduzindo com isso o espalhamento de luz nos espectros eletrônico de absorção, e também, para evitar a precipitação de grandes agregados de DMPC.

\subsection{Equipamentos utilizados}

\subsubsection{Espectroscopia UV-Vis}

Todas as medidas do espectro eletrônico de absorção da Emodina foram realizadas num espectrofotômetro digital UV-Vis Varian Cary 50 Bio, onde as amostras foram colocadas em cubetas de quartzo de caminho óptico de $1.0 \mathrm{~cm}$, e mantidas durante todo experimento nas condições normais de pressão (1 atm) e temperatura (25 $\left.{ }^{\circ} \mathrm{C}\right)$. Em todas as medidas, usamos um procedimento padrão de subtrair os espectros das amostras com Emodina de linha de base obtidas através de medidas do espectro nas amostras sem a Emodina. Esse procedimento foi necessário para eliminar a influência do solvente e material da cubeta nos espectros da Emodina. Para medir o pH das amostras de Emodina em água e metanol, usamos um pHmetro Mettler Toledo. No caso do metanol, as medidas foram realizadas na escala de $\mathrm{pH}$ aparente, $\mathrm{pH}_{\mathrm{ap}}(\mathrm{pH}$ medido com pHmetro calibrado para água), e aplicada a correção nos valores de $\mathrm{pH}_{\mathrm{ap}}$ obtidos, através da relação $\mathrm{pH}^{*}=\mathrm{pH}_{\mathrm{ap}}+2.30$, como discutido anteriormente na seção 3.3.1.

\subsubsection{Calorimetria diferencial de varredura (DSC)}

As medidas de DSC foram realizadas num calorímetro da Microcal, modelo VPDSC a uma taxa de varredura de $20{ }^{\circ} \mathrm{C} / \mathrm{h}$. As curvas de DSC foram normalizadas pela concentração e taxa de varredura, além disso, usamos também um procedimento padrão de subtrair essas curvas de DSC por uma linha de base, usando o programa Origin com ferramentas adicionais para tratamento de medidas de DSC com o calorímetro da Microcal. Uma descrição completa desse equipamento como também da 
técnica de DSC, podem ser encontrados nas seguintes referências [259, 268].

\subsection{Métodos teóricos}

\subsubsection{Cálculos quânticos}

Do ponto de vista teórico, cálculos quânticos (QM) com teoria do funcional da densidade (DFT) [161, 269-271], particularmente com o funcional híbrido B3LYP [187,272], têm descrito muito bem a estrutura eletrônica da Emodina em fase gasosa e em meio solvente com o solvente descrito com modelo contínuo polarizável [29, 32, 37, 273]. Assim, a geometria inicial da molécula Emodina neutra (EMH) foi otimizada usando o método B3LYP e a função de base 6-311++ $\mathrm{G}^{* *}[192,274]$. A geometria inicial otimizada da Emodina se encontra numa conformação planar, formando duas ligações de hidrogênio intramoleculares, os hidrogênios H8 e H1 com O9, ver as figuras 1.1 e 3.1. Os parâmetros geométricos dessa geometria estão em boa concordância com os parâmetros teóricos encontrados na literatura obtidos com DFT [29,275] e com os experimentais obtidos por difração de raio-X para a 1,8-dihidroxiantraquinona [276]. Otimizamos também as geometrias das formas tautoméricas dessa espécie com a hidroxila na posição 9, ou seja, a 3,8,9-trihidroxi-6-metil-1,10-antraquinona e a 1,3,9trihidroxi-6-metil-8,10-antraquinona, porém nenhuma dessas formas tautoméricas foram estáveis.

Otimizamos também, usando o mesmo método e função de base, a molécula de Emodina com uma desprotonação nas posições 1 (3,8-EM-), 3 (1,8-EM+) e 8 (1,3-EM+), e suas formas tautoméricas a 1,9-EM- (hidroxilas nas posições 1 e 9,), 3,9-EM- (hidroxilas nas posições 3 e 9) e 8,9-EM- (hidroxilas nas posições 8 e 9), a fim de investigar a posição mais favorável energeticamente para ocorrer a primeira desprotonação. Na figura 3.1 apresentamos as geometrias otimizadas das espécies estáveis. Todas essas geometrias encontram-se numa conformação planar, sendo a 1,8-EM- formando duas 

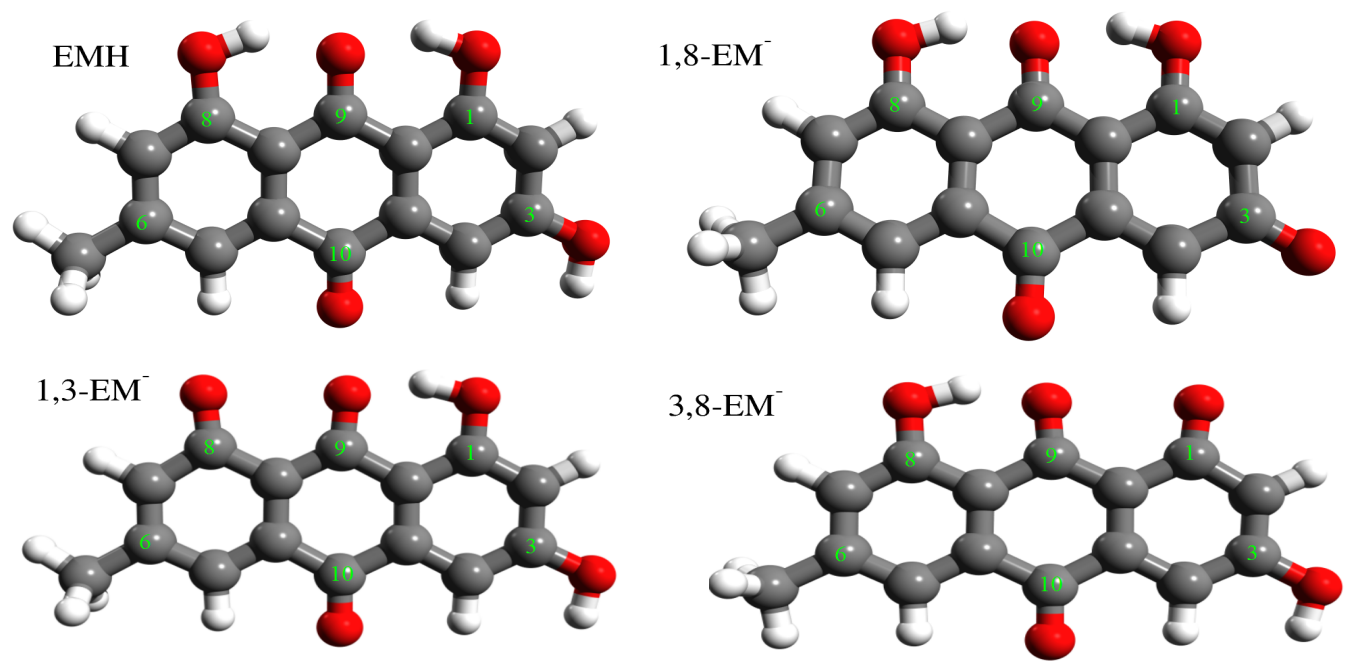

Figura 3.1: Geometrias obtidas com B3LYP/6-311++G** das espécies da Emodina neutra, EMH e desprotonadas, $1,8-\mathrm{EM}^{-}, 1,3-\mathrm{EM}^{-}$e $3,8-\mathrm{EM}^{-}$.

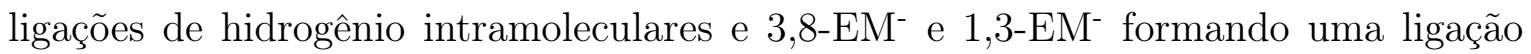
de hidrogênio intramolecular. A desprotonação das hidroxilas da EMH, provoca uma

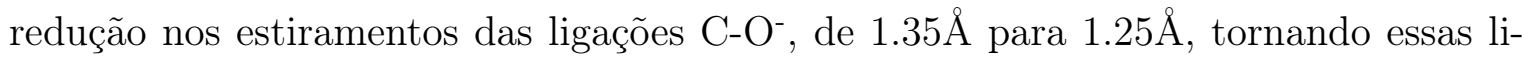
gações com características de ligações duplas, como as dos grupos carbonilas C9-O9 e C10-O10.

Adicionalmente, por completeza, demos sequência ao estudo dos processos de desprotonação da Emodina. Para isso, otimizamos a geometria da Emodina duplamente desprotonada nas posições 3 e 8 (1-EM $\left.{ }^{2-}\right), 3$ e 1 (8-EM $\left.{ }^{2-}\right)$, e a forma tautomérica, 9-EM ${ }^{2-}$, e triplamente desprotonada nas posições 1,3 e $8\left(\mathrm{EM}^{3-}\right)$, ver figura 3.2. Nessa parte, todas as geometrias se mantiveram planares, com exceção a espécie $\mathrm{EM}^{3-}$, pois registramos os oxigênios O8, O9 e O1 fora do plano da molécula. Na figura 3.2, mostramos todas as geometrias otimizadas para Emodina dupla e triplamente desprotonada.

A partir das geometrias otimizadas das espécies da Emodina estáveis, realizamos cáculos da energia livre de Gibbs $(G)$ dessas espécies em vácuo e em solução aquosa. Esses cálculos foram realizados usando o mesmo método e função de base do cálculo 


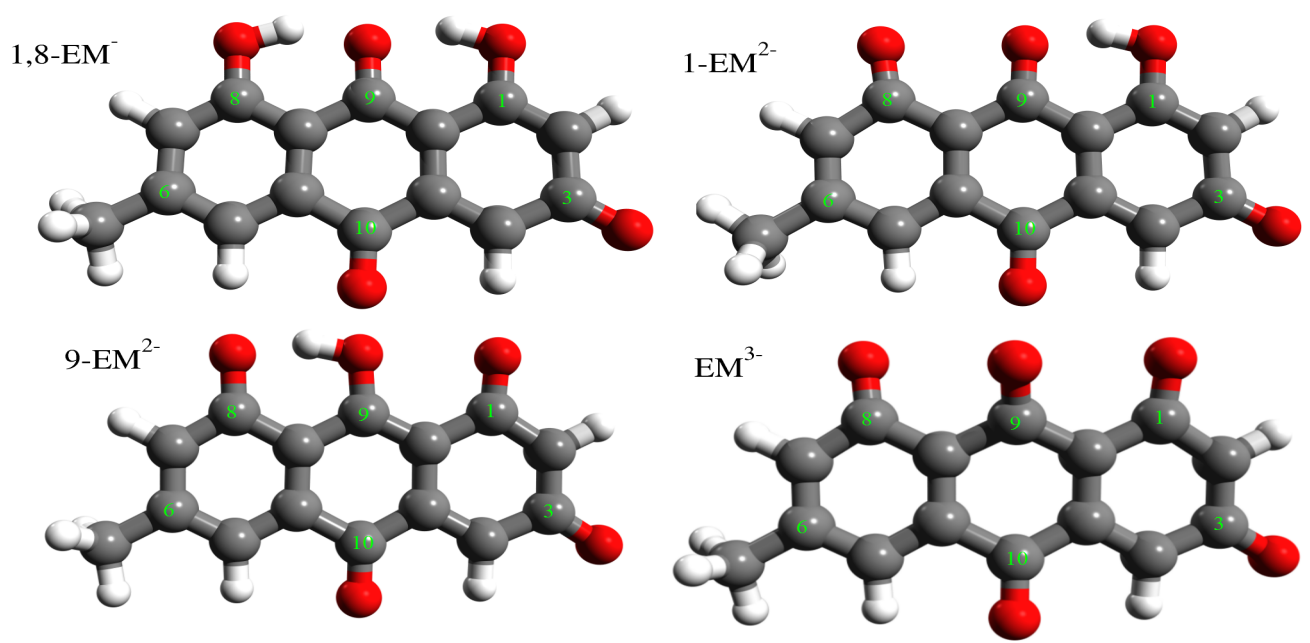

Figura 3.2: Geometrias obtidas com B3LYP $/ 6-311++\mathrm{G}^{* *}$ das espécies da Emodina despro-

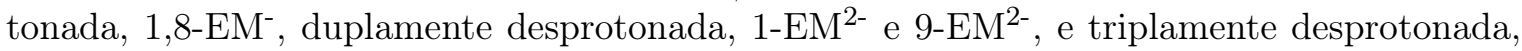
$\mathrm{EM}^{3-}$.

de otimização de geometria, e G foi calculado considerando a energia eletrônica da molécula e correções de ponto-zero, térmicas e entálpicas. Para as espécies EMH e 1,8- $\mathrm{EM}^{-}$, em vácuo e em meio solvente, realizamos cálculos das energias de transição eletrônica usando o método TD-B3LYP/6-311++G** [277]. Para descrever os efeitos dos solventes foi utilizado o modelo contínuo polarizável (PCM) nos cálculos da energia livre de Gibbs, energias de transição eletrônica, momento de dipolo e cargas atômicas. Todos os cálculos quânticos deste trabalho foram realizados com o programa Gaussian [278].

\subsubsection{Simulações computacionais}

\subsubsection{Simulação da hidratação da EMH e EM-}

Realizamos um estudo com as espécies da Emodina neutra (EMH) e Emodina desprotonada mais estável $\left(1,8-\mathrm{EM}^{-}\right)$, que denominaremos de agora em diante de $\mathrm{EM}^{-}$, em solução aquosa, através de simulações moleculares, utilizando um modelo de sol- 
vente, onde as moléculas são incluídas explicitamente [71]. As simulações foram realizadas com dinâmica molecular (MD) com as espécies da Emodina numa caixa cúbica com 500 moléculas de água descritas com o modelo SPC [279] no ensemble NPT, nas condições normais de pressão e temperatura. Utilizamos condições de contorno periódicas para caixa cúbica de aresta inicial de $24.98 \AA$, gerando, portanto uma densidade inicial de $1 \mathrm{~g} / \mathrm{cm}^{3}$. Para manter a temperatura e pressão flutuando em torno de $298 \mathrm{~K}$ e 1 atm, empregamos o termostato de Berendsen com a constante de acoplamento de 0.1 ps e barostato de Berendsen, usando uma compressibilidade isotérmica de $4.51 \times 10^{-5}$ bar $^{-1}$ e uma constante de acoplamento de 1 ps [223]. Para o cálculo da energia além do raio de corte de $12.49 \AA$, que é a metade da aresta da caixa, foi utilizada uma correção de longo alcance para o termo eletrostático através do metódo de campo de reação [234]. As equações de movimento foram integradas usando o algoritmo de leap-frog [280] com as moléculas flexíveis, usando o intervalo de tempo $\Delta \mathrm{t}=1$ fs de integração. Usamos o campo de força GROMOS 54a7 [104,105], para o potencial de interação molecular da Emodina. Nesse campo de força, o potencial intermolecular e intramolecular para átomos não ligados é representado pela interação de Lennard-Jones mais a interação de Coulomb, caracterizado pelo conjunto de parâmetros $\left(C^{(6)}, C^{(12)}\right.$, q), e o potencial intramolecular entre átomos ligados é representado por uma soma de quatro termos, a interação harmônica para as ligações químicas, interação harmônica para ligações angulares, interação através de série de Fourier para ângulos torcionais, próprios e impróprios, que são caracterizados pelo conjunto de parâmetros $\left(k_{r}, r_{e q}, k_{\theta}\right.$, $\left.\theta_{e q}, \phi_{s}, C_{i}\right)$, descritos na seção 2.2.2.4. Para mais detalhes desse campo de força veja as seguintes referências [106,229]. A interação eletrostática de ambas as espécies da Emodina foi descrita por conjuntos de cargas atômicas, obtidos através do ajuste do potencial eletrostático gerado com método B3LYP/6-311++G**/CHELPG [204,281], com o soluto em meio solvente, com o solvente descrito com o modelo PCM. Na tabela 3.1, apresentamos os conjuntos de cargas obtidos para a Emodina neutra e Emodina 
desprotonada usando essa metodologia.

Tabela 3.1: Conjuntos de cargas atômicas obtidas do ajuste do potencial eletrostático através de cálculos quânticos com método B3LYP/6-311++G**/CHELPG para EMH e EM- em meio solvente água e metanol. O solvente foi descrito com modelo contínuo polarizável PCM.

\begin{tabular}{|c|c|c|c|c|c|c|c|c|c|}
\hline \multirow[t]{2}{*}{ Átomos } & \multicolumn{2}{|c|}{ Água } & \multicolumn{2}{|c|}{ Metanol } & \multirow[t]{2}{*}{ átomos } & \multicolumn{2}{|c|}{ Água } & \multicolumn{2}{|c|}{ Metanol } \\
\hline & EMH & $\mathrm{EM}^{-}$ & $\mathrm{EMH}$ & $\mathrm{EM}^{-}$ & & $\mathrm{EMH}$ & $\mathrm{EM}^{-}$ & $\mathrm{EMH}$ & $\mathrm{EM}^{-}$ \\
\hline $\mathrm{C} 1$ & 0.551 & 0.595 & 0.550 & 0.595 & C8 & 0.556 & 0.540 & 0.555 & 0.540 \\
\hline $\mathrm{O} 1$ & -0.682 & -0.711 & -0.680 & -0.710 & $\mathrm{O} 8$ & -0.684 & -0.727 & -0.682 & -0.726 \\
\hline $\mathrm{H} 1$ & 0.501 & 0.489 & 0.500 & 0.488 & $\mathrm{H} 8$ & 0.495 & 0.512 & 0.494 & 0.511 \\
\hline $\mathrm{C} 2$ & -0.442 & -0.605 & -0.440 & -0.604 & C9 & 0.668 & 0.628 & 0.666 & 0.626 \\
\hline $\mathrm{H} 2$ & 0.243 & 0.207 & 0.242 & 0.206 & O9 & -0.670 & -0.741 & -0.669 & -0.741 \\
\hline $\mathrm{C} 3$ & 0.535 & 0.737 & 0.533 & 0.737 & $\mathrm{C} 10$ & 0.530 & 0.563 & 0.528 & 0.562 \\
\hline O3 & -0.677 & -0.843 & -0.674 & -0.839 & O10 & -0.570 & -0.604 & -0.567 & -0.602 \\
\hline H3 & 0.505 & -- & 0.502 & -- & $\mathrm{C} 11$ & -0.401 & -0.463 & -0.401 & -0.463 \\
\hline $\mathrm{C} 4$ & -0.366 & -0.330 & -0.365 & -0.328 & $\mathrm{C} 12$ & 0.073 & 0.018 & 0.074 & 0.017 \\
\hline $\mathrm{H} 4$ & 0.186 & 0.136 & 0.185 & 0.135 & $\mathrm{C} 13$ & 0.025 & 0.000 & 0.025 & 0.000 \\
\hline $\mathrm{C} 5$ & -0.254 & -0.252 & -0.253 & -0.252 & $\mathrm{C} 14$ & -0.368 & -0.342 & -0.368 & -0.342 \\
\hline $\mathrm{H} 5$ & 0.158 & 0.150 & 0.157 & 0.149 & $\mathrm{C} 15$ & -0.188 & -0.144 & -0.187 & -0.142 \\
\hline $\mathrm{C} 6$ & 0.259 & 0.212 & 0.258 & 0.211 & H16 & 0.063 & 0.047 & 0.063 & 0.046 \\
\hline $\mathrm{C} 7$ & -0.386 & -0.379 & -0.384 & -0.379 & H17 & 0.067 & 0.052 & 0.067 & 0.052 \\
\hline $\mathrm{H} 7$ & 0.206 & 0.202 & 0.206 & 0.201 & H18 & 0.067 & 0.054 & 0.067 & 0.064 \\
\hline
\end{tabular}


Todas as simulações foram realizadas com o programa GROMACS [238], e nas análises dos resultados foram empregados os programas ORDER [282] e o ANLGEOM [283]. O processo total da simulação foi realizado em duas etapas: (i) um processo de equilibração ou termalização, partindo de uma configuração totalmente aleatória levada até o estado de equilíbrio, com $10^{7}$ passos de MD, totalizando $10 \mathrm{~ns}$. (ii) um processo de simulação no equilíbrio com $5 \times 10^{7}$ passos de MD, totalizando $50 \mathrm{~ns}$.

\subsubsection{Cálculos do $\mathrm{pK}_{\mathrm{a}}$ da Emodina}

Os processos de protonação/desprotonação de um dado composto são governados por relações físico-químicas da termodinâmica. Nesses processos estamos quase sempre interessados em saber quais as condições termodinâmicas em termos dos parâmetros temperatura $(\mathrm{T})$, pressão $(\mathrm{P})$ e potencial químico $(\mu)$ que otimizam o produto desses processos, dado a condição de equilíbrio termodinâmico. Uma vez atingidas essas condições é possível caracterizar uma série de propriedades termodinâmicas, tais como entalpia $(\mathrm{H})$ e energia livre de Gibbs $(\mathrm{G})$ que estão relacionadas com as constantes de equilíbrio desses processos, tais como as constantes de acidez e basicidade. Teoricamente há diversas maneiras diferentes de obter essas constantes dos processos de protonação/desprotonação. Mas neste trabalho nós as calculamos através das diferenças de energia livres das espécies envolvidas nesses processos usando ciclos termodinâmicos. Encontramos na literatura alguns ciclos termodinâmicos tais como os usados por da Silva e colaboradores [284,285] e Palascak e Shields [286], que foram detalhadamente analisados nos seguintes trabalhos [287,288]. Neste trabalho, usamos o ciclo termodinâmico esquematizado no esquema 3.1, usado com sucesso por vários autores em cálculos da diferença da energia livre de protonação/desprotonação de vários compostos orgânicos [288-292]. Esse esquema mostra a reação ácido-base da Emodina 
com um solvente prótico $(\mathrm{SH})^{1}$ em fase gasosa e em solução, gerando a molécula de Emodina na forma desprotonada (aniônica, $\mathrm{EM}^{-}$). Teoricamente, estamos interessados em estudar o processo de desprotonação da Emodina, em água e metanol, que segundo o ciclo termodinâmico escolhido, a diferença de energia livre desse processo em solução $\left(\Delta \mathrm{G}_{\text {Sol. }}\right)^{2}$ é dada pela soma da diferença de energia livre de desprotonação em fase gasosa $\left(\Delta \mathrm{G}_{\mathrm{g}}\right)$ mais a diferença da variação de energia livre de solvatação $\left(\Delta \Delta \mathrm{G}_{\text {Solv. }}\right)$ das espécies envolvidas nesse processo,

$$
\Delta G_{\text {Sol. }}=\Delta G_{\mathrm{g}}+\Delta \Delta G_{\text {Solv. }},
$$

onde $\Delta \mathrm{G}_{\mathrm{g}}$ e $\Delta \Delta \mathrm{G}_{\text {Solv. }}$ são dadas pelas relações obtidas da condição de equilíbrio do ciclo termodinâmico mostrado no esquema 3.1,

$$
\begin{gathered}
\Delta G_{g}=G_{g}\left(S H_{2}^{+}\right)+G_{g}\left(E M^{-}\right)-G_{g}(S H)-G_{g}(E M H) \\
\Delta \Delta G_{\text {Solv. }}=\Delta G_{\text {Solv. }}\left(E M^{-}\right)+\Delta G_{\text {Solv. }}\left(S H_{2}^{+}\right)-\Delta G_{\text {Solv. }}(E M H)-\Delta G_{\text {Solv. }}(S H), \\
\Delta \Delta G_{\text {Solv. }}=\left[\Delta G_{\text {Solv. }}\left(E M^{-}\right)-\Delta G_{\text {Solv. }}(E M H)\right]+\left[\Delta G_{\text {Solv. }}\left(S H_{2}^{+}\right)-\Delta G_{\text {Solv. }}(S H)\right], \\
\Delta \Delta G_{\text {Solv. }}=\Delta \Delta G_{\text {Solv. }}(\text { Emodina })+\Delta \Delta G_{\text {Solv. }}(\text { Solvente }),
\end{gathered}
$$

onde $\mathrm{SH}$ e $\mathrm{SH}_{2}^{+}$representam as moléculas do solvente $\left(\mathrm{H}_{2} \mathrm{O}\right.$ ou $\left.\mathrm{CH}_{3} \mathrm{OH}\right)$ e suas formas catiônicas $\left(\mathrm{H}_{3} \mathrm{O}^{+}\right.$ou $\left.\mathrm{CH}_{3} \mathrm{OH}_{2}{ }^{+}\right)$, respectivamente.

$$
\begin{array}{ccccc}
\mathrm{EMH}_{(\mathrm{g})}+ & \mathrm{SH}_{(\mathrm{g})} & \stackrel{\Delta G_{\mathrm{g}}}{\longrightarrow} & \mathrm{EM}_{(\mathrm{g})}^{-}+ & \mathrm{SH}_{2}^{+} \\
\downarrow \Delta G_{\text {solv }}(E M H) & \downarrow \Delta G_{\text {solv }}(S H) & \downarrow \Delta G_{\text {solv }}\left(E M^{-}\right) & \downarrow \Delta G_{\text {solv }}\left(S H_{2}^{+}\right) \\
\mathrm{EMH}_{(\mathrm{sol})}+ & \mathrm{SH}_{(\mathrm{sol})} & \stackrel{\Delta \mathrm{G}_{\mathrm{sol}}}{\longrightarrow} & \mathrm{EM}_{(\mathrm{sol})}^{-}+ & \mathrm{SH}_{2}^{+}
\end{array}
$$

\footnotetext{
${ }^{1}$ Solvente prótico é um solvente que carrega uma ligação de hidrogênio entre um oxigênio como um grupo hidroxila ou um nitrogênio como em um grupo amina.

${ }^{2}$ Embora usamos o termo energia livre de desprotonação para o processo, $\Delta G_{\text {Sol. }}\left(E M H_{(S o l .)}+\right.$ $S H_{(\text {Sol. })} \longrightarrow E M_{(S o l .)}^{-}+S H_{2}^{+}{ }_{(S o l .)}$, chamamos atenção que nesse termo contém também a contribuição da energia livre de protonação da água, ou seja, $\Delta G_{\text {Sol. }}=\Delta G_{\text {Desp. }}($ Emodina $)+$ $\Delta G_{\text {Prot. }}(\bar{A} g u a$,$) , que pode ser facilmente demonstrado, se o processo acima for dividido em duas$

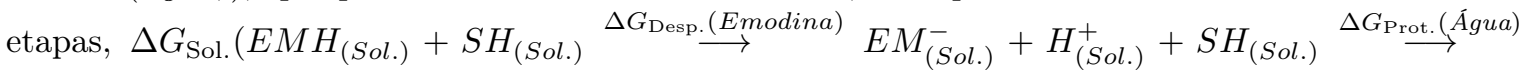
$E M_{(\text {Sol. })}^{-}+S H_{2}^{+}($Sol. $)$.
} 
Esquema 3.1: Ciclo termodinâmico usado no cálculo da diferença de energia livre da reação ácido-base da Emodina com o solvente prótico (SH).

O termo $\Delta \mathrm{G}_{\mathrm{g}}$ foi obtido através de cálculos quânticos, onde cada termo $G_{\mathrm{g}}(X)$ na equação 3.2, com $\mathrm{X}=\mathrm{EMH}, \mathrm{EM}^{-}, \mathrm{CH}_{3} \mathrm{OH}, \mathrm{CH}_{3} \mathrm{OH}_{2}{ }^{+}, \mathrm{H}_{2} \mathrm{O}$ e $\mathrm{H}_{3} \mathrm{O}^{+}$, foi obtido através do seguinte procedimento: a geometria inicial de cada espécie $\mathrm{X}$ foi otimizada com o método B3LYP/6-311 $++\mathrm{G}^{* *}$; Após essa otimização, as frequencias vibracionais foram calculadas e verificamos que todas eram positivas, indicando que a geometria otimizada estava num estado de mínima energia; Em seguida a energia livre de fase gasosa $G_{\mathrm{g}}(X)$ foi calculada considerando a energia eletrônica da molécula otimizada mais as correções de ponto zero, térmicas e entálpicas. Realizamos também esse mesmo procedimento descrito acima com o método MP2 utilizando a mesma função base, 6-311++ $\mathrm{G}^{* *}$ para fins de comparação, como será discutido na seção 4.2.2.

Para o cálculo do termo $\Delta \Delta \mathrm{G}_{\text {solv }}$ nós usamos uma combinação de dados teóricos e experimentais. A variação de energia livre de solvatação da Emodina $\Delta \Delta G_{\text {Solv. }}$ (Emodina) em água e metanol foi obtida através do uso de dois modelos teóricos de solvatação, um onde as moléculas foram incluídas explicitamente no cálculo usando as técnicas de simulações computacionais com método Monte Carlo, associado à teoria de perturbação termodinâmica que descreveremos logo a seguir, e o outro onde o solvente foi descrito com modelo contínuo polarizável $(\mathrm{PCM})$. As variações de energia livre de solvatação da água $\Delta \Delta G_{\text {Solv. }}\left(\bar{g} g u\right.$ ) e metanol $\Delta \Delta G_{\text {Solv. }}$ (Metanol) foram obtidos através do uso de valores experimentais encontrados na literatura. Segue os valores dessas diferenças de energia livre usadas neste trabalho: (i) $\Delta \Delta G_{\text {solv }}(A ́ g u a)=-103.88 \mathrm{kcal} / \mathrm{mol}$, valor obtido a partir dos valores de $\Delta G_{\text {solv }}\left(H_{3} \mathrm{O}^{+}\right)=-110.2 \pm 0.70 \mathrm{kcal} / \mathrm{mol}$, obtido por Pliego e Riveros $[293,294]$ e $\Delta G_{\text {Solv. }}\left(H_{2} O\right)=-6.32 \mathrm{kcal} / \mathrm{mol}$, obtido por Bem-Naim e Marcus [295]; (ii) $\Delta \Delta G_{\text {Solv. }}($ Metanol $)=-86.55 \mathrm{kcal} / \mathrm{mol}$, valor obtido a partir dos valores de $\Delta G_{\text {Solv. }}\left(\mathrm{CH}_{3} \mathrm{OH}\right)=-4.86 \mathrm{kcal} / \mathrm{mol}$, obtido por Bem-Naim e Marcus [295] 
e $\Delta G_{\text {Solv. }}\left(\mathrm{CH}_{3} \mathrm{OH}_{2}{ }^{+}\right)=-91.41 \pm 2.00 \mathrm{kcal} / \mathrm{mol}$, valor obtido por nós a partir da combinação de dados experimentais, veja nosso texto [296] no apêndice C.

Depois de obtido os valores para os dois termos da equação 3.1, calculamos o $\mathrm{pK}_{\mathrm{a}}$ do processo de desprotonação da Emodina em água e metanol usando a equação termodinâmica que relaciona o $\mathrm{pK}_{\mathrm{a}}$ com a diferença de energia livre de desprotonação,

$$
p K_{\mathrm{a}}=\frac{\Delta G_{\text {Sol. }}}{R T \ln 10}-\log [S H]
$$

onde $R$ é a constante universal dos gases $\left(R=1.987 \times 10^{-3} \mathrm{kcal} \cdot \mathrm{mol}^{-1} \cdot \mathrm{K}^{-1}\right)$ e $[\mathrm{SH}]$ é a concentração do solvente nas condições normais de pressão e temperatura. Veja na seção A.3, no apêndice A a demonstração dessa equação. Os valores da concentração da água e metanol usados neste trabalho foram: $\left[\mathrm{H}_{2} \mathrm{O}\right]=55.50 \mathrm{~mol} / \mathrm{L} \mathrm{e}\left[\mathrm{CH}_{3} \mathrm{OH}\right]=24.55$ mol/L. Nas condições normais de pressão $\mathrm{P}=1 \mathrm{~atm}$ e temperatura, $\mathrm{T}=298.15 \mathrm{~K}$, temos que $R T \ln 10=1.364 \mathrm{kcal} / \mathrm{mol}$.

\subsubsection{Cálculo da diferença de energia livre de solvatação.}

Realizamos cálculos da diferença de energia livre de solvatação $\left(\Delta \mathrm{G}_{\text {Solv. }}\right)$ da Emodina neutra (protonada), EMH e Emodina desprotonada (aniônica), EM- em água e metanol, usando simulações computacionais com método Monte Carlo associado à teoria de perturbação termodinâmica. Essas simulações foram realizadas com o programa DICE [231]. Para calcular essa propriedade, aplicamos um processo reverso ao processo de solvatação [295, 297,298]. Segundo Bem-Naim, o processo de solvatação de um soluto ocorre quando a molécula do soluto é transferida da fase gasosa para dentro da solução, nas condições termodinâmicas de temperatura $(\mathrm{T})$ e pressão $(\mathrm{P})$ e número de moléculas $(\mathrm{N})$ constantes, $\Delta G_{\text {Solv. }}\left(G_{\text {gas }}(\right.$ soluto $) \rightarrow G_{\text {Sol. }}($ soluto $\left.)\right)$. Assim, neste trabalho, usamos um processo reverso em que a molécula do soluto foi aniquilada em solução, e calculamos a energia livre de dessolvatação ou de aniquilação, $\Delta G_{\text {Aniq. }}\left(G_{\text {Sol. }}(\right.$ soluto $) \rightarrow G_{\text {gas }}($ soluto $\left.)\right)$, que é o negativo da energia livre de solvatação, $\Delta G_{\text {Solv. }}=-\Delta G_{\text {Aniq. }}[297-299]$. 
No esquema 3.2, apresentamos com mais detalhes o ciclo termodinâmico usado para determinar a energia livre de solvatação de um soluto $\left.\mathrm{X}\left(\Delta G_{\text {Solv }} . \mathrm{X}\right)\right)$, a partir da energia livre de aniquilação desse soluto em solução $\left(\Delta G_{\text {Aniq. }}(\mathrm{X})\right)$. Nesse ciclo, o $\mathrm{X}_{\mathrm{D}}$ representa um soluto modelo, contendo a mesma quantidade de sítios do soluto, X, mas com as interações intra e intermoleculares completamente desligadas, ou seja, com os conjuntos de parâmetros $\{\mathrm{q}\},\{\varepsilon\}$ e $\{\sigma\}$, todos igual a zero. Assim, não há variação de energia livre com a mudança do soluto $\mathrm{X}_{\mathrm{D}}$ de vácuo para solução, $\Delta G_{2}=0$. Impondo a condição de equilíbrio no ciclo termodinâmico, obtém-se a seguinte relação,

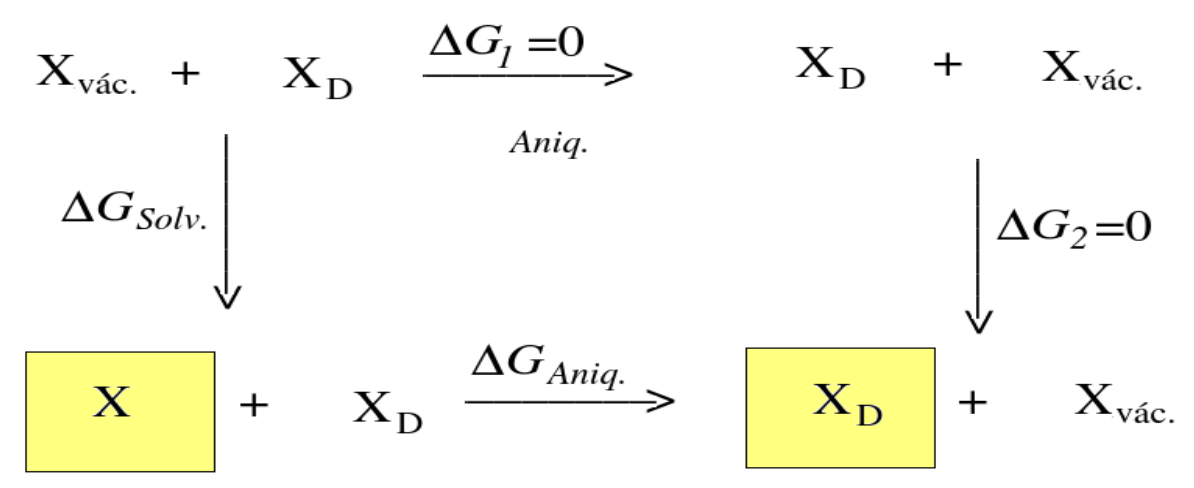

Esquema 3.2: Ciclo termodinâmico usado no cálculo da energia livre de solvatação de um soluto X. Nesse ciclo, $\mathrm{X}_{\text {vác }}$ representa o soluto $\mathrm{X}$ no vácuo, e $\mathrm{X}_{\mathrm{D}}$, um soluto modelo, ou seja, é uma representação fictícia da molécula sem nenhum tipo de potencial de interação, a caixa representa um solvente.

$$
\Delta G_{\text {Solv. }}(X)=-\Delta G_{\text {Aniq. }}(X)
$$

onde $\Delta G_{\text {Aniq. }}(X)$ é a diferença de energia livre de aniquilação do soluto $X$ em solução e em vácuo, que é dada pela seguinte equação,

$$
\Delta G_{\text {Aniq. }}(X)=\Delta G_{\text {Aniq. }}^{\text {sol. }}(X)-\Delta G_{\text {Aniq. }}^{\text {vác. }}(X)
$$

Separando a energia de interação em intra e intermolecular temos que,

$$
\Delta G_{\text {Aniq. }}(X)=\Delta G_{\text {Aniq-inter }}^{\text {sol. }}(X)+\Delta G_{\text {Aniq-intra }}^{\text {sol. }}(X)-\Delta G_{\text {Aniq-intra }}^{\text {vác. }}(X) .
$$


Portanto a energia livre de solvatação é dada por,

$$
\Delta G_{\text {Solv. }}(X)=-\Delta G_{\text {Aniq-inter }}^{\text {sol. }}(X)+\left[\Delta G_{\text {Aniq-intra }}^{\text {vác. }}(X)-\Delta G_{\text {Aniq-intra }}^{\text {sol. }}(X)\right] .
$$

Observamos na equação 3.10 duas contribuições importantes: a primeira que é a variação de energia livre intermolecular devido ao processo de aniquilação do soluto em solução, e a segunda que é a variação de energia livre interna do soluto devido à mudança do ambiente. Normalmente, essa primeira contribuição é calculada nos programas tradicionais de simulação computacional, porém a segunda contribuição é desprezada. Embora, atualmente, calcular a energia livre de solvatação desprezando essa segunda contribuição seja um procedimento padrão, ressaltamos aqui a importância dessa contribuição. Considerando que o campo de força do soluto é o mesmo, em fase gasosa e em solução, é de se considerar que esse termo seja aproximadamente nulo. Porém é conhecido que as moléculas se polarizam diferentemente em meios diferentes. Sendo assim, se a polarização for considerada, ou seja, se o soluto tiver uma interação eletrostática diferente em fase gasosa (ou vácuo) e em solução, é necessário considerar esse termo de energia livre de aniquilação. Assim, podemos reescrever a equação 3.10 separando as interações eletrostáticas $\left(\Delta G_{\text {Aniq-Elet. }}(X)\right)$ e não eletrostáticas $\left(\Delta G_{\text {Aniq-Não Elet. }}(X)\right)$,

$$
\begin{aligned}
\Delta G_{\text {Solv. }}(X)= & {\left[\Delta G_{\text {Aniq-Elet. }}^{\text {vác. }}(X)+\Delta G_{\text {Aniq-Nác. Elet. }}^{\text {vá. }}(X)-\Delta G_{\text {Aniq-Elet. }}^{\text {sol. }}(X)\right.} \\
& \left.-\Delta G_{\text {Aniq-Não Elet. }}^{\text {sol. }}(X)\right]-\Delta G_{\text {Aniq-inter }}^{\text {sol. }}(X) .
\end{aligned}
$$

Considerando que as interações intramoleculares não eletrostáticas do soluto não polarizado e polarizado são aproximadamente iguais, podemos desprezar a diferença desses termos, de modo que a equação 3.10 pode ser escrita como,

$$
\begin{aligned}
\Delta G_{\text {Solv. }}(X) & =\left[\Delta G_{\text {Aniq-Elet. }}^{\text {vá. }}(X)-\Delta G_{\text {Aniq-Elet. }}^{\text {sol. }}(X)\right]-\Delta G_{\text {Aniq-inter }}^{\text {sol. }}(X) \\
\Delta G_{\text {Solv. }}(X) & =\Delta G_{\text {Pol. }}(X)-\Delta G_{\text {Aniq-inter }}^{\text {sol. }}(X),
\end{aligned}
$$


onde o termo $\Delta G_{P o l}(X)$, é a diferença de energia livre de polarização do soluto X, ou seja, $\Delta G_{\text {Pol. }}(X)=\Delta G_{\text {Aniq-Elet. }}^{\text {vá. }}(X)-\Delta G_{\text {Aniq-Elet. }}^{\text {sol. }}(X)$.

No cálculo de $\Delta G_{\text {Solv. }}(X)$, cada estado inicial da simulação é uma caixa de simulação contendo um soluto mais as moléculas do solvente na condição termodinâmica de pressão 1 atm e temperatura $298.15 \mathrm{~K}$, e o estado final, é a caixa contendo somente as moléculas do solvente, na mesma pressão e temperatura do estado inicial. Geralmente, os valores experimentais de $\Delta G_{\text {Solv }}(X)$ são apresentados no estado de $1 \mathrm{~mol} / \mathrm{L}$, ou seja, $\mathrm{P}=24,46$ atm e $\mathrm{T}=298.15 \mathrm{~K}$ para o gás ideal. Portanto, para levar a energia livre calculada através de simulações realizadas na condição de $1 \mathrm{~atm}$, $\Delta G_{\text {Solv. }}(X)$ para o estado padrão de $1 \mathrm{~mol} / \mathrm{L}, \Delta G_{\text {Solv. }}^{*}(X)$, é necessário uma correção do tipo, $\Delta G_{\text {Solv. }}^{*}(X)=\Delta G_{\text {Solv. }}(X)-R T \ln (24.46)$, como discutido na seção 2.2.1.4. Assim, a energia livre de solvatação nesse estado padrão é dado por,

$$
\Delta G_{\text {Solv. }}^{*}(X)=\Delta G_{\text {Pol. }}(X)-\Delta G_{\text {Aniq-inter }}^{\text {sol. }}(X)-R T \ln (24.46)
$$

Separando a energia livre de aniquilação das interações intermoleculares em eletrostáticas e não eletrostáticas temos que,

$$
\Delta G_{\text {Solv. }}^{*}(X)=\Delta G_{\text {Pol. }}(X)-\Delta G_{\text {Aniq-elet. }}^{\text {sol. }}(X)-\Delta G_{\text {Aniq-não elet. }}^{\text {sol. }}(X)-R T \ln (24.46)
$$

Para uma melhor discussão, preferimos reescrever a equação 3.14 em termos das componentes da energia livre de solvatação,

$$
\Delta G_{\text {Solv. }}^{*}(X)=\Delta G_{\text {Pol. }}(X)+\Delta G_{\text {Elet. }}(X)+\Delta G_{N \tilde{a} o \text { elet. }}(X)-R T \ln (24.46),
$$

onde $\Delta G_{\text {Elet. }}=-\Delta G_{\text {Aniq-elet. }}^{\text {sol. }} \Delta G_{\text {Não elet. }}=-\Delta G_{\text {Aniq-nãa elet. }}$.

O cálculo da energia livre de solvatação, $\Delta G_{\text {Solv. }}^{*}(X)$ foi realizado através de duas etapas: na primeira etapa, calculamos a energia livre de polarização do soluto, ou seja, $\Delta G_{P o l}(X)$, que foi calculada através de cálculos quânticos usando a seguinte aproximação, $\Delta G_{P o l .}(X) \approx E_{P o l}-E_{\text {Vác. }}$, onde $E_{P o l .}=\left\langle\Psi_{P C M}\left|H_{0}\right| \Psi_{P C M}\right\rangle$, é a energia 
eletrônica do soluto isolado, porém calculada com a função de onda polarizada devido ao solvente, e $E_{\text {Vác. }}=\left\langle\Psi_{0}\left|H_{0}\right| \Psi_{0}\right\rangle$, é a energia eletrônica do soluto em vácuo, obtida com a função de onda de vácuo.

Tabela 3.2: Valores percentuais dos $\lambda_{\mathrm{i}}$ de perturbação utilizados para calcular as contribuições para a energia livre de aniquilação dos conjuntos de parâmetros do potencial Coulombiano $\left\{q_{i}\right\}$ e do potencial de Lennard-Jones $\left\{\varepsilon_{\mathrm{i}}\right\}$ e $\left\{\sigma_{\mathrm{i}}\right\}$.

\begin{tabular}{|c|c|c|c|c|c|c|c|c|}
\hline Moléculas & & EMH & & & & El & & \\
\hline$\lambda$ & $\left\{q_{i}\right\}$ & $\left\{\varepsilon_{\mathrm{i}}\right\}$ & $\left\{\sigma_{\mathrm{i}}\right\}$ & & $\left\{q_{i}\right\}$ & & $\left\{\varepsilon_{\mathrm{i}}\right\}$ & $\left\{\sigma_{\mathrm{i}}\right\}$ \\
\hline$\lambda_{1}$ & 100 & 100 & 100 & 100 & 80 & 60 & 100 & 100 \\
\hline$\lambda_{2}{ }^{*}$ & 95 & 87.5 & -- & 97.5 & 77.5 & 55 & 87.5 &.- \\
\hline$\lambda_{3}$ & 90 & 75 & 75 & 95 & 75 & 50 & 75 & 75 \\
\hline$\lambda_{4}{ }^{*}$ & 80 & 62.5 & -- & 92.5 & 72.5 & 45 & 62.5 & -- \\
\hline$\lambda_{5}$ & 70 & 50 & 50 & 90 & 70 & 40 & 50 & 50 \\
\hline$\lambda_{6}{ }^{*}$ & 55 & 37.5 & - - - & 87.5 & 67.5 & 35 & 37.5 & -- \\
\hline$\lambda_{7}$ & 40 & 25 & 25 & 85 & 65 & 30 & 25 & 25 \\
\hline$\lambda_{8}{ }^{*}$ & 20 & 12.5 & -- & 82.5 & 62.5 & 20 & 12.5 & -- \\
\hline$\lambda_{9}$ & 0 & 0.1 & 0 & 80 & 60 & 0 & 0.1 & 0 \\
\hline
\end{tabular}

$\lambda_{\mathrm{i}}{ }^{*}$ indica os pontos onde usamos o procedimento de simulação para os dois lados ("double-wide"), com exceção ao conjunto de parâmetros $\left\{\sigma_{\mathrm{i}}\right\}$, onde não foi aplicado esse procedimento.

Na segunda etapa, calculamos a energia livre de aniquilação das interações do soluto com o solvente, ou seja, $\Delta G_{\text {Aniq-inter }}^{\text {sol. }}(X)$. Como nas simulações computacionais 
que realizamos para calcular, $\Delta G_{\text {Aniq-inter }}^{\text {sol. }}(X)$, a molécula do soluto é rígida, portanto ela pode ser caracterizada por um conjunto de parâmetros do potencial de Coulomb e Lennard-Jones (q, $\varepsilon$ e $\sigma$ ). Assim, como realizado anteriormente em nosso grupo de pesquisa [32,193,297], nós dividimos o processo de aniquilação em três etapas independentes, onde para cada um dos parâmetros foi realizada uma etapa de perturbação termodinâmica até sua aniquilação.

$\mathrm{Na}$ primeira etapa, o conjunto de cargas atômicas foi aniquilado, mantendose os parâmetros de Lennard-Jones fixos. Esse processo se deu através de reduções gradativas das cargas atômicas $\left\{\mathrm{q}_{\mathrm{i}}\right\}$ de forma perturbativa, de tal modo que o conjunto de cargas variou de $100 \%$ até zero. Na segunda etapa, o poço atrativo do potencial de Lennard-Jones foi aniquilado, através da redução do conjunto de parâmetros $\{\varepsilon\}$, onde os parâmetros desse conjunto foram reduzidos de $100 \%$ até $0.1 \%$. Observe que esses parâmetros não podem ser anulados completamente, pois anularia completamente o potencial de interação, devido à forma como é escrito o potentical Lennard-Jones. Na terceira etapa, completa-se o processo de aniquilação, através da aniquilação do conjunto de parâmetros $\{\sigma\}$.

Na tabela 3.2, está mostrado um sumário das percentagens usadas no processo de aniquilação de cada conjunto de parâmetros. Para a aniquilação dos conjuntos $\left\{\mathrm{q}_{\mathrm{i}}\right\}$ e $\left\{\varepsilon_{\mathrm{i}}\right\}$, nós usamos o procedimento de simulação para os dois lados ("doublewide") [246], onde são necessárias 4 simulações para aniquilar cada conjunto para molécula Emodina. Por exemplo, para o conjunto $\left\{\mathrm{q}_{\mathrm{i}}\right\}$ da Emodina neutra, EMH, a primeira simulação foi realizada com o percentual de $95 \%$ das cargas, perturbando o sistema simultaneamente para $100 \%$ e $90 \%$; a segunda simulação com 80\%, perturbando o sistema simultaneamente para $90 \%$ e $70 \%$; a terceira com $55 \%$ perturbando para $70 \%$ e 40\%; e a última simulação com $20 \%$ perturbando para $40 \%$ e $0 \%$. Para o conjunto $\left\{\varepsilon_{\mathrm{i}}\right\}$, utilizamos esse mesmo procedimento de simulação para os dois lados, onde realizamos também 4 simulações em $87.5 \%, 62.5 \%, 37.5 \%$ e $12.5 \%$. Já para o 
conjunto de parâmetros $\left\{\sigma_{\mathrm{i}}\right\}$, não foi utilizado o procedimento de simulação para os dois lados, pois aparecem instabilidades numéricas, quando se aumenta o tamanho desses parâmetros. Assim, para esse conjunto foram realizadas 4 simulações, sendo uma em $100 \%$ perturbando para $75 \%$; outra de $75 \%$ perturbando para $50 \%$; outra de $50 \%$ para $25 \%$; e por último de $25 \%$ para $0 \%$. A contribuição de cada conjunto à energia livre de aniquilação é igual à soma das diferenças de energia livre obtidas em cada simulação.

Para aniquilar a Emodina desprotonada, EM-, em solução, usamos o mesmo procedimento descrito para EMH, com exceção da aniquilação do conjunto de cargas. Para esse conjunto foram necessárias 12 simulações, onde realizamos 4 simulações no intervalo de $100 \%$ a $80 \%$, mais 4 no intervalo de $80 \%$ a $60 \%$ e por último mais 4 simulações de $60 \%$ a $0 \%$, ou seja, simulações nos fatores $97.5,92.5,87.5,82.5,77.5$, $72.5,67.5,62.5,55,45,35$ e $20 \%$. Esse procedimento foi necessário porque a contribuição eletrostática para a energia potencial de moléculas carregadas é muito grande, de tal modo que pequenas variações na percentagem desse conjunto causam perturbações muito grandes na energia potencial do sistema. Na tabela 3.2, está mostrado um sumário das percentagens usadas no processo de aniquilação desse conjunto de parâmetros.

As simulações com a EMH e EM- nos solventes, água e metanol, foram realizadas usando o método de Monte Carlo com amostragem de Metropolis associado à teoria de perturbação termodinâmica (FEP) [245], onde foram usadas condições periódicas de contorno numa caixa com 500 moléculas de solvente no ensemble NPT nas condições normais de pressão e temperatura. Nessas simulações, as moléculas de água foram descritas pelo modelo SPC [279] e as moléculas de metanol pelo modelo OPLS [300]. O volume inicial de cada caixa de simulação foi obtido a partir da densidade experimental desses solventes, sendo, portanto para água $1.0 \mathrm{~g} / \mathrm{cm}^{3}$ e para metanol $0.78 \mathrm{~g} / \mathrm{cm}^{3}$. Configurações iniciais foram geradas, distribuindo aleatoriamente as 501 moléculas 
nessas caixas de simulação. Essas configurações iniciais foram geradas apenas para o estágio de aniquilação do conjunto de cargas $\left\{\mathrm{q}_{\mathrm{i}}\right\}$, e usadas também como pontos de partida para as simulações de aniquilação dos conjuntos $\left\{\varepsilon_{\mathrm{i}}\right\}$ e $\left\{\sigma_{\mathrm{i}}\right\}$.

As geometrias da EMH e EM- foram mantidas rígidas durante as simulações nas conformações mais prováveis obtidas das simulações com dinâmica molecular. Usamos os parâmetros do campo de força OPLS para o potencial de interação, com exceção dos conjuntos de cargas que foram obtidos por cálculos quânticos. Na tabela 3.3, estão listados os parâmetros dos conjuntos $\left\{\varepsilon_{\mathrm{i}}\right\}$ e $\left\{\sigma_{\mathrm{i}}\right\}$ do potencial de interação de LennardJones, onde foram usados os mesmos conjuntos para EMH e EM-, portanto no nosso modelo, não estamos levando em consideração mudanças nesses parâmetros com a desprotonação, o que é uma aproximação razoável. Já para o potencial eletrostático, utilizamos dois conjuntos de cargas diferentes, um para cada espécie da Emodina, onde foram obtidos através de cálculos quânticos do ajuste do potencial eletrostático gerado com método B3LYP/6-311++ $\mathrm{G}^{* *} / \mathrm{CHELPG}$ em vácuo e em meio solvente água e metanol com a descrição desses solventes com modelo contínuo polarizável PCM. Na tabela 3.1 estão apresentados esses conjuntos de cargas.

O cálculo da energia configuracional foi realizado para cada molécula dentro de uma circunferência de raio de corte $r_{\mathrm{c}}=\frac{1}{2} L$, onde $L$ é a aresta da caixa cúbica. Para interações fora dessa circunferência, foi realizada uma correção de longo alcance na energia potencial. A correção de longo alcance no potencial de Lennard-Jones foi realizada através da integração da função de distribuição radial de pares [71]. O processo de cada simulação foi dividido em duas etapas: (i) A termalização, partindo de uma configuração inicial totalmente aleatória gerada no estágio de aniquilação do conjunto de cargas $\left\{q_{i}\right\}$. Nesse processo usamos 90.000 (noventa mil) ciclos de MC, onde cada ciclo, $\mathrm{N}$ moléculas da caixa são selecionadas para mover; (ii) A simulação no equilíbrio, partindo da última configuração do processo de termalização. Nesse processo usamos 300.000 (trezentos mil) ciclos de MC. O tempo real de cada simulação 
por processador foi de 17 horas em água e 40 horas em metanol. Como são necessárias 12 e 20 simulações para completar os processos de aniquilação da EMH e EM-, assim os tempos totais para aniquilar a EMH em água e metanol foram de 204 e 480 horas o que equivale aproximadamente a 8 e 20 dias, já para aniquilar a $\mathrm{EM}^{-}$nesses solventes os tempos foram de 340 e 800 horas equivalentes a aproximadamente a 14 e 33 dias, respectivamente. Para calcular a incerteza padrão da energia livre de aniquilação de cada espécie da Emodina, realizamos 5 simulações independentes, onde foram tomadas configurações iniciais e sementes do gerador de números aleatórios diferentes para cada simulação.

Tabela 3.3: Conjuntos de parâmetros $\left\{\varepsilon_{\mathrm{i}}\right\}$ e $\left\{\sigma_{\mathrm{i}}\right\}$ do potencial de Lennard-Jones usados na Emodina neutra e Emodina desprotonada, obtidos do campo de força OPLS.

\begin{tabular}{ccc}
\hline \hline Átomos & $\left\{\varepsilon_{\mathrm{i}}\right\}$ em kcal $/ \mathrm{mol}$ & $\left\{\sigma_{\mathrm{i}}\right\}(\AA)$ \\
$\mathrm{C}$ (aromático) & 0.070 & 3.550 \\
$\mathrm{H}$ (aromático) & 0.030 & 2.420 \\
$\mathrm{O}$ (hidroxila) & 0.170 & 3.070 \\
$\mathrm{H}$ (hidroxila) & 0.000 & 0.000 \\
$\mathrm{O}($ carbonila $)$ & 0.210 & 2.960 \\
$\mathrm{C}($ metil $)$ & 0.066 & 3.500 \\
$\mathrm{H}($ metil $)$ & 0.030 & 2.500 \\
\hline \hline
\end{tabular}

A diferença de energia livre de solvatação das espécies da Emodina foi também determinada usando outra metodologia de solvatação, a QM-PCM [49, 62, 64], onde 
nessa metodologia o solvente é descrito com o modelo contínuo polarizável (PCM). Assim para determinar a diferença de energia livre de solvatação da EMH e EM-, foram tomadas as mesmas geometrias usadas nas simulações, e submetidas a cálculos usando o formalismo da mecânica quântica através do modelo PCM-UAHF ("Polarized Continum Model-United Atoms Hartree-Fock") com método HF/6-31+G* [301,302]. Vários trabalhos têm sido apresentados na literatura, mostrando que usando o modelo da cavidade com átomos unidos (UAHF) obtêm-se bons resultados para a energia livre de solvatação de compostos orgânicos [303-305], uma vez que esse conjunto de método/base e modelo da cavidade foram utilizados na parametrização dos termos não eletrostáticos da energia livre de solvatação, com a finalidade de produzir dados experimentais nas condições padrão de $1 \mathrm{~mol} / \mathrm{L}$. [193,306].

\subsubsection{Simulação em bicamada lipídica da EMH e EM- com MD}

Realizamos simulações computacionais com as espécies da Emodina neutra e Emodina desprotonada em bicamadas lipídicas hidratadas formadas pelo fosfolipídio DMPC, utilizando dinâmica molecular. Os sistemas simulados foram: (i) DMPC-puro - uma bicamada lipídica hidratada pura formada por 338 DMPC e 18786 moléculas de águas $\left(\mathrm{H}_{2} \mathrm{O}\right)$; (ii) DMPC + EMH - uma bicamada lipídica formada por 314 DMPC, $18785 \mathrm{H}_{2} \mathrm{O}$ e uma molécula da Emodina neutra; (iii) $\mathrm{DMPC}+\mathrm{EM}^{-}$- uma bicamada lipídica formada por 314 DMPC, $18785 \mathrm{H}_{2} \mathrm{O}$ e uma molécula da Emodina desprotonada.

Todas as simulações computacionais em bicamadas lipídicas foram realizadas com dinâmica molecular, usando o programa GROMACS versão 4.5.4 [238], onde as bicamadas lipídicas foram simuladas numa caixa retangular, utilizando condições periódicas de contorno. A temperatura do sistema foi mantida constante durante as simulações, através do termostato de Berendsen [223], na temperatura de $303 \mathrm{~K}$, com a constante de acoplamento de 0.1 ps. Assim, simulamos as bicamadas lipídicas na 
fase fluida, uma vez que a temperatura escolhida de $303 \mathrm{~K}$ está acima da temperatura de transição da fase gel-fluido de $296.55 \mathrm{~K}[259,268]$. A pressão nas 6 faces da caixa contendo a bicamada lipídica hidratada foi mantida constante durante as simulações, através do barostato de Berendsen em 1 bar, usando uma compressibilidade isotérmica de $4.6 \times 10^{-5}$ bar $^{-1}$ e uma constante de acoplamento de 1 ps [223]. Durante as simulações, as ligações químicas entre os átomos dos fosfolipídios foram mantidas fixas através do algoritmo de LINCS [307].

O cálculo da energia intermolecular foi realizado em todos os passos para os grupos moleculares com distância inferior ao raio de corte de $1.25 \mathrm{~nm}$. Para interações além desse raio de corte, foi realizada uma correção de longo alcance para o termo eletrostático através do método PME (Particle Mesh Ewald) [232], e para o termo de Lennard-Jones através integração da função de distribuição radial de pares [71]. Usamos o algoritmo de leap-frog [280] na integração das equações de movimento do sistema, usando um modelo molecular onde todas as moléculas são flexíveis nos ângulos e torções. Na descrição do potencial de interação, usamos para água o modelo SPC [279], e para os fosfolipídios e as espécies da Emodina usamos os parâmetros do campo de força GROMOS 54a7 [104,105], onde os grupos hidrocarbonetos alifáticos do tipo $\mathrm{CH}_{\mathrm{n}}\left(\mathrm{CH}_{2}\right.$ e $\left.\mathrm{CH}_{3}\right)$ foram incluídos implicitamente na simulação [308,309], ou seja para cada grupo CHn apenas um sítio de interação foi considerado. A interação eletrostática de ambas as espécies da Emodina foi descrita por conjuntos de cargas atômicas obtidos através de cálculos quânticos, como descrito na seção 3.5.2.1.

Inicialmente construímos a bicamada pura de DMPC com 338 lipídios, sendo, portanto 169 lipídios em cada monocamada, replicando um aglomerado de 2 fosfolipídios, um com a cabeça polar para cima e outro com a cabeça para baixo, alinhados no eixo z, numa matriz 13x13, com o espaçamento entre cada par de lipídio de $1 \mathrm{~nm}$. Em seguida hidratamos essa bicamada com 18786 moléculas de água, que corresponde a cerca de 55 moléculas de água por lipídio, atendendo portanto o nível mínimo de 
hidratação proposto por Nagle colaboradores de $45 \mathrm{H}_{2} \mathrm{O}$ /lipídio [310]. Na hidratação, tomamos o cuidado de inicialmente não permitir moléculas de água dentro da região da bicamada. Assim a área por lipídio $\left(\mathrm{A}_{\mathrm{L}}\right)$ inicial foi de $1.21 \mathrm{~nm}^{2} /$ lipídio, que é praticamente o dobro do valor experimental para bicamada lipídica de DMPC na fase fluida. Na literatura encontramos vários trabalhos experimentais que apresentam valores diferentes para $A_{L}$, porém todos dentro da faixa de 0.58 a $0.62 \mathrm{~nm}^{2} /$ lipídio, ver tabela 1.3. Assim realizamos uma minimização da bicamada hidratada usando o algoritmo "steep descent" [229], com o critério de convergência de 1 kJ/mol.nm. Depois da minimização do sistema, realizamos uma simulação 100 ps, à temperatura de $50 \mathrm{~K}$, partindo da configuração minimizada $(\mathrm{t}=0)$. Aumentamos a temperatura do sistema gradativamente, onde realizamos mais 5 simulações curtas de 100 ps cada uma, nas temperaturas 100, 150, 200, 250 e $303 \mathrm{~K}$, totalizando uma simulação de t=600 ps. Depois dessa série de simulações curtas, realizamos uma simulação de termalização de 110 ns, partindo da última configuração obtida da simulação a $303 \mathrm{~K}$ e depois verificamos as propriedades de convergência dessa simulação como área e volume por lipídio e energia. Na figura 2.3 apresentamos as configurações da bicamada lipídica hidratada no instante $\mathrm{t}=0 \mathrm{~ns}$ (logo após a minimização) e t=110.6 ns (após a simulação de termalização).

A análise da simulação de termalização da bicamada lipídica, mostra que o sistema sai de uma configuração ordenada ( $t=0$ ns) e vai para uma estrutura mais condensada e desordenada, onde é observado uma redução significativa nas coordenadas da caixa de simulação $\mathrm{L}_{\mathrm{x}}, \mathrm{L}_{\mathrm{y}}$ e um aumento em $\mathrm{L}_{\mathrm{z}}$. Essas reduções nas coordenadas $\mathrm{L}_{\mathrm{x}}$ e $\mathrm{L}_{\mathrm{y}}$, provocam o empacotamento do sistema, de tal modo que há redução nos valores de $A_{L}$ e $V_{L}$. Na figura 3.4 apresentamos a evolução temporal da área e volume por lipídio, que mostra que essas propriedades saem dos valores iniciais e gradativamente vão convergindo para valores muito próximos aos experimentais.

Uma comparação da evolução temporal dessas duas propriedades mostra que a convergência de $A_{L}$ é bastante lenta, pois só ocorre após os 30 primeiros ns de si- 


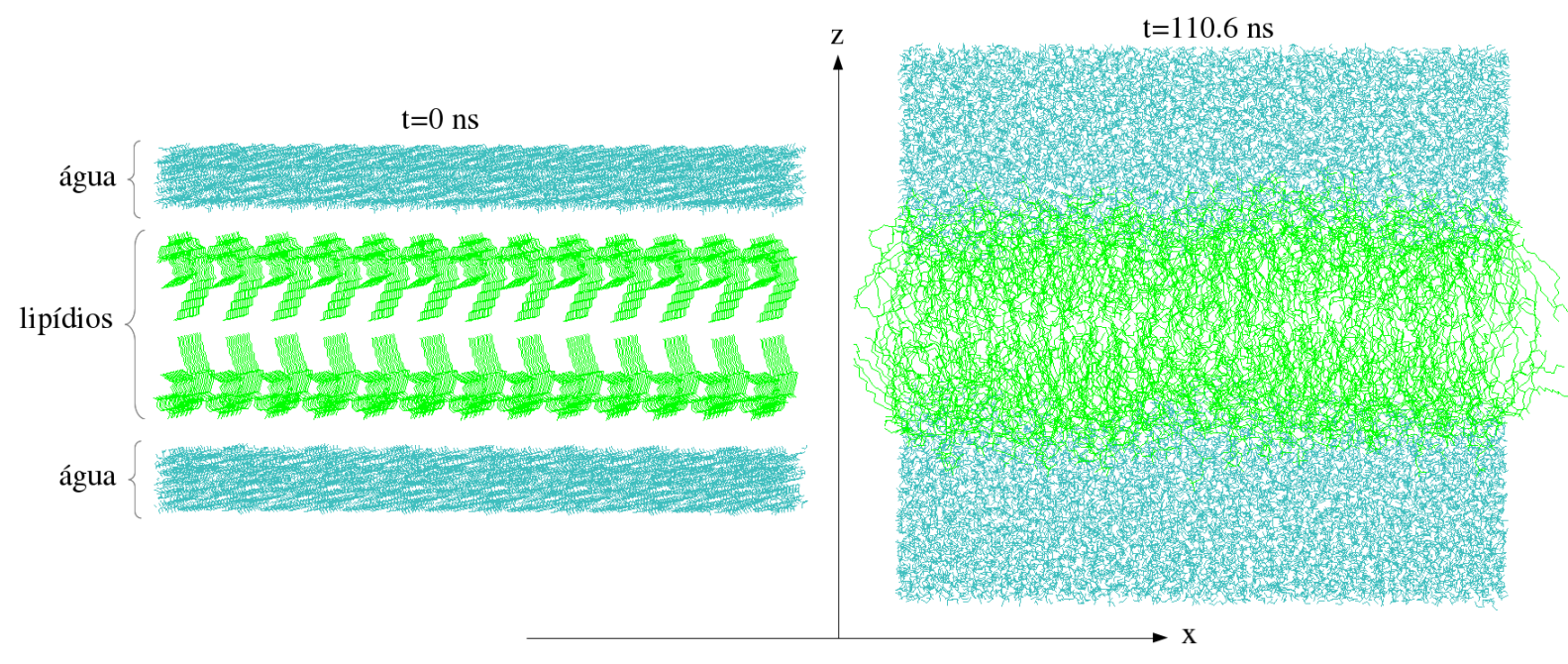

Figura 3.3: Configurações da bicamada lipídica hidratada de DMPC no instante de tempo t $=0$ ns ( logo após a minimização) e $\mathrm{t}=110.6$ ns (após a termalização).
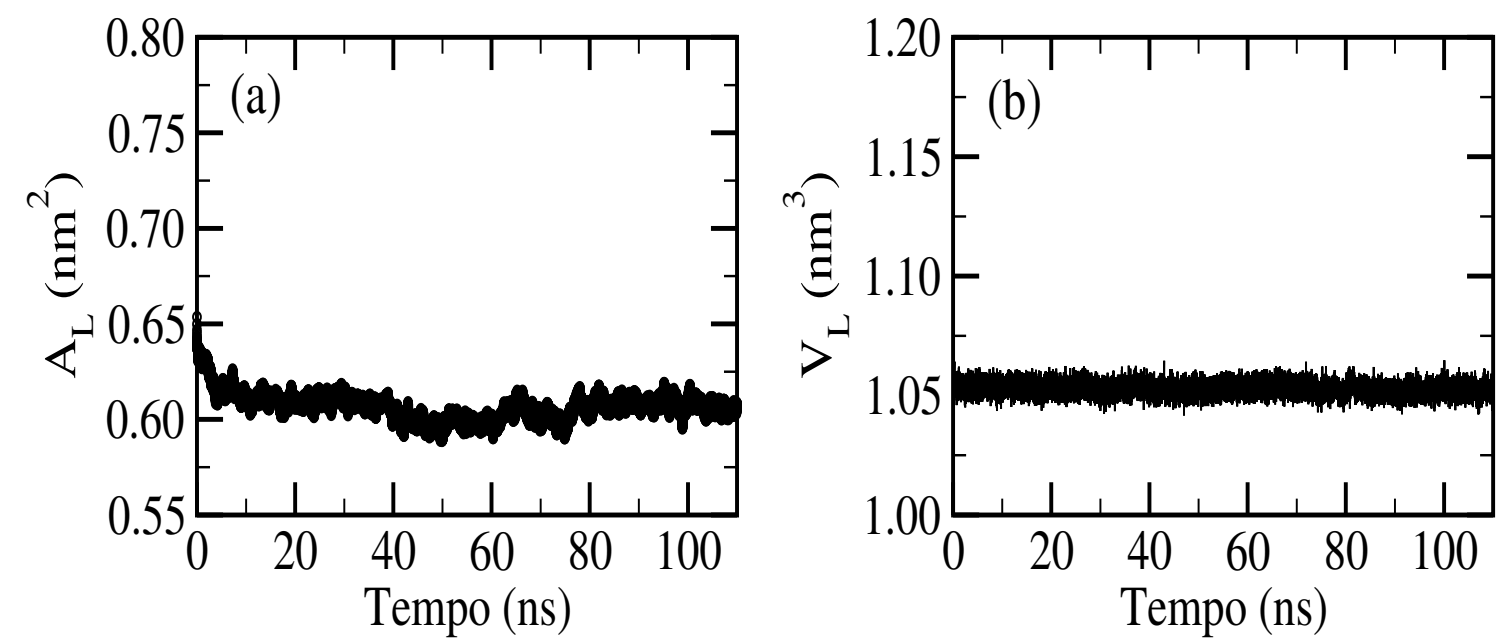

Figura 3.4: Evolução temporal da area (a), volume (b) por lipídio durante a simulação computacional da bicamada lipídica hidratada de DMPC.

mulação, já para $V_{L}$ a convergência é mais rápida, ocorre após 10 ns de simulação. Os valores médios obtidos para $A_{L}$ e $V_{L}$ nos últimos 80 ns de simulação foram 0.602 $\mathrm{nm}^{2} /$ lipídio e $1.050 \mathrm{~nm}^{3} /$ lipídio, que estão em boa concordância com os valores experimentais, ver tabela 1.3. Uma análise completa dessa simulação será apresentada no capítulo de resultados teóricos. 
(a)

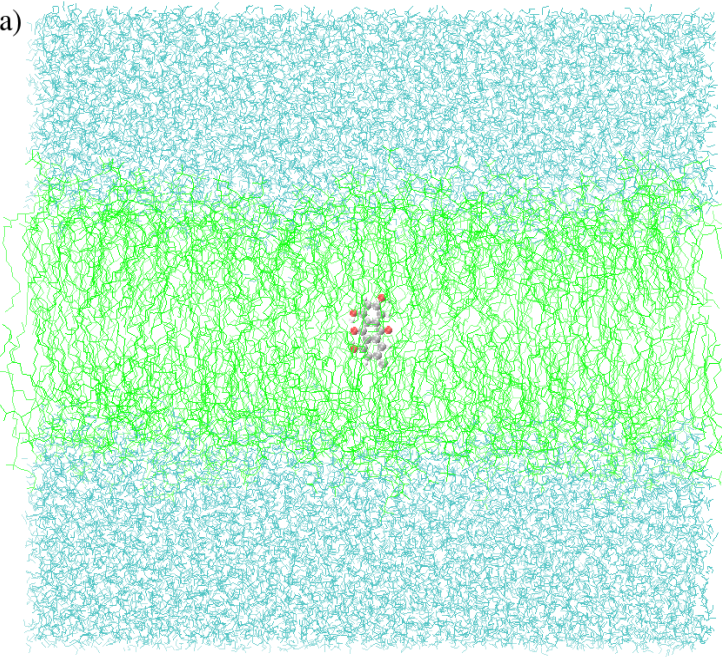

(b)

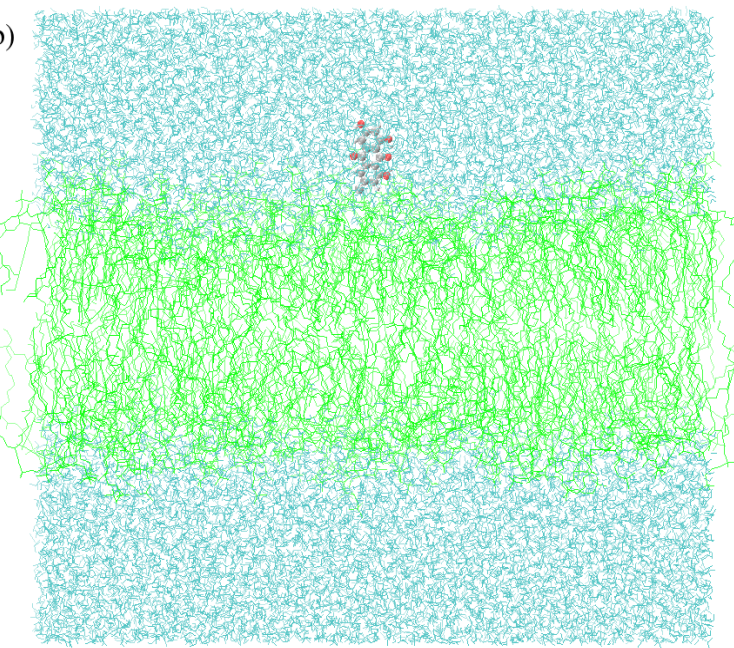

Figura 3.5: Configurações iniciais da EMH inserida na bicamada lipídica hidratada de DMPC, onde na figura (a) a EMH está inserida no centro da bicamada e na figura (b) está inserida na extremidade superior da bicamada lipídica.

Depois de obtida a estrutura da bicamada hidratada pura de DMPC, geramos 02 sistemas, $\mathrm{DMPC}+\mathrm{EMH}$ e $\mathrm{DMPC}+\mathrm{EM}^{-}$, através da inserção das espécies da Emodina na bicamada de DMPC. Para inserir as espécies da Emodina na bicamada foi colocada a molécula na posição desejada e retirada todas as outras moléculas que ficaram superpostas a ela. Desta forma, colocando a Emodina no centro da bicamada (figura 3.5 (a) foram retiradas 24 moléculas de DMPC e 1 molécula de água, no caso da Emodina inserida na extremidade superior da bicamada, foram retiradas 19 e 13 moléculas de DMPC e $\mathrm{H}_{2} \mathrm{O}$, respectivamente. As posições iniciais da $\mathrm{EM}^{-}$na bicamada lipídica são idênticas a EMH. Esse procedimento foi adotado para investigar a posição dessas espécies dentro da bicamada. Assim, como estamos trabalhando com duas espécies da Emodina, EMH e EM- $\mathrm{EM}^{-}$realizamos 04 simulações, sendo para cada espécie, duas simulações com condições iniciais diferentes, uma com a Emodina no centro da bicamada e a outra com a Emodina na borda superior da bicamada. 


\section{Capítulo 4}

\section{Resultados e Discussões}

\subsection{Introdução}

Neste capítulo apresentamos e discutimos os resultados teóricos e experimentais obtidos nesta tese. Esse capítulo está dividido em três partes. Na primeira, investigamos o processo de desprotonação da Emodina, focado em determinar as posições das desprotonações, assim como as constantes de acidez $\left(p K_{\mathrm{a}}\right)$ dessa molécula em água e em metanol. Nessa parte, utilizamos cálculos quânticos com a molécula de emodina em vácuo e em meio solvente, e simulações computacionais com método Monte Carlo. Adicionalmente, utilizamos a técnica experimental de titulação espectroscópica da Emodina em água e em metanol para determinação experimental do $\mathrm{pK}_{\mathrm{a}}$. Na segunda parte, analisamos os espectros de absorção da Emodina em diferentes ambientes, nas condições de $\mathrm{pH}$ ácido e alcalino, utilizando técnicas experimentais e métodos teóricos. Na última parte, investigamos a interação da Emodina com o ambiente, utilizando dinâmica molecular da Emodina em solução aquosa e bicamadas lipídicas e medidas de calorimetria de varredura. 


\subsection{Desprotonação da Emodina}

\subsubsection{Posições e ordem das desprotonações}

$\mathrm{Na}$ literatura existem algumas questões em aberto sobre os processos de desprotonação e de transferência de próton intramolecular (tautomerismo) da molécula Emodina em solução. Alguns questionamentos vêm sendo levantados a respeito desses processos, que ainda não estão totalmente esclarecidos para essa molécula, como por exemplo, as posições e ordem das desprotonações. Existe uma sugestão na literatura indicando que a primeira desprotonação é na posição 3, a segunda na posição 8 e a terceira na posição 1. [29]. Para esclarecer esse assunto, investigamos os processos de desprotonação da Emodina em todas essas posições. Inicialmente, otimizamos as geometrias das espécies da Emodina em vácuo e em solução aquosa, usando o método B3LYP e a função de base 6-311 $+\mathrm{G}^{* *}$, como apresentado na seção 3.5. Nesse cálculo, o solvente foi descrito com o modelo contínuo polarizável (PCM). As espécies da Emodina que tiveram suas geometrias otimizadas foram: Emodina neutra (EMH), as espécies da Emodina com uma desprotonação nas posições 1 (3,8-EM-', ou seja as duas hidroxilas ficaram nas posições 3 e 8), 3 (1,8-EM-, hidroxilas nas posições 1 e 8$)$ e 8

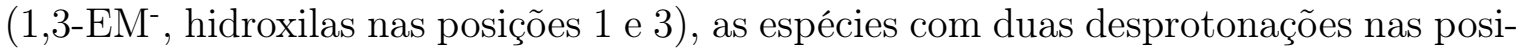
ções 3 e 1 (8-EM $\left.{ }^{2-}\right)$ e 3 e 8 (1-EM $\left.{ }^{2-}\right)$, e a espécie com três desprotonações nas posições 1 , 3 e $8\left(\mathrm{EM}^{3-}\right)$. Além dessas espécies, otimizamos as geometrias das formas tautoméricas da Emodina neutra com a hidroxila na posição 9, ou seja, a 3,8,9-trihidroxi-6-metil1,10-antraquinona e a 1,3,9-trihidroxi-6-metil-8,10-antraquinona; formas tautoméricas da Emodina com uma desprotonação, a 1,9-EM- (hidroxilas nas posições 1 e 9), 3,9-

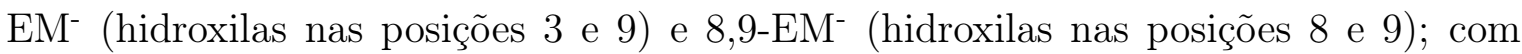
duas desprotonações a 9-EM ${ }^{2-}$. Nas figuras 3.1 e 3.2 mostramos as geometrias das espécies estáveis e na tabela 4.1 estão listados os valores das energias livres de Gibbs (em kcal/mol) e dos momentos de dipolos (D) dessas espécies. 
Todas as geometrias otimizadas das espécies da Emodina estáveis se encontram em conformações planares, com uma única exceção, a geometria da espécie $\mathrm{EM}^{3-}$, onde observamos que os oxigênios O8, O9 e O1 ficaram fora do plano dos anéis aromáticos da molécula. Obtivemos que a geometria da EMH forma duas ligações de hidrogênio intramoleculares (os hidrogênios H8 e H1 com O9) e que os parâmetros geométricos dessa geometria estão em boa concordância com os parâmetros teóricos encontrados na literatura obtidos com DFT, B3LYP $/ 6-31+\mathrm{G}^{* *}$ [29] e B3LYP/6-311++ G $^{* *}$ [275] e com os parâmetros experimentais de cristalografia da 1,8-dihidroxiantraquinona [276]. Ressaltamos que nenhuma das formas tautoméricas da Emodina neutra e da Emodina desprotonada (com uma desprotonação), listadas acima, foram estáveis no cálculo de otimização de geometria. Portanto, nossos resultados descartam a existência de uma estrutura de equilíbrio para as formas tautoméricas da Emodina neutra e com uma desprotonação em vácuo e em solução. Esse resultado está em boa concordância com o trabalho de Nguyen e colaboradores [29], que não obtiveram uma estrutura de equilíbrio para a forma tautomérica 3,8,9-trihidroxi-6-metil-1,10-antraquinona da Emodina em vácuo e em etanol.

Comparando a energia livre de vácuo das três espécies da Emodina com uma

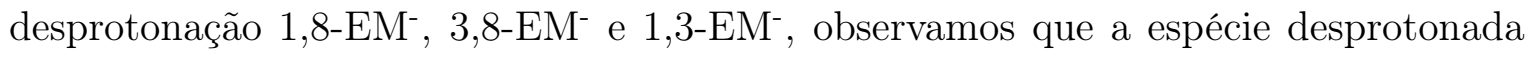
na posição 3, é mais estável e favorecida em comparação com as espécies 3,8-EM- e 1,3$\mathrm{EM}^{-}$, cerca de 15 e $6 \mathrm{kcal} / \mathrm{mol}$ em vácuo e em solução, respectivamente. Assim a espécie mais favorável para primeira desprotonação é a 1,8-EM- A principal contribuição

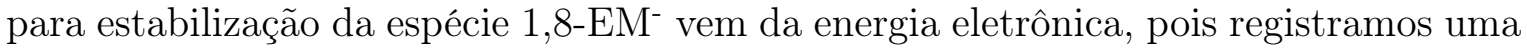
diferença de energia de aproximadamente 17 e $7 \mathrm{kcal} / \mathrm{mol}$, comparado com as espécies 3,8-EM- e 1,3-EM- em vácuo e em solução, respectivamente (ver tabela A.1 no apêndice A). A soma das correções de ponto-zero, térmicas e entálpicas $(\Delta=G-E)$, contribui pouco para estabilização da espécie 1,8-EM- em relação às outras espécies, cerca de 2 e $1 \mathrm{kcal} / \mathrm{mol}$, em vácuo e em solução. Apesar de o solvente reduzir cerca de $60 \%$ a 
diferença de energia entre essas espécies, a diferença de energia livre ainda é superior a $6 \mathrm{kcal} / \mathrm{mol}$ a favor da 1,8-EM- e isso em $100 \%$ dessa espécie no equilíbrio da reação da desprotonação. Portanto, concluímos que a primeira desprotonação da Emodina ocorre na posição 3, assim, para cálculos posteriores da energia livre de solvatação, pK $\mathrm{a}$, espectro eletrônico de absorção e modelagem molecular das espécies da Emodina em solução aquosa e bicamada lipídica, foi levado em consideração somente essa espécie, $1,8-\mathrm{EM}^{-}$.

Tabela 4.1: Energia livre total em $\mathrm{kcal} / \mathrm{mol}$ das espécies da emodina EMH, 3,8-EM- ${ }^{-}$1,8$\mathrm{EM}^{-}, 1,3-\mathrm{EM}^{-}, 1-\mathrm{EM}^{2-}, 9-\mathrm{EM}^{2-} \mathrm{e} \mathrm{EM}^{3-}$ seus respectivos momentos de dipolo (D), obtidos com cálculo quântico (QM), com nível B3LYP/ 6-311++G**, em vácuo, e em meio aquoso, com o solvente descrito com modelo PCM. Nesta tabela está também apresentada a diferença de energia entre as espécies tautoméricas onde foi tomada como referência a espécie mais estável energicamente.

\begin{tabular}{ccccccc}
\hline & \multicolumn{5}{c}{ Vácuo } & \multicolumn{3}{c}{ Solução aquosa } \\
\hline Emodina & $\mathrm{G}(\mathrm{kcal} / \mathrm{mol})$ & $\Delta \mathrm{G}(\mathrm{kcal} / \mathrm{mol})$ & $(\mathrm{D})$ & $\mathrm{G}(\mathrm{kcal} / \mathrm{mol})$ & $\Delta \mathrm{G}(\mathrm{kcal} / \mathrm{mol})$ & $(\mathrm{D})$ \\
\hline $\mathrm{EMH}$ & -598565.89 & 0.00 & 2.68 & -598572.34 & 0.00 & 3.49 \\
\hline $3,8-\mathrm{EM}^{-}$ & -598232.14 & 14.94 & 8.47 & -598281.32 & 5.96 & 12.91 \\
$1,8-\mathrm{EM}^{-}$ & -598247.08 & 0.00 & 10.44 & -598287.28 & 0.00 & 15.33 \\
$1,3-\mathrm{EM}^{-}$ & -598230.96 & 16.12 & 7.12 & -598280.94 & 6.34 & 11.36 \\
\hline $1-\mathrm{EM}^{2-}$ & -597840.54 & 0.00 & 8.04 & -597990.00 & 0.00 & 12.17 \\
$9-\mathrm{EM}^{2-}$ & -597832.27 & 8.27 & 12.78 & -597984.38 & 5.62 & 19.46 \\
\hline $\mathrm{EM}^{3-}$ & -597343.98 & 0.00 & 13.81 & -597681.60 & 0.00 & 21.68 \\
\hline \hline
\end{tabular}


Tomando a geometria da 1,8-EM-, mostrada na figura 3.1, como ponto de partida para próxima desprotonação, identificamos as posições 1 e 8 como as duas mais prováveis para ocorrência da segunda desprotonação. Assim, considerando essas posições, temos três possibilidades para espécie duplamente desprotonada: (i) 8-EM ${ }^{2-}$ - Emodina duplamente desprotonada nas posições 1 e 3; (ii) 1-EM ${ }^{2-}$ - Emodina duplamente desprotonadas posições 3 e 8; (iii) 9-EM ${ }^{2-}$ - a forma tautomérica da Emodina com duas desprotonações. A espécie 1-EM ${ }^{2-}$ apresentou ter uma estrutura planar e estável, mantendo uma ligação de hidrogênio intramolecular, o H1 com O9. Já a espécie 8-EM²-, mostrou ser instável, onde, nesse caso, verificamos um processo de transferência de próton intramolecular, da posição 8 para 9 , formando portanto a espécie tautomérica 9-EM ${ }^{2-}$, como está mostrado na figura 3.2. Comparando a energia livre dessas duas espécies estáveis, observamos que a espécie 1-EM ${ }^{2-}$ é mais estável do que a 9-EM²-, cerca de $8 \mathrm{kcal} / \mathrm{mol}$ em vácuo e $6 \mathrm{kcal} / \mathrm{mol}$ em meio aquoso. Portanto, concluímos que a segunda desprotonação da Emodina deve ocorrer na posição 8, consequentemente, a terceira deve ocorrer na posição 1, gerando a espécie triplamente desprotonada, EM ${ }^{3-}$. Assim, nossos resultados comprovam que a primeira desprotonação da Emodina em solução aquosa ocorre na posição 3, a segunda na posição 8 e a terceira na posição 1 , o que corrabora a sugestão do trabalho de Pal e colaboradores [28].

É interessante notar que as espécies desprotonadas 1,8-EM-, 1-EM ${ }^{2-}$ e $\mathrm{EM}^{3-}$ são estáveis tanto em vácuo como em solução aquosa. Embora a solução mantenha a estabilidade de vácuo dessas espécies, é observado que a solução provoca uma redistribuição de cargas das espécies desprotonadas, fato evidenciado pela grande diferença entre o momento de dipolo das espécie em vácuo $\left(\mu_{g}\right)$ e em solução aquosa $\left(\mu_{a q}\right)$. Observamos um aumento de 47, 51 e $57 \%$ nos momentos de dipolo das espécies 1,8-EM-, 1-EM $\mathrm{EM}^{2-}$ e $\mathrm{EM}^{3-}$, na mudança de vácuo para solução aquosa. Esse grande aumento nos momentos de dipolo dessas espécies, deve ser considerado na análise da estabilidade dessas espécies em solução. Assim, comparando os momentos de dipolos da Emodina 


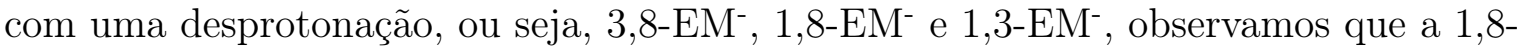
$\mathrm{EM}^{-}$tem maior momento de dipolo e, portanto sua interação eletrostática com a água é favorecida. Já a espécie 1-EM ${ }^{2-}$, que encontramos como sendo a espécie duplamente desprotonada mais estável, tem um momento de dipolo menor do que a 9-EM ${ }^{2-}$. O momento de dipolo da $9-\mathrm{EM}^{2-}$ é cerca de $60 \%$ maior do que da $1-\mathrm{EM}^{2-}$, o que pode levar a espécie 9-EM ${ }^{2-}$ interagir mais fortemente com a água, via ligações de hidrogênio. Essa interação pode estabilizar melhor essa espécie se um modelo mais realista para a solvatação aquosa for utilizado, como é o caso de modelos que consideram explicitamente as moléculas de água. Assim, é necessário um estudo mais detalhado dessas duas espécies em solução aquosa, com modelo explícito do solvente, para identificar qual delas é predominante em solução aquosa.

Para analisar a distribuição de cargas das espécies da Emodina desprotonadas, decidimos examinar as cargas atômicas dessas espécies em vácuo e em solução aquosa. As cargas foram obtidas através do ajuste do potencial eletrostático gerado com método B3LYP/6-311++G**/CHELPG, como apresentado na seção 3.5.2. Na figura 4.1 (a) e (c) mostramos as cargas dos oxigênios O8, O9 e O1 das espécies da Emodina em vácuo. Como era de se esperar, com o aumento do grau de desprotonação, há uma redistribuição de cargas na molécula, de tal forma que torna as cargas nos oxigênios mais negativas. Porém, com a primeira desprotonação da Emodina $\{\mathrm{EMH} \rightarrow$ 1,8-EM- $\mathrm{EM}^{-}$, esperávamos que a carga negativa ficasse mais localizada no oxigênio O3, entretanto, o que observamos é que todos os oxigênios O8, O1 e O3 têm praticamente a mesma carga (-0.71e). Já com a segunda desprotonação, $\left\{1,8-\mathrm{EM}^{-} \rightarrow 1-\mathrm{EM}^{2-}\right\}$, os oxigênios O3 e O8 da 1-EM²- ficam mais negativos, porém, com os valores das cargas ainda próximos do valor obtido para o oxigênio O1 da hidroxila. Assim, os conjuntos de cargas atômicas das espécies desprotonadas em vácuo não distinguem os sítios desprotonados na molécula, ou seja, os oxigênios das hidroxilas recebem praticamente as mesmas cargas. Portanto esses conjuntos de cargas não devem ser utilizados na 


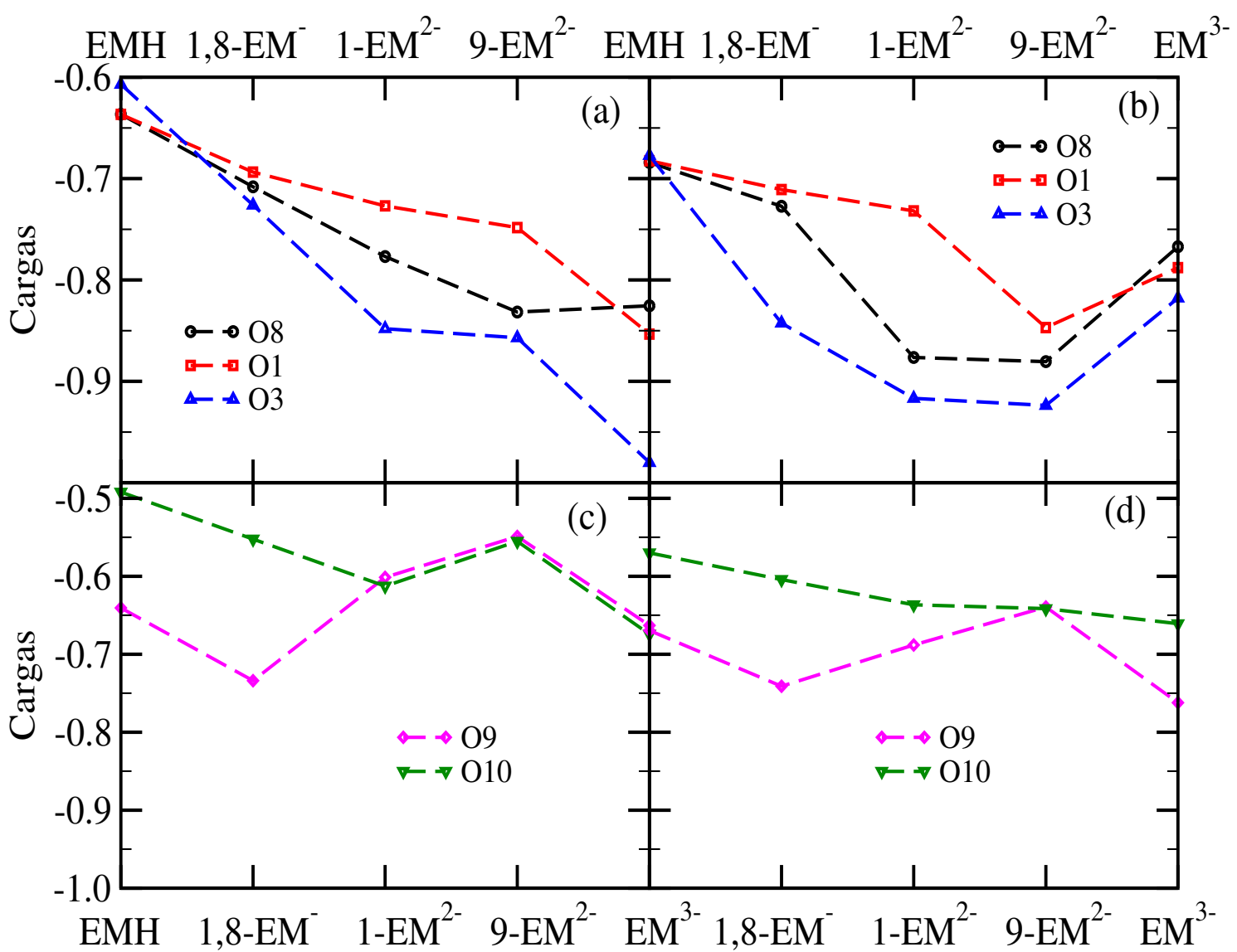

Figura 4.1: Cargas atômicas dos oxigênios O8, O1 e O3, pertencentes aos grupos hidroxilas e O9 e O10 pertencentes às carbonilas, nas espécies da Emodina, calculadas com método B3LYP/6-311++G**/CHELPG em vácuo (figuras (a) e (c)) e em solução aquosa (figuras (b) e (d)), com o solvente, descrito com o modelo contínuo polarizável PCM.

descrição da interação eletrostática dessas espécies com o ambiente.

Na figura 4.1 (b) e (d) estão mostradas as cargas dos oxigênios das espécies da Emodina obtidas em solução aquosa. Observe na espécie 1,8-EM-, que as cargas dos oxigênios O1, O3 e O8 são distintas em solução aquosa, com a carga no sítio da desprotonação (O3) mais negativa em relação aos outros oxigênios. Nessa espécie, obtivemos que as cargas dos oxigênios $\mathrm{O} 1$ e $\mathrm{O} 8$ são praticamente as mesmas, $-0.72 e$, enquanto a carga no oxigênio O3 é $-0.84 e$, portanto mais negativa. Na espécie da Emodina com duas desprotonações, 1-EM ${ }^{2-}$, a distribuição de cargas é similar a da 
1,8- $\mathrm{EM}^{-}$, porém com os dois oxigênios $\mathrm{O} 3$ e $\mathrm{O} 8$ mais negativos em relação ao oxigênio O1 da hidroxila. Portanto, esses resultados indicam que os efeitos da polarização nas espécies da Emodina desprotonadas são importantes, e devem ser levados em consideração, para uma descrição adequada da interação eletrostática dessas espécies com o ambiente.

Desta forma, nossos resultados preliminares mostram que o processo de desprotonação da Emodina é favorecido em meio aquoso descrito com o modelo PCM, pois estabiliza as espécies desprotonadas comparativamente ao processo em vácuo. Do ponto de vista teórico é interessante estudar as propriedades estruturais, eletrônicas e as interações intermoleculares da EMH, 1,8-EM- $\mathrm{EM}^{-}$1-EM ${ }^{2-}, 9-\mathrm{EM}^{2-}$ e $\mathrm{EM}^{3-}$ com o solvente. Porém, neste trabalho, as espécies de interesse são a EMH e a 1,8-EM-, embora mostraremos através de medidas experimentais, que a espécie duplamente desprotonada é factível na faixa de $\mathrm{pH}$ 9.0-13.8. Portanto a partir deste ponto nós estudaremos particularmente a Emodina neutra e a desprotonada na posição $3\left(1,8-\mathrm{EM}^{-}\right)$. Por simplificação resolvemos denominar a Emodina desprotonada $\left(1,8-\mathrm{EM}^{-}\right)$como EM${ }^{-}$. Como os $p K_{\mathrm{a}}$ desse processo de desprotonação em água e em metanol ainda não são conhecidos, determinamos essas propriedades utilizando cálculos quânticos e simulações computacionais que serão apresentados a seguir.

\subsubsection{Cálculo do $p K_{\mathrm{a}}$ da Emodina}

\subsubsection{Processo de desprotonação em fase gasosa: cálculo do $\Delta G_{g}$}

Como apresentado no esquema 3.1, o cálculo do $p K_{\mathrm{a}}$ requer o conhecimento da diferença de energia livre de fase gasosa envolvida no processo de desprotonação $\Delta G_{g}\left(E M H+S H \rightarrow E M^{-}+S H_{2}^{+}\right)$, onde SH representa a molécula de um solvente prótico, no nosso caso, água $\left(\mathrm{H}_{2} \mathrm{O}\right)$ ou metanol $\left(\mathrm{CH}_{3} \mathrm{OH}\right)$. Mas, antes de calcular o valor de $\Delta G_{g}$ para Emodina, calculamos essa propriedade para os solventes, ou seja, $\Delta G_{g}\left(2 S H \rightarrow S^{-}+S H_{2}^{+}\right)$, para água e metanol. Esses cálculos foram realizados 
utilizando ambos os métodos B3LYP e MP2, com a mesma função base, 6-311++G**, como discutido na seção 3.5.2.2.

Tabela 4.2: Energia livre de vácuo $\left(\mathrm{G}_{\mathrm{g}}\right)$ em $\mathrm{kcal} / \mathrm{mol}$ das espécies envolvidas no processo de desprotonação em fase gasosa das moléculas de água e metanol, $\Delta \mathrm{G}_{\mathrm{g}}($ Solvente $)=\Delta \mathrm{G}_{\mathrm{g}}\left(2 \mathrm{SH} \rightarrow \mathrm{S}^{-}+\mathrm{SH}_{2}{ }^{+}\right)$, e também da Emodina, $\Delta \mathrm{G}_{\mathrm{g}}($ Emodina $)=\Delta \mathrm{G}_{\mathrm{g}}\left(\mathrm{EMH}+\mathrm{SH} \rightarrow \mathrm{EM}^{-}+\mathrm{SH}_{2}{ }^{+}\right)$, onde $\mathrm{SH}$ representa a molécula do solvente $\mathrm{H}_{2} \mathrm{O}$ ou $\mathrm{CH}_{3} \mathrm{OH}$, e $\mathrm{SH}_{2}{ }^{+}$representa a molécula da espécie catiônica do solvente $\mathrm{H}_{3} \mathrm{O}^{+}$ou $\mathrm{CH}_{3} \mathrm{OH}_{2}{ }^{+}$. As energias livres foram obtidas através do cálculo das frequências vibracionais utilizando os métodos B3LYP e MP2, com a mesma função base, 6-311++G**.

\begin{tabular}{|c|c|c|c|c|}
\hline \multirow[t]{2}{*}{ Energia livre } & \multicolumn{2}{|c|}{ Água } & \multicolumn{2}{|c|}{ Metanol } \\
\hline & B3LYP & MP2 & B3LYP & MP2 \\
\hline $\mathrm{G}_{\mathrm{g}}(\mathrm{SH})$ & -47976.17 & -47860.70 & -72625.91 & -72444.89 \\
\hline $\mathrm{G}_{\mathrm{g}}\left(\mathrm{S}^{-}\right)$ & -47587.29 & -47469.68 & -72247.38 & -72626.01 \\
\hline $\mathrm{G}_{\mathrm{g}}\left(\mathrm{SH}_{2}{ }^{+}\right)$ & -48140.08 & -48025.93 & -72805.00 & -72061.05 \\
\hline$\Delta \mathrm{G}_{\mathrm{g}}($ Solvente $)$ & 224.97 & 225.80 & 199.45 & 202.73 \\
\hline$\Delta \mathrm{G}_{\mathrm{g}}($ Solvente $)-$ Exp. & \multicolumn{2}{|c|}{$226.00[287,311]$} & \multicolumn{2}{|c|}{$200.90[296]$} \\
\hline $\mathrm{G}_{\mathrm{g}}(\mathrm{EMH})$ & -598565.89 & -596948.38 & -598565.89 & -596948.38 \\
\hline $\mathrm{G}_{\mathrm{g}}\left(\mathrm{EM}^{-}\right)$ & -598247.08 & -596628.10 & -598247.08 & -596628.10 \\
\hline$\Delta \mathrm{G}_{\mathrm{g}}($ Emodina $)$ & 154.90 & 155.06 & 139.73 & 139.17 \\
\hline
\end{tabular}

Os valores obtidos para $\Delta G_{g}($ Água $)$ foram $224.97 \mathrm{kcal} / \mathrm{mol}$ com B3LYP e $225.80 \mathrm{kcal} /$ mol com MP2, que estão em excelente concordância com o valor experimental de 226.00 $\mathrm{kcal} / \mathrm{mol}[287,311]$. Similarmente, os valores obtidos para $\Delta G_{g}($ Metanol) foram 199.45 $\mathrm{kcal} / \mathrm{mol}$ com B3LYP e $202.73 \mathrm{kcal} / \mathrm{mol}$ com MP2, que também estão em excelente 
concordância com o valor experimental de $200.90 \mathrm{kcal} / \mathrm{mol}$ [296].

Assim usando os valores de $G_{g}(S H), G_{g}\left(S H_{2}^{+}\right), G_{g}(E M H)$ e $G_{g}\left(E M^{-}\right)$, listados na tabela 4.2 , determinamos $\Delta G_{g}$ (Emodina) do processo de desprotonação da Emodina em fase gasosa. Os valores obtidos desse cálculo foram: (i) $\Delta G_{g}(E M H+$ $\left.\mathrm{H}_{2} \mathrm{O} \rightarrow \mathrm{EM}^{-}+\mathrm{H}_{3} \mathrm{O}^{+}\right), 154.90 \mathrm{kcal} / \mathrm{mol} \mathrm{com}$ B3LYP e $155.06 \mathrm{kcal} / \mathrm{mol} \mathrm{com} \mathrm{MP} 2$; (ii) $\Delta G_{g}\left(E M H+\mathrm{CH}_{3} \mathrm{OH} \rightarrow E M^{-}+\mathrm{CH}_{3} \mathrm{OH}_{2}^{+}\right), 139.73 \mathrm{kcal} / \mathrm{mol} \mathrm{com}$ B3LYP e 139.17 $\mathrm{kcal} / \mathrm{mol}$ com MP2. Como pode ser observado, os valores obtidos com esses dois métodos são similares, apresentando uma pequena diferença de aproximadamente de 0.2 e $0.6 \mathrm{kcal} / \mathrm{mol}$ para o processo de desprotonação da Emodina em água e em metanol, respectivamente. Nesta tese de doutorado, adotamos os valores obtidos com o método $\mathrm{MP} 2 / 6-311++\mathrm{G}^{* *}$, como sendo nossos melhores valores $\left(\Delta G_{g}(\bar{g} g u a)=225.80 \mathrm{kcal} /-\right.$ mol, $\Delta G_{g}($ Metanol $)=202.73 \mathrm{kcal} / \mathrm{mol} \mathrm{e} \Delta G_{g}($ Emodina $)=155.06 \mathrm{kcal} / \mathrm{mol}$ em água e $\Delta G_{g}($ Emodina $)=139.17 \mathrm{kcal} / \mathrm{mol}$ em metanol $)$.

\subsubsection{Processo de desprotonação em solução: cálculo do $\Delta G_{S o l}$ e $p K_{\mathrm{a}}$}

Como apresentado na seção 3.5.2.2, o cálculo do $p K_{\mathrm{a}}$ da Emodina em meio solvente requer o conhecimento da energia livre de desprotonação, $\Delta G_{S o l .}{ }^{1}$ dessa molécula em solução, que está relacionada com a energia livre de desprotonação em vácuo, $\Delta G_{g}$, e as energias livres de solvatação das espécies envolvidas no processo de desprotonação. Assim, para calcular as energias livres de solvatação da EMH e EM- em água e em metanol, usamos duas metodologias: (i) MC-FEP - as energias foram calculadas através da equação 3.15 , onde os termos $\Delta G_{\text {Elet. }}(X)$ e $\Delta G_{N a \tilde{o} \text { elet. }}(X)$, que são as principais contribuições para a energia livre de solvatação, foram calculados através de

\footnotetext{
${ }^{1}$ Embora usamos o termo energia livre de desprotonação para o processo, $\Delta G_{\text {Sol. }}\left(E M H_{(S o l .)}+\right.$ $S H_{(S o l .)} \longrightarrow E M_{(S o l .)}^{-}+S H_{2}^{+}{ }_{(S o l .)}$, chamamos atenção que nesse termo contém também a contribuição da energia livre de protonação da água, ou seja, $\Delta G_{\text {Sol. }}=\Delta G_{\text {Desp. }}($ Emodina $)+$ $\Delta G_{\text {Prot. }}(\bar{A} g u a$,$) , que pode ser facilmente demonstrado, se o processo acima for dividido em duas$ etapas, $\Delta G_{\text {Sol. }}\left(E M H_{(\text {Sol. })}+S H_{(\text {Sol. })} \stackrel{\Delta G_{\text {Desp. }}(\text { Emodina })}{\longrightarrow} E M_{(\text {Sol. })}^{-}+H_{(\text {Sol. })}^{+}+S H_{(\text {Sol. })} \stackrel{\Delta G_{\text {Prot. (Água })}}{\longrightarrow}\right.$ $E M_{(\text {Sol. })}^{-}+S H_{2}^{+}($Sol. $)$.
} 
simulações computacionais com o método Monte Carlo combinado à teoria de perturbação termodinâmica, e o termo $\Delta G_{P o l .}(X)$, que é a energia livre de polarização, foi calculado através de cálculos quânticos com o solvente descrito com o modelo contínuo polarizável (PCM); (ii) QM-PCM, as energias livres foram obtidas através de cálculos quânticos, com o solvente descrito com o modelo contínuo polarizável. Essas duas metodologias estão descritas na seção 3.5.2.

Inicialmente, cálculamos as energias livres de polarização das espécies da Emodina, através de cálculos quânticos usando a seguinte aproximação, $\Delta G_{P o l}(X)=$ $E_{P o l}-E_{\text {Vác. }}$, onde $E_{P o l}$. é a energia eletrônica do soluto isolado, porém calculada com a função de onda polarizada devido ao solvente, e $E_{\text {Vác. }}$, é a energia eletrônica do soluto em vácuo, obtida com a função de onda de vácuo. Note que nessa aproximação, consideramos que as contribuições devido às correções térmicas para energia livre do soluto polarizado e em vácuo cancelam-se quando subtraídas. Os valores obtidos para $\Delta G_{P o l}(E M H)$ em água e em metanol foram $2.1(1.8)$ e $2.0(1.7) \mathrm{kcal} / \mathrm{mol}$ e para $\Delta G_{P o l}\left(E M^{-}\right)$, esses valores foram $4.5(4.4)$ e $4.2(4.2) \mathrm{kcal} / \mathrm{mol}$, respectivamente, onde em parêntese, são os valores obtidos através da metodologia QM-PCM, ver tabela 4.3. Esses resultados mostram que a diferença de energias livres de polarização das espécies da Emodina em água e metanol são pequenas $(\sim 0.1 \mathrm{kcal} / \mathrm{mol}$ para ambas EMH e $\left.\mathrm{EM}^{-}\right)$, porém a diferença dessas energias entre as duas espécies é considerável $(\sim 2.5$ $\mathrm{kcal} / \mathrm{mol}$ ), tendo a Emodina desprotonada, maior energia livre de polarização.

As contribuições das interações eletrostáticas, $\Delta G_{\text {Elet. }}$, e não eletrostáticas, $\Delta G_{N a \tilde{o} \text { elet. }}$, da energia livre de solvatação das espécies da Emodina em solução, foram calculadas a partir das contribuições da energia livre de aniquilação dessas interações, ou seja, $\Delta G_{\text {Elet. }}=-\Delta G_{\text {Aniq-elet. }}^{\text {sol. }} \Delta G_{\text {Não elet. }}=-\Delta G_{\text {Aniq-não elet. }}$, como apresentado na seção 3.5.2.3. Essa última contribuição, é dada pela soma das energias livres de aniquilação das interações dos termos atrativos, $r^{-6}$, e repulsivos, $r^{-12}$, do potencial de Lennard-Jones. Na tabela 4.3, mostramos um sumário dos valores médios das 


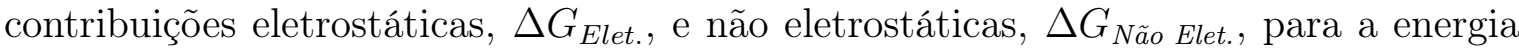
livre de solvatação das espécies da Emodina em água e em metanol. As contribuições obtidas com MC-FEP apresentadas nessa tabela, representam os valores médios dessas contribuições obtidos a partir de cinco simulações totalmente independentes (veja a tabela A.2 no apêndice A, com as contribuições individuais de cada simulação). O erro apresentado para o valor médio de cada contribuição é referente ao desvio padrão das 5 simulações independentes.

Os valores obtidos das contribuições eletrostáticas para as energias livres de solvatação da EMH em água e em metanol, ver tabela 4.3, foram -10.2 $\pm 0.2(-17.1)$ e $-5.9 \pm 0.3(-17.2) \mathrm{kcal} / \mathrm{mol}$, onde em parêntese, são os valores obtidos através da metodologia QM-PCM. Para a espécie EM- ${ }^{-}$essas contribuições foram -48.4 $\pm 0.2(-57.2)$ e $-40.3 \pm 0.4(-55.5) \mathrm{kcal} / \mathrm{mol}$, para a molécula em água e em metanol, respectivamente. Esses valores mostram que em termos eletrostáticos é mais favorável a solvatação das espécies EMH e EM- em água do que em metanol. Comparando os valores obtidos com MC-FEP, onde as moléculas do solvente são incluídas explicitamente no cálculo, com os obtidos com QM-PCM, onde o solvente é descrito como um meio contínuo polarizável, vemos que eles descrevem a mesma tendência da solvatação dessas espécies, porém, com diferenças entre esses valores de aproximadamente 7 e $11 \mathrm{kcal} / \mathrm{mol}$ para a EMH, 9 e $15 \mathrm{kcal} / \mathrm{mol}$ para a $\mathrm{EM}^{-}$, ambas em água e em metanol, respectivamente.

As contribuições não eletrostáticas, que são dadas pela soma da contribuição associada ao termo atrativo de van der Waals e cavitação, apresentaram, para ambas as espécies da Emodina, com as metodologias MC-FEP e QM-PCM, valores favoráveis à solvatação dessas espécies em metanol. Nesse solvente, essas contribuições para EMH e EM- foram -17.1 $\pm 0.7(-1.0)$ e $-18.7 \pm 0.5(-0.9) \mathrm{kcal} / \mathrm{mol}$, enquanto em água esses valores foram -8.1(3.7) e -9.17(3.7) $\mathrm{kcal} / \mathrm{mol}$, respectivamente. Assim, em termos não eletrostáticos é mais favorável a solvatação das espécies da Emodina em metanol do que em água. Uma comparação entre os valores obtidos com MC-FEP e QM- 
PCM, mostra uma discrepância grande entre eles, sendo no caso da solvatação em água, registramos sinais contrários, sendo negativos os valores obtidos com MC-FEP e positivos os obtidos com QM-PCM, com a diferença entre eles da ordem de 12 kcal/mol para ambas espécies. Já no caso da solvatação em metanol, os valores com ambas as metodologias apresentaram as mesmas tendências (valores negativos), porém a diferença entre esses valores é superior a $16 \mathrm{kcal} / \mathrm{mol}$ para ambas as espécies da Emodina. Embora essas diferenças entre as duas metodologias são grandes, mostramos a seguir que elas não aparecem efetivamente nos valores da energia livre de solvatação das espécies da Emodina.

Como obtivemos com as duas metodologias, tendências contrárias das contribuições eletrostáticas e não eletrostáticas para solvatação das espécies da Emodina em água e em metanol, espera-se que o valor total da energia livre de solvatação, defina melhor a afinidade dessas espécies nesses solventes. Assim, determinamos o valor total da energia livre de solvatação usando a equação 3.15, que reescrevemos abaixo,

$$
\Delta G_{\text {Solv. }}^{*}(X)=\Delta G_{\text {Pol. }}(X)+\Delta G_{\text {Elet. }}(X)+\Delta G_{\text {Não elet. }}(X)-R T \ln (24.46)
$$

onde os valores dos três primeiros termos dessa equação foram apresentados e discutidos acima, com exceção ao último termo, $R T \ln (24.46)$, que é a correção, no valor de $1.9 \mathrm{kcal} / \mathrm{mol}$, necessária para levar a diferença de energia livre ao estado padrão de $1 \mathrm{~mol} / \mathrm{L}$, visto que nossas simulações foram realizadas nas condições de temperatura e pressão de $298.15 \mathrm{~K}$ e 1 atm, veja seção 2.2.1.4. Esse termo de correção foi aplicado somente para os valores obtidos com a metodologia MC-FEP. Para os valores obtidos com QM-PCM, essa correção é desnecessária, pois a equação da energia livre usada nessa metodologia para calcular, $\Delta G_{\text {Solv. }}(X)$, é parametrizada para reproduzir os resultados experimentais dessa propriedade no estado padrão de $1 \mathrm{~mol} / \mathrm{L}$. 
Tabela 4.3: Valores das energias livres de solvatação, $\Delta G_{\text {Solv. }}^{*}(X)$, das espécies da Emodina $\left(X=\mathrm{EMH}\right.$ ou $\left.\mathrm{EM}^{-}\right)$em água e em metanol, obtidos através de simulações computacionais com método Monte Carlo combinado à teoria de perturbação termodinâmica (MC-FEP). Os valores de $\Delta G_{\text {Solv. }}^{*}(X)$ foram obtidos através da equação 3.15. Em parênteses são os valores calculados através da metodologia QM-PCM.

\begin{tabular}{|c|c|c|c|c|}
\hline & \multicolumn{2}{|c|}{ Água } & \multicolumn{2}{|c|}{ Metanol } \\
\hline & $\mathrm{EMH}$ & $\mathrm{EM}^{-}$ & EMH & $\mathrm{EM}^{-}$ \\
\hline$\Delta G_{\text {Pol. }}(X)$ & $2.1(1.8)$ & $4.5(4.4)$ & $2.0(1.7)$ & $4.2(4.2)$ \\
\hline$\Delta G_{\text {Elet. }}(X)$ & $\begin{array}{c}-10.2 \pm 0.2 \\
(-17.1)\end{array}$ & $\begin{array}{c}-48.4 \pm 0.2 \\
\quad(-57.2)\end{array}$ & $\begin{array}{r}-5.9 \pm 0.3 \\
(-16.2)\end{array}$ & $\begin{array}{c}-40.3 \pm 0.4 \\
\quad(-55.5)\end{array}$ \\
\hline$\Delta G_{N \tilde{a} o \text { elet. }}(X)$ & $\begin{array}{c}-8.1 \pm 0.8 \\
(3.7)\end{array}$ & $\begin{array}{c}-9.2 \pm 0.3 \\
\quad(3.8)\end{array}$ & $\begin{array}{c}-17.1 \pm 0.7 \\
\quad(-1.0)\end{array}$ & $\begin{array}{c}-18.7 \pm 0.5 \\
\quad(-0.9)\end{array}$ \\
\hline$-\mathrm{RT} \ln (24.46)$ & -1.9 & -1.9 & -1.9 & -1.9 \\
\hline$\Delta G_{S o l v .}^{*}(X)$ & $\begin{array}{c}-18.1 \pm 0.8 \\
(-11.6)\end{array}$ & $\begin{array}{c}-55.0 \pm 0.4 \\
\quad(-49.0)\end{array}$ & $\begin{array}{c}-22.9 \pm 0.8 \\
\quad(-15.5)\end{array}$ & $\begin{array}{c}-56.7 \pm 0.6 \\
(-52.2)\end{array}$ \\
\hline \multicolumn{2}{|c|}{$\Delta \Delta G_{\text {Solv. }}($ Emodina $)$} & $9(-37.4)$ & \multicolumn{2}{|c|}{$-33.8 \pm 1.0(-36.7)$} \\
\hline$\Delta \Delta G_{\text {Solv. }}($ Solvente $)$ & \multicolumn{2}{|c|}{$-103.9 \pm 0.7$} & \multicolumn{2}{|c|}{$-86.5 \pm 2.0$} \\
\hline$\Delta \Delta G_{\text {Solv }}$ & \multicolumn{2}{|c|}{$-140.8 \pm 1.1(-141.3 \pm 0.7)$} & \multicolumn{2}{|c|}{$-120.3 \pm 2.2(-123.2 \pm 2.0)$} \\
\hline$\Delta G_{\mathrm{g}}($ Emodina $)$ & \multicolumn{2}{|c|}{155.1} & \multicolumn{2}{|c|}{139.2} \\
\hline$\Delta G_{\text {Sol. }}$ & \multicolumn{2}{|c|}{$14.3 \pm 1.1(13.8 \pm 0.7)$} & \multicolumn{2}{|c|}{$18.9 \pm 2.2(16.0 \pm 2.0)$} \\
\hline$p K_{a 1}$ & \multicolumn{2}{|c|}{$8.7 \pm 0.8(8.4 \pm 0.5)$} & \multicolumn{2}{|c|}{$12.5 \pm 1.6(10.3 \pm 1.5)$} \\
\hline
\end{tabular}


Os valores obtidos para energia livre de solvatação das espécies EMH e EMnos solventes água e metanol estão listados na tabela 4.3. Esses valores indicam que essas espécies apresentam uma maior afinidade por metanol, pois os valores obtidos para $\Delta G_{\text {Solv. }}^{*}(X)$ da $E M H$ e $\mathrm{EM}^{-}$nesse solvente foram -22.9 $\pm 0.8(-15.5)$ e -56.7 \pm 0.6 ($52.2) \mathrm{kcal} / \mathrm{mol}$, enquanto em água, esses valores foram -18.1 $\pm 0.8(-11.6)$ e -55.0 $\pm 0.4(-$ 49.0) $\mathrm{kcal} / \mathrm{mol}$, respectivamente, onde em parênteses são os valores obtidos através da metodologia QM-PCM. Esses resultados estão em boa concordância com nossos resultados obtidos na dissertação de mestrado [32], onde obtivemos que essas espécies são mais solúveis em metanol do que em água, corroborando alguns trabalhos encontrados na literatura que asseguram que a Emodina se dissolve melhor em solventes orgânicos [28, 29].

No cálculo da energia livre de desprotonação, $\Delta G_{\text {Sol. }}$ da Emodina em água e em metanol, observamos que as principais contribuições para $\Delta G_{\text {Sol. são eletrostáticas. De }}$ acordo com a equação 3.5, essa contribuição pode ser calculada pela seguinte diferença, $\Delta \Delta G_{\text {Elet. }}($ Emodina $)=\Delta G_{\text {Elet. }}\left(E M^{-}\right)-\Delta G_{\text {Elet. }}(E M H)$, onde $\Delta G_{\text {Elet. }}(X)$ é a contribuição eletrostática para a energia livre de solvatação, já incluso o termo $\Delta G_{P o l}(X)$. Usando os valores listados na tabela 4.3, determinamos essas contribuições nos valores de -35.8(-37.5) e -32.2(-36.8) kcal/mol para a Emodina em água e em metanol, com as duas metodologias MC-FEP e (QM-PCM). Já as contribuições não eletrostáticas para $\Delta G_{\text {Sol. }}$ são praticamente nulas, pois essas contribuições para as energias livres de solvatação da EMH e EM- em ambos solventes são praticamente as mesmas, se cancelamento na seguinte subtração, $\Delta \Delta G_{\text {Não Elet. }}($ Emodina $)=\Delta G_{\text {Não Elet. }}\left(E M^{-}\right)$$\Delta G_{\text {Não Elet. }}(E M H)$, com uma diferença inferior a $1.6(0.2) \mathrm{kcal} / \mathrm{mol}$. Esse cancelamento é esperado, pois as estruturas química das espécies EMH e EM- são praticamente as mesmas, com uma diferença de um próton entre elas. Esses resultados estão em concordância com alguns trabalhos da literatura que consideram desprezíveis as contribuições não eletrostáticas para diferença de energia livre de desprotonação [312,313]. 
A soma das contribuições relativas eletrostáticas, $\Delta \Delta G_{\text {Elet. }}$ (Emodina), e não eletrostáticas, $\Delta \Delta G_{\text {Não Elet. }}($ Emodina $)$, fornece a diferença de energia livre relativa, $\Delta \Delta G_{\text {Solv. }}$ (Emodina), que é a principal contribuição dessa molécula para $\Delta G_{\text {Sol. }}$. Os valores obtidos para $\Delta \Delta G_{\text {Solv. }}$ (Emodina), em água e em metanol foram -36.9 $\pm 0.9(-37.4)$ e -33.8 $\pm 1.0(-36.7) \mathrm{kcal} / \mathrm{mol}$, respectivamente. As energias livres de desprotonação da Emodina nesses solventes foram determinadas a partir da equação 3.1, onde usamos para $\Delta \Delta G_{\text {Solv. }}$ (Solvente), os valores de $-103.9 \pm 0.7$ e $-86.5 \pm 2.0 \mathrm{kcal} / \mathrm{mol}$, para a água e o metanol, respectivamente, como apresentado na seção 3.5.2.2. Para a energia livre de desprotonação da Emodina em fase gasosa da Emodina, $\Delta G_{\mathrm{g}}($ Emodina $)$, usamos os valores de 155.1 e $139.2 \mathrm{kcal} / \mathrm{mol}$, em água e em metanol, respectivamente. Na tabela 4.3 , apresentamos os valores obtidos para $\Delta \mathrm{G}_{\text {sol. }}$. Os valores obtidos para essa propriedade em água e em metanol foram 14.3 $\pm 1.1(13.8 \pm 7)$ e $18.9 \pm 2.2(16.0 \pm 2.0) \mathrm{kcal} / \mathrm{mol}$, que de acordo com a equação 3.6, estão associados aos seguintes $p K_{\mathrm{a} 1} 8.7 \pm 0.8(8.4 \pm 0.5)$ e $12.5 \pm 1.6(10.3 \pm 1.5)$, respectivamente.

Uma comparação dos valores dos $p K_{\mathrm{a} 1}$ da Emodina em água e em metanol, obtidos através das metodologias MC-FEP e (QM-PCM), mostra uma boa concordância entre esses valores, com a diferença entre eles da ordem de 0.3 e 2.2 unidades de $p K_{\text {a }}$ para Emodina nesses solventes, respectivamente. Note que para o $p K_{\mathrm{a} 1}$ da Emodina em água, essa diferença está dentro do erro, porém para o metanol, essa diferença é superior ao erro estimado para os valores de $12.5 \pm 1.6(10.3 \pm 1.5)$, o que nos leva a questionar esses resultados. Suspeitamos de que essa discrepância desses valores se deve provavelmente à erros nos valores da energia livre de solvatação das espécies da Emodina em metanol com a metodologia QM-PCM, visto que a equação usada para calcular $\Delta G_{\text {Solv. }}^{*}(X)$ é parametrizada para reproduzir os resultados experimentais dessa propriedade em água, no estado padrão de $1 \mathrm{~mol} / \mathrm{L}$. Para discutir melhor a acurácia desses valores, resolvemos complementar nosso estudo teórico através do estudo experimental da titulação espectroscópica dessa molécula nesses solventes, através da 
medida dos espectros da Emodina nas condições normais de pressão e temperatura, em várias condições diferentes de $\mathrm{pH}$. Usando essa titulação, determinamos os $p K_{\mathrm{a}}$ da Emodina nesses dois solventes que serão apresentados e discutidos seguir.

\subsubsection{Titulação espectroscópica da Emodina em água e em me- tanol}

Nessa seção apresentamos e discutimos os resultados experimentais da titulação espectroscópica da Emodina em água e em metanol. Mas, antes de apresentar esses resultados, vamos fazer um sumário das medidas dos espectros eletrônicos de absorção da Emodina $\left(2.5 \times 10^{-5} \mathrm{~mol} / \mathrm{L}\right)$ na mistura de água $(25 \%)$ e metanol $(75 \%),(1: 3 \mathrm{v} / \mathrm{v})$, com o $\mathrm{pH}_{\mathrm{ap}}(\mathrm{pH}$ medido com pHmetro calibrado para água) variando de 2.09 a 12.66 . A escolha dessa mistura se deve principalmente pelo fato da Emodina ser solúvel nessa solução, e também, pelo fato da existência do trabalho Pal e colaboradores [28], que determinaram a constante de acidez da Emodina nessa mistura de água-metanol, no valor $\left(p K_{a 1}=7.2\right)$, na escala de $\mathrm{pH}_{\mathrm{ap}}$. Os resultados desse trabalho serviram para comparar com os nossos resultados obtidos nesta tese e validar a metodologia teórica adotada aqui para os ajustes das curvas de titulação espectroscópica (absorbância versus $\mathrm{pH}_{\mathrm{ap}}$, em um dado comprimento de onda). Na figura 4.2 mostramos os espectros de absorção da Emodina na mistura água e metanol, em diferentes $\mathrm{pH}_{\mathrm{ap}}$. Como pode ser observado nessa figura, os espectros de absorção dessa molécula são caracterizados por 4 bandas de absorção bastante sensíveis à variação de $\mathrm{pH}_{\mathrm{ap}}$ da solução. A primeira banda de absorção, em $\mathrm{pH}_{\mathrm{ap}}=12.66$, tem um máximo de absorbância em $\lambda=508$ $\mathrm{nm}$, que muda para região de menor comprimento de onda, quando o $\mathrm{pH}_{\mathrm{ap}}$ varia de 12.66 para 2.09, tendo nesse extremo, $\lambda=441 \mathrm{~nm}$. Esse comportamento dos espectros está em concordância com o trabalho de Pal e colaboradores [28], que atribui esse comportamento aos processos de desprotonação dessa molécula em solução.

Determinamos os valores das constantes de acidez $p K_{\text {ai }}$ da Emodina, através do 
ajuste das curvas de titulação usando a seguinte equação,

$$
A_{T}=A_{0}+\sum_{i=1}^{n} A_{i}\left(\frac{10^{ \pm\left(p H-p K_{a i}\right)}}{1+10^{ \pm\left(p H-p K_{a i}\right)}}\right) \text {, }
$$

onde $A_{0}$ e $A_{i}$ são constantes e $p K_{a i}$ corresponde ao valor do i-ésimo $p K_{a}$. Note na equação 4.2, que para cada termo escolhido para ajustar a absorbância, é necessário definir o sinal da função sigmóide. A escolha do sinal se dá através da seguinte regra: se a absorbância no dado comprimento de onda aumenta com o pH, então o sinal da função é positivo, e a função é crescente, caso contrário, o sinal é negativo, e a função é decrescente. Um dedução completa dessa equação está mostrada na seção A.2 no apêndice A.

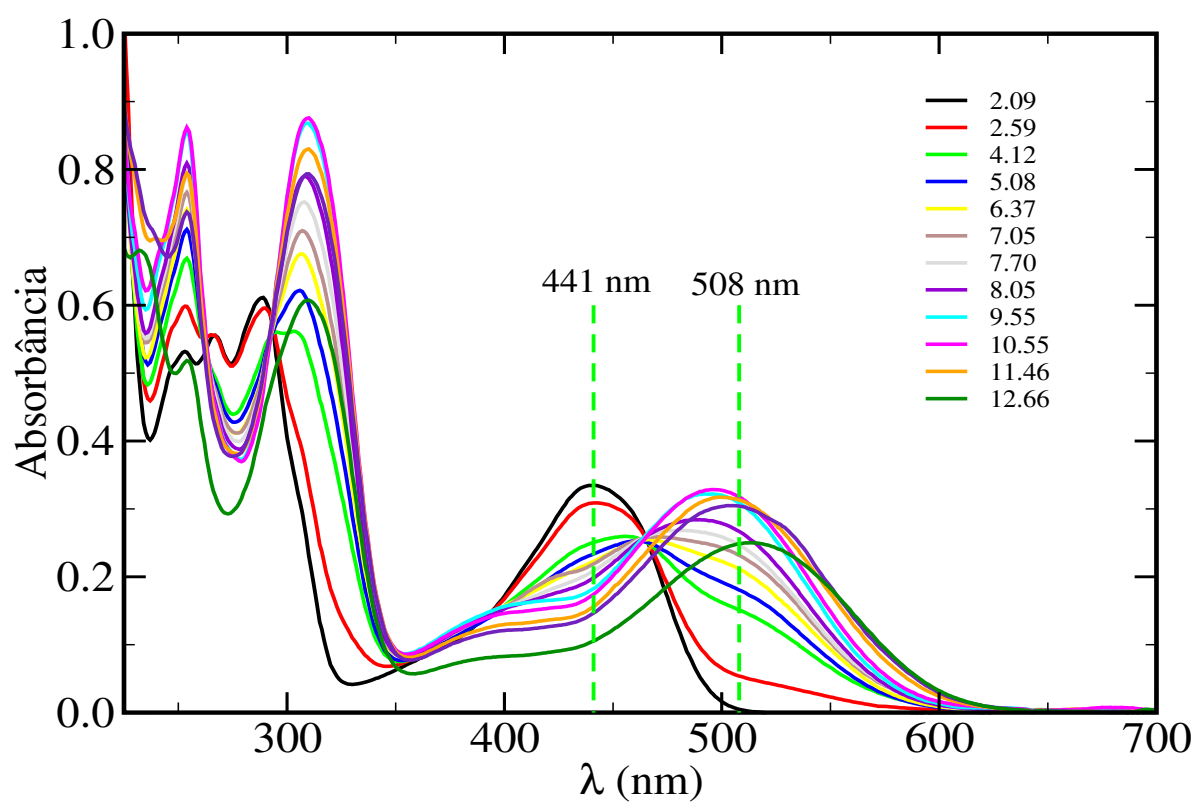

Figura 4.2: Efeito do $\mathrm{pH}_{\mathrm{ap}}$ no espectro de absorção da Emodina $\left(2.5 \times 10^{-5} \mathrm{~mol} / \mathrm{L}\right)$ na mistura água e metanol $(1: 3 \mathrm{v} / \mathrm{v})$, com o $\mathrm{pH}_{\mathrm{ap}}$ variando de 2.09 a 12.66. As linhas verdes verticais tracejadas mostram os comprimentos de onda máximos da primeira banda de absorção da Emodina em duas condições diferentes de $\mathrm{pH}_{\mathrm{ap}}: \lambda=441 \mathrm{~nm}, \mathrm{pH}_{\mathrm{ap}}<5.08$ e $\lambda=508 \mathrm{~nm}$, $\mathrm{pH}_{\mathrm{ap}}=12.66$.

Na figura 4.3, mostramos as curvas de titulação espectroscópica para dois comprimentos de onda selecionados, 508 e $441 \mathrm{~nm}$, e os respectivos ajustes pela equação 


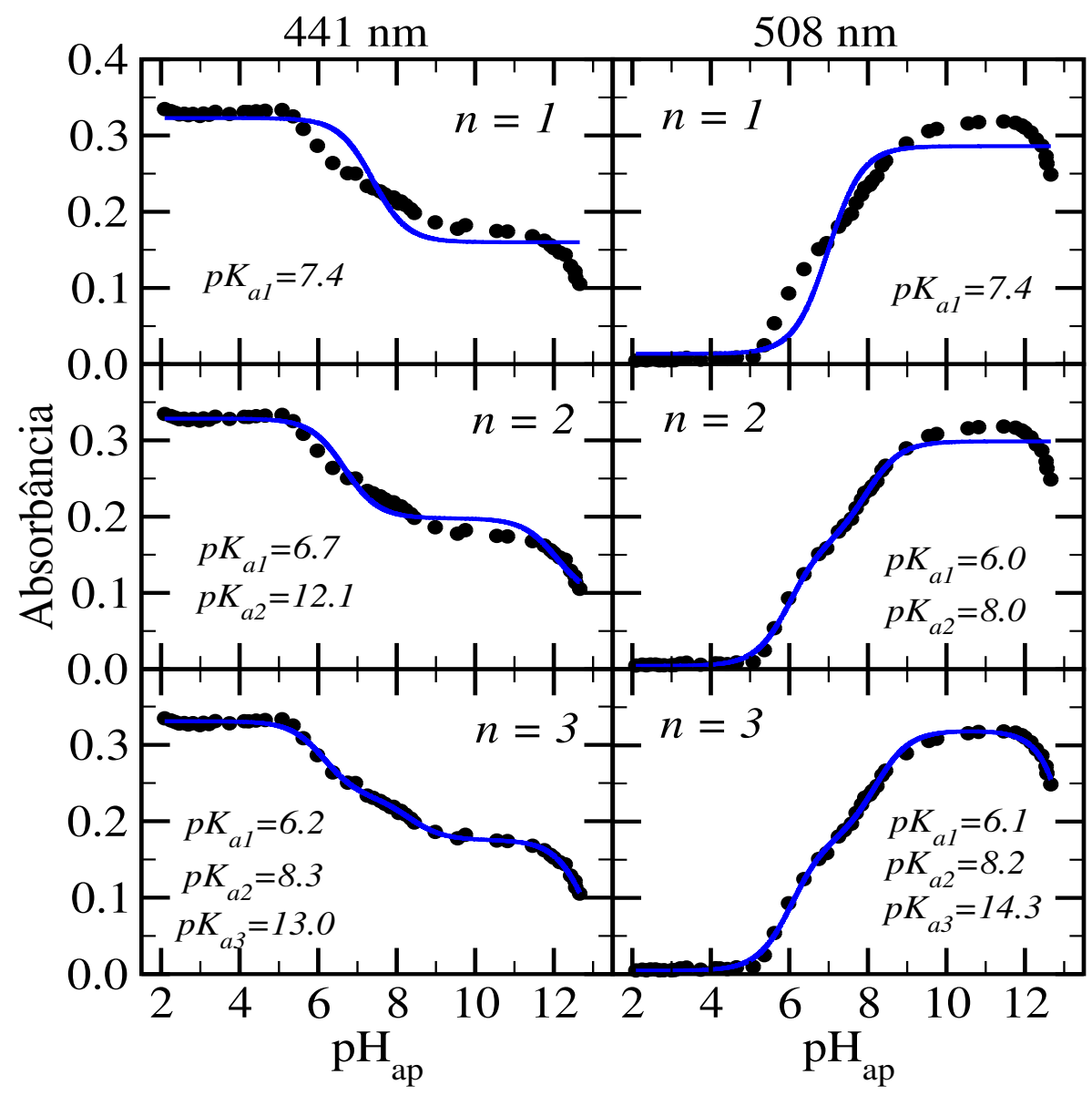

Figura 4.3: Efeito do $\mathrm{pH}_{\mathrm{ap}}$ na absorbância em $\lambda=441 \mathrm{~nm}$ (figuras do lado esquerdo) e $\lambda=508$ $\mathrm{nm}$ (figuras do lado direito), da Emodina $\left(2.5 \times 10^{-5} \mathrm{~mol} / \mathrm{L}\right)$ na mistura de água (25\%) e metanol $(75 \%)$, com os ajustes das curvas, considerando um termo $(n=1)$, dois termos $(n=2)$ e três termos $(\mathrm{n}=3)$ da equação 4.2 .

4.2, feitos para determinar os valores das constantes de acidez, $p K_{a i}$, na escala de $\mathrm{pH}_{\mathrm{ap}}$. Os primeiros ajustes foram feitos considerando somente uma desprotonação na molécula, ou seja, usamos apenas um termo $(n=1)$ da equação 4.2, para ajustar as curvas experimentais. A partir desses ajustes, determinamos a constante de acidez, no valor de $p K_{a 1}=7.4 \mathrm{em} \lambda=441 \mathrm{~nm}$ e $p K_{a 1}=7.0 \mathrm{em} \lambda=508 \mathrm{~nm}$. Esses valores estão em excelente concordância com o valor de 7.2 obtido no trabalho de Pal e colaboradores [28], na mesma mistura água e metanol (1:3 v/v), determinado com método Bjerrum $[314,315]$. 
Entretanto, observando a figura $4.3(\mathrm{n}=1)$, podemos notar que usando apenas um termo da equação 4.2 não ajusta bem os dados experimentais. Assim, tentamos ajustar esses dados com 2 e 3 termos dessa equação, ou seja, assumindo dois $(n=2)$ ou três $(n=3)$ sítios de desprotonações na molécula Emodina em solução na faixa de $\mathrm{pH}_{\text {ap }}$ entre 2.09 e 12.66. Na figura $4.3(\mathrm{n}=2$ e $\mathrm{n}=3)$, apresentamos também esses novos ajustes. A partir desses ajustes, determinamos para $\mathrm{n}=2$, os valores de $p K_{a 1}=6.7 \mathrm{e}$ $p K_{a 2}=12.1 \mathrm{em} \lambda=441 \mathrm{~nm}$ e $p K_{a 1}=6.0$ e $p K_{a 2}=8.0 \mathrm{em} \lambda=508 \mathrm{~nm}$, e para $\mathrm{n}=3$, os valores de $p K_{a 1}=6.2, p K_{a 2}=8.3$ e $p K_{a 3}=13.0$ em $\lambda=441 \mathrm{~nm}$ e $p K_{a 1}=6.2$, $p K_{a 2}=8.2$ e $p K_{a 3}=14.3 \mathrm{em} \lambda=508 \mathrm{~nm}$. Assim, usando 2 e 3 termos da equação 4.2 , observamos uma melhora significativa nos ajustes dos dados experimentais, porém o melhor ajuste foi obtido para $n=3$, ou seja, assumindo a existência de três constantes de acidez (três sítios de desprotonações) na faixa de $\mathrm{pH}_{\text {ap }}$ estudado. Comparando os ajustes em $\lambda=441 \mathrm{~nm}$ e $\lambda=508 \mathrm{~nm}$, para os três casos investigados ( $\mathrm{n}=1, \mathrm{n}=2$ e $\mathrm{n}=3$ ), observamos que eles fornecem, praticamente, os mesmos valores para as constantes de acidez, com poucas exceções, $p K_{a 2}$ para $\mathrm{n}=2$ e $p K_{a 3}$ para $\mathrm{n}=3$. Embora obtivemos para $\mathrm{n}=3$, valores para o $p K_{a 3}(13.0$ e 14.3$)$, vale ressaltar que nossas medidas foram feitas na faixa de $\mathrm{pH}_{\mathrm{ap}}$ entre 2.09 e 12.66, e portanto esses valores de $p K_{a 3}$ estão fora dessa faixa de $\mathrm{pH}_{\mathrm{ap}}$, de modo que eles não devem ser confiáveis. Ressaltamos também, que nossos melhores valores para as constantes de acidez da Emodina na mistura água e metanol $(1: 3 \mathrm{v} / \mathrm{v})$ são $p K_{a 1}=6.2 \pm 0.1, p K_{a 2}=8.3 \pm 0.1$ e $p K_{a 3}>12.7$. Essa nova análise das curvas de titulação espectroscópica da Emodina nessa mistura forneceu diferentes resultados comparado com os obtidos por Pal e colaboradores [28]. Essa nova análise parece estar em melhor concordância com os processos de desprotonação da Emodina, que ocorrem em solução nas posições das três hidroxilas, como apresentado na seção 4.2.1. Assim, concluímos que a Emodina nessa mistura, na faixa de $\mathrm{pH}_{\mathrm{ap}}$ entre $2.09 \mathrm{e}$ 12.66, sofre dois processos de desprotonação, perdendo dois prótons, sendo no primeiro, a desprotonação da Emodina neutra $\left(p K_{a 1}=6.2 \pm 0.1\right)$ e no segundo, a desprotonação 
da forma aniônica $\left(p K_{a 2}=8.3 \pm 0.1\right)$.

\subsubsection{Medida do $p K_{\mathrm{a}}$ da Emodina em água}

Realizamos medidas dos espectros da Emodina em solução aquosa nas concentrações 0.1 e 0.025 mM. Para cada concentração, realizamos duas medidas independentes. A medida com a concentração de $0.025 \mathrm{mM}$ representa uma tentativa para reduzir o efeito de espalhamento de luz presente no espectro de absorção dessa molécula em água, causado, provavelmente por agregados da Emodina na amostra para $\mathrm{pH}<7$, como discutido com mais detalhes no apêndice A, seção A.4.

Na figura 4.4 são mostrados os espectros eletrônicos de absorção da Emodina em água nas concentrações 0.1 e $0.025 \mathrm{mM}$, para duas metodologias adotadas, sendo as figuras $4.4\left(\mathrm{a}_{\mathrm{i}}\right)$ e $\left(\mathrm{a}_{\mathrm{ii}}\right)$, as medidas originais e as figuras $4.4\left(\mathrm{~b}_{\mathrm{i}}\right)$ e $\left(\mathrm{b}_{\mathrm{ii}}\right)$, sendo os espectros subtraídos uma linha de base, como discutido abaixo e no apêndice A, seção A.4. Essa figura mostra que os espectros eletrônicos de absorção da Emodina em água são caracterizados por 3 bandas de absorção bastante dependentes do pH da solução. A primeira banda é observada na região de $600-450 \mathrm{~nm}$, a segunda dentro de $325-280$ nm, e a última em 270-245 nm.

Uma análise qualitativa da dependência dos espectros com o pH da solução mostra que eles são muito sensíveis a mudanças do $\mathrm{pH}$, pois com o aumento do $\mathrm{pH}$ é observado um deslocamento da primeira banda para região de maior comprimento de onda (menor energia) de aproximadamente $70 \mathrm{~nm}$, enquanto a segunda e terceira bandas mantêm-se praticamente na mesma posição. Esse comportamento é similar ao discutido anteriormente para os espectros da Emodina na mistura água e metanol (1:3 v/v), onde atribuímos esse comportamento aos processos de desprotonação dessa mo-

lécula em solução. É conhecido que a Emodina sofre desprotonação em $\mathrm{pH}<6$, sendo em solução ácida a Emodina encontra-se na forma neutra (EMH) e em solução alcalina encontra-se na forma desprotonada $\left(\mathrm{EM}^{-}\right)$, e em solução neutra encontra-se uma co- 
(i) $\mathrm{C}=0.1 \mathrm{mM}$

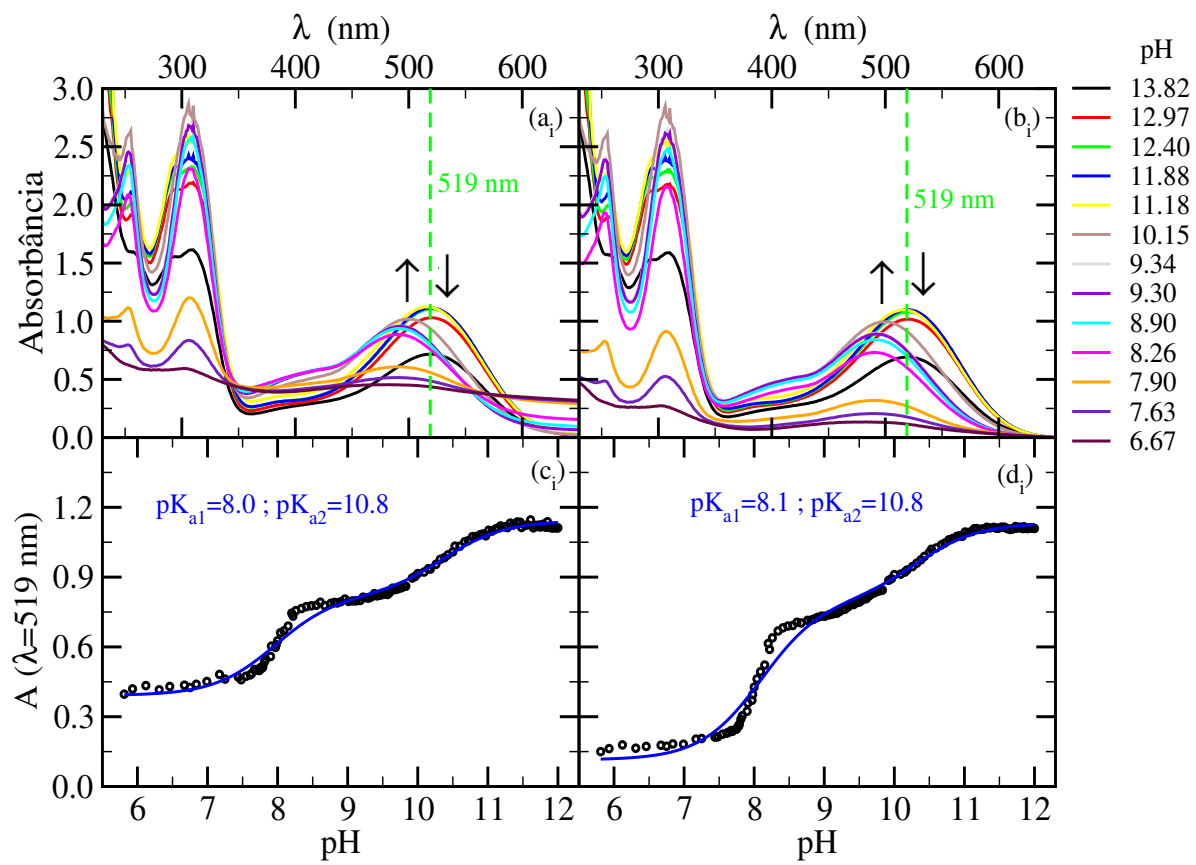

(ii) $\mathrm{C}=0.025 \mathrm{mM}$

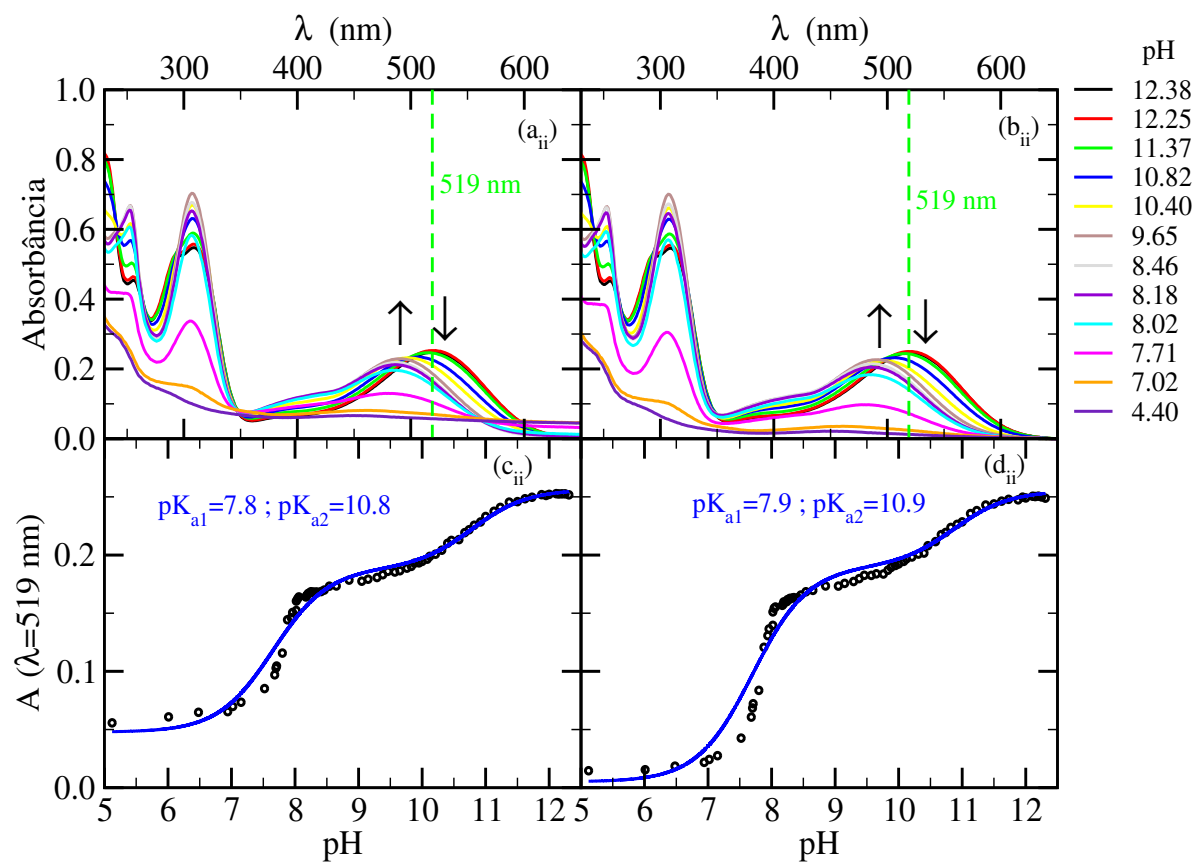

Figura 4.4: Efeito do pH nos espectros eletrônicos de absorção da Emodina em solução aquosa nas concentrações 0.1 e $0.025 \mathrm{mM}$. As figuras (a) e (c) são os dados experimentais sem nenhum tratamento; (b) e (d) são os dados depois da subtração de uma linha de base em $650 \mathrm{~nm}$. Nas figuras (c) e (d) está mostrado o efeito do pH na absorbância em $\lambda=519$ $\mathrm{nm}$, com os ajustes das curvas, considerando dois termos da equação 4.2. 
existência das duas formas $\left(\mathrm{EMH}+\mathrm{EM}^{-}\right)$. Desta forma, o deslocamento causado pelo aumento do pH da solução nos espectros é característico do processo de desprotonação da Emodina em solução, onde a molécula de Emodina perde um $\mathrm{H}^{+}$das hidroxilas, sofrendo portanto alteração na sua estrutura química, e consequentemente na sua estrutura eletrônica.

Como discutido acima, em solução ácida a Emodina encontra-se na forma neutra, $\mathrm{EMH}$, e de acordo com a figura 4.4, ela absorve luz na região de $450 \mathrm{~nm}$. Com o aumento do pH, a Emodina neutra sofre a desprotonação e deixa de absorver luz nessa região, e passa a absorver em regiões de maior comprimento de onda. Portanto em solução alcalina, a Emodina encontra-se na forma desprotonada, EM-' e absorve luz na região de 519 nm. A desprotonação da Emodina em solução tem sido fonte de discussão nos trabalhos de Pal e colaboradores [28] e Nguyen e colaboradores [29], onde estudaram esse processo de desprotonação da Emodina em solventes orgânicos.

Nas figuras $4.4\left(\mathrm{a}_{\mathrm{i}}\right)$ e $\left(\mathrm{a}_{\mathrm{ii}}\right)$ podemos ver que nos espectros para $\mathrm{pH}<7$, aparecem curvas de espalhamento de luz somadas aos espectros de absorção, que é provavelmente devido à presença de agregados da Emodina na amostra. Uma curva de espalhamento pode ser, em alguns casos, representada por uma função do tipo $a \lambda^{n}$, onde $a$ e $n$ são constantes. Efetuamos subtrações de algumas curvas do espectro por essa função e verificamos que as contantes apresentam uma dependência com o pH da solução, dificultando as análises. Devido a isso, decidimos subtrair um valor constante dos espectros, fazendo com que a absorbância em $\lambda=650 \mathrm{~nm}$ seja igual a zero, ou seja, $A(\lambda=650 \mathrm{~nm})=0$, como mostrado nas figuras $4.4\left(\mathrm{~b}_{\mathrm{i}}\right)$ e $\left(\mathrm{b}_{\mathrm{ii}}\right)$. Com essa subtração, verificamos para $\mathrm{pH}>7$ que as bandas de absorção ficaram mais bem definidas, porém para $\mathrm{pH}<7$, essas bandas não apresentaram melhoras significativas, indicando a persistência do espalhamento de luz.

Nas figuras 4.4 (c) e (d) estão mostradas as curvas da absorbância da Emodina versus $\mathrm{pH}$, em $\lambda=519 \mathrm{~nm}$. Uma análise qualitativa dessa figura mostra que a absor- 
(i) $\mathrm{C}=0.1 \mathrm{mM}$

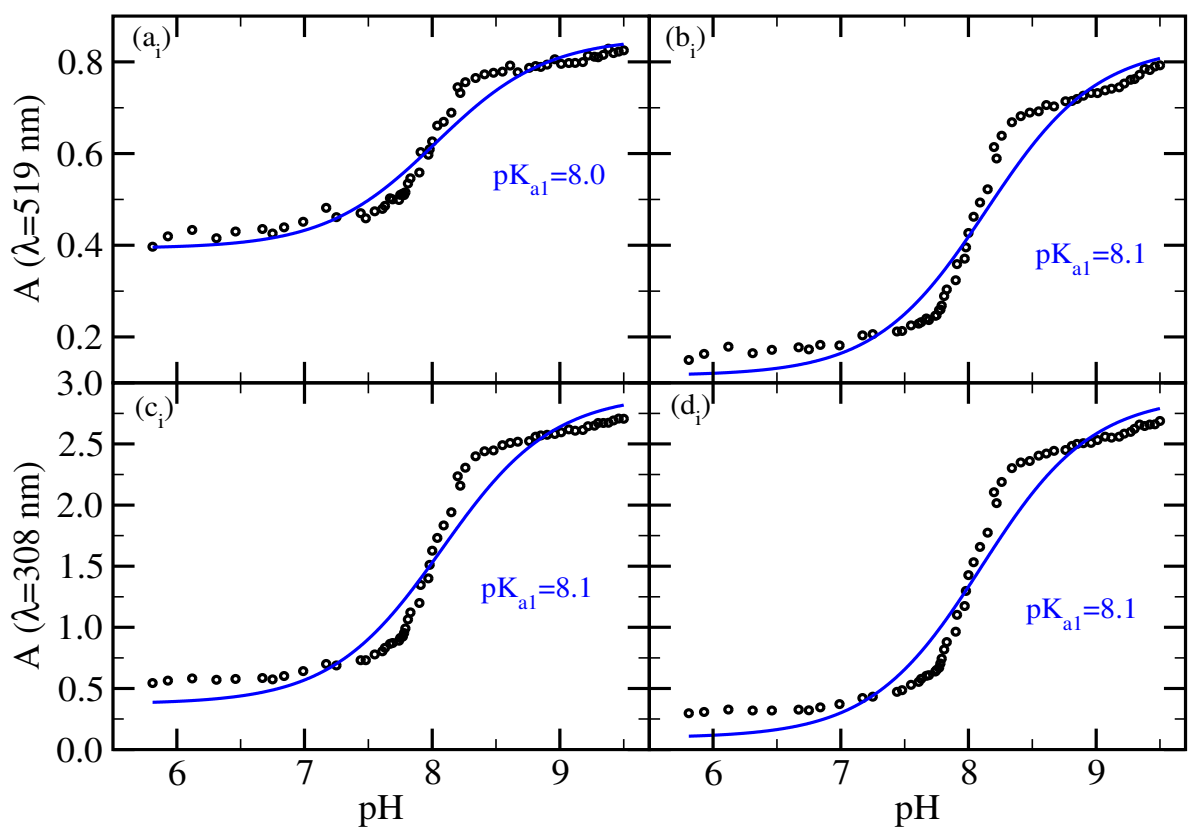

(ii) $\mathrm{C}=0.025 \mathrm{mM}$

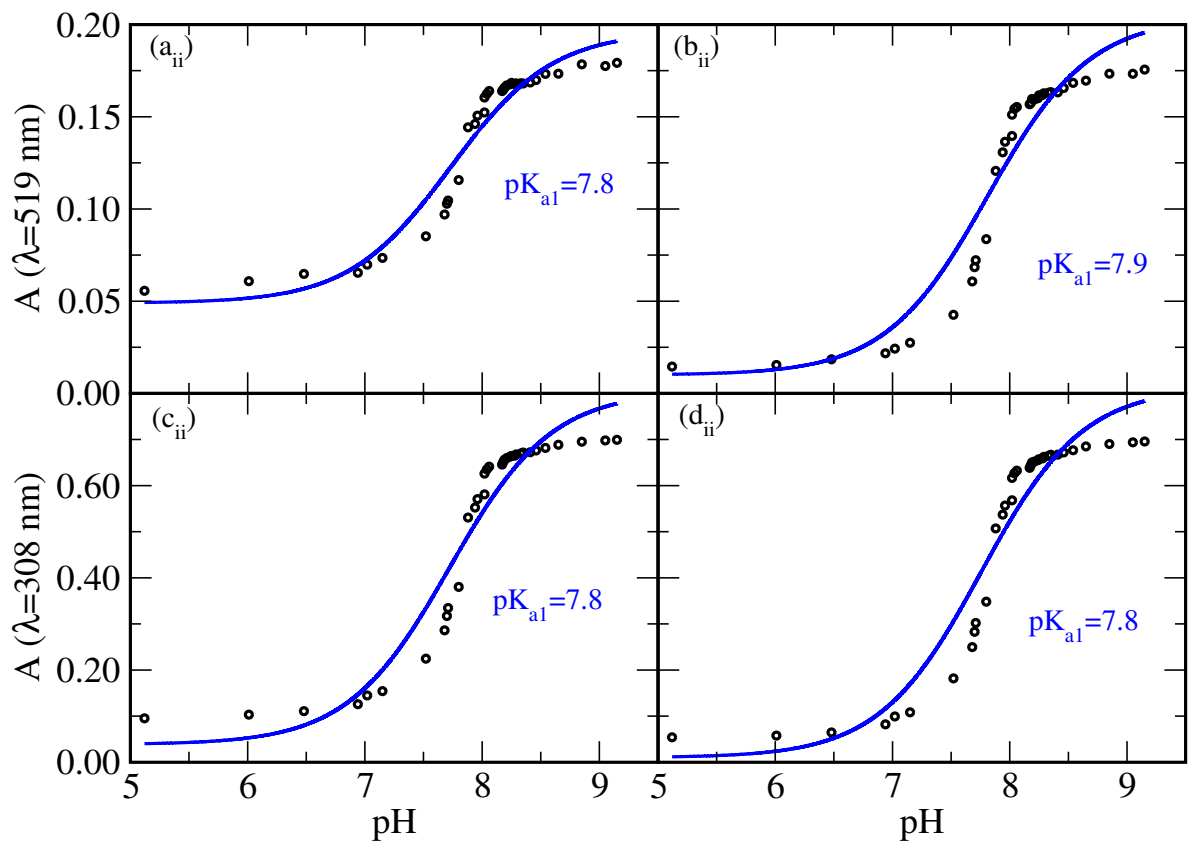

Figura 4.5: Efeito do pH na absorbância em $\lambda=519$ nm (a) e (b) e $\lambda=308$ nm (c) e (d), da Emodina em solução aquosa $0.025 \mathrm{mM}$, onde as figura (a) e (c) são as medidas experimentais sem nenhum tratamento e (b) e (d) depois da subtração de uma linha de base em $650 \mathrm{~nm}$. Nessas figuras estão mostrados também os ajustes das curvas, considerando um termo da equação 4.2 . 
bância da Emodina mantêm-se praticamente constante na região de $\mathrm{pH}<7.8$. Com o aumento do $\mathrm{pH}$ de 7.8 para 8.2 é observado um aumento súbito na absorbância, que está relacionado à primeira desprotonação, $p K_{\mathrm{a} 1}$ da Emodina. Aumentando o pH de 8.2 para 9.8 não é observada mudança significativa na absorbância. Aumentando o pH de 9.8 para 11.6 é observado mais um aumento, que está associado à segunda desprotonação, $\mathrm{pK}_{\mathrm{a} 2}$.

As constantes de acidez, $p K_{\mathrm{a} 1}$ e $p K_{\mathrm{a} 2}$ da Emodina em solução aquosa foram determinadas a partir do ajuste da absorbância em $\lambda=519$ nm (figuras 4.4 (c) e (d)) em função do pH, onde usamos dois termos da equação 4.2. O pK $\mathrm{a}_{\mathrm{a}}$, também foi determinado através do ajuste por um termo da equação 4.2 para variação da absorbância em $\lambda=519$ nm (figuras 4.5 (a) e (b)) e em $\lambda=308$ nm (figuras 4.5 (c) e (d) ) em função do pH. Esses ajustes foram feitos para as curvas do espectro da Emodina nas duas concentrações $0.1 \mathrm{mM}$ e $0.025 \mathrm{mM}$. Comparando esses ajustes da absorbância entre essas duas concentrações, observamos que eles apresentam o mesmo comportamento, pois tanto na figura 4.4 como na 4.5 , é observado que a equação 4.2 ajusta muito bem a absorbância para $\mathrm{pH}>9$, fornecendo valores confiáveis para o $\mathrm{pK}_{\mathrm{a} 2}$. Já para $\mathrm{pH}<9$, observamos uma diferença considerável entre a curva experimental e o ajuste pela equação de 4.2 , que será discutido a seguir.

Na tabela 4.4 listamos os valores obtidos para o $\mathrm{pK}_{\mathrm{a} 1}$ e $p K_{\mathrm{a} 2}$ determinados a partir dos ajustes da absorbância nos comprimentos de onda 519 e $308 \mathrm{~nm}$. Os ajustes da absorbância em $\lambda=519 n m$, foram feitos usando um e dois termos da equação HH, e em $\lambda=308 \mathrm{~nm}$, foram feitos usando apenas um termo dessa equação. Como podemos observar nessa tabela, a subtração das curvas do espectro por linhas de bases não provocou mudanças nos valores de $\mathrm{pK}_{\mathrm{a}}$, pois obtivemos praticamente os mesmos resultados com as medidas sem nenhum tratamento e com as medidas após a subtração de uma linha de base em $650 \mathrm{~nm}$. Os valores médios obtidos para o $\mathrm{pK}_{\mathrm{a} 1}$ e $\mathrm{pK}_{\mathrm{a} 2}$, determinados a partir dos ajustes da absorbância em $519 \mathrm{~nm}$ usando 
dois termos da equação 4.2 foram $\mathrm{pK}_{\mathrm{a} 1}=8.0(7.9) \pm 0.2$ e $\mathrm{pK}_{\mathrm{a} 2}=10.8(10.9) \pm 0.2$, onde em parêntese são os valores obtidos para a medida na concentração de Emodina 0.025 mM. Os valores obtidos para o $p K_{\mathrm{a} 1}$ a partir dos ajustes usando apenas um termo dessa equação em $519 \mathrm{~nm}$ foram de $\mathrm{pK}_{\mathrm{a} 1}=8.0(7.9) \pm 0.2$, que são praticamente os mesmos valores obtidos a partir dos ajustes da absorbância em 308 nm, onde determinamos o $\mathrm{pK}_{\mathrm{a} 1}=8.1(7.8) \pm 0.2$. Uma comparação desses valores nos mostra que as bandas de absorção da Emodina em $519 \mathrm{~nm}$ e $308 \mathrm{~nm}$ fornecem praticamente os mesmos valores para o $\mathrm{pK}_{\mathrm{a} 1}$, indicando que essas bandas devem estar acopladas, fornecendo assim, as mesmas informações para o equilíbrio químico da Emodina.

A tentativa de reduzir o efeito do espalhamento de luz nos espectros reduzindo a concentração de Emodina na amostra funcionou, porém não eliminou completamente esse efeito, principalmente para $\mathrm{pH}<8$, onde as curvas dos espectros aparecem somadas a perfis de espalhamento, como pode ser verificado nas figuras $4.4\left(b_{i}\right)$ e $\left(b_{i i}\right)$. Para essa região de $\mathrm{pH}$, registramos uma baixa qualidade dos ajustes da absorbância com a equação HH, isso ocorre, provavelmente, devido à presença de agregados de Emodina na amostra, que se formam devido ao caráter hidrofóbico dessa molécula. Essa precipitação apresenta uma dependência com o pH da solução, ela é observada para $\mathrm{pH}<8$. Assim, à medida que se reduz o $\mathrm{pH}$ da solução de 8.0 para valores mais baixos, é observado a formação de agregados de Emodina, que provavelmente são responsáveis pelo decaimento súbito da absorbância, o que dificulta o ajuste teórico. Como apresentado no apêndice A, seção A.2, a equação de Henderson-Hasselbalch adaptada para absorbância foi formulada a partir da combinação da equação original de HendersonHasselbalch com a lei de Lambert-Beer. Como apresentado na seção 2.3, essa lei é válida para soluções diluídas, sem a presença de agregados, ou fontes espalhadores de luz. Embora isso não explique, justifica a baixa qualidade do ajuste para região de $\mathrm{pH}<8$. 
Tabela 4.4: Valores do $p K_{\mathrm{a} 1}$ e $\mathrm{pK}_{\mathrm{a} 2}$ obtidos através das medidas dos espectros eletrônicos de absorção da Emodina em solução. Os valores em parênteses foram obtidos considerando a subtração da linha de base em $650 \mathrm{~nm}$ devido ao espalhamento de luz.

\begin{tabular}{cccc}
\hline \hline & & Abs.519nm & Abs.308nm \\
\hline Concentração(mM) & $p K_{\mathrm{a} 1}$ & $p K_{\mathrm{a} 2}$ & $\mathrm{pK}$ a1 \\
\hline 0.100 & $8.0 \pm 0.2$ & $10.8 \pm 0.2$ & $8.1 \pm 0.2$ \\
& $(8.1 \pm 0.2)$ & $(10.8 \pm 0.2)$ & $(8.1 \pm 0.2)$ \\
\hline 0.025 & $7.8 \pm 0.2$ & $10.8 \pm 0.2$ & $7.8 \pm 0.2$ \\
& $(7.9 \pm 0.2)$ & $(10.9 \pm 0.2)$ & $(7.8 \pm 0.2)$ \\
\hline \hline
\end{tabular}

Apesar da baixa qualidade do ajuste da absorbância da Emodina em água, os valores obtidos para o $\mathrm{pK}_{\mathrm{a} 1}$ estão em concordância com os valores esperados, porque o aumento súbito na absorbância na estreita faixa de $\mathrm{pH}$ entre 7.8 e 8.2, é bem definido em torno do $\mathrm{pH}=8.0$. Assim, os valores experimentais do $p K_{\mathrm{a} 1}$ e $p K_{\mathrm{a} 2}$ obtidos nesse trabalho são confiáveis, pois a comparação desses valores obtidos nas medidas com as concentrações 0.1 e $0.025 \mathrm{mM}$, mostra que eles são iguais, dentro de um erro de 0.1 unidade de $\mathrm{pK}_{\mathrm{a}}$. Na tabela 4.4 estão listados esses valores do $\mathrm{pK}_{\mathrm{a} 1}$ e $p K_{\mathrm{a} 2}$ obtidos para Emodina em solução aquosa nessas duas concentrações.

\subsubsection{Medida do $\mathrm{pK}_{\mathrm{a}}^{*}$ da Emodina em metanol}

Realizamos medidas dos espectros eletrônicos da Emodina em metanol na concentração $0.025 \mathrm{mM}$, a fim de determinar o $\mathrm{pK}_{\mathrm{a}}$ dessa molécula nesse solvente orgânico. É conhecido que a Emodina apresenta alta solubilidade em metanol, não apresentando nenhum vestígio de agregação, como foi observado em solução aquosa. Entretanto, diferentemente da água, o metanol é um solvente bastante volátil, apresentando uma taxa de evaporação muito grande comparado com a água. Devido a isso, a medida 
da titulação espectroscópica da Emodina nesse solvente exigiu um controle da evaporação do metanol. Embora, inicialmente, realizamos duas medidas sem preocupação com a evaporação do metanol, neste trabalho apresentaremos e discutiremos apenas as medidas realizadas com o controle da evaporação, mas as medidas sem o controle da evaporação estão apresentadas no apêndice A, para fins de comparação (veja nas figuras A.6 e A.7 uma comparação das medidas com e sem esse controle).

A metodologia usada aqui para minimizar a evaporação do metanol foi análoga à descrita na seção 3.3, com algumas modificações, como por exemplo, na solução inicial usamos um frasco cuja tampa tinha um orifício de diâmetro muito menor comparado ao diâmetro da tampa, onde era inserido o eletrodo do pHmetro, dificultando a evaporação de metanol durante a realização das medidas do $\mathrm{pH}_{\mathrm{ap}}$, e consequentemente evitando com isso mudanças na concentração da Emodina em solução. Além disso, aumentamos o volume da solução inicial ácida para $50 \mathrm{~mL}$ (nas medidas em meio aquoso foram usados $5 \mathrm{~mL}$ ). Portanto, nessas medidas, o volume inicial da solução ácida e alcalina foi de $50 \mathrm{~mL}$ e o $\mathrm{pH}_{\mathrm{ap}}$ da solução ácida foi ajustado acrescentando-se pequenas alíquotas da solução alcalina. O uso de volumes maiores foi importante na redução do efeito do aumento da concentração de Emodina, pois apesar de não conseguirmos reduzir totalmente a evaporação de metanol, o volume evaporado durante a medida foi desprezível comparado com o volume total, mantendo, portanto a concentração de Emodina em solução praticamente constante. Os resultados dessas medidas são apresentados e discutidos na escala de $\mathrm{pH}_{\mathrm{ap}}(\mathrm{pH}$ medido com pHmetro calibrado para água), e só os valores dos $p K_{\mathrm{a}}$ (na escala de $\mathrm{pH}_{\mathrm{ap}}$ ) foram corrigidos através da relação $p K_{\mathrm{a}}^{*}=p K_{\mathrm{a}}+2.3$, proposta por Ligny e colaboradores [264-266].

Na figura 4.6 apresentamos os espectros de absorção da Emodina em metanol na concentração de $0.025 \mathrm{mM}$. Uma análise desses espectros mostra que para valores de $\mathrm{pH}_{\text {ap }}$ abaixo de 8, os espectros são caracterizados por quatro bandas bem definidas, sendo a primeira banda na região de $500-375 \mathrm{~nm}$, a segunda na região de $322-273 \mathrm{~nm}$, 


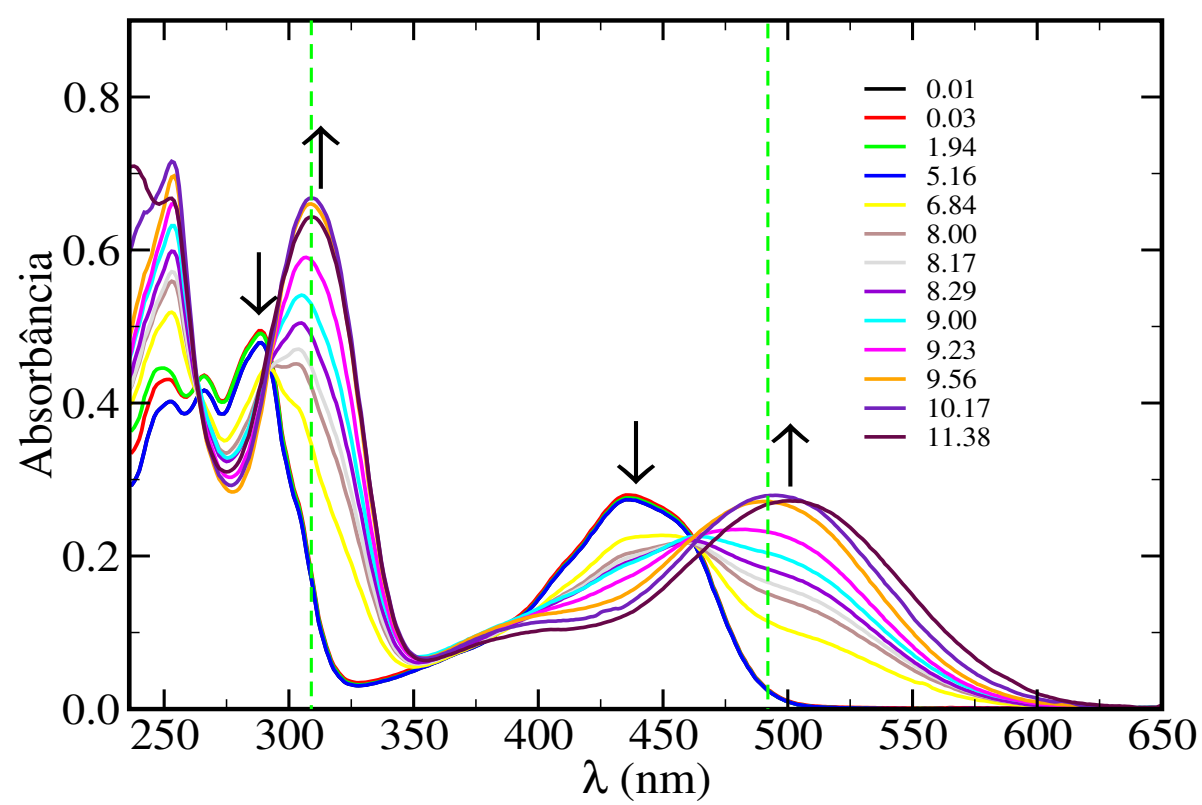

Figura 4.6: Efeito do $\mathrm{pH}_{\mathrm{ap}}$ no espectro eletrônico de absorção da Emodina em metanol na concentração de $0.025 \mathrm{mM}$.

a terceira na região de $273-257 \mathrm{~nm}$ e a quarta na região de $257-237 \mathrm{~nm}$. O espectro da Emodina, para $\mathrm{pH}_{\mathrm{ap}}>8$ é caracterizado apenas por 3 bandas de absorção bem definidas, sendo a primeira banda na região de 600-430 nm, a segunda na região de 350-275 nm e a terceira na região de $370-230 \mathrm{~nm}$. O efeito do $\mathrm{pH}_{\mathrm{ap}}$ na intensidade da primeira banda de absorção (figura 4.7 (a)) é análogo ao observado nos espectros medidos em solução aquosa (comparar com as figuras 4.4 (c) e (d)). Com o aumento do $\mathrm{pH}_{\mathrm{ap}}$ da solução é observado um deslocamento dessa primeira banda para a região de maior comprimento de onda (menor energia), que está associado ao fato da Emodina em solução de metanol a $\mathrm{pH}_{\mathrm{ap}}<8$ absorver luz na região de 500-375 nm e com o aumento do $\mathrm{pH}_{\mathrm{ap}}\left(\mathrm{pH}_{\mathrm{ap}}>8\right)$ ela passa à absorver luz na região de 600-430 nm. Esse comportamento é característico do processo de desprotonação da Emodina em solução alcalina, como discutido para a Emodina em solução aquosa na subseção 4.2.3.1.

Na figura 4.7 (a) apresentamos o efeito do $\mathrm{pH}_{\mathrm{ap}}$ na absorbância da Emodina em metanol em $\lambda=492 \mathrm{~nm}$. Uma análise da absorbância na faixa de $\mathrm{pH}_{\mathrm{ap}}$ entre 3 e 11, 


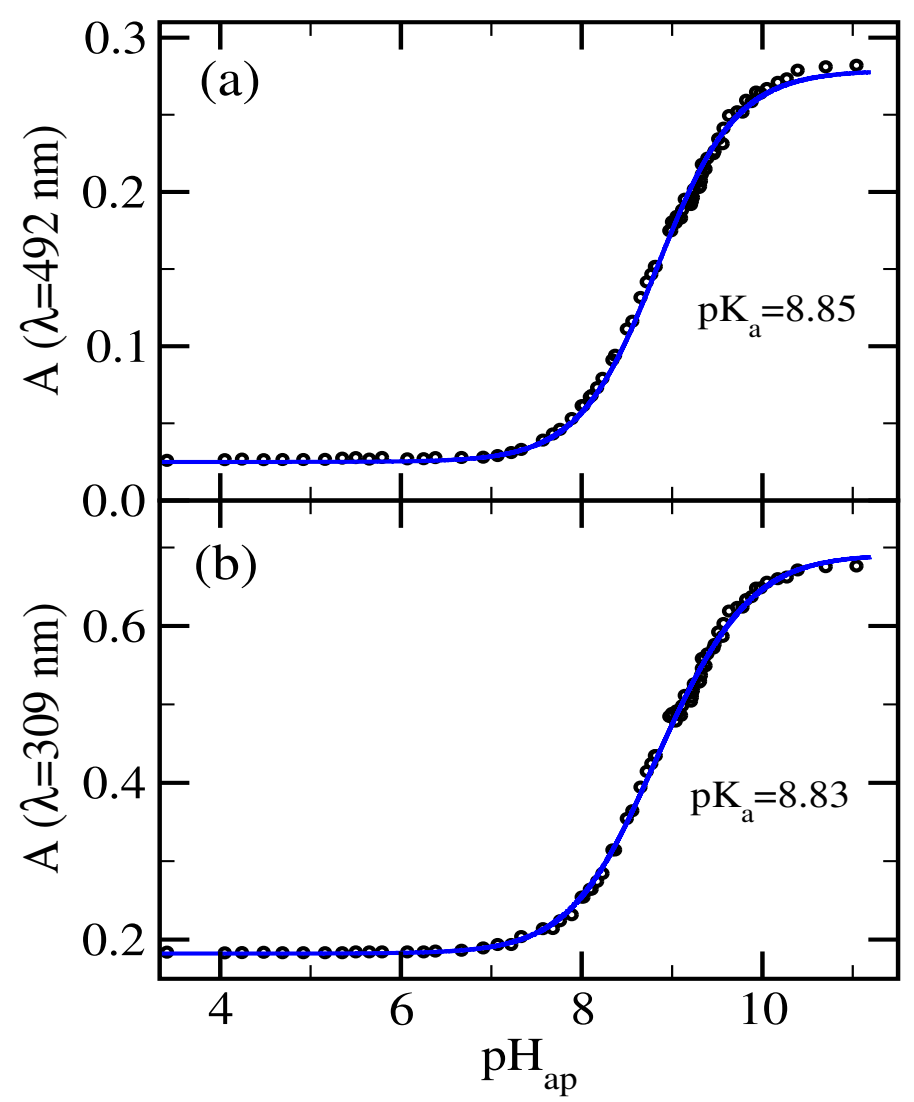

Figura 4.7: Efeito do $\mathrm{pH}_{\mathrm{a}}$ na absorbância da Emodina em metanol $(0.025 \mathrm{mM})$, em $\lambda=492$ nm (figura (a)) e em $\lambda=309 \mathrm{~nm}$ (figura (b)). Nessas figuras estão mostrados também os ajustes das curvas, considerando um termo da equação 4.2 .

mostra que existe apenas um forte aumento da absorbância na região de $\mathrm{pH}_{\mathrm{ap}}$ entre 8 e 10, caracterizando apenas a primeira desprotonação da Emodina nessa faixa de $\mathrm{pH}_{\mathrm{ap}}$. Isso indica que é possível caracterizar apenas o $\mathrm{pK}_{\mathrm{a} 1}$. O valor desse $p K_{\mathrm{a} 1}$ foi determinado a partir do ajuste da variação da absorbância em 492 nm usando um termo da equação 4.2. Como podemos observar na figura 4.7 (a), o ajuste ficou bom para descrever a absorbância em toda faixa de $\mathrm{pH}_{\mathrm{ap}}$ medido, apresentando assim uma qualidade melhor do que o ajuste em meio aquoso. Essa mesma análise também foi realizada para a segunda banda do espectro, ver a figura 4.7 (b), onde está mostrado o efeito do $\mathrm{pH}_{\mathrm{ap}}$ na absorbância da Emodina em $\lambda=309 \mathrm{~nm}$.

Uma comparação entre as figuras 4.7 (a) e (b), mostra que o efeito do $\mathrm{pH}_{\mathrm{ap}}$ 
na intensidade da primeira e segunda banda de absorção é similar. Portanto, essas duas bandas respondem da mesma forma à desprotonação da Emodina causada pela mudança do $\mathrm{pH}_{\mathrm{ap}}$ da solução. Os valores dos $p K_{\mathrm{a} 1}$ obtidos desses ajustes para as curvas da absorbância em 492 e 309 nm foram 8.85 e 8.83, respectivamente. Portanto o valor do $p K_{\mathrm{a} 1}$ da Emodina em metanol é $8.8 \pm 0.1$ determinado a partir da média desses dois valores.

Como em metanol trabalhamos na escala de $\mathrm{pH}$ aparente, $\mathrm{pH}_{\mathrm{ap}}$, o $p K_{\mathrm{a} 1}$ da Emodina determinado nesse solvente está nessa escala, e portanto requer uma correção através da relação $\mathrm{pK}_{\mathrm{a} 1}^{*}=\mathrm{pK}_{\mathrm{a} 1}+2.3$, para que tenha um significado termodinâmico, ou seja, uma relação com as concentrações dos íons $\mathrm{CH}_{3} \mathrm{OH}_{2}^{+}$e $\mathrm{CH}_{3} \mathrm{O}^{-}$. Aplicando essa correção, o valor determinado para o pK $\mathrm{p}_{\mathrm{a} 1}^{*}$ da Emodina em metanol é 11.1 \pm 0.1 . Analogamente em solução aquosa, essa constante apresenta a mesma informação do equilíbrio, que de acordo a equação convencional de Henderson-Hasselbalch, quando o $\mathrm{pH}^{*}=\mathrm{pK}_{\mathrm{a} 1}^{*}$, temos a igualdade das concentrações das espécies EMH e EM- em solução, veja a equação A.3 no apêndice A. Para mais informações de medidas de pH* em metanol, veja nosso texto [296], onde propomos, baseados nos trabalhos de Ligny e colaboradores [264-266] a escala de $\mathrm{pH}^{*}$ nesse solvente.

\subsubsection{Considerações parciais da desprotonação da Emodina}

Até o momento apresentamos os estudos teórico e experimental da desprotonação da Emodina. O estudo teórico mostrou, através de cálculos quânticos, que a primeira desprotonação da molécula Emodina ocorre na posição 3 (1,8-EM-), a segunda na

posição $8\left(1-\mathrm{EM}^{2-}\right)$ e a terceira na posição $1\left(\mathrm{EM}^{3-}\right)$, corroborando a sugestão de Pal e colaboradores.

Calculamos os valores de $p K_{\mathrm{a} 1}$ de desprotonação da Emodina em solução aquosa e em metanol através das metodologias MC-FEP e QM-PCM, descritos na seção 3.5. Nossos melhores valores dos $p K_{\mathrm{a} 1}$ da Emodina determinados nesses solventes foram 
$8.7 \pm 0.8(8.4 \pm 0.5)$ e $12.5 \pm 1.6(10.3 \pm 1.5)$, respectivamente, onde a sequência é referente às metodologias MC-FEP(QM-PCM). Esses valores estão em boa concordância com os valores experimentais obtidos nesta tese $\left(\mathrm{pK}_{\mathrm{a} 1}=8.0 \pm 0.2\right.$ e $\left.\mathrm{pK}_{\mathrm{a} 1}^{*}=11.1 \pm 0.1\right)$, com a diferença entre teórico e experimental de aproximadamente $0.7(0.4)$ e 1.4(0.8) unidades de $p K_{\mathrm{a}}$ para os solventes água e metanol, respectivamente. Portanto as duas metodologias MC-FEP e QM-PCM conseguem descrever bem os $p K_{\mathrm{a} 1}$ da Emodina em água e em metanol, porém, os valores obtidos com a metodologia QM-PCM estão em melhor concordância com os experimentais do que os obtidos com a MC-FEP. Portanto o esforço dedicado ao cálculo de $p K_{\mathrm{a}}$ com a metodologia MC-FEP é praticamente incompensável se comparado com a metodologia QM-PCM, que manteve seu compromisso de fornecer dados precisos para a solvatação de moléculas com baixo custo computacional.

É importante ressaltar que os valores teóricos do $p K_{\mathrm{a} 1}$ da Emodina em metanol, obtidos com as duas metodologias estão em melhor concordância com o valor experimental do $\mathrm{pK}_{\mathrm{a} 1}^{*}$ na escala de $\mathrm{pH}^{*}$, ou seja, com o valor corrigido de $11.1 \pm 0.1$, em vez de concordar com o valor do $p K_{\mathrm{a} 1}$ na escala de $p H_{\mathrm{ap}}$. Embora tenhamos determinado experimentalmente o $p K_{\mathrm{a} 2}$ da Emodina em água no valor de $10.8 \pm 0.2$, que está relacionado com a segunda desprotonação da Emodina, que pode ser na posição 1 ou 8, como discutido na seção 4.2.1, não determinamos aqui o valor teórico desse $p K_{\mathrm{a}}$.

Os valores teóricos e experimentais do $p K_{\mathrm{a} 1}$ da Emodina em água e metanol obtidos neste trabalho estão também coerentes com alguns trabalhos que determinaram essas propriedades em solventes orgânicos $[28,29]$. No trabalho de Pal e colaboradores [28], eles realizaram medidas do $p K_{\mathrm{a} 1}$ da Emodina em misturas de água (25\%) e metanol (75\%), e obtiveram o valor de 7.2. Porém, refizemos essas medidas da Emodina nessa mistura (ver seção 4.2.3), e mostramos que o melhor ajuste das curvas de titulação ocorre quando assumimos a existência de três sítios de desprotonação na molécula, ou seja, três constantes de acidez, que obtivemos nos valores de $p K_{a 1}=6.2 \pm 0.1$, 
$p K_{a 2}=8.3 \pm 0.1$ e $p K_{a 3}>12.7$. No trabalho de Pal, eles também testaram algumas condições, como por exemplo, mudanças nas concentrações do solvente, e observaram que aumentando a concentração de água na solução, o $p K_{\mathrm{a} 1}$ da Emodina é deslocado para regiões de valores mais baixos de $\mathrm{pH}$. Assim segundo essas observações, o $p K_{\mathrm{a} 1}$ da Emodina em água estaria abaixo de 7.2. Mas de acordo com nossos resultados, a melhor estimativa para o $p K_{\mathrm{a} 1}$ da Emodina em água é 8.0. Assim nossos resultados estão em contradição com os resultados do trabalho de Pal e colaboradores [28]. Entretanto, o valor do $p K_{\mathrm{a} 1}$ apresentado nesse trabalho está na escala de $\mathrm{pH}_{\mathrm{ap}}$, e portanto requer uma correção do tipo $p K_{\mathrm{a} 1}^{*}=p K_{\mathrm{a}}+\delta$, onde $\delta$, depende das proporções das misturas. Após a correção é esperado que o $p K_{\mathrm{a} 1}^{*}$ da Emodina na mistura de água e metanol se torne maior que 7.2 ou até mesmo maior que o $p K_{\mathrm{a} 1}$ da Emodina em água, pois $\delta>0$, de modo que ao reduzir a concentração de metanol na solução esperamos que $p K_{\mathrm{a} 1}^{*} \rightarrow p K_{\mathrm{a} 1}$. Nos livros de Bates [316] e Perrin e Dempsey [317] estão listados uma séries de valores para $\delta$ para mistura água/metanol, água/etanol e outras misturas.

Ressaltamos também que os valores obtidos para os $p K_{\mathrm{a} 1}$ da Emodina em água e em metanol estão coerentes com a relação proposta por Denison e Ramsey [318], e Gilkerson [319], que relaciona o $p K_{\mathrm{a}}$ de um dado composto em solução aquosa com $p K_{\mathrm{a}}^{\prime}$ desse mesmo composto em solventes orgânicos, através da seguinte equação,

$$
p K_{a}^{\prime}=p K_{a}+\frac{0.43 N_{a} e^{2}}{R T} \cdot \frac{Z_{1} Z_{2}}{r_{1}+r_{2}} \cdot \frac{1}{\varepsilon_{r}},
$$

onde $\mathrm{Z}_{1}$ e $\mathrm{Z}_{2}$ são os valores absolutos das cargas dos dois íons dos solventes, no caso água $\left(\mathrm{H}_{3} \mathrm{O}^{+}\right)$e metanol $\left(\mathrm{CH}_{3} \mathrm{OH}_{2}{ }^{+}\right) ; \mathrm{r}_{1}$ e $\mathrm{r}_{2}$ são os raios desses íons, e é carga de um elétron, $\varepsilon_{r}$ é constante dielétrica do solvente orgânico, $\mathrm{N}_{\mathrm{a}}$ é número de Avogadro, $\mathrm{R}$ constante universal dos gases ideias e T a temperatura. Assim, segundo a equação 4.3, a mudança de solvente de água $\left(\varepsilon_{\mathrm{r}}=78.4\right)$ para um solvente de menor constante dielétrica, por exemplo metanol $\left(\varepsilon_{\mathrm{r}}=32.7\right)$ provoca um aumento no valor do $p K_{\mathrm{a}}^{\prime}$. Portando de acordo com essa equação é esperado que o $p K_{\mathrm{a}}^{*}$ da Emodina em metanol seja maior do que o $p K_{\mathrm{a}}$ dessa molécula em água e isso está em concordância com 
nossos resultados obtidos neste trabalho.

\subsection{Efeito do ambiente no espectro de absorção}

Nesta seção apresentamos e discutimos nossas medidas do espectro eletrônico de absorção da Emodina em vários solventes e em bicamadas lipídicas, onde será caracterizado o efeito solvatocrômico da Emodina neutra e Emodina desprotonada nesses ambientes.

\subsubsection{Efeito do solvente no espectro de absorção}

Realizamos as medidas do espectro eletrônico de absorção da Emodina em solventes de diferentes polaridades (água, metanol, etanol, 2-propanol, acetonitrila, dimetilsulfóxido(DMSO), acetona, diclorometano, clorofórmio, dioxano e benzeno) a fim de caracterizar o efeito do ambiente nas propriedades eletrônicas dessa molécula. Os solventes listados estão apresentados de acordo com a escala de polaridade $\mathrm{E}_{\mathrm{T} 30}{ }^{2}$, cobrindo, portanto um grande intervalo de polaridade, sendo nos solventes que utilizamos, a água de maior polaridade e o benzeno o de menor. Essas medidas foram realizadas em três condições diferentes de pH: ácido, neutro e alcalino. Como apresentado anteriormente, a Emodina sofre processos de desprotonação em soluções neutras e alcalinas com solventes próticos, sendo em solução ácida encontra-se a Emodina neutra $(\mathrm{EMH})$, em solução alcalina encontra-se a Emodina na forma desprotonada, $\left(\mathrm{EM}^{-}\right)$, e em solução neutra encontra-se uma mistura de ambas as formas $\left(\mathrm{EMH}+\mathrm{EM}^{-}\right)$.

Na figura 4.8 mostramos o espectro eletrônico de absorção da Emodina neutra em solução ácida (mistura de hidroclorídrico/solvente (1:500 v:v)) nos solventes metanol, etanol, 2-propanol, acetonitrila e DMSO, e também em solução neutra nos solventes

\footnotetext{
${ }^{2} \mathrm{E}_{\mathrm{T} 30}$ é uma escala empírica de polaridade de solventes definida baseada no efeito solvatocrômico da molécula 6,6-difenil-4-(2,4,6-trifenil-1-1piridínio)-1-fenolato, conhecida como betaína 30 de Reichardt (B30). Para mais informação dessa escala, veja o capítulo 6 do livro do Reichardt [252].
} 


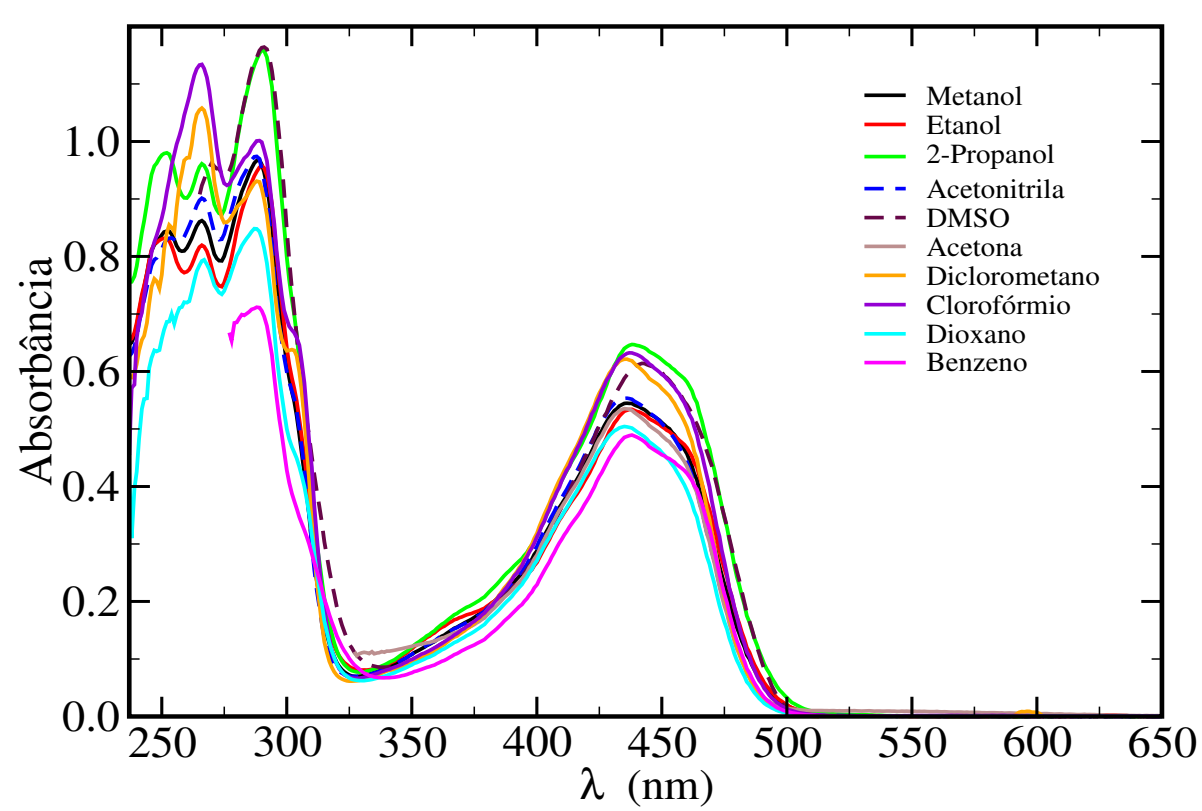

Figura 4.8: Espectro eletrônico de absorção da Emodina neutra (EMH) em solventes de diferentes polaridades, medidos nas condições normais de pressão e temperatura em solução ácida nos seguintes solventes: água, metanol, etanol, 2-propanol, acetonitrila e DMSO. Nessa figura estão mostrados também os espectros dessa molécula em acetona, diclorometano, clorofórmio, dioxano e benzeno. Os solventes estão organizados de acordo com a escala de polaridade $\mathrm{E}_{\mathrm{T} 30}$. A concentração usada para Emodina nesses solventes foi de $0.05 \mathrm{mM}$.

acetona, diclorometano, clorofórmio, dioxano e benzeno, todos com a concentração de Emodina de 0.05 mM. Nessa figura são identificadas 3 bandas de absorção, sendo a $1^{\mathrm{a}}$ banda na região de 500 a $350 \mathrm{~nm}$, com o máximo dessa banda em torno de $438 \pm 3$ nm, a segunda banda na região de 325 a $275 \mathrm{~nm}$, tendo o máximo dessa banda em torno de $290 \pm 5 \mathrm{~nm}$, e a terceira banda na região de 275 a $260 \mathrm{~nm}$, com o máximo dessa última banda em torno de $266 \pm 1 \mathrm{~nm}$. Os valores dos comprimentos de onda dos máximos das bandas para cada solvente estão mostrados na tabela 4.5. Na figura 4.8, pode-se observar que a mudança do solvente não provoca alterações significativas nas posições e formas das bandas de absorção, o que caracteriza que a estrutura eletrônica da Emodina neutra (EMH) é pouco sensível à mudança de ambientes. 


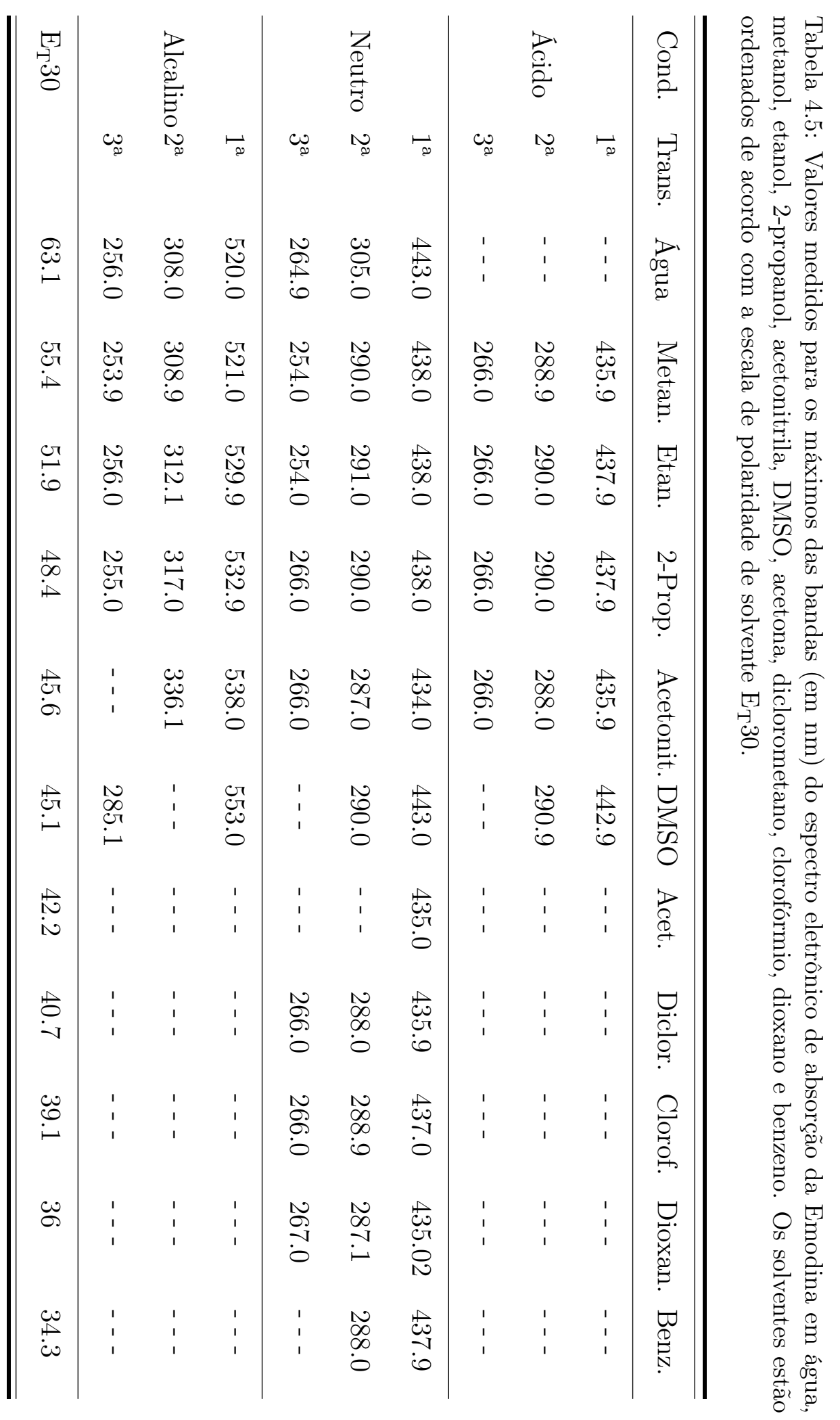




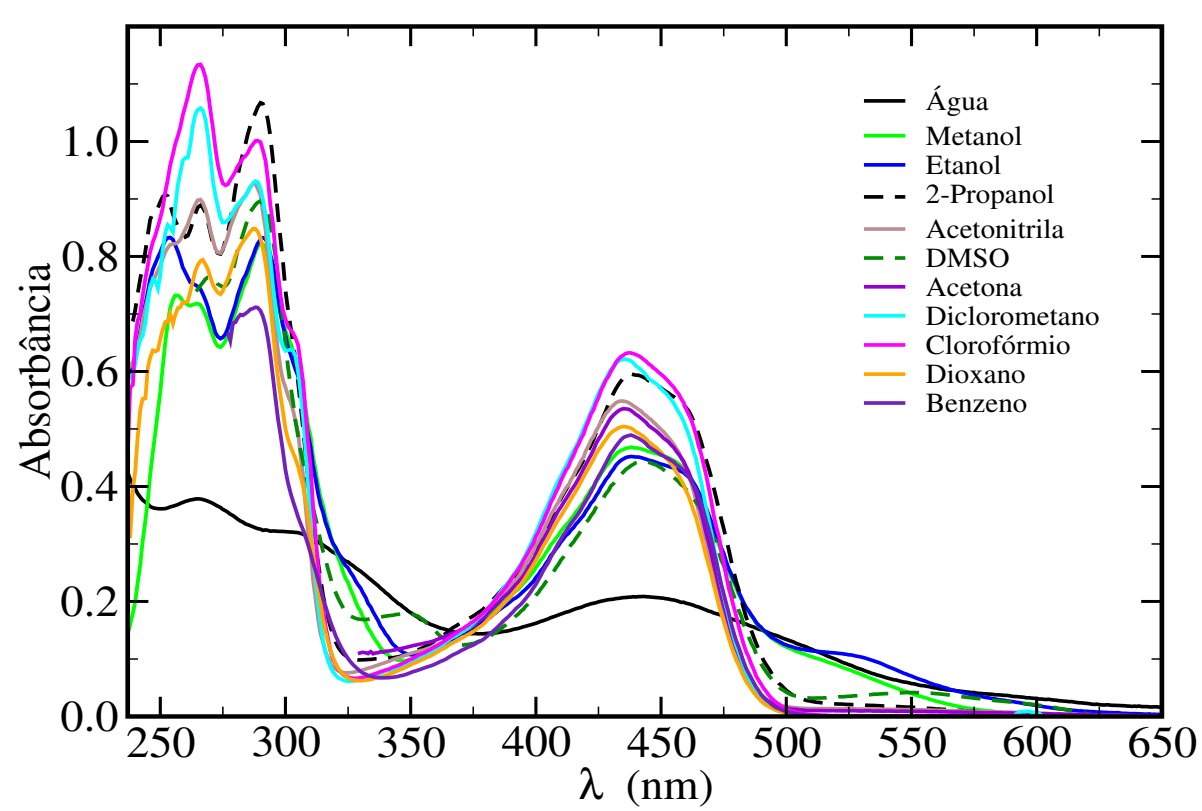

Figura 4.9: Espectro eletrônico de absorção da da mistura $\left(\mathrm{EMH}+\mathrm{EM}^{-}\right)$em solventes de diferentes polaridades, medidos nas condições normais de pressão e temperatura em solução neutra nos seguintes solventes: água, metanol, etanol, 2-propanol, acetonitrila, DMSO, acetona, diclorometano, clorofórmio, dioxano e benzeno. Os solventes estão organizados de acordo com a escala de polaridade $\mathrm{E}_{\mathrm{T}} 30$. A concentração usada para Emodina nesses solventes foi de $0.05 \mathrm{mM}$.

Como discutido na seção 4.2, a Emodina não é solúvel em solução aquosa ácida. Mostramos na figura 4.4, que nessas condições de pH, aparecem curvas de espalhamento de luz somadas aos espectros de absorção, que é provavelmente devido à presença de agregados na solução. Devido a isso, não mostramos o espectro dessa molécula em

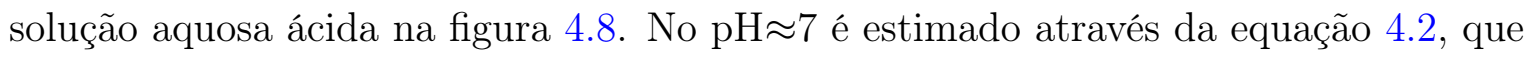
em solução aquosa existe uma mistura da $\operatorname{EMH}(94 \%)$ e $\operatorname{EM}^{-}(6 \%)$, e em metanol essas percentagens são 63 e 37\%, respectivamente, veja o espectro da Emodina em soluções neutras na figura 4.9. Uma comparação entre os espectros da EMH (figura 4.8) com os da mistura $\mathrm{EMH}+\mathrm{EM}^{-}$(figura 4.9), mostra que eles são bastante similares, visto que os espectros dessas figuras apresentam as mesmas característica de absorção da EMH. Entretanto, os espectros da mistura apresentam na região de 650 a $500 \mathrm{~nm}$ o surgimento de uma banda de absorção, sendo mais evidente nos solventes água, meta- 
nol, etanol e DMSO. Como discutido anteriormente, o surgimento dessa banda nessa região é devido ao processo de desprotonação da Emodina nessas soluções neutras com solventes polares, sendo que a mudança da Emodina de um meio ácido para neutro causa o processo de desprotonação dessa molécula $\left(\mathrm{EMH}+\mathrm{S} \rightarrow \mathrm{EM}^{-}+\mathrm{SH}^{+}\right)$onde $\mathrm{S}$ é a molécula do solvente.

Para os solventes apróticos (acetona, diclorometano, clorofórmio, dioxano e benzeno), os espectros eletrônicos de absorção apresentados nas figuras 4.8 e 4.9 são exclusivamente da EMH, sem qualquer vestígio de absorbância de $\mathrm{EM}^{-}$, uma vez que esses solventes apresentam baixa reatividade e também não é adicionado nenhum outro elemento reativo na solução a não ser a Emodina. Os espectros eletrônicos de absorção da Emodina nos solventes acetona, benzeno e DMSO foram interrompidos em 330, 280 e $265 \mathrm{~nm}$ devido às moléculas desses solventes absorverem luz para valores menores desses comprimentos de ondas.

Observamos na figura 4.8 que as intensidades de absorbâncias da EMH são sensíveis a mudanças do solvente, mas sem nenhuma relação com a polaridade do solvente, como mostrado na figura A.8 no apêndice A. Essas intensidades dependem apenas de alguns parâmetros específicos, tais como absortividade molar dessa molécula nesses solventes e também do grau de solubilidade da Emodina nesses solventes.

Na figura 4.10 está mostrado o espectro eletrônico de absorção da Emodina desprotonada $\left(\mathrm{EM}^{-}\right)$em solução alcalina (concentração de $\mathrm{NaOH}, 10.0 \mathrm{mM}$ ) nos solventes água, metanol, etanol, 2-propanol, acetonitrila e DMSO. Nessa figura são identificadas 3 bandas de absorção, sendo a $1^{\text {a }}$ banda na região de 625 a $450 \mathrm{~nm}$. A segunda banda está na região de 380 a 270 nm, e a terceira banda na região de 270 a 240 n (ver na tabela 4.5).

A figura 4.10 mostra que o espectro eletrônico de absorção da EM- é sensível à mudança de ambiente, apresentando alterações significativas nas posições das três primeiras bandas mais intensas com a mudança do solvente. Com o aumento da po- 


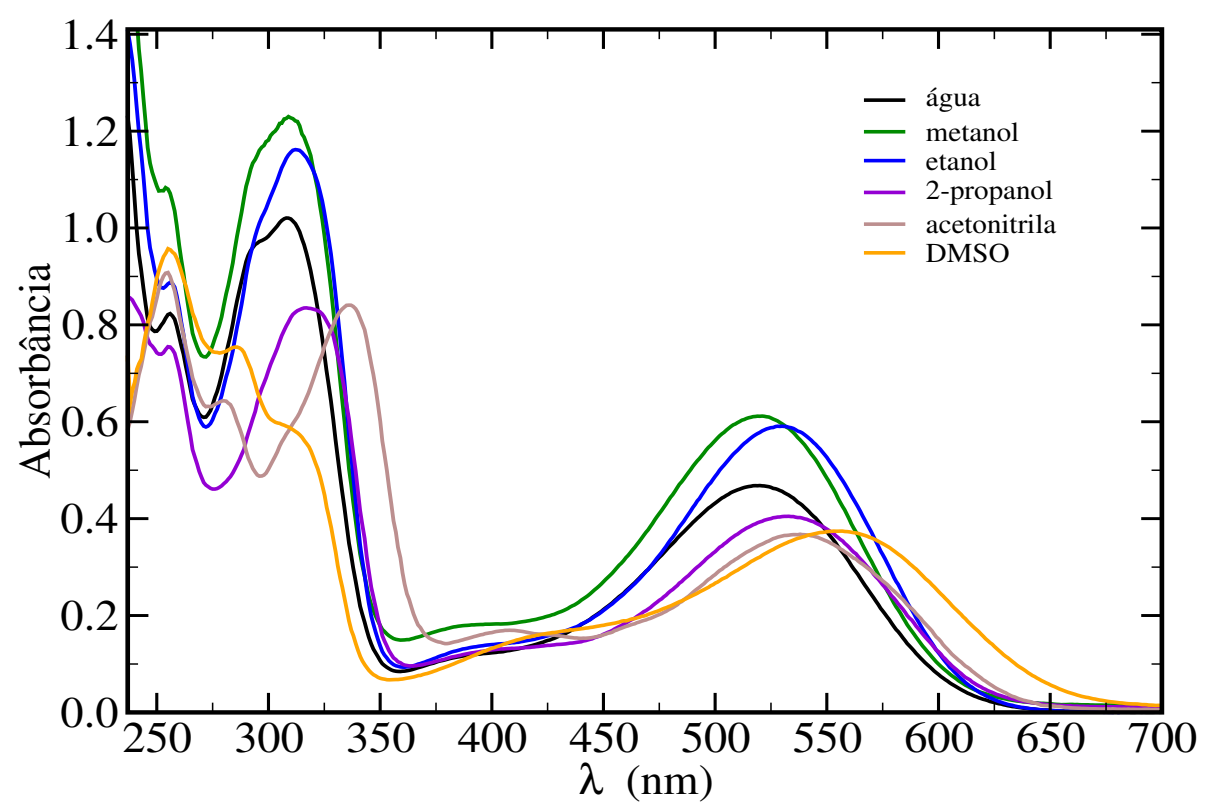

Figura 4.10: Espectro eletrônico de absorção da Emodina desprotonada $\left(\mathrm{EM}^{-}\right)$em solventes de diferentes polaridades, medidos nas condições normais de pressão e temperatura em solução alcalina nos seguintes solventes: água, metanol, etanol, 2-propanol, acetonitrila e DMSO. Os solventes estão organizados de acordo com a escala de polaridade $\mathrm{E}_{\mathrm{T}} 30$. a concentração usada para Emodina nesses solventes foi de $0.05 \mathrm{mM}$.

laridade do meio, por exemplo, de DMSO para água, é observado um deslocamento dessas bandas para região de menor comprimento de onda (maior energia) de aproximadamente $30 \mathrm{~nm}$ para as três bandas do espectro. Essa característica pode ser utilizada para indentificar a polaridade do meio em que essa molécula se encontra, por exemplo, em ambientes heterogêneos, como bicamadas lipídicas, pois é de nosso interesse identificar a localização dessa molécula em ambientes anfifílicos.

\subsubsection{Efeito da bicamada lipídica no espectro de absorção}

Nesta seção apresentamos e discutimos as medidas do espectro eletrônico de absorção das espécies da Emodina neutra e desprotonada em dispersões lipídicas de DMPC nas duas condições de $\mathrm{pH}$ : ácido $(\mathrm{pH}=6.0)$ e alcalino $(\mathrm{pH}=10.0)$, onde estão presentes as espécies EMH e EM-, respectivamente. Com essas medidas pretendemos 
caracterizar o efeito da bicamada lipídica nos espectros dessas espécies. Além disso pretendemos identificar o meio em que essas espécies se encontram, uma vez que lipídios em solução aquosa formam ambientes heterogêneos (bicamada lipídica hidratada).

Na figura 4.11 apresentamos os espectros eletrônicos das espécies da Emodina nos seguintes ambientes:(i) heterogêneos - Emodina nas dispersões lipídicas de DMPC em dois tampões diferentes, sendo um com $\mathrm{pH}=6.0$ e o outro com $\mathrm{pH}=10.0$; (ii) homogêneos - Emodina nesses tampões. Analisando essa figura, observamos que o espectro eletrônico da Emodina nas dispersões lipídicas no tampão $\mathrm{pH}=6.0$ é realmente característico da forma neutra, EMH. Isso está evidenciado pelas três bandas de absorção mais intensas do espectro absorvendo luz nas mesmas regiões de comprimento de onda da EMH, como comparado com a figura 4.8, onde a primeira banda absorve luz na região de 500 a $350 \mathrm{~nm}$, a segunda banda na região de 325 a $275 \mathrm{~nm}$, e a terceira banda na região de 275 a $260 \mathrm{~nm}$.

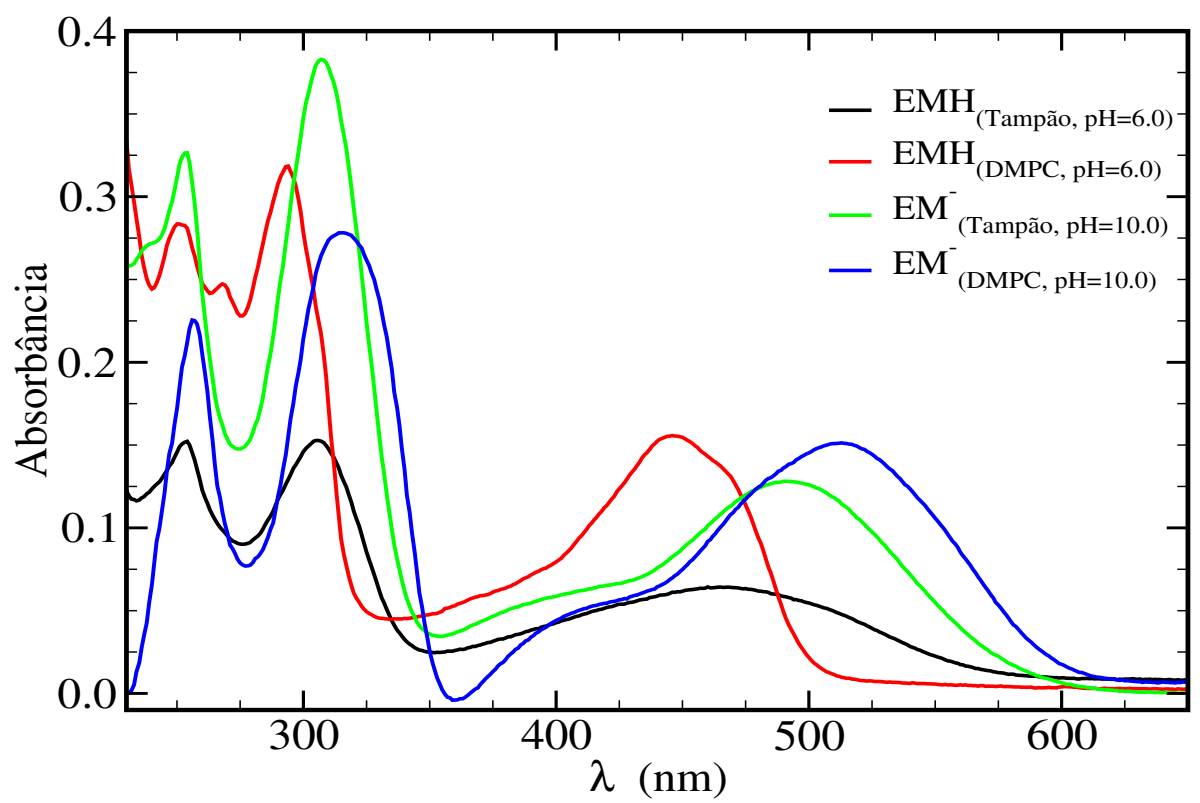

Figura 4.11: Espectro eletrônico de absorção da molécula de Emodina (0.025 mM) em dispersões lipídicas de DMPC (1 mM) nos tampões bifosfato/fosfato $(\mathrm{pH}=6.0)$ e bicarbonato/carbonato $(\mathrm{pH}=10.0)$. Estão também mostrados os espectros da Emodina nesses respectivos tampões. Todas as amostras foram extrusadas 31 vezes usando um filtro de $100 \mathrm{~nm}$. 
Na figura 4.11 é possível observar que as bandas de absorção do espectro eletrônico da Emodina em bicamada lipídica são mais bem definidas do que no tampão $\mathrm{pH}=6.0$. Nesse tampão o espectro da Emodina apresenta um perfil de espalhamento de luz devido à agregação dessa molécula, como discutido anteriormente. Além disso, esse espectro mostra vestígio da presença da Emodina desprotonada, visto que a primeira banda de absorção da Emodina nesse tampão é muito larga, ela inicia em $550 \mathrm{~nm}$ e termina em 350 nm, contemplando a região de absorção da forma desprotonada, EMPorém o espectro da Emodina nas dispersões lipídicas no tampão pH=6.0 não apresenta característica de espalhamento de luz, indicando que a Emodina em bicamada lipídica está predominante na forma monomérica, apresentando o mesmo espectro obtido para solventes orgânicos apróticos. Além disso, uma análise desse espectro nos mostra que não existe nenhum vestígio da presença da Emodina desprotonada nas dispersões lipídicas, o que nos leva a concluir que a Emodina neutra está inserida na bicamada lipídica.

Na figura 4.11 apresentamos também o espectro eletrônico da Emodina nas dispersões lipídicas de DMPC no tampão $\mathrm{pH}=10.0$. Uma comparação dessa figura com a figura 4.10 mostra que a curva do espectro da Emodina nessas dispersões lipídicas é análoga aos espectros da Emodina em solução alcalina, ou seja, da Emodina desprotonada, onde esse espectro é caracterizado por 3 bandas de absorção intensas, sendo a primeira banda na região de 625 a $450 \mathrm{~nm}$, a segunda banda na região de 360 a $270 \mathrm{~nm}$, e a terceira banda na região de 270 a $240 \mathrm{~nm}$ (ver tabela 4.6, onde apresentamos os valores dos comprimentos de onda para os máximos dessas bandas). Portanto, o espectro mostrado nessa figura da Emodina nas dispersões lipídicas em tampão $\mathrm{pH}=10.0$ é característico da Emodina desprotonada, e uma comparação com o espectro dessa molécula no tampão $\mathrm{pH}=10.0$, mostra que as bandas de absorção do espectro da $\mathrm{EM}^{-}$nas dispersões sofrem deslocamentos para região de maior comprimento de onda (menor energia), caracterizando que essa espécie está em um ambiente 
de polaridade menor do que da água, visto que o tampão $\mathrm{pH}=10.0$ consiste da mistura de água com carbonato e bicarbonato como apresentado na seção 3.3.

Tabela 4.6: Valores medidos para os máximos das bandas (em nm) do espectro eletrônico de absorção da Emodina em bicamada lipídica de DMPC nos tampões fosfato/bifosfato [10mM] $(\mathrm{pH}=6.0)$ e carbonato/bicarbonato $[10 \mathrm{mM}](\mathrm{pH}=10.0)$, e os valores nesses respectivos tampões.

\begin{tabular}{lllll}
\hline \hline Transição & $\begin{array}{l}\text { DMPC } \\
(\mathrm{pH}=6.0)\end{array}$ & $\begin{array}{l}\text { DMPC } \\
(\mathrm{pH}=10.0)\end{array}$ & $\begin{array}{l}\text { Tampão } \\
(\mathrm{pH}=6.0)\end{array}$ & $\begin{array}{l}\text { Tampão } \\
(\mathrm{pH}=10.0)\end{array}$ \\
\hline $1^{\mathrm{a}}$ & 446.1 & 512.9 & 460.0 & 491.0 \\
$2^{\mathrm{a}}$ & 294.0 & 314.0 & 306.0 & 307.0 \\
$3^{\mathrm{a}}$ & 268.0 & 256.1 & 254.0 & 254.0 \\
$4^{\mathrm{a}}$ & 250.1 & --- & $-\ldots$ &.-- \\
\hline \hline
\end{tabular}

Assim, a Emodina desprotonada não se encontra na região da água, e pouco provávelmente numa região de baixa polaridade como a região das cadeias hidrocarbônicas, mas numa região de polaridade intermediária como a região das cabeças dos lipídios. Isso é sustentado através do deslocamento para o vermelho da primeira banda do espectro causado pela mudança de ambiente de dispersões lipídicas para tampão, que é característico de um deslocamento causado pela mudança de água para um solvente de polaridade entre acetonitrila e DMSO, como mostrado na figura 4.10. Assim essas medidas representam a primeira indicativa que a espécie da Emodina desprotonada se encontra também inserida na bicamada lipídica, na região das cabeças polares dos lipídios, visto que o comprimento de onda máximo da primeira banda de absorção da EM$^{-}$em bicamada lipídica apresenta um desvio para região do vermelho de aproximadamente $22 \mathrm{~nm}$, que é aproximadamente o mesmo valor encontrado na mudança do 
solvente, água $\rightarrow$ acetonitrila ( $18 \mathrm{~nm})$. Assim, a comparação do espectro da Emodina em tampão e em dispersões lipídicas indicam que ambas espécies EMH e EM- estão inseridas na bicamada lipídica, numa região com polaridade equiparável à do etanol (glicerol). Isso fica evidente na comparação do espectro da Emodina em solvente e em dispersões lipídicas, mostrada na figura A.9 no apêndice A.

\subsubsection{Cálculo do Espectro eletrônico de absorção das espécies}

Como apresentado no capítulo 1, seção 1.1, foi realizado na dissertação de mestrado [32] um estudo teórico do espectro da Emodina neutra (EMH), onde foram realizados cálculos do espectro eletrônico de absorção dessa molécula utilizando o método INDO/CIS [320] com parametrização espectroscópica implementado no programa ZINDO [321]. Esses cálculos foram realizados com EMH isolada e em meio solvente com a descrição do solvente através do modelo contínuo (SCRF). Os principais resultados obtidos desse estudo mostraram que o espectro de absorção da EMH é pouco sensível ao ambiente, pois os valores teóricos obtidos para os máximos das cinco primeiras bandas do espectro dessa molécula isolada e em solução aquosa, em clorofórmio e em metanol foram 443, 350, 321, 291 e $258 \mathrm{~nm}$, todos com um desvio menor que 2 $\mathrm{nm}$, como sumarizado na tabela 1.2. Esse estudo foi complementado com as medidas do espectro dessa molécula nesses solventes, onde apresentaram excelente concordância com esses resultados teóricos (compare os valores das tabelas 1.1 e 1.2), levando a conclusão que a estrutura eletrônica da EMH não é muito sensível ao efeito do solvente e, portanto o espectro eletrônico de absorção não é uma boa propriedade para identificar mudanças do ambiente molecular dessa molécula.

Embora tenhamos realizado na dissertação de mestrado medidas do espectro eletrônico de absorção da Emodina desprotonada em água e em metanol, não fizemos nenhum estudo teórico do espectro dessa espécie em solução. Assim, dando continuidade a esse estudo, nesta tese de doutorado realizamos cálculos do espectro eletrônico 
de absorção da EM- e EMH isoladas e em meio solvente utilizando o método TDB3LYP $/ 6-311++\mathrm{G}^{* *}$, com a descrição do solvente com o modelo contínuo polarizável (PCM). A razão pela qual esse método foi escolhido para calcular essa propriedade se deve principalmente a trabalhos que mostraram que esse método determina com boa precisão o espectro da Emodina em solução [29,37].

Na tabela 4.7 apresentamos um sumário dos valores calculados para os máximos das 4 bandas mais intensas do espectro de absorção das espécies EMH e EM- isoladas e nos solventes água, metanol, acetonitrila e DMSO. Essa tabela mostra que a primeira banda de absorção dessas espécies envolve os orbitais moleculares HOMO $(\mathrm{H})$ e LUMO (L), onde HOMO é o orbital mais alto ocupado e o LUMO é o orbital mais baixo desocupado. Como mostrado nessa tabela, essa primeira banda de absorção nas espécies EMH e EM- é devida principalmente à transição $\mathrm{H} \rightarrow \mathrm{L}$, onde caracterizamos cerca de 85 e $80 \%$ de ocorrência dessa transição nessa banda nas espécies isoladas e em meio solvente. Como podemos observar na figura 4.12, os orbitais HOMO e LUMO nas espécies da Emodina, gerados com o método B3LYP/6-311++ $\mathrm{G}^{* *}$, estão perpendiculares ao plano das espécies e estão delocalizados sobre toda molécula. Sendo assim, considerando tais características classificamos esses orbitais moleculares do tipo $\pi$ e $\pi^{*}$, caracterizando assim a primeira transição como $\pi \rightarrow \pi^{*}$. 
Tabela 4.7: Valores calculados para os máximos das bandas dos espectros eletrônico de absorção das espécies EMH e EM- nos solventes água, metanol, acetonitrila e DMSO, com o solvente descrito com o modelo contínuo polarizável (PCM). Nessa tabela apresentamos também essas propriedades calculadas com essas espécies isolada e em solução aquosa, com as moléculas de água tratadas como cargas pontuais (CP), de 75 configurações obtidas de simulações computacionais (ver mais detalhes no texto). Os espectros foram calculados com o método TD-B3LYP $/ 6-311++\mathrm{G}^{* *}$.

\begin{tabular}{|c|c|c|c|c|c|c|}
\hline \multicolumn{4}{|c|}{ EMH } & \multicolumn{3}{|c|}{$\mathrm{EM}^{-}$} \\
\hline Ambiente & Transi. & Contrib. & F. Osc. & Trans. & Contrib. & F. Osc. \\
\hline \multirow{4}{*}{$\begin{array}{l}\text { Água } \\
\text { (PCM) }\end{array}$} & 447.4 & $\mathrm{H} \rightarrow \mathrm{L}(86 \%)$. & 0.23 & 551.7 & $\mathrm{H} \rightarrow \mathrm{L}(83 \%)$ & 0.12 \\
\hline & 315.3 & $\mathrm{H}-4 \rightarrow \mathrm{L}(83 \%)$. & 0.15 & 410.1 & $\mathrm{H}-1 \rightarrow \mathrm{L}(89 \%)$. & 0.13 \\
\hline & 285.0 & $\mathrm{H} \rightarrow \mathrm{L}+1(87 \%)$ & 0.20 & 330.6 & $\begin{array}{l}\mathrm{H}-4 \rightarrow \mathrm{L}(39 \%) \\
\mathrm{H} \rightarrow \mathrm{L}+1(39 \%)\end{array}$ & 0.14 \\
\hline & 258.8 & $\mathrm{H}-2 \rightarrow \mathrm{L}+1(81 \%)$ & 0.34 & 308.4 & $\begin{array}{l}\mathrm{H}-4 \rightarrow \mathrm{L}(28 \%) \\
\mathrm{H} \rightarrow \mathrm{L}+1(44 \%)\end{array}$ & 0.50 \\
\hline \multirow{4}{*}{$\begin{array}{l}\text { Metanol } \\
(\mathrm{PCM})\end{array}$} & 446.9 & $\mathrm{H} \rightarrow \mathrm{L}(86 \%)$ & 0.23 & 553.4 & $\mathrm{H} \rightarrow \mathrm{L}(83 \%)$ & 0.12 \\
\hline & 315.1 & $\mathrm{H}-4 \rightarrow \mathrm{L}(83 \%)$. & 0.15 & 410.3 & $\mathrm{H}-1 \rightarrow \mathrm{L}(89 \%)$. & 0.13 \\
\hline & 285.9 & $\mathrm{H} \rightarrow \mathrm{L}+1(87 \%)$ & 0.20 & 330.5 & $\begin{array}{l}\mathrm{H}-5 \rightarrow \mathrm{L}(46 \%) \\
\mathrm{H} \rightarrow \mathrm{L}+1(42 \%)\end{array}$ & 0.15 \\
\hline & 258.8 & $\mathrm{H}-2 \rightarrow \mathrm{L}+1(81 \%)$ & 0.33 & 308.4 & $\begin{array}{l}\mathrm{H}-5 \rightarrow \mathrm{L}(37 \%) \\
\mathrm{H} \rightarrow \mathrm{L}+1(41 \%)\end{array}$ & 0.50 \\
\hline \multirow{4}{*}{$\begin{array}{l}\text { Acetonit. } \\
\text { (PCM) }\end{array}$} & 447.1 & $\mathrm{H} \rightarrow \mathrm{L}(86 \%)$. & 0.23 & 553.5 & $\mathrm{H} \rightarrow \mathrm{L}(83 \%)$. & 0.12 \\
\hline & 315.2 & $\mathrm{H}-4 \rightarrow \mathrm{L}(83 \%)$. & 0.15 & 410.4 & $\mathrm{H}-1 \rightarrow \mathrm{L}(89 \%)$ & 0.13 \\
\hline & 286.0 & $\mathrm{H} \rightarrow \mathrm{L}+1(87 \%)$ & 0.20 & 330.6 & $\begin{array}{c}\mathrm{H}-5 \rightarrow \mathrm{L}(46 \%) \\
\mathrm{H} \rightarrow \mathrm{L}+1(42 \%)\end{array}$ & 0.15 \\
\hline & 258.8 & $\mathrm{H}-2 \rightarrow \mathrm{L}+1(81 \%)$ & 0.34 & 308.6 & $\begin{array}{l}\mathrm{H}-5 \rightarrow \mathrm{L}(37 \%) \\
\mathrm{H} \rightarrow \mathrm{L}+1(41 \%)\end{array}$ & 0.50 \\
\hline
\end{tabular}


Continuação da tabela 4.7

\begin{tabular}{|c|c|c|c|c|c|c|}
\hline \multirow[b]{2}{*}{ Ambiente } & \multicolumn{3}{|c|}{ EMH } & \multicolumn{3}{|c|}{$\mathrm{EM}^{-}$} \\
\hline & Transi. & Contrib. & F. Osc. & Trans. & Contrib. & F. Osc. \\
\hline \multirow{4}{*}{$\begin{array}{l}\text { DMSO } \\
(\mathrm{PCM})\end{array}$} & 448.9 & $\mathrm{H} \rightarrow \mathrm{L}(87 \%)$ & 0.25 & 555.5 & $\mathrm{H} \rightarrow \mathrm{L}(84 \%)$ & 0.13 \\
\hline & 316.1 & $\mathrm{H}-4 \rightarrow \mathrm{L}(84 \%)$. & 0.17 & 411.3 & $\mathrm{H}-1 \rightarrow \mathrm{L}(89 \%)$ & 0.15 \\
\hline & 286.6 & $\mathrm{H} \rightarrow \mathrm{L}+1(88 \%)$ & 0.22 & 331.2 & $\begin{array}{l}\mathrm{H}-5 \rightarrow \mathrm{L}(44 \%) \\
\mathrm{H} \rightarrow \mathrm{L}+1(44 \%)\end{array}$ & 0.17 \\
\hline & 259.4 & $\mathrm{H}-2 \rightarrow \mathrm{L}+1(83 \%)$ & 0.35 & 309.9 & $\begin{array}{l}\mathrm{H}-5 \rightarrow \mathrm{L}(38 \%) \\
\mathrm{H} \rightarrow \mathrm{L}+1(41 \%)\end{array}$ & 0.50 \\
\hline \multirow{4}{*}{ Isolada } & 434.8 & $\mathrm{H} \rightarrow \mathrm{L}(84 \%)$ & 0.19 & 620.9 & $\mathrm{H} \rightarrow \mathrm{L}(80 \%)$ & 0.06 \\
\hline & 306.6 & $\mathrm{H}-4 \rightarrow \mathrm{L}(80 \%)$. & 0.11 & 431.8 & $\mathrm{H}-2 \rightarrow \mathrm{L}(85 \%)$. & 0.06 \\
\hline & 282.7 & $\mathrm{H} \rightarrow \mathrm{L}+1(86 \%)$ & 0.10 & 350.3 & $\mathrm{H} \rightarrow \mathrm{L}+1(77 \%)$ & 0.30 \\
\hline & 255.2 & $\mathrm{H}-2 \rightarrow \mathrm{L}+1(72 \%)$ & 0.25 & 285.1 & $\begin{array}{l}\mathrm{H} \rightarrow \mathrm{L}+3(18 \%) \\
\mathrm{H} \rightarrow \mathrm{L}+5(32 \%)\end{array}$ & 0.08 \\
\hline \multirow{4}{*}{$\begin{array}{l}\text { Água } \\
(\mathrm{CP})\end{array}$} & 439.9 & $\mathrm{H} \rightarrow \mathrm{L}(82 \%)$ & 0.17 & 518.7 & $\mathrm{H} \rightarrow \mathrm{L}(81 \%)$ & 0.10 \\
\hline & 312.0 & $\mathrm{H}-3 \rightarrow \mathrm{L}(81 \%)$. & 0.10 & 345.5 & $\mathrm{H}-3 \rightarrow \mathrm{L}(80 \%)$. & 0.08 \\
\hline & 276.6 & $\mathrm{H} \rightarrow \mathrm{L}+1(88 \%)$ & 0.15 & 295.4 & $\mathrm{H} \rightarrow \mathrm{L}+1(76 \%)$ & 0.40 \\
\hline & 251.1 & $\mathrm{H}-2 \rightarrow \mathrm{L}+1(74 \%)$ & 0.23 & 271.8 & $\mathrm{H}-1 \rightarrow \mathrm{L}+1(85 \%)$. & 0.14 \\
\hline
\end{tabular}

Mostramos no capítulo 2, que o método B3LYP está fundamentado na densidade eletrônica do sistema, e não na função de onda, como o método HF e os métodos correlacionados pós-HF (teoria de perturbação de Møller-Plesset(MPn) [150], método 
de interação de configuração (CI) [151-153], os métodos Coupled-Cluster(CC)) [154]. Assim, é esperado que o B3LYP não descreva bem os orbitais moleculares. Para uma melhor descrição dos orbitais moleculares da EMH e EM-, realizamos um cálculo com o método CIS $/ 6-311++\mathrm{G}^{* *}$. Os orbitais obtidos com esse método apresentam as mesmas características dos obtidos com o método B3LYP/6-311 $++\mathrm{G}^{* *}$, mostrados na figura A.10, sendo os orbitais ocupados do tipo $\pi$ e os desocupados do tipo $\pi^{*}$. Assim, concluímos que as transições envolvidas nas bandas do espectro de absorção das espécies EMH e $\mathrm{EM}^{-}$são todas do tipo $\pi \rightarrow \pi^{*}$, inclusive a transição HOMOLUMO caracterizada na primeira banda do espectro da EMH.

Embora a primeira transição dos espectros das espécies da Emodina seja do mesmo tipo, $\pi \rightarrow \pi^{*}$, é evidente que a delocalização eletrônica nos orbitais envolvidos nessa transição é diferente. Como pode ser observado na figura 4.12, o orbital HOMO na EMH envolve majoritariamente os dois anéis aromáticos periféricos com as hidroxilas, enquanto na $\mathrm{EM}^{-}$esse mesmo orbital envolve principalmente o anel aromático periférico direito com as carbonilas C3O3 e C9O9. Essa delocalização da EMcorrobora a análise das cargas dessa espécie apresentada na figura 4.1, que conforme discutido anteriormente, é esperado que a desprotonação provoque uma reorganização da estrutura eletrônica da Emodina, delocalizando os elétrons na carbonila C3O3 e em sua vizinhança. Já os orbitais LUMO nas duas espécies são praticamente idênticos, visto que ambos encontram-se delocalizados sobre todas as espécies tendo majoritariamente os anéis centrais com suas carbonilas C9O9 e C10O10, e com pouca localização nas hidroxilas.

Na tabela 4.7 estão também mostradas as transições envolvidas nas demais bandas do espectro das espécies da Emodina, mostrando a contribuição dos diversos orbitais que participam dessas transições. Como podemos observar, as transições envolvidas nessas bandas da EMH não são iguais às envolvidas nas bandas correspondentes da $\mathrm{EM}^{-}$, como ocorre na primeira banda dessas espécies. Por exemplo, identificamos 

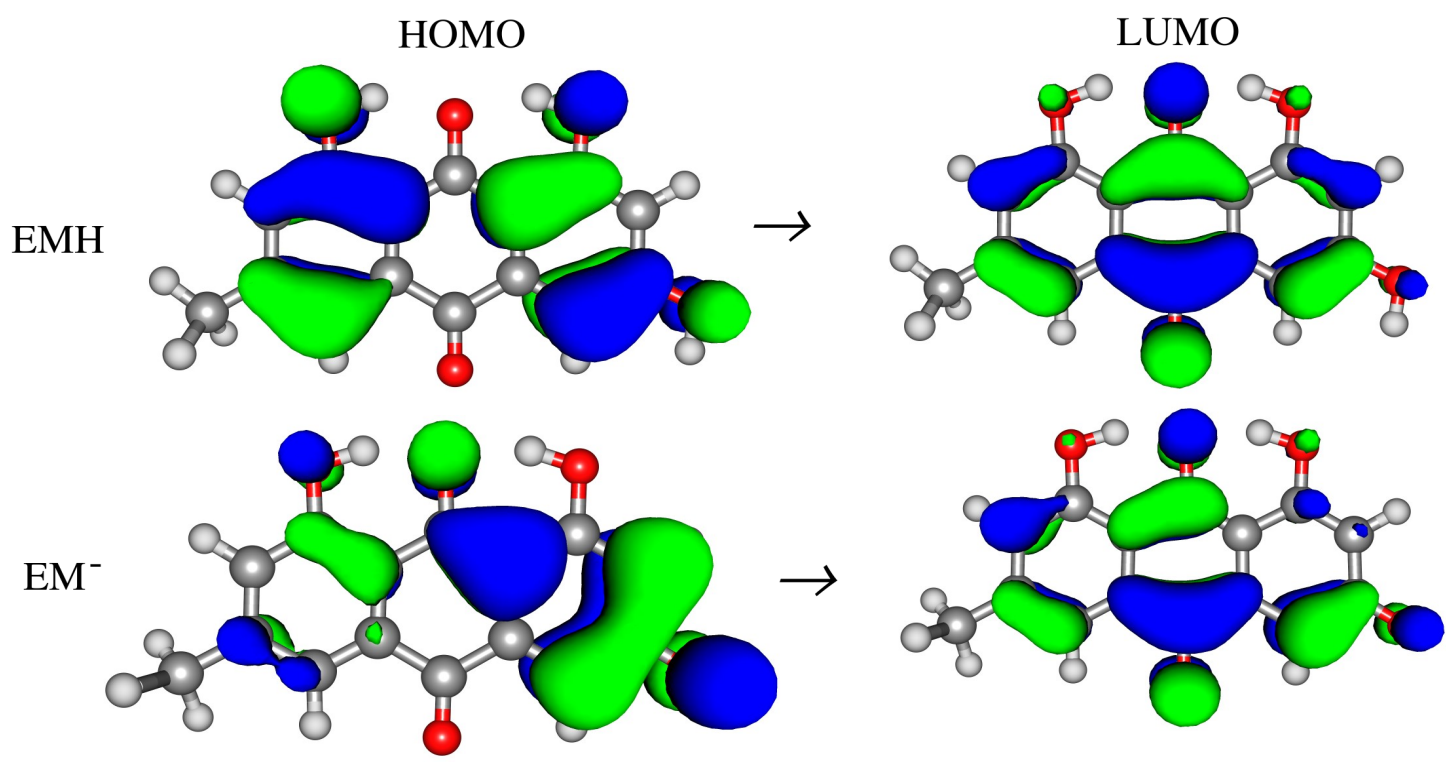

Figura 4.12: Orbitais moleculares envolvidos na primeira banda gerada pela transição HOMO $\rightarrow$ LUMO, caracterizada do tipo $\pi \rightarrow \pi^{*}$, obtidos com o método TD-B3LYP/6$311++\mathrm{G}^{* *}$.

na segunda banda da EMH a ocorrência da transição H-4 $\rightarrow$ L, enquanto na EM- identificamos outra transição para essa mesma banda que foi H-1 $\rightarrow$ L. Embora as transições sejam diferentes nessas espécies, todos os orbitais que participam majoritariamente nessas transições são perpendiculares ao plano das espécies e apresentam diferentes características na delocalização eletrônica nas espécies (veja a figura A.10, com todos os orbitais no apêndice A). Dessa forma caracterizamos que as demais bandas do espectro das espécies são também geradas por transições do tipo $\pi \rightarrow \pi^{*}$.

Uma comparação dos valores das posições dos máximos das bandas da EMH obtidos neste trabalho com os valores determinados na dissertação de mestrado com o método INDO/CIS e com os valores do trabalho de Nguyen e colaboradores [29], mostra uma boa concordância entre os valores, principalmente se compararmos as três bandas mais intensas do espectro considerando a força do oscilador. Por exemplo, em solução aquosa determinamos os valores de 447, 315 e 259 nm para os máximos 
dessas bandas utilizando o método TD-B3LYP $/ 6-311++\mathrm{G}^{* *}$, enquanto na dissertação determinamos os valores de 444, 321 e 259 nm com o método INDO/CIS, apresentando uma diferença de 3, 6 e 0 nm, respectivamente. No trabalho de Nguyen e colaboradores, eles determinaram os valores dos máximos dessas bandas da EMH em etanol utilizando o método TD-B3LYP/6-31+G** nos valores de 450, 318 e 257 nm, que estão em excelente concordância com os valores determinados neste trabalho e na dissertação de mestrado. Comparando também os valores dos máximos das bandas calculados neste trabalho, listado na tabela 4.7 com nossas medidas experimentais, listados na tabela 1.1 para EMH, observamos que os valores teóricos estão em excelente concordância com os experimentos, onde, por exemplo, em água obtivemos teoricamente a primeira banda em $447 \mathrm{~nm}$, e medimos ela em $443 \mathrm{~nm}$, portanto apresentando uma diferença de $4 \mathrm{~nm}$. Tanto nos cálculos teóricos como nas medidas experimentais obtivemos que os espectros da EMH não são sensíveis ao solvente, compare os valores para EMH nas tabelas 4.5 (experimental) e teórica 4.7 .

Para comparação dos espectros teóricos com os experimentais, apresentados na seção 4.3, também convoluímos os espectros obtidos com método TD-B3LYP/6$311++\mathrm{G}^{* *}$, usando funções gaussianas, com o programa Gaussum [322]. Cada espectro foi convolído em energia $\left(\mathrm{cm}^{-1}\right)$, e depois transformado para nanômetro $(\mathrm{nm})$. O valor usado para largura à meia altura, FWHM (full width at half maximum) foi 3000 $\mathrm{cm}^{-1}$. Nas figuras 4.13 e 4.14 mostramos a convolução desses espectros, normalizados em relação a primeira banda de absorção, para a EMH e EM-, respectivamente. Na figura 4.13, que temos a comparação dos espectros convoluídos da EMH em diferentes solventes, e o experimental em clorofórmio, observamos uma boa concordância entre os espectros teóricos e experimentais, principalmente na primeira banda na região de 500350, onde não é observado deslocamentos significativos dessa banda com a mudança do solvente.

Já na figura 4.14, temos a comparação dos espectros convoluídos da EM- em 


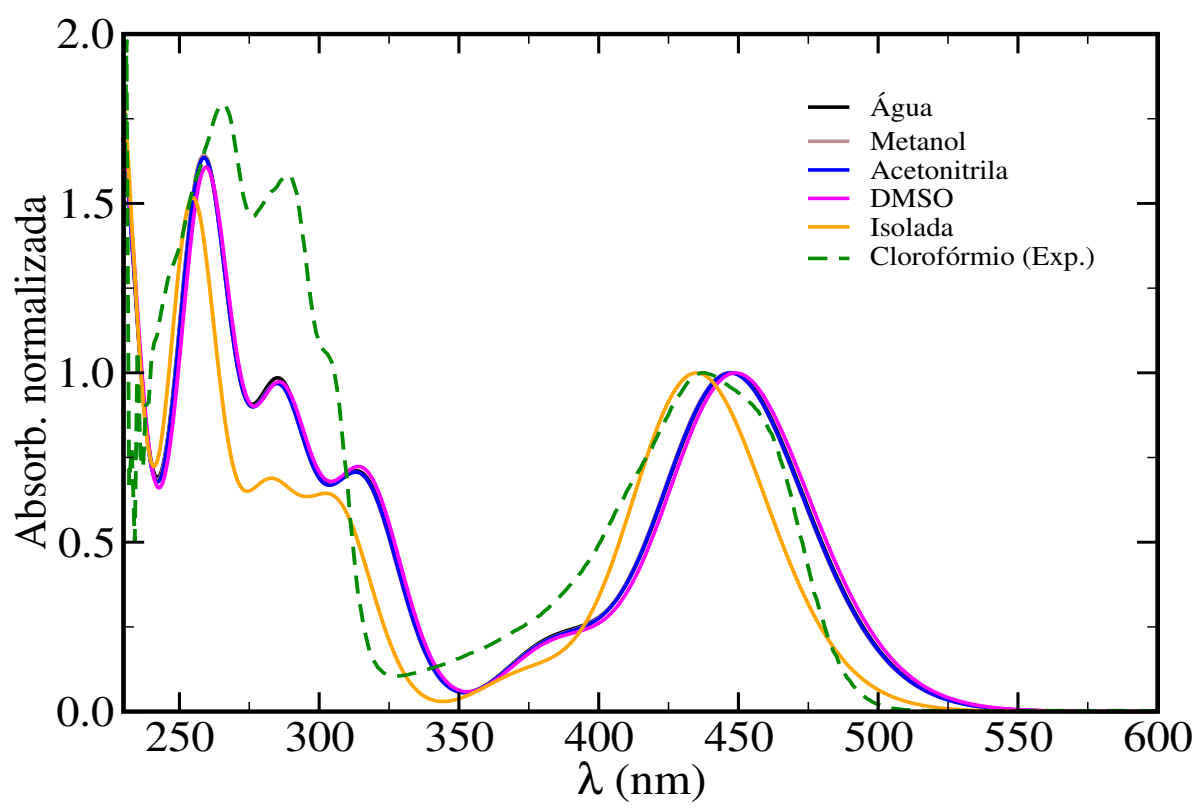

Figura 4.13: Convolução do espectro eletrônico de absorção da EMH isolada e nos solventes água, metanol, acetonitrila e DMSO, obtida a partir dos valores dos máximos das bandas do espectro calculados com o método TD-B3LYP /6-311++ G**, com a descrição do solvente com modelo PCM. Para fins de comparação apresentamos nessa figura o espectro experimental dessa espécie em clorofórmio na concentração de $0.05 \mathrm{mM}$.

diferentes solventes, descritos com o modelo PCM, e os experimentais em água e DMSO. Como podemos observar nessa figura, os espectros calculados foram pouco sensíveis ao solvente, pois os máximos da primeira banda dessa espécie nos solventes água, metanol, acetonitrila e DMSO foram 555, 553, 553 e $552 \mathrm{~nm}$, indicando um pequeno deslocamento para o azul, na mudança da espécie de DMSO para água de aproximadamente $3 \mathrm{~nm}$. Embora esse pequeno deslocamento siga a mesma tendência dos espectros experimentais, ele é bem menor do que o observado experimentalmente de $33 \mathrm{~nm}$. Uma comparação entre os valores teóricos e experimentais obtidos neste trabalho, listados na tabela 4.5, mostra que existem diferenças significativas entre esses valores de aproximadamente 32, 32, 16 e $3 \mathrm{~nm}$ para água, metanol, acetonitrila e DMSO, respectivamente. Assim, à medida que aumentamos a polaridade do meio, essa diferença se torna mais expressiva, indicando uma dependência dos espectros teóricos 


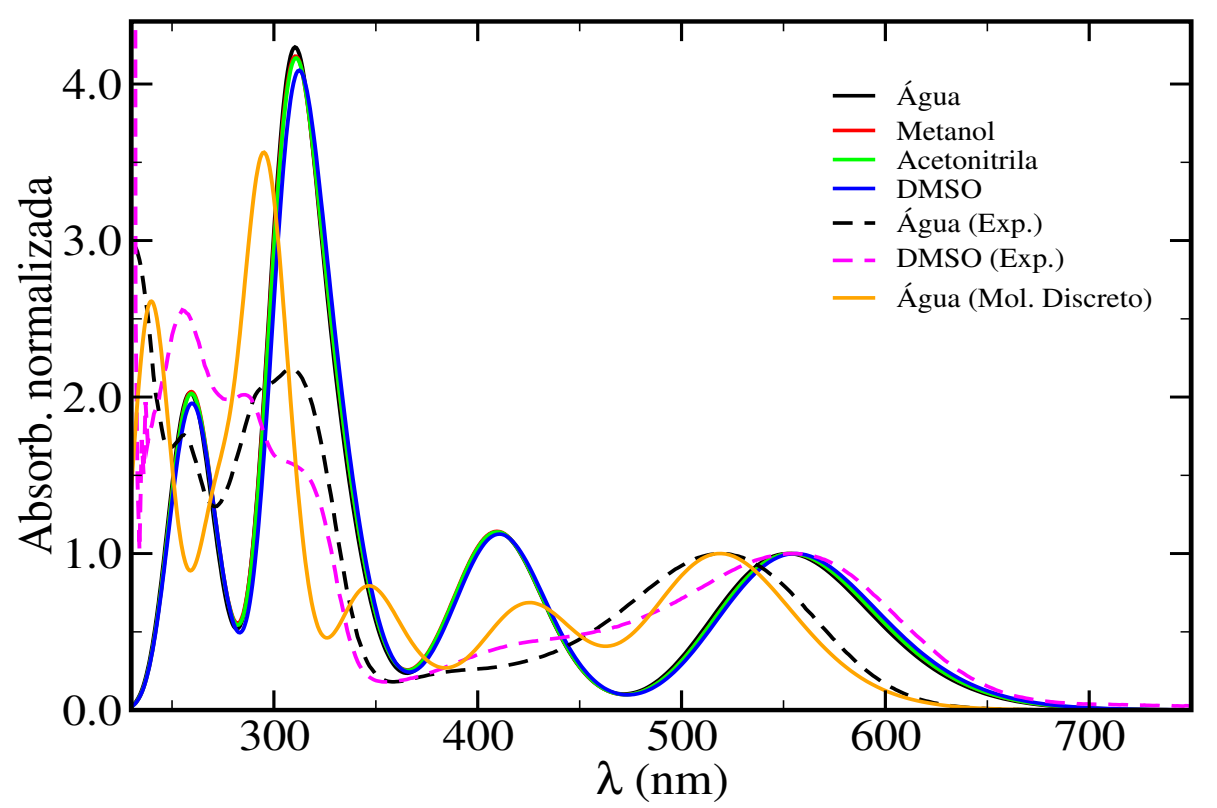

Figura 4.14: Convolução do espectro eletrônico de absorção da $\mathrm{EM}^{-}$nos solventes água, metanol, acetonitrila e DMSO, obtida a partir dos valores dos máximos das bandas do espectro calculados com o método TD-B3LYP/6-311++G**, com a descrição do solvente com modelo PCM. Para fins de comparação apresentamos nessa figura o espectro experimental dessa espécie em solução aquosa concentração de $0.05 \mathrm{mM}$.

com a polarização dessa espécie. Essa diferença é atribuída a não descrição realista da interação específica com o solvente, visto que os solventes de alta polaridade como a água e o metanol formam ligações de hidrogênios intermoleculares com a espécie $\mathrm{EM}^{-}$, e essas ligações não são incluídas no modelo contínuo de solvente.

A segunda e a terceira banda do espectro da EM- nos solventes água, metanol, acetonitrila e DMSO, determinadas teoricamente na região de $411 \pm 1$ e $331 \pm 1 \mathrm{~nm}$, com a força do oscilador da ordem de 0.1, não são observadas tão intensas nos experimentos, como indica a força do oscilador dessas bandas. Porém observando a figura 4.10 do espectro experimental dessa espécie é possível verificar que essas bandas se encontram registradas nessas regiões, principalmente a banda da região de $411 \mathrm{~nm}$, que aparece com baixa absorbância. Já a quarta banda determinada teoricamente na região de $(309 \pm 1)$ nm, é a que apresenta a maior força de oscilador, cerca de 0.5. O máximo 
dessa banda, como também a força do oscilador, estão coerentes com nossos resultados experimentais, pois de acordo com a figura 4.10, essa banda está localizada na região de 336 a 308 nm, apresentando também a mais alta absorbância dentre as três bandas mais intensas do espectro.

Para uma melhor descrição do espectro de absorção da $\mathrm{EM}^{-}$em meio aquoso, utilizamos um modelo de moléculas discreto para o solvente, em que diversas configurações do soluto rodeado por moléculas de água foram obtidas através de simulações computacionais para cálculos quânticos. Inicialmente realizamos uma simulação computacional com método Monte Carlo com a $\mathrm{EM}^{-}$numa caixa cúbica com 500 moléculas de água com modelo SPC [279] no ensemble NPT, nas condições normais de pressão e temperatura. Nessa simulação, a interação eletrostática dessa espécie foi descrita pelo conjunto de cargas atômicas, obtido através do processo de polarização iterativo do soluto. Dessa simulação, selecionamos 75 configurações estatisticamente descorrelacionadas e para cada configuração separamos essa espécie rodeada por 250 moléculas de água, que correspondem às moléculas água até a terceira camada de solvatação da $\mathrm{EM}^{-}$ determinada a partir da distribuição de mínima distância (MDDF) entre a espécie e as moléculas de água, como mostrado na figura A.17 do apêndice A.

Assim, realizamos cálculos quânticos do espectro eletrônico da EM- com o TDB3LYP $/ 6-311++\mathrm{G}^{* *}$ nas configurações selecionadas da simulação, considerando nesse cálculo as moléculas de água como cargas pontuais. Por completeza realizamos esse mesmo estudo para a EMH em água, veja a tabela 4.7 com os resultados. A inclusão do solvente como campo eletrostático descrito pelas cargas pontuais na solvatação da EMH não promoveu mudanças significativas nas posições das bandas do espectro dessa molécula, quando comparado com a solvatação com o modelo PCM (apenas $7 \mathrm{~nm}$ ). Porém, na solvatação da $\mathrm{EM}^{-}$, a inclusão do solvente como cargas pontuais promoveu um melhoramento significativo nas posições das bandas, quando comparado com os nossos resultados experimentais. Neste caso, registramos um deslocamento da 
primeira banda para o azul de aproximadamente $35 \mathrm{~nm}$, portanto levando essa banda para a posição de $519 \mathrm{~nm}$. Esse resultado está em excelente concordância com o valor experimental de $520 \mathrm{~nm}$, obtido neste trabalho para a EM- em solução aquosa.

Fundamentados em nossos resultados experimentais e teóricos obtidos neste trabalho, evidenciamos que a sensibilidade do espectro eletrônico de absorção da espécie EMH é devido muito mais a mudanças de $\mathrm{pH}$ do meio do que ao efeito do solvente. Essa informação nos leva a caracterizar a estrutura eletrônica dessa espécie como insensível ao efeito do solvente, e portanto o espectro dessa espécie não é uma boa propriedade para sondar o ambiente da sua vizinhança local. Por outro lado, evidenciamos que o espectro da $\mathrm{EM}^{-}$apresenta sensibilidade significativa ao solvente e a mudanças de $\mathrm{pH}$ do meio, de modo que essa espécie pode ser utilizada como sensor tanto do ambiente da sua vizinhança local como também de $\mathrm{pH}$, identificando ambientes ácido/alcalino e polar/apolar.

\subsection{Interação da Emodina com o ambiente}

Nesta seção apresentamos e discutimos a modelagem molecular das espécies EMH e $\mathrm{EM}^{-}$em solução aquosa e em bicamadas lipídicas de DMPC. Dessa modelagem extraímos informações da estrutura, da dinâmica e da interação dessas espécies com esses ambientes. Além disso, com a modelagem das espécies em bicamadas lipídicas caracterizamos a localização e a orientação dessas espécies nesses ambientes anfifílicos. Adicionamente elucidamos o efeito das espécies nas bicamadas lipídicas através da modelagem molecular e das medidas de calorimetria diferencial de varredura (DSC).

Na modelagem molecular realizamos simulações computacionais com dinâmica molecular dessas espécies nesses ambientes utilizando o campo de força GROMOS $54 a 7$ [104,105] no programa GROMACS [238]. Esse campo de força foi escolhido para as espécies e para o fosfolipídio DMPC, visto que trabalhos recentes $[110,111]$ validaram 
os parâmetros desse campo de força para o DMPC. Esses trabalhos mostraram que esse campo de força consegue descrever as propriedades das bicamadas lipídicas de DMPC tais como área e volume por cabeça lipídica, densidade eletrônica, ordem e conformação das cadeias hidrocarbônicas dos lipídicas em boa concordância com os resultados experimentais. As simulações da EMH e EM- em solução aquosa se fizeram necessárias para validar os parâmetros desse campo de força para essas espécies. A validação desses parâmetros se deu através da comparação dos resultados obtidos neste trabalho com os das simulações computacionais, tanto com dinâmica molecular, como com método Monte Carlo, realizadas com o campo de força OPLS, apresentadas e discutidas previamente [32].

\subsubsection{Modelagem da EMH e EM- em solução aquosa}

Antes de iniciar a apresentação dos resultados das simulações computacionais das espécies EMH e EM- em solução aquosa obtidos neste trabalho, gostaria de fazer um breve sumário dos resultados dos cálculos quânticos e das simulações computacionais realizados com a EMH na dissertação de mestrado. Como principais resultados da dissertação de mestrado, obtivemos através de cálculos com mecânica quântica (QM), com o método de estrutura eletrônica B3LYP/6-31G*, que a conformação da EMH mais favorável energeticamente é a que forma duas ligações de hidrogênio intramoleculares (H8 e H1 com O9). Essa conformação da EMH tem um momento de dipolo de 2.68 D. Do ponto de vista de QM, para a molécula sair dessa conformação para uma conformação com uma ligação de hidrogênio intramolecular é necessário fornecer uma energia em torno de $\sim 14 \mathrm{kcal} / \mathrm{mol}$ com uma barreira rotacional de $\sim 19 \mathrm{kcal} / \mathrm{mol}$. Realizamos também simulações computacionais em solução aquosa, usando dois modelos diferentes: um modelo de moléculas rígidas usando método Monte Carlo e um modelo de moléculas flexíveis usando dinâmica molecular, ambos utilizando o mesmo campo de força OPLS. Desse estudo obtivemos que as ligações de hidrogênio intramoleculares 
da Emodina são dificilmente quebradas, mesmo interagindo com água. Isso confere à Emodina um momento de dipolo $\sim 3$ D, atribuindo assim à EMH um caráter hidrofóbico. A modelagem molecular mostrou através dos dois métodos MC e MD que a interação da hidroxila O3H3 da Emodina com o solvente (água) foi mais fortemente em comparação com as outras hidroxilas. Assim, caracterizamos que essa hidroxila é mais vulnerável a uma desprotonação, o que está em concordância com a sugestão de Pal e colaboradores [28]. Uma versão completa da dissertação de mestrado está disponível na internet, ver referência [32].

Como discutido anteriormente, fizemos simulações computacionais apenas com a espécie EMH e nenhuma modelagem foi realizada com a EM- ${ }^{-}$Sendo assim, dando continuidade a esse estudo, neste trabalho realizamos simulações computacionais com dinâmica molecular com as duas espécies EMH e EM- separadamente em caixas cúbicas rodeadas por 500 moléculas de água no ensemble NPT, nas condições normais de temperatura e pressão como descrito na seção 3.5.2.

O equilíbrio das simulações foi monitorado através da análise temporal das seguintes propriedades: energia total, energia potencial, energia cinética, densidade e temperatura. Essa análise mostrou que as simulações atingiram o equilíbrio rapidamente, após os dois primeiros nanosegundos como mostrado na figura A.11 no apêndice A, a evolução temporal da energia potencial. Na tabela A.3, também no apêndice A está apresentado um sumário da análise estatística da energia total, energia potencial, energia cinética, densidade e temperatura dos sistemas em equilíbrio. A análise dessa tabela mostra que: (i) a densidade dos sistemas simulados no regime de equilíbrio apresentou pouca flutuação como esperado $\left(\varrho=0.99 \pm 0.01 \mathrm{~g} / \mathrm{cm}^{3}\right)$; (ii) a temperatura média ficou em torno de $300 \mathrm{~K}$ com uma flutuação de $7.5 \mathrm{~K}$; (iii) as energias total, potencial e cinética por molécula apresentaram pouca flutuação, sendo a cinética, cerca de $0.05 \mathrm{kcal} / \mathrm{mol}$ e a potencial cerca de $0.07 \mathrm{kcal} / \mathrm{mol}$.

Realizamos uma análise conformacional das geometrias da EMH e EM- a fim de 
investigar a flexibilidade dessas geometrias em solução aquosa e identificar as orientações mais prováveis das hidroxilas dessas espécies em solução. Para isso, realizamos uma análise dos diedros $\mathrm{C} 7 \mathrm{C} 8 \mathrm{O} 8 \mathrm{H} 8(\mathrm{dh} 8)$, C2C1O1H1(dh1) e C2C3O3H3(dh3) durante a dinâmica molecular, que estão associados às hidroxilas $\mathrm{O} 8 \mathrm{H} 8, \mathrm{O} 1 \mathrm{H} 1$ e O3H3, respectivamente, ver numeração dos átomos na figura 3.1. Na figura 4.15 estão mostradas as evoluções temporais dos diedros dh1 (figura (a)) e dh3 (figura (b)) e seus respectivos histogramas nas figuras (c) e (d), respectivamente, obtidos das simulações realizadas com EMH em solução aquosa. A análise dos diedros dh1 e dh8 no decorrer da simulação mostrou que eles apresentam comportamentos similares (compare as figuras 4.15 (a) e (c) com as figuras A.13 (a) e (b) no apêndice A), onde verificamos que eles ficaram a maior parte do tempo de simulação dentro do intervalo de $150^{\circ}$ a $210^{\circ}$, ou seja, com as hidroxilas O1H1 e O8H8 formando ligação hidrogênio intramolecular.

Tabela 4.8: Tempo total em ns e percentual (\%) em parêntese em que os ângulos diedros dh1, dh8 e dh3 ficaram nas seguintes conformações: (i) trans - intervalo de $150^{\circ}$ a $210^{\circ}$; (ii) cis - intervalo de $0^{\circ}$ a $30^{\circ}$ e de $360^{\circ}$ a $330^{\circ}$; (iii) transição - intervalo de $30^{\circ}$ a $150^{\circ}$ e de $210^{\circ}$ a $330^{\circ}$.

\begin{tabular}{cccccc}
\hline & \multicolumn{2}{c}{ EMH } & \multicolumn{2}{c}{ EM $^{-}$} \\
\hline Conform. & $\mathrm{dh} 1 \mathrm{~ns}(\%)$ & $\mathrm{dh} 8 \mathrm{~ns}(\%)$ & $\mathrm{dh} 3 \mathrm{~ns}(\%)$ & $\mathrm{dh} 1 \mathrm{~ns}(\%)$ & $\mathrm{dh} 8 \mathrm{~ns}(\%)$ \\
\hline trans & $41.1(82.2)$ & $33.8(67.6)$ & $21.2(42.4)$ & $49.2(98.4)$ & $45.3(90.7)$ \\
cis & $4.7(9.5)$ & $8.8(17.5)$ & $17.6(35.2)$ & $0.3(0.7)$ & $2.2(4.5)$ \\
transição & $4.2(8.3)$ & $7.4(14.9)$ & $11.2(22.4)$ & $0.4(0.9)$ & $2.4(4.8)$ \\
\hline \hline
\end{tabular}

Na tabela 4.8 mostramos o tempo em ns e o percentual em que esses diedros ficaram nas seguintes conformações conformações: trans - diedro no intervalo de $150^{\circ}$ 
a $210^{\circ}$; cis - no intervalo de $0^{\circ}$ a $30^{\circ}$ e também de $360^{\circ}$ a $330^{\circ}$; transição - no intervalo de $30^{\circ}$ a $150^{\circ}$ e também de $210^{\circ}$ a $330^{\circ}$. A análise dessa tabela mostra que cerca de 41.1 e 33.8 ns as hidroxilas O1H1 e O8H8 ficaram formando ligações de hidrogênio intramoleculares, que corresponde em termos de percentagem aproximadamente $82 \% \mathrm{e}$ $68 \%$ do tempo total simulado (50 ns). Embora o comportamento dessas duas hidroxilas sejam similares, registramos que a hidroxila $\mathrm{O} 1 \mathrm{H} 1$ ficou cerca de 7 ns a mais do que a hidroxila $\mathrm{O} 8 \mathrm{H} 8$ formando ligação de hidrogênio intramolecular, o que lhe atribui uma característica mais rígida em comparação com a hidroxila O8H8.

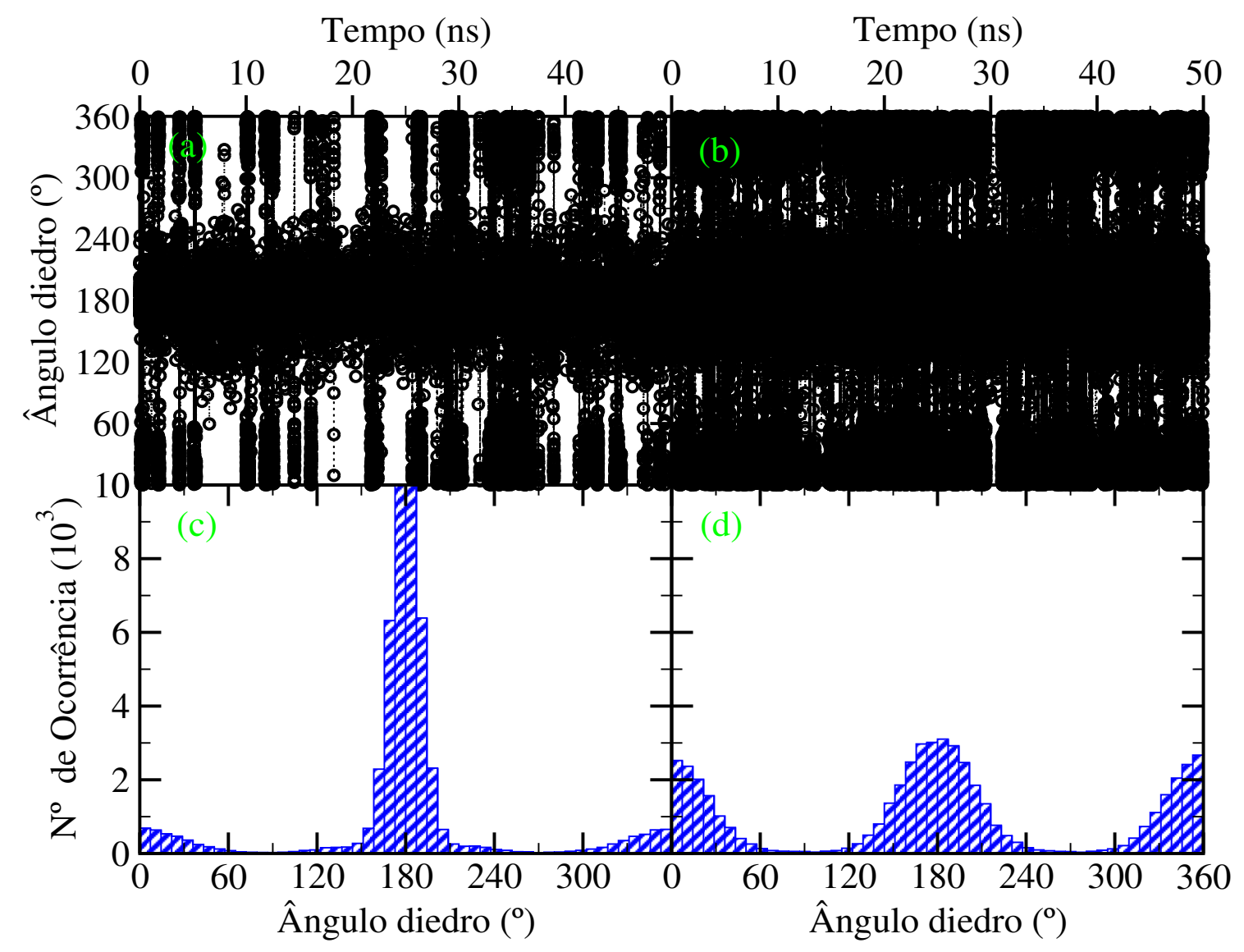

Figura 4.15: Evolução temporal dos ângulos diedros dh1 (a) e dh3 (b), e seus respectivos histogramas em (c) e (d), respectivamente, obtidos das simulações computacionais com dinâmica molecular da EMH em solução aquosa. As simulações foram realizadas utilizando o campo de força GROMOS (54a7). O comportamento do diedro dh8 é similar ao dh1. 
A evolução temporal do diedro dh3 mostrada na figura 4.15 mostrou que esse diedro que está associado à hidroxila O3H3 apresenta duas conformações preferenciais, a trans e a cis. A análise desse diedro durante as simulações mostrou que ele ficou 21.2 ns na conformação trans, que corresponde a $42 \%$ do tempo total de simulação. Já na conformação cis, esse diedro ficou 17.6 ns, que corresponde a 35\% do tempo total de simulação. Assim, dadas essas características, caracterizamos que esse diedro apresenta alta flexibilidade, tendo uma maior preferência pela conformação trans. A comparação da evolução temporal entre as três hidroxilas da EMH, mostrou que as hidroxilas $\mathrm{O} 1 \mathrm{H} 1$ e $\mathrm{O} 8 \mathrm{H} 8$ são bem rígidas ficando a maior parte do tempo formando ligações de hidrogênio intramolecular. Enquanto a hidroxila O3H3 apresentou ser mais flexível e livre de interações intramoleculares. Esse comportamento é razoável, pois essa hidroxila não participa de nenhuma ligação de hidrogênio intramolecular, se apresentando sempre livre para interagir com as moléculas de água.

A análise conformacional da Emodina desprotonada em solução aquosa mostrou que essa espécie é bastante rígida, pois os dois diedros dh1 e dh8 associados aos grupos hidroxilas ficaram mais de $90 \%$ do tempo de simulação em conformações formando ligações de hidrogênio intramoleculares. Os tempos observados para esses diedros nessas conformações foram de 49.2 ns e 45.3 ns, que corresponde a $98 \%$ e $91 \%$ do tempo total simulado, respectivamente. Na figura 4.16 mostramos a evolução temporal do ângulo diedro dh1 e dh2 e seus respectivos histogramas, que mostra que durante a simulação esses diedros ficaram em torno de $180^{\circ}$, ou seja, formando ligação de hidrogênio intramolecular. Assim, observamos que a desprotonação da hidroxila O3H3, torna as ligações de hidrogênio intramoleculares mais fortes, deixando as hidroxilas associadas a essas ligações mais rígidas. Isso ocorre devido a um aumento na atração eletrostática entre o grupo carbonila (C9O9) e as hidroxilas $\mathrm{O} 1 \mathrm{H} 1$ e $\mathrm{O} 8 \mathrm{H} 9$, pois o oxigênio O9 torna mais carregado negativamente com a desprotonação, como mostrado na figura 4.1. 


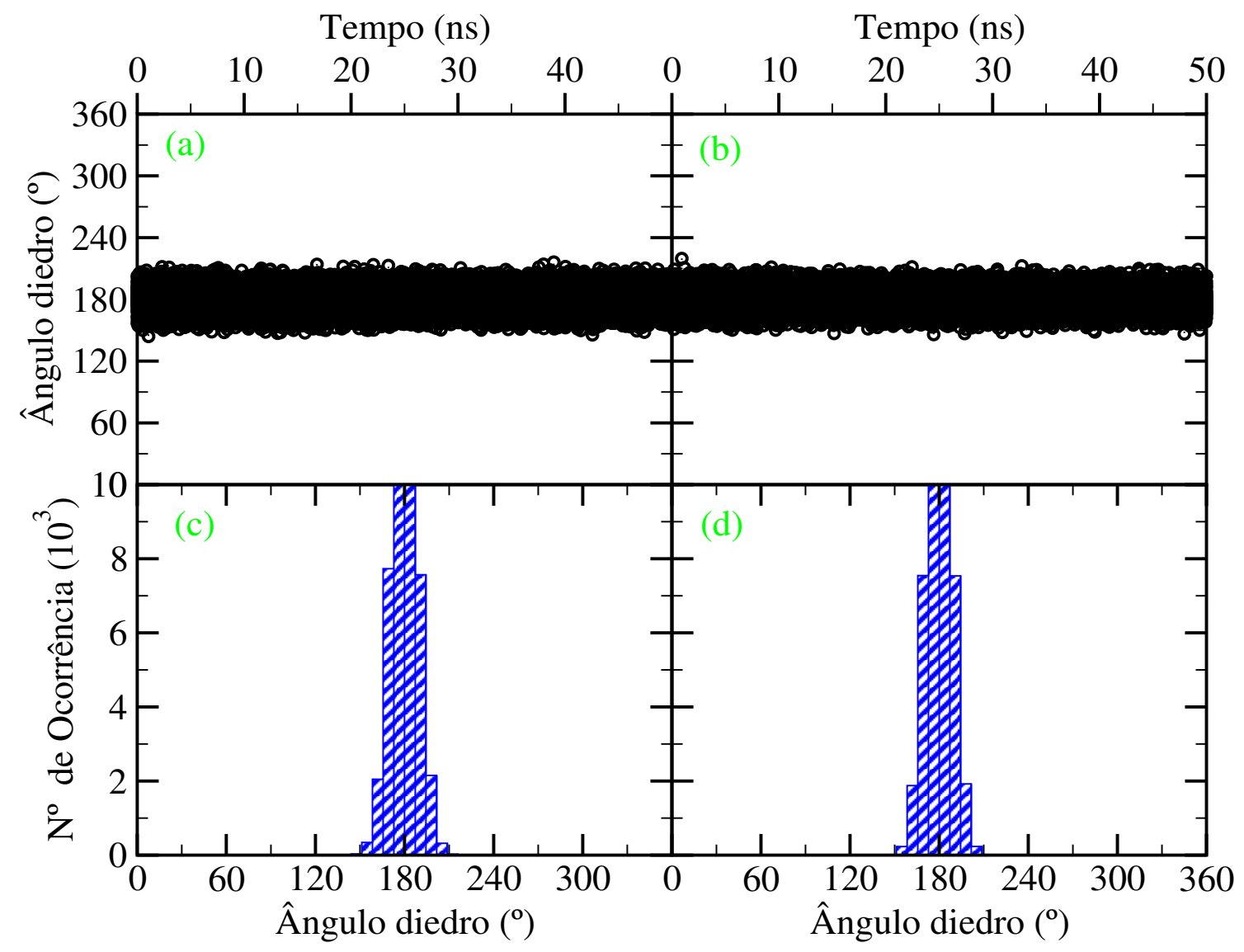

Figura 4.16: Evolução temporal dos ângulos diedros dh1 (a) e dh8 (b), e seus respectivos histogramas em (c) e (d), respectivamente, obtidos das simulações computacionais com dinâmica molecular da $\mathrm{EM}^{-}$em solução aquosa. As simulações foram realizadas utilizando o campo de força GROMOS (54a7).

Nas figuras A.12, A.13, A.14 e A.15 e na tabela A.4 apresentados no apêndice A mostramos uma comparação entre os resultados obtidos das simulações realizadas com os campos de forças GROMOS e OPLS. Essas figuras mostram que as evoluções temporais dos diedros analisados da EMH e EM- no decorrer das simulações com o GROMOS e OPLS apresentaram comportamentos similares, ficando praticamente nas mesmas conformações apresentadas na tabela 4.8. Embora esses dois campos de força tenham descrito as espécies da Emodina praticamente da mesma forma, observamos que a dinâmica com OPLS deixou as geometrias da EMH e $\mathrm{EM}^{-}$pouco mais rígidas. 
Isso foi evidenciado na análise das ligações de hidrogênio intramoleculares, que foram dificilmente quebradas em solução, e no diedro dh3 que ficou mais rígido, ficando mais tempo na conformação trans durante a simulação, cerca de $26 \%$ a mais comparado com a dinâmica com GROMOS.

Nas figuras A.16 e A.17 no apêndice mostramos as funções de distribuição de mínima distância $(\mathrm{MDDF})^{3}$ entre as espécies da Emodina e as moléculas de água, calculadas das simulações dessas espécies em solução aquosa com dinâmica molecular utilizando os campos de forças GROMOS e OPLS. A partir dessas funções determinamos o número de moléculas em cada camada de solvatação das espécies através da integração dos picos da MDDF, sendo que a integração do $1^{\circ}$ pico fornece o número de moléculas de água na primeira camada de solvatação e assim segue os demais. Essa análise mostrou que o número de moléculas em torno das espécies da Emodina obtido com os dois campos de forças GROMOS e OPLS é praticamente o mesmo, sendo para espécie EMH determinamos cerca de 7 moléculas de água na camada de ligações de hidrogênio e cerca de 65 moléculas de água na primeira camada de solvatação para ambos os campos de forças. Já para a espécie $\mathrm{EM}^{-}$esses números foram cerca de 9 moléculas de água na camada de ligações de hidrogênio e cerca de 70 moléculas de água na primeira camada de solvatação, indicando claramente uma maior hidratação para a espécie $\mathrm{EM}^{-}$.

Analisamos também as ligações de hidrogênio intermoleculares que a EMH e EMformaram com as moléculas de água durante as simulações. Essas ligações foram analisadas através dos critérios geométricos radial $R_{\text {OO }}$ e angular OÔH [105, 106]. Neste trabalho adotamos os seguintes critérios: $\mathrm{R}_{\mathrm{OO}} \leq 3.15$ Ae OÔH $\leq 30^{\circ}$. Na tabela 4.9, estão mostrados o número de ligações de hidrogênio por configuração $\left(\left\langle\mathrm{N}^{\mathrm{O}}\right\rangle_{\mathrm{HB}}\right)$, a energia média $\left(\langle\mathrm{E}\rangle_{\mathrm{HB}}\right)$ e o tempo de vida $(\tau)$ dessas ligações. A análise desses resultados

\footnotetext{
${ }^{3} \mathrm{~A}$ MDDF é interpretada como a probabilidade de encontrar um par de átomos $\left(\mathrm{a}_{\mathrm{i}}, \mathrm{b}_{\mathrm{j}}\right)$ do soluto(a) e solvente(b) numa menor distância $r_{i j}$, dentre todas as distâncias possívies entre todas os átomos do soluto e solvente.
} 
mostrou que existem em média cerca de 7 e 9 moléculas de água se ligando às espécies da EMH e EM- através de ligações de hidrogênio com a energia de ligação média em torno de 6 e $9 \mathrm{kcal} / \mathrm{mol}$, respectivamente. Uma análise mais detalhada foi realizada levando em consideração que essas ligações ocorrem apenas nos grupos hidroxilas e carbonilas, onde as hidroxilas desempenham funções de aceitadoras de ligações de hidrogênio, através dos átomos de oxigênios, e também funções de doadoras de ligações de hidrogênio, através dos hidrogênios. Já as carbonilas desempenham apenas funções de aceitadoras de ligações de hidrogênio, através dos átomos de oxigênio. Assim, realizamos análises das ligações de hidrogênio formadas pelas moléculas de água com as espécies da Emodina através dos grupos hidroxila (O1H1, O8H8, O3H3(EMH)) e carbonila (C9O9, C10O10 e C3O3(EM+).

Tabela 4.9: Número médio $\left(\left\langle\mathrm{N}^{\mathrm{O}}\right\rangle_{\mathrm{HB}}\right)$, tempo de vida médio em ps da primeira $\left(\tau_{1}\right)$, segunda $\left(\tau_{2}\right)$ e terceira $\left(\tau_{3}\right)$ ligação de hidrogênio, e energia média das ligações de hidrogênio em (kcal/mol), calculadas das simulações com dinâmica molecular com as espécies da Emodina em solução aquosa.

\begin{tabular}{ccccccc}
\hline \hline & \multicolumn{2}{c}{ EMH } & \multicolumn{3}{c}{$\mathrm{EM}^{-}$} \\
\hline Grupo & $\left\langle\mathrm{N}^{\circ}\right\rangle_{\mathrm{HB}}$ & $\tau_{1}\left(\tau_{2}\right)$ & $\langle\mathrm{E}\rangle_{\mathrm{HB}}$ & $\left\langle\mathrm{N}^{\circ}\right\rangle_{\mathrm{HB}}$ & $\tau_{1}\left(\tau_{2}\right)\left[\tau_{3}\right]$ & $\langle\mathrm{E}\rangle_{\mathrm{HB}}$ \\
\hline O1H1 & 1.2 & $2.7(0.6)$ & -5.3 & 1.5 & $3.7(0.6)$ & -6.7 \\
O8H8 & 1.4 & $2.9(0.6)$ & -5.9 & 1.5 & $3.4(0.5)$ & -6.3 \\
O3H3/C3O3 & 2.2 & $2.8(0.5)$ & -7.4 & 3.5 & $10.4(1.6)[0.4]$ & -11.9 \\
C9O9 & 0.8 & $2.4(0.7)$ & -5.3 & 1.1 & $2.7(0.5)$ & -6.0 \\
C10O10 & 1.6 & $3.7(0.6)$ & -5.2 & 1.9 & $5.0(0.7)$ & -7.4 \\
Total & 7.2 & $3.0(0.6)$ & -6.0 & 9.5 & $6.3(1.0)[0.4]$ & -8.6 \\
\hline \hline
\end{tabular}


Na tabela 4.9 estão mostradas as ligações de hidrogênio formado pelas moléculas de água com os grupos hidroxila e carbonila da EMH e EM- ${ }^{-}$Na interação da espécie EMH com água, observamos que a hidroxila O3H3 forma mais ligações de hidrogênio e interage mais fortemente com as moléculas de água do que as demais hidroxilas dessa espécie. Essa característica dessa hidroxila torna esse grupo mais vulnerável à desprotonação, o que está em boa concordância com nossos resultados obtidos anteriormente na análise do $p K_{a}$ e com o trabalho [28].

$\mathrm{Na}$ análise conformacional discutida acima mostramos que as hidroxilas $\mathrm{O} 1 \mathrm{H} 1$ e O8H8 ficaram a maior parte do tempo formando ligações de hidrogênio intramoleculares com o grupo carbonila C9O9. Essas ligações intramoleculares desfavorecem a interação das ligações de hidrogênio intermoleculares com as moléculas de água. Essa característica justifica o número baixo de ligações de hidrogênio que essas hidroxilas formam com as moléculas de água, que de acordo com a tabela 4.9, esse número representa aproximadamente a metade das ligações contabilizadas na hidroxila O3O3. Além disso, as ligações de hidrogênio intramoleculares formadas protegeram o grupo carbonila C9O9 de formar ligações de hidrogênio.

A análise das ligações de hidrogênio formadas pelas moléculas de água com a EMmostrou que a interação dessa espécie com a água é bastante forte, pois registraram um aumento de aproximadamente 30\% no número e 55\% na energia das ligações hidrogênio da Emodina após o processo de desprotonação. Uma análise mais detalhada mostrou que o número e a energia das ligações de hidrogênio formada pelas hidroxilas O1H1 e O8H8 aumentaram aproximadamente 15\% com o processo de desprotonação. Observamos também que essas hidroxilas da $\mathrm{EM}^{-}$formaram praticamente a mesma quantidade de ligações de hidrogênio por configuração, cerca de 1.5, com a energia de ligação média em torno de $6.5 \mathrm{kcal} / \mathrm{mol}$. Dadas essas características, ressaltamos que a partir da interação dessas hidroxilas com a água não é possível inferir qual delas será 
a próxima a desprotonar, visto que ambas interagem praticamente da mesma forma com a água. A carbonila C3O3 foi o grupo que apresentou a interação mais forte com as moléculas de águas, onde observamos cerca de 3 ligações de hidrogênio por configuração com energia média de aproximadamente $12 \mathrm{kcal} / \mathrm{mol}$. Essa característica é devido à localização de cargas negativas nesse grupo, em particular no oxigênio O3, como comprovado na figura 4.1.

Analisamos também o tempo de vida médio das ligações de hidrogênio, através da função de distribuição de probabilidades do tempo de vida dessas ligações formado pelas moléculas de água com os grupos hidroxila (O1H1, O8H8 e O3H3(EMH)) e carbonila (C9O9, C10O10 e C3O3(EM-)). O tempo de vida médio foi obtido a partir do ajuste da curva dessa distribuição pela seguinte equação,

$$
p(t)=\sum_{i=1}^{n} c_{i} e^{-t / \tau_{i}},
$$

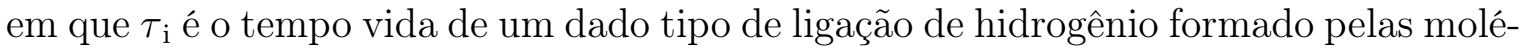
culas de água com os grupos hidroxila e carbonila da EMH e EM- . Para esses grupos, observamos que são necessários dois termos da equação 4.4 para ajustar adequadamente as curvas da distribuição de probabilidades, caracterizando assim dois tempos de vidas, associados à primeira $\left(\tau_{1}\right)$ e segunda $\left(\tau_{2}\right)$ ligação de hidrogênio. Houve uma exceção ao grupo C3O3 da $\mathrm{EM}^{-}$, para o qual foram necessários 3 três termos dessa equação para ajustar a curva, caracterizando assim o tempo de vida da terceira $\left(\tau_{3}\right)$ ligação de hidrogênio. Isso ocorre devido ao número médio de ligações de hidrogênio por configuração nos grupos analisados ser maior que 1, com exceção à carbonila C9O9 da $\mathrm{EMH}$, onde observamos que $\left\langle\mathrm{N}^{\circ}\right\rangle_{\mathrm{HB}}=0.8$. Embora o número médio de ligações de hidrogênio por configuração nessa carbonila seja menor que 1, observamos que existem algumas configurações em que esse grupo forma mais de uma ligação de hidrogênio, o que justifica o ajuste da curva da distribuição de probabilidades por dois termos da equação 4.4 . 


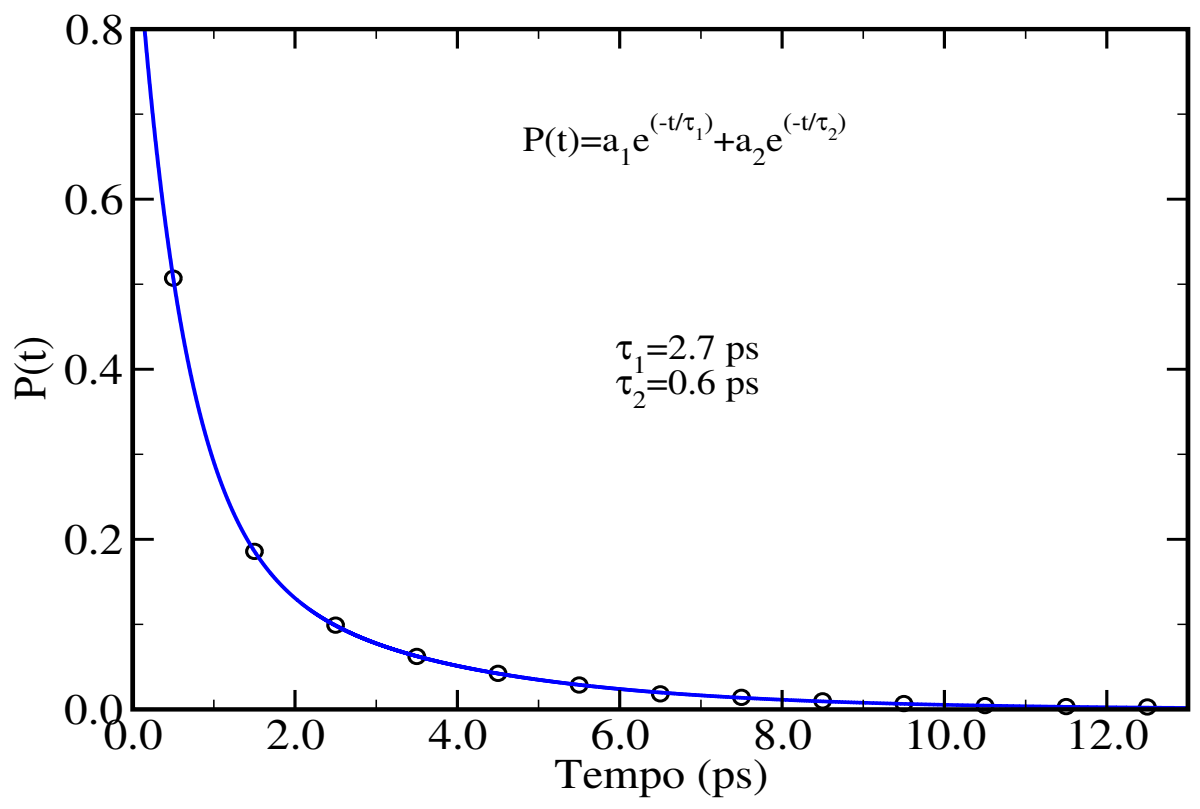

Figura 4.17: Função de distribuição de probabilidades do tempo de vida das ligações de hidrogênio formadas pelas moléculas de água com a hidroxila O8H8 da EMH durante a dinâmica molecular. Essa distribuição para os demais grupos hidroxila e carbonila da EMH e EM- são similares, veja as figuras A.18 e A.19 no apêndice A.

As distribuições de probabilidades do tempo de vida das ligações de hidrogênio formadas pelas moléculas de água com os grupos hidroxila e carbonila das espécies da Emodina são similares, apresentando apenas diferenças no fator de decaimento exponencial dessas distribuições à medida que se busca por ligações com tempos de vidas mais longos. Na figura 4.17 mostramos a curva dessa distribuição e o seu respectivo ajuste pela equação 4.4 para as ligações de hidrogênio formadas pelas moléculas de água com a hidroxila O8H8 da EMH. Como mostrado nessa figura, os tempos de vida das ligações de hidrogênio foram obtidos a partir do ajuste da distribuição de probabilidades pela equação 4.4. Essa mesma metodologia foi aplicada na determinação dos tempos de vidas das ligações de hidrogênios nos demais grupos hidroxila e carbonila da EMH e EM-, veja as figuras A.18 e A.19 no apêndice A.

Como discutido acima, para os grupos hidroxila e carbonila das espécies da Emodina caracterizamos dois tempos de vidas das ligações de hidrogênio, com exceção 
ao grupo $\mathrm{C} 3 \mathrm{O} 3$ da $\mathrm{EM}^{-}$, onde caracterizamos 3 tempos. Na tabela 4.9 apresentamos um sumário desses tempos de vidas, onde $\tau_{1}, \tau_{2}$ e $\tau_{3}$ são os tempos de vida associados a primeira, segunda e terceira ligação de hidrogênio, respectivamente. A análise dessa tabela mostra que as ligações de hidrogênio associadas a $\tau_{1}$ são caracterizadas por ligações fortes e tempos de vida longos. Os tempos de vida determinados para esse tipo de ligações na EMH e $\mathrm{EM}^{-}$foram aproximadamente 3 e 6 ps, respectivamente. Acredita-se que as ligações desse tipo sejam as primeiras a se formarem e as mais difíceis de serem quebradas. Já as ligações de hidrogênio associadas a $\tau_{2}$ que são caracterizadas por interações mais fracas com tempos de vidas menores, cerca de $80 \%$ a menos dos tempos de vida das primeiras ligações, ou seja, das ligações associadas a $\tau_{1}$. As ligações associadas a $\tau_{3}$ são as mais fracas e curtas de todas. Esse tipo de ligação foi observado apenas no grupo C3O3 da $\mathrm{EM}^{-}$, onde caracterizamos que o tempo de vida dessas ligações dura da ordem de 0.4 ps.

Na tabela A.5 apresentada no apêndice A mostramos uma comparação das propriedades relacionadas às ligações de hidrogênios formadas pelas moléculas de água com as espécies EMH e $\mathrm{EM}^{-}$calculadas das simulações computacionais realizadas com os campos de forças GROMOS e OPLS. A análise dessa tabela mostra que o número de ligações de hidrogênio e a energia dessas ligações são similares para ambos compos de forças, apresentando uma diferença de menos de uma ligação de hidrogênio por configuração e $0.5 \mathrm{kcal} / \mathrm{mol}$ na energia média dessas ligações. Uma análise mais detalhada mostrou que as interações dos grupos carbonila e hidroxila com as moléculas de água foram levemente mais fortes com o campo de força GROMOS que com OPLS, em particular aos grupos que participam das ligações de hidrogênio intramoleculares O1H1, O8H8 e C9O9. Observamos que: (i) a interação da carbonila C9O9 com a água foi menor do que a carbonila $\mathrm{C} 10 \mathrm{O} 10$, isso porque as ligações de hidrogênio intramoleculares protegeram a carbonila C9O9 da água; (ii) a interação da hidroxila O8H8 com água foi levemente mais forte do que a hidroxila O1H1, isso porque em ambos 
campos de forças a hidroxila O8H8 foi mais flexível, quebrando a ligação de hidrogênio intramolecular mais vezes; (iii) a interação da hidroxila O3H3(EMH) e carbonila $\mathrm{CO} 3\left(\mathrm{EM}^{-}\right)$com a água foi mais forte comparativamente aos outros.

Comparando as propriedades determinadas das simulações computacionais realizadas utilizando os campos de forças GROMOS e OPLS (veja as tabelas no apêndice A) mostramos que ambos campos de forças descrevem bem a dinâmica, a estrutura e a interação das espécies da Emodina com água, de modo que recomendamos o uso de qualquer um desses campos de forças, para modelagem dessas espécies através de simulações cumputacionais com dinâmica molecular. Assim, validamos aqui os parâmetros do campo de força GROMOS 54a7, para as espécies EMH e EM- e ressaltamos que, esses parâmetros estão aptos para serem utilizados na modelagem molecular dessas espécies em bicamadas lipídicas.

\subsubsection{Modelagem da EMH e EM- em bicamada lipídica}

Nessa seção apresentaremos e discutiremos os resultados das simulações computacionais das bicamadas lipídicas de DMPC com dinâmica molecular dos seguintes sistemas: DMPC-puro, DMPC $+\mathrm{EMH}, \mathrm{DMPC}+\mathrm{EM}^{-}$. A descrição completa desses sistemas como também a metodologia utilizada nas simulações estão apresentados na seção 3.5.2. Antes de apresentar nossos resultados, vamos fazer um breve sumário do comportamento desses sistemas, focado principalmente na localização das espécies da Emodina na bicamada lipídica. No decorrer das simulações monitoramos o equilíbrio das simulações através da energia potencial, área e volume por lipídio, onde observamos que o equilíbrio foi atingido após os primeiros 30 ns de simulação. Durante essas simulações monitoramos também as posições das espécies da Emodina nas bicamadas e verificamos que essas espécies apresentam forte tendência de ficar inseridas na bicamada lipídica, numa região próxima às cabeças polares dos fosfolipídios. Esse comportamento das espécies foi observado até mesmo para as simulações que partiram 
de configurações com as espécies da Emodina na extremidade superior da bicamada (fora da região dos fosfolipídios, mas dentro da região da água), onde observamos que que após os 50 ns de simulação, ambas as espécies se inseriram na bicamada lipídica, saindo, portanto da região da água e indo para região dos fosfolipídios. Nossos principais resultados das simulações das espécies EMH e EM- em bicamada mostram que elas ficam inseridas na bicamada lipídica numa região próxima aos gliceróis, como será discutido a seguir nas análises da evolução temporal das posições das espécies, densidade eletrônica e distribuição radial de pares. Dessa forma, todos os resultados apresentados nessa seção relacionados à dinâmica, localização, orientação, estrutura e interação das espécies com a bicamada hidratada serão, portanto, com a Emodina inserida na bicamada.

Ressaltamos que o foco principal desse estudo consistia em investigar as espécies da Emodina nas bicamadas lipídicas, mas antes de apresentar nossos resultados desse estudo, vamos apresentar e discutir as propriedades estruturais das bicamadas lipídicas determinadas nas simulações como área por lipídio $\left(A_{L}\right)$, volume por lipídio $\left(V_{L}\right)$, compressibilidade isotérmica da área $\left(K_{A}\right)$, os parâmetros de espessura da bicamada, parâmetros de ordem das cadeias hidrocarbônicas e densidade eletrônica.

\subsubsection{Propriedades das bicamadas lipídicas}

A fim de validar nossas simulações computacionais das bicamadas lipídicas de DMPC, realizamos uma análise das propriedades estruturais das bicamadas como área por lipídio $\left(A_{L}\right)$, volume por lipídio $\left(V_{L}\right)$, compressibilidade isotérmica $\left(K_{A}\right)$, parâmetro de ordem das cadeias hidrocarbônicas e densidade eletrônica de cada componente da bicamada. A área por lipídio foi calculada a partir da área lateral da caixa de simulação dividido pelo número de lipídios em cada monocamada. Na figura 4.18 apresentamos a evolução temporal da área por lipídio dos três sistemas simulados, onde mostra claramente que o equilíbrio dos três sistemas DMPC-puro, DMPC $+\mathrm{EMH}$, 
$\mathrm{DMPC}+\mathrm{EM}^{-}$foi atingido após os primeiros $30 \mathrm{~ns}$ de simulação. Essa informação garante que os sistemas encontram-se em equilíbrio durante as simulações de produção, ou seja, nos últimos 100 ns de simulação, período em que foram coletados nossos dados para fins de produção.

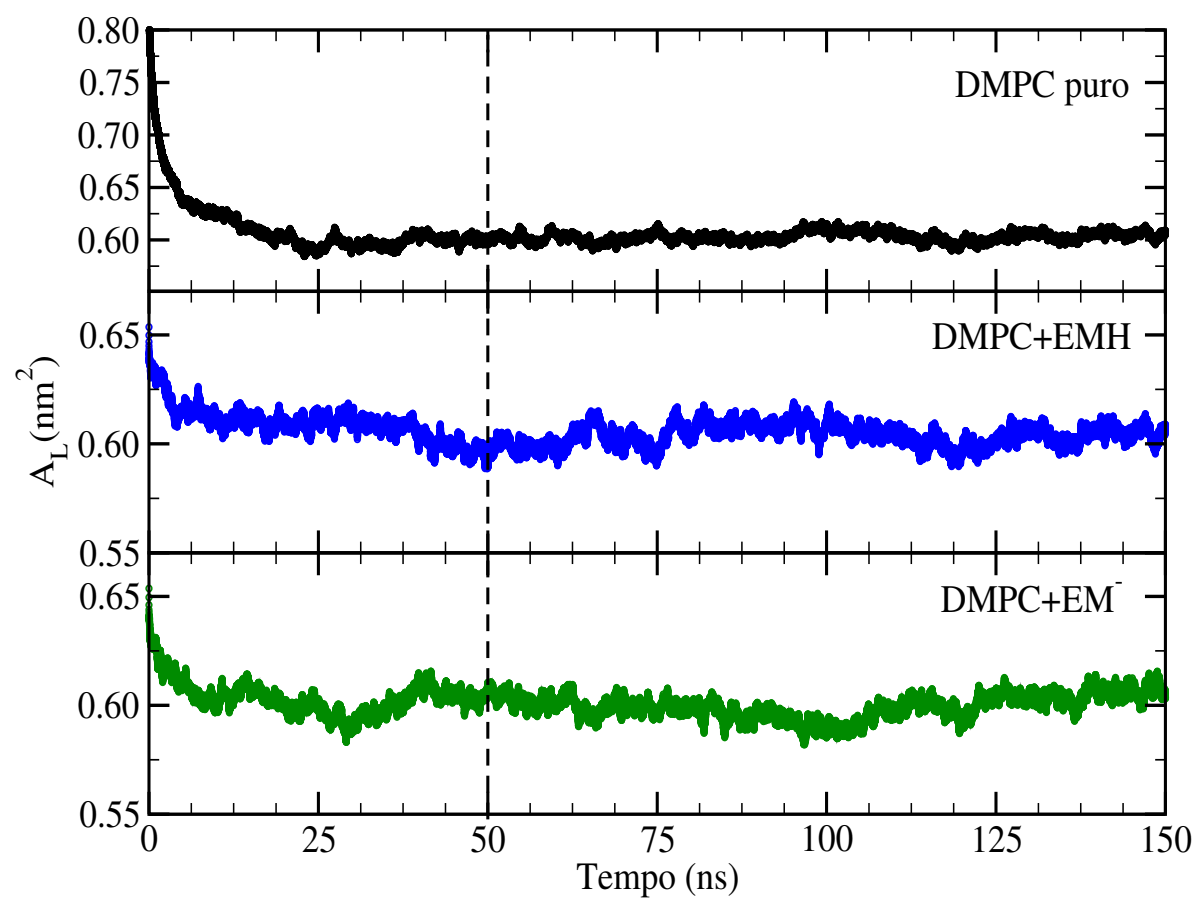

Figura 4.18: Evolução temporal da área por lipídio obtida das simulações dos sistemas DMPC-puro, DMPC $+\mathrm{EMH}$ e DMPC $+\mathrm{EM}^{-}$.

O valor médio da área por lipídio obtido nos três sistemas é de $0.602 \pm 0.005$ $\mathrm{nm}^{2} /$ lipídio, indicando que a inserção de apenas uma molécula de Emodina na bicamada lipídica não provoca efeito significativo na área por lipídio. Isso é esperado porque o cálculo dessa propriedade discutido acima não é local, ou seja, não é na vizinhança da espécie, mas global que envolve todo o sistema. Uma análise da área por lipídio na vizinhança local das espécies da Emodina mostra uma mudança significativa dessa propriedade em torno das espécies como será discutido na seção 4.4.2.5. O valor obtido para $A_{L}$ de $0.602 \pm 0.005 \mathrm{~nm}^{2} /$ lipídio é característico de bicamada lipídica de DMPC na fase fluida, uma vez que os valores experimentais de $A_{L}$ da bicamada nessa 
fase estão todos na faixa de 0.58-0.67 [112-119].

Embora o cálculo da área por lipídio nas simulações computacionais, seja relativamente simples, a medida experimental dessa propriedade é extremamente delicada, pois a maioria das técnicas experimentais como NMR, espalhamento de raios-X a baixo ângulo (SAXS) e espalhamento de nêutrons a baixo ângulo (SANS) obtém essa propriedade através de medidas indiretas, o que gera erros significativos. Isso explica a divergência dos valores encontrados na literatura para $A_{L}$ em vários trabalhos experimentais. Apesar disso, essa propriedade é bastante usada para validar simulações computacionais, mas existem na literatura trabalhos que mostram que $A_{L}$ não é um bom indicador para avaliar a qualidade do campo de forças usado na simulação, pois essa propriedade é altamente sensível a mudanças de campo de força, como também a parâmetros de controle da simulação tais como termostato, barostato e raio de corte [323].

Uma propriedade que vem sendo amplamente usada para avaliar a qualidade das simulações é o volume por lipídio $\left(V_{L}\right)$, pois apresenta uma convergência mais rápida do que a $A_{L}$ e pouca flutuação. Além disso, $V_{L}$ é obtido experimentalmente com melhor precisão como discutido nas seguintes referências $[118,128]$. Essa propriedade pode ser calculada usando a seguinte equação,

$$
V_{L}=\frac{V-n_{w} V_{w}}{n_{L}}
$$

onde $V$ é o volume da caixa de simulação, $n_{L}$ e $n_{w}$ são o número de moléculas de lipídios e de água, respectivamente, $V_{w}$ é o volume por molécula de águ, que foi calculado previamente no valor de $3.09 \times 10^{-2} \mathrm{~nm}^{3}$ [111]. Assim, usando a equação 4.5, nós calculamos o volume por lipídio para os três sistemas simulados. Na figura 4.19 apresentamos a evolução temporal dessa propriedade para os sistemas DMPC-puro, $\mathrm{DMPC}+\mathrm{EMH}, \mathrm{DMPC}+\mathrm{EM}^{-}$.

Os valores obtidos para $V_{L}$ nas simulações de produção desses sistemas são 


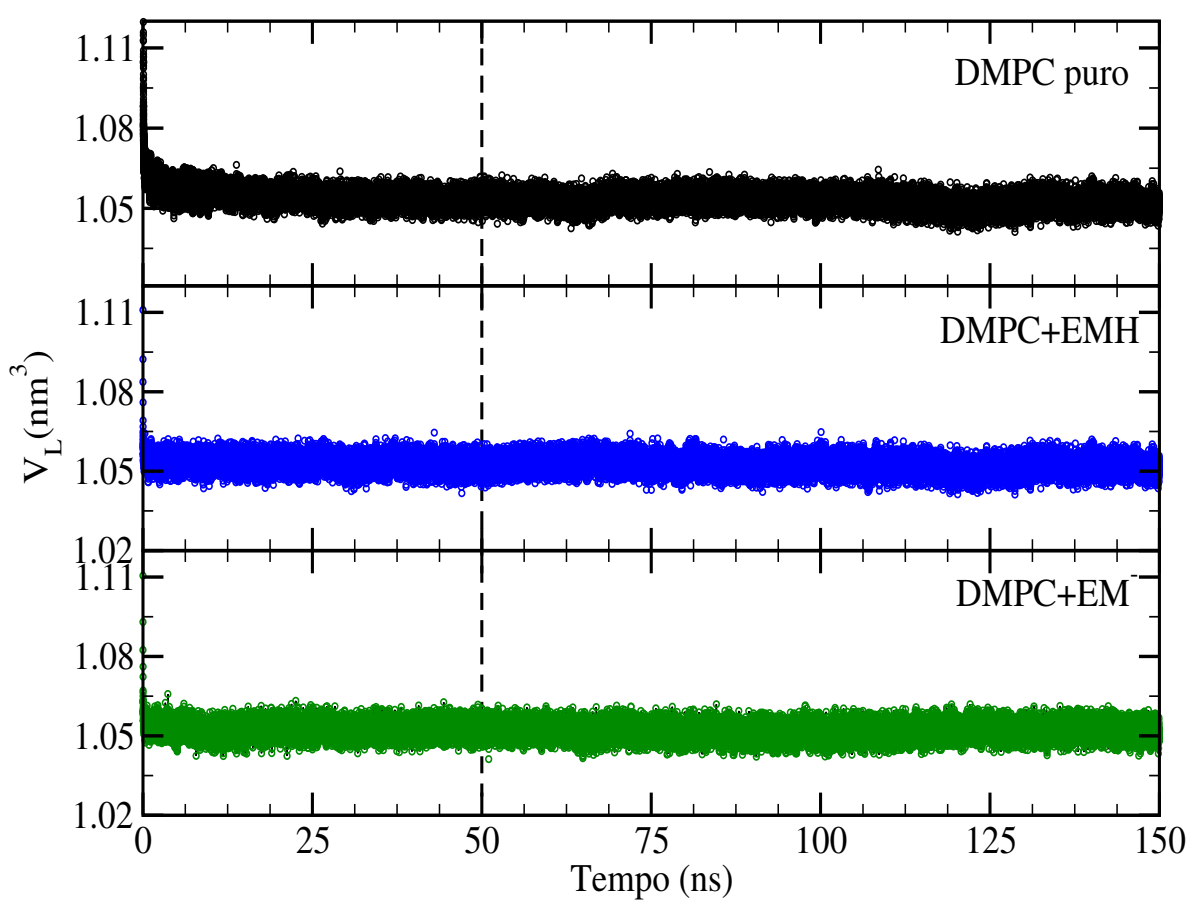

Figura 4.19: Evolução temporal do volume por lipídio obtida das simulações dos sistemas DMPC-puro, DMPC $+\mathrm{EMH}$ e DMPC $+\mathrm{EM}^{-}$.

praticamente os mesmos, onde obtemos $V_{L}=1.052 \pm 0.003 \mathrm{~nm}^{3} /$ lipídio. Esse valor está em boa concordância com os valores experimentais de 1.09 e $1.10 \mathrm{~nm}^{3} /$ lipídio $[81,118,119,127]$ e com valores de simulações encontrados na literatura que estão na faixa de 0.98 a $1.23 \mathrm{~nm}^{3} /$ lipídio $[110,111,128,129]$.

Outra propriedade usada para avaliar a qualidade de simulação de bicamada lipídica é a compressibilidade isotérmica da área $\left(K_{A}\right)$, que está relacionada com a elasticidade desse sistema. Essa propriedade pode ser determinada a partir de flutuações da área por lipídio através da seguinte equação,

$$
K_{A}=\frac{k_{B}\langle T\rangle\left\langle A_{L}\right\rangle}{n_{L}^{\prime} \sigma_{A}^{2}}
$$

onde $k_{B}$ é a constante de Boltzmann, $\langle T\rangle$ é o valor médio da temperatura, $\left\langle A_{L}\right\rangle$ é o valor médio da área por lipídio, $n_{L}^{\prime}$ é o número de fosfolipídio numa monocamada, e $\sigma_{A}^{2}$ é a variância associado a $A_{L}$. Os valores obtidos para $K_{A}$ nas simulações dos três 
sistemas DMPC-puro, DMPC+EMH e DMPC+EM- foram 571, 649 e 507 mN.m-1. Esses valores apresentam grandes flutuações, cerca de $80 \mathrm{mN} \cdot \mathrm{m}^{-1}$, mas apesar disso, estão todos dentro da faixa de valores teóricos encontrados na literatura de 226-600 mN.m ${ }^{-1}[110,111,129]$. Porém uma comparação com os valores experimentais de 234 e $257 \mathrm{mN} \cdot \mathrm{m}^{-1}[81,130]$, mostra que os valores obtidos para $K_{A}$ nas nossas simulações estão superestimados, pois são praticamente o dobro dos valores experimentais. Isso já era esperado, pois alguns trabalhos têm apresentado que o uso de condições de contorno periódicas na caixa de simulação, em particular simulações de sistemas pequenos, pode comprimir a área por lipídio, reduzindo assim o valor da variância $\sigma_{A}^{2}$, e com isso, superestimando o valor da compressibilidade isotérmica da área, ver as seguintes referências [110, 111,323].

Calculamos também o parâmetro de ordem das cadeias hidrocarbônicas dos fosfolipídios nas simulações computacionais, a fim de caracterizar a fase da bicamada lipídica, uma vez que esse parâmetro indica o grau da ordem dessas cadeias dentro da bicamada. Apesar das simulações terem sidas realizadas na temperatura de $303 \mathrm{~K}$, o que indicaria a bicamada na fase fluida, é necessário realizar a análise desse parâmetro de ordem, pois alguns trabalhos têm apresentado que do ponto de vista teórico a fase da bicamada é dependente não somente da temperatura mas também do campo de força aplicado na simulação [110,111].

Assim, calculamos especificamente o parâmetro de ordem deutério $\mathrm{S}_{\mathrm{CD}}$, que fornece informações das orientações relativas das ligações C-D das cadeias hidrocarbônicas com relação ao eixo z. Esse parâmetro para uma dada ligação C-D na posição $i$ da cadeia hidrocarbônica é definido como uma média no ensemble através da seguinte equação,

$$
S_{C D}^{i}=\frac{1}{2}\left\langle 3 \cos ^{2} \theta_{i}-1\right\rangle
$$

onde $\theta_{\mathrm{i}}$ é o ângulo entre o vetor da ligação C-D na posição $i$ da cadeia hidrocarbônica e o eixo z normal a bicamada lipídica. Como usamos a opção "united atoms" do campo 


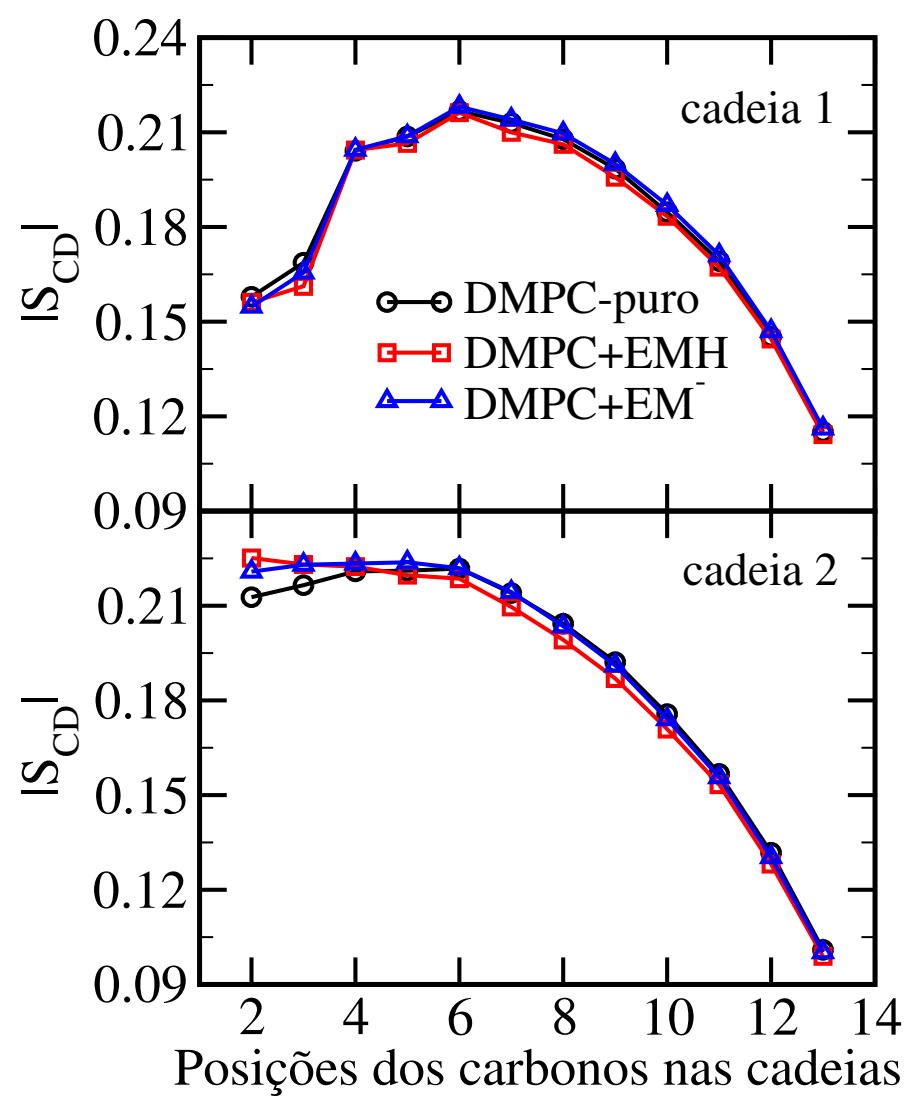

Figura 4.20: Parâmetro de ordem deutério $\left|\mathrm{S}_{\mathrm{CD}}\right|$ das cadeias hidrocarbônicas 1 e 2 do fosfolipídio DMPC, calculados das simulações de equilíbrio dos sistemas DMPC-puro, DMPC + EMH e $\mathrm{DMPC}+\mathrm{EM}^{-}$.

de força GROMOS 54a7, as posições dos deutérios foram construídas baseadas nas posições dos carbonos vizinhos na cadeia hidrocarbônica assumindo uma geometria tetraédrica.

Na figura 4.20, apresentamos o parâmetro de ordem $\left|\mathrm{S}_{\mathrm{CD}}\right|$ das cadeias hidrocarbônicas 1 e 2 do fosfolipídio DMPC, calculados das simulações de produção dos sistemas DMPC-puro, DMPC + EMH e DMPC + EM$^{-}$. Nesse cálculo definimos as cadeias hidrocarbônicas partindo do grupo carbonila e indo até o último carbono da extremidade da cadeia. Observe que numeramos esses carbonos das cadeias de 1 a 14 , sendo 1 o carbono do grupo carbonila e 14 o último carbono da cadeia, onde no cálculo esses dois carbonos das extremidades foram excluídos. Assim o parâmetro $\left|\mathrm{S}_{\mathrm{CD}}\right|$ apresentado 
nessa figura mostra que os carbonos iniciais, próximos da carbonila apresentam uma ordem maior do que dos carbonos da extremidade das cadeias, visto que o parâmetro de ordem desses carbonos é maior do que dos carbonos da extremidade da cadeia. Os parâmetros de ordem das cadeias 1 e 2 obtidas das simulações dos três sistemas são praticamente iguais, apresentando apenas pequenas diferenças.

Similarmente a análise da área por lipídio, quando é levado em consideração todo o sistema no cálculo dessas propriedades, a introdução de apenas uma molécula de Emodina na bicamada não altera significativamente essas propriedades. Entretanto, como mostraremos a seguir, um cálculo tanto da área por lipídio como também do parâmetro de ordem das cadeias hidrocarbônicas dos lipídios da vizinhança das espécies da Emodina mostra uma mudança significativa dessas propriedades em torno dessas espécies.

Uma comparação do parâmetro de ordem das duas cadeias hidrocarbônicas nos mostra que a cadeia 1 apresenta um comportamento interessante, pois observamos que os carbonos próximos à carbonila, por exemplo, o carbono 2, apresenta uma ordem menor do que o carbono 3, e à medida que se desloca ao longo da cadeia no sentido da extremidade, observamos que a ordem dos carbonos vai aumentando gradativamente chegando até um valor máximo, no carbono 6, e depois diminui à medida que desloca para a extremidade da cadeia. Esse comportamento dessa cadeia tem sido observado experimentalmente por Petrache e colaboradores [324] e Vermeer e colaboradores [325], que determinaram o parâmetro de ordem das cadeias hidrocarbônicas do DMPC através de medidas de NMR. A análise geral dos parâmetros de ordem nas duas cadeias hidrocarbônica mostra que os valores desses parâmetros para os carbonos das cadeias estão todos abaixo de 0.23 , o que indica um grau de ordem muito baixo, caracterizando assim a bicamada lipídica na fase fluida, uma vez que nessa fase as cadeias hidrocarbônicas apresentam alta desordem. Esses resultados estão em boa concordância com trabalhos experimentais [324-326] e com os trabalhos teóricos [111,129]. 
Também realizamos uma análise da densidade eletrônica de cada molécula nos sistemas simulados. Essa análise foi feita através do cálculo da densidade eletrônica em $5 \times 10^{5}$ configurações obtidas de cada simulação de produção, onde para cada configuração foi calculada essa propriedade, dividindo a caixa de simulação em pequenas fatias ao longo da bicamada, sendo todas normais ao eixo z, e calculado a densidade de cada átomo nessas fatias através da seguinte equação,

$$
\rho(z)=\frac{n_{a} \cdot e}{d V},
$$

onde $e$ é a carga de um elétron, $n_{a}$ é o número total de elétrons de cada átomo, ou seja, o número atômico, e $d V$ é o volume da fatia, dado pela relação $d V=z d x d y$. Uma vez calculada a densidade em cada configuração, é então calculado o valor médio dessa propriedade em cima de todas as configurações. Inicialmente realizamos uma análise da densidade eletrônica das moléculas de água e DMPC, em que a molécula de DMPC foi dividida em 8 grupos sendo: colina, fosfato, glicerol_1, glicerol_2, cadeia_1A, cadeia_1B, cadeia_2A e cadeia_2B, veja a definição desses grupos na figura 4.21.

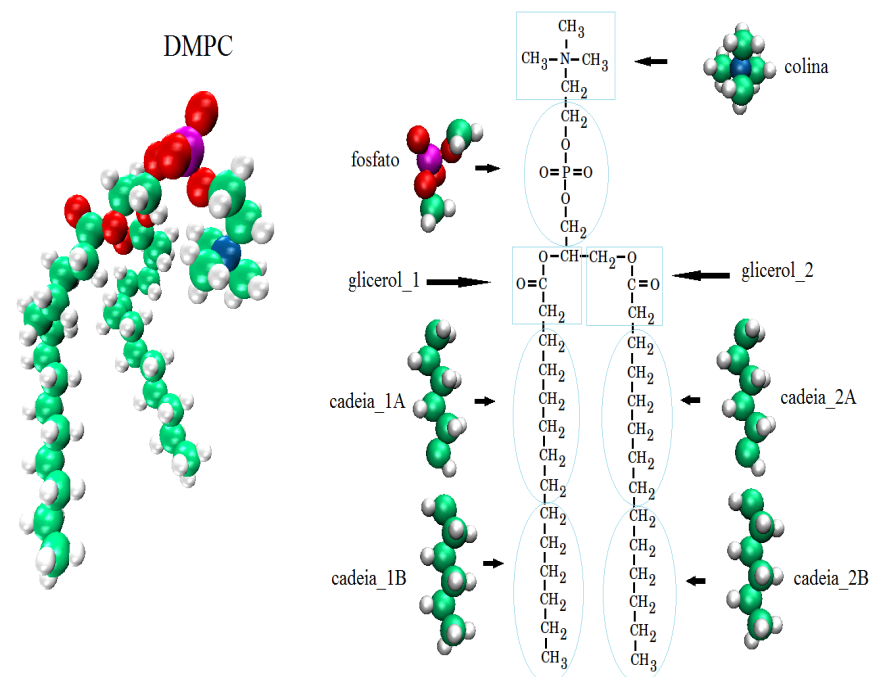

Figura 4.21: Ilustração da estrutura química da molécula de DMPC dividida nos grupos colina, fosfato, glicerol_1, glicerol_2, cadeia_1A, cadeia_1B, cadeia_2A e cadeia_2B.

Na figura 4.22 estão mostradas as contribuições da densidade eletrônica das mo- 
léculas de água e DMPC, como também dos 8 grupos do DMPC mostrados na figura 4.21 e a do sistema (água+DMPC). A análise da densidade eletrônica do sistema ao longo da coordenada z da caixa de simulação mostra que essa propriedade é caracterizada por dois picos de alta densidade nas regiões das cabeças polares dos fosfolipídios devido aos fosfatos, por serem eletronicamente mais densos. É também observada uma região de baixa densidade eletrônica, no centro da bicamada, justamente na interface entre as cadeias hidrocarbônicas das monocamadas lipídicas. Uma comparação com os trabalhos experimentais de Nagle e colaboradores [81,147], em que determinaram a densidade eletrônica de bicamadas de DMPC através de medidas de raio-X, indica que a densidade do sistema obtida neste trabalho apresenta características de bicamadas na fase fluida. Isso é comprovado pelo pico de alta densidade eletrônica na região das cabeças polares e tamtém, pelo ponto mínimo na região central da bicamada, que apresenta uma densidade da ordem de 240 e. $\mathrm{nm}^{-3}$, que é característico de bicamadas na fase fluida, pois ele é bem maior do que o valor medido para bicamada na fase gel [327].

A análise das densidades eletrônicas das moléculas de DMPC e água ao longo da coordenada $z$, mostra que na região entre a borda da caixa e a interface águafosfolipídio, a densidade da água é praticamente constante em torno de 330 e.nm ${ }^{-3}$, e dos fosfolipídios é nula nessa região, e à medida que se desloca em direção ao centro da bicamada, a densidade da água vai diminuindo gradativamente, até zero no centro da bicamada, e a dos fosfolipídios vai aumentando gradativamente, até um valor máximo na região das cabeças polares e, depois dessa região, ela vai diminuindo gradativamente, até um valor mínimo no centro da bicamada. Esse comportamento da densidade nessa região ocorre porque as cabeças polares dos fosfolipídios são mais densas eletronicamente do que as cadeias hidrocarbônicas.

A fim de obter mais detalhes da densidade eletrônica na região dos lipídios, realizamos uma análise dessa propriedade em que a molécula de DMPC foi divida nos 


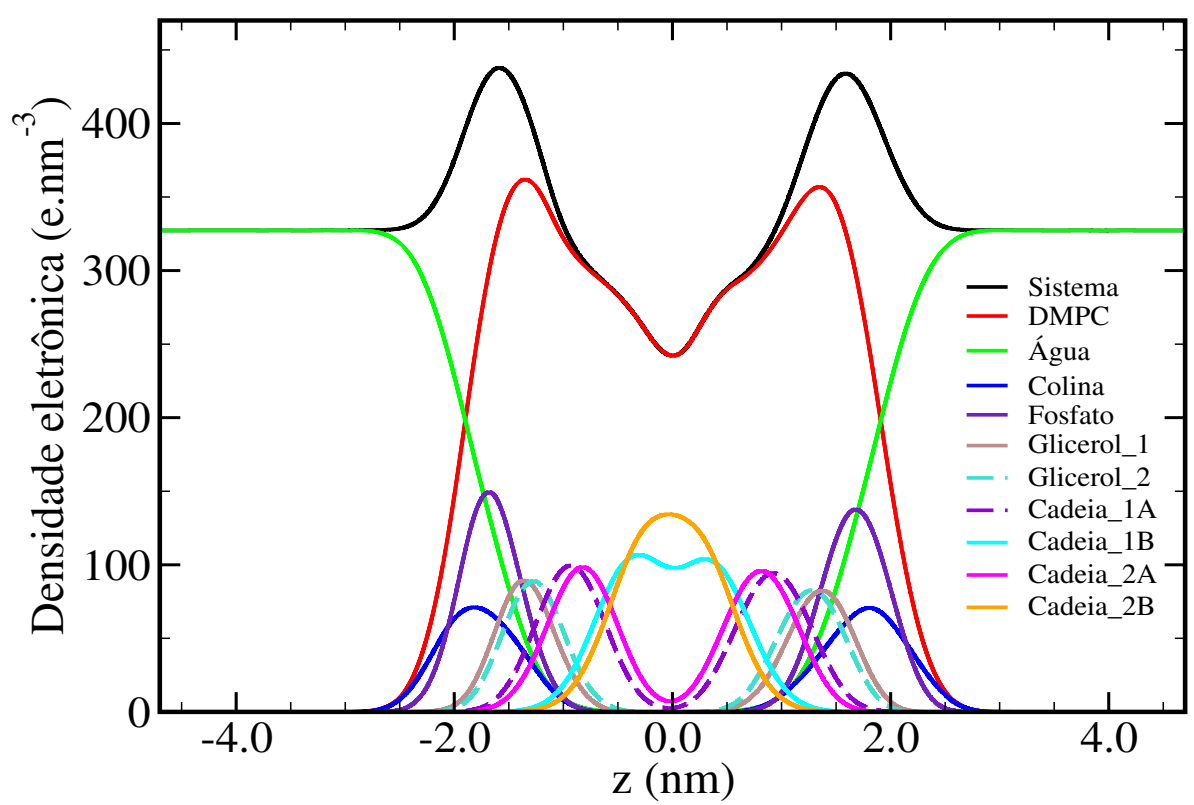

Figura 4.22: Densidade eletrônica da bicamada lipídica de DMPC e das contribuições das moléculas de água e DMPC, e também dos 08 grupos do DMPC colina, fosfato, glicerol_1, glicerol_2, cadeia_1A, cadeia_1B, cadeia_2A e cadeia_2B. A definição desses grupos está mostrada na figura 4.21 .

grupos colina, fosfato, glicerol_1, glicerol_2, cadeia_1A, cadeia_1B, cadeia_2A e cadeia_2B, ver a definição desses grupos na figura 4.21. As densidades eletrônicas desses grupos mostradas na figura 4.22, estão coerentes com a estrutura da bicamada lipídica, visto que o grupo colina encontra-se mais próximo da interface água-fosfolipídio, e em seguida vêm o fostado, depois os gliceróis, as cadeias do tipo A e por último as cadeias do tipo B, que estão mais próximas do centro da bicamada. Uma comparação entre os grupos do tipo 1 e 2 mostra que os máximos das densidades dos grupos do tipo 1, por exemplo, glicerol_1, cadeia_1A e cadeia_1B estão deslocados cerca de $1 \AA$ para região externa, comparados com os grupos do tipo 2. Isso ocorre devido à diferença de 1 átomo a mais na cadeia hidrocarbônica do tipo 2, justamente na região dos gliceróis, veja figura 4.21. Essa diferença provoca um efeito bastante interessante na região central da bicamada, bem na interface entre as duas monocamadas em que a cadeia_1B apresenta uma melhor definição do centro da bicamada do que a cadeia_2B, uma vez 
que a densidade eletrônica da cadeia_1B nesse ponto apresenta um mínimo, enquanto o a densidade da cadeia_2B apresenta um máximo nessa região.

Tabela 4.10: Sumário das propriedades estruturais das bicamadas lipídicas hidratadas de DMPC obtidas neste trabalho com simulações computacionais. Nessa tabela mostramos também para fins de comparação essas mesmas propriedades, encontradas na literatura, obtidas através de medidas experimentais e simulações computacionais com dinâmica molecular.

\begin{tabular}{cccc}
\hline \hline Propriedades & Tese doutorado & Simul. Liter. & Exper. Liter. \\
\hline $\mathrm{A}_{\mathrm{L}}\left(\mathrm{nm}^{2}\right)$ & $0.602 \pm 0.005$ & $0.57-0.66^{\beta}$ & $0.58-0.67^{\alpha}$ \\
$\mathrm{V}_{\mathrm{L}}\left(\mathrm{nm}^{3}\right)$ & $1.052 \pm 0.003$ & $0.98-1.23^{\varepsilon}$ & $(1.09,1.10)^{\chi}$ \\
$\mathrm{K}_{\mathrm{A}}\left(\mathrm{mN}^{-1} \mathrm{~m}^{-1}\right)$ & $576 \pm 70$ & $226-475^{\gamma}$ & $(234,257)^{\phi}$ \\
$\mathrm{D}_{\mathrm{HH}}(\mathrm{nm})$ & $3.26 \pm 0.02$ & $2.92-3.35^{\varepsilon}$ & $3.44-3.60^{\eta}$ \\
$2 \mathrm{D}_{\mathrm{c}}(\mathrm{nm})$ & $2.60 \pm 0.02$ & --- & $2.54,2.62^{\eta}$ \\
$\mathrm{D}_{\mathrm{B}}(\mathrm{nm})$ & $3.50 \pm 0.02$ & $2.99-3.49^{\varepsilon}$ & $3.07-3.69^{\eta}$ \\
\hline \hline
\end{tabular}

Ver as seguintes referências: $\alpha$ - [112-119] ; $\beta$ - [110,111,120-126]; $\chi$ - [81,118,119,127]; $\varepsilon-[110,111,128,129]$; $\phi-[81,130] \gamma-[110,111,129] ; \eta-[81,118,119]$.

Usando a densidade eletrônica do sistema mostrado na figura 4.22, determinamos alguns parâmetros comumente usados para caracterizar a fase da bicamada e avaliar a qualidade das simulações, visto que eles podem ser comparados diretamente com os parâmetros obtidos de medidas de raios-X, tais como as espessuras da região das cadeias hidrocarbônicas $\left(\mathrm{D}_{\mathrm{c}}\right)$, da bicamada lipídica $\left(\mathrm{D}_{\mathrm{HH}}\right)$ e de Luzzati $\left(\mathrm{D}_{\mathrm{B}}\right)$, veja a figura A.20 no apêndice A, com a ilustração desses parâmetros na curva da densidade eletrônica do sistema (água +lipídios). O parâmetro $\mathrm{D}_{\mathrm{HH}}{ }^{4}$ é definido como a distância

\footnotetext{
${ }^{4} \mathrm{O}$ parâmetro $\mathrm{D}_{\mathrm{HH}}$ é definido como a distância entre os dois picos de máxima densidade eletrônica,
} 
entre os dois picos de máxima densidade eletrônica do sistema. Os valores obtidos para esse parâmetro nas simulações dos três sistemas simulados foram praticamente os mesmos, $\mathrm{D}_{\mathrm{HH}}=3.26 \pm 0.02 \mathrm{~nm}$, que está em boa concordância com a faixa de valores experimentais encontrados na literatura de 3.44 a $3.60 \mathrm{~nm}[81,118,119]$.

A espessura da região das cadeias hidrocarbônicas $\left(D_{c}\right)$ é um parâmetro estrutural bastante importante do ponto de vista experimental, pois ele é frequentemente determinado a partir de medidas de espalhamento de raio-X e usado para determinar a área por lipídio através da seguinte relação, $A_{L}=\frac{V_{L}-V_{H L}}{D_{c}}$, onde $V_{L}$ e $V_{H L}$ são os valumes por lipídios e por metilas, respectivamente. O valor determinado para o parâmetro $\mathrm{D}_{\mathrm{c}}$ nas simulações das bicamadas lipídicas de DMPC foi $2.60 \pm 0.02 \mathrm{~nm}$, que está em excelente concordância com os valores experimentais de $2.54 \mathrm{~nm}$ [81] e 2.62 nm [119]. Determinamos também a espessura de Luzzati $\left(D_{B}\right)$, que é definido através da seguinte equação,

$$
D_{B}=L_{z}-2 \int_{0}^{L_{z} / 2} p_{w}(z) d z,
$$

onde $L_{z}$ é a coordenada $z$ da caixa de simulação, $p_{w}(z)$ é a distribuição de probabilidade de encontrar moléculas de água ao longo da coordenada $z$, e é dada através da seguinte equação,

$$
p_{w}(z)=\frac{n_{w}(z) V_{w}}{d V},
$$

em que $n_{w}(z)$ é o número médio de moléculas de água por fatia ao longo da coordenada $z$, e $d V$ é o volume médio dessas fatias. Os valores obtidos para $\mathrm{D}_{\mathrm{B}}$ nos três sistemas simulados foram praticamente os mesmos, $\mathrm{D}_{\mathrm{B}}=3.50 \pm 0.02 \mathrm{~nm}$, que está dentro da faixa de valores experimentais encontrados na literatura de 3.07-3.69 $\mathrm{nm}[81,118,119]$.

Na tabela 4.10 apresentamos um sumário de todos os parâmetros estruturais determinados das bicamadas lipídicas de DMPC simuladas neste trabalho. Como podemos observar nessa tabela, nossas simulações computacionais foram capazes de

que é determinado experimentalmente com alta precisão através de medidas de raio-X, pois o contraste na intensidade de espalhamento entre as regiões das cabeças polares e das cadeias hidrocarbônicas dos lipídios é bem definido, devido à grande diferença da densidade eletrônica dessas duas regiões. 
reproduzir as propriedades estruturais das bicamadas lipídicas de DMPC como área $\left(A_{L}\right)$ e volume $\left(V_{L}\right)$ por lipídio, compressibilidade isotérmica $\left(K_{A}\right)$ e os parâmetros de espessuras da região das cadeias hidrocarbônicas $\left(\mathrm{D}_{\mathrm{c}}\right)$, da bicamada lipídica $\left(\mathrm{D}_{\mathrm{HH}}\right)$ e de Luzzati $\left(D_{B}\right)$, que pode ser comprovado através da comparação com os valores encontrados na literatura dessas propriedades obtidas através de medidas experimentais e simulações computacionais com dinâmica molecular. Dada essa reprodutibilidade dessas propriedades, validamos aqui nossas simulações computacionais com dinâmica molecular das bicamadas lipídicas de DMPC, garantindo assim um modelo realista para o estudo das espécies da Emodina nas bicamadas lipídicas de DMPC.

\subsubsection{Localização e orientação das espécies da Emodina na bicamada}

Nossa primeira abordagem neste estudo foi investigar a localização das espécies EMH e EM- na bicamada lipídica. Para isso, monitoramos a evolução temporal das coordenadas z do centro de massa $(\mathrm{CM})$, do oxigênio O3 e do carbono do metil (MT) das espécies da Emodina, todas relativas ao centro da bicamada lipídica $(\mathrm{Z}=0)$, veja a figura 4.23. Essa figura mostra que durante os últimos 100 ns de simulação de produção, as espécies ficaram em equilíbrio localizadas dentro da bicamada hidratada. Uma comparação das coordenadas z dos átomos da extremidade superior (O3) e inferior (MT) das espécies mostra que o carbono do metil está mais próximo do centro do bicamada do que o oxigênio O3, e não é observado em nenhum instante a inversão completa dessas posições, indicando que a rotação de $180^{\circ}$ das espécies em relação ao eixo Z não ocorre durante as simulações. Os valores médios obtidos para as coordenadas z do centro de massa das espécies EMH e EM- foram 1.14 e $1.54 \mathrm{~nm}$, indicando que a espécie EMH está cerca de $0.4 \mathrm{~nm}$ mais próxima do centro da bicamada lipídica que a espécie $\mathrm{EM}^{-}$.

A fim de apresentar mais detalhes da localização das espécies da Emodina na bicamada lipídica, realizamos uma análise da densidade eletrônica das espécies EMH e 


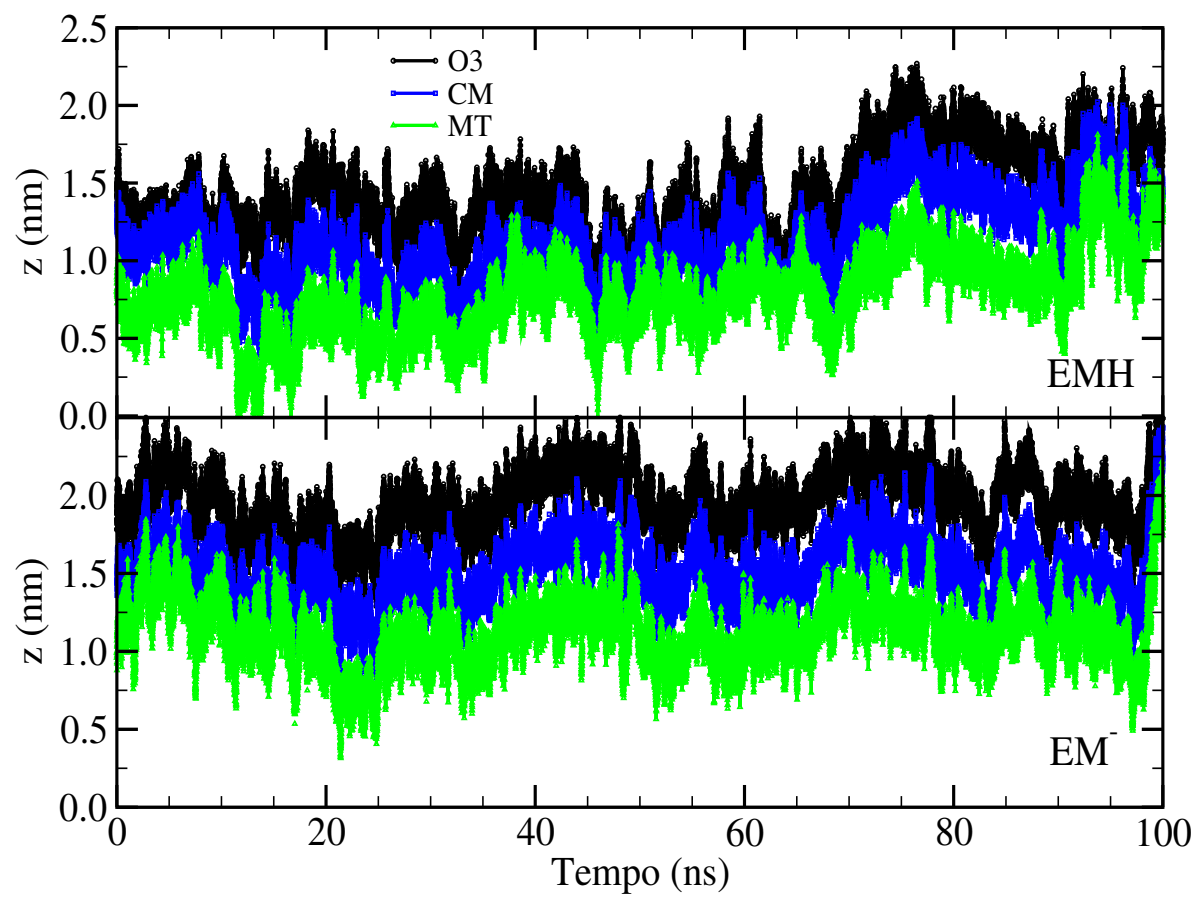

Figura 4.23: Evolução temporal das coordenadas das coordenadas z do centro de massa $(\mathrm{CM})$, do oxigênio $\mathrm{O} 3$ e do carbono do metil (MT) das espécies da Emodina, todas relativas ao centro da bicamada lipídica $(\mathrm{Z}=0)$.

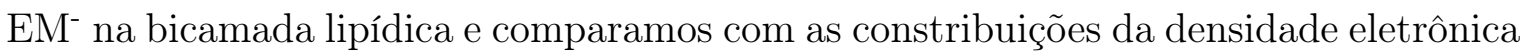
dos grupos colina, fosfato, glicerol_1 e glicerol_2. Devido à baixa densidade eletrônica das espécies EMH e $\mathrm{EM}^{-}$, suas densidades foram multiplicadas por um fator de 50 para uma melhor comparação com as densidades dos demais componentes do sistema.

Na figura 4.24, apresentamos a densidade eletrônica das espécies e também dos grupos colina, fosfato, glicerol_1 e glicerol_2. A análise dessa figura mostra que as espécies da Emodina ficaram inseridas na bicamada lipídica na região dos fosfolipídios bem próximas aos gliceróis. Essa análise corrobora com a figura 4.23 que mostra que a espécie $\mathrm{EM}^{-}$está mais próxima do grupo colina dos lipídios do que a EMH, indicando que a EM- está mais exposta à água do a EMH que está mais protegida na região das cadeias hidrocarbônicas dos fosfolipídios. Adicionalmente, as curvas da densidade eletrônica das espécies EMH e EM- apresentam formas e posições bem definidas, sendo 


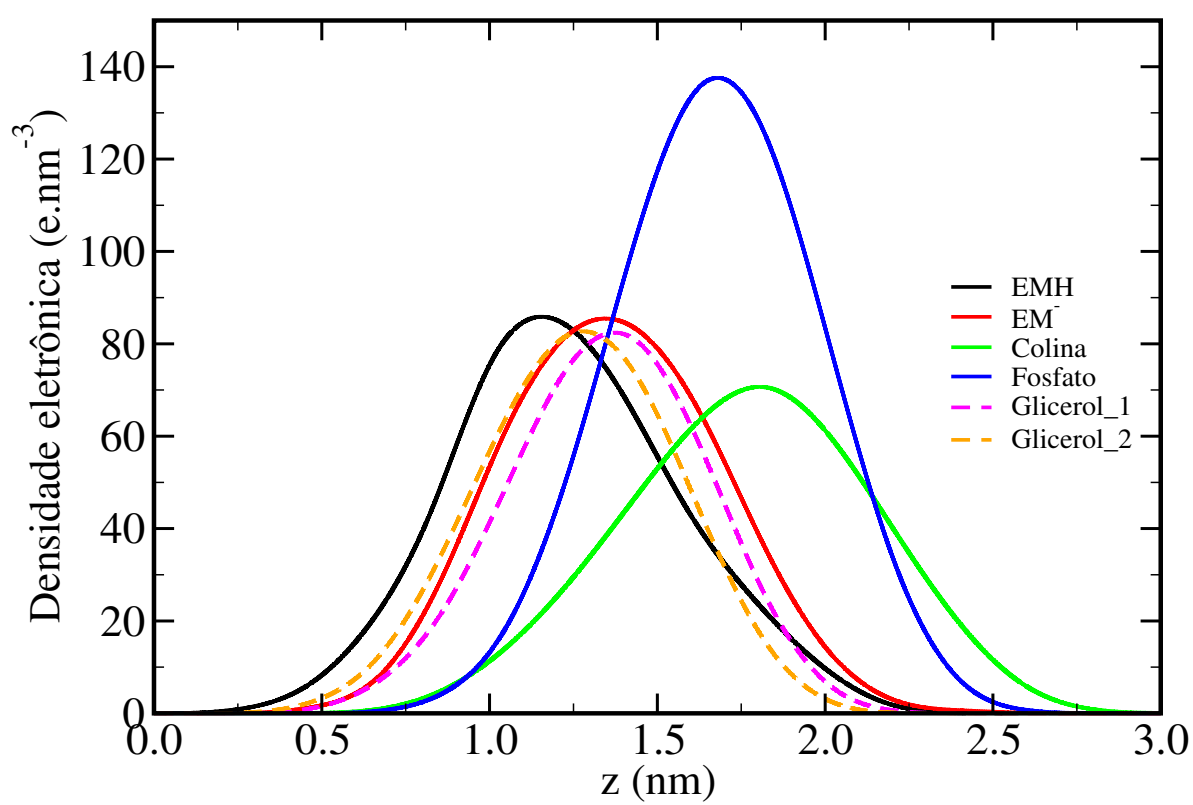

Figura 4.24: Densidade eletrônica das espécies EMH e EM- na bicamada lipídica de DMPC e das contribuições dos grupos colina, fosfato, glicerol_1 e glicerol_2. A definição desses grupos está mostrada na figura 4.21 .

as formas aproximadamente gaussianas com as posições dos máximos localizados em torno de 1.14 e $1.52 \mathrm{~nm}$, respectivamente. A diferença dessas posições nos leva à mesma informação obtida a partir da figura 4.23, de que a EMH está mais inserida na bicamada lipídica do que a $\mathrm{EM}^{-}$, cerca de $0.4 \mathrm{~nm}$.

Mais detalhes da vizinhança das espécies da Emodina em bicamada foram obtidos através da análise da função de distribuição radial (RDF) de pares das espécies com as moléculas de DMPC, especificamente com os grupos colina, fosfato, glicerol_1 e glicerol_2. Essa distribuição além de fornecer informações da vizinhança dessas espécies, fornece também informações da estrutura do meio em torno dessas espécies. O cálculo da RDF foi realizado considerando apenas uma espécie da Emodina na monocamada lipídica, exatamente a monocamada em que a espécie está inserida. Inicialmente esse cálculo foi realizado levando em consideração as coordenadas x, y e z das moléculas, ou seja, 3D. 


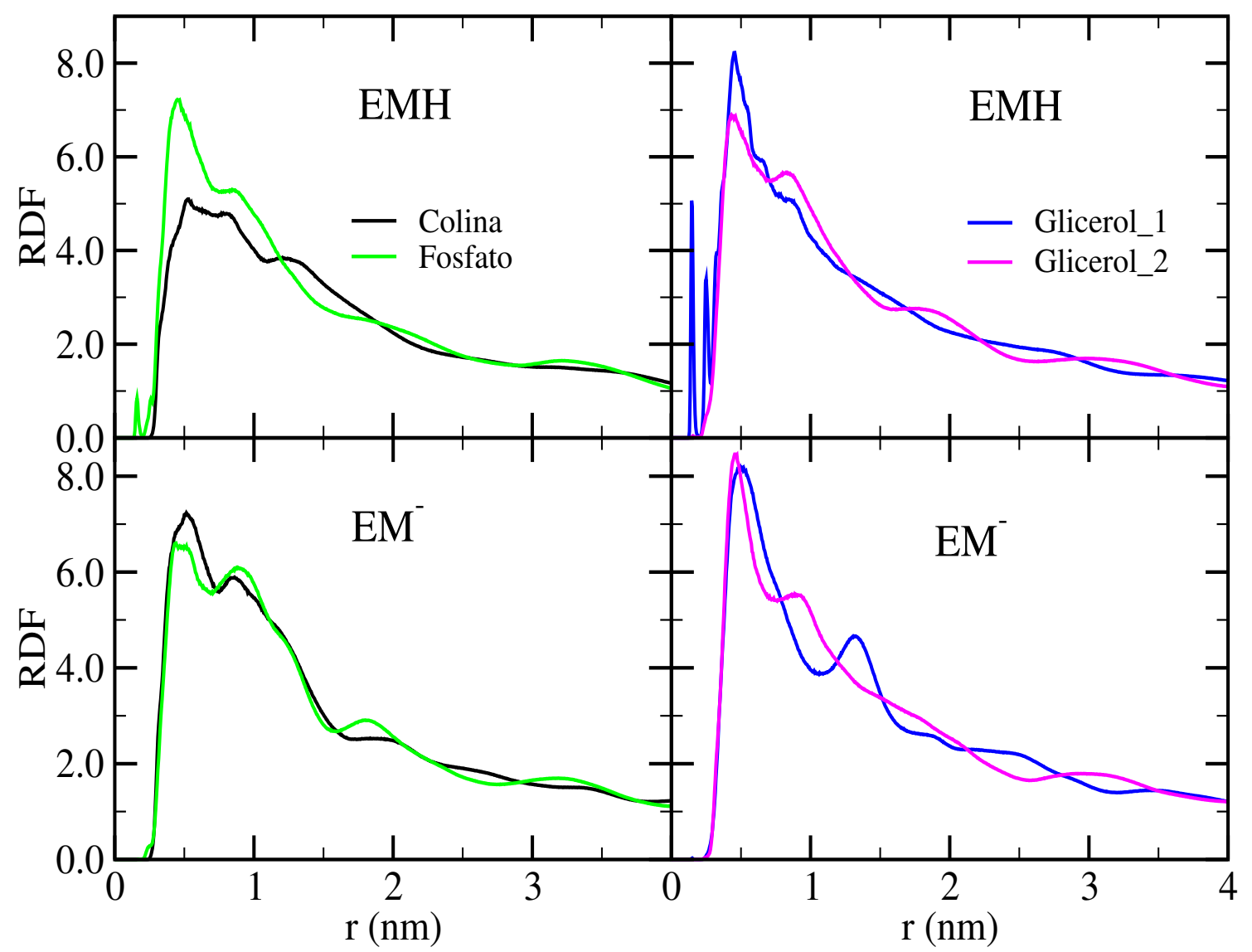

Figura 4.25: Funções de distribuição radial (RDF) de pares entre as espécies da Emodina com os grupos colina, fosfato, glicerol_1 e glicerol_2, calculadas para o sistema formado por uma espécie mais a monocamada lipídica, considerando as três coordenadas ( $\mathrm{x}, \mathrm{y}$ e z) das moléculas.

Na figura 4.25 apresentamos as RDFs das espécies EMH e EM- com os grupos do DMPC (colina, fosfato, glicerol_1 e glicerol_2) obtidas a partir das simulações computacionais dessas espécies em bicamada lipídica. Essas RDFs mostram que as distribuições de lipídios em torno das espécies EMH e EM- são semelhantes, mas com algumas notáveis diferenças como no número de picos, na forma e na posições desses picos. Uma comparação das RDFs das espécies com os grupos do DMPC mostra que o formato dos picos das RDFs da EM- é mais bem definido do que os da EMH, indicando que a estrutura e a interação dos lipídios com essas espécies são diferentes. 
Essa característica está mais evidente na distribuição do glicerol__ em torno da espécie $\mathrm{EM}^{-}$, onde existem dois picos bem definidos centrados nas posições 0.5 e $1.3 \mathrm{~nm}$ que estão associados à primeira e à segunda camada de lipídios em torno dessa espécie. Já a RDF do glicerol_1 com a espécie EMH mostra dois picos centrados nas posições de 0.1 e $0.2 \mathrm{~nm}$, que são característicos de ligações de hidrogênio entre essa espécie e o glicerol_1. Além desses dois picos, é observado um terceiro pico centrado na posição de $0.4 \mathrm{~nm}$, que corresponde à primeira camada de lipídios em torno da EMH. Note que não são observados os picos característicos de ligações de hidrogênio nas RDFs da espécie $\mathrm{EM}^{-}$, como os das distribuições de fosfato e glicerol_1 em torno da EMH. Essa informação é a primeira indicativa de que a espécie EMH interage com os lipídios através de ligações de hidrogênios, enquanto a $\mathrm{EM}^{-}$não apresenta essa interação. (Uma análise mais detalhada desse assunto será apresentada e discutida na seção 4.4.2.4.).

Uma análise das RDFs apresentadas na figura 4.25 nos fornece informações da localização das espécies da Emodina na bicamada lipídica. Essas informações são mais claras quando observamos as figuras A.21 e A.22 apresentadas no apêndice A contendo adicionalmente as distribuições das cadeias hidrocarbônicas do tipo A e B em torno das espécies. A análise dessas figuras mostra que durante as simulações, as espécies da Emodina ficaram localizadas próximas aos gliceróis, e em seguida do fosfato, da colina, das cadeias do tipo A e por último das cadeias do tipo B, visto que as RDFs dos gliceróis apresentaram os picos com os máximos em torno de $0.5 \mathrm{~nm}$ mais intensos comparativamente com os picos dos outros grupos. Note também que à medida que se afasta dos gliceróis, indo para as cadeias do tipo A e depois para as cadeias do tipo $\mathrm{B}$, os picos das RDFs centrados em $0.5 \mathrm{~nm}$ vão se tornando menos intensos, indicando um número menor de moléculas em torno das espécies. Essa informação corrobora com as obtidas acima através da análise da densidade eletrônica dessas espécies na bicamada e também com a análise da evolução temporal coordenadas dessas espécies durante as simulações de produção que mostraram que essas espécies ficaram inseridas 
na bicamada lipídica próximas aos gliceróis.

Adicionalmente caracterizamos o número de lipídios em torno das espécies através da integração do pico associado a primeira camada de lipídios. Tomamos a RDF do glicerol_1 com a espécie $\mathrm{EM}^{-}$como referência, em que o primeiro pico dessa distribuição está centrado em $0.5 \mathrm{~nm}$ e termina em $1 \mathrm{~nm}$. Assim, integramos todas as RDFs mostrada na figura 4.25 de 0 até $1 \mathrm{~nm}$, e determinamos o número de grupos de DMPC em torno dessas espécies dentro de um raio de $1 \mathrm{~nm}$.

Na tabela 4.11 apresentamos o número de grupos de colina, fosfato, glicerol_1, glicerol_2, cadeias do tipo A e B em torno das espécies da Emodina. Nessa tabela, os números que devem representar bem o número de lipídios em torno das espécies são os obtidos a partir da distribuição dos gliceróis, visto que as espécies encontram-se mais próximas deles do que dos demais grupos do DMPC. A análise dessa tabela mostra que existe aproximadamente 4 gliceróis em torno das espécies da Emodina, ou seja, 4 lipídios na primeira camada. Portanto, através dessa análise se obtém o mesmo número de lipídios em torno da $\mathrm{EMH}$ e $\mathrm{EM}^{-}$, indicando que embora a interação entre as espécies e lipídios seja diferente, o número de lipídios em torno delas é igual. Vale apena ressaltar que existe uma incerteza associada ao número de lipídios determinado nessa análise de \pm 1 lipídio e além disso as RDFs foram calculadas considerando a distância radial $\mathrm{r}$ entre os átomos das moléculas em três dimensões x, y e z.

A fim de caracterizar melhor o número de lipídios em torno das espécies da Emodina, realizamos uma análise das RDFs entre as espécies e os grupos do DMPC, considerando apenas as coordenadas x e y dos átomos das moléculas. Na figura 4.26 apresentamos essas RDFs em 2D, que mostra com mais detalhes a organização e a estrutura dos grupos de colina, fosfato, glicerol_1 e glicerol_2 em torno das espécies da Emodina. 
Tabela 4.11: Número médio de colina, fosfato, glicerol_1, glicerol_2, cadeia_1A, cadeia_1B, cadeia_2A e cadeia_2B em torno das espécies da Emodina, obtido a partir da integração das RDFs 3D e 2D no intervalo de 0 a $1 \mathrm{~nm}$.

\begin{tabular}{ccc|cc}
\hline & \multicolumn{2}{c|}{ 3D } & \multicolumn{2}{c}{$2 \mathrm{D}$} \\
\hline Colina & EMH & EM $^{-}$ & EMH & EM $^{-}$ \\
Fosfato & 3.2 & 4.2 & 4.9 & 5.8 \\
Glicerol_1 & 3.8 & 4.1 & 5.4 & 5.3 \\
Glicerol_2 & 3.9 & 3.8 & 4.6 & 4.6 \\
Cadeia_1A & 3.0 & 4.0 & 4.7 & 5.0 \\
Cadeia_1B & 1.4 & 0.8 & 4.2 & 4.5 \\
Cadeia_2A & 3.0 & 2.3 & 4.2 & 4.5 \\
Cadeia_2B & 1.4 & 0.7 & 4.7 & 5.9 \\
\hline Média & $\mathbf{3 . 0}$ & $\mathbf{2 . 8}$ & 4.8 & 5.0 \\
\hline DMPC & 3.0 & 2.8 & 4.7 & $\mathbf{5 . 0}$ \\
\hline \hline
\end{tabular}

Utilizamos a mesma metodologia descrita acima para caracterizar o número de lipídios dentro de um raio $1 \mathrm{~nm}$ em torno das espécies. Note que nesse cálculo das RDFs levamos em consideração apenas as coordenadas x e y das moléculas, portanto integrando as RDFs de 0 até $1 \mathrm{~nm}$, estamos determinando o número de lipídios dentro de uma circunferência de raio de $1 \mathrm{~nm}$ em torno das espécies, visto que todas as moléculas foram projetadas no plano xy. Na tabela 4.11, apresentamos os números de colina, fos- 
fato, glicerol_1, glicerol_2, cadeias do tipo A e B em torno das espécies da Emodina obtidos a partir da integração das RDFs 2D. (Veja as figuras A.23 e A.24 no apêndice A com as RDFs em 2D da cadeias do tipo A e B em torno das espécies da Emodina). Diferentemente da análise das RDFs 3D, no caso 2D todos os grupos são apropriados para representar os lipídios, pois o valores determinados para esses grupos em torno das espécies são praticamente os mesmos. A análise da tabela 4.11 mostra que existem $5 \pm 1$ lipídios em torno das espécies, que é praticamente o mesmo valor determinado através da análise das RDFs em 3D, visto que a incerteza determinada nos dois casos é de um 1 lipídio.

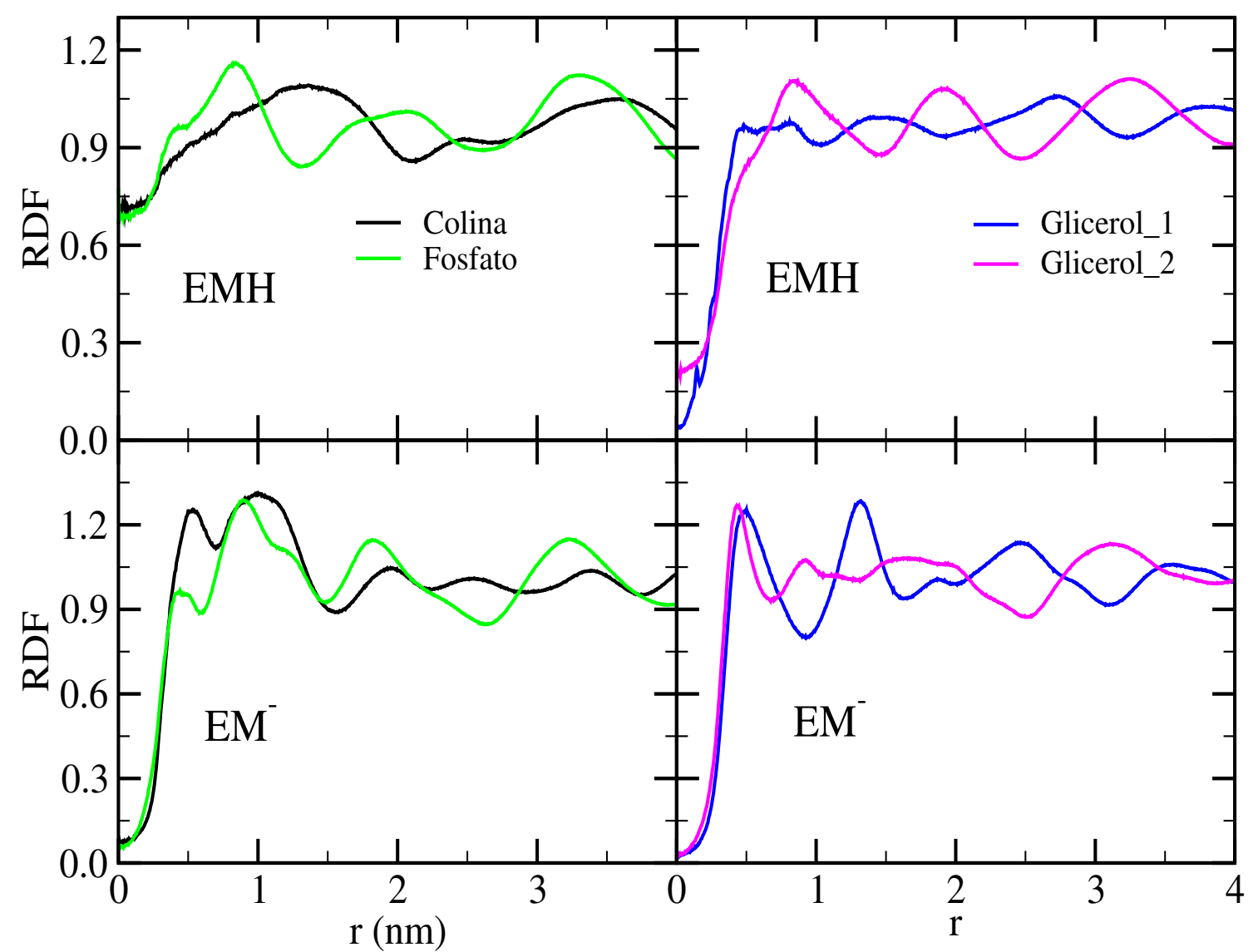

Figura 4.26: Funções de distribuição radial (RDF) de pares entre as espécies EMH e EM- e os grupos colina, fosfato, glicerol 1 e glicerol 2, calculadas para o sistema formado por uma espécie mais a monocamada lipídica, considerando as coordenadas (x e y) das moléculas. 
Uma comparação das RDFs 3D com as 2D mostra que as RDFs 2D apresentam uma melhor definição da quantidade, da forma e das posições dos picos nas RDFs, indicando que essas distribuições difinem melhor a estrutura dos fosfolipídios em torno das espécies da Emodina. Nas RDFs 2D é possível caracterizar até 4 camadas de lipídios em torno das espécies, enquanto nas RDFs 3D, são caracterizadas apenas duas camadas. Além disso, como discutido acima, as RDFs 2D são mais apropriadas para determinar o número de lipídios em torno das espécies, visto que esse número praticamente independe do grupo do lipídio tomado como referência. Como mostrado na tabela 4.11, até mesmo a integração das RDFs 2D entre as espécies e os lipídios inteiros fornecem excelentes resultados para o número de lipídios em torno das espécies. Veja que a integração dessas RDFs 2D de 0 a $1 \mathrm{~nm}$ fornecem aproximadamente 5 lipídios em torno das espécies, o mesmo número obtido a partir da integração das RDFs 2D entre grupos do DMPC e espécies. Já integração das RDFs 3D entre as espécies e lipídios nessa mesma faixa (0 a $1 \mathrm{~nm}$ ) fornecem aproximadamente 3 lipídios em torno das espécies, um número mais baixo que o valor determinado a partir da RDFs 3D dos gliceróis e espécies. Na figura A.25, apresentamos uma comparação entre as RDFs 2D e 3D entre as moléculas de DMPC e as espécies, e também entre o glicerol_1 e as espécies. Essa figura mostra que a estrutura das moléculas de DMPC em torno das espécies EMH e EM- é diferente, por exemplo na RDFs 2D dos glicerol_1 observamos uma melhor definição das camadas de lipídios em torno das espécies, embora isso não se refletiu no número de lipídios na primeira camada como mostrado na tabela 4.11.

Como discutido acima, a análise da evolução temporal das coordenadas z do centro de massa (CM), do oxigênio O3 e do carbono do metil (MT) das espécies da Emodina apresentada na figura 4.23, mostrou que a rotação de $180^{\circ}$ das espécies em relação ao eixo Z não ocorre durante as simulações. Entretanto é esperado que existam mudanças na orientação dessas espécies por ângulos menores que $180^{\circ}$, visto que a fluatação nas coordenadas apresentadas nessa figura é considerável. Assim, para 
fornecer mais detalhes da orientação dessas espécies dentro das bicamadas lipídicas calculamos a função de distribuição de probabilidades $\mathrm{P}(\theta)$ do ângulo entre o eixo $C \widehat{M-O} 3$ (que é paralelo ao eixo que passa pelo centro dos três aneis) e o eixo normal a bicamada lipídica (eixo z). Para mais detalhes desse ângulo, veja a figura 4.27. Na figura 4.28 mostramos a função $\mathrm{P}(\theta)$ obtida para as espécies EMH e EM- dentro da bicamada, que mostra que a orientação dessas espécies nesses meios anfifílicos é

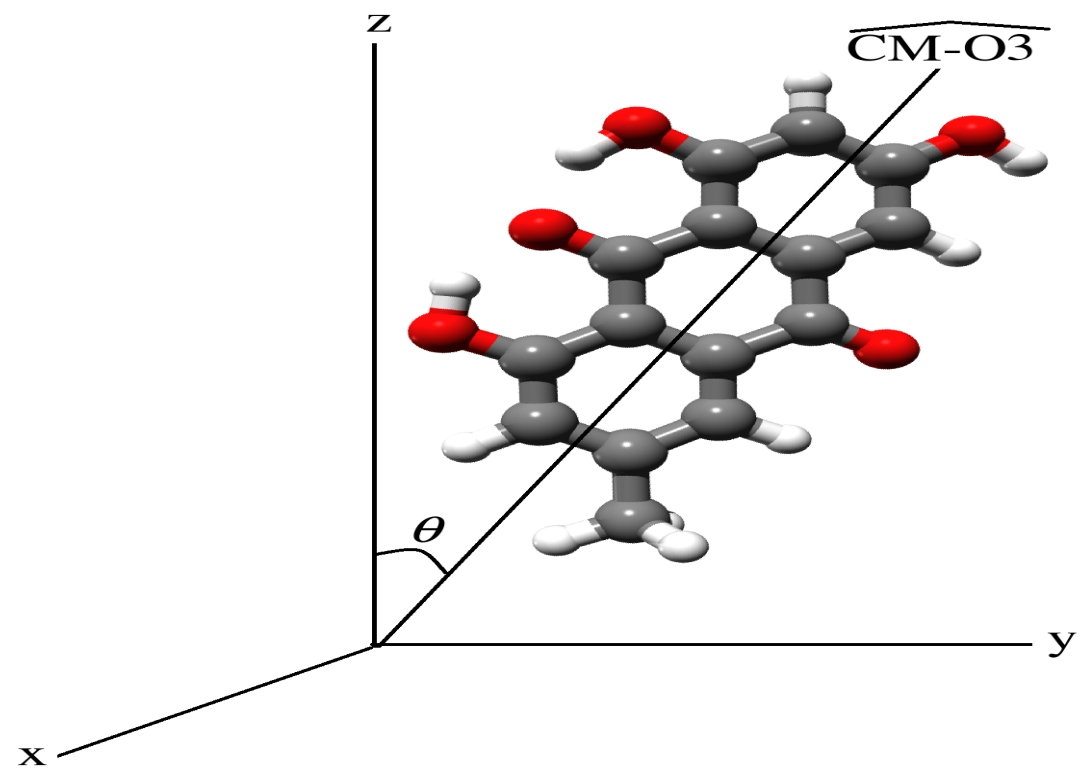

Figura 4.27: Ilustração da orientação da Emodina no cálculo da função de distribuição de probabilidades $\mathrm{P}(\theta)$.

diferente. A função $\mathrm{P}(\theta)$ da espécie EMH apresenta apenas um pico bastante largo, com seu máximo centrado em torno de $50^{\circ}$, indicando que essa espécie assume diversas orientações durante a dinâmica molecular, mas todas $\operatorname{com} \theta$ dentro da faixa de 0 a $80^{\circ}$. Já a função $\mathrm{P}(\theta)$ da espécie $\mathrm{EM}^{-}$apresenta duas orientações preferenciais, sendo a mais frequente com $\theta$ dentro da faixa de 0 a $32^{\circ}$, veja a figura 4.28. A distribuição $\mathrm{P}(\theta)$ dessa orientação é caracterizada por um pico grande na faixa de 0 a $32^{\circ} \mathrm{com}$ seu máximo centrado em $16^{\circ}$. A outra orientação preferencial da espécie $\mathrm{EM}^{-}$é analoga a da EMH, mas com menor frequência, em que a orientação é caracterizada com $\theta$ na 


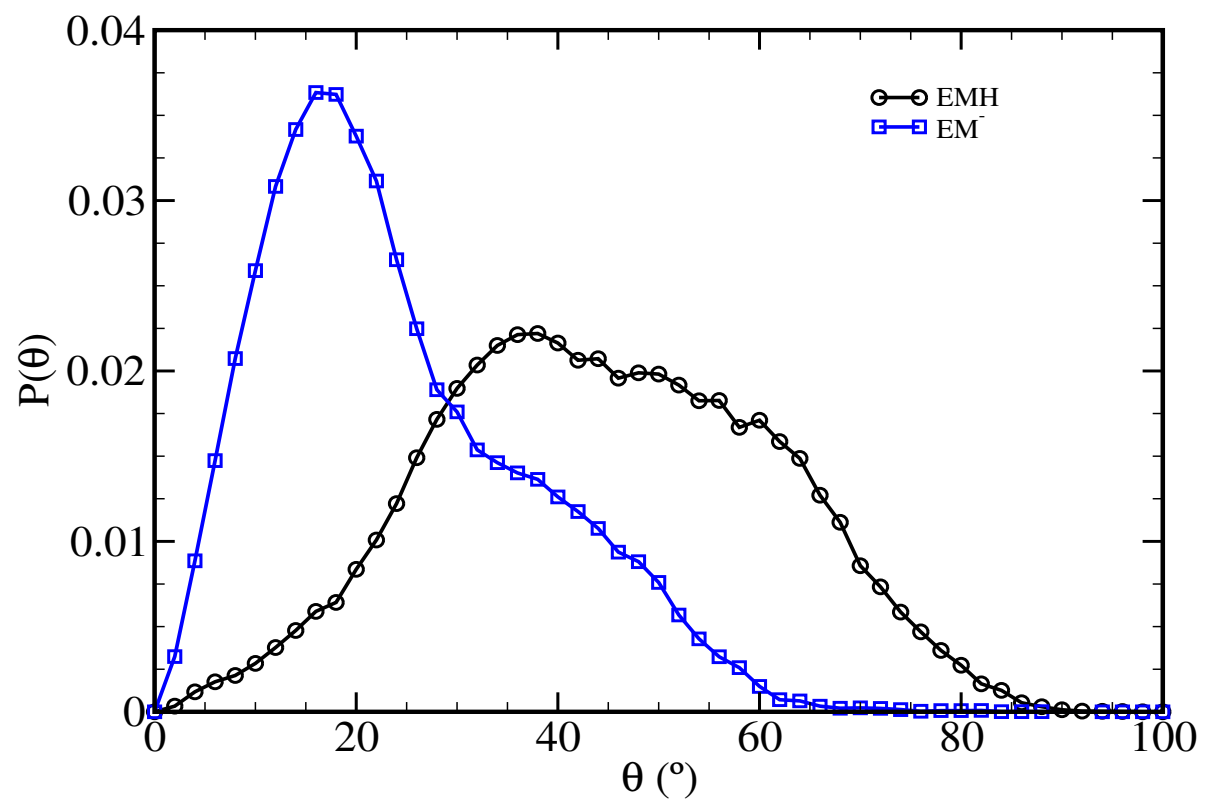

Figura 4.28: Função de distribuição de probabilidades $\mathrm{P}(\theta)$ do ângulo entre o eixo $C \widehat{M-O}$ e o eixo normal a bicamada lipídica (eixo z). Para mais detalhes, veja figura 4.27.

faixa de 30 a $60^{\circ}$. Uma comparação da função $\mathrm{P}(\theta)$ das espécies EMH e EM- mostra que ambas as espécies não ficaram totalmentes alinhadas ao eixo z como esperado, mas em orientações preferenciais característica de cada espécie. Como discutido acima, a orientação mais frequente da $\mathrm{EM}^{-}$é $\operatorname{com} \theta \sim 16 \pm 10^{\circ}$ e da EMH é com $\theta \sim 50 \pm 20^{\circ}$, onde essas incertezas refere a metade da largura da distribuição $\mathrm{P}(\theta)$.

\subsubsection{Análise estrutural das espécies da Emodina na bicamada lipídica}

Realizamos uma análise estrutural nas geometrias das espécies da Emodina em bicamada lipídica, a fim de estudar a flexibilidade dessas geometrias nesses meios anfifílicos. Além disso, investigamos o efeito causado pela mudança do meio de água para bicamada lipídica nas propriedades estruturais dessas espécies, visto que temos os resultados dessa análise das espécies em solução aquosa. Assim como nas simulações das espécies em solução aquosa, realizamos uma análise temporal da rotação dos diedros dh8, dh1 e dh3 que estão associados às seguintes hidroxilas O8H8, O1H1 e 
O3H3, respectivamente, ver figura 1.1. Na figura 4.29 apresentamos as evoluções temporais dos diedros dh8 (figura (a)) e dh3 (figura (b)) e seus respectivos histogramas nas figuras (c) e (d). Similarmente em solução aquosa, os diedros dh8 e dh1 apresentaram o mesmo comportamento durante a dinâmica molecular, pois observamos que eles ficaram a maior parte do tempo de simulação no intervalo de $150^{\circ}$ a $210^{\circ}$, com as hidroxilas $\mathrm{O} 8 \mathrm{H} 8$ e O1H1, correspondentes a esses diedros formando ligações de hidrogênio intramoleculares. Essas hidroxilas ficaram mais de 94\% do tempo total de simulação em conformações de ligações de hidrogênio intramoleculares. Na tabela A.6 no apêndice A, apresentamos de forma detalhada o tempo total em $n s$ e o percentual (\%) em que esses diedros ficaram nessas conformações.

A análise do diedro dh3 mostrou que ele ficou mais de $48 \%$ do tempo total de simulação na conformação trans, que está associada ao intervalo de $150^{\circ}$ a $210^{\circ}$, e mais de $29 \%$ na conformação cis, com o ângulo diedro dentro dos intervalos de $0^{\circ}$ a $30^{\circ}$ e também de $360^{\circ}$ a $330^{\circ}$. Uma comparação das propriedades conformacionais da espécie EMH em solução aquosa e em bicamada lipídica está mostrada na tabela A.6 no apêndice A, que mostra que a geometria dessa espécie é mais rígida em bicamada lipídica do que em água, pois é observado que mais de $94 \%$ do tempo total de simulação as hidroxilas $\mathrm{O} 1 \mathrm{H} 1$ e O8H8 ficaram em conformações formando ligações de hidrogênio intramoleculares, enquanto em água ficaram apenas $82 \%$ e $67 \%$ nessas conformações, respectivamente. Embora a hidroxila O3H3 tenha apresentado alta flexibilidade, tanto em água como em bicamada lipídica, observamos que essa hidroxila é mais rígida em bicamada lipídica, uma vez que ela ficou mais tempo na conformação trans do que na conformação cis, comparativamente as simulações em água. Essa alta flexibilidade dessa hidroxila em bicamada lipídica é uma indicativa que esse grupo interagiu com as moléculas do sistema, visto que apresentamos nos resultados das simulações em água, que a mudança de conformação de trans para cis ou vice-versa está associado a interação desse grupo com as moléculas de água. 


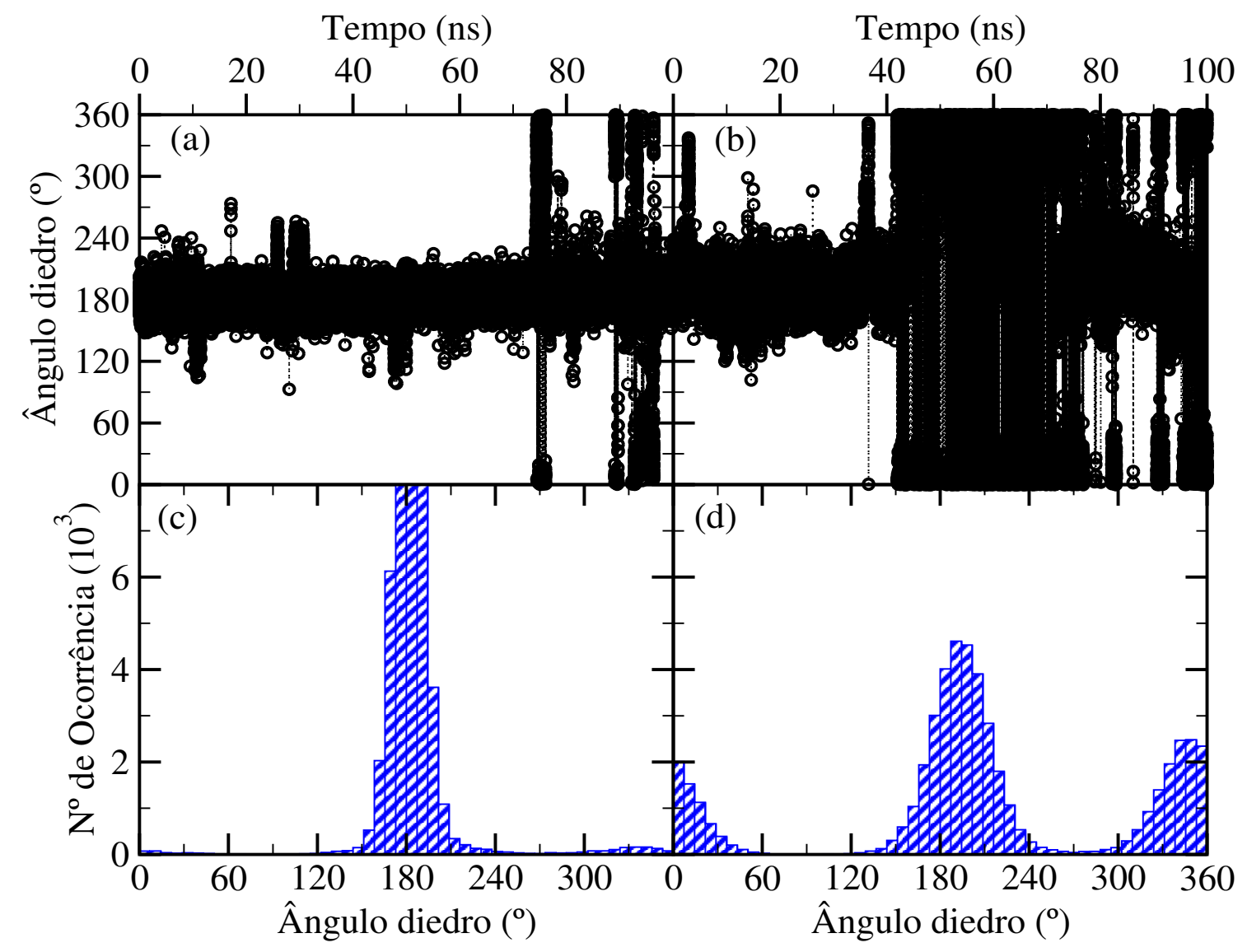

Figura 4.29: Evolução temporal dos ângulos diedros dh8, na figura (a) e dh3, na figura (b) e seus respectivos histogramas nas figuras (c) e (d), respectivamente, obtidos da simulação computacional com a espécie EMH em bicamada lipídica.

A análise conformacional da Emodina desprotonada em bicamada lipídica durante a dinâmica molecular mostrou que essa espécie é bastante rígida, pois suas hidroxilas ficaram mais de $99 \%$ do tempo total de simulação em conformações formando ligações de hidrogênio intramoleculares, ver figura 4.30. Nessa figura apresentamos a evolução temporal das duas hidroxilas da $\mathrm{EM}^{-}$e seus respectivos histogramas. Comparando as análises conformacionais dessa espécie em bicamada lipídica e em solução aquosa, verificamos que a geometria dessa espécie apresentou ser mais rígida em bicamada lipídica do que em água, pois observamos que em solução aquosa a quebra das ligações de hidrogênio intramoleculares foi maior. Essa é uma indicativa que em 


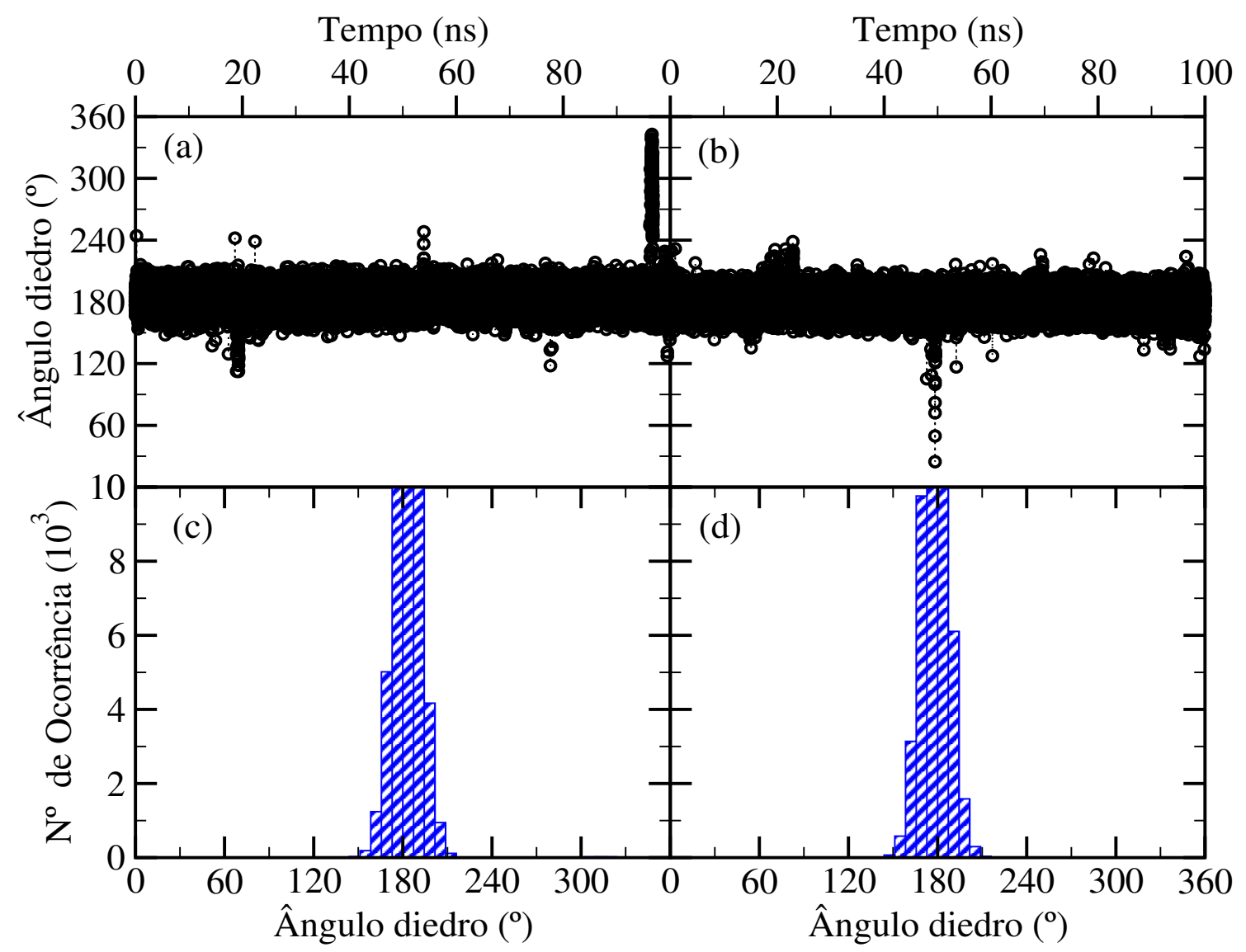

Figura 4.30: Evolução temporal dos ângulos diedros dh8, na figura (a) e dh1, na figura (b) e seus respectivos histogramas nas figuras (c) e (d), respectivamente, obtidos da simulação computacional com a espécie $\mathrm{EM}^{-}$em bicamada lipídica.

solução aquosa a $\mathrm{EM}^{-}$interagiu mais fortemente com as moléculas de água, enquanto em bicamada lipídica essa interação foi reduzida devido à proteção dos grupos carbonilas e hidroxilas pelas cabeças polares dos lipídios. Uma análise mais detalhada da interação das espécies EMH e EM- com os lipídios e também com as moléculas de água será apresentada e discutida a seguir a fim de elucidar a interação dessas espécies nesses meios anfifílicos. 


\subsubsection{Interação das espécies da Emodina com a bicamada hidratada}

A interação das espécies da Emodina com os lipídios e as moléculas de água foi investigada através da análise das ligações de hidrogênio que as espécies EMH e EMformaram com as moléculas de DMPC e água. Essas ligações foram analisadas usando os mesmos critérios de ligações de hidrogênio usados nas simulações dessas espécies em solução aquosa, $\mathrm{R}_{\mathrm{OO}} \leq 3.15 \AA$ e $\mathrm{OO} H \leq 30^{\circ}$. Nessa análise, consideramos que as ligações de hidrogênio na molécula de DMPC ocorrem nos grupos colina, fosfato, glicerol_1 e glicerol_2, ver a definição desses grupos na figura 4.27. Note que todos esses grupos desempenham apenas funções de aceitadores de ligações de hidrogênio, através dos átomos de nitrogênio, oxigênio e fosfato.

Inicialmente, realizamos a análise das ligações de hidrogênio que a EMH e EMformaram com as moléculas de DMPC e observamos que a espécie EMH interage mais fortemente com as moléculas de DMPC do que a espécie $\mathrm{EM}^{-}$. Isso é evidenciado pelo número de ligações de hidrogênio que essas espécies formaram com os lipídios, onde a EMH formou cerca de 1 ligação de hidrogênio por configuração, enquanto na espécie $\mathrm{EM}^{-}$, esse número foi praticamente zero, cerca de 0.01. Embora a EMH tenha formado mais ligações de hidrogênio com as moléculas de DMPC do que a $\mathrm{EM}^{-}$, quando analisamos os tempos de vida dessas ligações de hidrogênio, verificamos que eles são praticamente da mesma ordem. Determinamos esses tempos usando a mesma metodologia aplicada nas simulações dessas espécies em solução aquosa, em que esses tempos foram obtidos a partir do ajuste da distribuição de probabilidades do tempo de vida dessas ligações pela equação 4.4. Dessa análise obtivemos que os tempos de vida das ligações de hidrogênio que a EMH e EM- formaram com as moléculas de DMPC foram 6.88 e 7.57 ps, respectivamente. Assim, do ponto de vista de interação espécies/fosfolipídios, esperamos que essas espécies apresentassem as mesmas características de difusão nas bicamadas lipídicas. Porém, vale ressaltar que embora os tempos de vidas das ligações de hidrogênio das espécies sejam similares, 
a espécie EMH interage mais fortemente com os lipídios, e além disso a difusão dessas espécies nesses meios anfifílicos depende também da interação com as moléculas de água.

A fim de identificar os grupos do DMPC que mais formam ligações de hidrogênio com as espécies da Emodina, realizamos uma análise mais detalhada dessas ligações nos grupos colina, fosfato, glicerol_1 e glicerol_2. Dessa análise observamos que a colina não formou nenhuma ligação de hidrogênio com as espécies da Emodina, já o fosfato formou 0.25 e 0.01 ligações de hidrogênio por configuração com a EMH e EM-, respectivamente. Os grupos glicerol_1 e glicerol_2 formaram 0.74 e 0.01 ligações de hidrogênio por configuração com a EMH e 0.0 com a EM- Esses resultados corroboram à análise das RDFs entre as espécies e esses grupos do DMPC, mostrada na figura 4.25, em que foi observado nessas distribuições características de ligações de hidrogênio apenas entre a espécie EMH e os grupos fosfato e glicerol_1, veja a figura A.26 no apêndice A, com a ampliação dessas RDFs para $\mathrm{r}<0.5 \mathrm{~nm}$. Embora o número de ligações de hidrogênio por configuração formadas pela espécie $\mathrm{EM}^{-}$com os gliceróis seja igual a zero, não significa que é zero absoluto, pois observamos que os glicerol_1 e glicerol 2, formaram 174 e 23 ligações de hidrogênio nas 50000 configurações analisadas, dando portanto um número médio de ligações de hidrogênio por configuração aproximadamente 0.00 , com precisão de duas casas decimais.

Analisamos também as ligações de hidrogênio entre as espécies da Emodina com as moléculas de água a fim de caracterizar o efeito da bicamada lipídica na interação dessas espécies com a água. Na tabela 4.12, apresentamos uma comparação entre as propriedades das ligações de hidrogênio formadas pelas moléculas de água com as espécies EMH e EM- determinadas nas simulações computacionais dessas espécies em solução aquosa e em bicamada lipídica. A análise desses resultados mostrou que ambas as espécies da Emodina formaram ligações de hidrogênio com as moléculas de água na bicamada lipídica. Essa análise mostrou que em bicamada lipídica existem em média 
cerca de 2 e 6 moléculas de água se ligando as espécies EMH e EM- através de ligações de hidrogênio, enquanto em água pura, esses números foram cerca de 7 e 10 moléculas de água, respectivamente. Esse resultado deixa claro que a EMH em bicamada lipídica forma apenas cerca de 30\% das ligações de hidrogênio que formaria em água pura, já para a espécie $\mathrm{EM}^{-}$em bicamada esse percentual foi bem maior, cerca de $60 \%$, indicando que embora ambas as espécies estejam inseridas na bicamada lipídica, elas ainda interagem com as moléculas de água. Portanto a localização dessas espécies dentro das bicamadas lipídicas, que de acordo com análise da densidade eletrônica discutida acima, essa localização é próxima aos gliceróis, permite a interação dessas espécies com as moléculas de água, tendo a espécie $\mathrm{EM}^{-}$a interação mais fortemente com a água do que a espécie EMH. Esse resultado juntamente com a análise da densidade eletrônica discutida acima torna claro que a espécie EM- fica mais exposta à solução aquosa do que a EMH, e isso juntamente com o caracter eletrostático da EM- justifica a forte interação dessa espécie com a água.

Uma comparação do número de ligações de hidrogênio formadas pelas moléculas de água com os grupos carbonilas e hidroxilas das espécies da Emodina determinadas com essas espécies em solução aquosa e em bicamada lipídica, nos fornece informações dos grupos que interagiram mais fortemente com as moléculas de água na bicamada, como também, fornece informações que ajudam a identificar os grupos que ficaram mais próximos do centro da bicamada. Como mostrado na tabela 4.12, as hidroxilas O8H8, O1H1 e O3H3 da espécie EMH em bicamada formaram cerca de 0.1, 0.7, e 0.9 ligações de hidrogênio por configuração com as moléculas de água, enquanto em solução aquosa, essas hidroxilas formaram cerca de 1.4, 1.2 e 2.2 ligações de hidrogênio, respectivamente. Portanto esse resultado mostra que a EMH em bicamada lipídica interage com as moléculas de água, sendo o grupo O3H3 a hidroxila dessa espécie que mais interagiu fortemente com as moléculas de água, em seguida vem a hidroxila O1H1 e por último a hidroxila O8H8. Essa ordem da interação dessas hidroxilas com 
as moléculas de água fornece implicitamente informações da distância desses grupos em relação ao centro da bicamada. Esses resultados mostra que a hidroxila O3H3 está mais distante do centro da bicamada e mais próxima do "bulk" das moléculas de águas, o que favorece a interação desse grupos com a água, enquanto a hidroxila O8H8, está mais distante do "bulk" da água e mais próxima do centro da bicamada, ou seja, mais inserida na bicamada lipídica, o que dificulta a interação desse grupo com as moléculas de água.

Tabela 4.12: Comparação do número médio $\left(\left\langle\mathrm{N}^{\mathrm{O}}\right\rangle_{\mathrm{HB}}\right)$ e tempo de vida médio da primeira $\left(\tau_{1}\right)$ e segunda $\left(\tau_{2}\right)$ ligações de hidrogênio (em ps) formadas pelas moléculas de água com as espécies EMH e $\mathrm{EM}^{-}$, durante as simulações dessas espécies em bicamada lipídica de DMPC e em solução aquosa.

\begin{tabular}{|c|c|c|c|c|c|c|c|c|}
\hline \multirow[b]{3}{*}{ Grupo } & \multicolumn{4}{|c|}{ Bicamada lipídica } & \multicolumn{4}{|c|}{ Água } \\
\hline & \multicolumn{2}{|c|}{$\mathrm{EMH}$} & \multicolumn{2}{|c|}{$\mathrm{EM}^{-}$} & \multicolumn{2}{|c|}{ EMH } & \multicolumn{2}{|c|}{$\mathrm{EM}^{-}$} \\
\hline & $\left\langle\mathrm{N}^{\circ}\right\rangle_{1}$ & $\mathrm{~B} \tau_{1}\left(\tau_{2}\right)$ & $\left\langle\mathrm{N}^{\mathrm{o}}\right\rangle_{\mathrm{HB}}$ & $\tau_{1}\left(\tau_{2}\right)$ & $\left\langle\mathrm{N}^{\mathrm{o}}\right\rangle_{\mathrm{I}}$ & $\tau_{1}\left(\tau_{2}\right)$ & $\left\langle\mathrm{N}^{\mathrm{o}}\right\rangle_{\mathrm{HB}}$ & $\tau_{1}\left(\tau_{2}\right)$ \\
\hline O1H1 & 0.7 & $3.8(0.7)$ & 0.8 & $7.7(1.1)$ & 1.2 & $2.7(0.6)$ & 1.5 & $3.7(0.6)$ \\
\hline $\mathrm{O} 8 \mathrm{H} 8$ & 0.1 & $7.4(1.3)$ & 0.1 & $9.6(1.3)$ & 1.4 & $2.9(0.6)$ & 1.5 & $3.4(0.5)$ \\
\hline $\mathrm{O} 3 \mathrm{H} 3 / \mathrm{C} 3 \mathrm{O} 3$ & 0.9 & $6.7(1.1)$ & 3.3 & $14.7(1.5)$ & 2.2 & $2.8(0.5)$ & 3.5 & $10.4(1.6)(0.4)$ \\
\hline C9O9 & 0.1 & $4.1(0.9)$ & 0.1 & $5.7(1.0)$ & 0.8 & $2.4(0.7)$ & 1.1 & $2.7(0.5)$ \\
\hline $\mathrm{C} 10 \mathrm{O} 10$ & 0.6 & $16.4(2.3)$ & 1.4 & $12.9(1.7)$ & 1.6 & $3.7(0.6)$ & 1.9 & $5.0(0.7)$ \\
\hline Total & 2.4 & $8.2(1.3)$ & 5.7 & $13.0(1.5)$ & 7.2 & $3.0(0.6)$ & 9.5 & $6.3(1.0)(0.4)$ \\
\hline
\end{tabular}

O mesmo comportamento discutido acima para a EMH, também foi observado com a $\mathrm{EM}^{-}$em bicamada lipídica, em que os grupos O8H8, O1H1 e C3O3 formaram 
cerca de $0.1,0.8$ e 3.3, ligações de hidrogênio com as moléculas de água, enquanto em solução aquosa, esses números foram 1.5, 1.5 e 3.5, respectivamente. O grupo da EMque interagiu mais fortemente com as moléculas de água na bicamada lipídica foi o C3O3, apresentando praticamente o mesmo número de ligações hidrogênio formadas em solução aquosa. Já a análise das ligações de hidrogênio formadas pelas moléculas de águas com os grupos carbonila O9C9 e O10C10 das espécies da Emodina em bicamada lipídica, mostrou que essas carbonilas mantiveram as mesmas características apresentadas em água, onde a carbonila C9O9 formou menos ligações de hidrogênio do que a C10O10 para ambas as espécies. Esse comportamento da carbonila C9O9 é devido às ligações de hidrogênio intramoleculares que as hidroxilas O1H1 e O8H8 formam com esse grupo, que desfavorecem as ligações de hidrogênio com as moléculas de águas.

Similarmente as simulações em solução aquosa, realizamos uma análise dos tempos de vida das ligações de hidrogênio formadas pelas as moléculas de águas com as espécies da Emodina em bicamada lipídica, a fim de caracterizar o efeito da bicamada nessas propriedades. Nas figuras A.27 e A.28 no apêndice A, apresentamos as curvas da função de distribuição de probabilidades com os respectivos ajustes pela equação 4.4. Essas figuras mostram que os tempos de vida das ligações de hidrogênio nos grupos carbonilas e hidroxilas das espécies da Emodina são longos, quando comparados com os tempos de vidas obtidos das simulações das espécies da Emodina em solução aquosa, veja tabela 4.12. Essa característica se manteve até mesmo nos grupos que formaram poucas ligações de hidrogênio, como a carbonila C9O9 e a hidroxila O8H8. Embora o número de ligações de hidrogênio formadas pelas moléculas de água com as espécies da Emodina em bicamada lipídica seja menor do que em solução aquosa, o tempo de vida dessas ligações é maior, sendo em alguns grupos o dobro do tempo de vida determinado em solução aquosa. Isso é um indicativo de que a difusão dessas espécies em solução aquosa é maior do que em bicamada lipídica, pois o tempo de vida 
das ligações de hidrogênio das espécies da Emodina em bicamada lipídica é maior.

Portanto nossos resultados do estudo da interação das espécies da Emodina em bicamada lipídica mostra que a espécie EMH interagiu através de ligações de hidrogênio tanto com as moléculas de DMPC como com as moléculas de água, apresentando uma maior interação com as moléculas de água, pois o número de ligações de hidrogênio por configuração foi praticamente o dobro do número de ligações formadas com as moléculas de DMPC. Já a espécie $\mathrm{EM}^{-}$formou poucas ligações de hidrogênio com as moléculas de DMPC, pois verificamos que nesse caso, o número de ligações por configuração foi praticamente zero, enquanto com as moléculas de água, a interação foi mais forte, pois contabilizamos cerca de 6 moléculas de água formando ligações de hidrogênio com essa espécie. Para ambas as espécies caracterizamos tempos de vida longos das ligações hidrogênio formadas pelas moléculas de água, o que nos leva a concluir que as moléculas de água que entram na bicamada lipídica para interagir com as espécies formam uma espécie de aglomerado em torno das espécies da Emodina, em particular da espécie EM-', que caracterizamos que sua hidratação na bicamada lipídica é mais que o dobro da hidratação da espécie EMH nesses meios anfifílicos, veja a tabela 4.12. Assim para fornecer mais detalhes desses aglomerados em torno das espécies e o efeito tanto desses aglomerados como também das próprias espécies da Emodina na bicamada, realizamos uma análise das propriedades da bicamada considerando somente as moléculas de lipídios e de água dentro da vizinhança das espécies EMH e $\mathrm{EM}^{-}$, que será apresentado e discutido a seguir.

\subsubsection{Efeito das espécies da Emodina na bicamada}

A fim de apresentar mais detalhes da região da vizinhança das espécies da Emodina e quantificar o efeito dessas espécies nessa região, realizamos uma análise das propriedades da bicamada lipídica nessa região, em que foram levados em consideração apenas as moléculas de lipídios e de água em torno das espécies dentro de uma 
esfera de raio $1 \mathrm{~nm}$. A motivação da escolha do raio de $1 \mathrm{~nm}$ se deve a RDF do glicerol_1 com as espécies mostradas na figura 4.25, que mostra que esse raio define a primeira camada de lipídios em torno das espécies. Nossa primeira análise nesse estudo foi determinar o número de moléculas de lipídios e de água em torno das espécies $\mathrm{EMH}$ e $\mathrm{EM}^{-}$dentro dessas esferas de raio $1 \mathrm{~nm}$. Essas moléculas foram contadas considerando a menor distância dentre todos os átomos das moléculas de água ou lipídios com o centro de massa das espécies da Emodina.

Na figura 4.31 mostramos a distribuição de probabilidade das moléculas de lipídios e de água em torno das espécies da Emodina. Essa figura mostra que a distribuição de lipídios em torno das espécies EMH e EM- é similar, mas apresentando mais lipídios em torno da $\mathrm{EMH}$ do que da $\mathrm{EM}^{-}$, visto que os valores médios determinados a partir das distribuições foram 5 e 4 lipídios em torno dessas espécies, respectivamente. Esse resultado corrobora com a análise das RDFs discutida acima, em que mostramos através da análise das RDFs 3D e 2D que existe cerca de $4 \pm 1$ e $5 \pm 1$ lipídios em torno das espécies da Emodina, respectivamente. A figura 4.31 mostra também que a distribuição de lipídios em torno das espécies é assimétrica com relação ao pico principal da distribuição, pois a probabilidade de encontrar 4 ou 6 lipídios em torno da espécie EMH é 27 e 12\%, já para EM- essa probabilidade de encontrar 3 ou 5 lipídios em torno dessa espécie é 25 e 16\%, respectivamente. Esses resultados mostram que a organização de lipídios em torno das espécies EMH e EM- é ligeiramente diferente, e isso leva a valores diferentes da área por lipídio na vizinhança local dessas espécies. Os valores obtidos para área por lipídio em torno das espécies EMH e EM- foram 0.628 e 0.785 $\mathrm{nm}^{2}$, respectivamente, em que nesse cálculo foi levado em consideração a área de uma circunferência de raio de $1 \mathrm{~nm}$. Portanto esse resultado mostra que a inserção das espécies EMH e EM- na bicamada lipídica provoca um aumento na área por lipídio, na vizinhança local dessas espécies, da ordem de $\sim 4 \%$ e $\sim 30 \%$, indicando que o efeito da espécie $\mathrm{EM}^{-}$na bicamada é maior do que da EMH. 

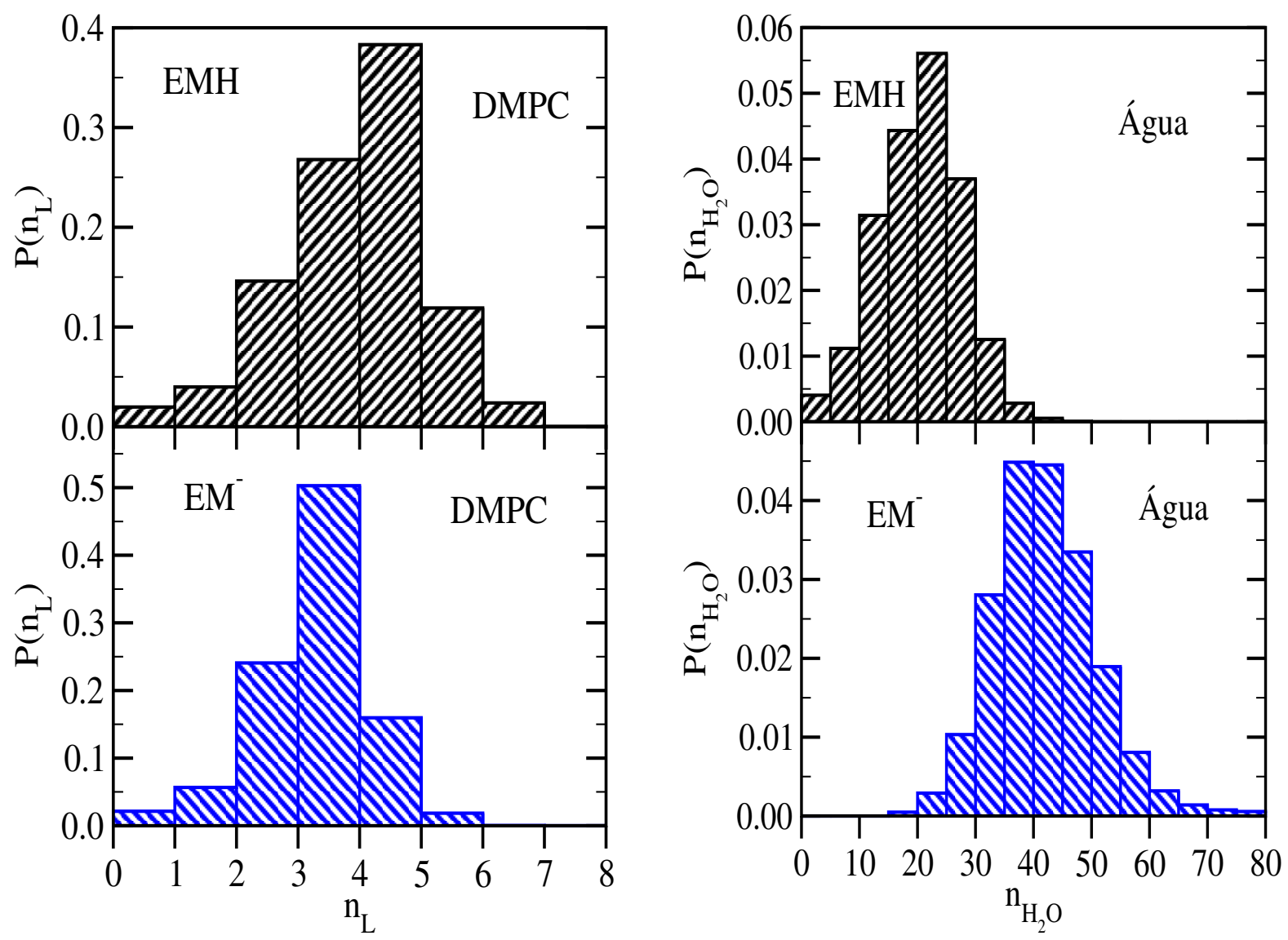

Figura 4.31: Distribuição de probabilidade de encontrar moléculas de lipídios ou moléculas de água em torno das espécies da Emodina dentro de uma esfera de raio de $1 \mathrm{~nm}$.

Na figura 4.31 mostramos também a distribuição de probabilidade das moléculas de água em torno das espécies da Emodina. A análise dessa figura mostra que existe cerca de 21 e 43 moléculas de água em torno das espécies EMH e EM-, portanto, indicando que a hidratação da espécie $\mathrm{EM}^{-}$é duas vezes maior do que a hidratação da EMH. Esse resultado corrobora a análise das ligações de hidrogênio formadas pelas moléculas de água com essas espécies, discutida acima, em que mostramos que o número de ligações de hidrogênio na $\mathrm{EM}^{-}$é mais do que o dobro do número na espécie EMH. Essa caracterísitca não foi observada em solução aquosa, como pode ser comprovado através da tabela 4.12, apenas em bicamada lipídica foi observada essa super hidratação da espécie $\mathrm{EM}^{-}$em comparação a EMH. 

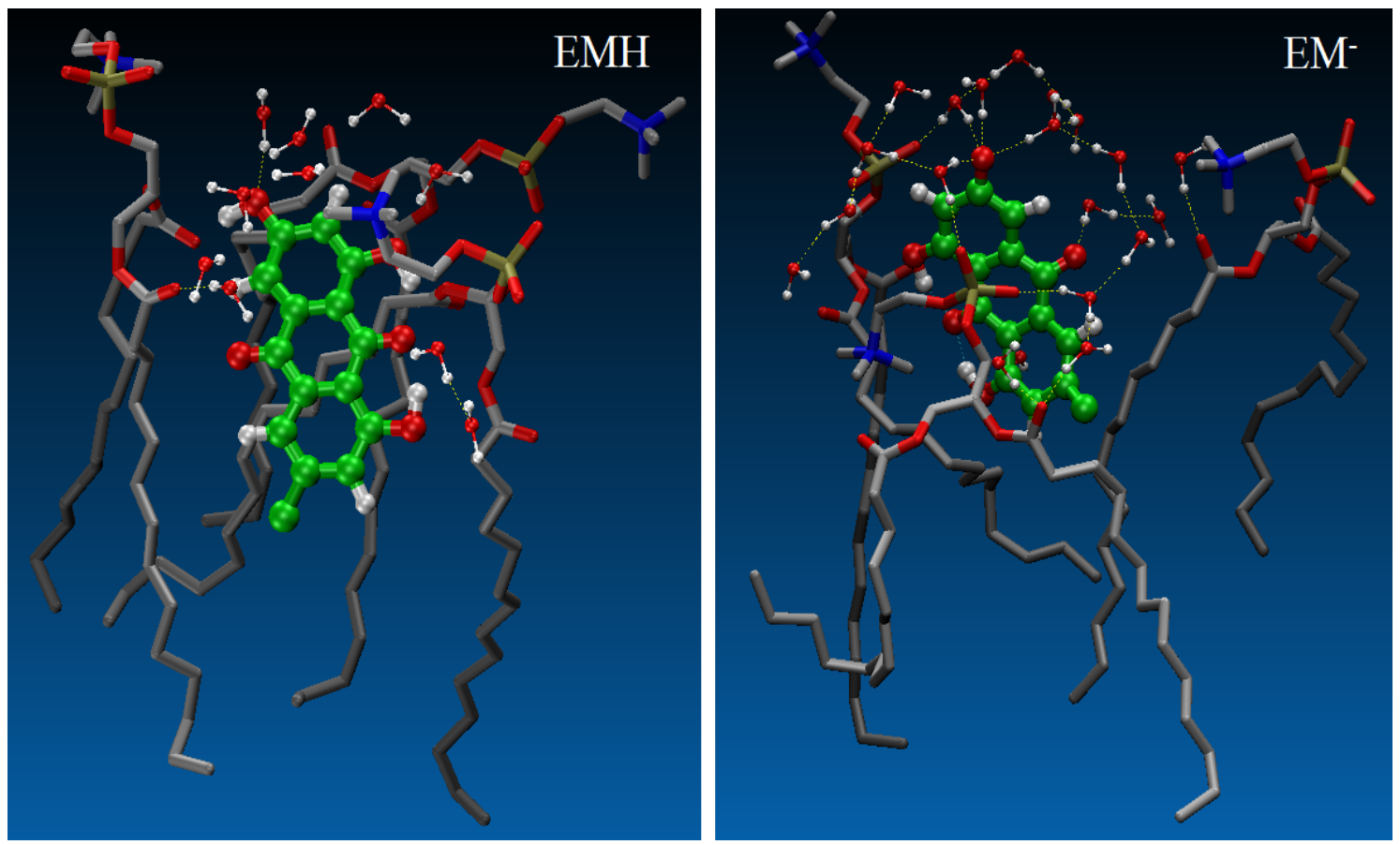

Figura 4.32: Ilustração da região da vizinhança das espécies da Emodina na bicamada lipídica. Nessa figura mostramos apenas as 3 moléculas de lipídios mais próximas das espécies como também apenas a metade da hidratação dessas espécies determinadas a partir das distribuições mostradas na figura 4.31 .

Assim esses resultados nos leva a concluir que o número de moléculas de água que entra na bicamada lipídica para interagir com a espécie $\mathrm{EM}^{-}$é maior do que com a EMH. Essas moléculas de água formam uma espécie de aglomerado em torno dessa espécie, solvatando-a de modo a não favorecer a interação dessa espécie com as moléculas de lipídios, veja figura 4.32. Esses aglomerados de água provocam um efeito de afastamento das cabeças polares dos lipídios em relação à espécie $\mathrm{EM}^{-}$, pois eles ocupam um volume maior do que o da molécula desidratada. Além disso, o próprio caracter eletrostático da espécie $\mathrm{EM}^{-}$provoca também um efeito nessas cabeças de modo a desalinhar os grupos fosfato e colina em relação ao eixo z. Esses efeitos reduz a cooperatividade dos lipídios, em particular das cabeças polares, causando grandes efeitos na estrutura da bicamada lipídica.

Para discutir melhor o efeito das espécies da Emodina na bicamada lipídica, reali- 


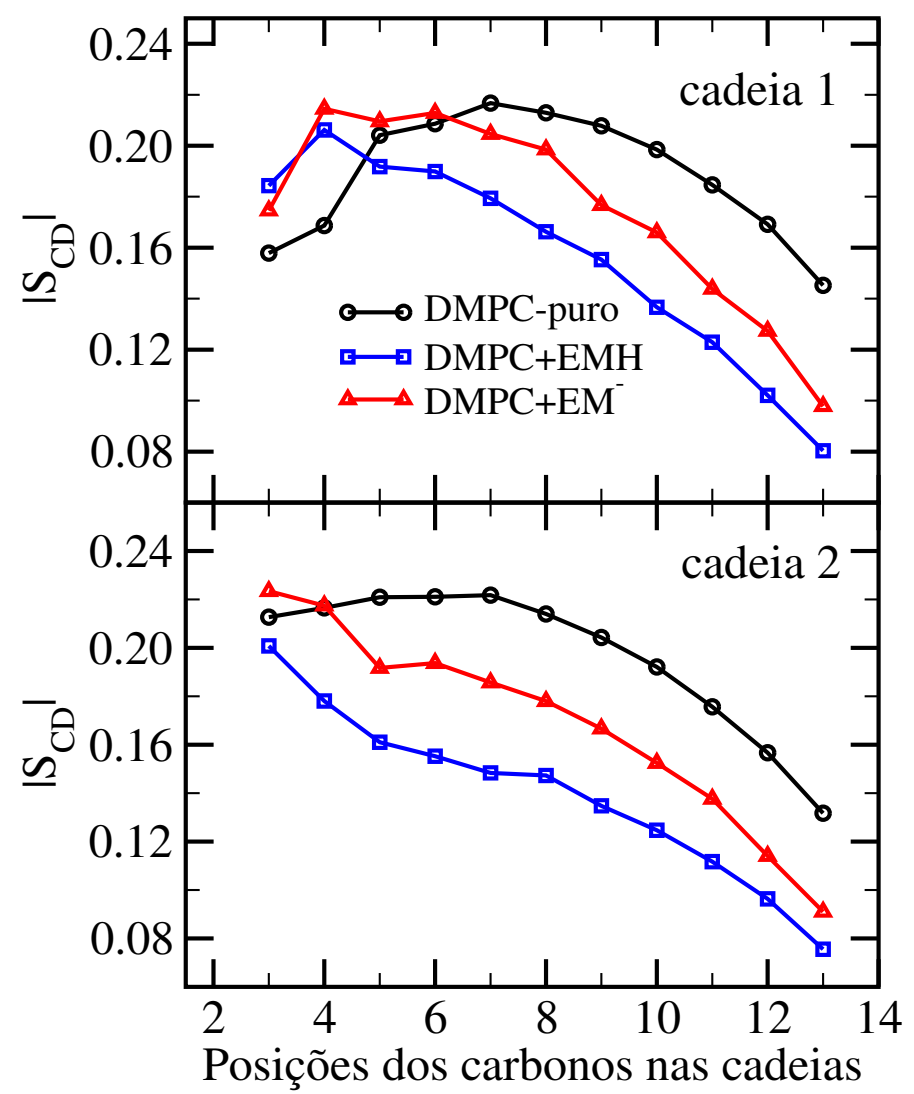

Figura 4.33: Parâmetro de ordem deutério $\left|\mathrm{S}_{\mathrm{CD}}\right|$ das cadeias hidrocarbônicas 1 e 2 do fosfolipídio DMPC, calculados das simulações de produção dos sistemas DMPC-puro, DMPC + EMH e DMPC $+\mathrm{EM}^{-}$, em que nos dois últimos sistemas foi levado em consideração apenas os lipídios da vizinhança das espécies da Emodina.

zamos uma análise do parâmetro de ordem das cadeias hidrocarbônicas dos lipídios da vizinhança da EMH e EM-. Esse parâmetro foi calculado usando a mesma metodologia discutida na seção 4.4.2.1. Na figura 4.33 mostramos uma comparação do parâmetro de ordem $\left|\mathrm{S}_{\mathrm{CD}}\right|$ das cadeias hidrocarbônicas 1 e 2 do lipídio de DMPC, calculados nas simulações de produção dos sitemas DMPC-puro, DMPC $+\mathrm{EMH}$ e $\mathrm{DMPC}+\mathrm{EM}^{-}$, em que nos dois últimos sistemas foram levados em consideração somente os lipídios da vizinhança das espécies. Essa figura mostra que ambas as espécies da Emodina provocam grandes efeitos na ordem das cadeias hidrocarbônicas dos lipídios, que são em geral diferentes em cada cadeia. Na cadeia 1, observamos que a EMH aumenta 
a ordem dos 2 primeiros carbonos, e reduz a ordem dos 9 carbonos da extremidade da cadeia hidrocarbônica, quando comparado com a bicamada pura. Similarmente é o efeito da espécie $\mathrm{EM}^{-}$nessa cadeia, em que é observado um aumento na ordem dos 4 primeiros carbonos e uma redução na ordem dos 7 carbonos da extremidade dessa cadeia. Já o efeito das espécies da Emodina na cadeia 2 reduziu o parâmetro de ordem de todos os carbonos dessa cadeia quando comparado com a bicamada pura, com uma exceção o efeito da $\mathrm{EM}^{-}$no primeiro carbono, em que foi observado um aumento nesse parâmetro, quando comparado com a bicamada pura.

Assim, a figura 4.33 mostra, no geral, que ambas as espécies da Emodina reduzem os parâmetros de ordem dos 8 carbonos das extremidades das cadeias hidrocarbônicas dos lipídios. Entretanto, o efeito da espécie EMH nessas cadeias é maior do que o da espécie $\mathrm{EM}^{-}$, visto que a EMH reduziu o parâmetro de ordem dos carbonos dessas cadeias cerca de $30 \%$ enquanto a $\mathrm{EM}^{-}$reduziu apenas 15\%, indicando que o efeito da EMH nessas cadeias é duas vezes maior do que o da EM- ${ }^{-}$Esse comportamento é justificável, pois mostramos através da análise da densidade eletrônica discutida acima que a espécie EMH encontra-se mais próxima das cadeias hidrocarbônicas do que a espécie $\mathrm{EM}^{-}$, e portanto, já era esperado que a espécie EMH causasse um efeito maior nessas cadeias. Já a espécie $\mathrm{EM}^{-}$está localizada mais próxima da região dos grupos fosfato e colina do que a EMH, e portanto já era esperado que essa espécie desprotonada provocasse um efeito maior nos carbonos iniciais das cadeias hidrocarbônicas, o que é evidenciado pelo efeito da $\mathrm{EM}^{-}$no parâmetro de ordem do primeiro carbono da cadeia 1, que mostra que a ordem desse carbono é menor do que o obtido com a espécie EMH.

Embora o efeito da espécie EMH sejam maior nas cadeias hidrocarbônicas do que o da $\mathrm{EM}^{-}$, ele não é o efeito mais determinante na mudança estrutural da bicamada lipídica. O que observamos é que o efeito da espécie $\mathrm{EM}^{-}$nas cabeças polares dos lipídios provoca uma mudança maior na estrutura da bicamada lipídica do que o efeito propriamente nas cadeias hidrocarbônicas. O mecanismo molecular que leva a espécie 

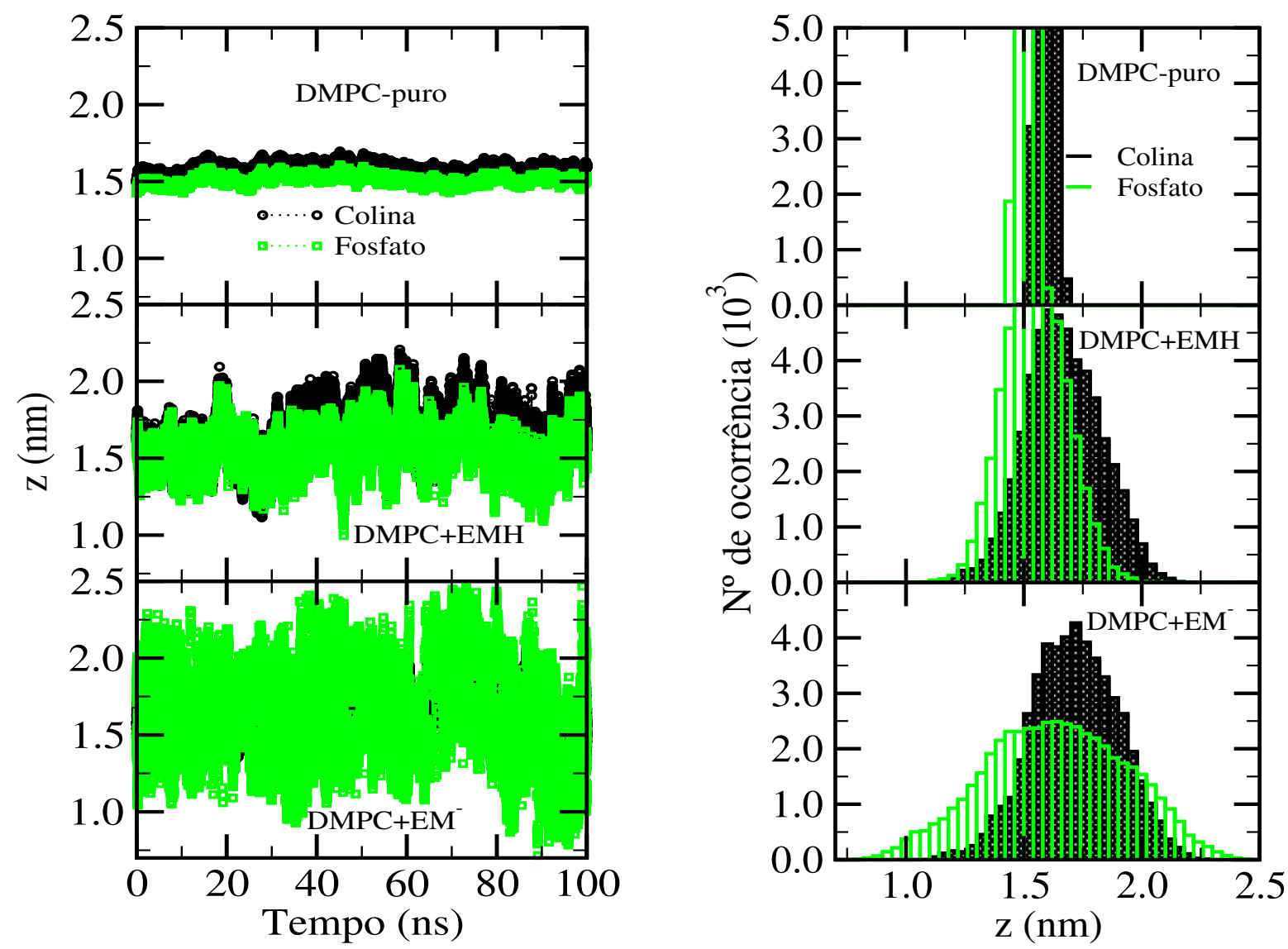

Figura 4.34: Comparação da evolução temporal das coordenadas dos átomos nitrogênio e fosfato dos grupos colina e fosfato, respectivamente nos sistemas DMPC-puro, DMPC + EMH e DMPC $+\mathrm{EM}^{-}$, em que nos dois últimos sistemas foi levado em consideração apenas os lipídios da vizinhança das espécies da Emodina.

$\mathrm{EM}^{-}$a causar um maior efeito na estrutura da bicamada é explicado aqui baseado na formação de aglomerados de água em torno dessa espécie na bicamada como discutido na seção 4.4.2.4. Esses aglomerados provocam um afastamento das cabeças polares dos lipídios em relação à espécie $\mathrm{EM}^{-}$, que consequentemente reduz a cooperatividade entre esses lipídios, de modo que podemos considerá-los fracamente correlacionados. Essa fraca correlação dos lipídios em torno da espécie $\mathrm{EM}^{-}$provoca um efeito na região da vizinhança dessa espécie, em que a maioria das cabeças dos lipídios dessa região fica desalinhada em relação ao eixo z, e cravada na bicamada lipídica, apresentando a coor- 
denada z do grupo colina mais próxima do grupo fosfato. Esse efeito fica mais evidente quando comparamos as coordenadas dos átomos nitrogênio e fosfato dos grupos colina e fosfato, respectivamente dos sistemas DMPC-puro, DMPC $+\mathrm{EMH}$ e DMPC $+\mathrm{EM}^{-}$, em que nos dois últimos sistemas foram levados em consideração apenas os lipídios da vizinhança das espécies da Emodina, veja figura 4.34. Nessa figura, mostramos também os histogramas obtidos a partir da evolução temporal das coordenadas desses átomos, em que fica claro que ambas as espécies da Emodina provocam grandes efeitos na região das cabeças polares dos lipídios, porém esse efeito é maior em torno da espécie $\mathrm{EM}^{-}$, pois a largura da distribuição do histograma dessa espécie é duas vezes maior do que o da espécie EMH.

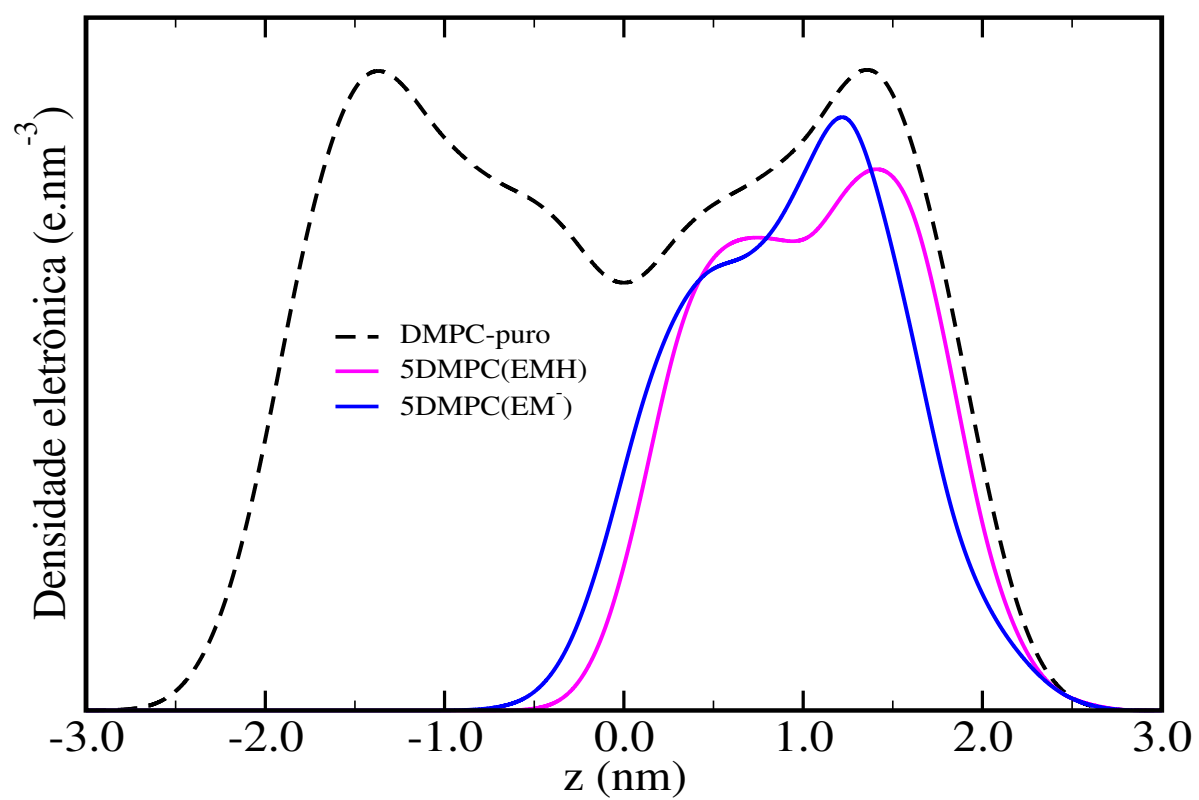

Figura 4.35: Comparação entre a densidade eletrônica dos 5 lipídios mais próximos das espécies da Emodina com a densidade dos lipídios da bicamada pura. Nesse figura, a densidade do DMPC da bicamada pura foi dividida por 26 a fim de comparar com a densidade de 5 lipídios.

Outra propriedade que corrobora os resultados discutidos acima é a densidade eletrônica dos lipídios da vizinhança dessas espécies, que também mostra que o efeito da espécie $\mathrm{EM}^{-}$na estrutura da bicamada lipídica é maior do que o da espécie EMH. 
Na figura 4.35 mostramos uma comparação entre a densidade eletrônica dos lipídios da bicamada pura com a densidade dos 5 lipídios mais próximos das espécies da Emodina. Para fins de comparação, a densidade dos lipídios da bicamada pura foi dividida por 26. Essa figura mostra que a densidade eletrônica dos lipídios em torno da EMH apresenta praticamente o mesmo perfil da densidade dos lipídios da bicamada pura, apresentando o pico característico das cabeças polares dos lipídios quase na mesma região, sendo na bicamada pura esse pico está centrado em $1.36 \mathrm{~nm}$ e com a espécie EMH, esse pico está em $1.41 \mathrm{~nm}$, apresentando assim uma pequena diferença entre eles de $0.05 \mathrm{~nm}$. Já para espécie $\mathrm{EM}^{-}$essa diferença é bem maior, visto que esse pico está centrado na posição de $1.22 \mathrm{~nm}$, portanto, apresentando uma diferença do valor da bicamada pura de $0.15 \mathrm{~nm}$. Essa mudança no perfil da densidade eletrônica dos lipídios em torno da espécie $\mathrm{EM}^{-}$, está relacionada ao fato das cabeças dos lipídios da vizinhança dessa espécie estarem mais inseridas na bicamada lipídica cerca de $1.5 \AA$ quando são comparadas com a bicamada pura. Essa característica das cabeças dos lipídios em torno da $\mathrm{EM}^{-}$cria buracos acima dessas cabeças que são ocupados por moléculas de água, as mesmas identificadas na análise da figura 4.31. Esses buracos geram uma região de instabilidade em torno das espécies, de modo que a bicamada lipídica minimiza a energia modificando a sua estrutura nessa região. Portanto, dados esses resultados das espécies da Emodina em bicamada lipídica, concluímos que o efeito da espécie desprotonada é maior do que o da espécie neutra.

\subsubsection{Medidas de calorimetria de varredura}

Nesta seção apresentaremos os resultados de calorimetria diferencial de varredura (DSC), obtidos das dispersões lipídicas de DMPC em presença e ausência das espécies da Emodina, a fim de investigar experimentalmente o efeito dessas espécies nessas dispersões. Como discutido na seção 3.3, as medidas de DSC das dispersões lipídicas de DMPC contendo as espécies da Emodina nos tampões $\mathrm{pH}=6.0(\mathrm{EMH})$ e $\mathrm{pH}=10.0$ 
$\left(\mathrm{EM}^{-}\right)$foram realizadas a fim de analisar separadamente o efeito de cada espécie na bicamada lipídica de DMPC.

Na figura 4.36 apresentamos as curvas de DSC dessas dispersões lipídicas de DMPC (5 mM) para ambas as espécies da Emodina nas frações molares de 5, 10, 15 e 20 mol\% de Emodina em relação a concentração total de DMPC (5 mM). Analisando essa figura, observamos que há mudanças significativas nos formatos e posições dos picos da pré-transição e transição de fase (gel-fluido) com o aumento da concentração de ambas as espécies da Emodina nas dispersões lipídicas. Essa análise mostra que o efeito das espécies da Emodina nas dispersões lipídicas é bastante similar, pois o aumento da concentração das espécies nas dispersões provoca deslocamentos da pré-transição e da transição de fase (gel-fluido) para região de menor temperatura, acompanhado por reduções da variação de entalpia, veja a tabela A.7 no apêndice A.

Na tabela A.7 estão listados os valores determinados para as entalpias e temperaturas de transição de fase (gel-fluido) para as diferentes frações molares das espécies da Emodina. Essa tabela mostra que os valores determinados para as temperaturas de transição de fase das dispersões lipídicas contendo as espécies da Emodina nas frações molares de 0, 5, 10, 15 e $20 \mathrm{~mol} \%$ foram 23.3, 22.9, 22.6, 22.1 e $19.3{ }^{\circ} \mathrm{C}$ para a espécie EMH e 23.2, 22.7, 22.2, 21.4 e $17.5^{\circ} \mathrm{C}$ para a espécie $\mathrm{EM}^{-}$, respectivamente. Note que com o aumento da fração molar das espécies da Emodina de 15\% para $20 \%$ é observado um deslocamento muito grande do pico de transição de fase (gel-fluido) para região de menor temperatura, acompanhado por um alargamento muito grande nesse pico para as regiões de menor e maior temperatura, de modo a provocar quase o desaparecimento total desse pico. Portanto, esses resultados mostram que o aumento da concentração das espécies da Emodina nas dispersões lipídicas provoca um efeito muito grande na transição de fase dessas dispersões, indicando que ambas as espécies interagem com a bicamada lipídica. Esses resultados corroboram os nossos resultados das simulações computacionais e os resultados experimentais de absorção eletrônica, 
todos discutidos acima, em que mostramos que as espécies EMH e EM- inserem-se na bicamada lipídica de DMPC.
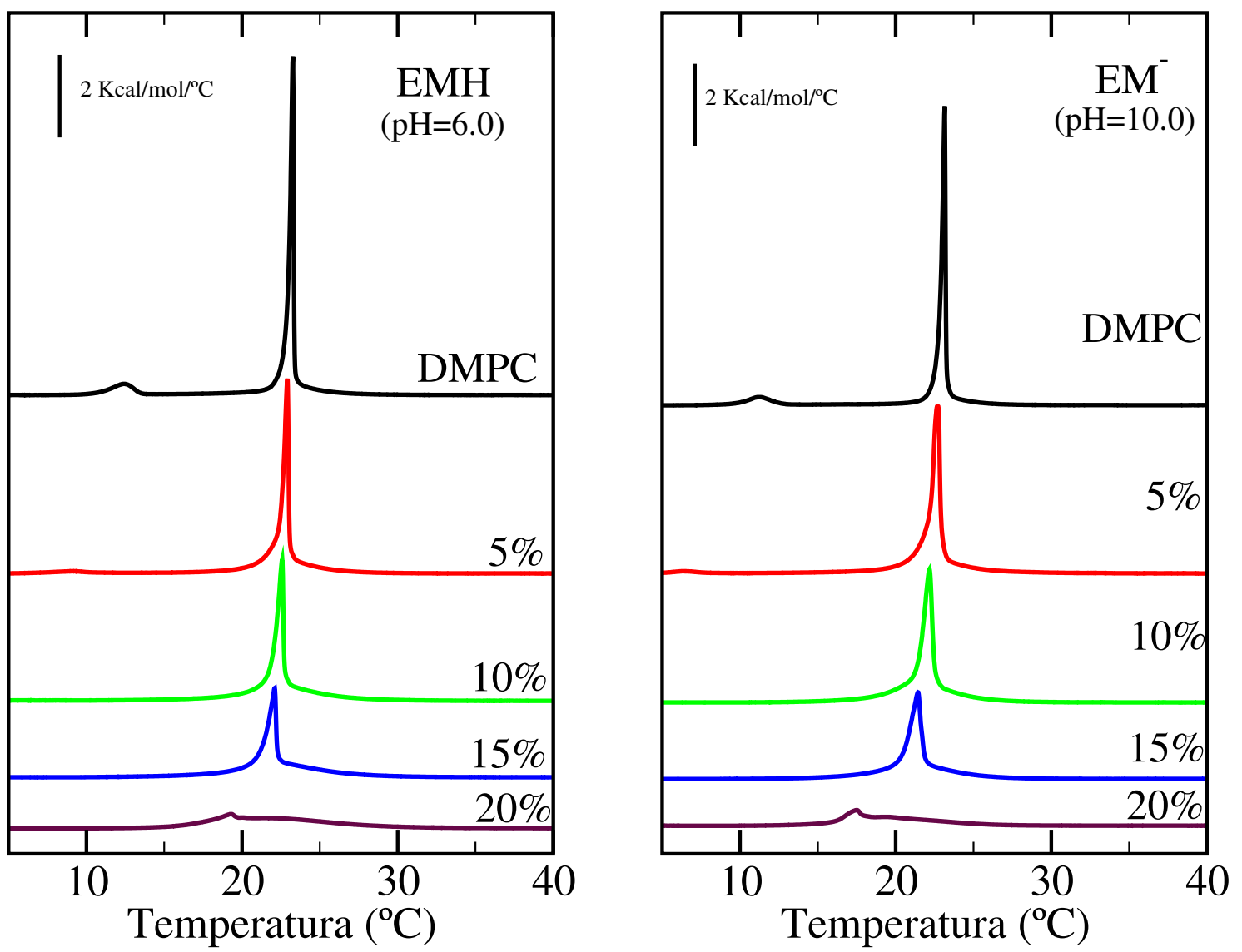

Figura 4.36: Curvas de DSC de dispersões lipídicas de DMPC na concentração 5 mM mais espécies da Emodina nas concentrações 5, 10, 15 e $20 \%$ em relação a $5 \mathrm{mM}$ (concentração de DMPC) nos tampão bifosfato/fosfato $\mathrm{pH} 6.0$ (EMH) e bicarbonato/carbonato $\mathrm{pH} 10.0$ $\left(\mathrm{EM}^{-}\right)$. A taxa de aquecimento foi $20^{\circ} \mathrm{C} / \mathrm{h}$.

Assim, o aumento da fração molar de ambas as espécies da Emodina nas dispersões lipídicas provoca alargamentos dos picos da transição de fase (gel-fluido) para as regiões de menor e maior temperatura. Esse aumento na largura desses picos pode ser um indicativo de que a introdução das espécies da Emodina nas dispersões lipídicas provoca uma redução da cooperatividade dos lipídios na bicamada lipídica, assim, favorecendo uma transição de fase para baixos valores de temperatura. 


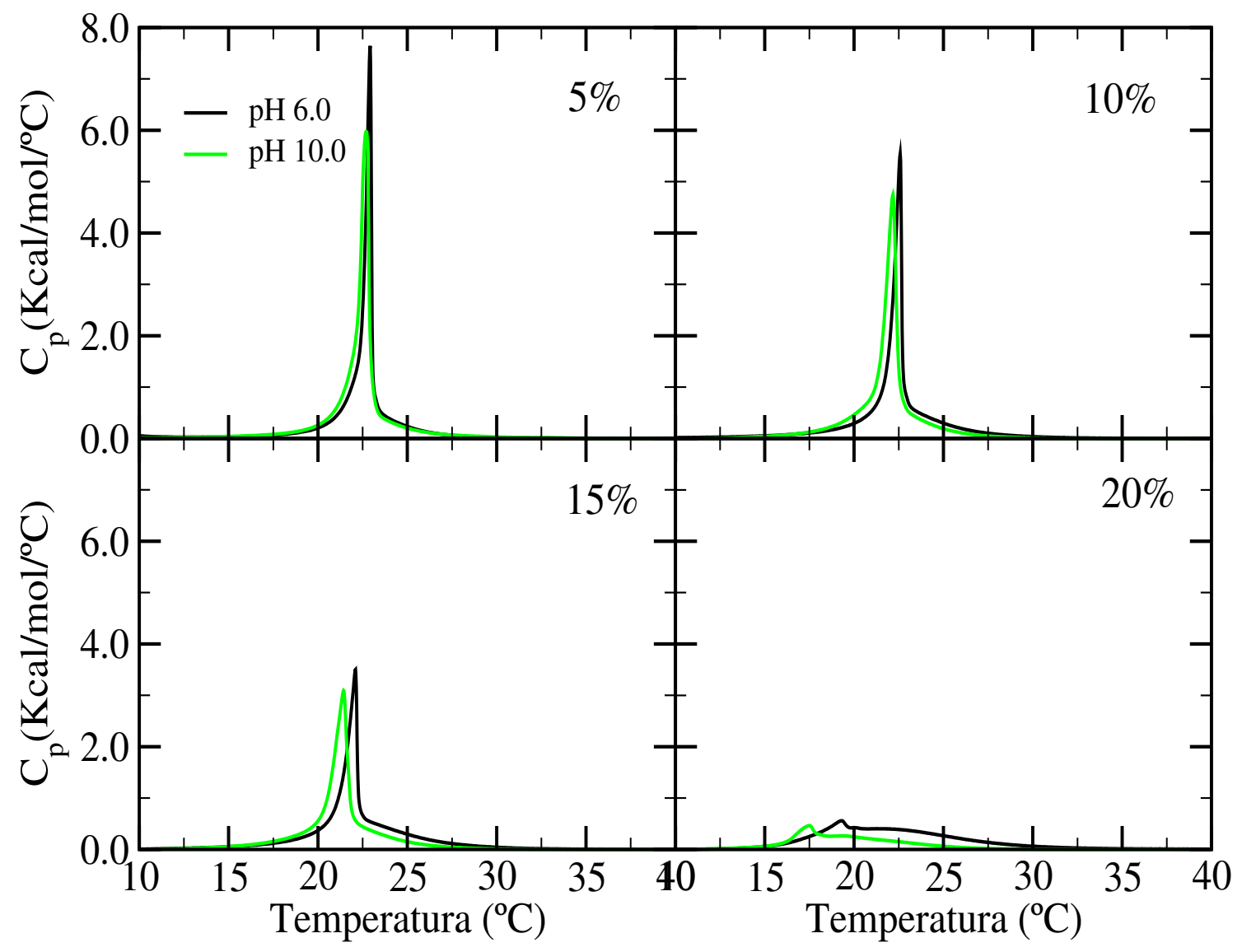

Figura 4.37: Comparação das curvas de DSC de dispersões lipídicas de DMPC na concentração $5 \mathrm{mM}$ mais Emodina nas concentrações 5, 10, 15 e $20 \mathrm{~mol} \%$ em relação a $5 \mathrm{mM}$ (concentração de DMPC) nos dois tampões bifosfato/fosfato $\mathrm{pH} 6.0$ e bicarbonato/carbonato $\mathrm{pH}$ 10.0. A taxa de aquecimento foi $20^{\circ} \mathrm{C} / \mathrm{h}$.

Embora registramos que ambas as espécies da Emodina provocam alargamentos e deslocamentos do pico de transição de fase para região de menor temperatura, observamos que esses efeitos são ligeiramente maiores com a espécie $\mathrm{EM}^{-}$do que com a EMH. Isso fica claro na análise da figura 4.37, em que mostramos uma comparação entre o efeito da EMH e EM- nas curvas de DSC das dispersões lipídicas de DMPC. Como podemos observar, mudando a fração molar da Emodina nas dispersões lipídicas de 0 para $20 \mathrm{~mol} \%$, o pico da transição de fase (gel-fluido) das curvas de DSC 
dessas dispersões apresentou um maior desvio para regiões de menores temperaturas com a espécie $\mathrm{EM}^{-}$, cerca de $6{ }^{\circ} \mathrm{C}$, enquanto para a $\mathrm{EMH}$, esse desvio foi de $4{ }^{\circ} \mathrm{C}$. Ressaltamos que esse desvio não é devido exclusivamente à mudança do tampão, ou seja, do tampão $\mathrm{pH}=6.0$ para o tampão $\mathrm{pH}=10.0$, pois nesse caso registramos apenas um pequeno desvio de $0.1{ }^{\circ} \mathrm{C}$, veja a figura A.29 no apêndice $\mathrm{A}$, as curvas de DSC de dispersões lipídicas de DMPC nesses dois tampões. A contribuição principal para esse alto desvio é devida ao efeito da espécie $\mathrm{EM}^{-}$na bicamada de DMPC. Essa espécie reduz a cooperatividade dos lipídios em maior intensidade do que a espécie EMH, isso fica evidente quando comparamos as larguras dos picos de transição de fase (gelfluido) das dispersões lipídicas com ambas as espécies, que mostra que a EM- provoca um alargamento maior nesse picos do que a EMH.

Esses resultados experimentais corroboram com os nossos resultados obtidos das simulações computacionais, onde concluímos que o efeito da Emodina desprotonada na estrutura da bicamada lipídica é maior comparado com o da Emodina neutra. Mostramos que esse efeito é devido principalmente à alta hidratação da $\mathrm{EM}^{-}$dentro da bicamada lipídica, que forma aglomerados de água, e gera uma região de alta instabilidade dos lipídios em torno dessa espécie. 


\section{Capítulo 5}

\section{Conclusões}

Nesta tese de doutorado realizamos estudos experimentais e teóricos de propriedades estruturais, eletrônicas e termodinâmicas das espécies da Emodina neutra $(\mathrm{EMH})$ e desprotonada $\left(\mathrm{EM}^{-}\right)$, ambas em meio solvente e em bicamada lipídica. O estudo experimental foi realizado utilizando técnicas de espectroscopia eletrônica de absorção de luz, na região do visível e ultravioleta próximo, das espécies da Emodina em meio solvente e em bicamada lipídica, e medidas de calorimetria diferencial de varredura de dispersões lipídicas de DMPC, na ausência e na presença das espécies da Emodina em diferentes frações molares. Na parte teórica, utilizamos modelos atomísticos com cálculo quântico, com funcional de densidade (B3LYP), conjunto de função base de Pople (6-311++G**), modelo contínuo polarizável (PCM) e simulações computacionais da EMH e EM- em meio solvente e em bicamada lipídica. Com esses estudos, conseguimos apresentar respostas para as nossas cinco perguntas chave, respostas diretas e quantitativas, que elucidaram diversos aspectos das espécies da Emodina, não conhecidos na literatura até o momento. Por exemplo: (i) as posições na molécula onde ocorrem as desprotonações; (ii) as constantes de acidez $\left(\mathrm{pK}_{\mathrm{a}}\right)$ da Emodina em água e em metanol; (iii) a interação das espécies da Emodina com água e bicamada lipídica; (iv) as posições preferenciais das espécies na bicamada lipídica; 
(v) e o efeito das espécies na estrutura da bicamada lipídica.

O estudo teórico da desprotonação da Emodina, através de cálculos quânticos mostrou que a primeira desprotonação na molécula Emodina ocorre na posição 3 (gerando a espécie da Emodina com uma desprotonação, $\mathrm{EM}^{-}$), a segunda na posição 8 (gerando a espécie com duas desprotonações, 1-EM²- e a terceira na posição 1 (gerando a espécie $\mathrm{EM}^{3-}$ ), corroborando a proposta do trabalho de Pal e colaboradores [28]. Mostramos que a Emodina com uma desprotonação, EM- ${ }^{-}$é favorecida em relação às espécies desprotonadas nas posições 1 e 8 (a perda do próton $\mathrm{H}^{+}$das hidroxilas O1H1 e O8H8). Registramos que a inclusão do solvente como PCM reduziu cerca de $60 \%$ a diferença de energia entre essas espécies desprotonadas, mas registramos uma diferença de energia livre da ordem de $6 \mathrm{kcal} / \mathrm{mol}$ a favor da Emodina desprotonada na posição $3\left(\mathrm{EM}^{-}\right)$, e essa diferença de energia livre produz 100\% dessa espécie no equilíbrio do processo de desprotonação.

Nosso modelo teórico construído para as espécies da Emodina foi capaz de descrever as propriedades relacionadas à reatividade da Emodina em solução, como as diferenças de energia livre e as constantes de acidez $\left(\mathrm{pK}_{\mathrm{a} 1}\right)$ envolvidas no processo da primeira desprotonação dessa molécula. Essas propriedades foram calculadas nos solventes água e metanol, através das metodologias MC-FEP (Simulações computacionais com o método Monte Carlo, associado à teoria de perturbação termodinâmica) e QMPCM (cálculos quânticos, com o solvente descrito com o modelo contínuo polarizável). Os valores dos $\mathrm{pK}_{\mathrm{a} 1}$ da Emodina determinados nesses solventes foram $8.7 \pm 0.8(8.4 \pm 0.5)$ e 12.5 $\pm 1.6(10.3 \pm 1.5)$, respectivamente, onde a sequência é referente às metodologias MC-FEP e (QM-PCM). Esses valores estão em boa concordância com os valores experimentais obtidos nesta tese de $\left(\mathrm{pK}_{\mathrm{a} 1}=8.0 \pm 0.2 \mathrm{e} \mathrm{pK}_{\mathrm{a} 1}^{*}=11.1 \pm 0.1\right)$. Experimentalmente determinamos o $\mathrm{pK}_{\mathrm{a} 2}$ da Emodina em água no valor de 10.8 \pm 0.2 .

O estudo dos espectros de absorção eletrônica das espécies da Emodina em solventes de diferentes polaridades, mostrou que o espectro medido da espécie EMH é 
pouco sensível à polaridade do solvente, pois as posições e as formas das bandas do espectro quase que não alteraram, quando o solvente mudou de benzeno para metanol. Por outro lado, observamos que o espectro medido da espécie EM- é bastante sensível ao solvente, pois registramos um deslocamento nas posições das bandas do espectro para região de menor comprimento de onda (maior energia) de aproximadamente 30 nm, quando mudamos o solvente de DMSO para água. Essa característica do espectro dessa espécie foi usada para caracterizar o meio em que ela se encontra numa dispersão lipídica de DMPC, onde mostramos de forma qualitativa, que ela fica inserida na bicamada lipídica, numa região de polaridade intermediária, como a região das cabeças dos lipídios, visto que o comprimento de onda máximo da primeira banda de absorção da $\mathrm{EM}^{-}$em bicamada lipídica apresentou um desvio para região do vermelho de aproximadamente $22 \mathrm{~nm}$, que é aproximadamente o mesmo valor encontrado na mudança do solvente, água $\rightarrow$ acetonitrila $(\sim 18 \mathrm{~nm})$.

O estudo comparativo das propriedades determinadas das simulações computacionais com dinâmica molecular, realizadas utilizando os campos de forças GROMOS $54 a 7$ e OPLS, mostrou que esses dois campos de forças são capazes de descrever bem a dinâmica, a estrutura e a interação das espécies da Emodina com a água. Os resultados dessas simulações mostraram que as ligações de hidrogênio intramoleculares dessas espécies são raramente quebradas devido às interações com água, e as geometrias tanto da espécie neutra como da desprotonada são bastante rígidas. Esse estudo também mostrou que a interação da hidroxila O3H3 da EMH com água foi mais forte comparativamente às outras hidroxilas. Isso está em concordância com o estudo teórico da desprotonação dessa molécula, pois mostramos que é na posição 3 que ocorre a primeira desprotonação, o que está também em concordância com a proposta experimental dessa desprotonação [28].

Os resultados das simulações das espécies da Emodina em bicamada lipídica de DMPC mostraram que tanto a espécie EMH como a EM- ficam inseridas na bicamada 
lipídica, na região das cabeças polares dos fosfolipídios, próximos aos gliceróis. Esses resultados estão em plena concordância com os resultados experimentais obtidos neste trabalho, pois mostramos, através de medidas do espectro de absorção óptica, que ambas as espécies encontram-se inseridas na bicamada lipídica, na região das cabeças polares dos fosfolipídios. Esses resultados também estão em concordância com nosso trabalho de mestrado [32], onde calculamos a energia livre de partição da Emodina água/metanol e água/clorofórmio nos valores de $-4.9 \pm 1.3$ e $-2.6 \pm 1.5 \mathrm{kcal} / \mathrm{mol}$, respectivamente, mostrando que entre esses três solventes a Emodina apresenta uma maior afinidade pelo metanol, portanto mostra uma maior afinidade por ambientes próticos, ou seja, com habilidades em formar ligações de hidrogênio.

Um estudo detalhado da interação das espécies da Emodina com a bicamada lipídica hidratada mostrou que a interação da espécie $\mathrm{EM}^{-}$com as moléculas de DMPC, não é tão forte como a interação da EMH. A espécie EM- interagiu muito pouco, cerca de 0.01 ligações de hidrogênio por configuração (HB), enquanto na espécie EMH, esse número foi aproximadamente 1.0 HB. Apesar da espécie EMH interagir mais fortemente com as moléculas de DMPC do que a $\mathrm{EM}^{-}$, a interação dela com as moléculas de água dentro da bicamada lipídica foi menor, cerca de $2 \mathrm{HB}$, se comparado com aproximadamente $6 \mathrm{HB}$ na espécie $\mathrm{EM}^{-}$. A comparação dos resultados das simulações das espécies da Emodina em água pura e em bicamada lipídica mostra que a espécie EMH em bicamada lipídica forma apenas cerca de 30\% das ligações de hidrogênio que formaria em água pura, enquanto na espécie $\mathrm{EM}^{-}$em bicamada esse percentual foi bem maior, cerca de $60 \%$. Portanto a localização dessas espécies dentro das bicamadas lipídicas, permite a interação dessas espécies com as moléculas de água, tendo a espécie desprotonada a maior hidratação.

A análise das propriedades estruturais da bicamada lipídica na região da vizinhança das espécies da Emodina, como área por lípidio $\left(A_{L}\right)$, mostrou que a inserção das espécies EMH e EM- na bicamada provoca um aumento na $\mathrm{A}_{\mathrm{L}}$ da ordem de $\sim 4 \%$ e 
$\sim 30 \%$, se comparado com $\mathrm{A}_{\mathrm{L}}$ da bicamada lipídica pura. Mostramos também através da análise da distribuição de moléculas de água em torno das espécies da Emodina que a hidratação da espécie EM- é duas vez maior do que a hidratação da EMH. Além disso, a análise da densidade eletrônica dos lipídios na vizinhança dessas espécies mostrou que a espécie $\mathrm{EM}^{-}$perturba a organização dos lipídios de sua vizinhança em maior intensidade do que a registrada com a espécie EMH. Todas essas informações nos leva à conclusão de que o efeito da Emodina desprotonada na bicamada lipídica é maior do que o da Emodina neutra. Esse efeito também foi comprovado através das medidas de DSC das dispersões lipídicas de DMPC na presença das espécies da Emodina, onde observamos que o aumento da fração molar das espécies da Emodina nas dispersões lipídicas, provoca, além de deslocamentos para região de menor temperatura, alargamentos do pico de transição de fase (gel-fluido), o que reduz a cooperatividade dos lipídios na bicamada lipídica, favorecendo uma transição de fase para baixos valores de temperatura. 


\section{Referências Bibliográficas}

[1] A. Kumar, S. Dhawan e B. B. Aggarwal. Oncogene. 17, 913 (1998).

[2] Y. C. Kuo, H. C. Meng e W. J. Tsai. Inflamm. Res. 50, 73 (2001).

[3] B. A. P. Van den Gorkom, E. G. E. de Vries, A. Karrenbeld e J. H. Kleibeuker. Aliment. Pharm. and Therap. 13, 443 (1999).

[4] D. L. Barnard, J. H. Huffman, J. L. Morris, S. G. Wood, B. G. Hughes e R. W. Sidwell. Antiviral. Research. 17, 63 (1992).

[5] K. Kawai, T. Kato, H. Mori, J. Kitamura e Y. Nozawa. Toxicol. Lett. 20, 155 (1984).

[6] X. M. Zhou e Q. H. Chen. Acta. Pharmac. Sinica. 23, 17 (1988).

[7] R. K. Goel, G. Das Gupta, S. N. Ram e V. B. Pandey. J. of Exper. Biolog. 29, 230 (1991).

[8] Y. C. Chen, S. C. Shen, W. R. Lee, E. L. Hsu, H. Y. Lin, C. H. Ko e S. W. Tseng. Biochem. Pharmacol. 64, 1713 (2002).

[9] G. Srinivas, R. J. Anto, P. Srinivas, S. Vidhyalakshmi, V. P. Senan e D. Karunagaran. Eur. J. Pharmacol. 473, 117 (2003).

[10] U. P. Singh, K. P. Singh, S. P. Singh e V. B. Ram. Fitop. Brasileira. 17, 420 (1992). 
[11] H. H. Wang. J. Ethnopharmac. 40, 111 (1993).

[12] S. P. D. Dwivedi, V. B. Pandey, A. H. Shah e Y. B. Rao. Phytother. Res. 2, 51 (1988).

[13] W. C. Evans. Treas and Evans Pharmacognosy. W. B. Saunders, London, (1996).

[14] J. Bruneton. Pharmacognosy, phytochemistry, medical plants. Intercept Ltd and Lavoisier Publishing, Paris, (1999).

[15] D. S. Alves, L. Pérez-Fons, A. Estepa e V. Micol. Biochem. Pharm. 68, 549 (2004).

[16] E. L. Duarte, T. R. Oliveira, D. S. Alves, V. Micol e M. T. Lamy. Langmuir. 24, 4041 (2008).

[17] S. Rahimipour, I. Bilkis, V. Peron, G. Gescheidt, F. Barbosa, Y. Mazur, Y. Koch, L. Weiner e M. Fridkin. Photochem. Photobiol. 74, 226 (2001).

[18] V. Y. Fain, B. E. Zaitsev e M. A. Ryabov. Chem. Natural. Comp. 41, 411 (2005).

[19] R. H. Thomson. Naturally Occurring Quinones III. Recent Advances, London, Chapman and Hall, (1986).

[20] S. Wang, T. Chen, R. Chen, Y. Hu, M. Chen e Y. Wang. Inter. J. Pharma. 430, $238,2012$.

[21] R. J. Sydiskis, D. G. Owen, J. L. Lohr, K. H. Rosler e R. N. Blomster. Antimicrob Agents Chemother. 35, 2463 (1991).

[22] S. J. Semple, S. M. Pyke, G. D. Reynolds e R. L. P. Flower. Antiv. Res. 49, 169 (2001).

[23] C. Y. Hsiang e T-. Y. Ho. British J. of Pharmac. 155, 227 (2008). 
[24] H. R. Xiong, J. Luo, W. Hou, H. Xiao e Z-Q. Yang. J. Ethnopharmac. 133, 718 (2011).

[25] B. Francke, H. Moss, M. C. Timbury e J. Hay. J. Virology. 26, 209 (1978).

[26] P. J. Hoffmann e Y. C. Cheng. J. Biol. Chem. 253, 3557 (1978).

[27] D. J. McGeoch, A. Dolan e M. C. Frame. Nucleic. Acids Res. 14, 3435 (1986).

[28] T. Pal e N. R. Jana. Analyst. 118, 1337 (1993).

[29] S. C. Nguyen, B. K. V. Hansen, S. V. Hoffmann e J. S. -Larsen. Chem. Phys. 352, 167 (2008).

[30] D. Wang, G. Yang e X. Song. Electroph. 22, 464 (2001).

[31] L. H. Keith e D. B. Walters. National Toxicology Programs Chemical Solubility Compendium. Lew. Publish. United States (1992).

[32] A. R. da Cunha. Estudos Teóricos de Propriedades Estruturais e Eletrônicas da molécula Emodina em Solução. Dissertação de mestrado, Universidade de São Paulo, São Paulo (2009).

[33] Y. Xu, C. Wang, G. Zhou, Y. Wu e J. Chen. Applied Surf. Sci. 258, 6366 (2012).

[34] S. T. Saito, G. Silva, C. Pungartnik e M. Brendel. J. Photochem. Photobiolog. B: biology. 111, 59 (2012).

[35] V. Y. Fain, B. E. Zaittserv e M. A. Ryabov. Russ. J. Org. Chem. 43, 1460 (2007).

[36] V. Y. Fain, B. E. Zaittserv e M. A. Ryabov. Russ. J. General Chem. 78, 2167 (2008).

[37] D. Jacquemin, X. Assfeld, J. Preat e E. A. Perpete. Mol. Phys. 105, 325 (2007). 
[38] M. Born. Z. Phys. 1, 45 (1920).

[39] L. Onsager. J. Chem. Soc. 58, 1486 (1936).

[40] J. G. Kirkwood. J. Chem. Phys. 2, 351 (1934).

[41] D. Rinaldi e J. L. Rivail. Theor. Chim. Acta. 32, 57 (1973).

[42] D. Rinaldi e J. L. Rivail. Chem. Phys. 18, 233 (1976).

[43] O. Tapia e O. Goscinski. Mol. Phys. 29, 1653 (1975).

[44] J. Tomasi e M. Persico. Chem. Rev. 94, 2027 (1994).

[45] S. Chalmet, D. Rinaldi e M. F. Ruiz-López. Inter. J. Quantum Chem. 84, 559 (2001).

[46] P. Bandyopadhyay, M. S. Gordon, B. Mennucci e J. Tomasi. J. Chem. Phys. 116, $5023(2002)$.

[47] P. F. B. Goncalves e H. Stassen. J Chem Phys. 123, 214109 (2005).

[48] P. F. B. Goncalves e H. Stassen. Pure Appl. Chem. 76, 231 (2004).

[49] J. Tomasi, B. Mennucci e R. Cammi. Chem. Rev. 105, 2999 (2005).

[50] G. J. Hoijtink, E. de Boer, P. H. van der Meij e W. P. Weijland. Recl. Trav. Chim. Pays-Bas Belg. 75, 487 (1956).

[51] O. Tapia. In Quantum Theory of Chemical Reactions. Editado por R. Daudel, A. Pullman, L. Salem, e A. Veillard. A. Eds. Wiley, London, (1981).

[52] O. Tapia, J. Mol. Struct. 6, 59 (1991).

[53] A. Bondi. J. Phys. Chem. 68, 441 (1964).

[54] R. S. Rowland e R. J. Taylor. Phys. Chem. 100, 7384 (1996). 
[55] S. Miertus, E. Scrocco e J. Tomasi. Chem. Phys. 55, 117 (1981).

[56] B. Mennucci, E. Cances e J. Tomasi. J. Phys. Chem. B 101, 10506 (1997).

[57] A. Klamt e G. Schuurmann. J. Chem. Soc.-Perkin Trans. 2, 799 (1993).

[58] E. Cances e B. Mennucci. J. Math Chem. 23, 309 (1998).

[59] V. Barone e M. Cossi. J. Phys. Chem. A 102, 1995 (1998).

[60] L. Frediani, R. Cammi, S. Corni e J. Tomasi. J. Chem. Phys. 120, 3893 (2004).

[61] F. Zhou e K. Schulten. J. Phys. Chem. 99, 2194 (1995).

[62] C. J. Cramer e D. G. Truhlar. Chem. Rev. 99, 2161 (1999).

[63] M. Orozco e F. J. Luque. Chem. Rev. 100, 4187 (2000).

[64] B. Mennucci. Adv. Rev. Comput. Mol. Sci. 2, 386 (2012).

[65] C. P. Kelly, C. J. Cramer e D. G. Truhlar. J. Phys. Chem. B 110, 16066 (2006).

[66] G. J. Tawa, I. A. Topol, S. K. Burt, R. A. Caldwell e A. A. Rashin. J. Chem. Phys. 109, 4852 (1998).

[67] F. C. Hagemeister, C. J. Gruenloh e T. S. Zwier. J. Phys. Chem. A 102, 82 (1998).

[68] N. Metropolis, A. W. Rosenbluth, M. N. Rosenbluth, A. H. Teller e E. Teller. J. Chem. Phys. 21, 1087 (1953).

[69] B.J. Alder e T.E. Wainwright. J. Chem. Phys. 27, 1208 (1957).

[70] B.J. Alder e T.E. Wainwright. J. Chem. Phys. 31, 459 (1959).

[71] M. P. Allen e D. J. Tildesley. Computer Simulation of Liquids. Claredon Press, London, (1987). 
[72] K. Coutinho. Modelo Discreto de Solvente Solvatocromismo no Espectro de Absorção Molecular. Tese de doutoramento, Universidade de São paulo, São Paulo (1997).

[73] S. E. Feller. Curr. Opin Coll Interface Sci. 5, 217 (2000).

[74] D. P. Tieleman, S. J. Marrink e H. J. C. Berendsen. Biochim. Biophys. Acta. 1331, 235 (1997).

[75] D. F. Bocian e S. I. Chan. Ann. Rev. Phys. Chem. 29, 307 (1978).

[76] Y. H. C. Chan e S. G. Boxer. Curr Opin Chem. Biol. 11, 581 (2007).

[77] T. Broemstrup e N. Reuter. Biophys. J. 99, 825 (2010).

[78] J. Sabín, G. Prieto, J. M. Ruso, P. V. Messina, F. J. Salgado, M. Nogueira, M. Costas e F. Sarmiento. J. Phys. Chem. B 113, 1655 (2009).

[79] F. L. Grohmann, F. Csempesz e M. Szögyi. Colloid. Polym. Sci. 276, 66 (1998).

[80] B. H. S. Cho, J. R. Park, M. T. Nakamura, B. M. Odintsov, M. A. Wallig e B. H. Chung. Exp. Biol. and Medic. 235, 1194 (2010).

[81] N. Kučerka, Y. Liu, N. Chu, H. I. Petrache, S. Tristram-Nagle e J. F. Nagle. Biophys. J. 88, 2626 (2005).

[82] T. Heimburg. Thermal Biophysics of Membranes. Weinheim: Wiley-VCH, (2007).

[83] B. E. Warren. Phys. Rev. 44, 0969 (1933).

[84] Y. K. Levine e M. H. F. Wilkins. Nature. 230, 69 (1971).

[85] S. -J. Marrink e A. E. Mark. J. Am. Chem. Soc. 125, 11144 (2003). 
[86] V. Luzzati. X-ray diffraction studies of lipid-water systems. D. Chapman (Ed.), Biological Membranes, Academic Press, New York, (1968).

[87] J. Lemmich, K. Mortensen, J. H. Ipsen, T. Hønger, R. Bauer e O. G. Mouritse. Phys. Rev. E. 53, 5169 (1996).

[88] H. Heller, M. Schäfer e K. Schulten. J. Phys. Chem. 97, 8343 (1993).

[89] E. Egberts, S. J. Marrink, H. J. C. Berendsen. Eur. Biophys. J. 22, 423 (1994).

[90] W. K. Nitschke, C. C. Vequi-Suplicy, K. Coutinho e H. Stassen. J. Phys. Chem. B 116, 2713 (2012).

[91] S. -J. Marrink, E. Lindahl, O. Edholm e A. E. Mark. J. Am. Chem. Soc. 123, 8638 (2001).

[92] A. H. de Vries, A. E. Mark e S. -J. Marrink. J. Am. Chem. Soc. 126, 4488 (2004).

[93] S. -J. Marrink, F. Jähnig e H. Berendsen. J. Biophys. Chem. 71, 632 (1996).

[94] A. A. Gustovenko e J. Anwar. J. Phys. Chem. B 111, 10453 (2007).

[95] S. -J. Marrink, J. Risselada e A. E. Mark. Chem. Phys. Lipids. 135, 223 (2005).

[96] A. H. de Vries, S. Yefimov, A. E. Mark e S. -J. Marrink. Proc. Natl. Acad. Sci. U.S.A. 102, 5392 (2005).

[97] D. Jamroz, M. Kepczynski e M. Nowakowska. Langmuir 26, 15076 (2010).

[98] S. J. Marrink e H. J. C. Berendsen. J. Phys. Chem. 100, 16729 (1996).

[99] A. D. MacKerell, D. Bashford, M. Bellott, R. L. Dunbrack, J. D. Evanseck, M. J. Field, S. Fischer, J. Gao, H. Guo, S. Ha, D. Joseph-McCarthy, L. Kuchnir, K. Kuczera, F. T. K. Lau, C. Mattos, S. Michnick, T. Ngo, D. T. Nguyen, B. 
Prodhom, W. E. Reiher, B. Roux, M. Schlenkrich, J. C. Smith, R. Stote, J. Straub, M. Watanabe, J. Wiórkiewicz-Kuczera, D. Yin, e M. Karplus. J. Phys. Chem. B 102, 3586 (1998).

[100] S. E. Feller e A. D. MacKerell, Jr. J. Phys. Chem. B 104, 7510 (2000).

[101] O. Berger, O. Edholm e F. Jähnig. Biophys. J. 72, 2002 (1997).

[102] W. L. Jorgensen e J. Tirado-Rives. J. Am. Chem. Soc. 110, 1657 (1988).

[103] W. F. van Gunsteren, S. R. Billeter, A. A. Eising, P. H. Hünenberger, P. Krüger, A. E. Mark, W. R. P. Scott e I. G. Tironi. Biomolecular Simulation: The GROMOS96 Manual and User Guide. vdf Hochschulverlag AG an der ETH Zürich and BIOMOS B. V.: Zürich, Switzerland, (1996).

[104] W. Huang, Z. Lin e W. F. van Gunsteren. J. Chem. Theory Comp. 7, 1237 (2011).

[105] N. Schmid, A. P. Eichenberger, A. Choutko, S. Riniker, M. Winger, A. E Mark e W. F. van Gunsteren. Eur. Biophy. J. 40, 843 (2011).

[106] C. Oostenbrink, A. Vila, A. E. Mark e W. F. van Gunsteren. J. Comput. Chem. 25, 1656 (2004).

[107] C. Oostenbrink, T. A. Soares, N. F. van der Vegt e W. F. van Gunsteren. Eur. Biophys. J. 34, 273 (2005).

[108] A. Villa, H. Fan, T. Wassenaar e A. E. Mark. J. Phys. Chem. B 111, 6015 (2007).

[109] S. W. Chiu, M. Clark, V. Balaji, S. Subramaniam, H. L. Scott, e E. Jakobsson. Biophys. J. 69, 1230 (1995).

[110] D. Poger, A. E. Mark e W. F. van Gunsteren. J. Comp. Chem. 31, 1117 (2010). 
[111] D. Poger e A. E. Mark. J. Chem. Theory Comp. 6, 325 (2010).

[112] J. E. Davis, O. Rahaman e S. Patel. Biophys J. 96385 (2009).

[113] L. R. De Young e K. A. Dill. Biochem. 27, 5281 (1988).

[114] J. M. Smaby, M. M. Momsen, H. L. Brockman e R. E. Brown. Biophys. J. 73, $1492(1997)$.

[115] L. J. Lis, M. McAlister, N. Fuller, R. P. Rand e V. A. Parsegian. Biophys. J. 37, 657 (1982).

[116] R. P. Rand e V. A. Parsegian. Biochim. Biophys. Acta. 988, 351 (1989).

[117] B. W. Koenig, H. H. Strey e K. Gawrisch. Biophys. J. 73, 1954 (1997).

[118] H. I. Petrache, S. T-. Nagle e J. F. Nagle. Chem. Phys. Lipid. 95, 83 (1998).

[119] J. F. Nagle e S. T-. Nagle. Biochim. Biophys. Acta. 1469, 159 (2000).

[120] P. B. Moore, C. F. Lopez e M. L. Klein. Biophys. J. 81, 2484 (2001).

[121] C. F. Lopez, S. O. Nielsen, M. L. Klein e P. B. Moore. J. Phys. Chem. B 108, 6603 (2004).

[122] I. Z. Zubrzycki, Y. Xu, M. Madrid e P. Tang. J. Chem. Phys. 112, 3437 (2000).

[123] M. P-. Gierula, Y. Takaoka, H. Miyagawa, K. Kitamura e A. Kusumi. Biophys. J. 73, 1228 (1999).

[124] A. Kukol. J. Chem. Theory Comput. 5, 615 (2009).

[125] S. W. Chiu, S. A. Pandit, H. L. Scott e E. Jakobsson. J. Phys. Chem. B 113, 2748 (2009). 
[126] A. A. Gurtovenko, M. Patra, M. Karttunen e I. Vattulainen. Biophys. J. 86, 3461 (2004).

[127] S. C. Costigan, P. J. Booth e R. H. Templer. Biochim. Biophys. Acta. 1468, 41 (2000).

[128] J. N. Sachs, H. I. Petrache e T. B. Woolf. Chem. Phys. Lipid. 126, 211 (2003).

[129] J. P. M. Jämbeck e A. P. Lyubartsev. J. Phys. Chem. B 116, 3164 (2012).

[130] W. Rawicz, K. C. Olbrich, T. McIntosh, D. Needham e E. Evans. Biophys. J. $\mathbf{7 9}, 328(2000)$.

[131] K. M. Merz, Jr. e B. Roux. Biological Membranes, A Molecular Perpective from Computation and Experiment. Birkhäuser, Boston, (1996).

[132] R. Lipowsky e E. Sackmann. Structure and Dynamics of Membranes, From Cells to Vesicles. Elsevier, New York, (1995).

[133] A. A. Spector e M. A. Yorek. J. Lipd. Res. 26, 1015 (1985).

[134] R. C. Aloia, H. Tian e F. C. Jensen. Proc. Natl. Acad. Sci. USA. 90, 5181 (1993).

[135] I. L. V. Genderen, R. Brandimarti, M. Torrisi, G. Campadelli-Fiume e G. V. Meer. Virology. 200, 831 (1994).

[136] A. L. Lomize, I. D. Pogozheva e H. I. Mosberg. Protein Sci. 13, 2600 (2004).

[137] S. Li, F. Eghiaian, C. Sieben, A. Herrmann e I. A. T. Schaap. Biophys J. 100, 637 (2011).

[138] P. Walde e S. Ichikawa. Biomol. Engineer. 18, 143 (2001).

[139] J. J. Cheetham e R. M. Epand. Bioscience Reports. 7, 225 (1987). 
[140] S. K. Srinivas, R. V. Srinivas, G. M. Anantharamaiah, J. P. Segrest e R. W.Compans. J. Biolog. Chem. 267, 7121 (1992).

[141] S. G-. Manyes, G. Oncins e Fausto Sanz. Biophys. J. 89, 1812 (2005).

[142] S. K. Jain, R. K. Jain, M. K. Chourasia, A. K. Jain, K. B. Chalasani, V. Soni e A. Jain. AAPS PharmSciTech. 6, E35 (2005).

[143] C. Wang, F. Ye, G. F. Velardez, G. H. Peters e P. Westh. J. Phys. Chem. B 115, $196(2011)$.

[144] J. Wohlert e O. Edholm. J. Chem. Phys. 125, 204703 (2006).

[145] A. R. Braun, E. G. Brandt, O. Edholm, J. F. Nagle e J. N. Sachs. Biophys. J. 100, $2112(2011)$.

[146] I. Komljenovic, D. Marquardt, T. A. Harroun e E. Sternin. Chem. Phys. Lipid. 163, 480 (2010).

[147] S. T-. Nagle, Y. Liu, J. Legleiter e J. F. Nagle. Biophys. J. 83, 3324, (2002).

[148] D. R. Hartree. Proceedings of the Cambridge Philosophical Society. 24, 89 (1928).

[149] J. C. Slater. Phys. Rev. 34, 1293 (1929).

[150] C. Moller e M. S. Plesset. Phys. Rev. 46, 0618 (1934).

[151] J. A. Pople, J. S. Binkley e R. Seeger. Inter. J. Quantum Chem. 10, 1 (1976).

[152] J. A. Pople, R. Seeger e R. Krishnan. Inter. J. Quantum Chem. 12, 149 (1977).

[153] R. Krishnan, H. B. Schlegel e A. Pople. J. Chem. Phys. 72, 4654 (1980).

[154] R. J. Bartlett e M. Musial. Rev. Mod. Phys. 79, 291 (2007). 
[155] J. D. M. Vianna e A. Fazzio, S. Canuto. Teoria Quântica de Moléculas e Sólidos, Simulação Computacional. Livraria da Física, São Paulo, (2004).

[156] N. H. Morgon e K. Coutinho. Métodos de Química Teórica e Modelagem Molecular. Livraria da Física, São Paulo, (2007).

[157] C. J. Cramer. Essentials of Computational Chemistry: Theories and Models. John Wiley, Minnesota, (2005).

[158] I. N. Levine. Quantum Chemistry. Prentice Hall, New Jersey, 5 edição, (2000).

[159] A. Szabo e N. S. Ostlund. Modern Quantum Chem. Dover, New York, (1996).

[160] K. I. Ramachandran, G. Deepa, K. Namboori. Computational Chemistry and Molecular Modeling: Principles and Applications. Springer-Verlag GmbH, Germany, (2008).

[161] W. Kohn e P. Hohenberg. Physical Review. 136, B864 (1964).

[162] J. M. Seminario. Recent Developments and Applications of Modern DFT. Elsevier, Amsterdam, (1996).

[163] C. J. Cramer. Essentials of Computational Chemistry. Wiley, Chichester, (2002).

[164] R. Pariser e R. G. Parr. J. Chem. Phys. 21, 466 (1953).

[165] J. A. Pople, D. P. Santry e G. A. Segral. J. Chem. Phys. 43, S129 (1965).

[166] J. A. Pople e G. A. Segral. J. Chem. Phys. 43, S136 (1965).

[167] J. A. Pople e G. A. Segral. J. Chem. Phys. 44, 3289 (1966).

[168] J. A. Pople, D. L. Beveridge e P. A. Dobosh. J. Chem. Phys. 47, 2026 (1967).

[169] M. Zerner. Reviews in Computational Chemistry. Eds. K. B. Lipkowitz e D. B. Boyd, VCH, New York, 313, (1991). 
[170] M. J. S. Dewar e W. Thiel. J. Amer. Chem. Soc. 99, 4899 (1977).

[171] W. Thiel. The MNDOC method, a correlated version of the MNDO model. J. Am. Chem. Soc. 103, 1413 (1981).

[172] M. J. S. Dewar, E. G. Zoebisch, E. F. Healy e J. J. P. Stewart. J. Amer. Chem. Soc. 107, 3902 (1985).

[173] J. J. P. Stewart. J. Comput. Chem. 10, 209 (1989).

[174] G. B. Rocha, R. O. Freire, A. M. Simas e J. J. P. Stewart. J. Comput. Chem. 27, 1101 (2006).

[175] M. Born e J. R. Oppenheimer. Ann. Phys. Leipzig. 84, 457 (1927).

[176] D. Joulbert. Density Functionals: Theory and Applications. Springer Lecture Notes in Physics, Vol. 500, Berlin, (1998).

[177] C. Fiolhais, F. Nogueira e M. Marques. A Primer in Density Functional Theory. Springer Lecture Notes in Physics, Vol. 620, berlin, (2003).

[178] W. Kohn e J. Pople. Electronic Structure of Matter - Wave Functions and Density Functionals. Nobel Lecture, Nobelprize.org, (1998).

[179] W. Kohn e L. J. Sham. Phys. Rev. 140, A1133 (1965).

[180] U. von Barth e L. Hedin. J. Phys. C 5, 1629 (1992).

[181] J. P. Perdew. Phys. Rev. Lett. 55, 1665 (1985).

[182] J. P. Perdew e Y. Wang. Phys. Rev. B 33, 8800 (1986).

[183] J. P. Perdew. Phys. Rev. B 33, 8822 (1986).

[184] A. D. Becke. J. Chem. Phys. 84, 4524 (1986). 
[185] A. D. Becke. Phys. Rev. A 38, 3098 (1988).

[186] S. Dressler e W. Thiel. Chem. Phys. Lett. 273, 71 (1997).

[187] C. Lee, W. Yang e R. G. Parr. Phys. Rev. B 37, 785 (1988).

[188] A. D. Becke. J. Chem. Phys. 109, 2092 (1998).

[189] K. Kim e K. D. Jordan. J. Phys. Chem. 98, 10098 (1994).

[190] P. J. Stephens, F. J. Devlin, C. F. Chabalowski e M. J. Frisch. J. Phys. Chem. 98, 11623 (1994).

[191] J. A. Chevary, S. H. Vosko, K. A. Jackson, M. R. Pederson e D. J. Singh. Phys. Rev. B 46, 6671 (1992).

[192] F. A. Momany, M. Appell, J. L. Willetta e W. B. Bosmac. Carbohyd. Research. 340, 1638 (2005).

[193] M. V. A. Damasceno, B. J. C. Cabral e K. Coutinho. Theor. Chem. Acc. 131, $1214(2012)$.

[194] H. Hooshyar, H. Rahemi, M. H. A. Shad e B. Khezri.J. Mol. Model. 15, 525 (2009).

[195] C. Trindle, Z. Altun. Theor. Chem. Acc. 122, 145 (2009).

[196] C. J. Balehausen e H. B. Gray. Molecular Orbital Theory: An introductory Lecture Note and Reprint. W. A. Benjamin, INC, New York, (1965).

[197] R. M. Balabin. J. Chem. Phys. 132, 211103 (2010).

[198] R. Ditchfield, W. J. Hehre e J. A. Pople. J. Chem. Phys. 54, 724 (1971)

[199] F. Jensen. Introduction to Computational Chemistry. John Wiley\&Sons, Chichester, (1999). 
[200] R. S. Mulliken. J. Chem. Phys. 23, 1833 (1955).

[201] U. C. Singh e P. A. Kollman. J. Comp. Chem. 5, 129 (1984).

[202] F. Weinhold e C. R. Landis. Chem. Educ. Res. Pract. Eur. 2, 91 (2001).

[203] C. I. Bayly, P. Cieplak, W. Cornell , P. A. Kollman. J. Phys. Chem. 97, 10269 (1993).

[204] C. M. Breneman e K. B. Wiberg. J. Comp. Chem. 11, 361 (1990).

[205] V. Ludwig, K. Coutinho e S. Canuto. Phys. Chem. Chem. Phys. 9, 4907 (2007).

[206] H. C. Georg, K. Coutinho e S. Canuto. J. Chem. Phys. 126, 34507 (2007).

[207] T. L. Fonseca, K. Coutinho e S. Canuto. J. Chem. Phys. 126, 34508 (2007).

[208] H. C. Georg, K. Coutinho e S. Canuto. Chem. Phys. Lett. 429, 119 (2006).

[209] A. C. Borin, L. S-. Andrés, V. Ludwig, K. Coutinho e S. Canuto. Int. J. Quantum Chem. 106, 2564 (2006).

[210] M. W. Schmidt, K. K. Baldridge, J. A. Boatz, S. T. Elbert, M. S. Gordon, J. H. Jensen, S. Koseki, N. Matsunaga, K. A. Nguyen, S. Su, T. L. Windus, M. Dupuis, J. A. Montgomery J. Comput. Chem. 14, 1347 (1993).

[211] Y. Marcus. Ion Solvation. Wiley, New York, (1985).

[212] A. Ben-Naim. Solvation Thermodynamics. Plenum, New York, (1987).

[213] A. R. Leach. Molecular Modelling, Principles and Applications. Pearson, Prentice Hall, $2^{\text {a }}$ ed. New York, (2001).

[214] D. Frenkel e B. Smit. Understanding Molecular Simulation. Academic Press, New York, (1996). 
[215] A. Rahman. Phys. Rev. 136, A405 (1964).

[216] A. Rahman e F. H. Stillinger. J. Chem. Phys. 55, 3336 (1971).

[217] W. F. van Gunsteren e H. J. C. Berendsen. Mol. Phys. 34, 1311 (1977).

[218] H. J. C. Berendsen e W. F. van Gunsteren. Practical algorithms for dynamic simulations. Molecular dynamics simulation of statistical mechanical systems. Soc. Italiana di Fisica, Bologna, 34, (1977).

[219] L. Verlet. Phys. Rev. 159, 98 (1967).

[220] D. Fincham e D. M. Heyes. CCP5 Quarterly. 6, 4 (1982).

[221] H. J. C. Berendsen, W. F. van Gunsteren, in: G. Ciccotti, W. G. Hoover (Eds.). Molecular-Dynamics Simulation of Statistical-Mechanical Systems. North-Holland, Amsterdam, (1986).

[222] S. R. A. Salinas. Introdução à Física Estatística. EDUSP, São Paulo, (2005).

[223] H. J. C. Berendsen, J. P. M. Postma, A. DiNola e J. R. Haak. J. Chem. Phys. 81, $3684(1984)$.

[224] S. Nosé. Mol. Phys. 52, 255 (1984).

[225] W. G. Hoover. Phys. Rev. A 31, 1695 (1985).

[226] G. Bussi, D. Donadio e M. Parrinello. J. Chem. Phys. 126, 014101 (2007).

[227] M. Parrinello e A. Rahman. J. Appl. Phys. 52, 7182 (1981).

[228] S. Nosé e M. L. Klein. Mol. Phys. 50, 1055 (1983).

[229] D. van der Spoel, E. Lindahl, B. Hess, A. R. van Buuren, E. Apol, P. J. Meulenhoff, D. P. Tieleman, A. L. T. M. Sijbers, K. A. Feenstra, R. van Drunen 
e H. J. C. Berendsen. Gromacs User Manual version 4.5.6, www.gromacs.org, (2010).

[230] T. Tomé e M J. de Oliveira. Dinâmica Estocástica e Irreversibilidade. EDUSP, São Paulo, (2001).

[231] K. Coutinho e S. Canuto. DICE: A Monte Carlo program for liquid simulation. University of São Paulo, São Paulo (2003).

[232] T. Darden, D. York e L. Pedersen. J. Chem. Phys. 98, 10089 (1993).

[233] U. Essmann, L. Perera, M. L. Berkowitz, T. Darden, H. Lee, L. G. Pedersen. J. Chem. Phys. 103, 8577 (1995).

[234] I. G. Tironi, R. Sperb, P. E. Smith e W. F. van Gunsteren. J. Chem. Phys. 102, $5451(1995)$.

[235] B. R. Brooks, R. E. Bruccoleri, B. D. Olafson, D. J. States, S. Swaminathan e M. Karplus. J Comput. Chem. 4, 187 (1983).

[236] R. S-. Ferrer, D. A. Case e R. C. Walker. WIREs Comput. Mol. Sci. 3, 198 (2013).

[237] D. A. Case, T. E. Cheatham, III, T. Darden, H. Gohlke, R. Luo, K. M. Merz, Jr., A. Onufriev, C. Simmerling, B. Wang e R. Woods. J. Computat. Chem. 26, $1668(2005)$.

[238] E. Lindahl, B. Hess e D. van der Spoel. GROMACS 3.0: A package for molecular simulation and trajectory analysis. J. Mol. Mod. 7, 306 (2001).

[239] W. F. V. Gunsteren e P. K. W. Weiner. Computer Simulation of Biomolecular Systems: Theoretical and Experimental Aplications. Escom, Leiden, (1989).

[240] D. L. Beveridge, F. M. DiCapua. Annu. rev. Biophys. 18, 431 (1989). 
[241] P. Kollman. Chem. Rev. 93, 2395 (1993).

[242] P. A. Bash, U. C. Singh, R. Langridge e P. Kollman. Science. 236, 564 (1987).

[243] M. Mezei e D. L. Beveridge. Free Energy Simulations. Ann. N. Y. Acad. Sci. 482, 1 (1986).

[244] C. H. Bennett. J. Comp. Phys. 22, 245 (1976).

[245] R. W. Zwanzing. J. Chem. Phys. 22, 1420 (1954).

[246] W. L. Jorgensen, J. M. Briggs e M. L. Contreras. J. Phys. Chem. 94, 1683 (1990).

[247] D. L. Pavia, G. M. Lampman, G. S. Kriz e J. R. Vyvyan. Introduction to Spectroscopy. 4th Edition. Brooks/Cole, Belmon, (2009).

[248] H. H. Jaffé e M. Orchin. Theory and Applications of Ultraviolet Spectroscopy. Jon Wiley and Sons, New York, (1964).

[249] P. A. M. Dirac. Proceedings of the Royal Society A 114, 243 (1927).

[250] C. R. Cantor e P. R. Schimmel. Part II: Techniques for the study of biological structure and function. New York: W.H. Freeman and Company, (1980).

[251] B. Valeur. Molecular Fluorescence: Principles and Applications. Weinheim: Wiley-VCH Verlag GmbH, (2001).

[252] C. Reichardt. Solvents and Solvent Effects in Organic Chemistry. Weinheim: Wiley-VCH, (2004).

[253] J. N. Murrell. The Theory of the Electronic Spectra of Organic molecules. Methuen and Co., London, (1963).

[254] J. Franck e E. G. Dymond. Trans. Faraday Soc. 21, 536 (1926). 
[255] A. S. Coolidge, H. M. James e R. D. Present. J. Chem. Phys. 4, 193 (1936).

[256] P. F. Bernath. Spectra of Atoms and Molecules. Oxford University Press, New York, (1995).

[257] P. Y. Ren e J. W. Ponder. J. Comp. Chem. 23, 1497 (2002).

[258] G. Höhne, W. Hemminger e H. J. Flammersheim Differential Scanning Calorimetry. Springer, (2003).

[259] R. P. Barroso. Dispersões Lipídicas de Dimiristoil Fosfatidilglicerol: Um Estudo Termo-estrutural. Tese de doutoramento, Universidade de São paulo, São Paulo (2010).

[260] J. M. Sturtevant. Ann. Rev. Phys. Chem. 38, 463 (1987).

[261] H. Heerklotz. J. Phys. Condens. Matter. 16, R441 (2004).

[262] T. R. de Oliveira. Caracterização estrutural de agregados formados pelo antifúngico anfotericina B e lipídios catiônicos: uma possivel formulação farmacológica. Dissertação de mestrado, Universidade de São paulo, São Paulo (2008).

[263] K. A. Riske, L. Q. Amaral e M. T. Lamy-Freund. Biochim. Biophys. Acta. 1511, 297 (2001).

[264] C. L. de Ligny, P. F. M. Luykx, M. Rehbach e A. A. Wieneke. Rec. Trav. Chim. 79, 699 (1960).

[265] C. L. de Ligny, P. F. M. Luykx, M. Rehbach e A. A. Wieneke. Rec. Trav. Chim. 79, $713(1960)$

[266] C. L. de Ligny e M. Rehbach. Rec. Trav. Chim. 79, 727 (1960).

[267] J. L. Beckers, M. T. Ackermans e P. Bocek. Electrophoresis. 24, 1544 (2003). 
[268] T. Heimburh. Thermal Biophyssics of Membranes. Wiley-VCH, Verlag GmbH\&Co.KGaA, (2007).

[269] T. Ziegler. Chem. Rev. 91, 651 (1991).

[270] W. Kohn, A. D. Becke e R. G. Parr. J. Phys. Chem. 100, 12974 (1996).

[271] H. Chermette. Coord. Chem. Rev. 180, 699 (1998).

[272] F. A. Hamprecht, A. J. Cohen, D. J. Tozer e N. C. Handy. J. Chem. Phys. 109, $6264(1998)$.

[273] S. C. Nguyen. Linear Dichroism Spectroscopic and Theoretical Investigations of the Compound Emodin. Master Thesis, Roskilde University, Roskilde (2004).

[274] R. Krishnan, J. S. Binkley, R. Seeger, e J. A. Pople. J. Chem. Phys. 72, 650 (1980).

[275] Z. S. Marković e N. T. Manojlović. Monastsh. Chem. 140, 1311 (2009).

[276] A. Prakash. Z. Kristallogr. 113, 272 (1965).

[277] E. Runge e E. K. U. Gross. Phys. Rev. Lett. 52, 997 (1984).

[278] M. J. Frisch, et al. Gaussian 03: Connected system of programs for performing semiempirical, ab initio, and density functional molecular orbital (MO) calculations, Gaussian, Inc. Wallingford CT, (2004).

[279] H. J. C. Berendsen, J. P. M. Postma, W. F. van Gunsteren, e J. Hermans. B. Pullman. Intermolecular Forces, Ed. Reidel, Dordrecht, (1981).

[280] R. W. Hockney, S. P. Goel e J. Eastwood. J. Comp. Phys. 14, 148 (1974).

[281] D. Young. Computational Chemistry. John Wiley\&Sons, INC, New York, (2001). 
[282] K. Coutinho. Programa ORDER. University of São Paulo, São Paulo (2003).

[283] K. Coutinho. Programa ANLGEOM. University of São Paulo, São Paulo (2010).

[284] C. O. da Silva, E. C. da Silva e M. A. C. Nascimento. J. Phys. Chem. A 104, $2402(2000)$.

[285] C. O. da Silva, E. C. da Silva e M. A. C. Nascimento. J. Phys. Chem. A 103, 11194 (1999).

[286] M. W. Palascak e G. C. Shields. J. Phys. Chem. A 108, 3692 (2004).

[287] D. M. Camaioni e C. A. Schwerdtfeger. J. Phys. Chem. A 109, 10795 (2005).

[288] J. R. Pliego Jr. Chem. Phys. Lett. 367, 145 (2003).

[289] M. Namazian e H. Heidary. J. Mol. Struct. 620, 257 (2003).

[290] R. Casasnovas, J. Frau, J. Ortega-Castro, A. Salva, J. Donoso e F. Muñuz. J. Mol. Struct. 912, 5 (2009).

[291] C. P. Kelly, C. J. Cramer e D. Truhlar. J. Phys. Chem. B 110, 16066 (2006).

[292] B. G-. Choobar, H. Dezhampanah, P. Nikparsa e A. G-. Shomani. Inter. J. Quant. Chem. 112, 2275 (2012).

[293] J. R. Pliego Jr. e J. M. Riveros. Chem. Phys. Lett. 332, 597 (2000)

[294] J. R. Pliego Jr. e J. M. Riveros. Phys. Chem. Chem. Phys. 4, 1622 (2002).

[295] A. Ben-Naim e Y. J. Marcus. J. Chem. Phys. 81, 2016 (1984).

[296] A. R. da Cunha, J. M. Riveros, S. Canuto e K. Coutinho. Defining the $p H^{*}$ scale in methanol: Determination of accurate values the solvation free energies of $\mathrm{CH}_{3} \mathrm{O}^{+}$and $\mathrm{CH}_{3} \mathrm{O}^{-}$in methanol. (review process, see Appendix), São Paulo, 2014. 
[297] H. C. Georg, K. Coutinho e S. Canuto. Chem. Phys. Lett. 413, 16 (2005).

[298] A. Ben-Naim. J. Phys. Chem. 82, 792 (1978).

[299] W. L. Jorgensen, J. Buckner, S. Boudon e J. Tirado-Rives. J. Chem. Phys. 89, $3742(1988)$.

[300] W. L. Jorgensen, D. S. Maxwell e J. Tirado-Rives. J. Am. Chem. Soc. 118, 11225 (1996).

[301] M. Cossi, V. Barone, R. Cammi e J. Tomasi. Chem. Phys. Lett. 255, 327 (1996).

[302] V. Barone, M. Cossi e J. Tomasi. J. Chem. Phys. 107, 3210 (1997).

[303] J. Ho, A. Klamt e M. L. Coote. J. Phys. Chem. A 114, 13442 (2010).

[304] T. N. Brown e N. M-. Diez. J. Phys. Chem. B 110, 20546 (2006).

[305] T. N. Brown e N. M-. Diez. J. Phys. Chem. B 110, 9270 (2006).

[306] G. Schuurmann, M. Cossi, V. Barone e J. Tomasi. J. Phys. Chem A 102, 6706 (1998).

[307] B. Hess, H. Bekker, H. J. C. Berendsen e J. G. E. M. Fraaije. J. Comput. Chem. 18, 1463 (1997).

[308] X. Daura, A. E. Mark e W. F. van Gunsteren J. Comp. Chem. 19, 335 (1998).

[309] W. F. van Gunsteren e H. J. C. Berendsen. Groningen Molecular Simulation (GROMOS) Library Manual, BIOMOS b.v., Groningen, (1987).

[310] J. F. Nagle, R. Zhang, S. T-. Nagle, W. Sun, H. I. Petrache e R. M. Suter. Biophys. J. 70, 1419 (1996).

[311] J. R. Pliego e J. M. Riveros. J. Phys. Chem. B, 104, 5155 (2000). 
[312] D. M. Popovic, J. Quenneville e A. A. Stuchebrukhov. Theory and Applications of Computational Chemistry: The First Forty Years. Elsevier, U.S.A, University of California, (2006).

[313] M. A-. Arzo e V. M. Aguilella. Eur. Phys. J. E 31, 429 (2010).

[314] C. B. Andersen. J. Geosc. Educ. 50, 389 (2002).

[315] D. A. Wolf-Gladrow, R. E. Zeebe, C. Klaas, A. Körtzinger e A. G. Dickson. Marine Chem. 106, 287 (2007).

[316] R. G. Bates. Determination of $p H$ Theory and Practice. John Wiley\&Sons, New York, (1954).

[317] D. D. Perrin e B. Dempsey. Buffers for pH and Metal Ion Control. Chapman and Hall Ltd, London, (1974).

[318] J. T. Denison e J. B. Ramsey. J. Am. Chem. Soc. 71, 1496 (1949).

[319] W. R. Gilkerson. J. Chem. Phys. 25, 1199 (1956).

[320] J. A. Pople, D. L. Beveridge e P. A. Dobosh. J. Chem. Phys. 47, 2026 (1967).

[321] M. C. Zerner. ZINDO: A semi-empirical program package, University of Florida, Gainesville, FL 32611.

[322] N. M. O’boyle1, A. L. Tenderholt e K. M. Langner. J. Comput. Chem. 29, 839 (2008).

[323] C. Anézo, A. H. de Vries, H. D. Höltje, D. P. Tieleman e S. J. Marrink. J. Phys. Chem. B 1079424 (2003).

[324] H. I. Petrache, S. W. Dodd e M. F. Brown. Biophys. J. 79, 3172 (2000). 
[325] L. S. Vermeer, B. L. de Groot, V. Réat, A. Milon e J. Czaplicki. Eur. Biophys. J. 36, 919 (2007).

[326] J. P. Douliez, A. Léonard e E. J. Dufoure. Biophys. J. 68, 1727 (1995).

[327] S. T-. Nagle e J. F. Nagle. Chem. Phys. Lip. 127, 3 (2004).

[328] D. A. McQuarrie e J. D. Simon. Molecular Thermodynamics. Sausalito, Calif, University Science Books, (1999).

[329] P. Costa, V. Ferreira, P. Esteves e M. Vasconcellos. Ácidos e Bases em Química Orgânica. Soc. Brasileira de Química, Bookman, Porto Alegre, (2005)

[330] R. M. Fernandez, R. F. F. Vieira, C. R. Nakaie, A. S. Ito e M. T. Lamy. Peptides. 26, 1825 (2005).

[331] S. Wang, T. Chen, R. Chen , Y. Hu , M. Chen e Y. Wang. Int. J. Pharmac. 430, 238 (2012).

[332] P. Sevilla, F. G-. Blanco, J. V. G-. Ramos e S. S-. Corte. Phys. Chem. Chem. Phys. 11, 8342 (2009).

[333] T. Wang, X. Yin, Y. Lu, W. Shan e S. Xiong. Int. J Nanomed. 7, 2325 (2012). 


\section{Apêndice A}

\section{Informações Complementares}

\section{A.1 Introdução}

Neste apêndice contêm as deduções das equações 3.6 (Eq. do pK $\mathrm{a}_{\mathrm{a}}$ ) e 4.2 (Eq. de Henderson-Hasselbalch). A equação 3.6 foi deduzida a partir do processo de protonação/desprotonação da Emodina em solução aquosa, usando uma metodologia similar a utilizada no livro do McQuarrie [328]. A equação de Henderson-Hasselbalch é comumente encontrada em livros textos na sua fórmula original, para titulação volumétrica ácido-base [329]. Aqui essa equação foi adaptada para titulação espectroscópica da Emodina num solvente prótico (SH), através de uma combinação algébrica entre a equação original e a Lei de Lambert-Beer. Embora a demonstração dessas equações tenham sido feitas aqui para Emodina nesse solvente, elas são gerais, válidas para qualquer processo de protonação/desprotonação em solução.

Adicionalmente, neste apêndice contêm a descrição das análises dos espectros de absorção da Emodina em diferentes solventes e bicamada lipídica, e também o conjunto de tabelas e figuras complementares que são referênciados no texto desta tese. As tabelas apresentadas aqui contém dados adicionais, e fornecem mais detalhes das tabelas que são apresentadas no texto de forma resumida. Similarmente, apresentamos aqui as figuras adicionais, que na maioria dos casos, são figuras que apresentam mais 
detalhes e dados complementares das figuras do corpo da tese. No geral, as tabelas e figuras apresentadas neste apêndice são mais completas, e são requeridas para um melhor entendimento do texto desta tese.

\section{A.2 Henderson-Hasselbalch (Eq. 4.2)}

O primeiro processo de protonação/desprotonação da Emodina em solução aquosa é governado pela seguinte equação,

$$
E M H+S H \stackrel{K_{a_{1}}}{\longrightarrow} E M^{-}+S H_{2}^{+},
$$

onde $K_{a_{1}}$ é a constante de acidez, definida como,

$$
K_{a_{1}}=\frac{\left[E M^{-}\right]\left[S H_{2}^{+}\right]}{[E M H]} \Rightarrow-\log \left[S H_{2}^{+}\right]=-\log K_{a_{1}}-\log \frac{[E M H]}{\left[E M^{-}\right]},
$$

em que $[E M H],\left[E M^{-}\right]$e $\left[S H_{2}^{+}\right]$correspondem as concentrações das espécies $E M H$, $E M^{-}$e $S H_{2}^{+}$, respectivamente. Usando a definição de pH de Sørensen $\left(p H=-\log \left[\mathrm{SH}_{2}^{+}\right]\right)$, podemos escrever a equação A.2, da seguinte forma,

$$
p H=p K_{a_{1}}+\log \frac{\left[E M^{-}\right]}{[E M H]},
$$

onde foi definido, $p K_{a_{1}}=-\log K_{a_{1}}$.

A equação A.3 é a fórmula original da equação de Henderson-Hasselbalch da titulação volumétrica ácido-base. Essa equação pode ser reescrita em termo da concentração total da Emodina $\left([E M]_{T}=[E M H]+\left[E M^{-}\right]\right)$,

$$
\begin{aligned}
& {[E M H]=[E M]_{T}\left(\frac{1}{1+10^{p H-p K_{a_{1}}}}\right)} \\
& {\left[E M^{-}\right]=[E M]_{T}\left(\frac{10^{p H-p K_{a_{1}}}}{1+10^{p H-p K_{a_{1}}}}\right) .}
\end{aligned}
$$

Essas equações fornecem uma relação direta entre as concentrações $[E M H],\left[E M^{-}\right]$ e $[E M]_{T}$, com o pH e o $p K_{a_{1}}$. Elas são comumente usadas em ajustes de curvas de titulação volumétrica ácido-base para a extração do valor do $p K_{a 1}[316,329,330]$. 
Uma adaptação da equação de Henderson-Hasselbalch para absorbância pode ser feita, para compostos que absorvem radiações na região do visível e ultravioleta próximo, e apresenta o espectro de absorção altamente sensível ao pH do meio, como no caso da Emodina. Como a absorbância está diretamente relacionada com a concentração da molécula absorvedora de luz pela Lei de Lambert-Beer (Equação 2.70), podemos escrever a absorbância da mistura das espécies da Emodina em solução, em um dado comprimento de onda, como,

$$
A_{T}=\epsilon^{E M H} \cdot[E M H] . l+\epsilon^{E M^{-}} \cdot\left[E M^{-}\right] . l,
$$

onde $\epsilon^{E M H}$ e $\epsilon^{E M^{-}}$são os coeficientes de extinção molar das espécies $E M H$ e $E M^{-}$, e $l$ é o caminho ótico. Assim, substituindo as equações A.4 e A.5 na equação A.6, obtém-se a seguinte equação,

$$
A_{T}=A_{1}\left(\frac{1}{1+10^{p H-p K_{a_{1}}}}\right)+A_{2}\left(\frac{10^{p H-p K_{a_{1}}}}{1+10^{p H-p K_{a_{1}}}}\right),
$$

em que para um dado comprimento de onda $\lambda_{i}, A_{1}=\epsilon^{E M H}\left(\lambda_{1}\right) \cdot l \cdot[E M]_{T}$ e $A_{2}=$ $\epsilon^{E M^{-}}\left(\lambda_{2}\right) . l .[E M]_{T}$ são constantes que podem ser determinadas. Como pode ser mostrado, a soma dos termos, $P_{1}=\frac{1}{1+10^{x}}$ e $P_{2}=\frac{10^{x}}{1+10^{x}}$, para $x=p H-p K_{a_{1}}$, é sempre igual a 1 , para qualquer valor de $p K_{a_{1}}$, ou seja, $P_{1}(p H)+P_{2}(p H)=1$, ver figura A.1. Portanto $P_{1}$ e $P_{2}$ são complementares e podem ser interpretados como funções de probabilidades de uma molécula com um dado $p K_{a_{1}}$ protonar/desprotonar num dado $p H$. A função $P_{1}(p H)$ é decrescente e $P_{2}(p H)$ é crescente com o $p H$, de modo que essas funções não podem ser aplicadas simultaneamente para o mesmo $\lambda_{i}$. Assim, o ajuste da absorbância das curvas de titulação pela equação A.7 é feito através da seguinte regra: se a protonação/desprotonação provoca um decrescimento na absorbância da molécula em $\lambda_{i}$, aplica-se a função $A_{1} P_{1}(p H)$, caso contrário, aplica-se a função $A_{2} P_{1}(p H)$. Como a função $P_{1}(p H)$ pode ser escrita como, $P_{1}=\frac{1}{1+10^{x}}=\frac{10^{-x}}{1+10^{-x}}$, podemos escrever a equação A.7 como,

$$
A_{T}=A_{0}+A_{1}\left(\frac{10^{-\left(p H-p K_{a_{1}}\right)}}{1+10^{-\left(p H-p K_{a_{1}}\right)}}\right)+A_{2}\left(\frac{10^{\left(p H-p K_{a_{1}}\right)}}{1+10^{\left(p H-p K_{a_{1}}\right)}}\right)
$$




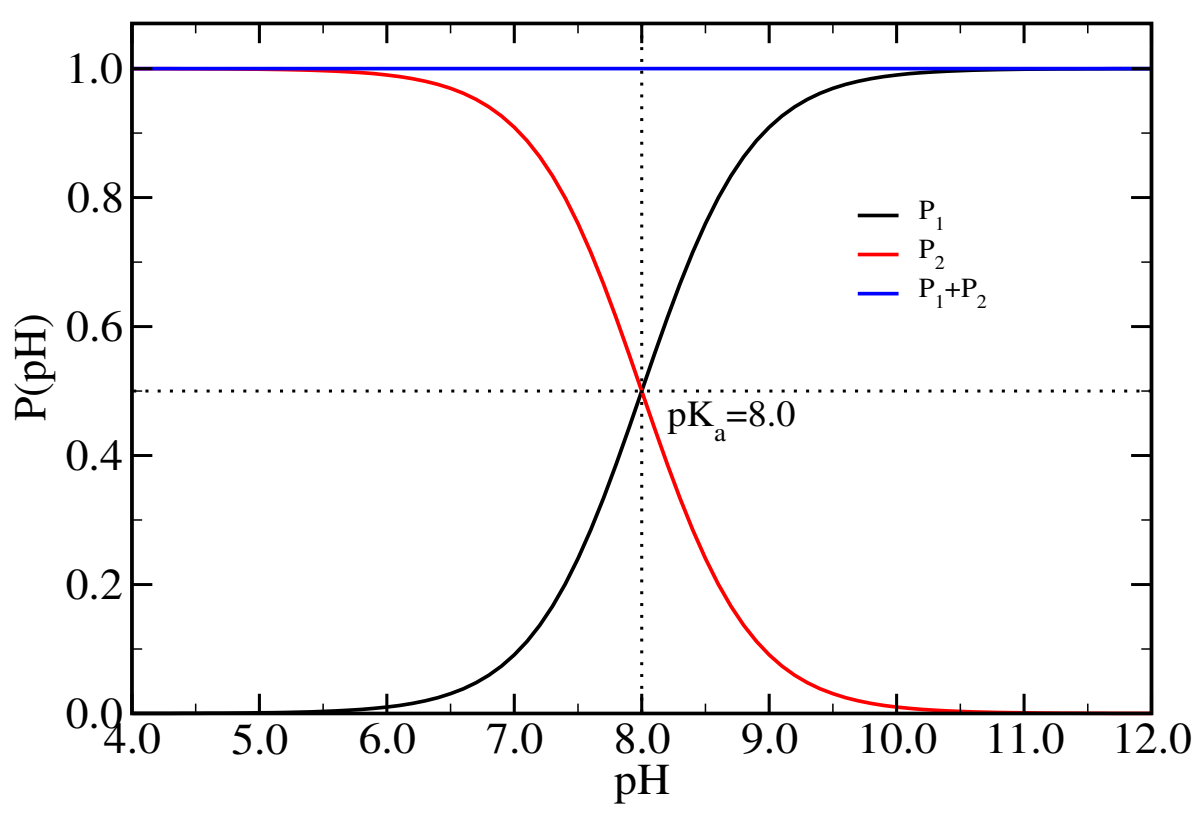

Figura A.1: Ilustração das funções $P_{1}(p H)$ e $P_{2}(p H)$ para o $p K_{a}=8.0$.

onde acrescentamos uma constante $A_{0}$, pois a absorbância em curvas de titulação ${ }^{1}$ não necessariamente inicia do zero. Como discutido acima, o termo $A_{0}+A_{1} P_{1}(p H)$ ou $A_{0}+A_{2} P_{2}(p H)$, se aplica a sistemas contendo duas espécies, ou seja, em sistemas que ocorre somente o primeiro processo de protonação/desprotonação. Para sistemas contendo várias espécies, e portanto vários $p K_{a}$, a equação A.8 pode ser escrita numa fórmula geral como,

$$
A_{T}=A_{0}+\sum_{i=1}^{n} A_{i}\left(\frac{10^{ \pm\left(p H-p K_{a_{i}}\right)}}{1+10^{ \pm\left(p H-p K_{a_{i}}\right)}}\right),
$$

onde os parâmetros $A_{0}, A_{i}$ e $p K_{a_{i}}$ são determinados a partir de ajustes da absorbância nas curvas de titulação espectroscópica (absorbância versus pH, em um dado comprimento de onda). A escolha adequada dos termos da equação A.9, pode descrever o comportamento da absorbância nas curvas de titulação de sistemas que sofrem múltiplas desprotonações. Discutimos acima o comportamento da absorbância para sistemas que ocorre somente o primeiro processo de protonação/desprotonação, em que a função que descreve a curva de titulação pode ser crescente ou decrescente. Para sistemas que so-

\footnotetext{
${ }^{1}$ Curva da absorbância, num dado comprimento de onda, em função do $p H$.
} 
frem duas protonação/desprotonações, portanto um sistema de três espécies, teremos quatro possibilidades de curvas de titulação, como mostra a figura A.2. Para esses sistemas a equação A.9 pode ser escrita como, $A_{T}=A_{0}+A_{1} P_{1}\left(p H, p K_{a_{1}}\right)+A_{2} P_{2}\left(p H, p K_{a_{2}}\right)$, de modo que nessa equação as funções $P_{1}$ e $P_{2}$ podem apresentar as seguintes características (i) $P_{1}$ e $P_{2}$ podem ser crescentes; (ii) $P_{1}$ pode ser crescente e $P_{2}$ pode ser decrescente; (iii) $P_{1}$ pode ser decrescente e $P_{2}$ pode ser crescente; (iv) $P_{1}$ e $P_{2}$ podem ser decrescentes. Embora a equação A.9 não seja exatamente a equação original de Henderson-Hasselbalch, preferimos chamá-la de equação de Henderson-Hasselbalch adaptada para a absorbância, ou simplesmente equação de Henderson-HasselbalchLambert-Beer (Eq. de HHLB). Nesta tese doutorado, essa equação foi utilizada para ajustar as curvas de titulação espectroscópica da Emodina em solução e determinar os valores $\operatorname{dos} p K_{a}$ dessa molécula, como apresentado e discutido na seção 4.2.3.

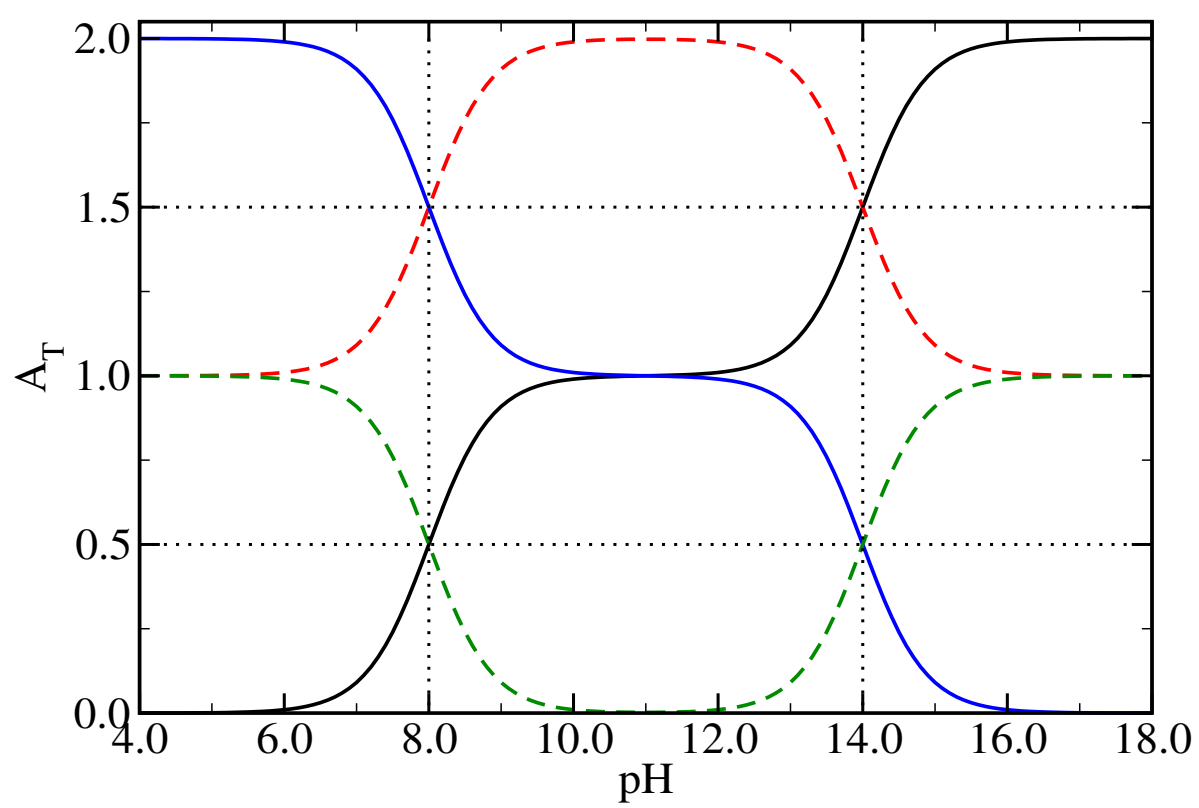

Figura A.2: Ilustração das possibilidades de curvas de titulação para um sistema de três espécies, ou seja, que sofrem dois processos de protonação/desprotonação $\left(p K_{a_{1}}=8.0 \mathrm{e}\right.$ $\left.p K_{a_{1}}=14.0\right)$. Essas curvas foram geradas com a função, $A_{T}=A_{0}+A_{1} P_{1}\left(p H, p K_{a_{1}}\right)+$ $A_{2} P_{2}\left(p H, p K_{a_{2}}\right)$, onde na curva preta, usamos $P_{1}$ e $P_{2}$ crescentes, na azul, $P_{1}$ e $P_{2}$ decrescentes, na verde tracejada, $P_{1}$ decrescente e $P_{2}$ crescente, e na vermelha tracejada, $P_{1}$ crescente e $P_{2}$ decrescente. Os parâmetros usados foram, $A_{0}=0, A_{1}=A_{2}=1$. 


\section{A.3 Equação do $\mathrm{pK}_{\mathrm{a}}(\mathrm{Eq}$. 3.6)}

A equação que relaciona o $p K_{a}$ da Emodina com a diferença de energia livre do processo de desprotonação é deduzida aqui a partir da equação A.1, que a reescrevemos da seguinte maneira,

$$
E M H_{(s o l)}+S H_{(\text {sol. })} \stackrel{\Delta G_{s o l .}}{\longrightarrow} E M_{(\text {sol. })}^{-}+S H_{2}^{+}(\text {sol. }),
$$

onde $\Delta G_{\text {sol. }}$ é a variação de energia livre envolvida no processo de desprotonação da Emodina em solução. Para esse processo podemos considerar um sistema contendo os reagentes e os produtos nas condições termodinâmicas, em que a temperatura $(T)$ e a pressão $(P)$ sejam constantes. Assim a energia livre de Gibbs desse sistema é dado em função das grandezas intensivas $T, P, \eta_{E}, \eta_{S}, \eta_{E^{-}}$e $\eta_{S^{+}}$(onde $\eta_{j}$ é o número de mols dos reagentes e produtos), de tal modo que podemos escrever essa propriedade como $G=G\left(T, P, \eta_{E}, \eta_{S}, \eta_{E^{-}}, \eta_{S^{+}}\right)$. Assim a derivada total de $G$ é dada por:

$$
\begin{gathered}
d G=\left(\frac{\partial G}{\partial T}\right)_{P, \eta_{j}} d T+\left(\frac{\partial G}{\partial P}\right)_{T, \eta_{j}} d P+\left(\frac{\partial G}{\partial \eta_{E}}\right)_{T, P, \eta_{j \neq E}} d \eta_{E} \\
+\left(\frac{\partial G}{\partial \eta_{S}}\right)_{T, P, \eta_{j \neq S}} d \eta_{S}+\left(\frac{\partial G}{\partial \eta_{E^{-}}}\right)_{T, P, \eta_{j \neq E^{-}}} d \eta_{E^{-}}+\left(\frac{\partial G}{\partial \eta_{S^{+}}}\right)_{T, P, \eta_{j \neq S^{+}}} d \eta_{S^{+}}
\end{gathered},
$$

onde $\eta_{j}$ representa as variáveis $\eta_{E}, \eta_{S}, \eta_{E^{-}}$e $\eta_{S^{+}}$. Usando as seguintes definições termodinâmicas,

$$
\left(\frac{\partial G}{\partial T}\right)_{P, \eta_{j}}=-S ; \quad\left(\frac{\partial G}{\partial P}\right)_{T, \eta_{j}}=V ; \quad\left(\frac{\partial G}{\partial \eta_{E}}\right)_{T, P, \eta_{j \neq E}}=\mu_{E},
$$

onde $S$ é a entropia do sistema, $V$ é o volume e $\mu_{E}$ é o potencial químico da Emodina. Essa definição do potencial químico é análoga para $\mu_{S}, \mu_{E^{-}}$e $\mu_{S^{+}}$. Assim, substituindo as funções $S, V$ e $\mu_{j}$ na equação A.11, obtém-se,

$$
d G=-S d T+V d P+\mu_{E} d \eta_{E}+\mu_{S} d \eta_{S}+\mu_{E^{-}} d \eta_{E^{-}}+\mu_{S^{+}} d \eta_{S^{+}} .
$$

Considerando que o processo ocorre a temperatura e pressão constantes, assim, a equação A.13 se resume a,

$$
\left.d G=\mu_{E} d \eta_{E}+\mu_{S} d \eta_{S}+\mu_{E^{-}} d \eta_{E^{-}}+\mu_{S^{+}} d \eta_{S^{+}} \quad \text { (T e P constantes }\right) .
$$


O número de mols dos reagentes $\left(\eta_{r}\right)$ e produtos $\left(\eta_{p}\right)$ pode ser dado pelas seguintes relações, $\eta_{r}=\eta_{r 0}-\xi$ e $\eta_{p}=\eta_{p 0}+\xi$, onde $\eta_{i 0}$ é o número de mol inicial de cada componente e $\xi$ é definido como extensão da reação, que tem dimensão de mol. Como a reação ocorre dos reagentes para os produtos, temos, portanto que $\xi$ varia de 0 até um dado valor máximo, que é definido pela estequiometria da reação. Assim, diferenciando essas relações, obtém-se, $d \eta_{r}=-d \xi$ e $d \eta_{p}=+d \xi$, onde os sinais negativos indicam que os reagentes estão diminuindo, enquanto os produtos estão aumentando. Assim, substituindo $d \eta_{j}$ na equação A.14 e reorganizando, obtém-se,

$$
\left(\frac{\partial G}{\partial \xi}\right)_{T, P}=\mu_{E^{-}}+\mu_{S^{+}}-\mu_{E}-\mu_{S} .
$$

Considerando também que todas as concentrações dos componentes envolvidos no processo são pequenas, o suficiente para se comportarem como uma solução ideal, podemos usar a seguinte definição para o potencial químico,

$$
\mu_{X}(T,[X])=\mu_{X}^{*}(T)+R T \ln \left(\frac{[X]}{[X]^{*}}\right)
$$

onde $\mu_{X}^{*}(T)$ é o potencial químico do componente $X$ num dado estado conhecido, que tomamos como o estado padrão da matéria $\left([X]^{*}=1 \mathrm{~mol} / L\right)$. Assim substituindo a função $\mu_{X}(T,[X])$ na equação A.15, obtém-se,

$$
\begin{aligned}
& \left(\frac{\partial G}{\partial \xi}\right)_{T, P}=\left\{\mu_{E^{-}}^{*}(T)+\mu_{S^{+}}^{*}(T)-\mu_{E}^{*}(T)-\mu_{S}^{*}(T)\right\} \\
+ & R T\left\{\ln \left[E M^{-}\right]+\ln \left[S H_{2}^{+}\right]-\ln [E M H]-\ln [S H]\right\} .
\end{aligned}
$$

Na equação A.17, a grandeza $\left(\frac{\partial G}{\partial \xi}\right)_{T, P}$ tem dimensão de potencial químico, que de acordo com o potencial de Gibbs pode ser definido como, $\left(\frac{\partial G}{\partial \xi}\right)_{T, P}=\Delta G$, que é justamente a variação da energia livre de Gibbs com a extensão da reação $\xi$. A soma dos potenciais químicos na equação A.17, ou seja, o primeiro termo dessa equação é definido como,

$$
\Delta G^{*}=\mu_{E^{-}}^{*}(T)+\mu_{S^{+}}^{*}(T)-\mu_{E}^{*}(T)-\mu_{S}^{*}(T),
$$


onde $\Delta G^{*}$ é a variação de energia livre envolvida no processo de desprotonação, logo após atingir o equilíbrio químico, que de acordo com a equação A.10, $\Delta G^{*}=\Delta G_{\text {sol. }}$. Assim, substituindo a função $\Delta G_{\text {sol. }}$ na equação A.17, e reorganizando essa equação, obtém-se,

$$
\Delta G=\Delta G_{s o l .}+R T \ln \left(\frac{\left[E M^{-}\right]\left[S H_{2}^{+}\right]}{[E M H][S H]}\right)
$$

Quando o sistema está em equilíbrio, a energia livre de Gibbs deve ser mínima com relação à extensão da reação $\xi$, ou seja, $\Delta G=0$.

$$
\Delta G_{\text {sol. }}=-R T \ln \left(\frac{\left[E M^{-}\right]\left[S H_{2}^{+}\right]}{[E M H][S H]}\right)
$$

O termo em parêntese na equação A.20, representa a constante de equilíbrio $\left(K_{\text {eq. }}\right)$ do processo de desprotonação, que de acordo com a equação A.2, está relacionada com a constante de acidez $\left(K_{a}\right)$. Portanto a equação A.20 pode ser escrita da seguinte maneira,

$$
\Delta G_{\text {sol. }}=-R T \ln \left(\frac{K_{a}}{[S H]}\right) \quad \Rightarrow \quad K_{a}=[S H] e^{-\frac{\Delta G_{s o l .}}{R T}},
$$

que passando a função logarítmica em ambos os lados da equação A.21, obtém-se a seguinte equação,

$$
p K_{a}=\frac{\Delta G_{\text {sol. }}}{R T \ln 10}-\log [S H]
$$

onde usamos a definição de que $p K_{a}=-\log \left(K_{a}\right)$. A equação A.22, representa uma relação direta entre a constante de acidez $\left(p K_{a}\right)$ e a diferença de energia livre do processo, $\Delta G_{\text {sol. }}\left(E M H+S H \longrightarrow E M^{-}+S H_{2}^{+}\right)$. Note que a equação A.22, também se aplica ao processo dado por, $\Delta G_{\text {sol. }}\left(E M H \longrightarrow E M^{-}+H^{+}\right)$, porém devemos omitir o último termo dessa equação. A demonstração da equação A.22 apresentada aqui foi baseada no livro do McQuarrie [328], como discutido acima, mas encontramos na literatura outras maneiras de demontração dessa equação, veja o trabalho de Pliego Jr. [288], onde essa equação foi demonstrada a partir de ciclos termodinâmicos. 


\section{A.4 Análise dos Espectros de Absorção}

Os espectros de absorção da Emodina em diferentes solventes e bicamada lipídica foram todos analisados seguindo o seguinte roteiro: (i) medíamos o espectro do solvente puro, sem a Emodina, para obtermos a curva do solvente com a cubeta de quartzo, chamada aqui de linha de base do solvente (ver figura A.3 (b)); (ii) medíamos o espectro da Emodina com solvente na mesma cubeta de quartzo ((ver figura A.3 (a))); (iii) subtraíamos o espectro da Emodina pela linha de base do solvente (ver figura A.3 (c)). Para as medidas em bicamada lipídica a linha de base foi obtida a partir da medida do espectro da dispersão lipídica sem a Emodina.

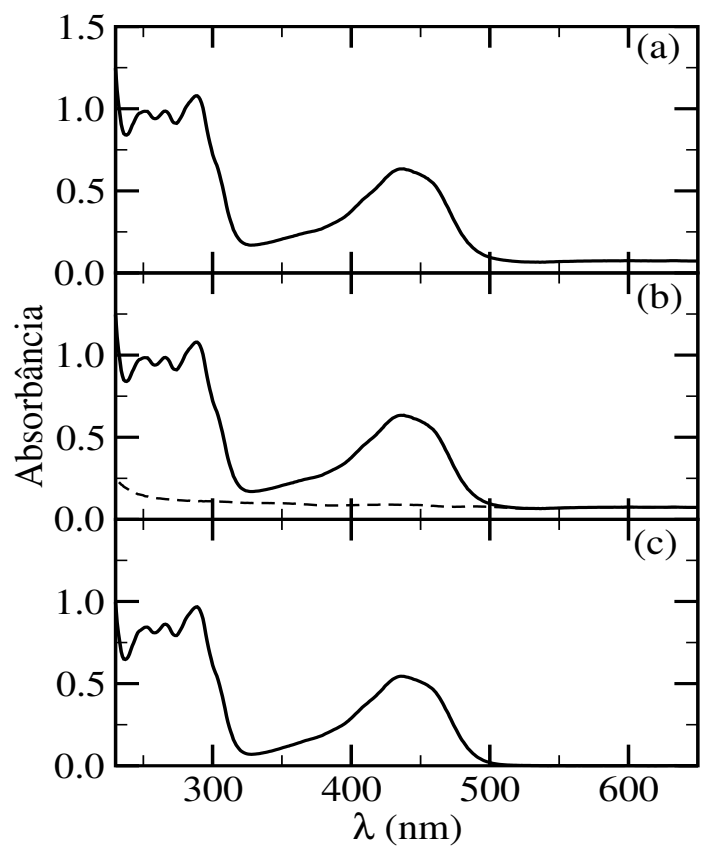

Figura A.3: Detalhes da análise do espectro de absorção da Emodina em metanol, onde em (a) apresentamos o espectro da Emodina sem nenhum tratamento, em (b) apresentamos o espectro da Emodina da figura (a) mais a linha de base do metanol puro (linha tracejada), e em (c) apresentamos o espectro da Emodina em metanol já subtraído a linha de base do solvente. 
Os espectros de absorção da Emodina em água apresentaram mais dificuldades para analisar, devido à dependência da solubilidade dessa molécula com o pH da solução: em solução aquosa alcalina a Emodina apresentou cor vemelha e alta solubilidade; em solução aquosa ácida ela apresentou cor amarela e baixa solubilidade, ver figura A.4. A baixa solubilidade da Emodina em solução aquosa ácida é devido principalmente a sua agregação em solução, como relatado em várias referências [28, 331-333].

A agregação da Emodina em solução aquosa foi evidenciada, além da precipitação da Emodina em solução, pela presença de perfis de espalhamento de luz somados aos espectros da Emodina em água $\mathrm{pH}<7$, ver figura 4.9. O espalhamento de luz presente nas curvas dos espectros da Emodina é provavelmente devido a presença de agregados de Emodina na solução que se formam devido o caráter hidrofóbico dessa molécula. Devido a isso, uma etapa adicional foi incluída na análise dos espectros de absorção da Emodina em água, onde subtraímos uma constante das curvas dos espectros em $\lambda=650 \mathrm{~nm}$, para levar o espectro a zero nesse comprimento de onda, ver a figura A.5.

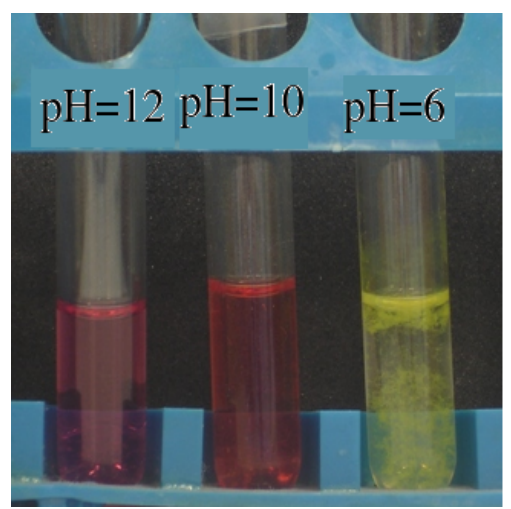

Figura A.4: Amostra de Emodina em solução aquosa em diferentes pH: 12, 10 e 6. 


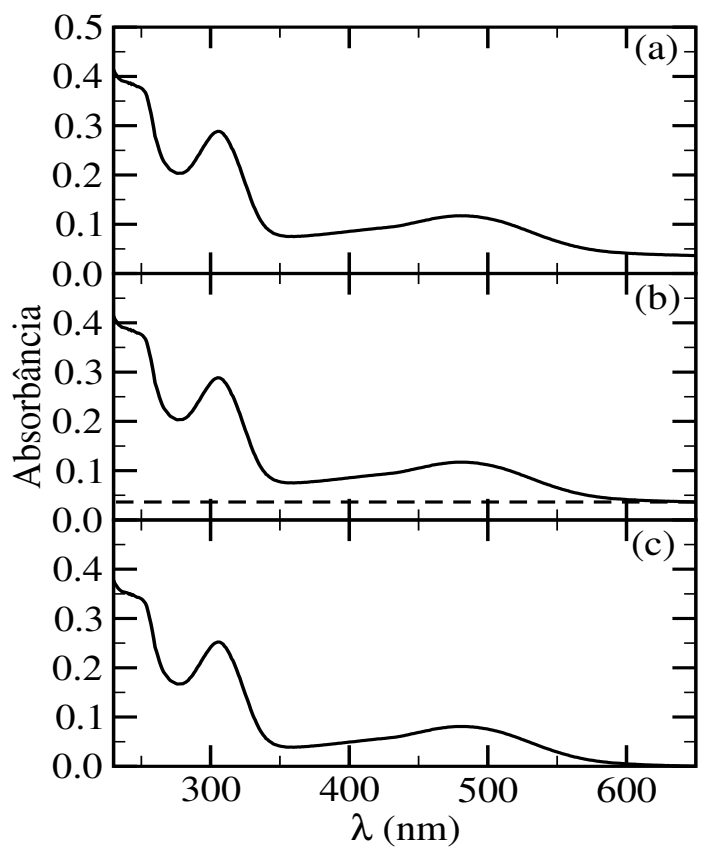

Figura A.5: Detalhes da análise do espectro de absorção da Emodina em água ( $\mathrm{pH}=7.7)$, onde em (a) apresentamos o espectro da Emodina já subtraído a linha de base do solvente, em (b) apresentamos o espectro da Emodina da figura (a) mais a linha constante (linha tracejada), e em (c) apresentamos o espectro da Emodina em água já subtraído essa linha constante, levando o espectro a zero em $\lambda=650 \mathrm{~nm}$. 


\section{A.5 Tabelas Complementares}

Tabela A.1: Energias das espécies da Emodina EMH, 3,8-EM- ${ }^{-}$1,8-EM+', 1,3-EM-, 1-EM ${ }^{2-}$, 9-EM ${ }^{2-}$ e $\mathrm{EM}^{3-}$ em kcal/mol e seus respectivos momentos de dipolo (D), obtidos com cálculo quântico (QM), com nível B3LYP/ 6-311++G**, em vácuo e em meio aquoso, com o solvente descrito com modelo PCM. Nesta tabela está também apresentada a diferença de energia ( $\mathrm{kcal} / \mathrm{mol})$ entre as espécies tautoméricas onde foi tomada como referência a espécie mais estável energicamente.

\begin{tabular}{ccccccc}
\hline \hline & \multicolumn{3}{c}{ Vácuo } & \multicolumn{3}{c}{ Solução aquosa } \\
\hline Emodina & $\mathrm{E}(\mathrm{kcal} / \mathrm{mol})$ & $\Delta \mathrm{E}(\mathrm{kcal} / \mathrm{mol})$ & $\mu(D)$ & $\mathrm{E}(\mathrm{kcal} / \mathrm{mol})$ & $\Delta \mathrm{E}(\mathrm{kcal} / \mathrm{mol})$ & $\mu(D)$ \\
\hline $\mathrm{EMH}$ & -598676.30 & 0.00 & 2.68 & -598691.62 & 0.00 & 3.49 \\
\hline $3,8-\mathrm{EM}^{-}$ & -598331.83 & 17.15 & 8.47 & -598391.67 & 7.31 & 12.91 \\
$1,8-\mathrm{EM}^{-}$ & -598348.98 & 0.00 & 10.44 & -598398.98 & 0.00 & 15.33 \\
$1,3-\mathrm{EM}^{-}$ & -598331.78 & 17.20 & 7.12 & -598391.63 & 7.35 & 11.36 \\
\hline $1-\mathrm{EM}^{2-}$ & -597932.60 & 0.00 & 8.04 & -598094.18 & 0.00 & 12.17 \\
$9-\mathrm{EM}^{2-}$ & -597925.16 & 7.44 & 12.78 & -598089.13 & 5.05 & 19.46 \\
\hline $\mathrm{EM}^{3-}$ & -597426.91 & 0.00 & 13.81 & -597777.04 & 0.00 & 21.68 \\
\hline \hline
\end{tabular}


Tabela A.3: Valores médios da energia total por molécula $\left(\mathrm{E}_{\mathrm{T}} / \mathrm{N}\right)$, energia potencial por molécula $(\mathrm{U} / \mathrm{N})$, energia cinética por molécula $(\mathrm{K} / \mathrm{N})$, temperatura $(\mathrm{K})$ e densidade $(\mathrm{g} / \mathrm{cm} 3)$. Todos esses valores foram calculadas das simulações computacionais com Dinâmica Molécular com as espécies EMH e EM- em soluçao aquosa. As energias estão em kcal/mol.

\begin{tabular}{cccccccccccc}
\hline \multicolumn{3}{c}{$\begin{array}{c}\text { MD com Emodina } \\
\text { neutra (EM) }\end{array}$} & \multicolumn{7}{c}{$\begin{array}{c}\text { MD com Emodina } \\
\text { desprotonada }\left(\mathrm{EMH}^{-}\right)\end{array}$} \\
\hline & $\mathrm{E}_{\mathrm{T}} / \mathrm{N}$ & $\mathrm{U} / \mathrm{N}$ & $\mathrm{K} / \mathrm{N}$ & $\mathrm{T}$ & $\varrho$ & $\mathrm{E}_{\mathrm{T}} / \mathrm{N}$ & $\mathrm{U} / \mathrm{N}$ & $\mathrm{K} / \mathrm{N}$ & $\mathrm{T}$ & $\varrho$ \\
Média & $\mathbf{- 7 . 8}$ & $\mathbf{- 9 . 8}$ & $\mathbf{1 . 8}$ & $\mathbf{3 0 0 . 5}$ & $\mathbf{1 . 0}$ & $\mathbf{- 8 . 1}$ & $\mathbf{- 9 . 9}$ & $\mathbf{1 . 8}$ & $\mathbf{3 0 0 . 6}$ & $\mathbf{1 . 0}$ \\
Mínimo & -8.3 & -10.2 & 1.6 & 265.8 & 0.9 & -8.4 & -10.2 & 1.6 & 270.1 & 0.9 \\
Máximo & -7.6 & -9.5 & 2.0 & 332.5 & 1.0 & -7.7 & -9.6 & 2.0 & 334.3 & 1.0 \\
Desvio & 0.1 & 0.1 & 0.1 & 7.5 & 0.1 & 0.1 & 0.1 & 0.1 & 7.5 & 0.1 \\
\hline \hline
\end{tabular}

Tabela A.7: Valores das temperaturas de transição de fase (gel-fluida) e entalpia obtidas das curvas de DSC das dispersões lipídicas de DMPC em presença e ausência das espécies da Emodina em diferentes frações molares ( $\left.\mathrm{X}_{\text {espécie }} \%\right)$

\begin{tabular}{ccccccc}
\hline \hline Espécie & $\mathrm{X}_{\text {espécie }} \%$ & 0 & 5 & 10 & 15 & 20 \\
\hline \multirow{2}{*}{ EMH } & $\mathrm{T}_{\alpha \rightarrow \mathrm{d}}$ & 23.3 & 22.9 & 22.6 & 22.1 & 19.3 \\
& $\Delta \mathrm{H}(\mathrm{kcal} / \mathrm{mol})$ & 6.5 & 6.2 & 6.5 & 5.8 & 1.7 \\
\hline $\mathrm{EM}^{-}$ & $\mathrm{T}_{\alpha \rightarrow \mathrm{d}}$ & 23.2 & 22.7 & 22.2 & 21.4 & 17.5 \\
\hline & $\Delta \mathrm{H}(\mathrm{kcal} / \mathrm{mol})$ & 6.6 & 6.7 & 6.5 & 6.4 & 3.7 \\
\hline \hline
\end{tabular}




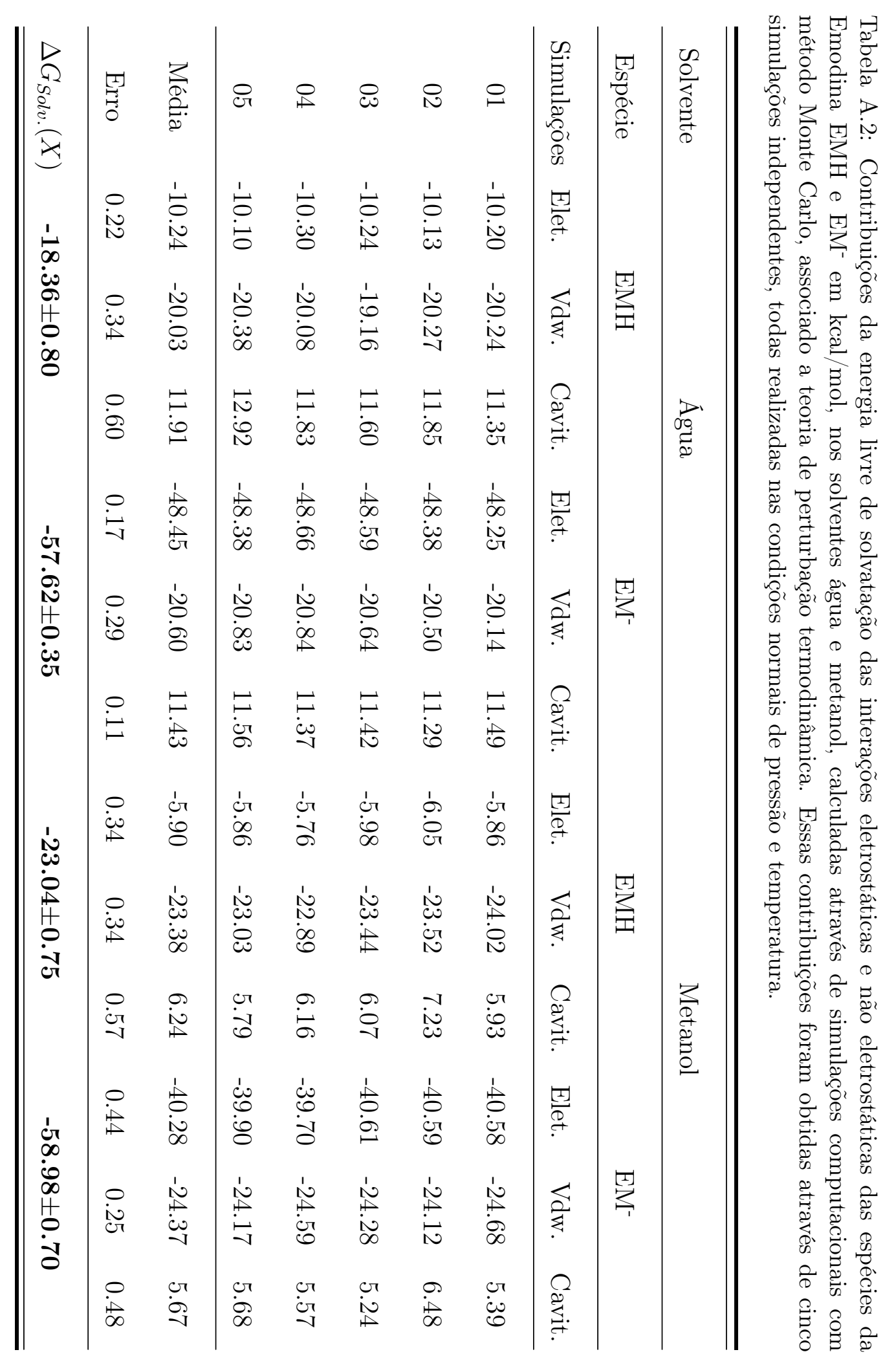




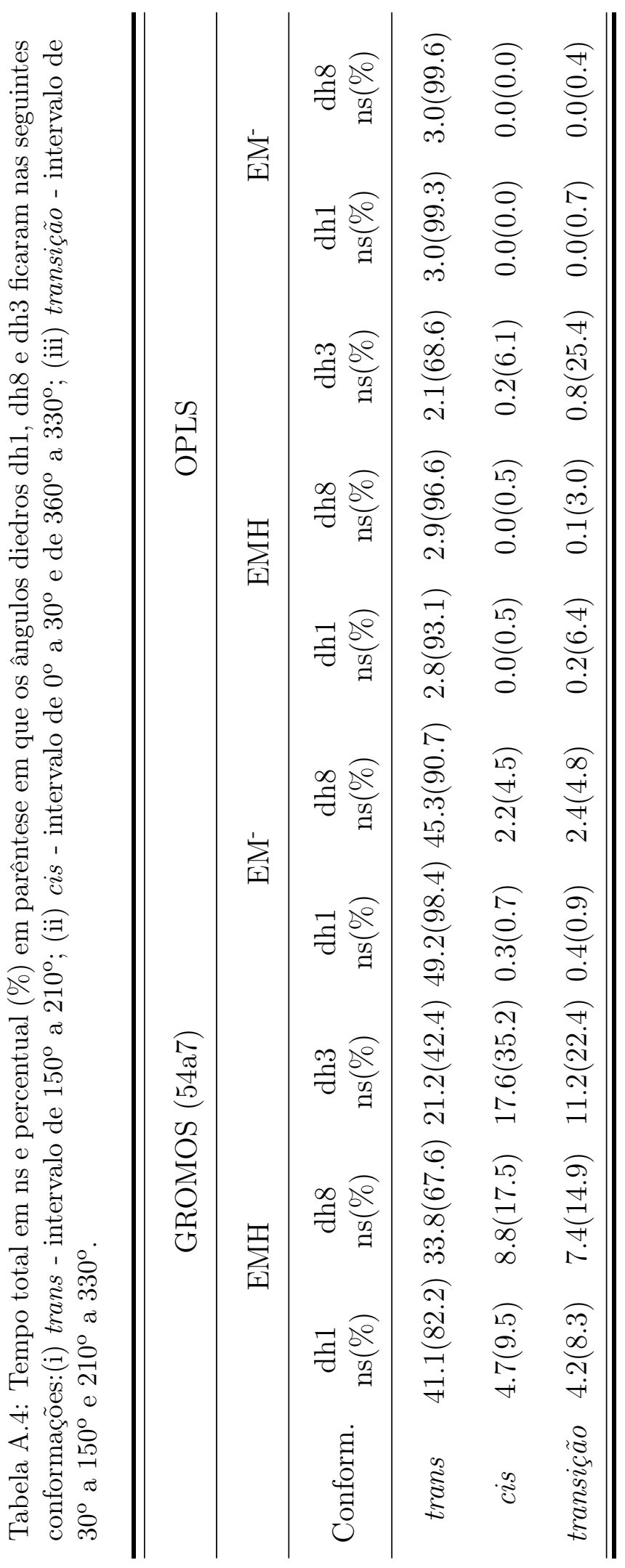




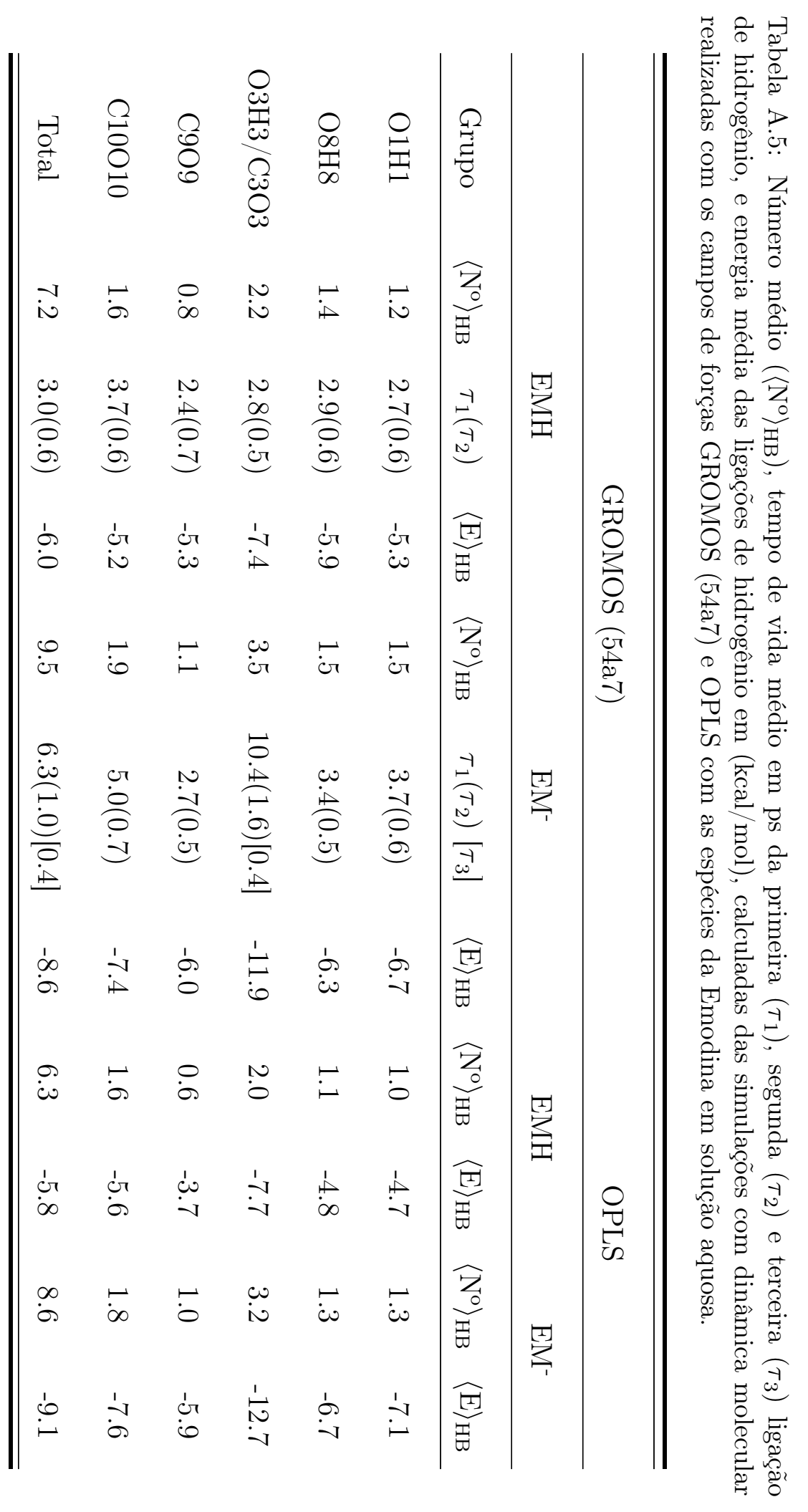




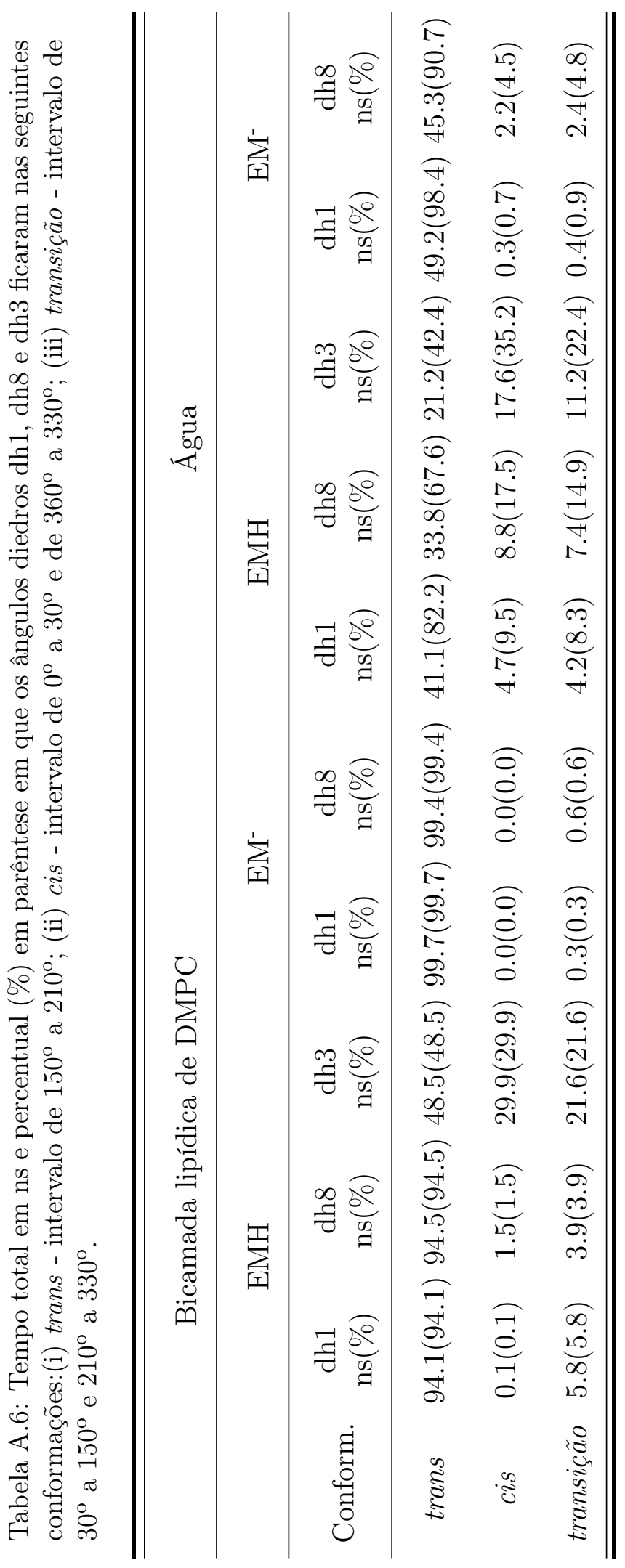




\section{A.6 Figuras Complementares}

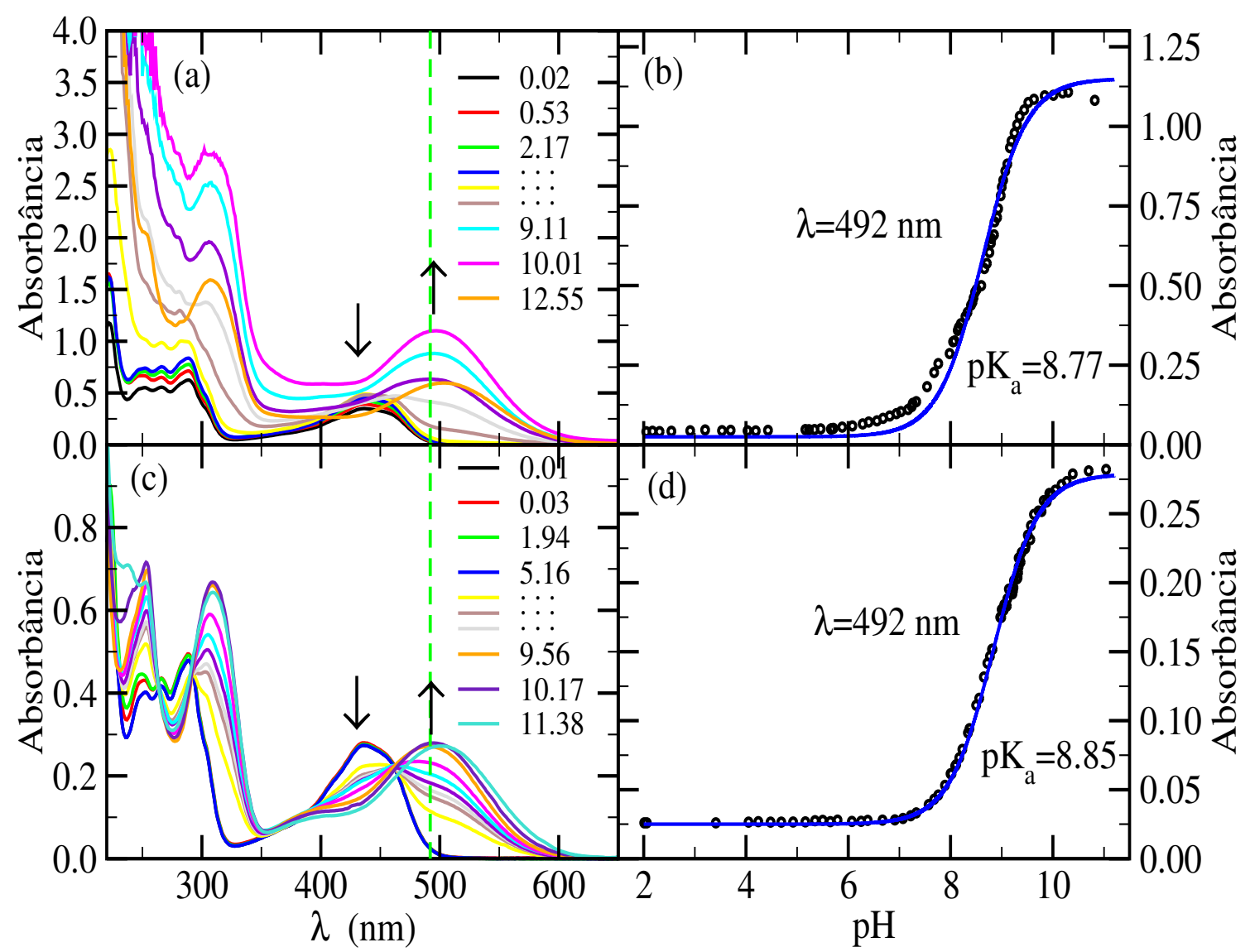

Figura A.6: Efeito do pH nos espectros eletrônicos de absorção da Emodina em metanol na concentração de $0.025 \mathrm{mM}$, onde na figura (a) são as medidas sem controle da evaporação do metanol e figura (c) com o controle da evaporação. Nas figuras (b) e (d) estão mostrados o efeito do $\mathrm{pH}$ na absorbância em $\lambda=492 \mathrm{~nm}$, com os ajustes das curvas pela equação 4.2 para as medidas as medidas mostradas em (a) e (c). As setas indicam o sentido da titulação. 


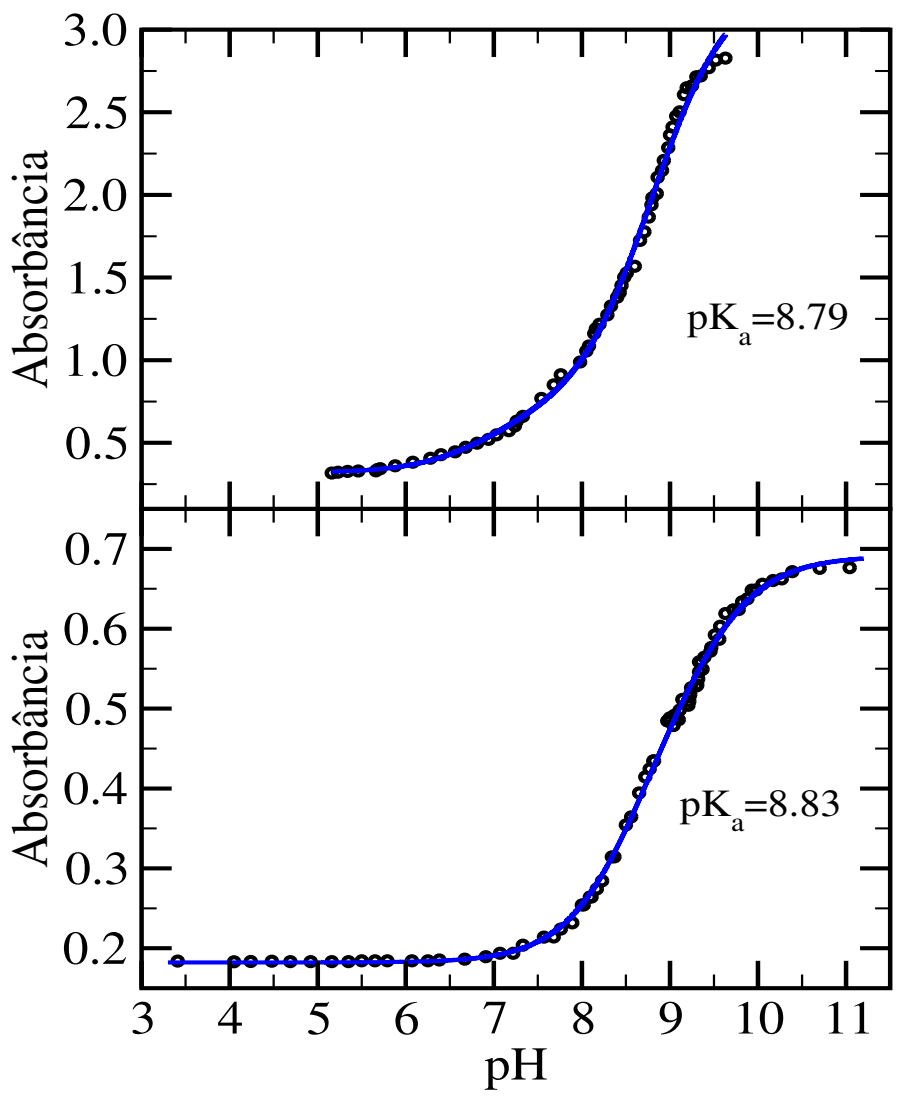

Figura A.7: Efeito do pH na absorbância da Emodina em metanol (0.025 mM), em $\lambda=309$ nm sem controle da evaporação do metanol (figura (a)) e com controle da evaporação (figura (b)). Nessas figuras estão mostrados também os ajustes das curvas pela equação 4.2. 


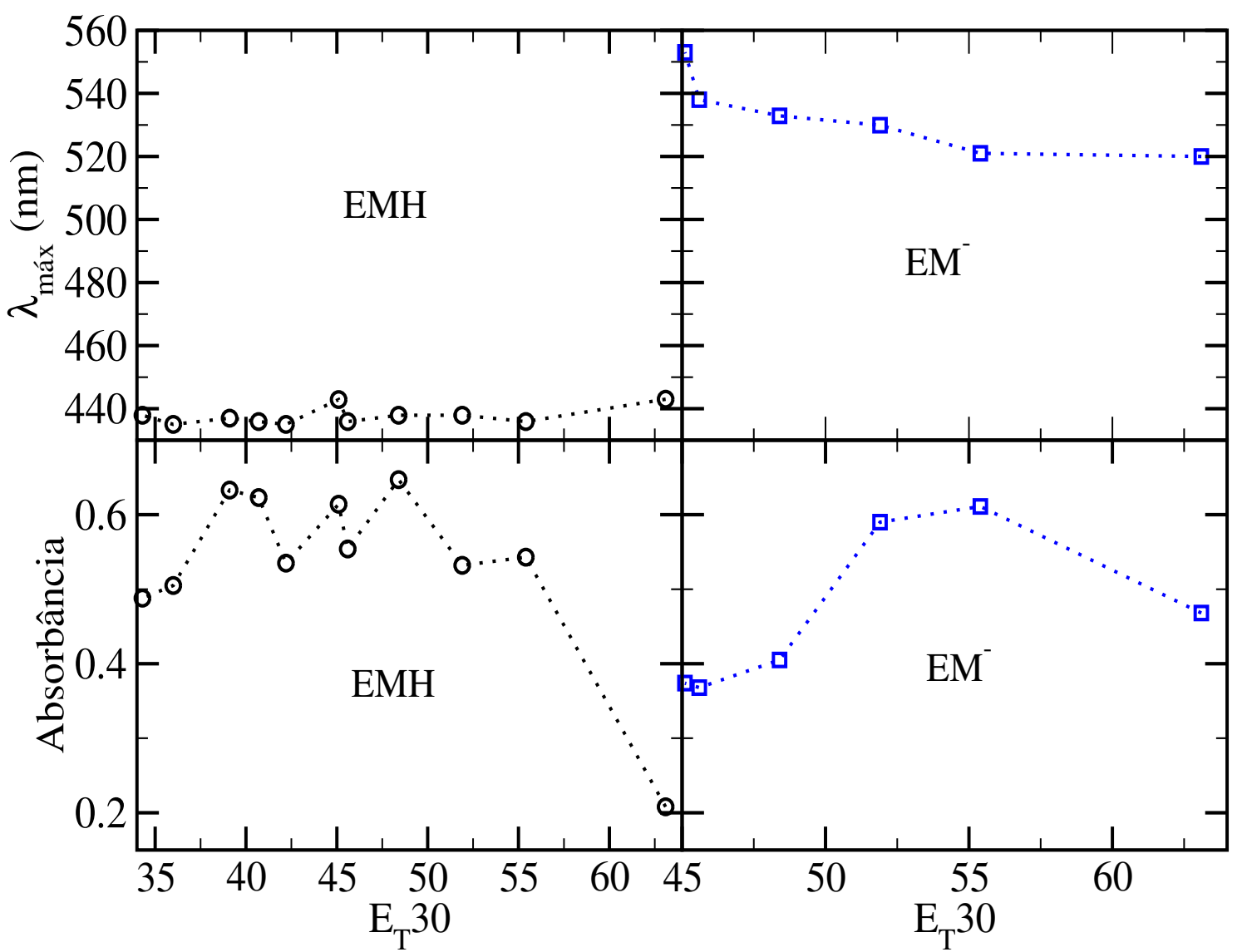

Figura A.8: Comprimento de onda e absorbância em $\lambda_{\text {máximo da primeira banda de absorção }}$ da $\mathrm{EMH}$ e $\mathrm{EM}^{-}$versus valores de $\mathrm{E}_{\mathrm{T}} 30$ para os solventes água, metanol, etanol, 2-propanol, acetonitrila, dimetilsulfóxido(DMSO), acetona, diclorometano, clorofórmio, dioxano e benzeno. 


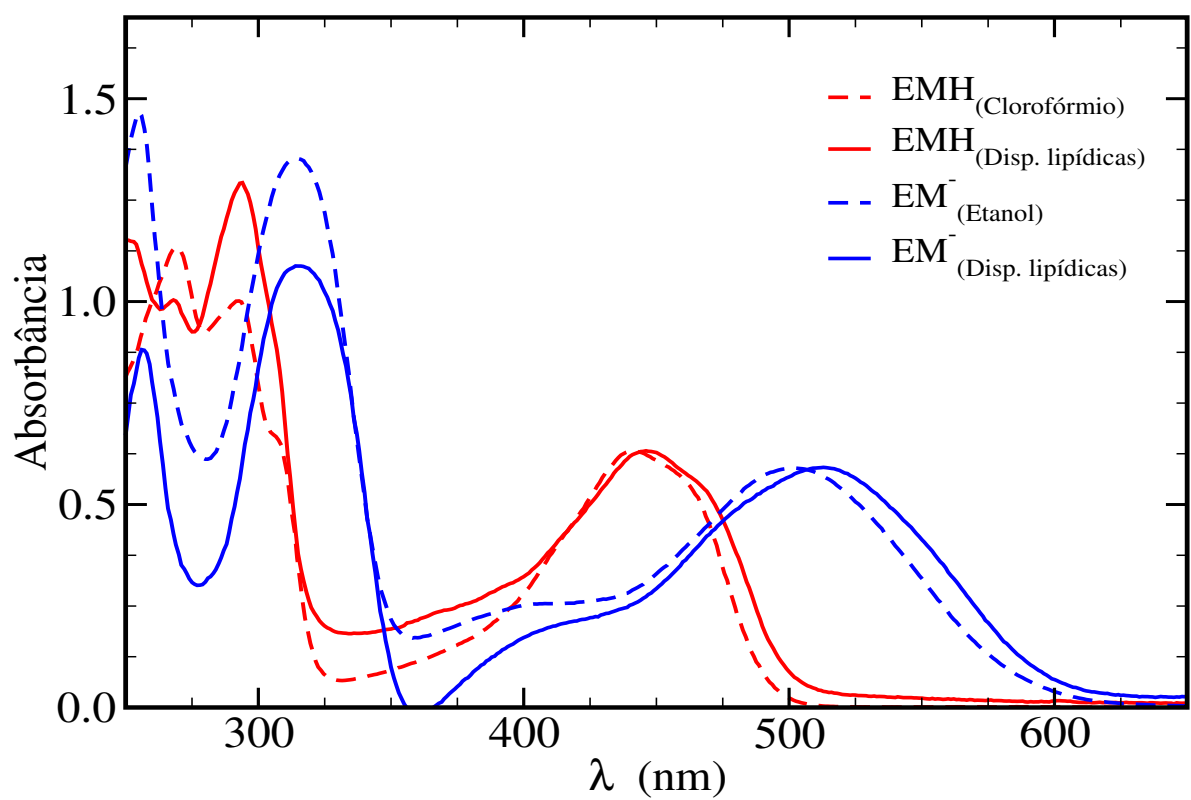

Figura A.9: Comparação do espectro eletrônico de absorção da molécula de Emodina em solvente (EMH - clorofórmio puro, e $\mathrm{EM}^{-}$- etanol mais $\left.\mathrm{NaOH}, \mathrm{pH}_{\mathrm{ap}} \sim 9\right)$ e em dispersões lipídicas de DMPC nos tampões bifosfato/fosfato $(\mathrm{pH}=6.0)$ e bicarbonato/carbonato $(\mathrm{pH}=10.0)$. 

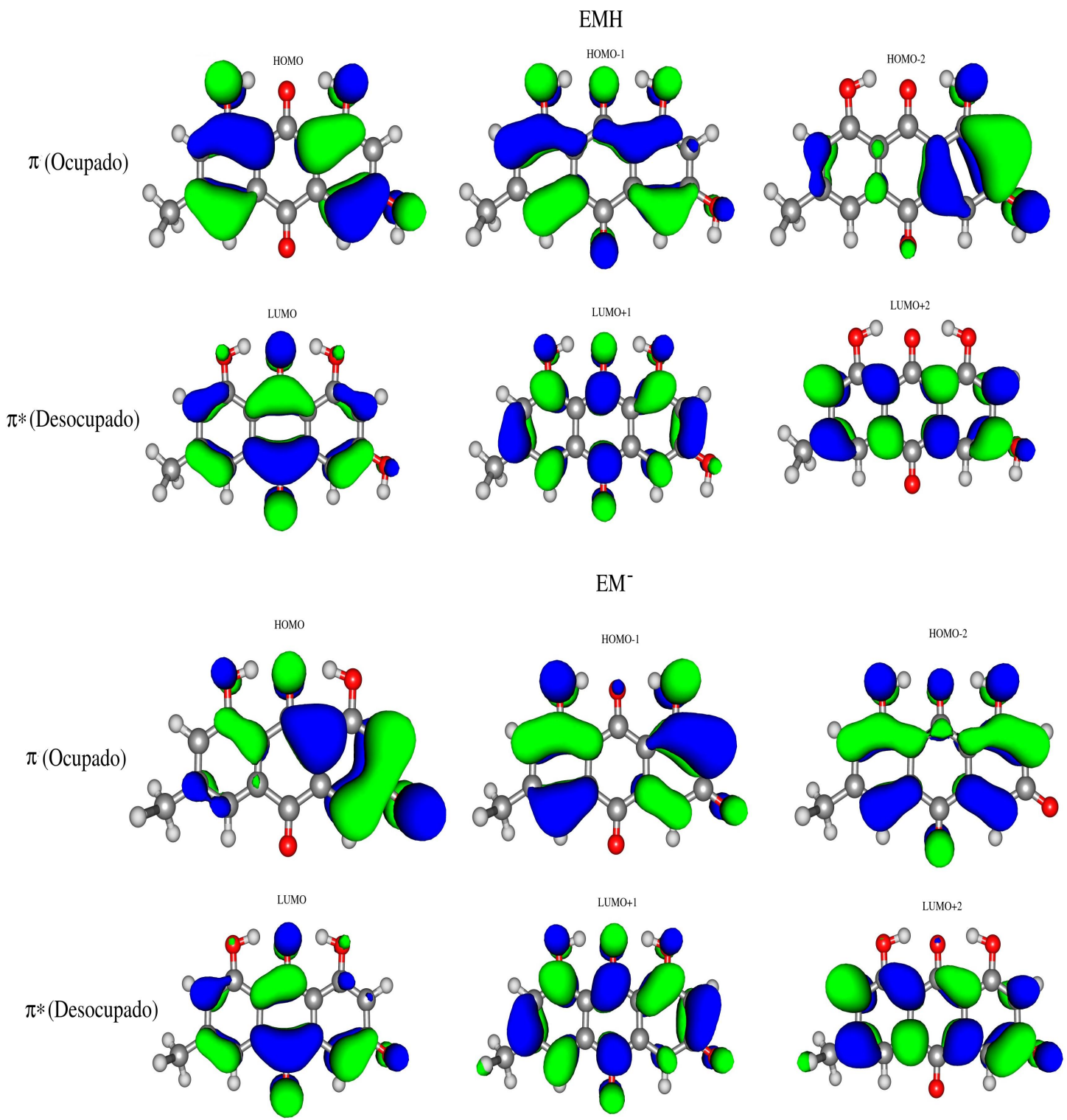

Figura A.10: Orbitais moleculares envolvidos nas transições eletrônicas das espécies EMH e $\mathrm{EM}^{-}$, gerados com o método B3LYP $/ 6-311++\mathrm{G}^{* *}$. 


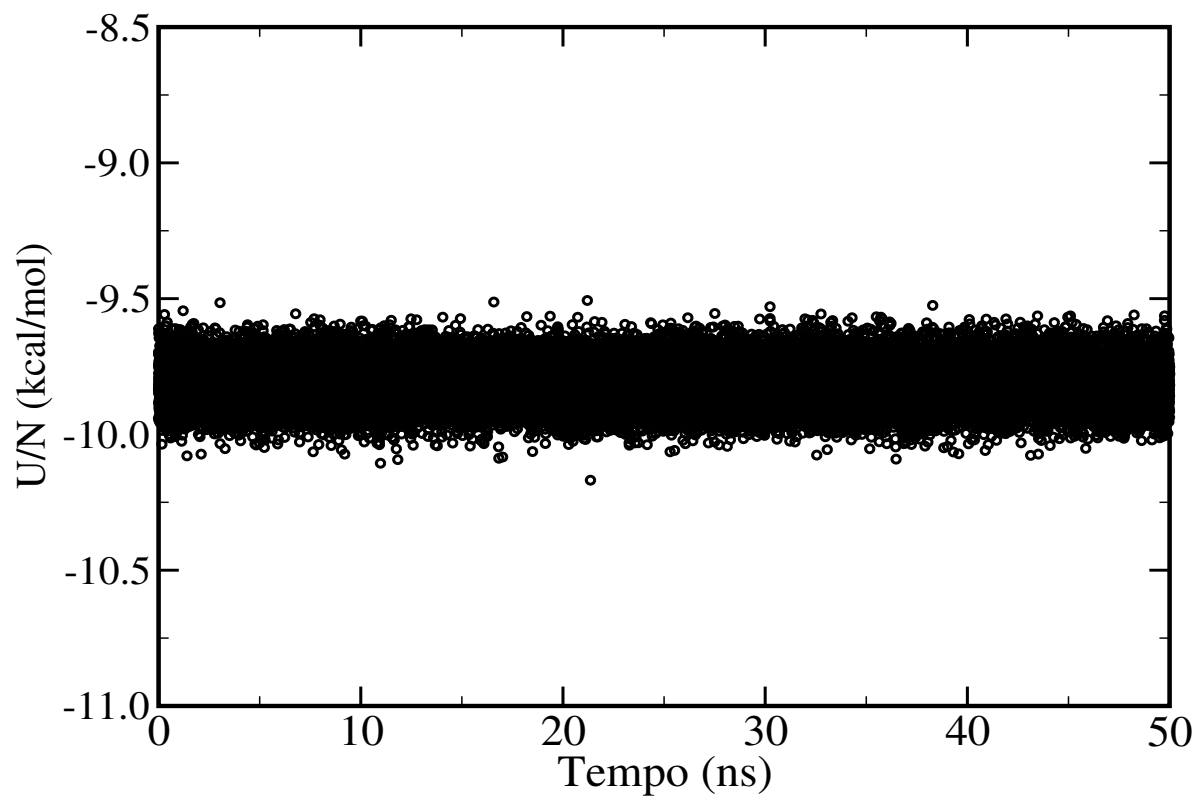

Figura A.11: Evolução temporal da energia potencial obtida da dinâmica molecular da espécie EMH em solução aquosa. 


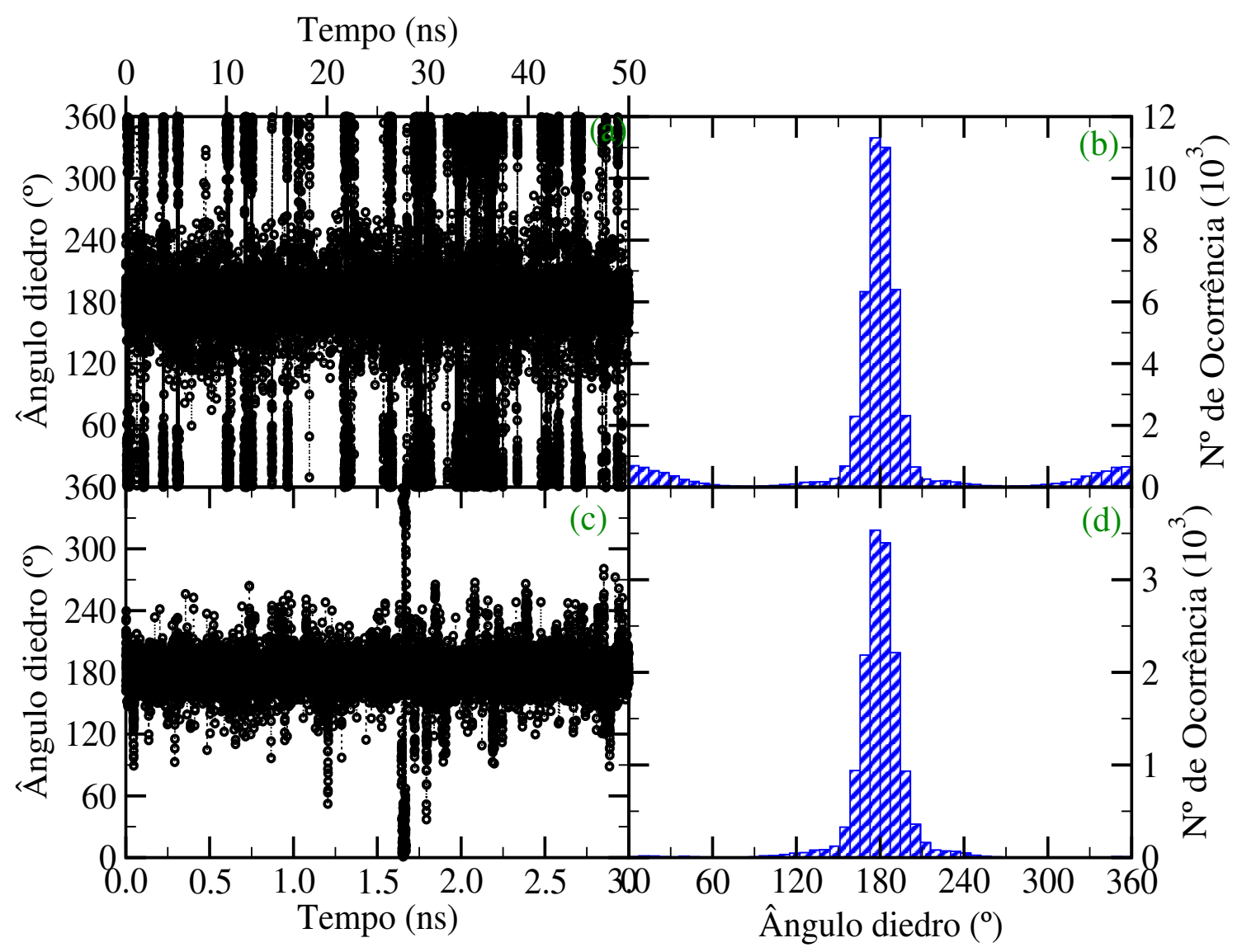

Figura A.12: Evolução temporal do ângulo diedro dh1 e seus respectivos histogramas obtidos das simulações computacionais com dinâmica molecular da EMH em solução aquosa, realizadas com campo de força GROMOS (54a7) nas figuras (a) e (b) e campo de força OPLS nas figuras (c) e (d). 


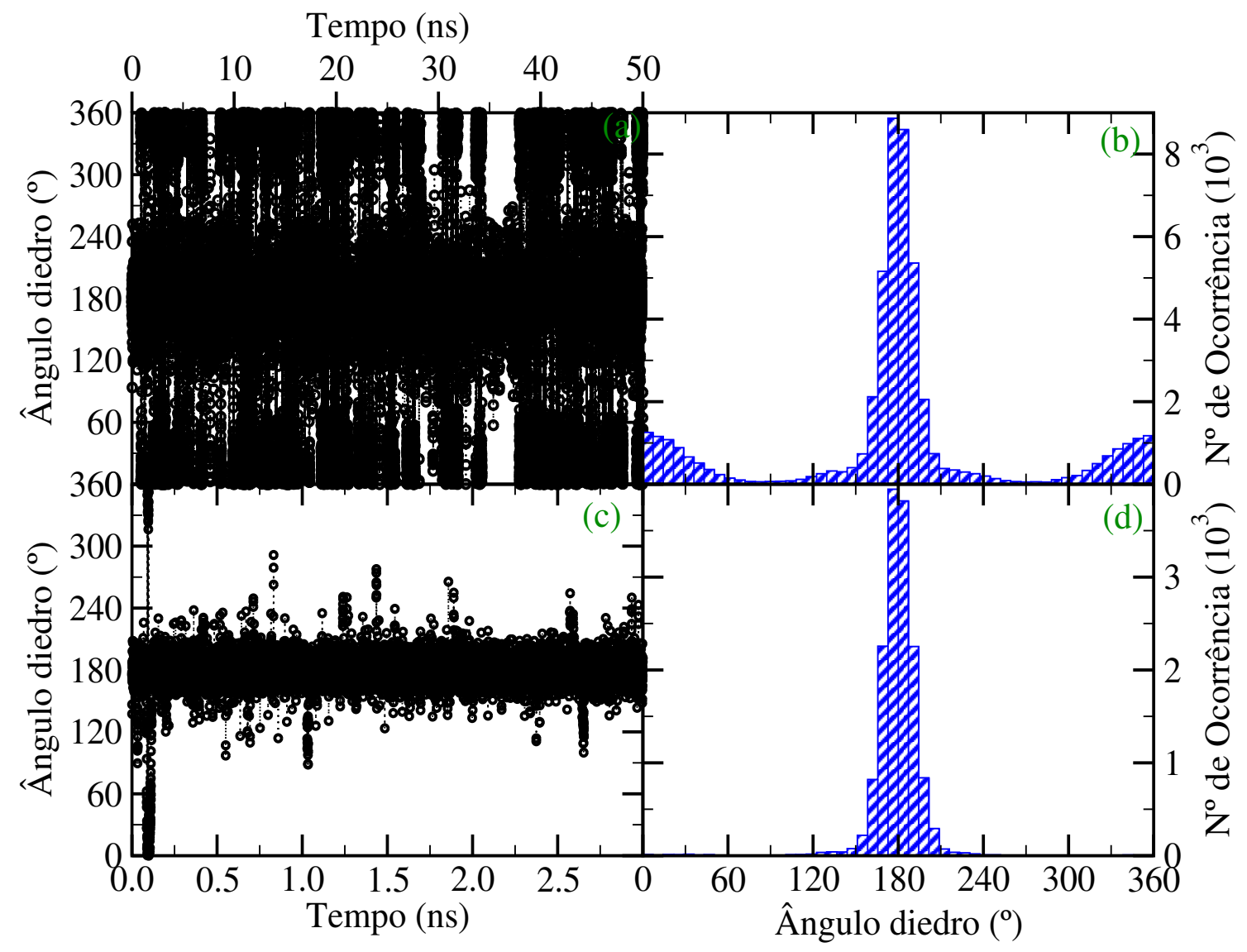

Figura A.13: Evolução temporal do ângulo diedro dh8 e seus respectivos histogramas obtidos das simulações computacionais com dinâmica molecular da EMH em solução aquosa, realizadas com campo de força GROMOS (54a7) nas figuras (a) e (b) e campo de força OPLS nas figuras (c) e (d). 


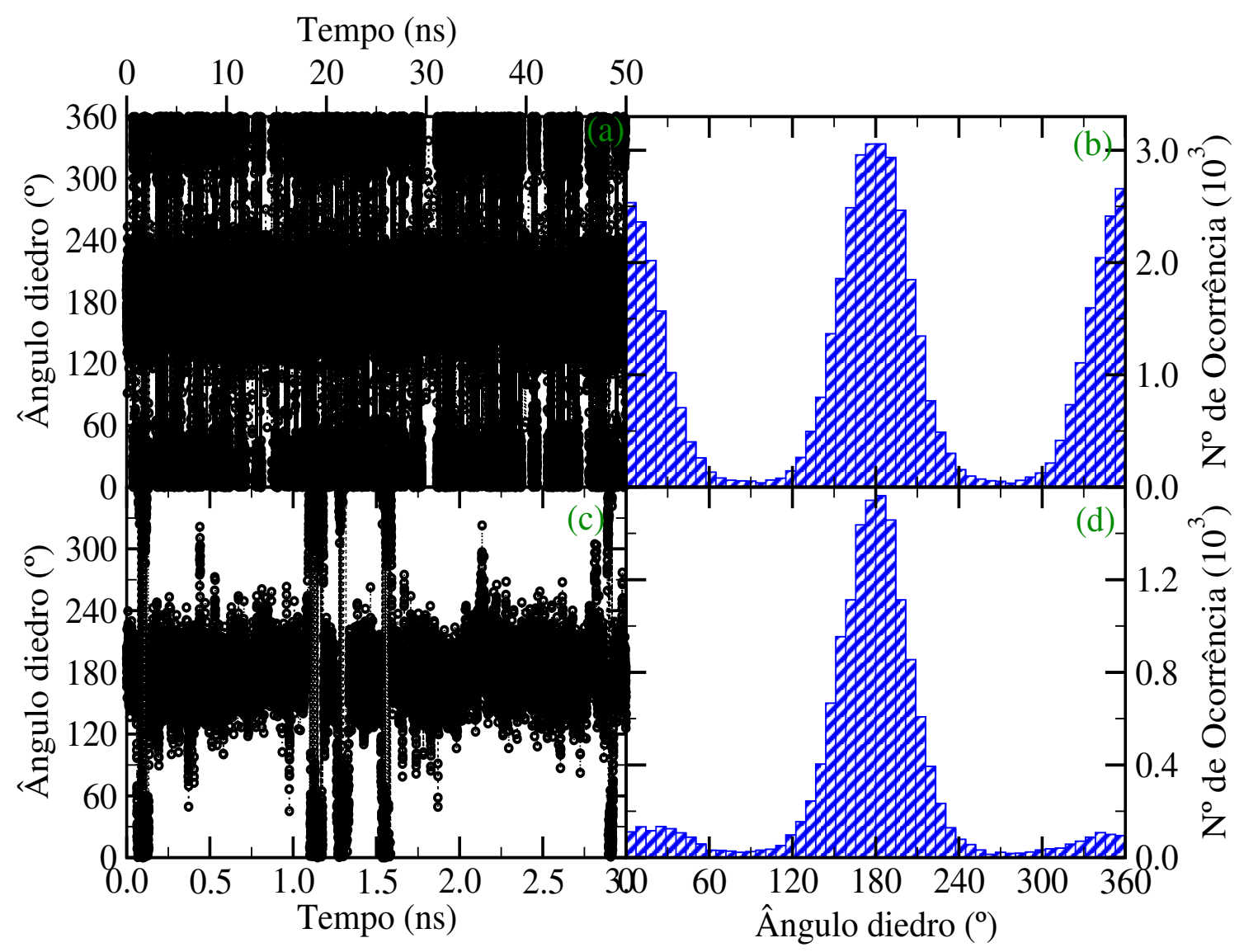

Figura A.14: Evolução temporal do ângulo diedro dh3 e seus respectivos histogramas obtidos das simulações computacionais com dinâmica molecular da EMH em solução aquosa, realizadas com o campo de força GROMOS (54a7) nas figuras (a) e (b) e campo de força OPLS nas figuras (c) e (d). 


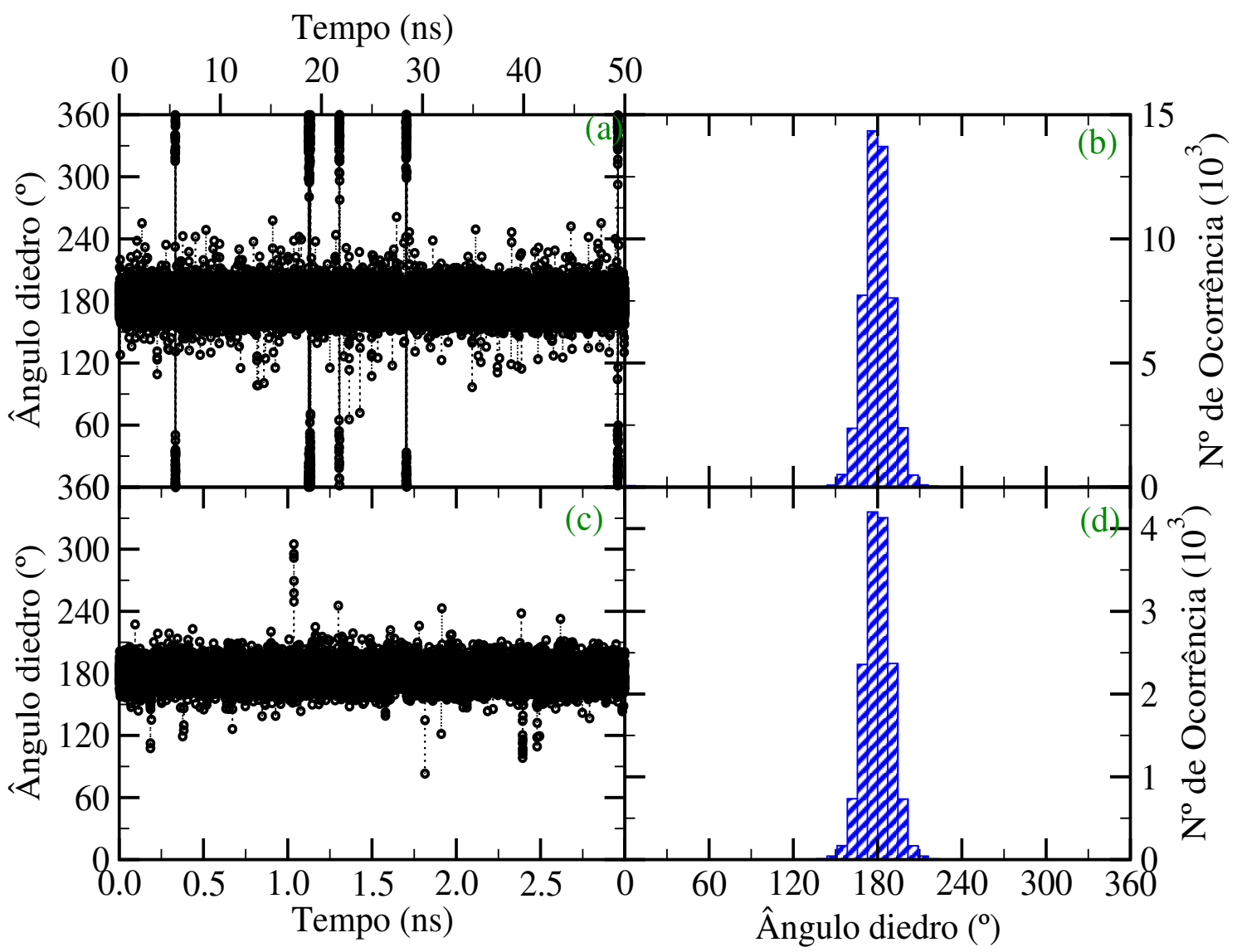

Figura A.15: Evolução temporal do ângulo diedro dh1 e seus respectivos histogramas obtidos das simulações computacionais com dinâmica molecular da EM- em solução aquosa, realizadas com o campo de força GROMOS (54a7) nas figuras (a) e (b) e campo de força OPLS nas figuras (c) e (d). 


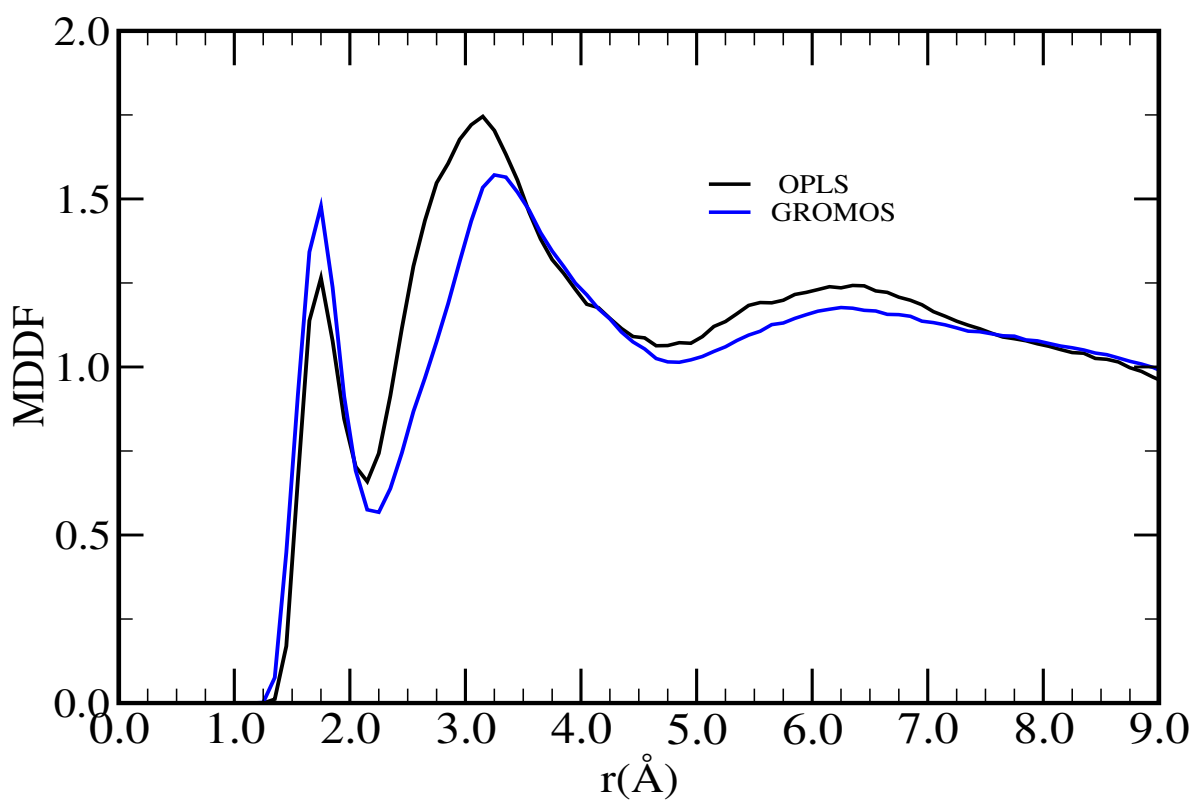

Figura A.16: Comparação da função de distribuição de mínima distância (MDDF), entre a espécie EMH e as moléculas de água calculadas das simulações computacionais com dinâmica molecular dessa espécie em solução aquosa realizadas utilizando os campos de forças GROMOS e OPLS. 


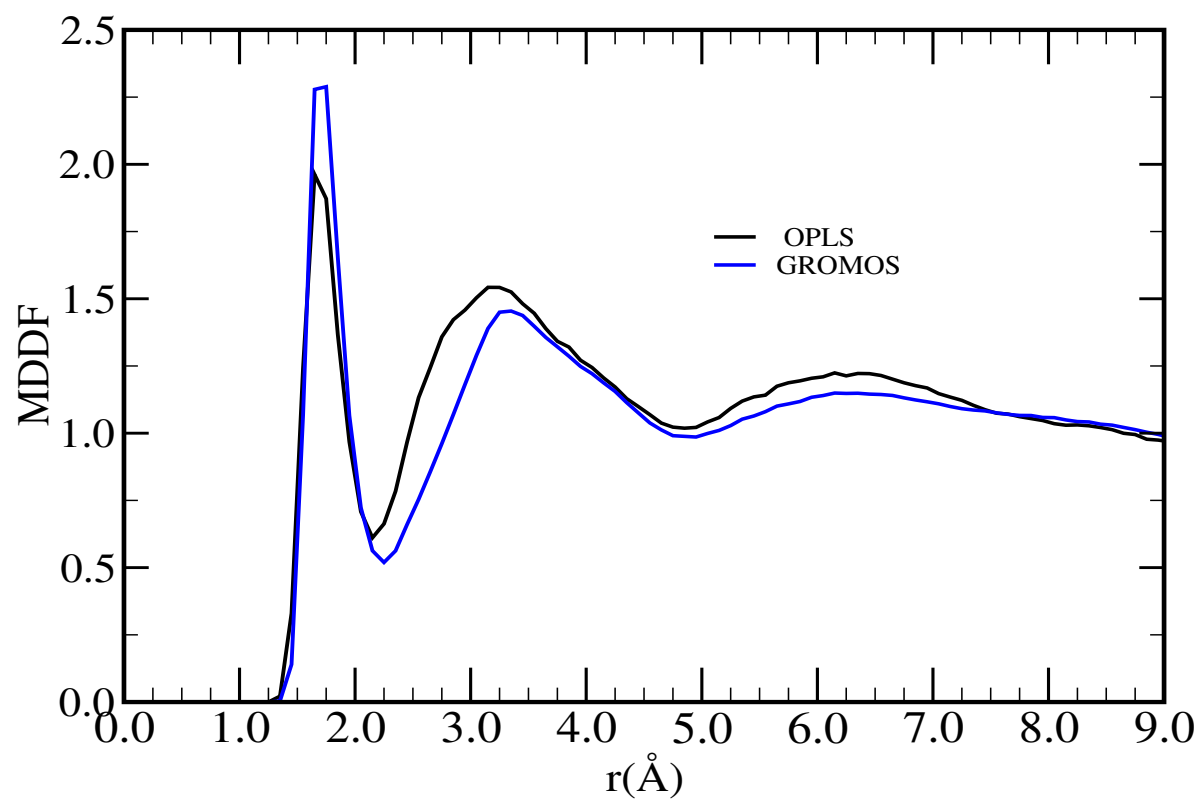

Figura A.17: Comparação da função de distribuição de mínima distância (MDDF), entre a espécie $\mathrm{EM}^{-}$e as moléculas de água calculadas das simulações computacionais com dinâmica molecular dessa espécie em solução aquosa realizadas utilizando os campos de forças GROMOS e OPLS. 


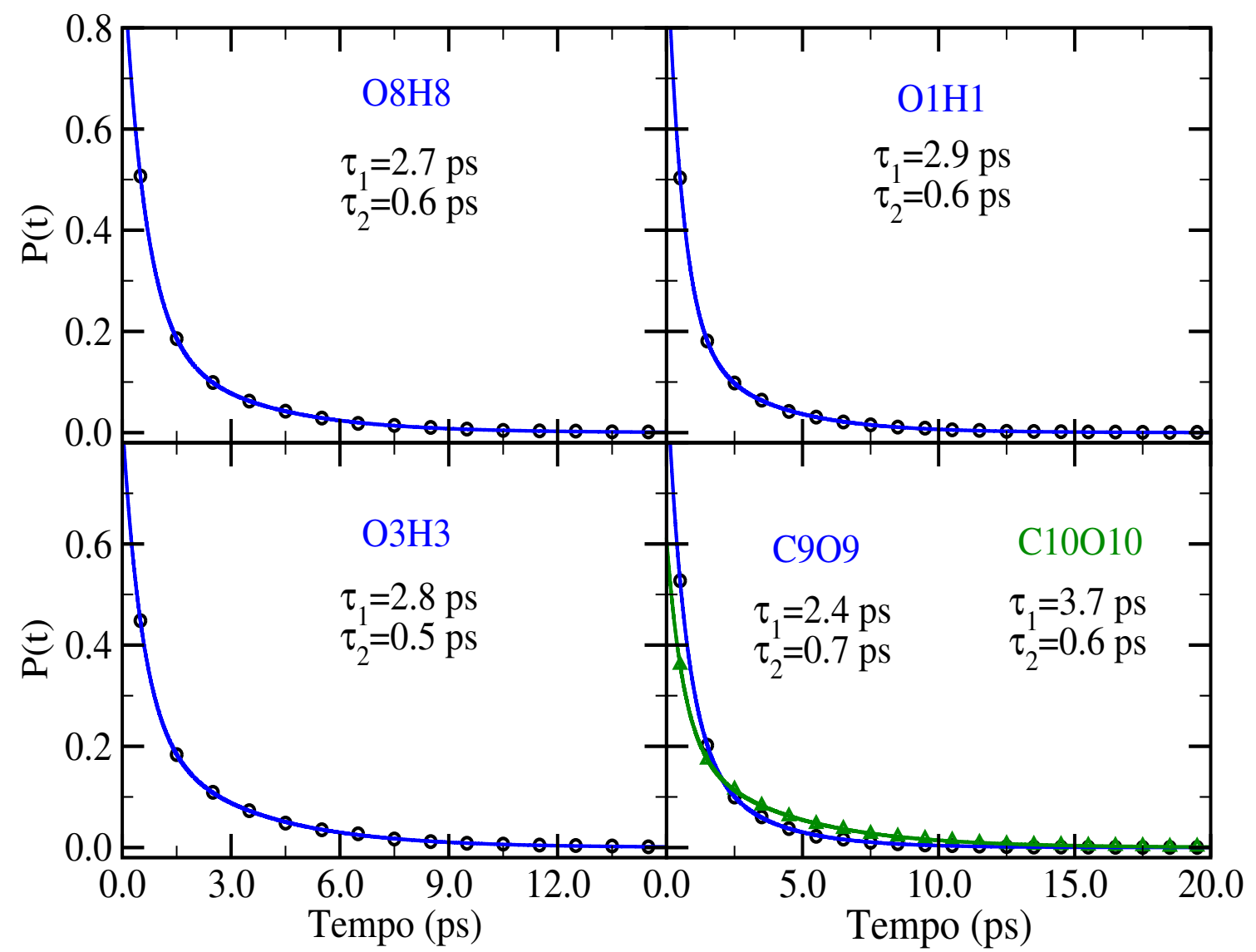

Figura A.18: Funções de distribuição de probabilidades dos tempos de vida das ligações de hidrogênio formadas pelas moléculas de água com os grupos hidroxila (O1H1, O8H8 e O3H3) e carbonila (C9O9 e C10O10) da espécie EMH durante a dinâmica molecular. 


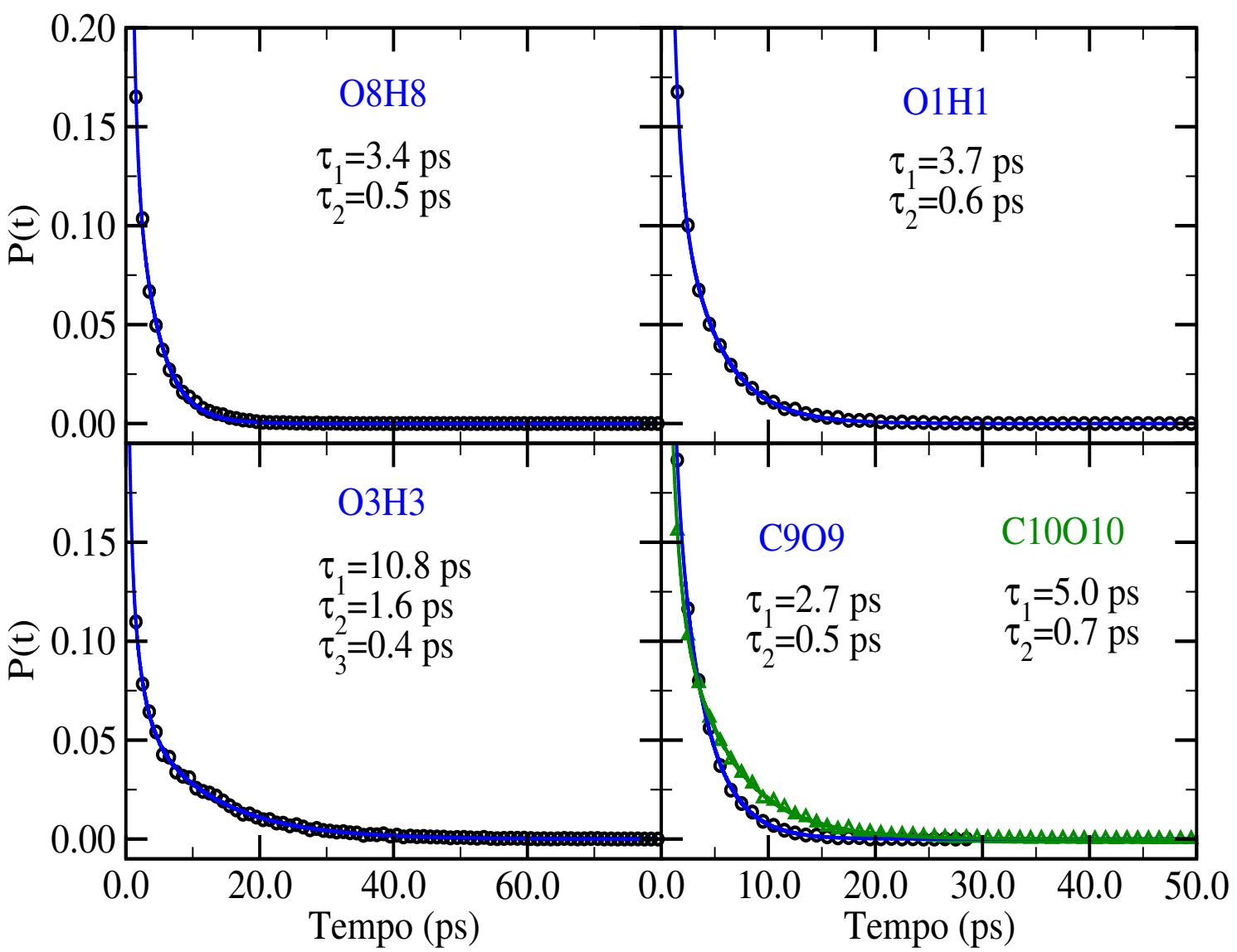

Figura A.19: Funções de distribuição de probabilidades dos tempos de vida das ligações de hidrogênio formadas pelas moléculas de água com os grupos hidroxila (O1H1 e O8H8) e carbonila (C9O9, C10O10 e C3O3) da espécie EM- durante a dinâmica molecular. 


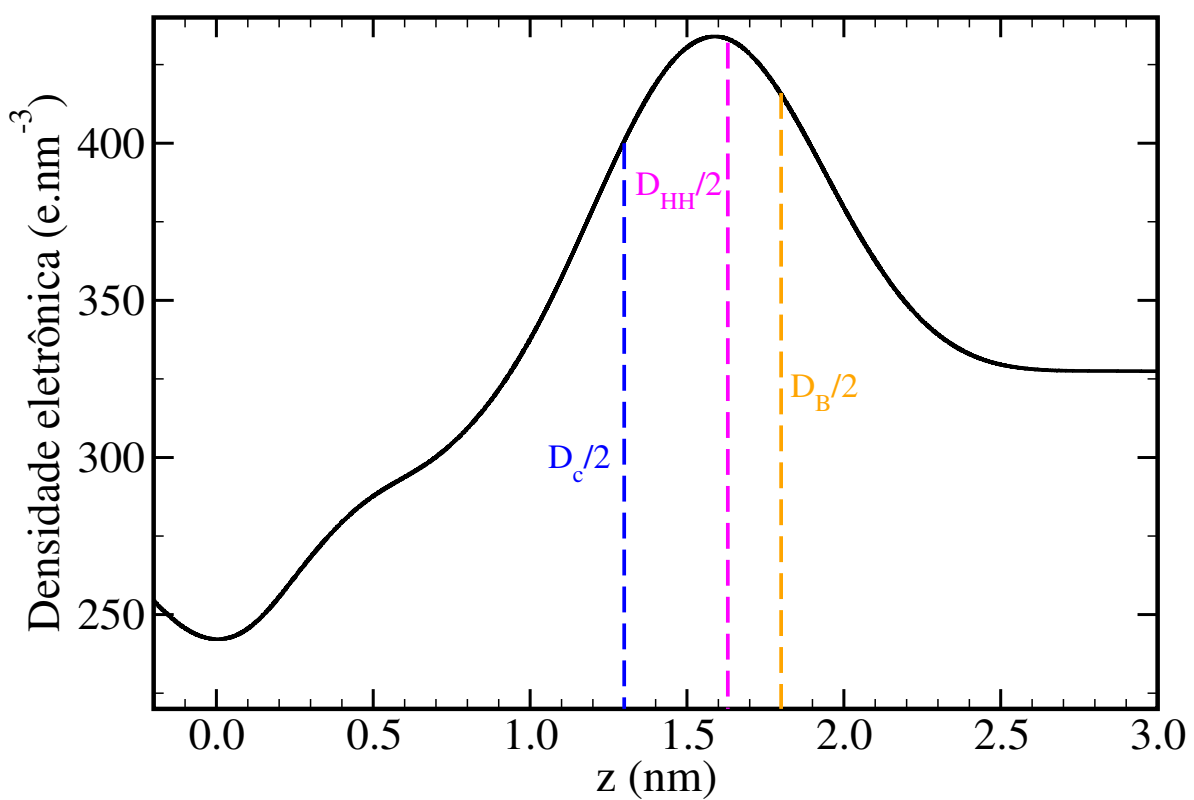

Figura A.20: Ilustração dos parâmetros de espessura da região das cadeias hidrocarbônicas $\left(D_{c}\right)$, da bicamada lipídica $\left(D_{\mathrm{HH}}\right)$ e de Luzzati $\left(\mathrm{D}_{\mathrm{B}}\right)$ no perfil da densidade eletrônica do sistema (água+lipídios). 


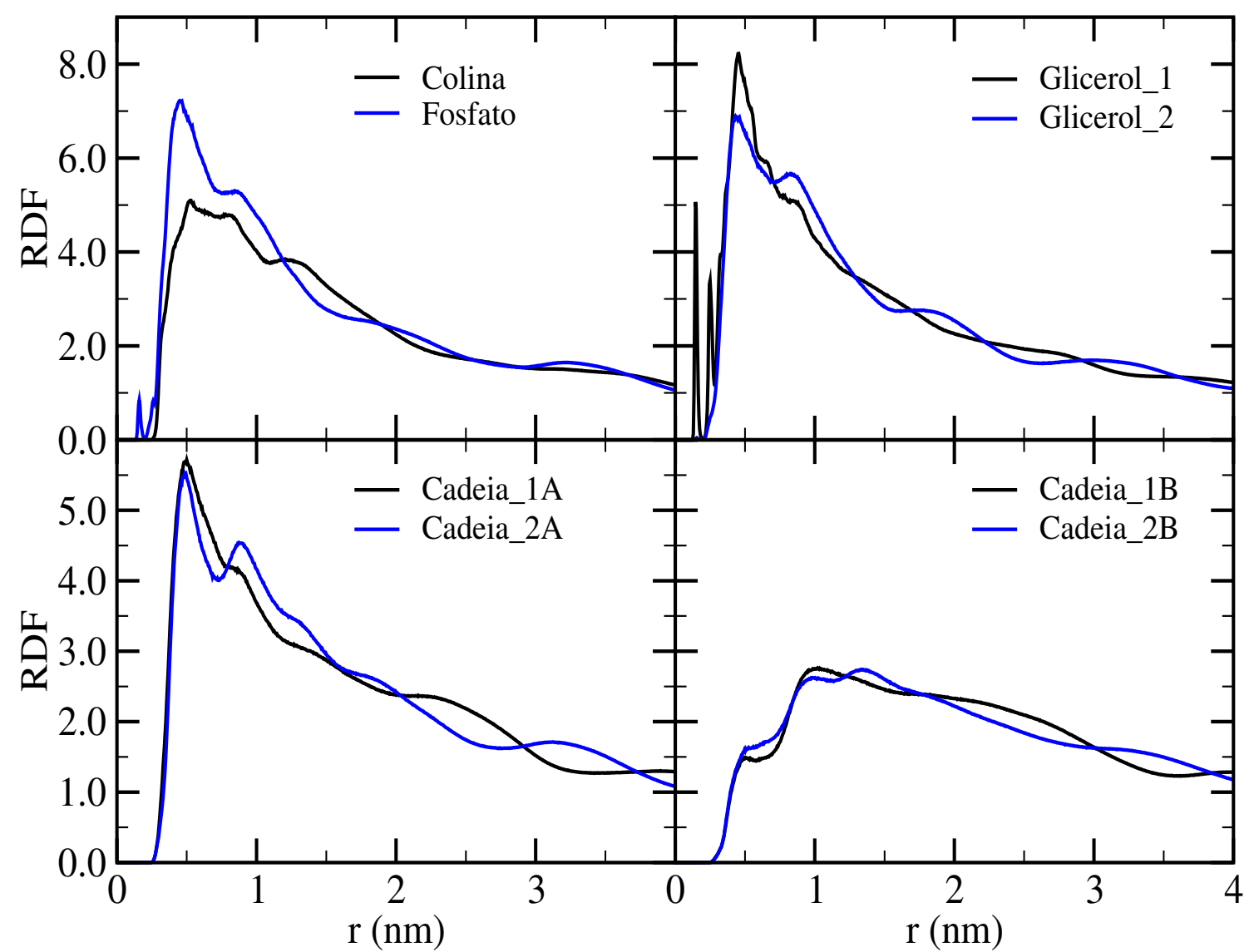

Figura A.21: Funções de distribuição radial (RDF) de pares entre a espécie EMH e os grupos colina, fosfato, glicerol_1, glicerol_2, cadeia_1A, cadeia_1B, cadeia_2A e cadeia_2B, calculadas para o sistema formado por uma espécie mais a monocamada lipídica, considerando as três coordenadas das moléculas x, y e z. 


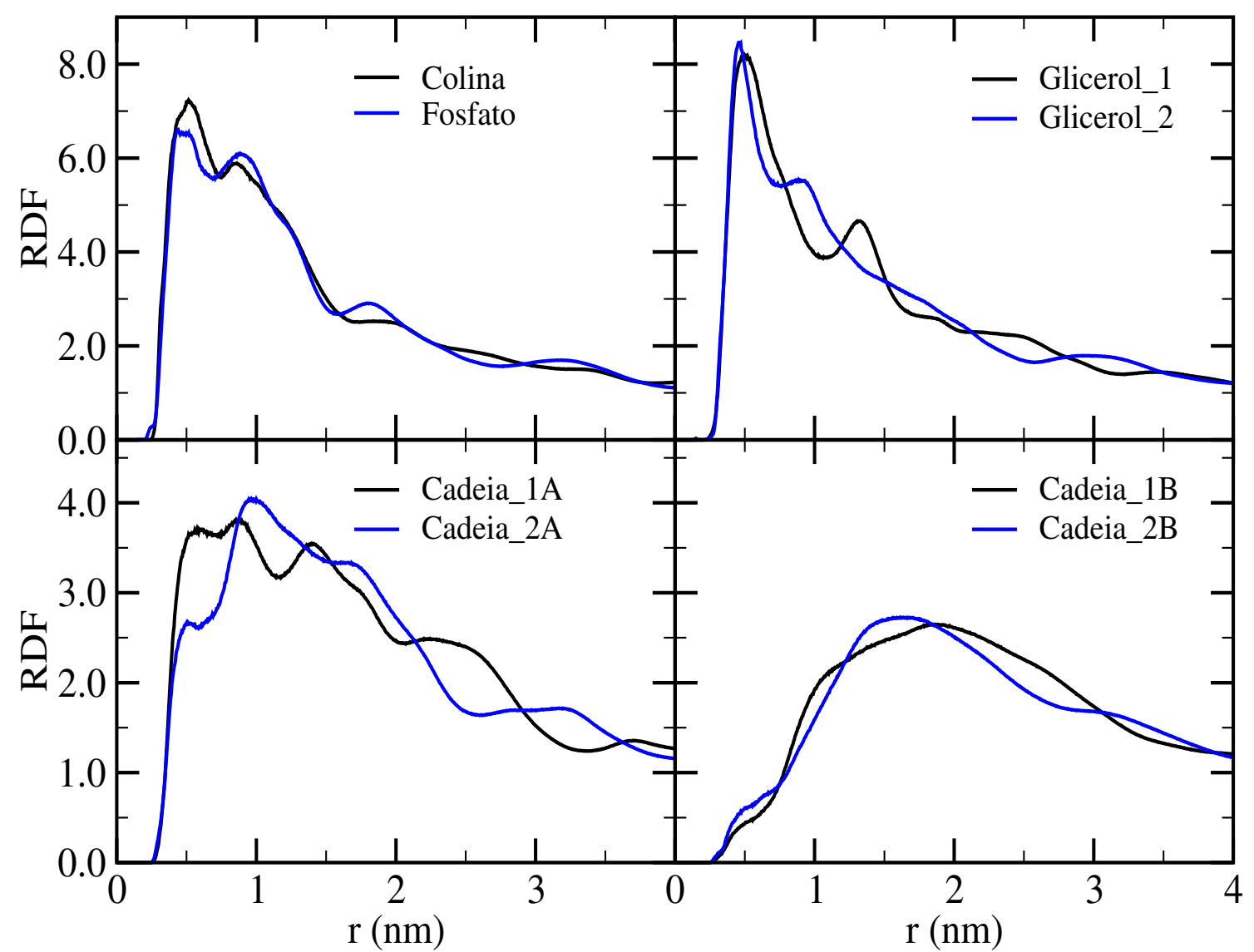

Figura A.22: Funções de distribuição radial (RDF) de pares entre a espécie $\mathrm{EM}^{-}$e os grupos colina, fosfato, glicerol_1, glicerol_2, cadeia_1A, cadeia_1B, cadeia_2A e cadeia_2B, calculadas para o sistema formado por uma espécie mais a monocamada lipídica, considerando as três coordenadas das moléculas $\mathrm{x}, \mathrm{y}$ e $\mathrm{z}$. 


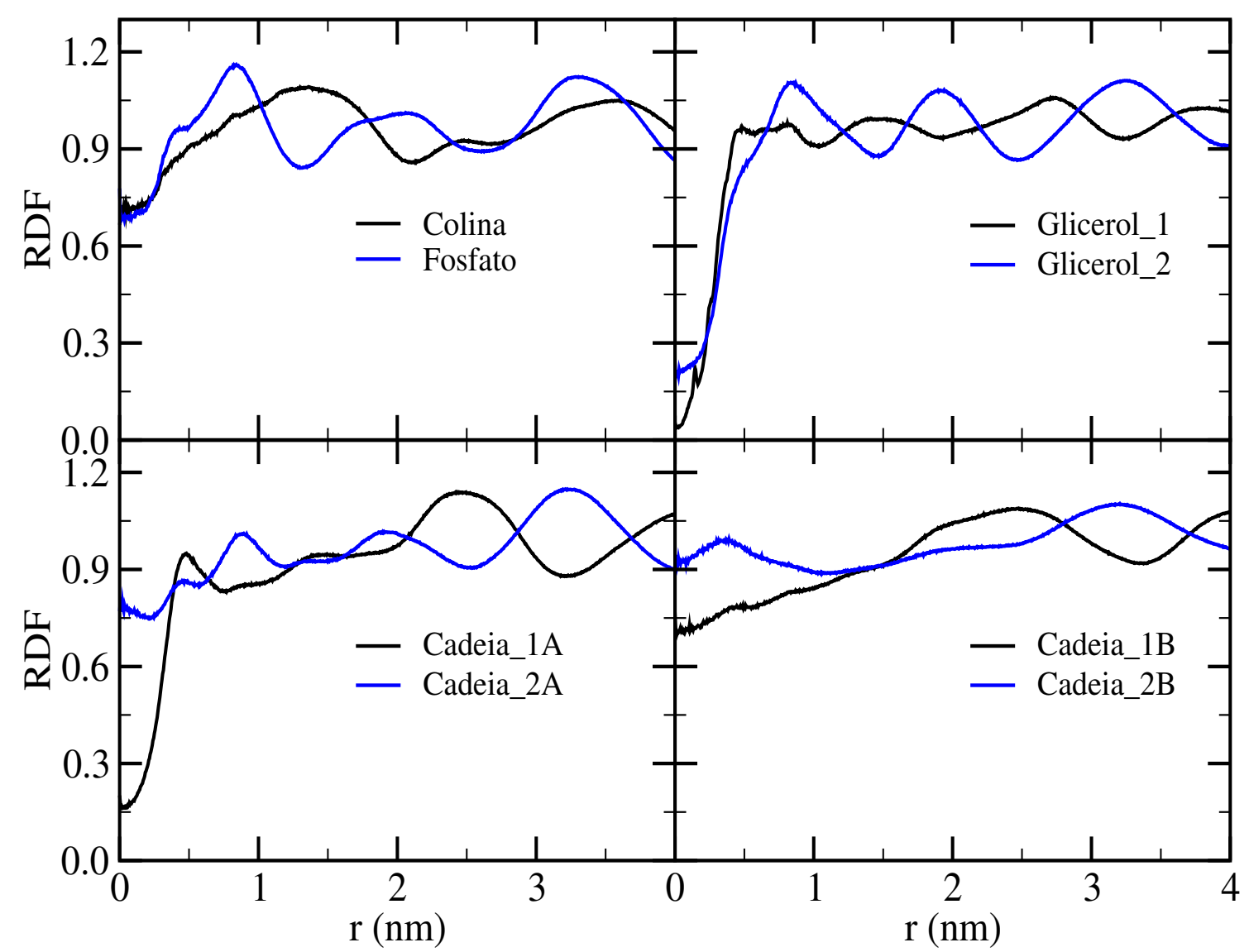

Figura A.23: Funções de distribuição radial (RDF) de pares entre a espécie EMH e os grupos cos grupos colina, fosfato, glicerol_1, glicerol_2, cadeia_1A, cadeia_1B, cadeia_2A e cadeia_2B, calculadas para o sistema formado por uma espécie mais a monocamada lipídica, considerando apenas as coordenadas das moléculas x e y. 


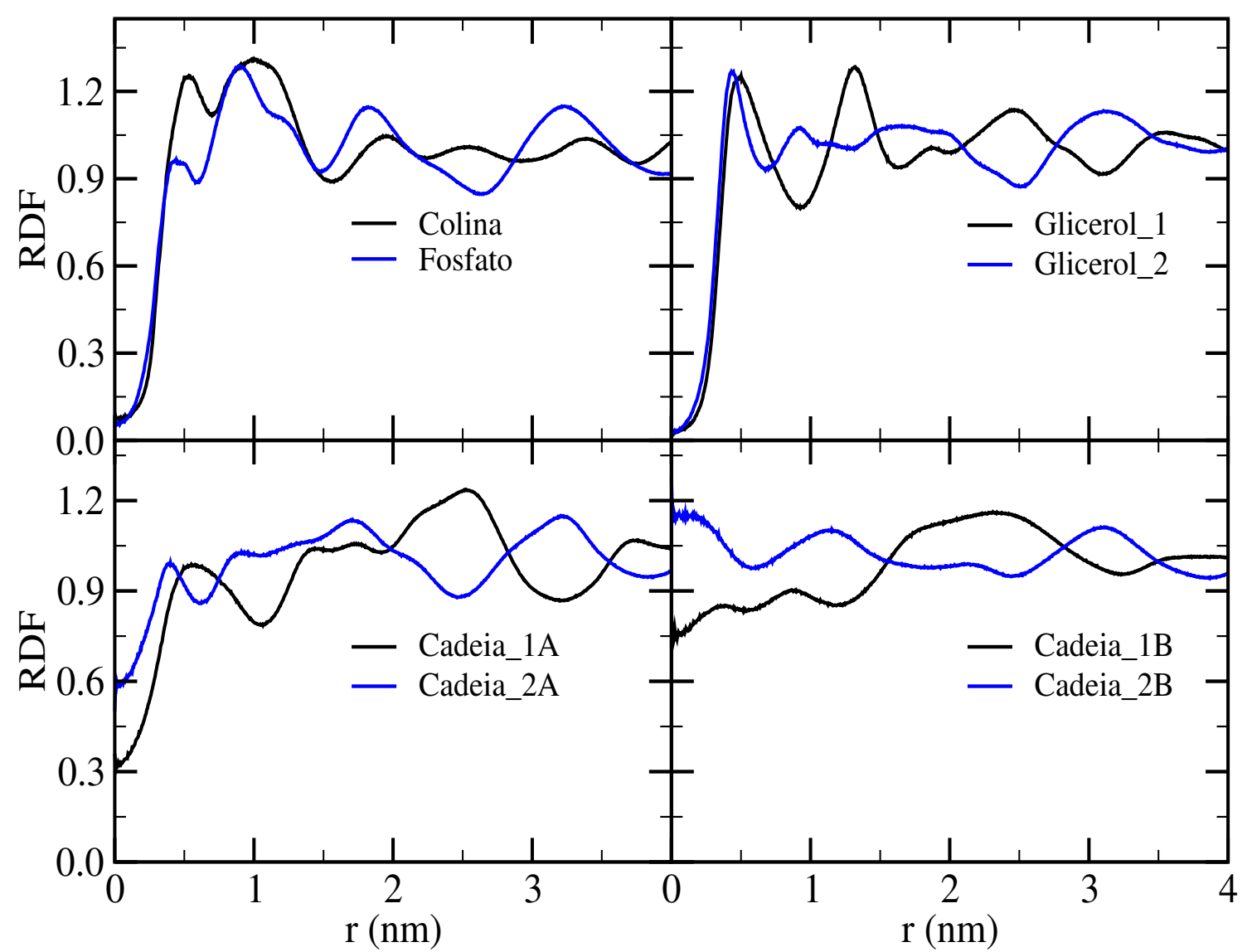

Figura A.24: Funções de distribuição radial (RDF) de pares entre a espécie EM- e os grupos cos grupos colina, fosfato, glicerol_1, glicerol_2, cadeia_1A, cadeia_1B, cadeia_2A e cadeia_2B, calculadas para o sistema formado por uma espécie mais a monocamada lipídica, considerando apenas as coordenadas das moléculas x e y. 


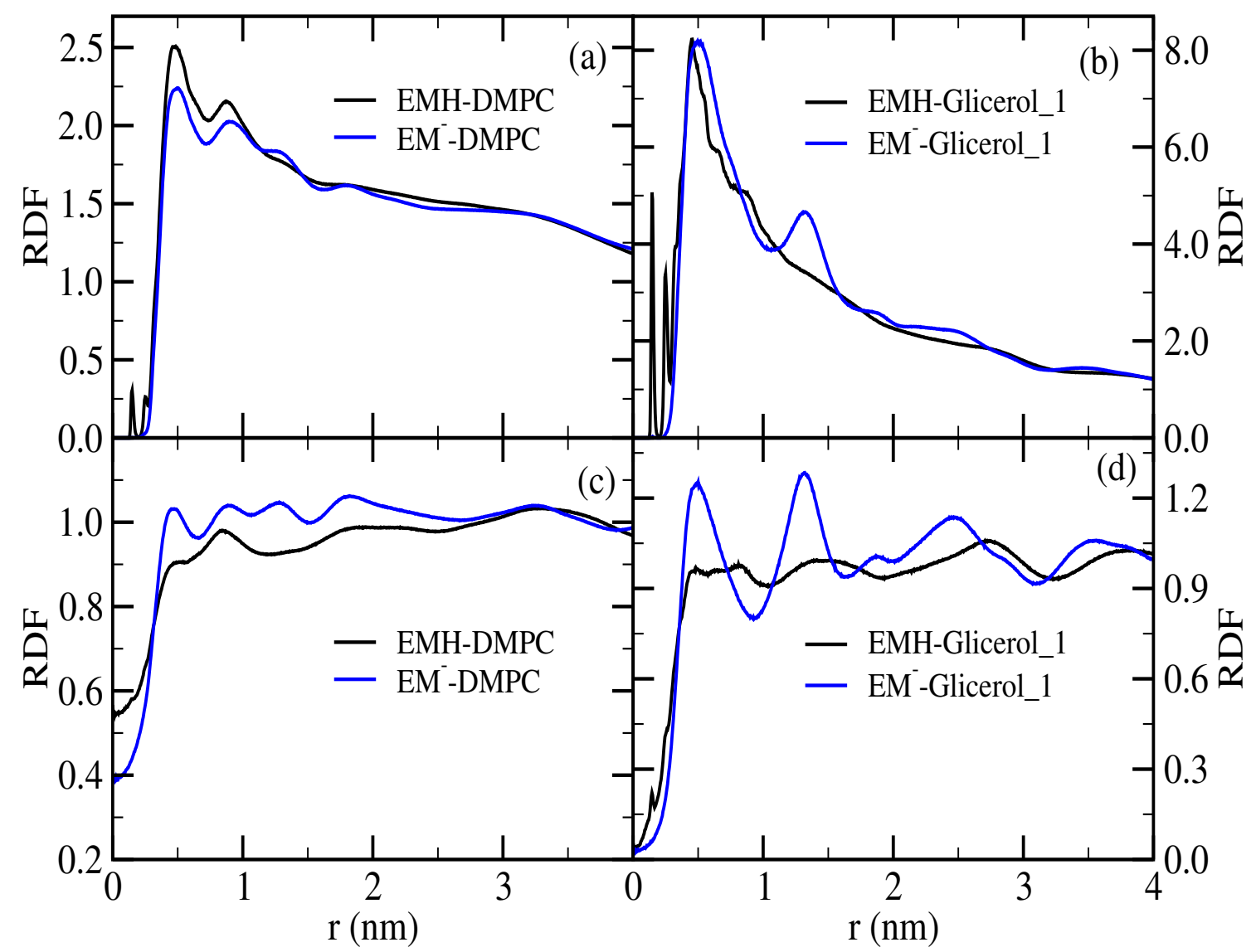

Figura A.25: Comparação das funções de distribuição radial (RDF) de pares entre as espécies EMH e EM- com os lipídios de DMPC e o grupo glicerol_1 desses lipídios, em que nas figuras (a) e (b) estão apresentadas as RDFs 3D e nas figuras (c) e (d) as RDFs 2D. 


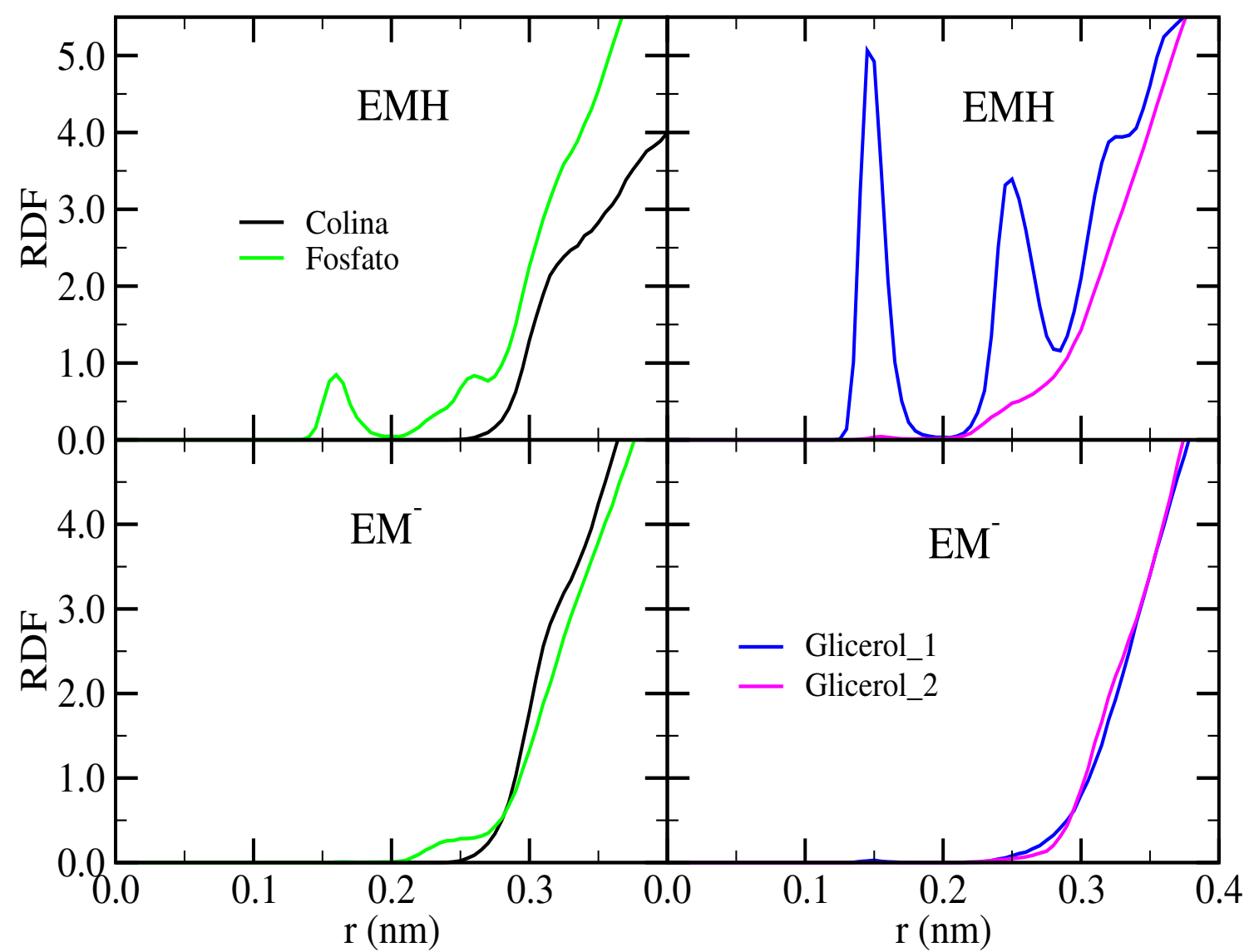

Figura A.26: Ampliação para $\mathrm{r}<0.4 \mathrm{~nm}$ das funções de distribuição radial (RDF) de pares entre as espécies da Emodina com os grupos colina, fosfato, glicerol_1 e glicerol_2. Essa RDF foi calculada para o sistema formado por uma espécie mais a monocamada lipídica,considerando as três coordenadas das moléculas $\mathrm{x}, \mathrm{y}$ e z. 


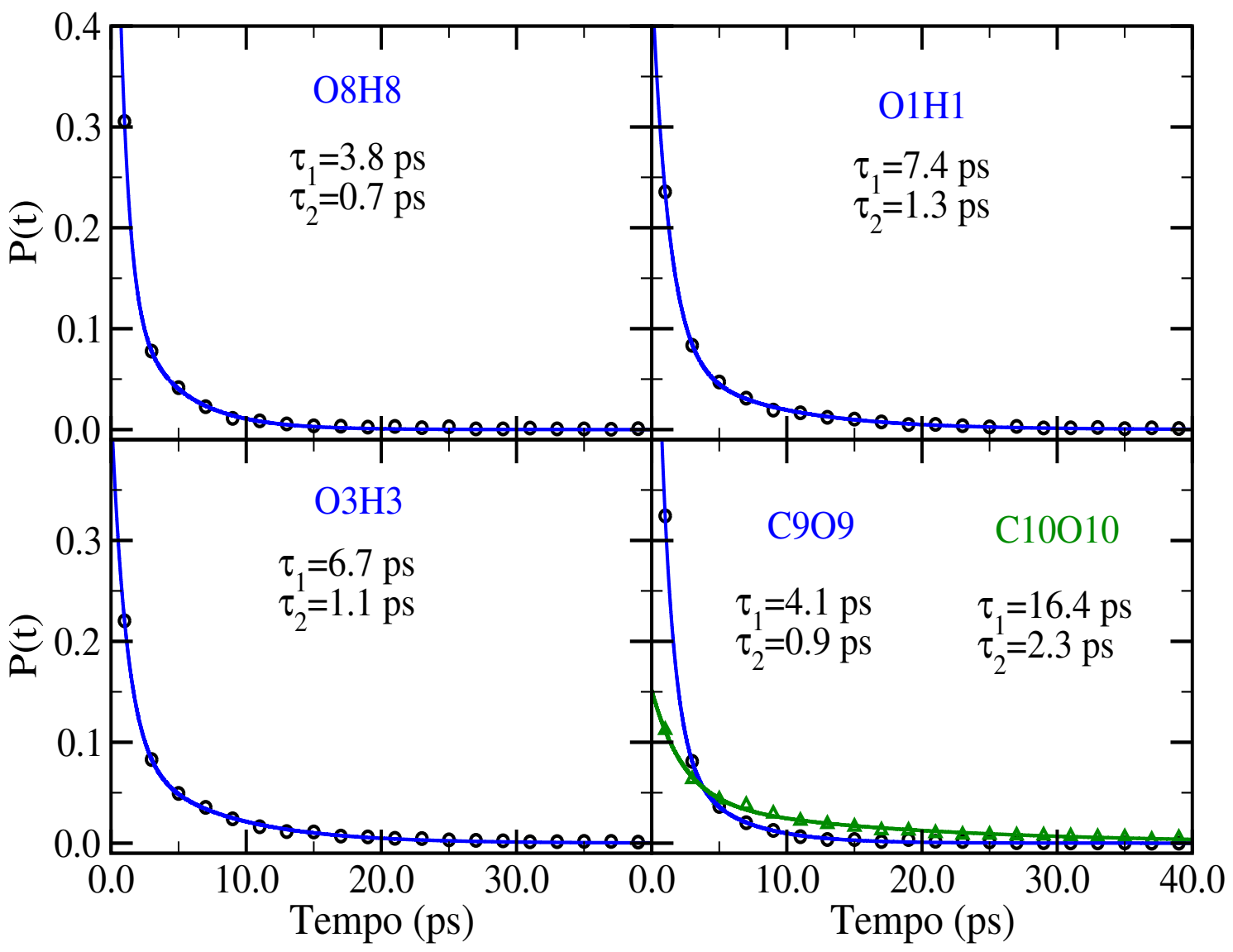

Figura A.27: Funções de distribuição de probabilidades dos tempos de vida das ligações de hidrogênio formadas pelas moléculas de água com os grupos hidroxilas (O1H1 e O8H8 e O3H3) e carbonilas (C9O9 e C10O10) da espécie EMH durante a Dinâmica Molecular dessa espécie em bicamada lipídica. 


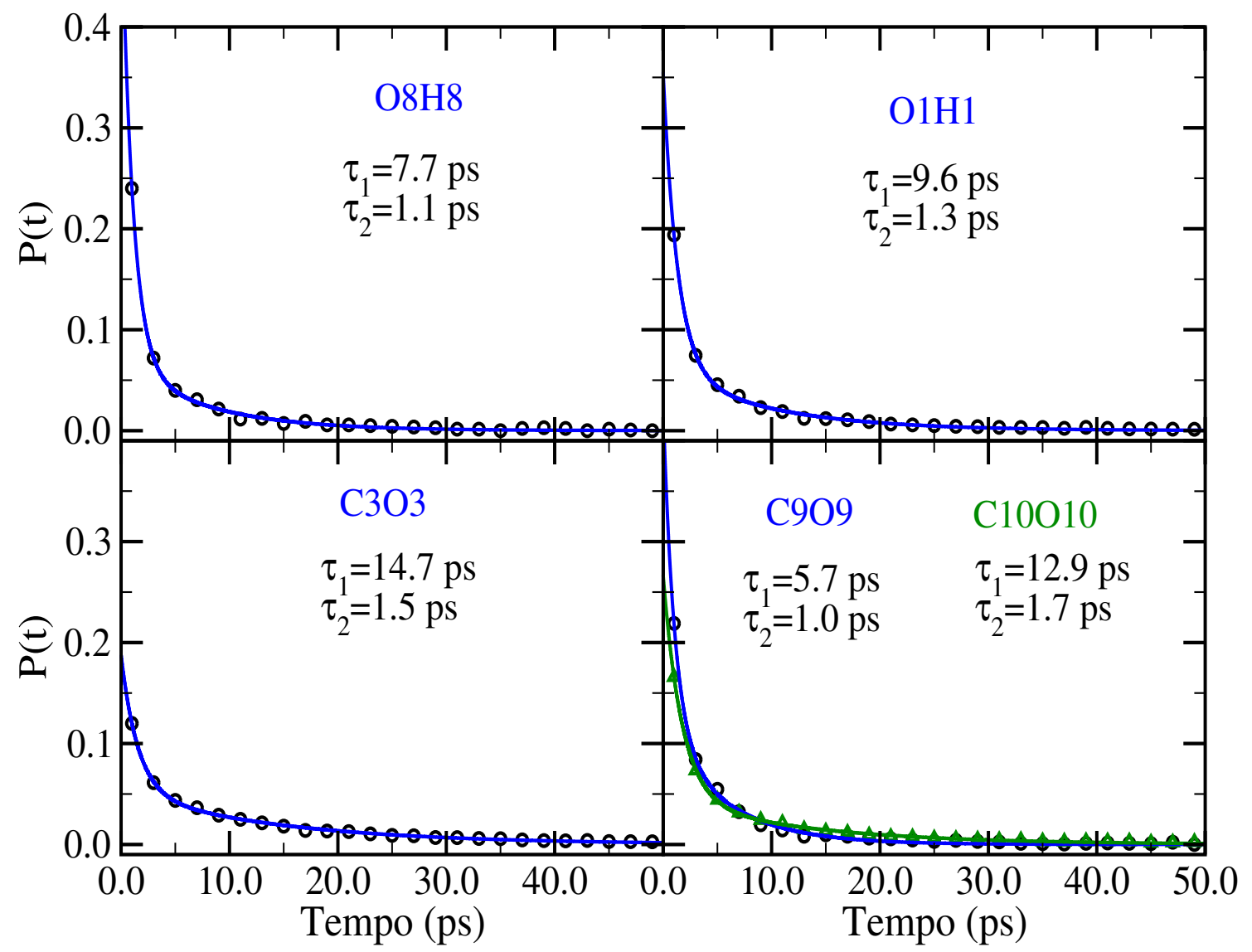

Figura A.28: Funções de distribuição de probabilidades dos tempos de vida das ligações de hidrogênio formadas pelas moléculas de água com os grupos hidroxilas (O1H1 e O8H8) e carbonilas (C9O9, C10O10 e C3O3) da espécie EM- durante a Dinâmica Molecular dessa espécie em bicamada lipídica. 


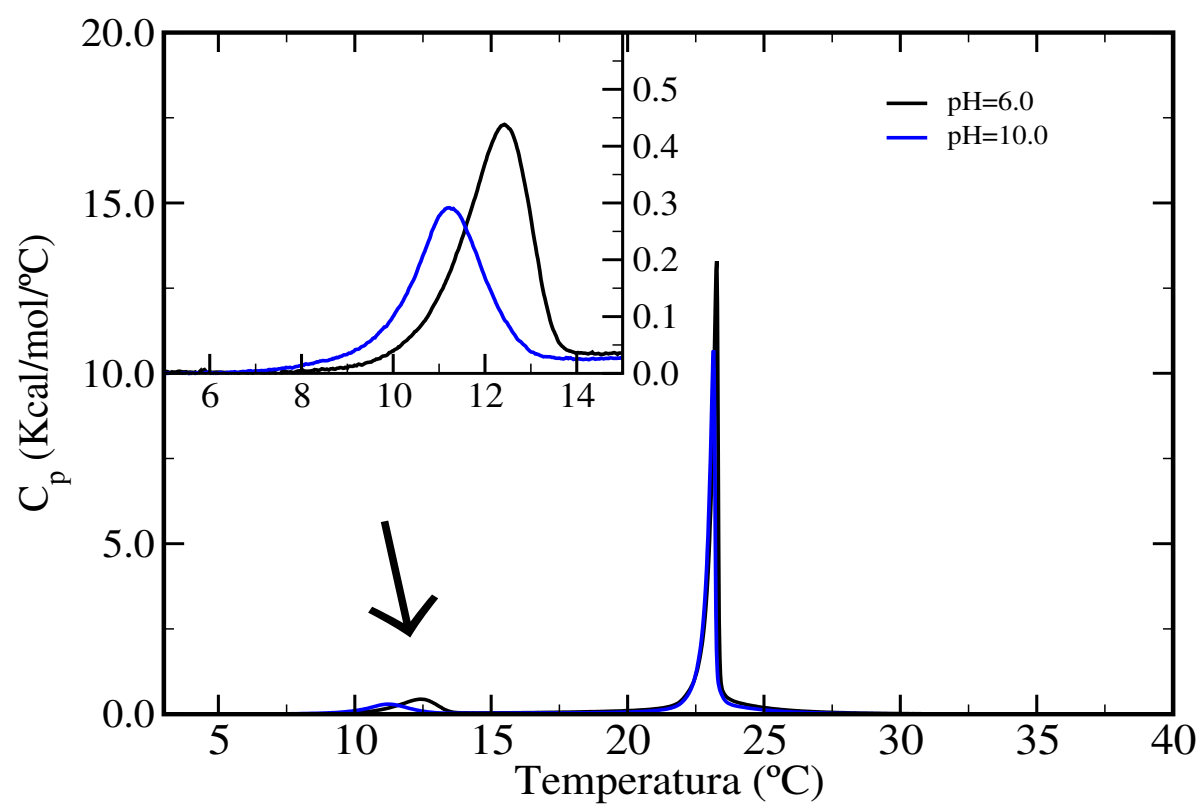

Figura A.29: Curvas de DSC de dispersões lipídicas de DMPC na concentração $5 \mathrm{mM}$ nos tampões bifosfato/fosfato $\mathrm{pH} 6.0$ e bicarbonato/carbonato $\mathrm{pH}$ 10.0. A taxa de aquecimento foi $20{ }^{\circ} \mathrm{C} / \mathrm{h}$. 


\section{Apêndice B}

\section{Arquivos de Coordenadas e de Topologia das espécies da Emodina e da molécula de DMPC}

\section{B.1 Arquivo EMH.gro}

$\begin{array}{crrrrr}\begin{array}{c}\text { Molecule } \\ 27\end{array} & \text { of Emodin specie EMH } & & \\ \text { 1EMH } & \text { C1 } & 1 & 2.133 & 1.767 & 2.000 \\ \text { 1EMH } & \text { C2 } & 2 & 2.273 & 1.767 & 2.000 \\ \text { 1EMH } & \text { C3 } & 3 & 2.345 & 1.887 & 2.000 \\ \text { 1EMH } & \text { C4 } & 4 & 2.276 & 2.009 & 2.000 \\ \text { 1EMH } & \text { C5 } & 5 & 1.858 & 2.272 & 2.000 \\ \text { 1EMH } & \text { C6 } & 6 & 1.718 & 2.280 & 2.000 \\ \text { 1EMH } & \text { C7 } & 7 & 1.644 & 2.162 & 1.999 \\ \text { 1EMH } & \text { C8 } & 8 & 1.706 & 2.036 & 1.999 \\ \text { 1EMH } & \text { C9 } & 9 & 1.914 & 1.895 & 1.999 \\ \text { 1EMH } & \text { C10 } & 10 & 2.070 & 2.144 & 2.000 \\ \text { 1EMH } & \text { C11 } & 11 & 2.061 & 1.890 & 2.000 \\ \text { 1EMH } & \text { C12 } & 12 & 2.137 & 2.010 & 2.000 \\ \text { 1EMH } & \text { C13 } & 13 & 1.922 & 2.148 & 2.000 \\ \text { 1EMH } & \text { C14 } & 14 & 1.848 & 2.027 & 1.999 \\ \text { 1EMH } & \text { O15 } & 15 & 1.627 & 1.927 & 1.999 \\ \text { 1EMH } & \text { H16 } & 16 & 1.689 & 1.849 & 1.999 \\ \text { 1EMH } & \text { O17 } & 17 & 1.844 & 1.792 & 1.999 \\ \text { 1EMH } & \text { O18 } & 18 & 2.066 & 1.650 & 2.000 \\ \text { 1EMH } & \text { H19 } & 19 & 1.968 & 1.668 & 2.000 \\ \text { 1EMH } & \text { O20 } & 20 & 2.479 & 1.878 & 2.000 \\ \text { 1EMH } & \text { H21 } & 21 & 2.520 & 1.969 & 2.000 \\ \text { 1EMH } & \text { O22 } & 22 & 2.137 & 2.247 & 2.001\end{array}$


286Apêndice . Arquivos de Topologia das espécies da Emodina e da molécula de DMPC

$\begin{array}{lcrrlll}26 & 1 \mathrm{EMH} & \mathrm{C} 23 * & 23 & 1.648 & 2.414 & 1.999 \\ 27 & 1 \mathrm{EMH} & \mathrm{H} 24 & 24 & 1.535 & 2.164 & 1.999 \\ 28 & 1 \mathrm{EMH} & \mathrm{H} 25 & 25 & 1.919 & 2.362 & 2.001 \\ 29 & 1 \mathrm{EMH} & \mathrm{H} 26 & 26 & 2.327 & 1.672 & 2.000 \\ 30 & 1 \mathrm{EMH} & \mathrm{H} 27 & 27 & 2.330 & 2.103 & 2.000 \\ 31 & 4.00000 & 4.00000 & 4.00000 & & \end{array}$

\section{B.2 Arquivo EM-.gro}

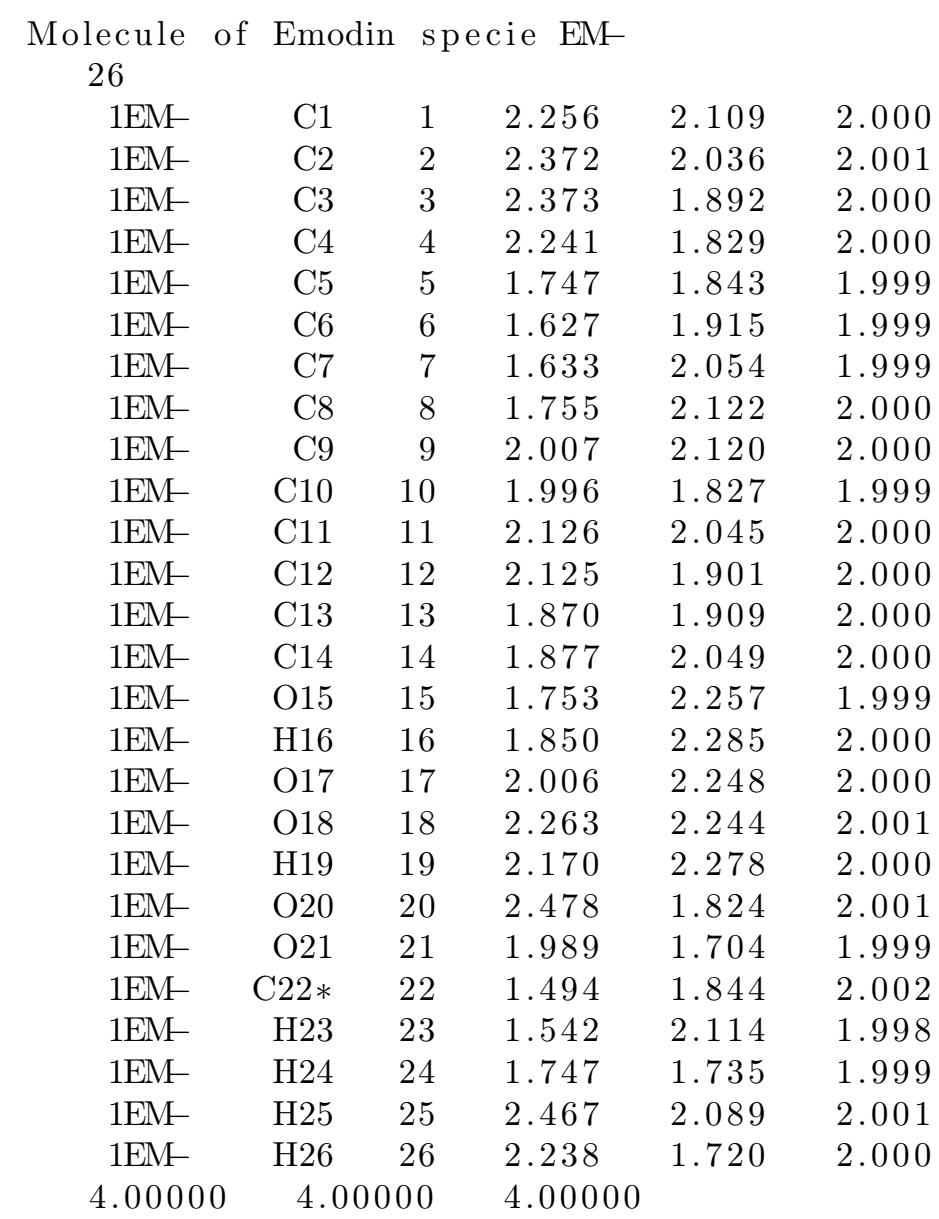

\section{B.3 Arquivo DMPC.gro}

\footnotetext{
Molecule of DMPC
} 
46

\begin{tabular}{|c|c|c|c|c|c|}
\hline 1DMPC & CN1 & 1 & 6.461 & 6.643 & 3.420 \\
\hline 1DMPC & CN3 & 2 & 6.396 & 6.860 & 3.489 \\
\hline 1DMPC & CN2 & 3 & 6.248 & 6.729 & 3.355 \\
\hline 1DMPC & NTM & 4 & 6.389 & 6.765 & 3.37 \\
\hline 1DMPC & $\mathrm{CA}$ & 5 & 6.450 & 6.827 & 3.25 \\
\hline 1DMPC & $\mathrm{CB}$ & 6 & 6.445 & 6.757 & 3.12 \\
\hline 1DMPC & $\mathrm{OA}$ & 7 & 6.496 & 6.625 & 3.12 \\
\hline 1DMPC & $\mathrm{P}$ & 8 & 6.424 & 6.534 & 3.01 \\
\hline 1DMPC & $\mathrm{OC}$ & 9 & 6.460 & 6.597 & 2.89 \\
\hline 1DMPC & $\mathrm{OB}$ & 10 & 6.287 & 6.539 & 3.07 \\
\hline 1DMPC & OD & 11 & 6.497 & 6.399 & 3.0 \\
\hline 1DMPC & $\mathrm{CC}$ & 12 & 6.452 & 6.353 & 3.1 \\
\hline 1DMPC & $\mathrm{CD}$ & 13 & 6.545 & 6.260 & 3.2 \\
\hline 1DMPC & $\mathrm{OE}$ & 14 & 6.489 & 6.235 & 3.39 \\
\hline 1DMPC & $\mathrm{C} 1 \mathrm{~A}$ & 15 & 6.537 & 6.135 & 3.46 \\
\hline 1DMPC & $\mathrm{OF}$ & 16 & 6.633 & 6.069 & 3.42 \\
\hline 1DMPC & C1B & 17 & 6.460 & 6.115 & 3.59 \\
\hline 1DMPC & $\mathrm{C} 1 \mathrm{C}$ & 18 & 6.546 & 6.074 & 3.71 \\
\hline 1DMPC & C1D & 19 & 6.455 & 6.058 & 3.8 \\
\hline 1DMPC & $\mathrm{C} 1 \mathrm{E}$ & 20 & 6.530 & 6.025 & \\
\hline 1DMPC & $\mathrm{C} 1 \mathrm{~F}$ & 21 & 6.626 & 6.138 & 4.00 \\
\hline 1DMPC & $\mathrm{C} 1 \mathrm{G}$ & 22 & 6.651 & 6.140 & \\
\hline 1DMPC & $\mathrm{C} 1 \mathrm{H}$ & 23 & 6.526 & 6.187 & 4.23 \\
\hline 1DMPC & C1I & 24 & 6.546 & 6.191 & \\
\hline 1DMPC & C1J & 25 & 6.418 & 6.238 & 4.44 \\
\hline 1DMPC & $\mathrm{C} 1 \mathrm{~K}$ & 26 & 6.433 & 6.242 & \\
\hline 1DMPC & $\mathrm{C} 1 \mathrm{~L}$ & 27 & 6.302 & 6.288 & 4.66 \\
\hline 1DMPC & $\mathrm{C} 1 \mathrm{M}$ & 28 & 6.315 & 6.291 & 4.81 \\
\hline 1DMPC & $\mathrm{C} 1 \mathrm{~N}$ & 29 & 6.184 & 6.336 & 4.88 \\
\hline 1DMPC & $\mathrm{CE}$ & 30 & 6.687 & 6.321 & 3.25 \\
\hline 1DMPC & OG & 31 & 6.702 & 6.457 & 3.30 \\
\hline 1DMPC & $\mathrm{C} 2 \mathrm{~A}$ & 32 & 6.818 & 6.514 & 3.26 \\
\hline 1DMPC & $\mathrm{OH}$ & 33 & 6.910 & 6.450 & 3.21 \\
\hline 1DMPC & $\mathrm{C} 2 \mathrm{~B}$ & 34 & 6.825 & 6.658 & 3.30 \\
\hline 1DMPC & $\mathrm{C} 2 \mathrm{C}$ & 35 & 6.960 & 6.697 & 3.36 \\
\hline 1DMPC & $\mathrm{C} 2 \mathrm{D}$ & 36 & 6.964 & 6.695 & 3.51 \\
\hline 1DMPC & $\mathrm{C} 2 \mathrm{E}$ & 37 & 6.929 & 6.560 & 3.57 \\
\hline 1DMPC & $\mathrm{C} 2 \mathrm{~F}$ & 38 & 6.957 & 6.559 & 3.72 \\
\hline 1DMPC & $\mathrm{C} 2 \mathrm{G}$ & 39 & 6.893 & 6.438 & 3.79 \\
\hline 1DMPC & $\mathrm{C} 2 \mathrm{H}$ & 40 & 6.742 & 6.455 & 3.81 \\
\hline 1DMPC & $\mathrm{C} 2 \mathrm{I}$ & 41 & 6.715 & 6.558 & 3.92 \\
\hline 1DMPC & $\mathrm{C} 2 \mathrm{~J}$ & 42 & 6.565 & 6.574 & 3.95 \\
\hline 1DMPC & $\mathrm{C} 2 \mathrm{~K}$ & 43 & 6.544 & 6.675 & 4.06 \\
\hline 1DMPC & $\mathrm{C} 2 \mathrm{~L}$ & 44 & 6.395 & 6.694 & 4.10 \\
\hline 1DMPC & $\mathrm{C} 2 \mathrm{M}$ & 45 & 6.376 & 6.796 & 4.21 \\
\hline 1DMPC & $\mathrm{C} 2 \mathrm{~N}$ & 46 & 6.228 & 6.816 & 4.24 \\
\hline .10487 & 12.8 & 79 & 7.384 & & \\
\hline
\end{tabular}




\section{B.4 Arquivo EMH.top}

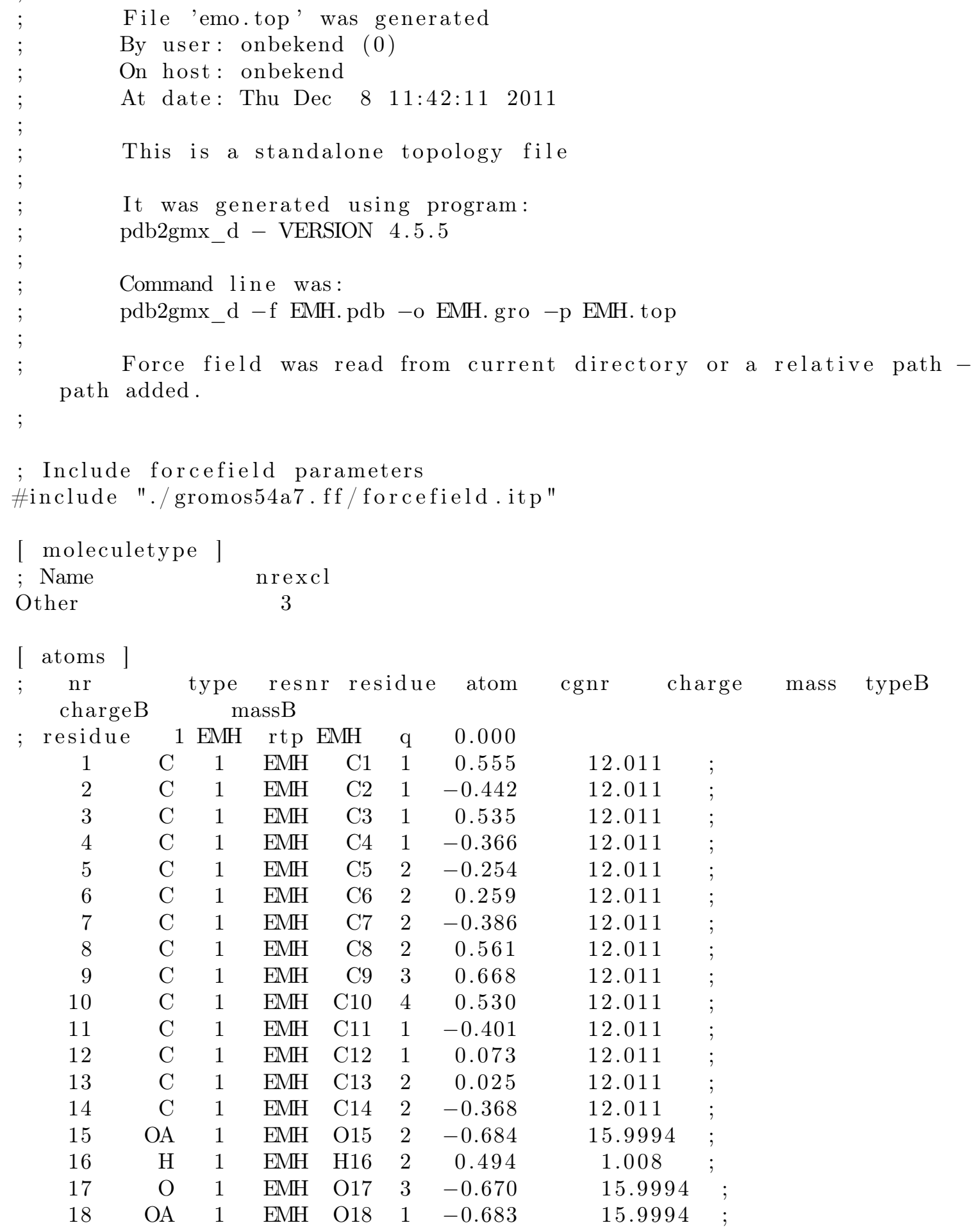




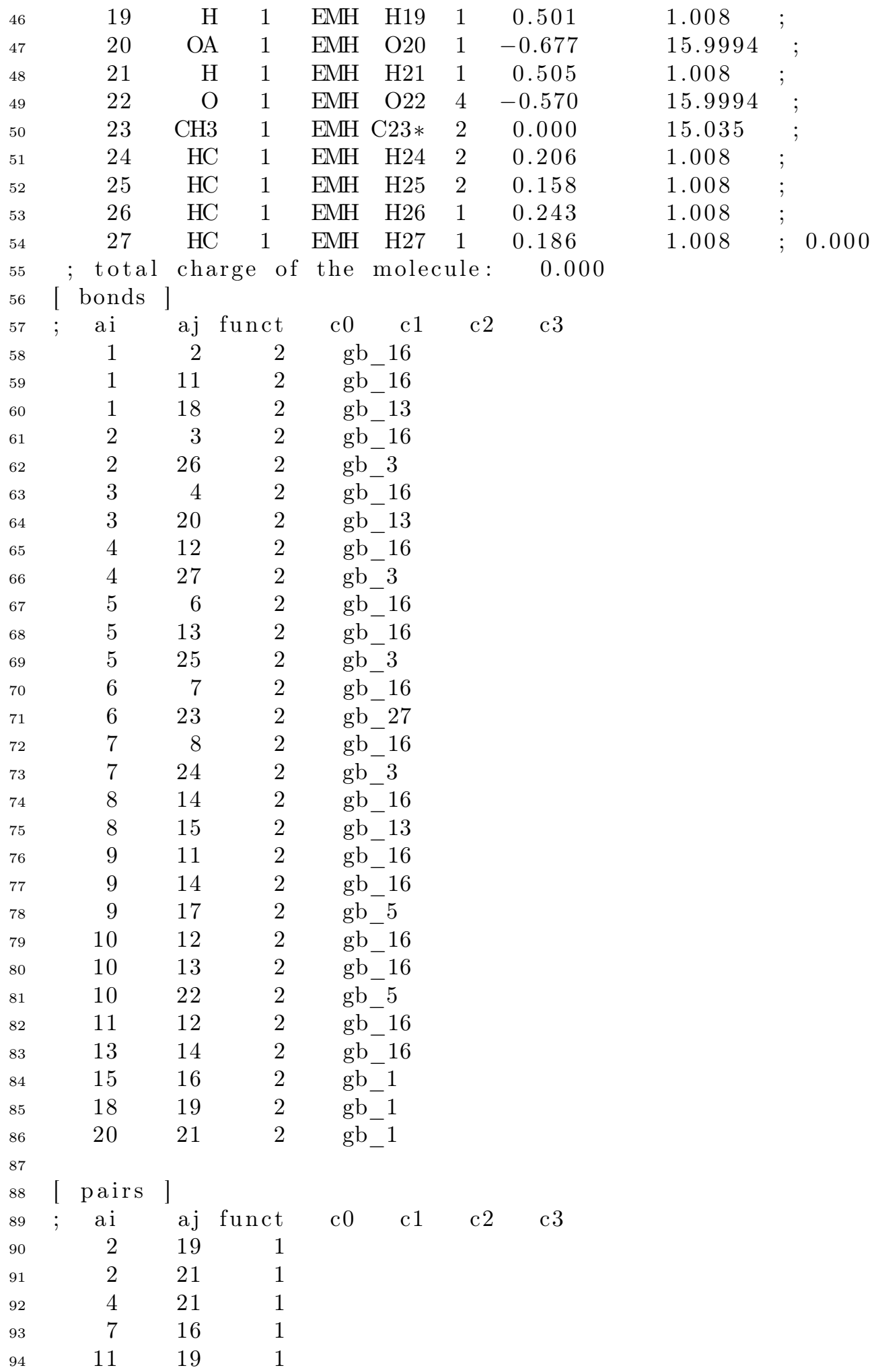


290Apêndice . Arquivos de Topologia das espécies da Emodina e da molécula de DMPC

\begin{tabular}{|c|c|c|c|c|c|c|c|}
\hline \multirow{2}{*}{$\begin{array}{l}95 \\
96\end{array}$} & 14 & 16 & \multirow[t]{2}{*}{1} & & & & \\
\hline & & & & & & & \\
\hline 97 & angles & ] & & & & & \\
\hline 98 & $\mathrm{ai}$ & $\mathrm{aj}$ & $\mathrm{ak}$ & funct & $\mathrm{c} 0$ & $\mathrm{c} 2$ & $\mathrm{c} 3$ \\
\hline 99 & 2 & 1 & 11 & 2 & ga_27 & & \\
\hline 100 & 2 & 1 & 18 & 2 & ga_19 & & \\
\hline 101 & 11 & 1 & 18 & 2 & ga_-19 & & \\
\hline 102 & 1 & 2 & 3 & 2 & ga_27 & & \\
\hline 103 & 1 & 2 & 26 & 2 & ga_25 & & \\
\hline 104 & 3 & 2 & 26 & 2 & ga_25 & & \\
\hline 105 & 2 & 3 & 4 & 2 & ga_27 & & \\
\hline 106 & 2 & 3 & 20 & 2 & $\mathrm{ga}^{-} 19$ & & \\
\hline 107 & 4 & 3 & 20 & 2 & $\mathrm{ga}_{-} 19$ & & \\
\hline 108 & 3 & 4 & 12 & 2 & $\mathrm{ga}^{-} 27$ & & \\
\hline 109 & 3 & 4 & 27 & 2 & ga_25 & & \\
\hline 110 & 12 & 4 & 27 & 2 & ga_25 & & \\
\hline 111 & 6 & 5 & 13 & 2 & ga_27 & & \\
\hline 112 & 6 & 5 & 25 & 2 & ga-25 & & \\
\hline 113 & 13 & 5 & 25 & 2 & ga_25 & & \\
\hline 114 & 5 & 6 & 7 & 2 & $\mathrm{ga}-27$ & & \\
\hline 115 & 5 & 6 & 23 & 2 & $\mathrm{ga}_{-} 15$ & & \\
\hline 116 & 7 & 6 & 23 & 2 & ga_-15 & & \\
\hline 117 & 6 & 7 & 8 & 2 & ga_27 & & \\
\hline 118 & 6 & 7 & 24 & 2 & ga_25 & & \\
\hline 119 & 8 & 7 & 24 & 2 & ga_25 & & \\
\hline 120 & 7 & 8 & 14 & 2 & ga_27 & & \\
\hline 121 & 7 & 8 & 15 & 2 & ga_-19 & & \\
\hline 122 & 14 & 8 & 15 & 2 & ga_-19 & & \\
\hline 123 & 11 & 9 & 14 & 2 & ga_27 & & \\
\hline 124 & 11 & 9 & 17 & 2 & ga_30 & & \\
\hline 125 & 14 & 9 & 17 & 2 & ga_30 & & \\
\hline 126 & 12 & 10 & 13 & 2 & ga_27 & & \\
\hline 127 & 12 & 10 & 22 & 2 & $\mathrm{ga}^{-} 30$ & & \\
\hline 128 & 13 & 10 & 22 & 2 & ga_30 & & \\
\hline 129 & 1 & 11 & 9 & 2 & ga-27 & & \\
\hline 130 & 1 & 11 & 12 & 2 & ga_27 & & \\
\hline 131 & 9 & 11 & 12 & 2 & ga-27 & & \\
\hline 132 & 4 & 12 & 10 & 2 & $\mathrm{ga}-27$ & & \\
\hline 133 & 4 & 12 & 11 & 2 & ga_27 & & \\
\hline 134 & 10 & 12 & 11 & 2 & ga_27 & & \\
\hline 135 & 5 & 13 & 10 & 2 & $\mathrm{ga}_{-} 27$ & & \\
\hline 136 & 5 & 13 & 14 & 2 & ga_27 & & \\
\hline 137 & 10 & 13 & 14 & 2 & $\mathrm{ga}_{-} 27$ & & \\
\hline 138 & 8 & 14 & 9 & 2 & ga_27 & & \\
\hline 139 & 8 & 14 & 13 & 2 & ga_27 & & \\
\hline 140 & 9 & 14 & 13 & 2 & ga_27 & & \\
\hline 141 & 8 & 15 & 16 & 2 & $\mathrm{ga}^{-} 12$ & & \\
\hline 142 & 1 & 18 & 19 & 2 & $\mathrm{ga}_{-} 12$ & & \\
\hline 143 & 3 & 20 & 21 & 2 & $\mathrm{ga}^{-} 12$ & & \\
\hline
\end{tabular}




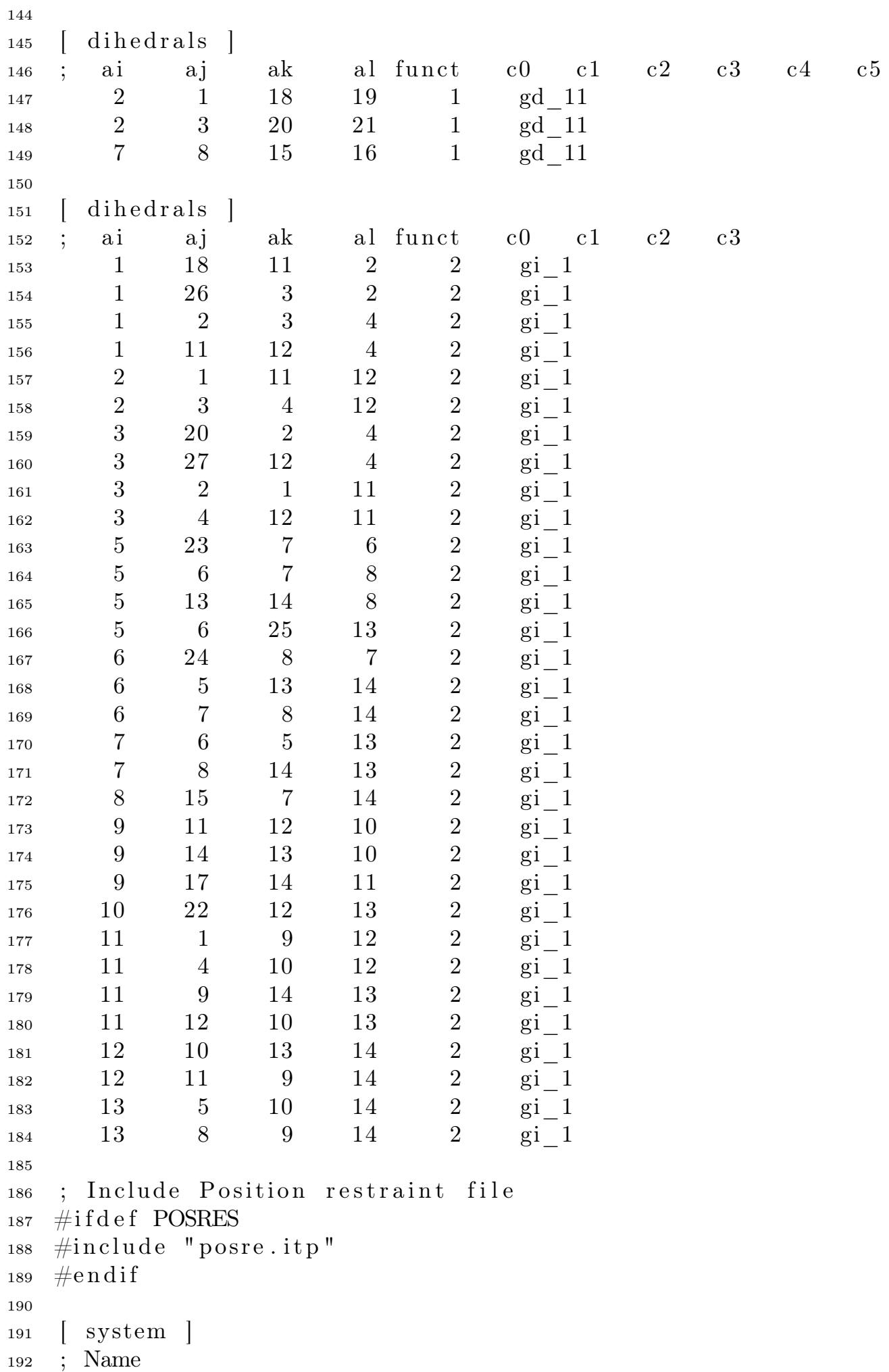




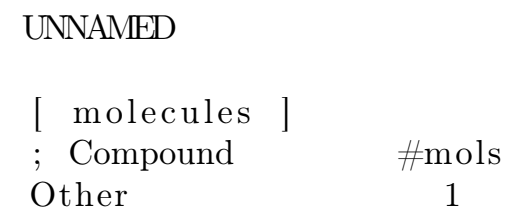

\section{B.5 Arquivo EM-.top}

File 'emo.top' was generated

By user: onbekend (0)

On host: onbekend

At date: Thu Dec 22 10:37:56 2011

This is a standalone topology file

It was generated using program:

pdb2gmx_d - VERSION 4.5.5

Command line was:

pdb2gmx_d -f EM-.pdb -o EM-.gro -p EM-.top

Force field was read from current directory or a relative path path added.

; Include forcefield parameters

\#include "./gromos54a7.ff/forcefield.itp"

[ moleculetype ]

; Name

Other

nrexcl

3

[ atoms ]

$\mathrm{nr}$
typeB

type resnr

chargeB

$\operatorname{mass} B$

charge

mass

; residue 1 EM- rtp EM- q -1.0

$\begin{array}{llllll}1 & \mathrm{C} & 1 & \mathrm{EM} & \mathrm{C} 1 & 1\end{array}$

$\begin{array}{llllll}2 & \mathrm{C} & 1 & \mathrm{EM} & \mathrm{C} 2 & 1\end{array}$

12.011

$3 \quad \mathrm{C} \quad 1 \quad \mathrm{EM}$

C3 1

12.011

$\begin{array}{lll}4 & \mathrm{C} & 1\end{array}$

EM-

C4 1

0.737

12.011

$\begin{array}{llll}5 & \mathrm{C} & 1 & \mathrm{EM}\end{array}$

C5 2

$-0.330$

12.011

$\begin{array}{lll}6 & \mathrm{C} & 1\end{array}$

EM-

C6 2

$-0.252$

12.011

$\begin{array}{lll}7 & \mathrm{C} & 1\end{array}$

EM-

C7 2

0.212

12.011

$\begin{array}{lll}8 & \mathrm{C} & 1\end{array}$

EM-

C8 2

$-0.379$

12.011

9

C 1

EM-

C9 3

12.011

0.540

12.011 ; 


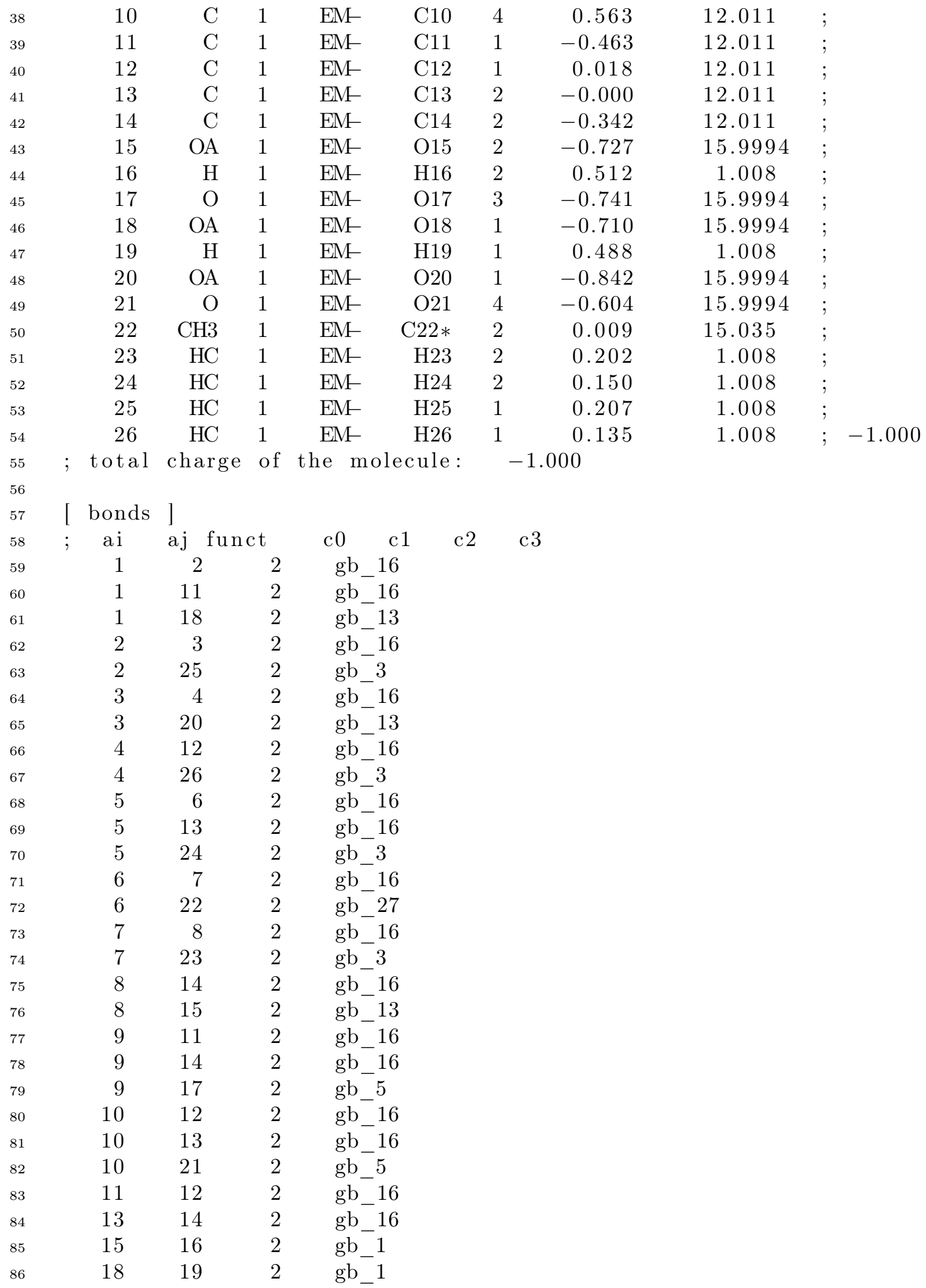




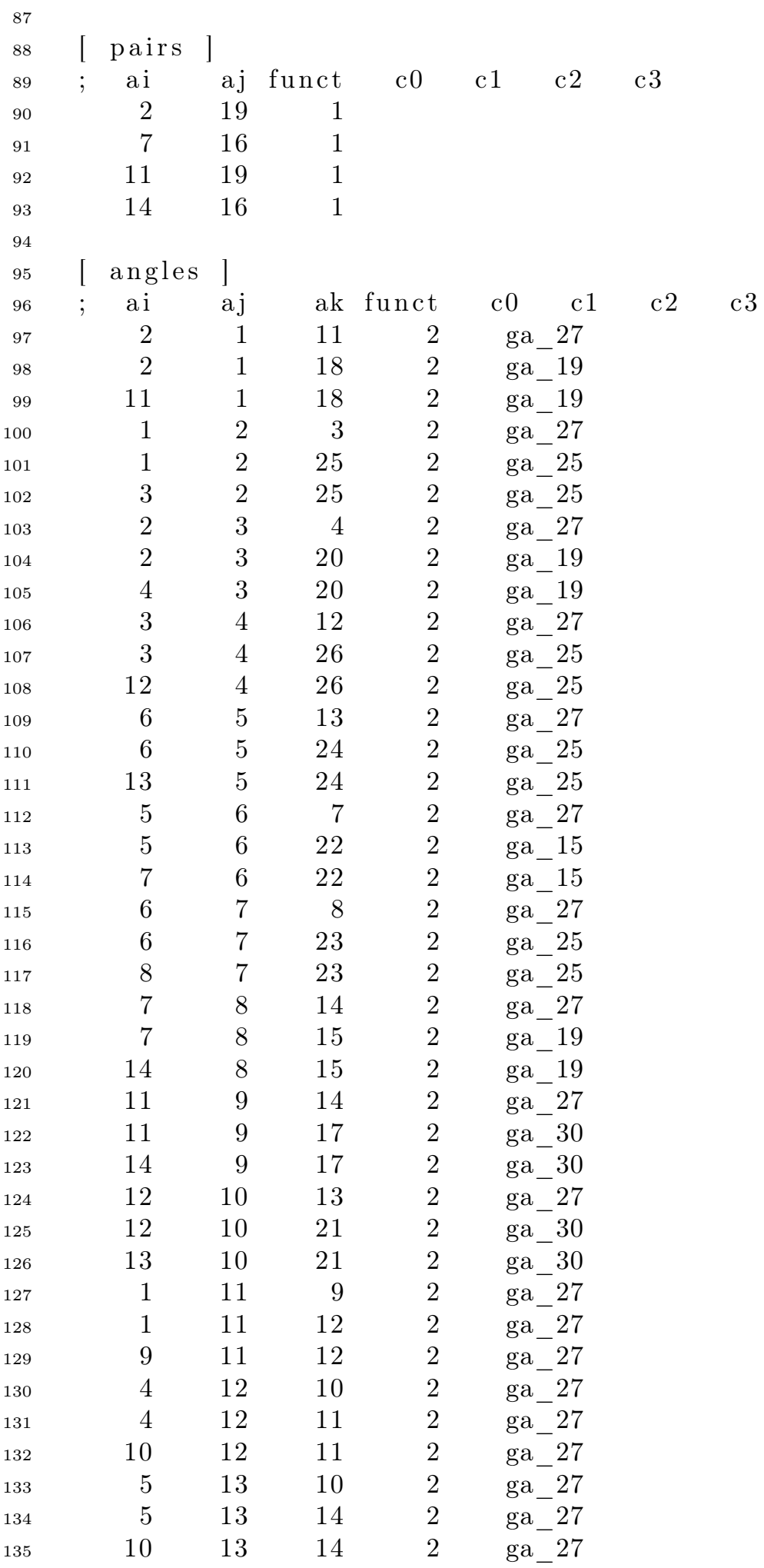




$\begin{array}{lrrrll}136 & 8 & 14 & 9 & 2 & \text { ga_27 } \\ 137 & 8 & 14 & 13 & 2 & \text { ga_27 } \\ 138 & 9 & 14 & 13 & 2 & \text { ga_27 } \\ 139 & 8 & 15 & 16 & 2 & \text { ga_12 } \\ 140 & 1 & 18 & 19 & 2 & \text { ga_12 }\end{array}$

$142 \quad$ [ dihedrals ]

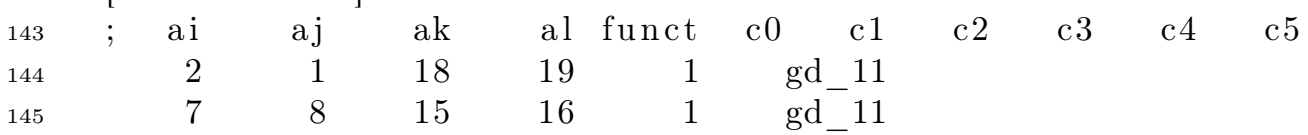

146 [ dihedrals ]

$148 ;$ ai $\quad$ aj $\quad$ ak al funct $c 0$ c1 12 c2 3

$149 \quad \begin{array}{llllll}1 & 18 & 11 & 2 & 2 & \text { gi } 1\end{array}$

$\begin{array}{lllllll}150 & 1 & 25 & 3 & 2 & 2 & \mathrm{gi}-1\end{array}$

$\begin{array}{lllllll}151 & 1 & 2 & 3 & 4 & 2 & \text { gi_ } 1\end{array}$

$\begin{array}{lllllll}152 & 1 & 11 & 12 & 4 & 2 & \text { gi_- } 1\end{array}$

$\begin{array}{lllllll}153 & 2 & 1 & 11 & 12 & 2 & \text { gi }-1\end{array}$

$\begin{array}{lllllll}154 & 2 & 3 & 4 & 12 & 2 & \text { gi_ } 1\end{array}$

$\begin{array}{lllllll}155 & 3 & 20 & 2 & 4 & 2 & \text { gi_- } 1\end{array}$

$\begin{array}{lllllll}156 & 3 & 26 & 12 & 4 & 2 & \text { gi }-1\end{array}$

$\begin{array}{lllllll}157 & 3 & 2 & 1 & 11 & 2 & \text { gi_ } 1\end{array}$

$\begin{array}{lllllll}158 & 3 & 4 & 12 & 11 & 2 & \text { gi_- } 1\end{array}$

$\begin{array}{lllllll}159 & 5 & 22 & 7 & 6 & 2 & \text { gi_ } 1\end{array}$

$\begin{array}{lllllll}160 & 5 & 6 & 7 & 8 & 2 & \text { gi_ } 1\end{array}$

$\begin{array}{rrrrrrr}161 & 5 & 13 & 14 & 8 & 2 & \text { gi }-1\end{array}$

$\begin{array}{rrrrrrr}162 & 5 & 6 & 24 & 13 & 2 & \text { gi_ } 1\end{array}$

\begin{tabular}{rrrrrrr}
6 & 23 & 8 & 7 & 2 & gi 1 \\
\hline 6 & 6 & 5 & 13 & 14 & 2 & gi 1
\end{tabular}

$\begin{array}{rrrrrrr}64 & 6 & 13 & 14 & 2 & \text { gi } 1 \\ 165 & 6 & 7 & 8 & 14 & 2 & \text { gi } 1\end{array}$

$\begin{array}{lllllll}165 & 6 & 7 & 8 & 14 & 2 & \mathrm{gi}-1 \\ 166 & 7 & 6 & 5 & 13 & 2 & \text { gi }-1\end{array}$

$\begin{array}{lllllll}166 & 7 & 8 & 14 & 13 & 2 & \text { gi } 1\end{array}$

$\begin{array}{lllrlll}168 & 8 & 15 & 7 & 14 & 2 & \mathrm{gi}_{-}{ }^{-1}\end{array}$

$\begin{array}{lllllll}169 & 9 & 11 & 12 & 10 & 2 & \text { gi } 1\end{array}$

$\begin{array}{lllllll}170 & 9 & 14 & 13 & 10 & 2 & \text { gi_ } 1\end{array}$

$\begin{array}{lllllll}171 & 9 & 17 & 14 & 11 & 2 & \text { gi_1 }\end{array}$

$\begin{array}{lllllll}172 & 10 & 21 & 12 & 13 & 2 & \text { gi_- } 1\end{array}$

$\begin{array}{lllllll}173 & 11 & 1 & 9 & 12 & 2 & \text { gi_ } 1\end{array}$

$\begin{array}{lllllll}174 & 11 & 4 & 10 & 12 & 2 & \mathrm{gi}_{-}{ }^{-1}\end{array}$

$\begin{array}{rrrrrrr}175 & 11 & 9 & 14 & 13 & 2 & \text { gi_ } 1\end{array}$

$\begin{array}{lllllll}176 & 11 & 12 & 10 & 13 & 2 & \text { gi_1 }\end{array}$

$\begin{array}{lllllll}177 & 12 & 10 & 13 & 14 & 2 & \text { gi_ } 1\end{array}$

$\begin{array}{lllllll}178 & 12 & 11 & 9 & 14 & 2 & \text { gi } 1\end{array}$

$\begin{array}{rrrrrrl}179 & 13 & 5 & 10 & 14 & 2 & \text { gi } 1 \\ 180 & 13 & 8 & 9 & 14 & 2 & \text { gi } 1\end{array}$

181 ; Include Position restraint file

$183 \quad \#$ ifdef POSRES

184 \#include "posre.itp" 


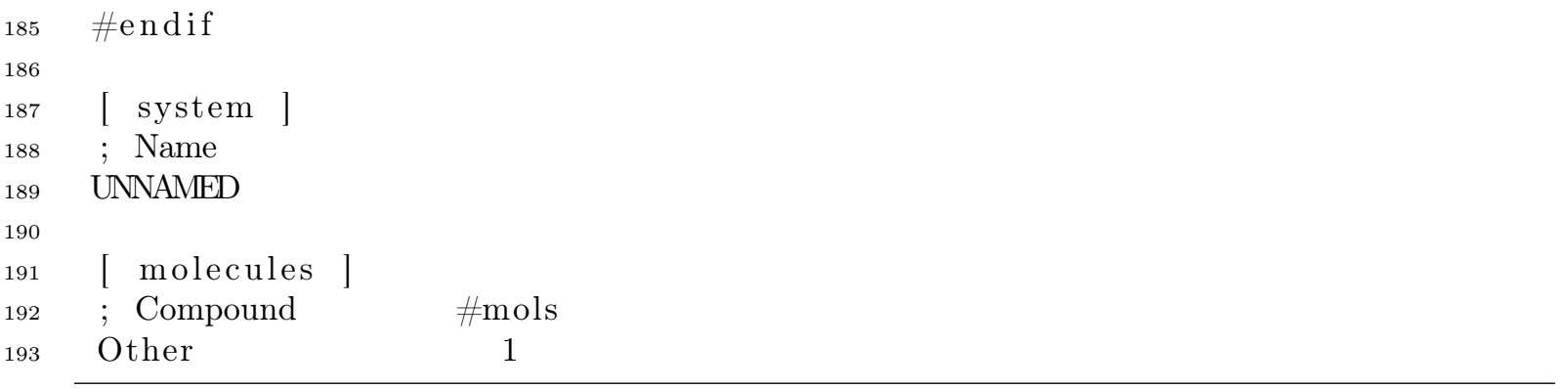

\section{B.6 Arquivo DMPC.top}

\begin{tabular}{|c|c|c|c|c|c|c|c|c|c|}
\hline \multicolumn{10}{|c|}{ Parameters for DMPC (1,2-dimyristoyl-sn-glycero 3 -phosphocholine) } \\
\hline \multirow{2}{*}{\multicolumn{10}{|c|}{$\begin{array}{l}\text { To be used in conjunction with the GROMOS } 54 \text { a } 7 \text { forcefield files. } \\
\text { Please cite the following references when using this topology: }\end{array}$}} \\
\hline & & & & & & & & & \\
\hline \multicolumn{10}{|c|}{$\begin{array}{l}\text { Poger D, van Gunsteren WF \& Mark AE (2010) J. Comput. Chem. 31(6), } \\
1117-1125\end{array}$} \\
\hline \multicolumn{4}{|c|}{$\begin{array}{l}\text { Poger D \& Mark AE (2010) } \\
\text { moleculetype ] }\end{array}$} & \multicolumn{4}{|c|}{ J. Chem. Theory Comput. 6(1) } & \multirow{2}{*}{\multicolumn{2}{|c|}{$325-336$}} \\
\hline Nam & nre & $\mathrm{xcl}$ & & & & & & & \\
\hline $\mathbb{P C}$ & 3 & & & & & & & & \\
\hline \multicolumn{10}{|c|}{ atoms ] } \\
\hline $\mathrm{nr}$ & type & resnr & resid & atom & $\operatorname{cgnr}$ & charge & mass & total & charge \\
\hline 1 & CH3p & 1 & DMPC & $\mathrm{CN} 1$ & 1 & 0.400 & 15.0350 & & \\
\hline 2 & CH3p & 1 & DMPC & CN3 & 1 & 0.400 & 15.0350 & & \\
\hline 3 & CH3p & 1 & DMPC & $\mathrm{CN} 2$ & 1 & 0.400 & 15.0350 & & \\
\hline 4 & NL & 1 & DMPC & NTM & 1 & -0.500 & 14.0067 & & \\
\hline 5 & $\mathrm{CH} 2$ & 1 & DMPC & $\mathrm{CA}$ & 1 & 0.300 & 14.0270 & ; & 1.000 \\
\hline 6 & $\mathrm{CH} 2$ & 1 & $\mathrm{DMPC}$ & $\mathrm{CB}$ & 2 & 0.400 & 14.0270 & & \\
\hline 7 & OA & 1 & DMPC & $\mathrm{OA}$ & 2 & -0.800 & 15.9994 & & \\
\hline 8 & $\mathrm{P}$ & 1 & DMPC & $\mathrm{P}$ & 2 & 1.700 & 30.9738 & & \\
\hline 9 & $\mathrm{OM}$ & 1 & $\mathrm{DMPC}$ & $\mathrm{OC}$ & 2 & -0.800 & 15.9994 & & \\
\hline 10 & $\mathrm{OM}$ & 1 & DMPC & $\mathrm{OB}$ & 2 & -0.800 & 15.9994 & & \\
\hline 11 & $\mathrm{OA}$ & 1 & DMPC & OD & 2 & -0.700 & 15.9994 & ; & -1.000 \\
\hline 12 & $\mathrm{CH} 2$ & 1 & $\mathrm{DMPC}$ & $\mathrm{CC}$ & 3 & 0.400 & 14.0270 & & \\
\hline 13 & CH1 & 1 & DMPC & CD & 3 & 0.300 & 13.0190 & & \\
\hline 14 & $\mathrm{OE}$ & 1 & DMPC & $\mathrm{OE}$ & 3 & -0.700 & 15.9994 & & \\
\hline 15 & $\mathrm{C}$ & 1 & DMPC & $\mathrm{C} 1 \mathrm{~A}$ & 3 & 0.700 & 12.0110 & & \\
\hline 16 & $\mathrm{O}$ & 1 & DMPC & $\mathrm{OF}$ & 3 & -0.700 & 15.9994 & ; & 0.000 \\
\hline 17 & $\mathrm{CH} 2$ & 1 & DMPC & $\mathrm{C} 1 \mathrm{~B}$ & 4 & 0.000 & 14.0270 & ; & 0.000 \\
\hline 18 & $\mathrm{CH} 2$ & 1 & $\mathrm{DMPC}$ & $\mathrm{C} 1 \mathrm{C}$ & 5 & 0.000 & 14.0270 & ; & 0.000 \\
\hline 19 & $\mathrm{CH} 2$ & 1 & DMPC & C1D & 6 & 0.000 & 14.0270 & ; & 0.000 \\
\hline 20 & $\mathrm{CH} 2$ & 1 & DMPC & $\mathrm{C} 1 \mathrm{E}$ & 7 & 0.000 & 14.0270 & ; & 0.000 \\
\hline 21 & $\mathrm{CH} 2$ & 1 & $\mathrm{DMPC}$ & $\mathrm{C} 1 \mathrm{~F}$ & 8 & 0.000 & 14.0270 & ; & 0.000 \\
\hline 22 & $\mathrm{CH} 2$ & 1 & DMPC & $\mathrm{C} 1 \mathrm{G}$ & 9 & 0.000 & 14.0270 & ; & 0.000 \\
\hline 23 & $\mathrm{CH} 2$ & 1 & DMPC & $\mathrm{C} 1 \mathrm{H}$ & 10 & 0.000 & 14.0270 & ; & 0.000 \\
\hline
\end{tabular}




\begin{tabular}{|c|c|c|c|c|c|c|c|c|c|c|}
\hline 35 & 24 & $\mathrm{CH} 2$ & 1 & DMPC & C1I & 11 & 0.000 & 14.0270 & ; & 0.000 \\
\hline 36 & 25 & $\mathrm{CH} 2$ & 1 & DMPC & $\mathrm{C} 1 \mathrm{~J}$ & 12 & 0.000 & 14.0270 & ; & 0.000 \\
\hline 37 & 26 & $\mathrm{CH} 2$ & 1 & DMPC & $\mathrm{C} 1 \mathrm{~K}$ & 13 & 0.000 & 14.0270 & , & 0.000 \\
\hline 38 & 27 & $\mathrm{CH} 2$ & 1 & DMPC & C1L & 14 & 0.000 & 14.0270 & ; & 0.000 \\
\hline 39 & 28 & $\mathrm{CH} 2$ & 1 & DMPC & $\mathrm{C} 1 \mathrm{M}$ & 15 & 0.000 & 14.0270 & ; & 0.000 \\
\hline 40 & 29 & CH3 & 1 & DMPC & $\mathrm{C} 1 \mathrm{~N}$ & 16 & 0.000 & 15.0350 & , & 0.000 \\
\hline 41 & 30 & $\mathrm{CH} 2$ & 1 & DMPC & $\mathrm{CE}$ & 17 & 0.500 & 14.0270 & & \\
\hline 42 & 31 & $\mathrm{OE}$ & 1 & DMPC & OG & 17 & -0.700 & 15.9994 & & \\
\hline 43 & 32 & $\mathrm{C}$ & 1 & DMPC & $\mathrm{C} 2 \mathrm{~A}$ & 17 & 0.800 & 12.0110 & & \\
\hline 44 & 33 & $\mathrm{O}$ & 1 & DMPC & $\mathrm{OH}$ & 17 & -0.600 & 15.9994 & ; & 0.000 \\
\hline 45 & 34 & $\mathrm{CH} 2$ & 1 & DMPC & $\mathrm{C} 2 \mathrm{~B}$ & 18 & 0.000 & 14.0270 & ; & 0.000 \\
\hline 46 & 35 & $\mathrm{CH} 2$ & 1 & DMPC & $\mathrm{C} 2 \mathrm{C}$ & 19 & 0.000 & 14.0270 & ; & 0.000 \\
\hline 47 & 36 & $\mathrm{CH} 2$ & 1 & DMPC & $\mathrm{C} 2 \mathrm{D}$ & 20 & 0.000 & 14.0270 & ; & 0.000 \\
\hline 48 & 37 & $\mathrm{CH} 2$ & 1 & DMPC & $\mathrm{C} 2 \mathrm{E}$ & 21 & 0.000 & 14.0270 & ; & 0.000 \\
\hline 49 & 38 & $\mathrm{CH} 2$ & 1 & DMPC & $\mathrm{C} 2 \mathrm{~F}$ & 22 & 0.000 & 14.0270 & ; & 0.000 \\
\hline 50 & 39 & $\mathrm{CH} 2$ & 1 & DMPC & $\mathrm{C} 2 \mathrm{G}$ & 23 & 0.000 & 14.0270 & ; & 0.000 \\
\hline 51 & 40 & $\mathrm{CH} 2$ & 1 & DMPC & $\mathrm{C} 2 \mathrm{H}$ & 24 & 0.000 & 14.0270 & ; & 0.000 \\
\hline 52 & 41 & $\mathrm{CH} 2$ & 1 & DMPC & $\mathrm{C} 2 \mathrm{I}$ & 25 & 0.000 & 14.0270 & ; & 0.000 \\
\hline 53 & 42 & $\mathrm{CH} 2$ & 1 & DMPC & $\mathrm{C} 2 \mathrm{~J}$ & 26 & 0.000 & 14.0270 & ; & 0.000 \\
\hline 54 & 43 & $\mathrm{CH} 2$ & 1 & DMPC & $\mathrm{C} 2 \mathrm{~K}$ & 27 & 0.000 & 14.0270 & ; & 0.000 \\
\hline 55 & 44 & $\mathrm{CH} 2$ & 1 & DMPC & $\mathrm{C} 2 \mathrm{~L}$ & 28 & 0.000 & 14.0270 & ; & 0.000 \\
\hline 56 & 45 & $\mathrm{CH} 2$ & 1 & DMPC & $\mathrm{C} 2 \mathrm{M}$ & 29 & 0.000 & 14.0270 & ; & 0.000 \\
\hline 57 & 46 & CH3 & 1 & DMPC & $\mathrm{C} 2 \mathrm{~N}$ & 30 & 0.000 & 15.0350 & ; & 0.000 \\
\hline
\end{tabular}

58 ; total charge of the molecule: 0.000

[ bonds]

\begin{tabular}{|c|c|c|c|c|c|}
\hline 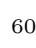 & $\mathrm{ai}$ & $\mathrm{aj}$ & funct & $\mathrm{c} 0$ & $\mathrm{c} 1$ \\
\hline 61 & 1 & 4 & 2 & 0.1470 & $8.7100 \mathrm{e}+06$ \\
\hline 62 & 2 & 4 & 2 & 0.1470 & $8.7100 \mathrm{e}+06$ \\
\hline 63 & 3 & 4 & 2 & 0.1470 & $8.7100 \mathrm{e}+06$ \\
\hline 64 & 4 & 5 & 2 & 0.1470 & $8.7100 \mathrm{e}+06$ \\
\hline 65 & 5 & 6 & 2 & 0.1530 & $7.1500 \mathrm{e}+06$ \\
\hline 66 & 6 & 7 & 2 & 0.1430 & $8.1800 \mathrm{e}+06$ \\
\hline 67 & 7 & 8 & 2 & 0.1610 & $4.8400 \mathrm{e}+06$ \\
\hline 68 & 8 & 9 & 2 & 0.1480 & $8.6000 \mathrm{e}+06$ \\
\hline 69 & 8 & 10 & 2 & 0.1480 & $8.6000 \mathrm{e}+06$ \\
\hline 70 & 8 & 11 & 2 & 0.1610 & $4.8400 \mathrm{e}+06$ \\
\hline 71 & 11 & 12 & 2 & 0.1430 & $8.1800 \mathrm{e}+06$ \\
\hline 72 & 12 & 13 & 2 & 0.1530 & $7.1500 \mathrm{e}+06$ \\
\hline 73 & 13 & 14 & 2 & 0.1430 & $8.1800 \mathrm{e}+06$ \\
\hline 74 & 13 & 30 & 2 & 0.1530 & $7.1500 \mathrm{e}+06$ \\
\hline 75 & 14 & 15 & 2 & 0.1330 & $1.1800 \mathrm{e}+07$ \\
\hline 76 & 15 & 16 & 2 & 0.1230 & $1.6600 \mathrm{e}+07$ \\
\hline 77 & 15 & 17 & 2 & 0.1480 & $7.6400 \mathrm{e}+06$ \\
\hline 78 & 17 & 18 & 2 & 0.1530 & $7.1500 \mathrm{e}+06$ \\
\hline 79 & 18 & 19 & 2 & 0.1530 & $7.1500 \mathrm{e}+06$ \\
\hline 80 & 19 & 20 & 2 & 0.1530 & $7.1500 \mathrm{e}+06$ \\
\hline 81 & 20 & 21 & 2 & 0.1530 & $7.1500 \mathrm{e}+06$ \\
\hline 82 & 21 & 22 & 2 & 0.1530 & $7.1500 \mathrm{e}+06$ \\
\hline 83 & 22 & 23 & 2 & 0.1530 & $7.1500 \mathrm{e}+06$ \\
\hline
\end{tabular}




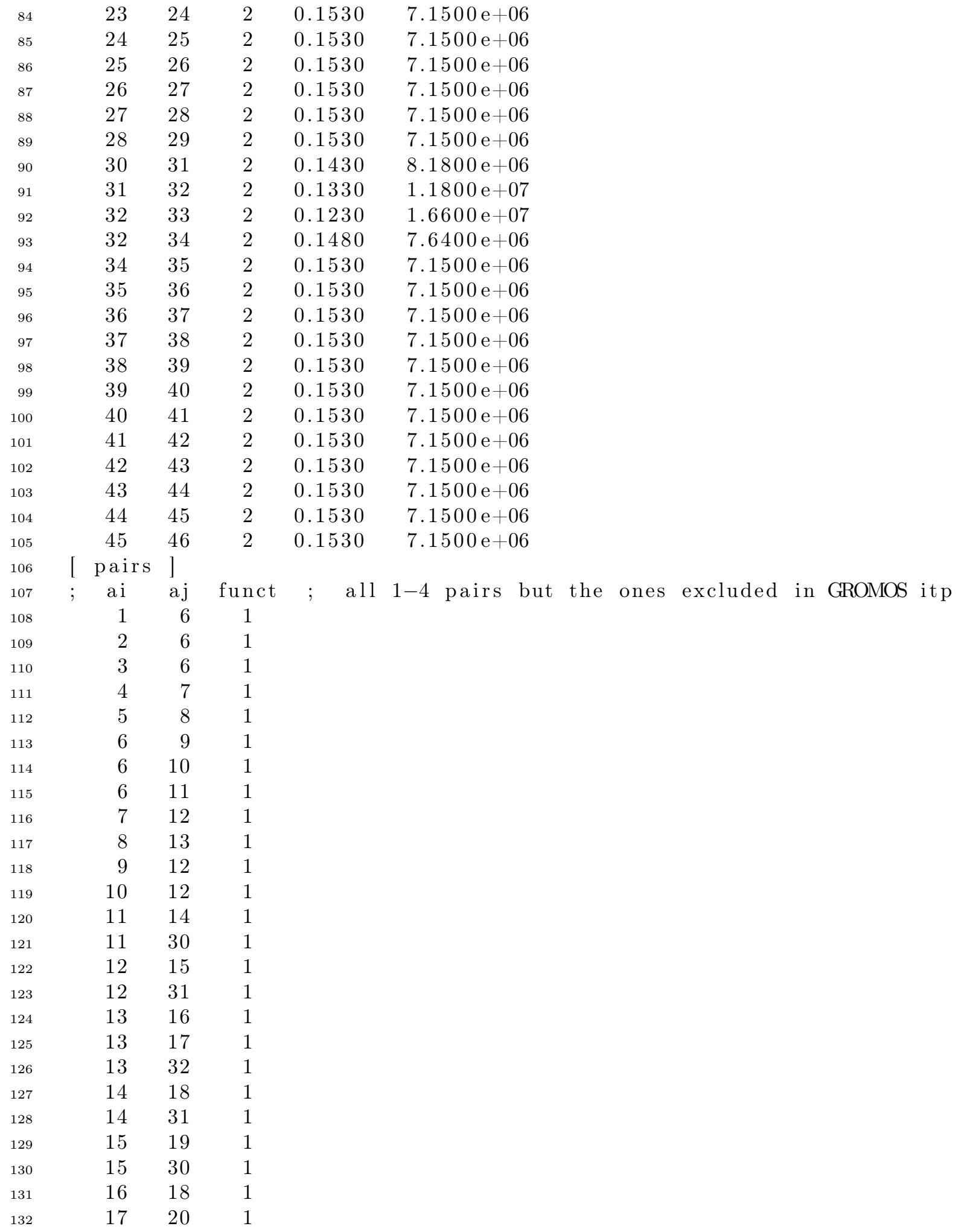




\begin{tabular}{|c|c|c|c|c|c|c|c|}
\hline 133 & & 18 & 21 & 1 & & & \\
\hline 134 & & 19 & 22 & 1 & & & \\
\hline 135 & & 20 & 23 & 1 & & & \\
\hline 136 & & 21 & 24 & 1 & & & \\
\hline 137 & & 22 & 25 & 1 & & & \\
\hline 138 & & 23 & 26 & 1 & & & \\
\hline 139 & & 24 & 27 & 1 & & & \\
\hline 140 & & 25 & 28 & 1 & & & \\
\hline 141 & & 26 & 29 & 1 & & & \\
\hline 142 & & 30 & 33 & 1 & & & \\
\hline 143 & & 30 & 34 & 1 & & & \\
\hline 144 & & 31 & 35 & 1 & & & \\
\hline 145 & & 32 & 36 & 1 & & & \\
\hline 146 & & 33 & 35 & 1 & & & \\
\hline 147 & & 34 & 37 & 1 & & & \\
\hline 148 & & 35 & 38 & 1 & & & \\
\hline 149 & & 36 & 39 & 1 & & & \\
\hline 150 & & 37 & 40 & 1 & & & \\
\hline 151 & & 38 & 41 & 1 & & & \\
\hline 152 & & 39 & 42 & 1 & & & \\
\hline 153 & & 40 & 43 & 1 & & & \\
\hline 154 & & 41 & 44 & 1 & & & \\
\hline 155 & & 42 & 45 & 1 & & & \\
\hline 156 & & 43 & 46 & 1 & & & \\
\hline 157 & [ & ang & ] & & & & \\
\hline 158 & ; & ai & $a j$ & ak & funct & angle & $\mathrm{fc}$ \\
\hline 159 & & 1 & 4 & 2 & 2 & 109.50 & 520.00 \\
\hline 160 & & 1 & 4 & 3 & 2 & 109.50 & 520.00 \\
\hline 161 & & 1 & 4 & 5 & 2 & 109.50 & 520.00 \\
\hline 162 & & 2 & 4 & 3 & 2 & 109.50 & 520.00 \\
\hline 163 & & 2 & 4 & 5 & 2 & 109.50 & 520.00 \\
\hline 164 & & 3 & 4 & 5 & 2 & 109.50 & 520.00 \\
\hline 165 & & 4 & 5 & 6 & 2 & 111.00 & 530.00 \\
\hline 166 & & 5 & 6 & 7 & 2 & 111.00 & 530.00 \\
\hline 167 & & 6 & 7 & 8 & 2 & 120.00 & 530.00 \\
\hline 168 & & 7 & 8 & 9 & 2 & 109.60 & 450.00 \\
\hline 169 & & 7 & 8 & 10 & 2 & 109.60 & 450.00 \\
\hline 170 & & 7 & 8 & 11 & 2 & 103.00 & 420.00 \\
\hline 171 & & 8 & 11 & 12 & 2 & 120.00 & 530.00 \\
\hline 172 & & 9 & 8 & 10 & 2 & 120.00 & 780.00 \\
\hline 173 & & 9 & 8 & 11 & 2 & 109.60 & 450.00 \\
\hline 174 & & 10 & 8 & 11 & 2 & 109.60 & 450.00 \\
\hline 175 & & 11 & 12 & 13 & 2 & 111.00 & 530.00 \\
\hline 176 & & 12 & 13 & 14 & 2 & 109.50 & 520.00 \\
\hline 177 & & 12 & 13 & 30 & 2 & 109.50 & 520.00 \\
\hline 178 & & 13 & 14 & 15 & 2 & 117.00 & 635.00 \\
\hline 179 & & 13 & 30 & 31 & 2 & 111.00 & 530.00 \\
\hline 180 & & 14 & 13 & 30 & 2 & 109.50 & 520.00 \\
\hline 181 & & 14 & 15 & 16 & 2 & 122.00 & 700.00 \\
\hline
\end{tabular}




\begin{tabular}{|c|c|c|c|c|c|c|c|c|c|}
\hline 182 & & 14 & 15 & 17 & 2 & 113. & \multicolumn{2}{|c|}{545.00} & \\
\hline 183 & & 15 & 17 & 18 & 2 & 111. & \multicolumn{2}{|c|}{530.00} & \\
\hline 184 & & 16 & 15 & 17 & 2 & 125. & \multicolumn{2}{|c|}{750.00} & \\
\hline 185 & & 17 & 18 & 19 & 2 & 111. & \multicolumn{2}{|c|}{530.00} & \\
\hline 186 & & 18 & 19 & 20 & 2 & 111. & \multicolumn{2}{|c|}{530.00} & \\
\hline 187 & & 19 & 20 & 21 & 2 & 111. & \multicolumn{2}{|c|}{530.00} & \\
\hline 188 & & 20 & 21 & 22 & 2 & 111. & \multicolumn{2}{|c|}{530.00} & \\
\hline 189 & & 21 & 22 & 23 & 2 & 111. & \multicolumn{2}{|c|}{530.00} & \\
\hline 190 & & 22 & 23 & 24 & 2 & 111. & \multicolumn{2}{|c|}{530.00} & \\
\hline 191 & & 23 & 24 & 25 & 2 & 111. & \multicolumn{2}{|c|}{530.00} & \\
\hline 192 & & 24 & 25 & 26 & 2 & 111. & \multicolumn{2}{|c|}{530.00} & \\
\hline 193 & & 25 & 26 & 27 & 2 & 111. & \multicolumn{2}{|c|}{530.00} & \\
\hline 194 & & 26 & 27 & 28 & 2 & 111. & \multicolumn{2}{|c|}{530.00} & \\
\hline 195 & & 27 & 28 & 29 & 2 & 111. & \multicolumn{2}{|c|}{530.00} & \\
\hline 196 & & 30 & 31 & 32 & 2 & 117. & \multicolumn{2}{|c|}{635.00} & \\
\hline 197 & & 31 & 32 & 33 & 2 & 122. & \multicolumn{2}{|c|}{700.00} & \\
\hline 198 & & 31 & 32 & 34 & 2 & 113. & \multicolumn{2}{|c|}{545.00} & \\
\hline 199 & & 32 & 34 & 35 & 2 & 111. & \multicolumn{2}{|c|}{530.00} & \\
\hline 200 & & 33 & 32 & 34 & 2 & 125. & \multicolumn{2}{|c|}{750.00} & \\
\hline 201 & & 34 & 35 & 36 & 2 & 111. & \multicolumn{2}{|c|}{530.00} & \\
\hline 202 & & 35 & 36 & 37 & 2 & 111. & 530 & & \\
\hline 203 & & 36 & 37 & 38 & 2 & 111. & 530 & & \\
\hline 204 & & 37 & 38 & 39 & 2 & 111. & 530 & & \\
\hline 205 & & 38 & 39 & 40 & 2 & 111. & 530 & & \\
\hline 206 & & 39 & 40 & 41 & 2 & 111. & 530 & & \\
\hline 207 & & 40 & 41 & 42 & 2 & 111. & 530 & & \\
\hline 208 & & 41 & 42 & 43 & 2 & 111. & 531 & & \\
\hline 209 & & 42 & 43 & 44 & 2 & 111. & 531 & & \\
\hline 210 & & 43 & 44 & 45 & 2 & 111. & 531 & & \\
\hline 211 & & 44 & 45 & 46 & 2 & 111. & 531 & & \\
\hline 212 & & dihe & rals & & & & & & \\
\hline 213 & ; & GRON & $\mathrm{S}$ im & roper & dil & drals & & & \\
\hline 214 & ; & $\mathrm{ai}$ & $\mathrm{aj}$ & $\mathrm{ak}$ & al & funct & angle & $\mathrm{fc}$ & \\
\hline 215 & & 13 & 14 & 30 & 12 & 2 & 35.26 & 334.72 & \\
\hline 216 & & 15 & 14 & 16 & 17 & 2 & 0.00 & 167.36 & \\
\hline 217 & & 32 & 31 & 33 & 34 & 2 & 0.00 & 167.36 & \\
\hline 218 & [ & dihe & rals & & & & & & \\
\hline 219 & ; & $\mathrm{ai}$ & $\mathrm{aj}$ & ak & al & funct & ph0 & $\mathrm{cp}$ & mult \\
\hline 220 & & 1 & 4 & 5 & 6 & 1 & 0.00 & 3.77 & 3 \\
\hline 221 & & 2 & 4 & 5 & 6 & 1 & 0.00 & 3.77 & 3 \\
\hline 222 & & 3 & 4 & 5 & 6 & 1 & 0.00 & 3.77 & 3 \\
\hline 223 & & 4 & 5 & 6 & 7 & 1 & 180.00 & 5.86 & 1 \\
\hline 224 & & 4 & 5 & 6 & 7 & 1 & 0.00 & 8.62 & 3 \\
\hline 225 & & 5 & 6 & 7 & 8 & 1 & 0.00 & 3.77 & 3 \\
\hline 226 & & 6 & 7 & 8 & 11 & 1 & 0.00 & 5.09 & 2 \\
\hline 227 & & 6 & 7 & 8 & 11 & 1 & 0.00 & 3.19 & 3 \\
\hline 228 & & 7 & 8 & 11 & 12 & 1 & 0.00 & 5.09 & 2 \\
\hline 229 & & 7 & 8 & 11 & 12 & 1 & 0.00 & 3.19 & 3 \\
\hline 230 & & 8 & 11 & 12 & 13 & 1 & 0.00 & 3.77 & 3 \\
\hline
\end{tabular}




\begin{tabular}{|c|c|c|c|c|c|c|c|c|}
\hline 231 & 11 & 12 & 13 & 30 & 1 & 0.00 & 5.92 & 3 \\
\hline 232 & 12 & 13 & 14 & 15 & 1 & 0.00 & 3.77 & 3 \\
\hline 233 & 12 & 13 & 30 & 31 & 1 & 0.00 & 5.92 & 3 \\
\hline 234 & 13 & 14 & 15 & 17 & 1 & 180.00 & 24.00 & 2 \\
\hline 235 & 13 & 30 & 31 & 32 & 1 & 0.00 & 3.77 & 3 \\
\hline 236 & 14 & 15 & 17 & 18 & 1 & 0.00 & 1.00 & 6 \\
\hline 237 & 15 & 17 & 18 & 19 & 1 & 0.00 & 5.92 & 3 \\
\hline 238 & 17 & 18 & 19 & 20 & 1 & 0.00 & 5.92 & 3 \\
\hline 239 & 18 & 19 & 20 & 21 & 1 & 0.00 & 5.92 & 3 \\
\hline 240 & 19 & 20 & 21 & 22 & 1 & 0.00 & 5.92 & 3 \\
\hline 241 & 20 & 21 & 22 & 23 & 1 & 0.00 & 5.92 & 3 \\
\hline 242 & 21 & 22 & 23 & 24 & 1 & 0.00 & 5.92 & 3 \\
\hline 243 & 22 & 23 & 24 & 25 & 1 & 0.00 & 5.92 & 3 \\
\hline 244 & 23 & 24 & 25 & 26 & 1 & 0.00 & 5.92 & 3 \\
\hline 245 & 24 & 25 & 26 & 27 & 1 & 0.00 & 5.92 & 3 \\
\hline 246 & 25 & 26 & 27 & 28 & 1 & 0.00 & 5.92 & 3 \\
\hline 247 & 26 & 27 & 28 & 29 & 1 & 0.00 & 5.92 & 3 \\
\hline 248 & 30 & 31 & 32 & 34 & 1 & 180.00 & 24.00 & 2 \\
\hline 249 & 31 & 32 & 34 & 35 & 1 & 0.00 & 1.00 & 6 \\
\hline 250 & 32 & 34 & 35 & 36 & 1 & 0.00 & 5.92 & 3 \\
\hline 251 & 34 & 35 & 36 & 37 & 1 & 0.00 & 5.92 & 3 \\
\hline 252 & 35 & 36 & 37 & 38 & 1 & 0.00 & 5.92 & 3 \\
\hline 253 & 36 & 37 & 38 & 39 & 1 & 0.00 & 5.92 & 3 \\
\hline 254 & 37 & 38 & 39 & 40 & 1 & 0.00 & 5.92 & 3 \\
\hline 255 & 38 & 39 & 40 & 41 & 1 & 0.00 & 5.92 & 3 \\
\hline 256 & 39 & 40 & 41 & 42 & 1 & 0.00 & 5.92 & 3 \\
\hline 257 & 40 & 41 & 42 & 43 & 1 & 0.00 & 5.92 & 3 \\
\hline 258 & 41 & 42 & 43 & 44 & 1 & 0.00 & 5.92 & 3 \\
\hline 259 & 42 & 43 & 44 & 45 & 1 & 0.00 & 5.92 & 3 \\
\hline 260 & 43 & 44 & 45 & 46 & 1 & 0.00 & 5.92 & 3 \\
\hline
\end{tabular}


302Apêndice . Arquivos de Topologia das espécies da Emodina e da molécula de DMPC 


\section{Apêndice C}

\section{Realizações no Doutorado}

\section{Disciplinas cursadas:}

- Física Atômica e Molecular.

- Espectroscopia de Fluorescência: Fundamentos e Aplicações em Biomoléculas.

- Métodos Teóricos Avançados para o Estudo de Sistemas Moleculares.

- Introdução às Técnicas de Espalhamento de Nêutrons e Raios-X a Baixos Ângulos.

\section{Monitorias:}

- Monitoria bolsista do Laboratório de Física para Engenharia II FEP2198, carga horária, 6 horas semanais no $2^{\circ}$ semestre dos anos 2009, 2010, 2011 e 2012. Nessa monitoria, ministrei aulas de laboratório de Física, sob supervisão dos Profs. Drs. Dirceu Pereira e Pedro Kiyohara, onde participei de elaboração do programa, avaliação, preparo de material didático de apoio.

- Monitoria bolsista de Física para Biologia, carga horária, 6 horas semanais no $1^{\mathrm{o}}$ semestre de 2010. Nessa monitoria, minitrei aulas de Física Básica para Ciências Biológicas I, sob supervisão da Profa. Dra. Marilia J. Caldas 
e Prof. Dr. Airton Deppman onde participei de elaboração do programa, avaliação, preparo de material didático de apoio.

- Monitoria PAE de Física II para IO - 4300112, carga horária, 6 horas semanais no $1^{\circ}$ semestre de 2011, sob supervisão da Profa. Dra. Kaline Coutinho.

\section{Artigo publicado dentro do doutorado:}

- A. R. da Cunha, E. L. Duarte, M. T. Lamy e K. Coutinho. Protonation/deprotonation process of Emodin in aqueous solution and $p K_{a}$ determination: $U V /$ Visible spectrophotometric titration and quantum/molecular mechanics calculations. Chemical Physics, 2014.

\section{Artigos em processo de revisão:}

- A. R. da Cunha, J. M. Riveros, S. Canuto e K. Coutinho. Defining the $p H^{*}$ scale in methanol: Determination of accurate values the solvation free energies of $\mathrm{CH}_{3} \mathrm{O}^{+}$and $\mathrm{CH}_{3} \mathrm{O}^{-}$in methanol. São Paulo, 2014.

- A. R. da Cunha, E. L. Duarte, M. T. Lamy, H. Stassen e K. Coutinho. The Location of Emodin in a Lipid Bilayer of DMPC as Revealed by Experimental and Theoretical Studies. São Paulo, 2014.

\section{Artigo publicado fora do doutorado:}

- L. F. da Silva, R. N. C. Filho, A. R. da Cunha, A. M. Filho, M. Serva, U. L. Fulco, E. L. Albuqueque. Critical properties of the SIS model dynamics on the Apollonian network. Journal of Statistical Mechanics. 2013, v (2013).

\section{Trabalhos apresentados em congressos:}

- A. R. da Cunha, M. T. Lamy e K. Coutinho. Estudo do Caráter Hidro/Lipofílico da Molécula Emodina (Solvatação Diferencial e Espectro UV-Vis.) XV Simpósio Brasileiro de Química teórica, Poços de Caldas, MG, (2009). 
- A. R. da Cunha, E. L. Duarte, M. T. Lamy e K. Coutinho. Theoretical and Esperimental Studies of Emodin in Solution. XXXIII Encontro Nacional de Física da matéria Condensada, Águas de Lindóia, SP, (2010).

- A. R. da Cunha, E. L. Duarte, M. T. Lamy e K. Coutinho. Experimental and Theoretical UV-Vis Spectra of Emodin. $3^{\text {rd }}$. International Workshop on Spectroscopy for Biology, Maresias, SP, (2010).

- A. R. da Cunha, E. L. Duarte, M. T. Lamy e K. Coutinho. Experimental and Theoretical Studies of Deprotonation Process $f$ the Emodin in Aqueous Solution. Encontro de Física 2011, Foz do Iguaçu, PR, (2011).

- A. R. da Cunha, E. L. Duarte, M. T. Lamy e K. Coutinho. Study of the Solvatochromic shift of the Barbaloin. $7^{\text {th }}$ International Meeting on photodynamics, Maresias, SP, (2012).

- A. R. da Cunha, E. L. Duarte, M. T. Lamy e K. Coutinho. Experimental and Theoretical Studies of Emodin in Lipid Bilayer. Workshop on Biomolecular Theory-Experiment Interplay, São Paulo, SP, (2013).

- A. R. da Cunha, E. L. Duarte, M. T. Lamy e K. Coutinho. Experimental and Theoretical Investigations of Emodin in a DMPC Bilayer. XXXVII Encontro Nacional de Física da Matéria Condensada, Costa do Sauípe, BA, (2014).

\section{Seminários apresentados:}

- Problems with Some Current Water Models for Close Pair Interactions That are not Near the Minimum Energy. No Departamento de Física Geral do Instituto de Física da USP, São Paulo, SP (2010).

- Aspectos Termoquímicos do Processo de Desprotonação da Molécula Emodina: uma visão experimental e teórica. No Departamento de Física Geral do Instituto de Física da USP, São Paulo, SP (2011). 
- Prévia Qualificação: Estudos Teórico e Experimental de Propriedades Estruturais e Eletrônicas da Molécula Emodina em Meio Solvente e em Bicamadas Lipídicas. No Departamento de Física Geral do Instituto de Física da USP, São Paulo, SP (2012).

- Areas of Lipids in Membranes, in School of Chemistry and Molecular Biosciences faculty of Science, University of Queensland, Brisbane, Australia, (2013).

- Effect of Carbon layers on lipid Membranes, in School of Chemistry and Molecular Biosciences faculty of Science, University of Queensland, Brisbane, Australia, (2013).

- The Location of Emodin in a Lipid Bilayer of DMPC as Revealed by Experimental and Theoretical Studies, Workshop: Prospects for collaborative work between the Department of Chemistry, University of Copenhagen and the Group of Molecular PhysicsModeling, Institute of Physics, University of São Paulo, Institute of Physics, University of São Paulo and University of Copenhagen, Institute of Physics, University of São Paulo, (2014).

\section{Estágio (Doutorado Sanduíche):}

- No período de 15/01/2013 a 22/07/2013 fiquei afastado do Instituto de Física da USP, devido meu estágio de doutorado sanduíche na Universidade de Queensland, Brisbane, QLD, Austrália, fomentado pelo $\mathrm{CNPq}\left(\mathrm{N}^{\circ}\right.$ processo 236669/2012-5) dentro do programa Ciência Sem Fronteiras. Nesse estágio, trabalhei no projeto de doutorado sanduíche "Estudos de Propriedades Estruturais e Eletrônicas da Emodina em Bicamadas Lipídicas" supervisionado pelo Prof. Alan E. Mark, especialista em simulações computacionais com o método de Dinâmica molecular de bicamadas lipídicas.

\section{Texto do item 3 deste apêndice:}




\title{
Protonation/deprotonation process of Emodin in aqueous solution and $p K_{a}$ determination: $\mathrm{UV} /$ Visible spectrophotometric titration and quantum/molecular mechanics calculations
}

\author{
Antonio R. da Cunha, Evandro L. Duarte, M. Teresa Lamy, Kaline Coutinho* \\ Instituto de Física, Universidade de São Paulo, SP, Brazil
}

\section{A R T I C L E I N F O}

\section{Article history:}

Received 13 February 2014

In final form 11 June 2014

Available online 24 June 2014

\section{Keywords:}

Protonation/deprotonation process

Acidity constant

Deprotonation free energy

Theoretical calculation

Experimental measurement

UV/Visible spectrophotometric titration

curves

\begin{abstract}
A B S T R A C T
We combined theoretical and experimental studies to elucidate the important deprotonation process of Emodin in water. We used the UV/Visible spectrophotometric titration curves to obtain its $p K_{a}$ values, $p K_{a 1}=8.0 \pm 0.1$ and $p K_{a 2}=10.9 \pm 0.2$. Additionally, we obtained the $p K_{a}$ values of Emodin in the water-methanol mixture $(1: 3 \mathrm{v} / \mathrm{v})$. We give a new interpretation of the experimental data, obtaining apparent $p K_{a 1}=6.2 \pm 0.1, p K_{a 2}=8.3 \pm 0.1$ and $p K_{a 3}>12.7$.

Performing quantum mechanics calculations for all possible deprotonation sites and tautomeric isomers of Emodin in vacuum and in water, we identified the sites of the first and second deprotonation. We calculated the standard deprotonation free energy of Emodin in water and the $p K_{a 1}$, using an explicit model of the solvent, with Free Energy Perturbation theory in Monte Carlo simulations obtaining, $\Delta G_{a q}=12.1 \pm 1.4 \mathrm{kcal} / \mathrm{mol}$ and $p K_{a 1}=8.7 \pm 0.9$. With the polarizable continuum model for the solvent, we obtained $\Delta G_{a q}=11.6 \pm 1.0 \mathrm{kcal} / \mathrm{mol}$ and $p K_{a 1}=8.3 \pm 0.7$. Both solvent models gave theoretical results in very good agreement with the experimental values.
\end{abstract}

(ㄷ) 2014 Elsevier B.V. All rights reserved.

\section{Introduction}

Emodin (1,3,8-trihydroxy-6-methyl-9,10-anthraquinone, Fig. 1) is one of the most abundant anthraquinone derivatives found in nature [1]. It is the active principle of herbal medicines deriving from Polygonaceae, Rhamnaceae and Cassieae [2]. This anthraquinone is known to have biological activity, such as anti-bacterial [3-5], antiviral [6,7], anti-inflammatory [8,9], anti-cancer activities [10-12] and virucidal agent [2].

The UV/Visible spectrum of the Emodin has been used to study its interaction with the biological environment, like DNA $[13,14]$ and human serum albumin (HSA) [15], and also as a spectrophotometric reagent for detection of various metal ions [16]. Emodin is a yellow amorphous solid, insoluble in water at acidic $p H$, but red and soluble in water at alkaline $p H$. In acidic aqueous solution and in common organic solvents, there is a broad UV/Visible absorption band between 350 and $500 \mathrm{~nm}$ in the Emodin spectrum with a $\lambda_{\max }$ around $440 \mathrm{~nm}$ that is responsible for the yellow color of these solutions. In alkaline solutions, this broad band is red shifted to $450-600 \mathrm{~nm}$ with a $\lambda_{\max }$ varying between 520 and

\footnotetext{
* Corresponding author. Tel.: +55 1130916745.

E-mail addresses: antcunha@if.usp.br (A.R. da Cunha), elduarte@if.usp.br (E.L. Duarte), mtlamy@if.usp.br (M.T. Lamy),kaline@if.usp.br (K. Coutinho).
}

$555 \mathrm{~nm}$ depending on solvent and yielding a red color to these solutions. The UV/Visible absorption spectra and the first band $\lambda_{\max }$ of Emodin in several solvents in acidic and alkaline $p H$ are presented in the Supplementary Material. It is known that this noticeable change in color of Emodin in solution with different $p H$ is due to a deprotonation process [16]. The neutral form of the Emodin $(\mathrm{EMH})$ is yellow and the anionic/deprotonated form $\left(\mathrm{EM}^{-}\right)$is red. Based on the potentiometric titration of the Emodin in a methanol-water mixture, Pal and Jana [16] established the one-proton dissociation equilibrium in the range $p H$ 2-10 and determined an apparent $p K_{a 1}$ of 7.2 in this mixture. They also suggested a stepwise dissociation of three protons: first in position 3 (3-oxido-6-methyl-1,8-dihydroxy-9,10-anthraquinone), second in position 8 (3,8-oxido-6-methyl-1-hydroxy-9,10-anthraquinone) and third in position 1 (1,3,8-oxido-6-methyl-9,10-anthraquinone). An experimental and theoretical investigation of the electronic transitions of Emodin and its conjugated base with deprotonation at position 3 in ethanol has been published [17]. They used synchrotron linear dichroism spectroscopy and quantum mechanics calculations with Density Functional Theory (TD-B3LYP/ $6-31+G(d, p))$ to characterize the absorption spectrum of Emodin. In their calculation, the solvent was included using the polarizable continuum model (PCM) and one additional explicit solvent molecule hydrogen bonded to the deprotonated oxygen of Emodin. 


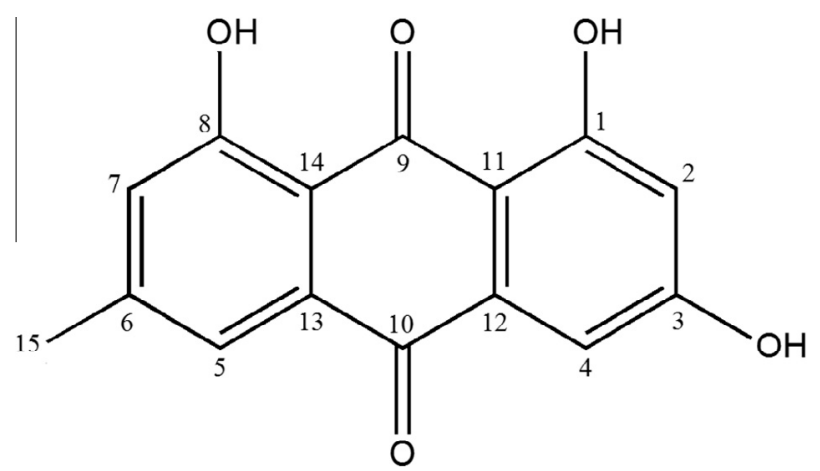

Fig. 1. Chemical structure and atomic numbering of Emodin in its neutral form (EMH).

The protonation/deprotonation process of a pharmacophore is a topic of large interest in physics, chemistry and pharmaceutical industry, because it can change the pharmacological activity of a compound $[18,19]$. Frequently, a well-defined acidity constant $\left(p K_{a}\right)$ describes the chemical reactivity of molecules [20]. Hence, the determination of the value of the $p K_{a}$ has been the object of many experimental and theoretical studies. The experimental methods commonly used for the determination of the $p K_{a}$ are: dissolution rate method [21], ionophoretic techniques [22], isotachophoresis [23], conductivity [24], potentiometric titration [25], nuclear magnetic resonance spectroscopy [26], UV/Visible spectrophotometric titration [27], thermodynamics [28], Z-scan technique [29] and capillary electrophoresis [30]. On the other hand, the theoretical works have utilized computer simulations with explicit solvent models and Free Energy Perturbation [31-34], PoissonBoltzmann equation with continuum solvent models [35,36], quantum mechanics calculation associated with continuum solvent models [37-42] and cluster based quantum mechanics calculation [43].

The protonation/deprotonation processes of Emodin in organic solutions were experimentally analyzed, and acidity constants of Emodin were determined in water-methanol [16], water-ethanol [17], water-acetonitrile and acetonitrile [30]. However, to our knowledge, experimental and theoretical studies of the Emodin in aqueous solution have never been reported. This is a non-trivial task, due to the low solubility of the Emodin in acidic aqueous solution [16].

In the present work, we study the protonation/deprotonation process of Emodin in aqueous solution, using experimental and theoretical techniques. With the UV/Visible spectrophotometric titration technique, we determined the $p K_{a}$ of Emodin in water. The solubility difficulty was minimized by titrating the Emodin in aqueous solution from alkaline to acidic $p H$ (from 13.8 to 2.0), and measuring the UV/Visible absorption spectrum immediately after strongly vortexing the sample.

Additionally to the experimental assay, we performed a theoretical study to identify the position of the first deprotonation of Emodin in aqueous solution. The theoretical approach was based in thermodynamic cycles obtained from two different equilibrium reactions, $\mathrm{XH} \Longleftrightarrow \mathrm{X}^{-}+\mathrm{H}^{+}$and $\mathrm{XH}+\mathrm{H}_{2} \mathrm{O} \Longleftrightarrow \mathrm{X}^{-}+\mathrm{H}_{3} \mathrm{O}^{+}$, where the $\mathrm{XH}$ is the molecule of interest and the reactions were investigated in gas phase and in aqueous solution. These thermodynamic cycles were previously used $[39,40,44,45]$ to calculate the deprotonation free energy of the $\mathrm{XH}$ in aqueous solution $\left(\Delta G_{a q}\right)$, and additionally the $p K_{a}$. The values of the $\Delta G_{a q}$ were calculated using an expression, obtained from the thermodynamic cycle, that relates $\Delta G_{a q}$ with the free energy of deprotonation in gas phase $\left(\Delta G_{g}\right)$ and the relative free energies of solvation $\left(\Delta \Delta G_{\text {solv }}\right)$ of the neutral and ionic species involved in the reactions $\left(\Delta G_{a q}=\Delta G_{g}+\Delta \Delta G_{s o l v}\right)$.
The $\Delta G_{g}$ was computed by quantum mechanical calculations, using Density Functional Theory (DFT) and Møller-Plesset second order perturbation theory (MP2). All the possibilities of the first deprotonation form and the tautomeric isomers of the Emodin in gas phase and in aqueous solution were analyzed. We identified that the first deprotonation at position 3 and the second deprotonation at position 8 are the most favored situation. This result is in agreement with the Pal and Jana suggestion [16]. The solvation free energies of each Emodin species, $\Delta G_{\text {solv }}(\mathrm{EMH})$ and $\Delta G_{\text {solv }}\left(\mathrm{EM}^{-}\right)$, were calculated using Monte Carlo (MC) simulations combined with Free Energy Perturbation theory (FEP) and the $\Delta G_{a q}$ values were obtained using the two thermodynamic cycles. Finally, the theoretical value for the $p K_{a 1}$ was obtained and it presents a very good agreement with the experimental data.

\section{Experimental}

\subsection{Materials}

Emodin $\left(\mathrm{C}_{15} \mathrm{H}_{10} \mathrm{O}_{5}\right.$, Fig. 1), Hydrochloric acid $(\mathrm{HCl})$, Sodium hydroxide $(\mathrm{NaOH})$ and Methanol $\left(\mathrm{CH}_{3} \mathrm{OH}\right)$ were purchased from Sigma-Aldrich Co. (St. Louis, MO, USA) and used without further purification. Milli-Q water was used throughout.

\subsection{Sample preparation}

A $10 \mathrm{mM}$ Emodin stock solution was prepared in ethanolmethanol mixture at $4: 1 \mathrm{v} / \mathrm{v}$. Aliquots of this stock solution were separated in glass vials, dried under a stream of $\mathrm{N}_{2}$, and left under reduced pressure for a minimum of two hours, to remove traces of organic solvents. The Emodin film so formed was dissolved in water at two different concentrations, 0.1 and $0.025 \mathrm{mM}$, and in water-methanol mixture $(1: 3 \mathrm{v} / \mathrm{v})$ at concentration of $0.025 \mathrm{mM}$. For each concentration, two different $p H$ samples were prepared at room temperature: an alkaline at $p H \sim 13$, and an acidic at $p H \sim 2$, by the addition of $\mathrm{NaOH}$ and $\mathrm{HCl}$, respectively. In water, at $p H \sim 2$ the Emodin aggregates, and precipitates after a minute, hence the sample had to be strongly vortexed before used.

\subsection{UV/Visible spectrophotometric titration}

Absorbance measurements were performed with a Varian Cary 50 UV/Visible Spectrophotometer, at room temperature. Samples were placed in quartz cuvettes with $10 \mathrm{~mm}$ optical pathway. Absorbance measurements of the Emodin solution samples were performed from alkaline to acidic $p H$ values, by successive addition of small aliquots (around $5 \mu \mathrm{L}$ ) of the Emodin acidic solution $(1: 500 \mathrm{v} / \mathrm{v}$ of $\mathrm{HCl})$. For the two studied concentrations, two independent samples were prepared for each $\mathrm{pH}$ and around $70 \mathrm{UV} / \mathrm{Vis}$ ible spectra were measured in the $p H$ interval, from $\sim 13$ to 2 . The samples were homogenized by strongly vortexing immediately before each measurement and its $p H$ was measured with a Mettler Toledo $\mathrm{pH}$-meter. Therefore, in the case of the water-methanol mixture the $p H$ presented are the apparent $p H$ values.

\subsection{Determination of acidity constant}

The deprotonation probability of a single site in a solute molecule is given by Eq. (1), algebraically equivalent to the HendersonHasselbalch $(\mathrm{HH})$ equation, describing an increasing sigmoidal standard titration curves:

$$
\xi=\frac{10^{\left(p H-p K_{a}\right)}}{\left(1+10^{\left(p H-p K_{a}\right)}\right)}
$$


Hence, the $p K_{a}$ value of an isolated titratable site is equal to the $\mathrm{pH}$ at which the deprotonation probability of this site is 0.5 and the concentration of the deprotonated form $\left(\left[\mathrm{EM}^{-}\right]\right)$is given by

$\left[\mathrm{EM}^{-}\right]=\frac{[\mathrm{EM}] 10^{\left(p H-p K_{a}\right)}}{\left(1+10^{\left(p H-p K_{a}\right)}\right)}$

where $[\mathrm{EM}]=[\mathrm{EMH}]+\left[\mathrm{EM}^{-}\right]$is the total concentration of the solute as a sum of the neutral and anionic/deprotonated forms.

For $n$ multiple decoupled deprotonation process, the probability of deprotonating each site $i$ is then given by the $\mathrm{HH}$ titration curve

$\xi_{i}=\frac{10^{\left(p H-p K_{a i}\right)}}{\left(1+10^{\left(p H-p K_{a i}\right)}\right)} \quad$ and $\quad\left[\mathrm{EM}^{-i}\right]=\frac{[\mathrm{EM}] 10^{\left(p H-p K_{a i}\right)}}{\left(1+10^{\left(p H-p K_{a i}\right)}\right)}$

where $K_{i}=10^{-p K_{a i}}$ is the deprotonation constant of site $i$, [EM $\left.{ }^{-i}\right]$ is the concentration of the $i$ th deprotonated form, [EM] is the total concentration of the solute as a sum of the neutral form and the deprotonated forms, and the total probability of the molecule deprotonation is just the sum of individual HH curves [46].

Using the UV/Visible spectrophotometric titration (UV/Visible ST) [47] and assuming that the $n$ possible deprotonation forms of a chromophore solute are decoupled and non-interacting, the Bouguer-Lambert-Beer law can be written by a sum of individual absorbance:

$A \equiv \log \left(\frac{I_{0}}{I}\right)=\varepsilon_{0}[\mathrm{EMH}] l+\sum_{i=1}^{n} \varepsilon_{i}\left[\mathrm{EM}^{-i}\right] l$

where $A$ is the measured absorbance, $I_{0}$ and $I$ are the intensities of the light at a fixed wavelength before and after crossing the sample, respectively, $\varepsilon_{0}$ and $\varepsilon_{n}$ are the molar extinction coefficient of the neutral and $n$th deprotonated form, respectively, and $l$ is the optical pathlength. Therefore, Eqs. (3) and (4) yield the following generalized expression:

$A=A_{0}+\sum_{i=1}^{n} A_{i} \frac{10^{\left(p H-p K_{a i}\right)}}{\left(1+10^{\left(p H-p K_{a i}\right)}\right)}$

where $A$ is the total absorbance measured of the system at a given wavelength and $A_{0}, A_{i}$ and $p K_{a i}$ values are determined by the best fitting of the UV/Visible ST curve, over the range of $p H$ values, in which $A$ increases with an increasing $p H$. Note that, in a specific wavelength, if $A$ decreases in a range of $p H$, then the term $p H-p K_{a i}$ of Eq. (5) should be inverted to $p K_{a i}-p H$ for describing a decreasing sigmoidal standard titration curve. Thus, the experimental values for

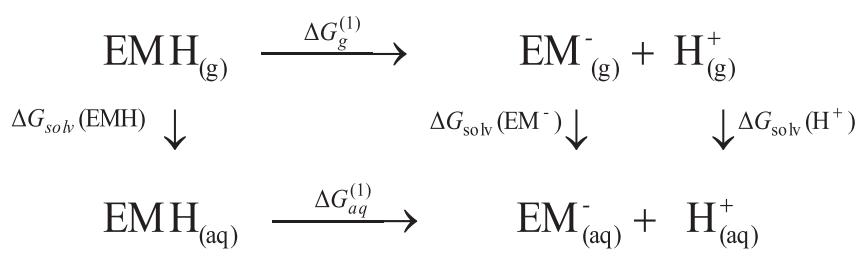

Scheme 1. The thermodynamic cycle 1 with the direct dissociation of the Emodin in the anionic specie $\left(\mathrm{EM}^{-}\right)$and the proton $\left(\mathrm{H}^{+}\right)$in gas phase and in aqueous solution. the acidity constants $p K_{a i}$ were obtained using the UV/Visible ST curves and the best fitting of the Eq. (5).

\section{Theoretical calculations}

\subsection{Thermodynamic cycles}

The theoretical approach was based in two different thermodynamic cycles, shown in Schemes 1 and 2, to calculate the free energy of deprotonation in aqueous solution, $\Delta G_{a q}$, and additionally the $p K_{a}$. Both thermodynamic cycles combine the deprotonation process of Emodin in gas phase and in aqueous solution. In the Scheme 1, there is a direct dissociation of the neutral form of Emodin $(\mathrm{EMH})$ into the deprotoned/anionic form $\left(\mathrm{EM}^{-}\right)$and the proton $\left(\mathrm{H}^{+}\right)$, and in the Scheme 2, there is a base-acid reaction between the Emodin and water molecules producing the same anionic species, $\mathrm{EM}^{-}$, and the hydronium cation $\left(\mathrm{H}_{3} \mathrm{O}^{+}\right)$. It was discussed and shown by several authors $[39,40,44,45]$ that both thermodynamic cycles give the same value of $p K_{a}$ although the free energies involved are different. The $\Delta G_{a q}^{(1)}$ is the deprotonation free energy obtained from the direct dissociation reaction (shown in Scheme 1) and $\Delta G_{a q}^{(2)}$ is obtained from the base-acid reaction with the water molecule (shown in Scheme 2). Then, in the theoretical approach the expression that relates the $p K_{a}$ and the $\Delta G_{a q}$ depends on the deprotonation reaction, but in the experimental approach the reported $\Delta G_{a q}$ is always associated to the direct dissociation reaction, i.e. the $\Delta G_{a q}^{(1)}$.

The thermodynamic cycle 1 yields the following equation to calculate the $\Delta G_{a q}^{(1)}$ using the free energy of deprotonation in gas phase, $\Delta G_{g}^{(1)}$, and the relative free energy of solvation, $\Delta \Delta G_{\text {solv }}^{(1)}$, of the neutral and ionic species:

$\Delta G_{a q}^{(1)}=\Delta G_{a q}^{(1)}+\Delta \Delta G_{\text {solv }}^{(1)}$,

where

$\Delta G_{g}^{(1)}=G_{g}\left(E M^{-}\right)+G_{g}\left(\mathrm{H}^{+}\right)-G_{g}(\mathrm{EMH})$

$\Delta G_{g}^{(1)}=\left(G_{g}\left(E M^{-}\right)-G_{g}(\mathrm{EMH})\right)+G_{g}\left(\mathrm{H}^{+}\right)$

$\Delta G_{g}^{(1)}=\Delta G_{g}($ Emodin $)+G_{g}\left(\mathrm{H}^{+}\right)$

$\Delta \Delta G_{\text {solv }}^{(1)}=\Delta G_{\text {solv }}\left(E \mathrm{M}^{-}\right)+\Delta G_{\text {solv }}\left(\mathrm{H}^{+}\right)-\Delta G_{\text {solv }}(\mathrm{EMH})$

$\Delta \Delta G_{\text {solv }}^{(1)}=\left(\Delta G_{\text {solv }}\left(E \mathrm{M}^{-}\right)-\Delta G_{\text {solv }}(\mathrm{EMH})\right)+\Delta G_{\text {solv }}\left(\mathrm{H}^{+}\right)$

$\Delta \Delta G_{\text {solv }}^{(1)}=\Delta \Delta G_{\text {solv }}($ Emodin $)+\Delta G_{\text {solv }}\left(\mathrm{H}^{+}\right)$

$G_{g}(X)$ is the free energy of a specific specie $X\left(X=\mathrm{EMH}, \mathrm{EM}^{-}\right.$and $\left.\mathrm{H}^{+}\right)$ in gas phase and $\Delta G_{\text {solv }}(X)$ is the solvation free energy of the species $X$ in aqueous solution. Thus, the $p K_{a 1}$ is obtained through the use of acidity constant definition, $K_{a 1}=\left[\mathrm{EM}^{-}\right]\left[\mathrm{H}^{+}\right] /[\mathrm{EMH}]$, that leads to the thermodynamics equation:

$p K_{a 1}=\frac{\Delta G_{a q}^{(1)}}{R T \ln 10}$

$$
\begin{array}{cccc}
\mathrm{EMH}_{(\mathrm{g})}+\mathrm{H}_{2} \mathrm{O}_{(\mathrm{g})} \stackrel{\Delta G_{g}^{(2)}}{\longrightarrow} & \mathrm{EM}_{(\mathrm{g})}^{-}+ & \mathrm{H}_{3} \mathrm{O}_{(\mathrm{g})}^{+} \\
\Delta G_{\text {solv }}(\mathrm{EMH}) \downarrow & \downarrow^{\Delta G_{\text {solv }}\left(\mathrm{H}_{2} \mathrm{O}\right)} & \Delta G_{\text {solv }}\left(\mathrm{EM}^{-}\right) \downarrow & \downarrow \\
\mathrm{EMH}_{(\mathrm{aq})}+\mathrm{H}_{2} \mathrm{O}_{(\mathrm{aq})} \stackrel{\Delta G_{\text {sq }}^{(2)}}{\longrightarrow} & \mathrm{EM}_{(\mathrm{aq})}^{-}+ & \mathrm{H}_{3} \mathrm{O}_{(\mathrm{aq})}^{+}
\end{array}
$$

Scheme 2. The thermodynamic cycle 2 with the acid-base reaction between the Emodin and water in gas phase and in aqueous solution. 
where $R$ is the ideal gas constant. Then, $p K_{a 1}=0.733 \Delta G_{a q}^{(1)}$ at $25^{\circ} \mathrm{C}$.

The thermodynamic cycle 2 yields the following equation to calculate the $\Delta G_{a q}^{(2)}$ that is equivalent to Eq. (6):

$\Delta G_{a q}^{(2)}=\Delta G_{a q}^{(2)}+\Delta \Delta G_{s o l v}^{(2)}$,

where

$$
\begin{aligned}
\Delta G_{g}^{(2)}= & G_{g}\left(E \mathrm{M}^{-}\right)+G_{g}\left(\mathrm{H}_{3} \mathrm{O}^{+}\right)-G_{g}(\mathrm{EMH})-G_{g}\left(\mathrm{H}_{2} \mathrm{O}\right) \\
\Delta G_{g}^{(2)}= & \left(G_{g}\left(E \mathrm{M}^{-}\right)-G_{g}(\mathrm{EMH})\right)+\left(G_{g}\left(\mathrm{H}_{3} \mathrm{O}^{+}\right)+G_{g}\left(\mathrm{H}_{2} \mathrm{O}\right)\right) \\
\Delta G_{g}^{(2)}=\Delta G_{g}(\text { Emodin })+\Delta G_{g}(\text { Water }) & \\
\Delta \Delta G_{\text {solv }}^{(2)}= & \Delta G_{\text {solv }}\left(E \mathrm{M}^{-}\right)+\Delta G_{\text {solv }}\left(\mathrm{H}_{3} \mathrm{O}^{+}\right)-\Delta G_{\text {solv }}(\mathrm{EMH}) \\
& -\Delta G_{\text {solv }}\left(\mathrm{H}_{2} \mathrm{O}\right) \\
\Delta \Delta G_{\text {solv }}^{(2)}= & \left(\Delta G_{\text {solv }}\left(E \mathrm{EM}^{-}\right)-\Delta G_{\text {solv }}(\mathrm{EMH})\right)+\left(\Delta G_{\text {solv }}\left(\mathrm{H}_{3} \mathrm{O}^{+}\right)\right. \\
& \left.-\Delta G_{\text {solv }}\left(\mathrm{H}_{2} \mathrm{O}\right)\right)
\end{aligned}
$$

$\Delta \Delta G_{\text {solv }}^{(2)}=\Delta \Delta G_{\text {solv }}($ Emodin $)+\Delta \Delta G_{\text {solv }}($ Water $)$

Now the acidity constant is defined as $K_{a 1}=\left[\mathrm{EM}^{-}\right]\left[\mathrm{H}_{3} \mathrm{O}^{+}\right] /[\mathrm{EMH}]$ and the $p K_{a 1}$ is obtained through the relation:

$p K_{a 1}=\frac{\Delta G_{a q}^{(2)}}{R T \ln 10}-\log \left[\mathrm{H}_{2} \mathrm{O}\right]$

where $\left[\mathrm{H}_{2} \mathrm{O}\right]=55.50 \mathrm{M}$ is the water concentration at room thermodynamic condition of $T$ and $P$. Then, $p K_{a 1}=0.733 \Delta G_{a q}^{(2)}-1.744$ at $25{ }^{\circ} \mathrm{C}$.

\subsection{Geometry and Gibbs free energy}

The neutral form of Emodin (EMH, see Fig. 1), all the deprotonated hydroxyl forms $\left(\mathrm{EM}^{-1}, \mathrm{EM}^{-2}\right.$ and $\left.\mathrm{EM}^{-3}\right)$, its tautomeric isomers with the hydroxyl at position $9(1,10-$ and 8,10 anthraquinones), the water molecule $\left(\mathrm{H}_{2} \mathrm{O}\right)$, the hydroxyl $\left(\mathrm{OH}^{-}\right)$ and the hydronium $\left(\mathrm{H}_{3} \mathrm{O}^{+}\right)$ions have the geometry optimized and the vibrational frequencies calculated with quantum mechanics (QM). These calculations were performed using Density Functional Theory (DFT) [48] with the B3LYP exchange-correlation functional $[49,50]$ and Pople basis set functions, $6-311++G(d, p)$ [51]. This DFT functional has produced results with a good compromise between computational cost and accuracy of the results for molecules of the anthraquinone family $[17,52,53]$ and other organic molecules [54].

The solvent effect in the geometry was included using the polarizable continuum model (PCM) [55] with the same level of QM calculation. Hence, all geometries were obtained in vacuum and in aqueous solution. The differences found in both geometries (in gas phase and in aqueous solution) were negligible. Therefore, all the further calculations were performed in the vacuum optimized geometries.

The Gibbs free energies of all stable species, in gas phase $\left(G_{g}\right)$ and in aqueous solution $\left(G_{a q}\right)$, were calculated considering the electronic energy of the system and the corrections of zero-point energy, thermal and enthalpy at the same level of QM calculation, B3LYP/6-311++G(d,p). For the case of the proton $\left(\mathrm{H}^{+}\right)$, its gas phase free energy was obtained using the equilibrium reaction $\mathrm{H}_{2} \mathrm{O} \Longleftrightarrow \mathrm{OH}^{-}+\mathrm{H}^{+}$, which $\Delta G_{g}\left(\mathrm{H}_{2} \mathrm{O} \rightarrow \mathrm{OH}^{-}+\mathrm{H}^{+}\right)=G_{g}\left(\mathrm{OH}^{-}\right)+$ $G_{g}\left(\mathrm{H}^{+}\right)-G_{g}\left(\mathrm{H}_{2} \mathrm{O}\right)$. Therefore, we determined the $G_{g}\left(\mathrm{H}^{+}\right)$using the experimental value of the $\Delta G_{g}\left(\mathrm{H}_{2} \mathrm{O} \rightarrow \mathrm{OH}^{-}+\mathrm{H}^{+}\right)=385.6 \pm 0.2$ $\mathrm{kcal} / \mathrm{mol}$ obtained by Bartmess and co-authors [56,57] and the calculated values of the $G_{g}\left(\mathrm{OH}^{-}\right)$and the $G_{g}\left(\mathrm{H}_{2} \mathrm{O}\right)$.
Comparing the $G_{a q}$ of the isomers with the same quantity of deprotonation sites, we analyze the preferential position for the first and second deprotonation process of Emodin in aqueous solution. The free energy of the first deprotonation of Emodin in gas phase, $\Delta G_{g}$, was calculated for both thermodynamic cycles, using Eq. (7) for the $\Delta G_{g}^{(1)}$ and Eq. (11) for the $\Delta G_{g}^{(2)}$. Additionally, to increase the numerical precision in the calculation of $\Delta G_{g}$, the electronic energies of the involved species were also calculated with Møller-Plesset second order perturbation theory (MP2) [58,59] with the same basis function, MP2/6-311++G(d,p).

\subsection{Free energy of solvation and $p K_{a}$}

The standard solvation free energies, $\Delta G_{\text {solv }}(X)$, for $X=\mathrm{EMH}$ and $\mathrm{EM}^{-}$were calculated with the Free Energy Perturbation method (FEP) [60-63], implemented in the Monte Carlo (MC) simulations [64-68]. For comparison the $\Delta G_{\text {solv }}(X)$ was also obtained with QM calculations, where the solvent effect was included using PCM, which describes the solvent as a continuum polarizable dielectric medium [55].

For the other species, $X=\mathrm{H}^{+}, \mathrm{H}_{2} \mathrm{O}$ and $\mathrm{H}_{3} \mathrm{O}^{+}$, several authors have studied its standard free energies of solvation in aqueous solution $[34,43-45,56,69-72]$. Therefore, we decided to use in this work the experimental value of the $\Delta G_{\text {solv }}\left(\mathrm{H}_{2} \mathrm{O}\right)=-6.32 \pm 0.2 \mathrm{kcal} /$ mol obtained by Ben-Naim and Marcus [70], the $\Delta G_{\text {solv }}\left(\mathrm{H}_{3} \mathrm{O}^{+}\right)=$ $-110.2 \pm 0.7 \mathrm{kcal} / \mathrm{mol}$ obtained by Pliego and Riveros [34] and the $\Delta G_{\text {solv }}\left(\mathrm{H}^{+}\right)=-265.9 \mathrm{kcal} / \mathrm{mol}$ obtained by Tissandier and co-authors [72], all in standard condition (concentration of $1.0 \mathrm{M}$ in gas phase). Then, the $\Delta G_{\text {solv }}\left(\mathrm{H}^{+}\right)$and the $\Delta \Delta G_{\text {solv }}$ (water) $=\Delta G_{\text {solv }}\left(\mathrm{H}_{3} \mathrm{O}^{+}\right)-\Delta G_{\text {solv }}\left(\mathrm{H}_{2} \mathrm{O}\right)=-103.88 \mathrm{kcal} / \mathrm{mol}$ were used in the calculations of the relative solvation free energy, $\Delta \Delta G_{\text {solv }}^{(1)}$ and $\Delta \Delta G_{\text {solv }}^{(2)}$ of the Schemes 1 and 2 (using Eqs. (7) and (12)), respectively.

The MC simulations were performed with the Metropolis sampling technique [73] and standard procedures as presented before [74]. The system was composed by one solute $X$ and 500 water molecules in the isothermal-isobaric NPT ensemble, where the number of molecules $N$, the pressure $P$, and the temperature $T$ are fixed at $N=501, P=1 \mathrm{~atm}$ and $T=25^{\circ} \mathrm{C}$. The periodic boundary conditions and the image method were used in a cubic box that was initialized with edge of $L=24.98 \AA$ and the density of $1 \mathrm{~g} / \mathrm{cm}^{3}$. Throughout the simulation, the geometry and potential parameters of the molecules are kept fixed, where each molecule interacts with all other molecules within a spherical region that is defined by the cutoff radius $r_{c}=L / 2 \approx 12.5 \AA$. The long-range corrections of the potential are calculated beyond this cutoff distance, as before [74]. The intermolecular interaction was described by standard Lennard-Jones plus Coulomb potential, where each interacting site $i$ has three parameters $\left(\varepsilon_{i}, \sigma_{i}\right.$ and $\left.q_{i}\right)$, that are related by the combination rule: $\varepsilon_{i j}=\left(\varepsilon_{i} \varepsilon_{j}\right)^{1 / 2}$ and $\sigma_{i j}=\left(\sigma_{i} \sigma_{j}\right)^{1 / 2}$. The water was described with the SPC model [75] and for the solutes, EMH and $\mathrm{EM}^{-}$, the following parameters were used: $\{\varepsilon\}$ and $\{\sigma\}$ of the OPLS force field [76] and the set of atomic charges $\{q\}$ calculated with the CHELPG procedure to fit the electrostatic potential [77] at the B3LYP/6-311++G(d,p) level of QM calculation, with the solute embedded in the solvent described by PCM. Therefore, the atomic charges of the solute include implicitly the electronic polarization due to the aqueous solutions, $\{q\}_{a q}$. This procedure, for studying properties of molecules in aqueous solution, has been shown to be better than the standard procedure of calculating the charges with $\mathrm{HF} / 6-31 \mathrm{G}(\mathrm{d}) \quad[68,78-80]$. The potential parameters (Lennard-Jones $\{\varepsilon$ and $\sigma\}$ and the atomic charges $\{q\}_{a q}$ ) of EMH and $\mathrm{EM}^{-}$used in this work are shown in Supplementary Material.

As used before, the solvation free energy was obtained as the negative value of the annihilation free energy in solution, i.e. $\Delta G_{\text {solv }}(X)=-\Delta G_{\text {annih }}(X)[65,67,68,81]$. The annihilation free energy 
was calculated using a hypothetical vanishing process, $\Delta G_{\text {annih }}(X)=\Delta G(X \rightarrow 0)$, where the solute-solvent interactions are switched-off in several simulations, using the double-wide sampling technique $[62,81]$. In this process the initial state of the simulation is a system composed by one polarized solute in aqueous solution at $1 \mathrm{~atm}$ and the final state has only the solution. In other words, the solute is removed from the solution and takes it to the gas phase with the polarized set of atomic charges at $1 \mathrm{~atm}$ condition. Then, two additional steps should be done to obtain the correct state of the non-polarized solute in gas phase at the standard condition (concentration of $1 \mathrm{M}$ ). Thus, $\Delta G_{\text {solv }}(X)=-\Delta G_{\text {annih }}(X)+\Delta G_{p o l}(X)+\Delta G\left(P_{i} \rightarrow P_{f}\right)$, where $\Delta G_{p o l}(X)$ is the free energy variation due to the polarization process of the solute going from the gas phase to the aqueous solution and the $\Delta G\left(P_{i} \rightarrow P_{f}\right)$ is the free energy variation due to the change in the pressure of the gas phase from the standard condition $\left(P_{i}=24.46\right.$ $\mathrm{atm})$ to the condition in equilibrium with the pressure of the solution $\left(P_{f}=1 \mathrm{~atm}\right)$. The $\Delta G_{p o l}(X)$ involves a variation in the internal energy of the solute due to its polarization, $\Delta E_{p o l}(X)$, that can be obtained by QM calculations considering the difference of the solute electronic energy with a wavefunction polarized in water with PCM $\left(\Psi_{\mathrm{PCM}}\right)$ and in vacuum $\left(\Psi_{\mathrm{o}}\right), \Delta E_{p o l}(X)=\left\langle\Psi_{\mathrm{PCM}}\left|\mathrm{H}_{\mathrm{o}}\right| \Psi_{\mathrm{PCM}}\right\rangle-$ $\left\langle\Psi_{\mathrm{o}}\left|\mathrm{H}_{\mathrm{o}}\right| \Psi_{\mathrm{o}}\right\rangle$, where $\mathrm{H}_{\mathrm{o}}$ is the Hamiltonian of the isolated solute. The relation $\Delta G_{p o l}(X)=\Delta E_{p o l}(X)$ is a good approximation considering a rigid solute. As usual $[43,82]$, using thermodynamic relations it is obtained that $\Delta G\left(P_{i} \rightarrow P_{f}\right)=R T \ln \left(P_{f} / P_{i}\right)=-R T \ln (24.46)$.

The annihilation process was performed in three stages: first, the polarized atomic charges of the solute $\{q\}_{a q}$ were slowly reduced to zero and the negative of the solute-solvent electrostatic term of the solvation free energy, $-\Delta G_{\text {ele }}(X)$, was calculated; then, the attractive term of the Lennard-Jones potential, $r^{-6}$, was vanished and the negative of the van der Waals term of the solvation free energy, $-\Delta G_{v d W}(X)$, was calculated; and finally, the repulsive term of the Lennard-Jones potential, $r^{-12}$, was also vanished and the negative of the cavitation term of the solvation free energy, $-\Delta G_{\text {cav }}(X)$, was calculated.

Then, the total value of the standard solvation free energy of each species was obtained as:

$$
\begin{aligned}
\Delta G_{\text {solv }}(X)= & \Delta G_{\text {ele }}(X)+\Delta G_{v d W}(X)+\Delta G_{c a v}(X)+\Delta G_{p o l}(X) \\
& -R T \ln (24.46)
\end{aligned}
$$

where the first three terms were calculated with FEP-MC simulation $[65,66,83]$ and takes into account only the solute-solvent (intermolecular) interaction, the $\Delta G_{p o l}(X)$ were calculated with PCM and consider the changes of the solute (intramolecular) due to its polarization process in going from the gas phase to the solution, and the last term, $-R T \ln (24.46)$, is equal to $1.9 \mathrm{kcal} / \mathrm{mol}$ at $25^{\circ} \mathrm{C}$ and consider the change in the ideal gas at the standard concentration of $1 \mathrm{M}$ to the condition of $1 \mathrm{~atm}$ in equilibrium with the solution.

The series of MC simulations was composed by a total of twenty simulations performed to make the solute $X$ disappears slowly from the solution in three stages: (i) 12 simulations with double-wide sampling were performed to annihilate the Coulomb potential, $\lambda_{i}\{q\}_{a q}$, with $\lambda_{i}=1.000 \leftarrow 0.975 \rightarrow 0.950,0.950 \leftarrow 0.925 \rightarrow 0.900$, $0.9000 \leftarrow 0.875 \rightarrow 0.850,0.850 \leftarrow 0.825 \rightarrow 0.800,0.800 \leftarrow 0.775 \rightarrow$ $0.750, \quad 0.750 \leftarrow 0.725 \rightarrow 0.0700, \quad 0.700 \leftarrow 0.675 \rightarrow 0.650,0.650 \leftarrow$ $0.625 \rightarrow 0.600, \quad 0.600 \leftarrow 0.550 \rightarrow 0.500, \quad 0.500 \leftarrow 0.450 \rightarrow 0.400$, $0.400 \leftarrow 0.350 \rightarrow 0.300,0.300 \leftarrow 0.200 \rightarrow 0.00$; (ii) 4 simulations with double-wide sampling to annihilate the attractive term of the LJ potential with $\lambda_{i}=1.000 \leftarrow 0.875 \rightarrow 0.750,0.750 \leftarrow 0.625 \rightarrow$ $0.500,0.500 \leftarrow 0.375 \rightarrow 0.250,0.250 \leftarrow 0.125 \rightarrow 0.00$; and (iii) 4 simulations without double-wide sampling to annihilate the repulsive term of the LJ potential with $\lambda_{i}=1.00 \rightarrow 0.75,0.75 \rightarrow 0.50$, $0.50 \rightarrow 0.25,0.25 \rightarrow 0.00$. For each $\lambda$, five independent simulations with double-wide sampling were performed to calculate the aver- age and the standard deviation of the free energy between the states $\lambda_{i} \rightarrow \lambda_{i+1}$ and $\lambda_{i} \rightarrow \lambda_{i-1}$. Each simulation was divided in two large stages, thermalization and equilibrium, both with $1.5 \times 10^{8}$ MC steps. More details about this procedure can be found in Refs. [64,65].

For comparison the standard solvation free energies, $\Delta G_{\text {solv }}(\mathrm{EMH})$ and $\Delta G_{\text {solv }}\left(\mathrm{EM}^{-}\right)$, were also carried out using the PCM with the United Atom for Hartree Fock (UAHF) model for the cavity shape at $\mathrm{HF} / 6-31+\mathrm{G}(\mathrm{d})$ level of calculation [84]. Many works have shown that this $\mathrm{HF} / 6-31+\mathrm{G}(\mathrm{d}) / \mathrm{PCM} / \mathrm{UAHF}$ level provides reliable standard solvation free energies of neutral and charged molecules giving results in excellent agreement with experimental data, due to the internal parametrization of the non-electrostatic terms of the free energy in the PCM method [85-87]. In this calculation the electrostatic term of the solvation free energy, $\Delta G_{\text {ele }}(X)$, already includes the solute polarization term, $\Delta G_{p o l}(X)$, because it takes into account the inter and intramolecular interaction. To better compare the values obtained with PCM and FEP-MC, we presented these two terms separately (in Section 4.4) and adding both terms one can get the total electrostatic term of the solvation free energy.

All QM calculations were performed with Gaussian 03 program [88] and the MC simulations and FEP calculations with DICE program [89].

\section{Results and discussions}

\subsection{Experimental UV/Visible spectrophotometric titration and $p K_{a}$}

Before setting the assay of Emodin in water, we performed the experimental measures of the UV/Visible absorption spectra of the Emodin in water-methanol mixture $(1: 3 \mathrm{v} / \mathrm{v})$ at concentration of $0.025 \mathrm{mM}$ varying the apparent $p H$ from 12.66 to 2.09 . This mixture is simpler than the aqueous solution because no aggregation of the Emodin was observed. In Fig. 2 the UV/Visible spectra of

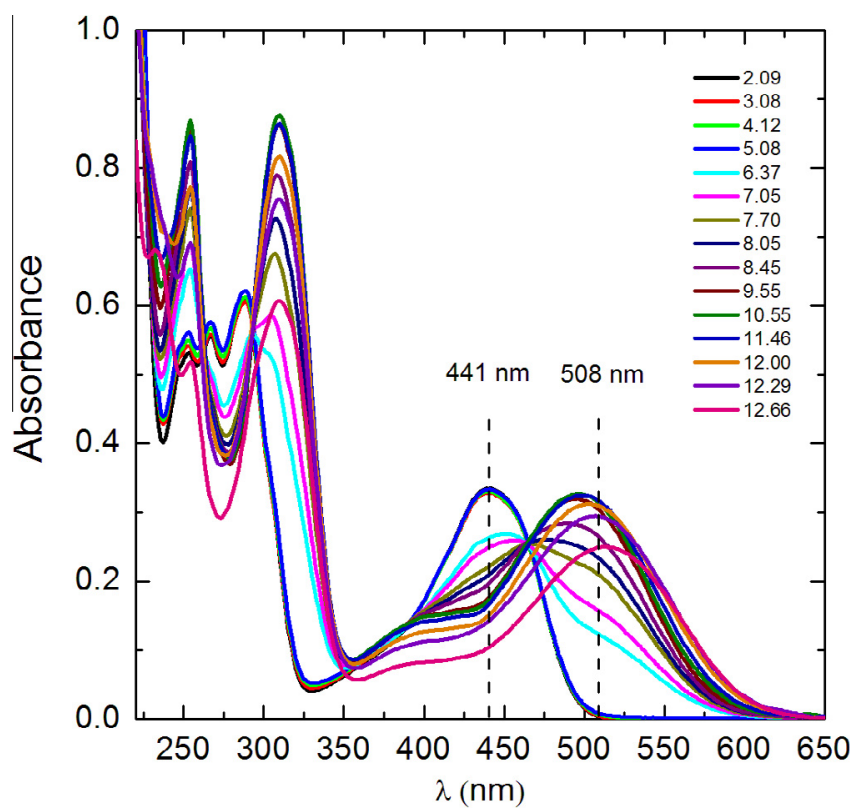

Fig. 2. The effect of the apparent $p H$ on the UV/Visible absorption spectra of the Emodin in water-methanol mixture $(1: 3 \mathrm{v} / \mathrm{v})$ at concentration of $0.025 \mathrm{mM}$. The vertical dashed lines show the $\lambda_{\max }$ of the first band of the Emodin in alkaline mixture, $p H=12.66$, at $508 \mathrm{~nm}$ and in acidic mixture, $p H<5.08$, at $441 \mathrm{~nm}$. 


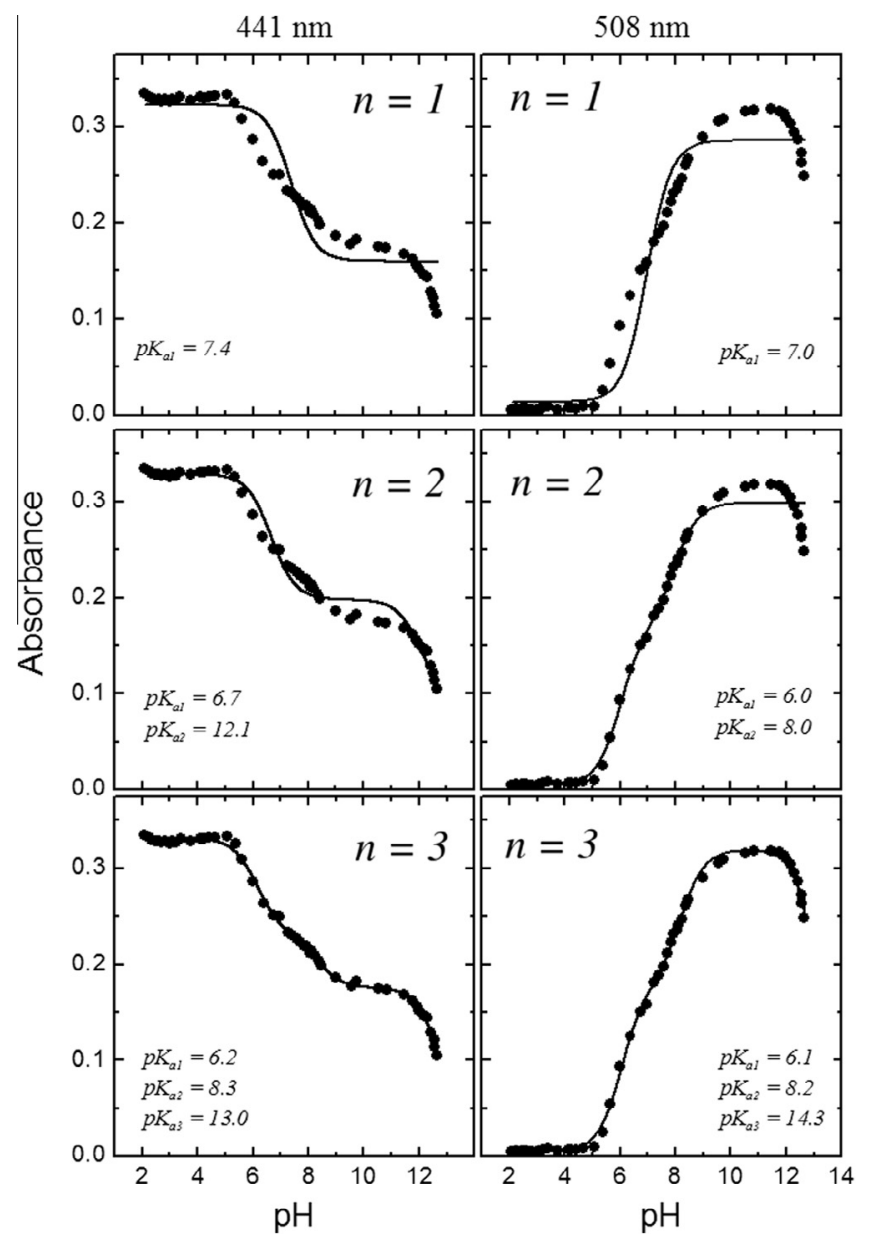

Fig. 3. (symbols) The Emodin absorbance at two wavelengths, $441 \mathrm{~nm}$ (left) and $508 \mathrm{~nm}$ (right), versus the apparent $\mathrm{pH}$ of the water-methanol mixture and (line) the best fit of the Eq. (5) with one term of the $\operatorname{sum}(n=1$, top), two term of the sum ( $n=2$, middle) and three terms of the sum $(n=3$, bottom).

the Emodin in the mixture are shown for 15 illustrative samples selected in the studied $\mathrm{pH}$ range.

As it can be seen the absorption spectrum of Emodin is very sensitive to the $p H$ variation. The first absorption band changes its maximum absorbance from $508 \mathrm{~nm}$ to $441 \mathrm{~nm}$ when the apparent $p H$ varies from 12.66 to 2.09 . This is in agreement with previous measurements performed by Pal and Jana [16].

We selected these two wavelengths, 508 and $441 \mathrm{~nm}$, to perform the UV/Visible ST curves and used Eq. (5) to obtain the $p K_{a i}$, (see Fig 3). Considering only one deprotonation process in the entire range of the $p H\left(n=1\right.$ in Eq. (5)), we obtained $p K_{a 1}=7.4$ at $441 \mathrm{~nm}$ and $p K_{a 1}=7.0$ at $508 \mathrm{~nm}$. These values are in agreement with the value of 7.2 obtained previously by Pal and Jana [16] in the same mixture proportion of water-methanol by Bjerrum's method. However, in Fig. 3 (top) it is easy to see that the best fit of Eq. (5) with only one term of the sum does not adjust well the experimental data. Then, we try also to fit the Eq. (5) with $n=2$ and 3, i.e. assuming two or three decoupled and non-interacting deprotonation sites of the Emodin in the mixture at the $\mathrm{pH}$ range between 12.66 and 2.09. These two additional fitting of Eq. (5) are also presented in Fig. 3 (middle and bottom). For $n=2$ (see Fig. 3, middle), we obtained $p K_{a 1}=6.7$ and $p K_{a 2}=12.1$ at $441 \mathrm{~nm}$, and $p K_{a 1}=6.0$ and $p K_{a 2}=8.0$ at $508 \mathrm{~nm}$ and for $n=3$ (see Fig. 3, bottom), we obtained $p K_{a 1}=6.2, p K_{a 2}=8.3, p K_{a 3}=13.0$ at $441 \mathrm{~nm}$ and $p K_{a 1}=6.1, p K_{a 2}=8.2, p K_{a 3}=14.3$ at $508 \mathrm{~nm}$. Perusal of Fig. 3 shows that the best fitting of the experimental data is obtained assuming the existence of three acidity constants in the studied range of $p H$. Furthermore, the values of $p K_{a 1}$ and $p K_{a 2}$ obtained for the two different wavelengths are equivalent when the three deprotonations were assumed. Since our measurements were performed with $p H$ up to 12.66 , the values obtained for $p K_{a 3}$ (13.0 and 14.3) are in the limiting of the $p H$ range used. Therefore, we believe that the $p K_{a 3}$ values are not reliable, but we are confident that our best values for the apparent acidity constants of the Emodin in water-methanol mixture $(1: 3 \mathrm{v} / \mathrm{v})$ are $p K_{a 1}=6.2 \pm 0.1, p K_{a 2}=8.3 \pm 0.1$ and $p K_{a 3}>12.7$.

This new analysis of the experimental titration curve gives a different conclusion compared with that one obtained by Pal and Jana [16]. However, it seems to be more adequate to the picture of a stepwise dissociation of the protons of the three-hydroxyl groups existent in Emodin. Then, we conclude that the Emodin in water-methanol mixture (1:3 v/v), from $p H 2.09$ to 12.66 , loses two protons, going from the neutral form to the charged divalent anionic form, with apparent acidity constants of 6.2 and 8.3. The acidity constant of the third deprotonation is larger than 12.7 .

For completeness, we tested two additional fittings of the Eq. (5), with $n=4$ and 5. With these new fittings, we obtained: (i) the same values of the $p K_{a 1}$ and $p K_{a 2}$ as obtained with $n=3$; (ii) the values of the $p K_{a 3}$ with small variation for the two analyzed wavelength $\left(p K_{a 3}=14.4 \pm 0.1\right.$ ); (iii) negative values for the $p K_{a 4}$ and $p K_{a 5}$; and (iv) a negligible improvement in the agreement with the experimental data. Thus, we conclude that the best fitting of the titration curve with the Eq. (5) was obtained with $n=3$.

In the case of the aqueous solution, the experiment titration curve was obtained by the UV/Visible absorption spectra of the Emodin decreasing the sample $p H$ value from 13.8 to 2.0. Around $70 \mathrm{UV} /$ Visible spectra were measured in this $\mathrm{pH}$ range at each different concentration $(0.1$ and $0.025 \mathrm{mM}$ ). Due to the Emodin aggregation and the precipitation at lower $\mathrm{pH}$ values, samples were strongly vortexed immediately before each optical assay. In Fig. 4a the UV/Visible spectra of the Emodin in water are shown for 11 illustrative samples selected in the studied $p H$ range. They show a large dependence of the optical absorption spectrum of the Emodin on the $p H$ of the medium. At higher $p H$ values, the Emodin is deprotonated and charged, and the sample is clear and reddish. As the $p H$ goes down, the color of the sample changes, untill it gets yellow at low $p H$ values. Below $p H=8$, Emodin aggregates, precipitating after around one minute. In Fig. $4 \mathrm{a}$, at $\mathrm{pH}$ values $7.71,7.02,4.40$ and 2.0, the presence of the Emodin aggregates is evidenced by the scattering profile underneath the optical absorption spectrum (light scattering depends on wavelength as $\lambda^{-x}$, where $x$ depends on the scattering particle dimensions [90]). Due to the presence of the absorption bands, it is not possible to precisely subtract the light scattering from the Emodin absorption spectrum. Therefore, each spectrum was roughly corrected by subtracting the absorbance value at $650 \mathrm{~nm}$. This correction assumes that there is no electronic absorption transition of the Emodin in the region near $650 \mathrm{~nm}$, and then the absorbance is zero. The corrected spectra are shown in Fig. $4 \mathrm{~b}$.

The dependence of the absorbance at 519 and $308 \mathrm{~nm}$ (see Fig. $4 \mathrm{~b}$ ) with respect to the $p H$ leads to the UV/Visible ST curves shown in Fig. 5. These wavelength values are the maxima of the first two bands at $p H>11$. The best fit of those UV/Visible ST curves by Eq. (5) yield to two acidity constants, $p K_{a 1}$ and $p K_{a 2}$, for the Emodin in aqueous solution. The fitting with three acidity constants does not improve significantly the agreement with the experimental data of the titration curve. So then, we decided to stay with the simpler adjustment with two terms (Eq. (5) with $n=2$ ). For both wavelengths, the best fitted values for the first and second acidity constants were similar. Therefore, the best values for the acidity constants are $p K_{a 1}=8.0 \pm 0.1$ and $p K_{a 2}=10.9 \pm 0.2$. These values are the average and error for four 


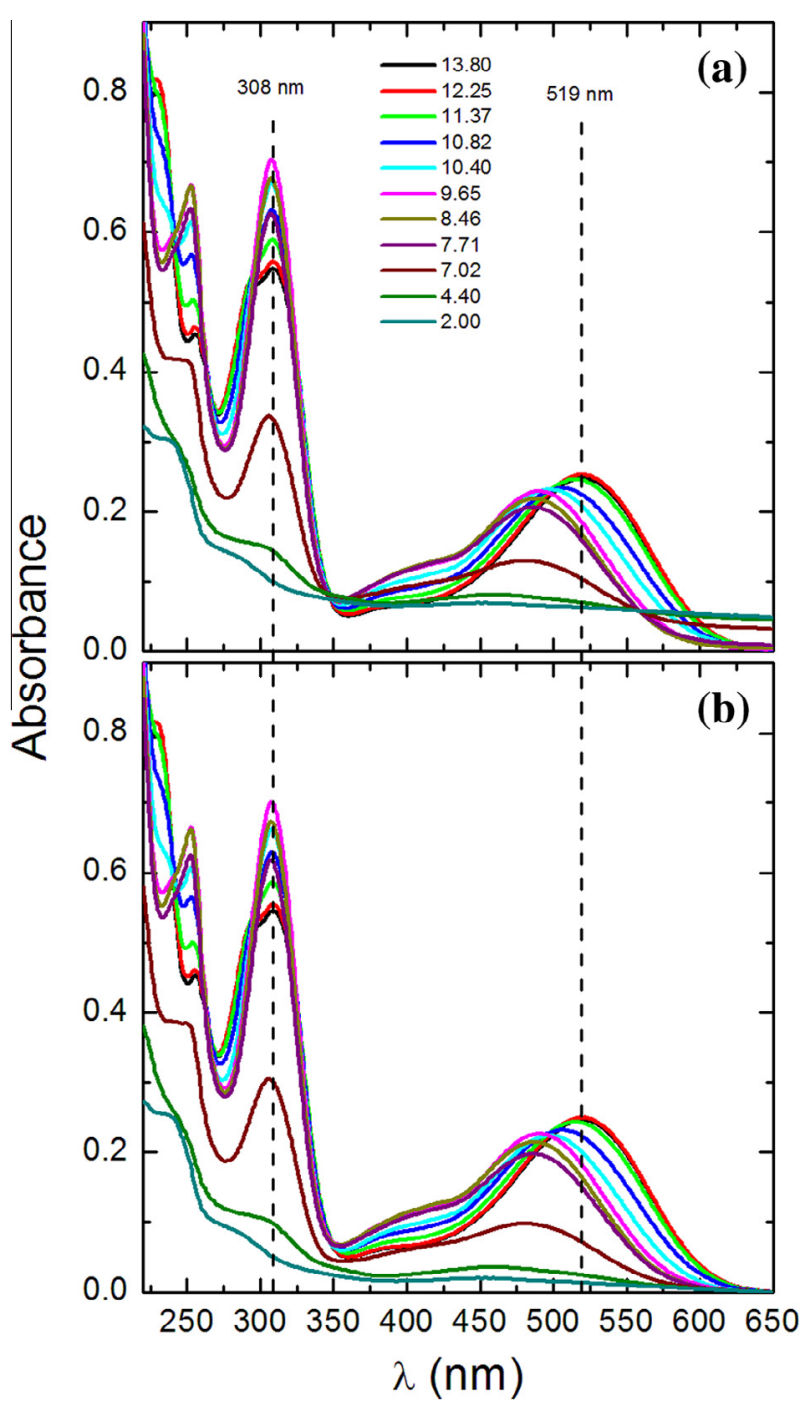

Fig. 4. The effect of the $p H$ on the UV/Visible absorption spectra of the Emodin in aqueous solution at concentration of $0.025 \mathrm{mM}$, without corrections (a) and with light scattering correction (b). The vertical dashed lines show the $\lambda_{\max }$ of the first and second bands of the Emodin in alkaline solution, $p H>11$, at 519 and $308 \mathrm{~nm}$, respectively.

different experiments, two experiments for each concentration of 0.025 and $0.100 \mathrm{mM}$ of the Emodin.

The reason for assaying different Emodin concentrations was to test whether the formation of Emodin aggregates or the presence of light scattering would affect the best fitted $p K_{a}$ values. However, the great similarity among the results obtained with different Emodin concentrations and at different wavelengths reinforce the accuracy of the $p K_{a 1}$ and $p K_{a 2}$ values, i.e. the first deprotonation of the Emodin in aqueous solution at $p K_{a 1}=8.0 \pm 0.1$ and second deprotonation at $p K_{a 2}=10.9 \pm 0.2$. According to Eq. (9), these $p K_{a}$ values give a standard first and second deprotonation free energy of the Emodin in water as $10.9 \pm 0.2 \mathrm{kcal} / \mathrm{mol}$ and $14.9 \pm 0.3 \mathrm{kcal} /$ mol, respectively. Note that the Emodin aggregates are detected bellow the value of $p K_{a 1}$, where there is a predominance of the neutral Emodin, EMH. Therefore, the Emodin in aqueous solution, from pH 2.0 to 13.8 , loses two protons, going from the neutral form to the charged divalent form, with acidity constants of 8.0 and 10.9. The acidity constant of the third deprotonation is out of the $\mathrm{pH}$ range studied here, i.e. larger than 13.8. Our best value of $8.0 \pm 0.1$ for the $p K_{a 1}$ of the Emodin in water is in agreement with the value showed in the graphic of Fig. 4 of the Ref. [30]. This

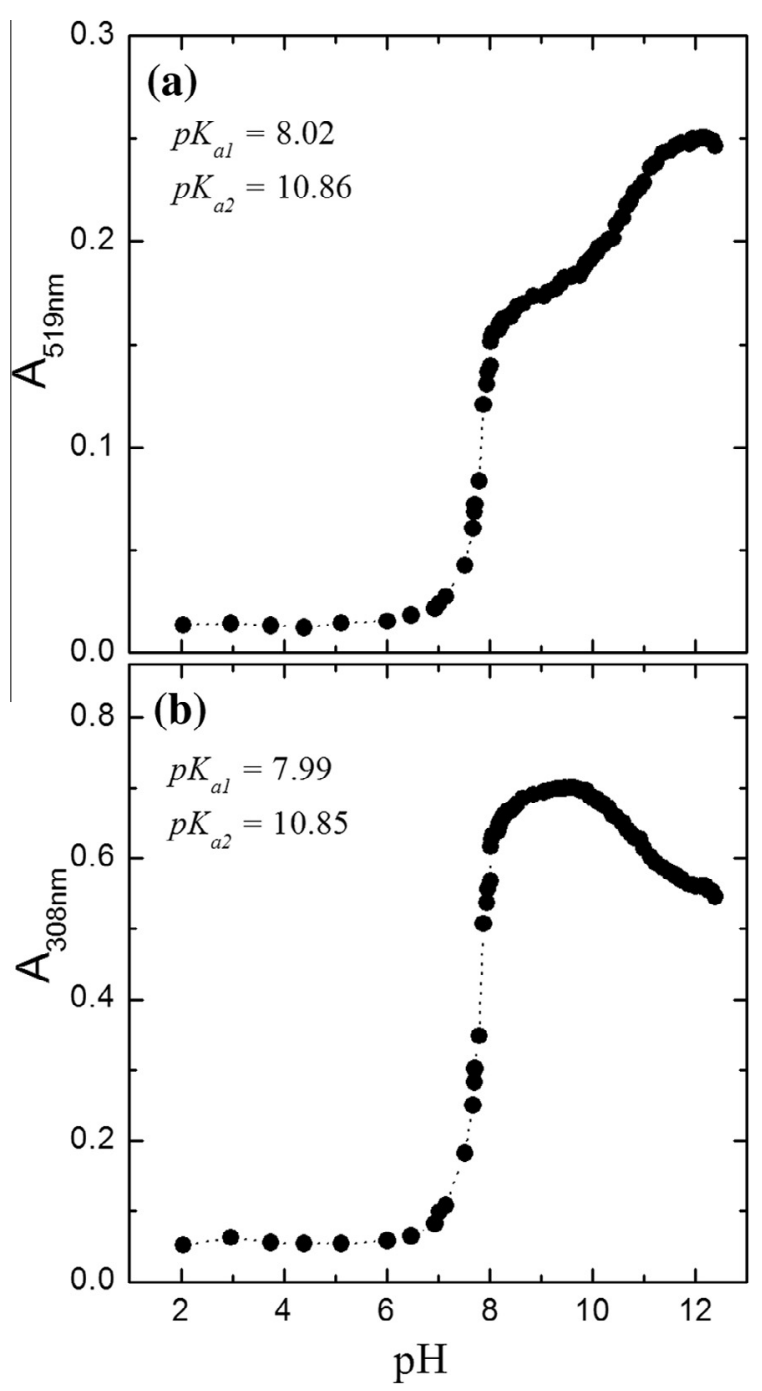

Fig. 5. The effect of the $p H$ on the Emodin absorbance values (corrected by the light scattering, see text) at 519 and $308 \mathrm{~nm}$ with concentration of $0.025 \mathrm{mM}$. The $p K_{a}$ values were obtained from the best fitting of Eq. (5) with two terms $(n=2)$.

graphic shows the effect of the acetonitrile concentration on the $p K_{a}$ values of five molecules of the anthraquinone family in water-acetonitrile mixture. In the case of Emodin, the point at $0 \%$ of acetonitrile gives a $p K_{a}$ of $\sim 8.2$ for Emodin in water.

\subsection{Geometry optimization and relative stability of the isomers}

Initially we performed geometry optimization for the isolated molecules in vacuum with the B3LYP/6-311++G(d,p) level of calculation. The optimized systems were: the neutral Emodin, all the deprotonated hydroxyl forms and the tautomeric isomers with the hydroxyl at position 9, i.e. the 1,10- and 8,10-anthraquinone tautomeric forms. We found, as stable structures, only the 9,10anthraquinone neutral form, 6 anionic/deprotonated forms of Emodin, in which 3 of them presented one deprotonation site, 2 presented two deprotonation sites and 1 presented three deprotonation sites. These forms are: 3,8-EM ${ }^{-}$(9,10-anthraquinone with deprotonation at position 1 and two hydroxyl groups at positions 3 and 8), 1,8-EM ${ }^{-}(9,10$-anthraquinone with deprotonation at position 3 and two hydroxyl groups at positions 1 and 8 ), 1,3-EM ${ }^{-}$(9,10-anthraquinone with deprotonation at position 8 and two hydroxyl groups at positions 1 and 3), 1-EM ${ }^{2-}$ (9,10-anthraquinone with deprotonation sites at positions 3 and 
Table 1

The electronic energy ( $E_{\mathrm{g}}$ in $\left.\mathrm{kcal} / \mathrm{mol}\right)$, free energy $\left(G_{\mathrm{g}}\right.$ in $\left.\mathrm{kcal} / \mathrm{mol}\right)$ and the dipole moment $\left(\mu_{\mathrm{g}}\right.$ in $\left.\mathrm{D}\right)$ of the Emodin forms $X$ in vacuum using B3LYP/6-311++G(d,p) level of QM calculation. In aqueous solution, the free energies $\left(G_{a q}\right)$ and the dipole moment $\left(\mu_{a q}\right)$ were obtained using the solvent described by PCM with the same level of calculation. The

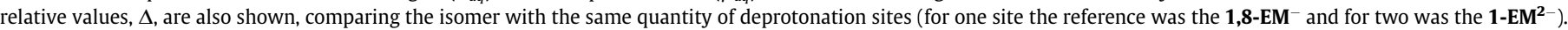
The dipole moments for the anionic forms were calculated with the origin at the center of the nuclear changes.

\begin{tabular}{|c|c|c|c|c|c|}
\hline$X$ & $E_{g}$ & $G_{g}$ & $G_{a q}$ & $\mu_{g}$ & $\mu_{a q}$ \\
\hline EMH & -598676.30 & -598565.89 & -598572.34 & 2.68 & 3.49 \\
\hline 3,8-EM ${ }^{-}$ & -598331.83 & -598232.14 & -598281.32 & 8.47 & 12.91 \\
\hline 1,8-EM ${ }^{-}$ & -598348.98 & -598247.08 & -598287.28 & 10.44 & 15.33 \\
\hline 1,3-EM & -598331.78 & -598230.96 & -598280.93 & 7.12 & 11.36 \\
\hline$\Delta\left(1,8-\mathrm{EM}^{-} \rightarrow 3,8-\mathrm{EM}^{-}\right)$ & 17.15 & 14.94 & 5.96 & & \\
\hline$\Delta\left(1,8-\mathrm{EM}^{-} \rightarrow 1,3-\mathrm{EM}^{-}\right)$ & 17.20 & 16.12 & 6.35 & & \\
\hline 1-EM ${ }^{2-}$ & -597932.60 & -597840.54 & -597990.00 & 8.04 & 12.17 \\
\hline 9-EM ${ }^{2-}$ & -597925.15 & -597832.27 & -597984.38 & 12.78 & 19.46 \\
\hline$\Delta\left(1-\mathrm{EM}^{2-} \rightarrow\right.$ 9-EM $\left.{ }^{2-}\right)$ & 7.45 & 8.27 & 5.62 & & \\
\hline $\mathbf{E M}^{3-}$ & -597426.91 & -597343.98 & -597681.60 & 13.81 & 21.68 \\
\hline
\end{tabular}

8 and one hydroxyl group at position 1$), \mathbf{9}-\mathbf{E M}^{2-}(8,10$-anthraquinone with deprotonation sites at positions 1 and 3 and one hydroxyl group at position 9) and $\mathbf{E M}^{\mathbf{3}-}$ (deprotonation sites at positions 1,3 and 8). The electronic energy, Gibbs free energy and dipole moment of those stable structures in vacuum are shown in Table 1.

All the optimized geometries were found to be planar and having intramolecular hydrogen bonds with oxygen 09, in good agreement with the geometries obtained with DFT, B3LYP/ $6-31+G(d, p)$ [17] and B3LYP/6-311++G(d,p) [53], and with the crystallographic experimental data of 1,8-dihydroxyanthraquinone $[91,92]$. We identified that none of the following tautomeric forms of Emodin are stable, at the B3LYP/6-311++G(d,p) level, considering the neutral form of the 1,10-anthraquinone and 8,10anthraquinone; with one deprotonation site: 1,9-EM ${ }^{-}(8,10-$ anthraquinone with the hydroxyl groups at positions 1 and 9), 3,9-EM ${ }^{-}(1,10$-anthraquinone and 8,10-anthraquinone with the hydroxyl groups at positions 3 and 9) and 8,9-EM ${ }^{-}$(1,10-anthraquinone with the hydroxyl groups at positions 8 and 9); and two deprotonation sites: 8-EM ${ }^{-}$(1,10-anthraquinone and 9,10anthraquinone with one hydroxyl group at position 8). Starting the geometry optimization with any one of these tautomeric forms, they spontaneously became one of the stable forms shown in Table 1. Therefore, our results do not support the existence of an equilibrium structure for the 1,10-anthraquinone and 8,10-anthraquinone tautomeric forms of neutral Emodin in vacuum and in aqueous solution. Then, these tautomers do not contribute to any property of Emodin in these two environments. This result is in agreement with the one obtained by Nguyen and co-authors [17], that could not obtain an equilibrium geometry for the 1,10 anthraquinoid tautomer of Emodin in vacuum or in ethanol.

In Table 1 , comparing the free energy in gas phase, $G_{g}$, of the three isomeric forms with one deprotonation, 3,8-EM ${ }^{-}, \mathbf{1 , 8}-\mathbf{E M}^{-}$

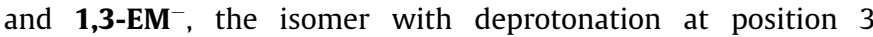
$\left(\mathbf{1 , 8}-\mathbf{E M}^{-}\right)$is the most stable compared with the others, $\Delta G_{g}\left(\mathbf{1}, \mathbf{8}-\mathbf{E M}^{-} \rightarrow \mathbf{3 , 8}-\mathbf{E M}^{-}\right)=14.9 \mathrm{kcal} / \mathrm{mol} \quad$ and $\quad \Delta G_{g}\left(\mathbf{1}, \mathbf{8}-\mathbf{E M}^{-} \rightarrow\right.$

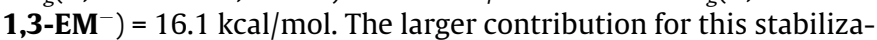
tion comes from the electronic energy $\left(\Delta E_{g}\left(\mathbf{1}, \mathbf{8}-\mathbf{E M}^{-} \rightarrow \mathbf{3}\right.\right.$, 8-EM $\left.{ }^{-}\right)=17.1 \mathrm{kcal} / \mathrm{mol}$ and $\Delta E_{g}\left(\mathbf{1 , 8}-\mathbf{E M}^{-} \rightarrow \mathbf{1 , 3}-\mathbf{E M}^{-}\right)=17.2 \mathrm{kcal} /$ $\mathrm{mol}$ ). Although the energies corrections (sum of zero-point, thermal and enthalpy) obtained after the vibration frequencies calculations are large (around $100 \mathrm{kcal} / \mathrm{mol}$, see $G_{g}-E_{g}$ in Table 1 ), the differences between the isomers are small, around $1.5 \mathrm{kcal} / \mathrm{mol}$.

Comparing the free energy in aqueous solution, $G_{a q}$, the isomer 1,8-EM ${ }^{-}$remains more stable by $5.9 \mathrm{kcal} / \mathrm{mol}$ compared to

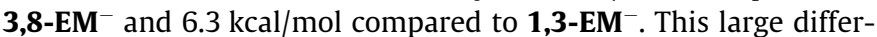
ence in the free energy of the isomers in aqueous solution leads to an equilibrium system with only the $\mathbf{1 , 8}-\mathbf{E M}^{-}$isomer at room temperature $(R T \approx 0.6 \mathrm{kcal} / \mathrm{mol})$. Thus, we conclude that the first deprotonation of the Emodin takes place at position 3 and for further calculations of the free energy of solvation and $p K_{a}$, only this isomer was considered, i.e. $\mathrm{EM}^{-}=\mathbf{1 , 8}-\mathbf{E M}^{-}$. Analyzing the divalent anionic forms, the isomer $\mathbf{1 - \mathbf { E M } ^ { 2 - }}{ }^{\mathbf{2}}$ is $5.6 \mathrm{kcal} / \mathrm{mol}$ more stable than the isomer $\mathbf{9}-\mathbf{E M}^{\mathbf{2}}$. Therefore, we conclude that the second deprotonation of Emodin in water takes place at position 8. Our results for the location of the first (at position 3 ) and second (at position 8) deprotonation process of Emodin in aqueous solution obtained with QM calculation are in agreement with the stepwise proton dissociation proposed by Pal and Jana [16].

It is interesting to note that the aqueous environment maintains the same stability of these isomers in the gas phase. But the environment plays a significant rule in the charge redistribution and electronic polarization of the anionic/deprotonated forms that can be seen in the large difference between the dipole moment in vacuum $\left(\mu_{g}\right)$ and in aqueous solution $\left(\mu_{a q}\right)$. There is an increase of $50-60 \%$ of the dipole moment of the deprotonated forms of Emodin in water compared to vacuum. Analyzing the atomic charge of the molecules in vacuum and in water, we identify that in general there is an increase in the modules of the charges calculated in water. However, this increase in not uniform. In the case of neutral form, EMH, the three oxygen atoms of the hydroxyl groups (01, 03 and 08) have almost the same charge (around -0.63 in vacuum and -0.68 in water, an increase of $\sim 8 \%$ ). However the two oxygen atoms of the carbonyl groups (09 and 010) have distinct charges ( -0.64 and -0.49 in vacuum and -0.67 and -0.57 in water, an increase of $5 \%$ in 09 and $16 \%$ in 010 ) due to the two intramolecular hydrogen bonds formed between $01 \mathrm{H} 1$ and $08 \mathrm{H} 8$ with 09. In the case of the first deprotonated form, 1,8-EM ${ }^{-}$, the three oxygen atoms of the hydroxyl groups have almost the same charge in vacuum (around -0.71 ), but became distinct in water leaving the deprotonated oxygen more negative than the others (around -0.72 for 01 and 08 and -0.84 for 03 ). Thus, we identified that the solvent effect on the electronic polarization of this type of molecules is important and cannot be neglected for a good description of its interaction with the solvent. For this reason, we used a set of polarized atomic charges, $\{q\}_{a q}$, in the simulations of EMH and $\mathrm{EM}^{-}$in water.

For further consideration, the variation in the internal energies of the $\mathrm{EMH}$ and $\mathrm{EM}^{-}$due to their polarization in the presence of a water reaction field, $\Delta E_{p o l}(X)$ (see Section 3.3 for computational details), were calculated as 2.1 and $4.5 \mathrm{kcal} / \mathrm{mol}$, respectively. The value of the $\left\langle\Psi_{\mathrm{PCM}}\left|\mathrm{H}_{\mathrm{o}}\right| \Psi_{\mathrm{PCM}}\right\rangle$ term was obtained in the same QM calculation as the ${ }_{a q}$ and $\Delta G_{a q}$ (shown in Table 1) and the value of the $\left\langle\Psi_{\mathrm{o}}\left|\mathrm{H}_{\mathrm{o}}\right| \Psi_{\mathrm{o}}\right\rangle$ term was obtained in the vacuum QM calculation. These values were used in the polarization free energy, $\Delta G_{p o l}(X)$, that will be discussed in the following sections.

\subsection{Theoretical deprotonation process in gas phase}

The gas phase free energy of the first deprotonation of the Emodin, $\Delta G_{g}$ was calculated using the free energy of the involved 
Table 2

The free energy in vacuum (in $\mathrm{kcal} / \mathrm{mol}$ ) for the species involved in the deprotonation process of water and Emodin in gas phase. The geometries were optimized with B3LYP/6-311++G(d,p) and the corrections of zero-point, thermal and enthalpy were obtained after the vibrational frequencies calculations. The electronic energies were calculated with two different methods: B3LYP and MP2 with the same basis function.

\begin{tabular}{lll}
\hline Free energy in gas phase, $G_{g}$ & B3LYP & MP2 \\
\hline$G_{g}\left(\mathrm{H}_{2} \mathrm{O}\right)$ & -47976.17 & -47860.70 \\
$G_{g}\left(\mathrm{H}_{3} \mathrm{O}^{+}\right)$ & -48140.08 & -48025.93 \\
$G_{g}\left(\mathrm{OH}^{-}\right)$ & -47587.29 & -47469.68 \\
$\Delta G_{g}\left(2 \mathrm{H}_{2} \mathrm{O} \rightarrow \mathrm{OH}^{-}+\mathrm{H}_{3} \mathrm{O}^{+}\right)$ & 224.97 & 225.80 \\
$\Delta G_{g}\left(2 \mathrm{H}_{2} \mathrm{O} \rightarrow \mathrm{OH}^{-}+\mathrm{H}_{3} \mathrm{O}^{+}\right)$Experimental & \\
$\Delta G_{g}\left(\mathrm{H}_{2} \mathrm{O} \rightarrow \mathrm{OH}^{-}+\mathrm{H}^{+}\right)$Experimental $^{\mathrm{b}}$ & $226.0 \pm 0.2$ & \\
$G_{g}\left(\mathrm{H}^{+}\right)=\Delta G_{g}\left(\mathrm{H}_{2} \mathrm{O} \rightarrow \mathrm{OH}^{-}+\mathrm{H}^{+}\right)+G_{g}\left(\mathrm{H}_{2} \mathrm{O}\right)-G_{g}\left(\mathrm{OH}^{-}\right)$ & $-3.3 \pm 0.2$ & $-5.4 \pm 0.2$ \\
$\Delta G_{g}($ Water $)=G_{g}\left(\mathrm{H}_{3} \mathrm{O}^{+}\right)-G_{g}\left(\mathrm{H}_{2} \mathrm{O}\right)$ & -163.91 & -165.23 \\
$G_{g}(\mathrm{EMH})$ & $-598565.89^{\mathrm{c}}$ & -596948.38 \\
$G_{g}\left(\mathrm{EM}^{-}\right)=G_{g}\left(1,8-\mathrm{EM}^{-}\right)$ & $-598247.08^{\mathrm{c}}$ & -596628.10 \\
$\Delta G_{g}($ Emodin $)=G_{g}\left(\mathrm{EM}^{-}\right)-G_{g}(\mathrm{EMH})$ & 318.81 & 320.28 \\
$\Delta G_{g}^{(1)}=\Delta G_{g}($ Emodin $)+G_{g}\left(\mathrm{H}^{+}\right)$ & $315.5 \pm 0.2$ & $314.9 \pm 0.2$ \\
$\Delta G_{g}^{(2)}=\Delta G_{g}($ Emodin $)+\Delta G_{g}($ Water $)$ & $154.9 \pm 0.2$ & $155.1 \pm 0.2$
\end{tabular}

${ }^{\text {a }}$ Value obtained from Refs. $[34,44]$.

b Value obtained from Refs. [56,57].

c The same values presented in Table 1 .

species as shown in Eqs. (7) and (11). For completeness, the calculations of the gas phase deprotonation free energy of water, $\Delta G_{g}\left(\mathrm{H}_{2} \mathrm{O} \rightarrow \mathrm{OH}^{-}+\mathrm{H}^{+}\right)$and $\Delta G_{g}\left(2 \mathrm{H}_{2} \mathrm{O} \rightarrow \mathrm{OH}^{-}+\mathrm{H}_{3} \mathrm{O}^{+}\right)$, were also calculated and compared with the best experimental values of $385.6 \pm 0.2 \mathrm{kcal} / \mathrm{mol}[56,57]$ and $226.0 \pm 0.2 \mathrm{kcal} / \mathrm{mol}$ [34,44], respectively.

The free energy of each species in vacuum was calculated with B3LYP/6-311++G(d,p) adding the electronic energy with the corrections of zero-point, thermal and enthalpy. Except for the $\mathrm{H}^{+}$, which we used the equilibrium reaction $\mathrm{H}_{2} \mathrm{O} \Longleftrightarrow \mathrm{OH}^{-}+\mathrm{H}^{+}$to obtain the $G_{g}\left(\mathrm{H}^{+}\right)$. Additionally, to increases the numerical precision of the free energy values, the calculations of the electronic energies were improved using MP2 method with the same basis set. These values are shown in Table 2 .

The calculated values of the $\Delta \mathrm{G}_{\mathrm{g}}\left(2 \mathrm{H}_{2} \mathrm{O} \rightarrow \mathrm{OH}^{-}+\mathrm{H}_{3} \mathrm{O}^{+}\right)$is 225.8 (224.9) $\mathrm{kcal} / \mathrm{mol}$ with MP2 (B3LYP). These values are in very good agreement with the experimental value of $226.0 \pm 0.2 \mathrm{kcal} / \mathrm{mol}$ $[34,44]$. We obtained the $G_{g}\left(\mathrm{H}^{+}\right)$as $-5.4(-3.3) \mathrm{kcal} / \mathrm{mol}$ with
MP2 (B3LYP), using the experimental value of $\Delta G_{g}\left(\mathrm{H}_{2} \mathrm{O} \rightarrow \mathrm{OH}^{-}+\right.$ $\left.\mathrm{H}^{+}\right)=385.6 \pm 0.2 \mathrm{kcal} / \mathrm{mol}$ and the calculated values of $G_{g}\left(\mathrm{H}_{2} \mathrm{O}\right)$ and the $G_{g}\left(\mathrm{OH}^{-}\right)$. For further calculations, we adopted the MP2 values as our best results, $\Delta G_{g}$ (water) $=-165.2 \pm 0.2 \mathrm{kcal} / \mathrm{mol}$, $G_{g}\left(H^{+}\right)=-5.4 \pm 0.2 \mathrm{kcal} / \mathrm{mol}, \quad \Delta G_{g}^{(1)}=314.9 \pm 0.2 \mathrm{kcal} / \mathrm{mol} \quad$ using Eq. (7) and $\Delta G_{g}^{(2)}=155.1 \pm 0.2 \mathrm{kcal} / \mathrm{mol}$ using Eq. (11).

\subsection{Theoretical free energy of solvation and $p K_{a}$}

The three terms of the standard solvation free energies, $\Delta G_{e l e}(X), \Delta G_{v d w}(X), \Delta \Delta G_{c a v}(X)$, for $X=\mathrm{EMH}$ and $\mathrm{EM}^{-}$, in aqueous solution were calculated using FEP-MC simulations, as presented in Section 3.3. Five independent sets of simulations were performed and the final values and standard deviations were evaluated (shown in Table 3). Each set was composed by 20 simulations: 12 simulations for vanishing the electrostatic term of the solute-solvent interactions and calculating the $\Delta G_{\text {ele }}(X) ; 4$ simulations for vanishing the attractive part of the Lennard-Jones term of the solute-solvent interactions and calculating the $\Delta G_{v d W}(X)$; and 4 simulations for vanishing the repulsive part of the Lennard-Jones term of the solute-solvent interactions and calculating the $\Delta G_{c a v}(X)$. The polarization free energies, $\Delta G_{p o l}(X)$, were calculated as 2.1 and $4.5 \mathrm{kcal} / \mathrm{mol}$ for $\mathrm{EMH}$ and $\mathrm{EM}^{-}$, respectively (see Sections 3.3 and 4.2). Then, using Eq. (14) the value of $\Delta G_{\text {solv }}(X)$ were obtained; using Eqs. (8) and (12) the values of $\Delta \Delta G_{\text {solv }}($ Emodin $), \quad \Delta \Delta G_{\text {solv }}$ (water), $\Delta \Delta G_{\text {solv }}^{(1)}$ and $\Delta \Delta G_{\text {solv }}^{(2)}$ were obtained; using Eqs. (6) and (10) the values of $\Delta G_{a q}^{(1)}$ and $\Delta G_{a q}^{(2)}$ were obtained; and finally, using Eqs. (9) and (13) the values of $p K_{a 1}$ were obtained. All these values are shown in Table 3. For comparison, the four terms of the standard solvation free energies were also calculated using PCM with UAHF model for the cavity shape at $\mathrm{HF} /$ $3-61+G(d)$. These values are also shown in Table 3, in parenthesis.

The total electrostatic term of the solvation free energies, $\Delta G_{\text {total-ele }}(X)=\Delta G_{\text {ele }}(X)+\Delta G_{\text {pol }}(X)$, are $-8.1(-15.2) \mathrm{kcal} / \mathrm{mol}$ for $\mathrm{EMH}$ and $-43.9(-52.8) \mathrm{kcal} / \mathrm{mol}$ for $\mathrm{EM}^{-}$using FEP-MC model (PCM). We observed an agreement in the tendency of both solvent models: FEP-MC model where the solvent molecules are explicitly included in the calculation, and the PCM where the solvent is treated as a polarizable continuum medium. However, comparing the non-electrostatic terms, $\Delta G_{\text {total-nonele }}(X)=\Delta G_{v d w}(X)+\Delta G_{\text {cav }}(X)-R T$

Table 3

Standard solvation free energies in $(\mathrm{kcal} / \mathrm{mol})$ of the species involved in the first deprotonation process of the Emodin in water following the equilibrium reaction shown in Schemes 1 and 2. The values were calculated using FEP-MC simulation and in parenthesis using QM calculation with HF/6-31+G(d)/PCM/UAHF.

\begin{tabular}{|c|c|c|c|}
\hline Free Energy & $X=\mathrm{EMH}$ & $X=\mathrm{EM}^{-}$ & Relative values (EM ${ }^{-}$- EMH) \\
\hline$\Delta G_{e l e}(X)$ & $-10.2 \pm 0.2(-17.1)$ & $-48.4 \pm 0.2(-57.2)$ & $-38.2 \pm 0.2(-40.1)$ \\
\hline$\Delta G_{v d W}(X)$ & $-20.0 \pm 0.4(-27.0)$ & $-20.6 \pm 0.3(-26.7)$ & $-0.6 \pm 0.5(0.3)$ \\
\hline$\Delta G_{\text {cav }}(X)$ & $11.9 \pm 0.6(30.7)$ & $11.4 \pm 0.6(30.5)$ & $-0.5 \pm 0.6(-0.2)$ \\
\hline$\Delta G_{p o l}(X)$ & $2.1(1.8)$ & $4.5(4.4)$ & $2.4(2.6)$ \\
\hline$-\mathrm{RT} \ln (24.46)$ & -1.9 & -1.9 & 0.0 \\
\hline$\Delta G_{\text {total-ele }}(X)$ & $-8.1 \pm 0.2(-15.3)$ & $-43.9 \pm 0.2(-52.8)$ & $-35.8 \pm 0.2(-37.5)$ \\
\hline$\Delta G_{\text {total-nonele }}(X)$ & $-10.0 \pm 0.7(3.7)$ & $-11.1 \pm 0.7(3.8)$ & $-1.1 \pm 0.7(0.1)$ \\
\hline$\Delta G_{\text {solv }}(X)$ & $-18.1 \pm 0.7(-11.6)$ & $-55.0 \pm 0.7(-49.0)$ & $\Delta \Delta G_{\text {solv }}($ Emodin $)=-36.9 \pm 1.4(-37.4 \pm 1.0)$ \\
\hline \multirow[t]{2}{*}{$\Delta G_{\text {solv }}(X)$} & $\begin{array}{l}X=\mathrm{H}_{2} \mathrm{O} \\
-6.3 \pm 0.2^{\mathrm{a}}\end{array}$ & $\begin{array}{l}X=\mathrm{H}_{3} \mathrm{O}^{+} \\
-110.2 \pm 0.7^{\mathrm{b}}\end{array}$ & $\begin{array}{l}\Delta \Delta G_{\text {solv }}(\text { Water })=-103.9 \pm 0.7 \\
\Delta G_{\text {solv }}\left(\mathrm{H}^{+}\right)=-265.9 \pm 0.2^{\mathrm{C}}\end{array}$ \\
\hline & $\Delta \Delta G_{\text {solv }}^{(i)}$ & $\Delta G_{g}^{(i) \mathrm{d}}$ & $\Delta G_{a q}^{(i)}$ \\
\hline$i=$ Scheme 1 & $-302.8 \pm 1.4(-303.3 \pm 1.0)$ & $314.9 \pm 0.2$ & $12.1 \pm 1.4(11.6 \pm 1.0)$ \\
\hline$i=$ Scheme 2 & $-140.8 \pm 1.4(-141.3 \pm 1.0)$ & $155.1 \pm 0.2$ & $14.3 \pm 1.4(13.8 \pm 1.0)$ \\
\hline \multirow[t]{2}{*}{$p K_{a 1}$} & $8.8 \pm 0.9(8.5 \pm 0.7)$ from $\Delta G_{a q}^{(1) \mathrm{e}}$ & & $8.0 \pm 0.1$ Our exp. result \\
\hline & $8.7 \pm 0.9(8.4 \pm 0.7)$ from $\Delta G_{a q}^{(2) \mathrm{f}}$ & & \\
\hline
\end{tabular}

\footnotetext{
a Value obtained from Ref. [70].

b Value obtained from Ref. [34]

c Value obtained from Ref. [72].

d MP2 values of Table 2.

e Using Eq. (9).

${ }^{f}$ Using Eq. (13).
} 
$\ln (24.46)$, we identified a discrepancy between the two models, -10.0 (3.7) $\mathrm{kcal} / \mathrm{mol}$ for EMH and -11.1 (3.8) $\mathrm{kcal} / \mathrm{mol}$ for $\mathrm{EM}^{-}$using FEP-MC simulations (PCM). For the explicit solvent model the contribution of the non-electrostatic term is negative, around 10$11 \mathrm{kcal} / \mathrm{mol}$, but for the continuum solvent model this term is positive, around $4 \mathrm{kcal} / \mathrm{mol}$. These difference between the two models appears clearly in the total values of the standard solvation free energy of each species, $\Delta G_{\text {solv }}(E M H)=-18.1 \pm 0.7(-11.6) \mathrm{kcal} / \mathrm{mol}$ and $\Delta G_{\text {solv }}\left(\mathrm{EM}^{-}\right)=-55.0 \pm 0.7(-49.0) \mathrm{kcal} / \mathrm{mol}$, for FEP-MC model (PCM). On the other hand, this difference of the two solvent models does not appear in the relative free energy of solvation, $\Delta \Delta G_{\text {solv }}$ $($ Emodin $)=\Delta G_{\text {solv }}\left(\mathrm{EM}^{-}\right)-\Delta G_{\text {solv }}(\mathrm{EMH})=-36.9 \pm 1.4(-37.4 \pm 1.0)$ $\mathrm{kcal} / \mathrm{mol}$, and in the standard deprotonation free energy of Emodin in aqueous solution by the direct dissociation $\Delta G_{a q}^{(1)}=12.1 \pm 1.4$ $(11.6 \pm 1.0) \mathrm{kcal} / \mathrm{mol}$ using Scheme 1 and by the acid-base reaction with water $\Delta G_{a q}^{(2)}=14.3 \pm 1.4(13.8 \pm 1.0) \mathrm{kcal} / \mathrm{mol}$ using Scheme 2 . The difference between these values obtained with FEP-MC and PCM is less than $1.0 \mathrm{kcal} / \mathrm{mol}$ and this is caused by the cancelation of the non-electrostatic term of EMH and $\mathrm{EM}^{-}$that are very similar. Finally, we should mention an excellent agreement between the calculated $p K_{a 1}$ values of the Emodin in aqueous solution, $8.8 \pm 0.9(8.5 \pm 0.7)$ using Scheme 1 and $8.7 \pm 0.9$ (8.4 \pm 0.7$)$ using Scheme 2, with FEP-MC (PCM) and the experimental data obtained from the UV/Visible spectrophotometric titration curves, $8.0 \pm 0.1$.

\section{Conclusions}

We obtained the first and second $p K_{a}$ values of the Emodin in aqueous solution using the UV/Visible spectrophotometric titration curves, $p K_{a 1}=8.0 \pm 0.1$ and $p K_{a 2}=10.9 \pm 0.2$. The UV/Visible absorption spectra of the Emodin were measured in a $p H$ interval of $\sim 13$ to 2 . We observe aggregation of the Emodin at $p H<7.5$. The samples were homogenized by strongly vortexing immediately before each measurement. For analyzing the existence of the aggregation effects in the obtained $p K_{a}$ values, the measurements were performed in two concentrations, 0.100 and $0.025 \mathrm{mM}$, and the titration curves were analyzed in two wavelengths, 519 and $308 \mathrm{~nm}$. Our results showed to be robust and present insignificant influence due to the aggregation of the Emodin in lower $\mathrm{pH}$. Therefore, we are confident on the accuracy of these $p K_{a}$ values.

Additionally, we obtained the $p K_{a}$ values of the Emodin in the water-methanol mixture $(1: 3 \mathrm{v} / \mathrm{v})$ using the same procedure. No aggregation of the Emodin was observed. For this system, we put forward a new interpretation for the experimental data. Using the hypothesis of only one deprotonation of the Emodin in this mixture at the $p H$ interval of $\sim 13$ to 2 , we obtained the result of apparent $p K_{a 1}=7.4$ with the titration curve fitting at $441 \mathrm{~nm}$ and $p K_{a 1}=7.0$ at $508 \mathrm{~nm}$, in good agreement with the value of 7.2 obtained previously by Pal and Jana [16]. However, the experimental data were not well adjusted by the fitting (see Fig. 3 ). Then, using a hypothesis of three deprotonations of the Emodin, we obtained the experimental data well fitted by Eq. (5), and the apparent acidity constants are $p K_{a 1}=6.2 \pm 0.1, p K_{a 2}=8.3 \pm 0.1$ and $p K_{a 3}>12.7$ for the Emodin in water-methanol mixture $(1: 3 \mathrm{v} / \mathrm{v})$.

Performing quantum mechanics calculations (B3LYP and MP2 with $6-311++G(d, p)$ ) for all possible deprotonation sites and its tautomeric isomers of the Emodin in vacuum and in aqueous solution using polarizable continuum model (PCM), we conclude that the first deprotonation takes place at position 3 and the second at position 8. Considering a deprotonation at position 3, we calculated the standard first deprotonation free energy of Emodin in aqueous solution, by two different thermodynamic cycles and using an explicit model of the solvent, with Free Energy Perturbation theory in Monte Carlo simulation, $\Delta G_{a q}=12.1 \pm 1.4 \mathrm{kcal} / \mathrm{mol}$, and for comparison with the polarizable continuum model
(HF/3-31G(d)/PCM/UAHF), $\Delta G_{a q}=11.6 \pm 1.0 \mathrm{kcal} / \mathrm{mol}$. Both solvent models gave theoretical results in very good agreement with the experimental estimated value of $10.9 \pm 0.2 \mathrm{kcal} / \mathrm{mol}$ obtained from the acidity constant, $p K_{a 1}=8.0 \pm 0.1$, using Eq. (9).

It is interesting to note (see Table 3 ) that the values obtained for the standard solvation free energy of the neutral and deprotonated species of Emodin in aqueous solution are significantly different, $\Delta G_{\text {solv }}(\mathrm{EMH})=-18.1 \pm 0.7 \quad(-11.6) \mathrm{kcal} / \mathrm{mol}$ and $\Delta G_{\text {solv }}\left(\mathrm{EM}^{-}\right)=$ $-55.0 \pm 0.7(-44.5) \mathrm{kcal} / \mathrm{mol}$, for FEP-MC model (PCM) and this difference is caused mostly by the non-electrostatic terms. Therefore, we conclude that due to the cancelation of the non-electrostatic term of the deprotonation free energy, the calculation of this property is more accurate than the solvation free energy of the species involved in the deprotonation process.

\section{Conflict of interest}

The authors declare no conflict of interest.

\section{Acknowledgements}

Work partially supported by CNPq, CAPES, FAPESP, INCT-FCX, NAP-FCx(USP) and nBioNet (Brazil). Additionally, ARC acknowledges the fellowship from $\mathrm{CNPq} / \mathrm{CAPES}$, and MTL and $\mathrm{KC}$ research fellowships from CNPq.

\section{Appendix A. Supplementary data}

Supplementary data associated with this article can be found, in the online version, at http://dx.doi.org/10.1016/j.chemphys. 2014.06.009.

\section{References}

[1] R.H. Thomson, Naturally Occurring Quinones, vol. 3, Chapman and Hall, London, New York, 1987.

[2] D.S. Alves, L. PérezFons, A. Estepa, V. Micol, Biochem. Pharmacol. 68 (2004) 549.

[3] H. Anke, I. Kolthoum, H. Laatsch, Biol. Act. Arch. Microbiol. 126 (1980) 231.

[4] T.L. Van, Acta Agrar. Silv. Ser. Agrar. 23 (1984) 235.

[5] W.H. Wang, J.G. Chung, Curr. Microbiol. 35 (1997) 262.

[6] D.L. Barnard, J.H. Huffman, J.L. Morris, S.G. Wood, B.G. Hughes, R.W. Sidwell, Antiviral Res. 17 (1992) 63.

[7] K. Kawai, T. Kato, H. Mori, J. Kitamura, Y. Nozawa, Toxicol. Lett. 20 (1984) 155.

[8] A. Kumar, S. Dhawan, B.B. Aggarwal, Oncogene 17 (1998) 913.

[9] Y.C. Kuo, H.C. Meng, W.J. Tsai, Inflammation Res. 50 (2001) 73.

[10] Y.C. Chen, S.C. Shen, W.R. Lee, E.L. Hsu, H.Y. Lin, C.H. Ko, S.W. Tseng, Biochem. Pharmacol. 64 (2002) 1713.

[11] G. Srinivas, R.J. Anto, P. Srinivas, S. Vidhyalakshmi, V.P. Senan, D. Karunagaran, Eur. J. Pharmacol. 473 (2003) 117.

[12] T.C. Chan, C.J. Chang, N.M. Koonchanok, R.L. Geahlen, Biochem. Biophys. Res. Commun. 193 (1993) 1152.

[13] L. Wang, L. Lin, B. Ye, J. Pharm. Biomed. Anal. 42 (2006) 625.

[14] S.T. Saito, G. Silva, C. Pungartnik, M. Brendel, J. Photochem. Photobiol. B 111 (2012) 59.

[15] G. Fabriciova, S. Sanchez-Cortes, J.V. Garcia-Ramos, P. Miskovsky, Biopolymers 74 (2004) 125

[16] T. Pal, N.R. Jana, Analyst 118 (1993) 1337.

[17] S.C. Nguyen, B.K.V. Hansen, S.V. Hoffmann, J. Spanget-Larsen, Chem. Phys. 352 (2008) 167.

[18] G.H. Rochester, Acidity Functions, Academic Press, New York, 1971.

[19] C.R. Cantor, P.R. Schimmel, Biophysical Chemistry. Part III: The Behavior of Biological Macromolecules, W.H. Freeman and Co.,, New York, 1980.

[20] M. Uudsemaa, T. Kanger, M. Lopp, T. Tamm, Chem. Phys. Lett. 485 (2010) 83.

[21] J.B. Hansen, O. Hafliger, J. Pharmacol. Sci. 72 (1983) 429.

[22] S. Singh, D. Gupta, M.M. Tewari, P.C. Yadava, S.R. Tripathi, K.L. Yadava, Electrochim. Acta 39 (1985) 105.

[23] J. Pospichal, M. Deml, P. Bocek, J. Chromatogr. 390 (1987) 17.

[24] M. Roses, M.J. Bonet, E. Bosch, Anal. Chim. Acta 333 (1996) 241.

[25] S.-D. Kim, J.-K. Kim, Anal. Sci. Technol. 10 (1997) 256.

[26] D.L. Rabenstein, S.P. Hari, A. Kzerner, Anal. Chem. 69 (1997) 4310.

[27] J.B. Clistunoff, K.P. Johnston, J. Phys. Chem. B 102 (1998) 3993.

[28] J.Z. Yang, J. Liu, Thermochim. Acta 308 (1998) 171.

[29] A.G. Bezerra Jr., I.E. Borissevitch, A.S.L. Gomes, C.B. de Araújo, Opt. Lett. 25 (2000) 323. 
[30] D. Wang, G. Yang, X. Song, Electrophoresis 22 (2001) 464.

[31] W.L. Jorgensen, J.M. Briggs, J. Gao, J. Am. Chem. Soc. 109 (1987) 6857.

[32] W.L. Jorgensen, J.M. Briggs, J. Am. Chem. 111 (1989) 4190.

[33] P. Beroza, D.R. Fredkin, M.Y. Okamura, G. Feher, Proc. Natl. Acad. Sci. USA 88 (1991) 5804.

[34] J.R. Pliego Jr., J.M. Riveros, J. Phys. Chem. B 104 (2000) 5155.

[35] B. Honing, K. Sharp, A.-S. Yang, J. Phys. Chem 97 (1993) 1101.

[36] H.W.T. van Vlijmen, M. Schaefer, M. Karplus, Funct. Bioinform. 33 (1998) 145.

[37] C.J. Cramer, D.G. Truhlar, J. Am. Chem. Soc. 113 (1991) 8305.

[38] C. Lim, D. Bashford, M. Karplus, J. Phys. Chem. 95 (1991) 5610.

[39] G. Schüürmann, M. Cossi, V. Barone, J. Tomasi, J. Phys. Chem. A 102 (1998) 6706.

[40] J.R. Pliego Jr., Chem. Phys. Lett. 367 (2003) 145.

[41] A. Klamt, F. Eckert, M. Diedenhofen, M.E. Beck, J. Phys. Chem. A 107 (2003) 9380.

[42] S. Zhang, J. Comp. Chem 33 (2012) 2469.

[43] C.P. Kelly, C.J. Cramer, D.G. Truhlar, J. Phys. Chem. B 110 (2006) 16066.

[44] D.M. Camaioni, C.A. Schwerdtfeger, J. Phys. Chem. A 109 (2005) 10795.

[45] R. Casanovas, J. Frau, J. Ortega-Castro, A. Salvà, J. Donosco, J. Mol. Struct. THEOCHEM 912 (2009) 5.

[46] A. Onufriev, D.A. Case, G.M. Ullmann, Biochemistry 40 (2001) 3413.

[47] H-.H. Perkampus, UV-Vis Spectroscopy and Its Applications, Springer-Verlag, Berlin, 1992.

[48] R.G. Parr, W. Yang, Density Functional Theory of Atoms and Molecules, Oxford Science Publications, Oxford, 1994.

[49] A.D. Becke, J. Chem. Phys. 98 (1993) 5648.

[50] Y. Imamura, T. Otsuka, H. Nakai, J. Comput. Chem. 28 (2007) 2067.

[51] D. Ditchfield, W.J. Hehre, J.A. Pople, J. Chem. Phys. 54 (1971) 724

[52] D. Jacquemin, X. Assfeld, J. Preat, E.A. Perpete, Mol. Phys. 105 (2007) 325.

[53] Z.S. Marković, N.T. Manojlović, Monastsh. Chem. 140 (2009) 1311.

[54] J. Tirado-Rives, W.L. Jorgensen, J. Chem. Theory Comput. 4 (2008) (2008) 297.

[55] S. Miertus, E. Scrocco, J. Tomasi, Chem. Phys. 55 (1981) 117.

[56] J.E. Bartmess, J.A. Scott, R.T. McIver Jr., J. Am. Chem. Soc. 101 (1979) 6056.

[57] J.E. Bartmess, in: P.J. Linstrom, W.G. Mallard, NIST Chemistry WebBook, NIST Standard Reference Database Number 69, National Institute of Standards and Technology, Gaithersburg, March 2003, <http://webbook.nist.gov>.

[58] C. Møller, M.S. Plesset, Phys. Rev. 46 (1934) 618.

[59] R. Krishnan, J.A. Pople, Int. J. Quantum Chem. 14 (1978) 91.

[60] R.W. Zwanzig, J. Chem. Phys. 22 (1954) 1420.

[61] P.R. Schleyer (Ed.), Encyclopedia of Computational Chemistry, vol. 2, John Wiley \& Sons, New York, 1998. D.A. Pearlman, B.G. Rao, p. 1036; W.L. Jorgensen, p. 1061; A.E. Mark, p. 1070.

[62] W.L. Jorgensen, C. Ravimohan, J. Chem. Phys. 83 (1985) 3050

[63] W.L. Jorgensen, L.L. Thomas, J. Chem. Theory Comput. 4 (2008) 869.

[64] R.C. Guedes, K. Coutinho, B.J.C. Cabral, S. Canuto, J. Phys. Chem. B 107 (2003) 4304.

[65] H.C. Georg, K. Coutinho, S. Canuto, Chem. Phys. Lett. 413 (2005) 16.

[66] M.C.P. Lima, K. Coutinho, S. Canuto, W.R. Rocha, J. Phys. Chem. A 110 (2006) 7253.

[67] H. Pasalic, A.J.A. Aquino, D. Tunega, G. Haberhauer, M.H. Gerzabek, H.C. Georg, T.F. Moraes, K. Coutinho, S. Canuto, H. Lischka, J. Comput. Chem. 31 (2010) 2046.
[68] M.V.A. Damasceno, B.J.C. Cabral, K. Coutinho, Theor. Chem. Acc. 131 (2012) 1214.

[69] R.W. Taft, J.F. Wolf, J.L. Beauchamp, G. Scorrano, E.M. Arnett, J. Am. Chem. Soc. 100 (1978) 1240.

[70] A. Ben-Naim, Y.J. Marcus, J. Chem. Phys. 81 (1984) 2016.

[71] M.W. Palascak, G.C. Shields, J. Phys. Chem. A 108 (2004) 3692.

[72] M.D. Tissandier, K.A. Cowen, W.Y. Feng, E. Gundlach, M.J. Cohen, A.D. Earhart, J.V. Coe, J. Phys. Chem. A 102 (1998) 7787.

[73] M.P. Allen, D.J. Tildesley, Computer Simulation of Liquids, Clarendon, Oxford, 1987.

[74] K.J. de Almeida, K. Coutinho, W.B. de Almeida, W.R. Rocha, S. Canuto, Phys. Chem. Chem. Phys. 3 (2001) 1583.

[75] H.J.C. Berendsen, J.P.M. Postma, W.F. van Gunsteren, J. Hermans, in: B. Pullman (Ed.), Intermolecular Forces, Dordrecht, Reidel, 1981.

[76] W.L. Jorgensen, D.S. Maxwell, J. Tirado-Rives, J. Am. Chem. Soc. 118 (1996) 11225.

[77] W.L.C.M. Breneman, K.B. Wiberg, J. Comp. Chem. 11 (1990) 361.

[78] R.C. Barreto, K. Coutinho, H.C. Georg, S. Canuto, Phys. Chem. Chem. Phys. 11 (2009) 1388.

[79] V. Manzoni, M.L. Lyra, R.M. Gester, K. Coutinho, S. Canuto, Phys. Chem. Chem. Phys. 12 (2010) 14023.

[80] V. Manzoni, M.L. Lyra, K. Coutinho, S. Canuto, J. Chem. Phys. 135 (2011) 144103.

[81] W.L. Jorgensen, J.K. Buckner, S. Boudon, J. Tiradorives, J. Chem. Phys. 89 (1988) 3742.

[82] P. Cieplak, P.A. Kollman, J. Am. Chem. Soc. 110 (1988) 3734.

[83] P.F.B. Gonçalves, H. Stassen, J. Comput. Chem. 24 (2003) 1758.

[84] V. Barone, M. Cossi, J. Tomasi, J. Chem. Phys. 107 (1997) 3210.

[85] J. Ho, A. Klamt, M.L. Coote, J. Phys. Chem. A 114 (2010) 13442.

[86] T.N. Brown, N. Mora-Diez, J. Phys. Chem. B 110 (2006) 20546.

[87] T.N. Brown, N. Mora-Diez, J. Phys. Chem. B 110 (2006) 9270.

[88] M.J. Frisch, G.W. Trucks, H.B. Schlegel, G.E. Scuseria, M.A. Robb, J.R. Cheeseman, J.A. Montgomery Jr., T. Vreven, K.N. Kudin, J.C. Burant, J.M. Millam, S.S. Iyengar, J. Tomasi, V. Barone, B. Mennucci, M. Cossi, G. Scalmani, N. Rega, G.A. Petersson, H. Nakatsuji, M. Hada, M. Ehara, K. Toyota, R. Fukuda, J. Hasegawa, M. Ishida, T. Nakajima, Y. Honda, O. Kitao, H. Nakai, M. Klene, X. Li, J.E. Knox, H.P. Hratchian, J.B. Cross, V. Bakken, C. Adamo, J. Jaramillo, R. Gomperts, R.E. Stratmann, O. Yazyev, A.J. Austin, R. Cammi, C. Pomelli, J.W. Ochterski, P.Y. Ayala, K. Morokuma, G.A. Voth, P. Salvador, J.J. Dannenberg, V.G. Zakrzewski, S. Dapprich, A.D. Daniels, M.C. Strain, O. Farkas, D.K. Malick, A.D. Rabuck, K. Raghavachari, J.B. Foresman, J.V. Ortiz, Q. Cui, A.G. Baboul, S. Clifford, J. Cioslowski, B.B. Stefanov, G. Liu, A. Liashenko, P. Piskorz, I. Komaromi, R.L. Martin, D.J. Fox, T. Keith, M.A. Al-Laham, C.Y. Peng, A. Nanayakkara, M. Challacombe, P.M.W. Gill, B. Johnson, W. Chen, M.W. Wong, C. Gonzalez, J.A. Pople, Gaussian 03, Revision C.02, Gaussian Inc, Wallingford, CT, 2004.

[89] K. Coutinho, S. Canuto, DICE: A Monte Carlo Program for Liquid Simulation, University of São Paulo, São Paulo, 2003.

[90] C.R. Cantor, P.R. Schimmel, Biophysical Chemistry. Part II. Techniques for the Study of Biological Structure and Function, W.H. Freeman and Co., New York, 1980.

[91] A. Prakash, Z. Kristallogr. 113 (1965) 272.

[92] A. Prakash, Acta Cryst. 22 (1967) 439 